Supporting Information for

\title{
Sulfur $\left[{ }^{18} \mathrm{~F}\right]$ Fluoride Exchange Click Chemistry Enabled Ultrafast Late-stage Radiosynthesis
}

Qinheng Zheng ${ }^{1,5}$, Hongtao Xu ${ }^{2,5}$, Hua Wang ${ }^{1,3}$, Wen-Ge Han $\mathrm{Du}^{4}$, Nan Wang ${ }^{2}$, Huan Xiong ${ }^{2}$, Yuang $\mathrm{Gu}^{2}$, Louis Noodleman ${ }^{4}, \mathrm{~K}$. Barry Sharpless ${ }^{1 *}$, Guang Yang ${ }^{2 *}$, and Peng $\mathrm{Wu}^{3 *}$

${ }^{1}$ Department of Chemistry, The Scripps Research Institute, La Jolla, CA 92037, United States. ${ }^{2}$ Shanghai Institute for Advanced Immunochemical Studies (SIAIS), ShanghaiTech University, Shanghai 201210, China. ${ }^{3}$ Department of Molecular Medicine, The Scripps Research Institute, La Jolla, CA 92037, United States. ${ }^{4}$ Department of Integrative Structural and Computational Biology, The Scripps Research Institute, La Jolla, CA 92037, United States. ${ }^{5}$ These authors contributed equally: Qinheng Zheng, Hongtao Xu. *E-mail: pengwu@scripps.edu (P.W.), sharples@scripps.edu (K.B.S.), yangguang@shanghaitech.edu.cn (G.Y.).

This PDF file includes:

Table of Contents

Materials and Methods

Supplementary Text

Figs. $\mathrm{S} 1$ to $\mathrm{S} 137$

Tables S1 to S31

Additional References 


\section{Table of Contents}

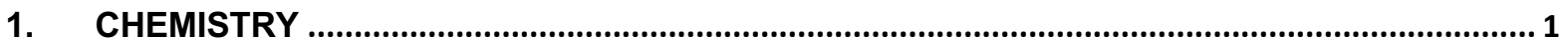

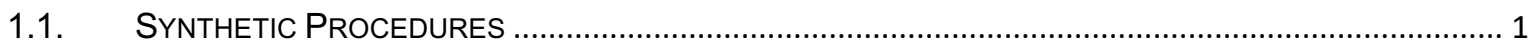

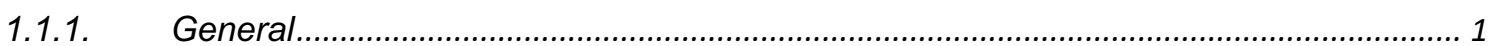

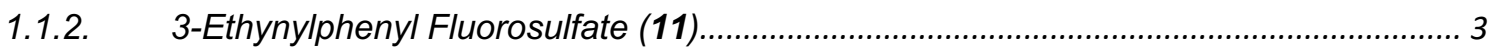

1.1.3. 2,5-Dioxopyrrolidin-1-yl 4-((fluorosulfonyl)oxy)benzoate (15) ...................................... 4

1.1.4. 4-(2,5-Dioxo-2,5-dihydro-1H-pyrrol-1-yl)phenyl Fluorosulfate (16) ............................... 5

1.1.5. 4-(6-Methyl-1,2,4,5-tetrazin-3-yl)phenyl Fluorosulfate (18) .............................................. 6

1.1.6. 3-(6-Methyl-1,2,4,5-tetrazin-3-yl)phenyl Fluorosulfate (19) .......................................... 7

1.1.7. 4-(2-(3,4,5-Tris(prop-2-yn-1-yloxy)benzamido)ethyl)phenyl Fluorosulfate (20)........... 8

1.1.8. 5-(((2S,3S, 5R)-2-(Hydroxymethyl)-5-(5-methyl-2,4-dioxo-3,4-dihydropyrimidin-1(2H)yl)tetrahydrofuran-3-yl)carbamoyl)-1,3-phenylene Bis(fluorosulfate) (21).

1.1.9. Benzyl (S)-2-(((benzyloxy)carbonyl)amino)-3-(4-((fluorosulfonyl)oxy)phenyl)

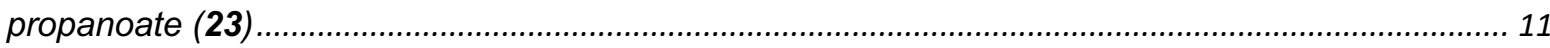

1.1.10. (E)-4-(4-((tert-Butoxycarbonyl)(methyl)amino)styryl)phenyl Fluorosulfate (29) .......... 12

1.1.11. (E)-5-(4-((tert-Butoxycarbonyl)(methyl)amino)styryl)pyridin-2-yl Fluorosulfate (30) ... 13

1.1.12. 2-(4-(Methylamino)phenyl)benzo[d]thiazol-5-yl fluorosulfate (31) ............................... 14

1.1.13. 4-((2-(2-((2-(4-(Methylamino)phenyl)benzo[d]thiazol-6-yl)oxy)ethoxy)ethyl) carbamoyl)

Phenyl Fluorosulfate (32)......................................................................................................... 16

1.1.14. tert-Butyl (RS)-2-((RS)-(2-((fluorosulfonyl)oxy)phenoxy)(phenyl)methyl)morpho-line-4-

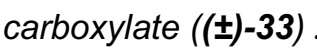

1.1.15. 4-(2-(4-(2-Fluoro-5-((4-oxo-3,4-dihydrophthalazin-1-yl)methyl)benzoyl) piperazin-1-yl)-

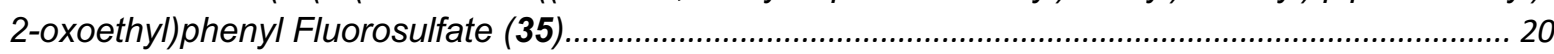

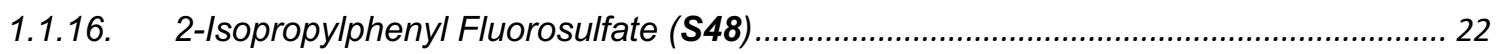

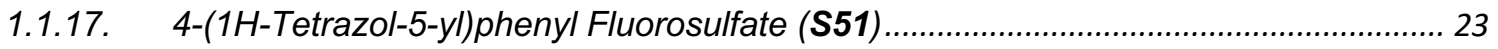

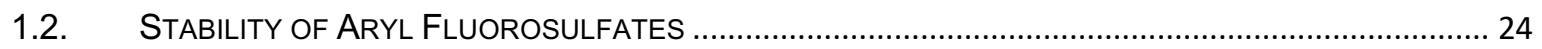

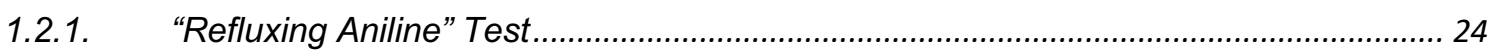

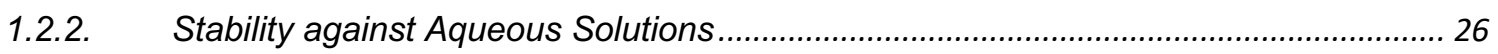

1.2.3. Stability against Reactive Amino Acids in Aqueous Buffers......................................... 28

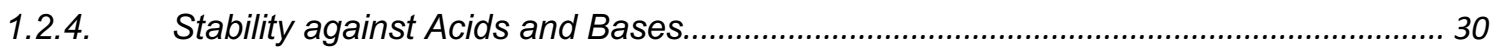

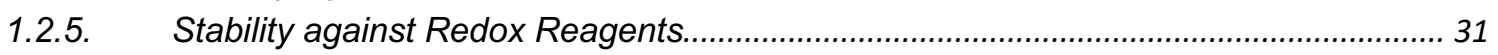

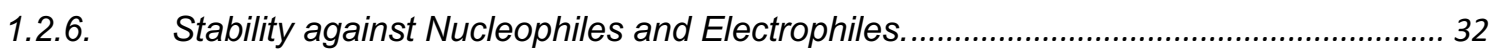

1.2.7. Stability in the Most Frequently Used Reactions in Medicinal Chemistry..................... 34

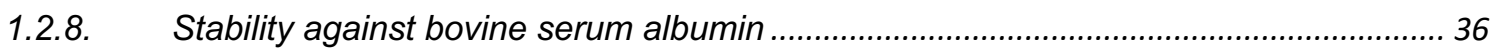

1.3. TIME-DEPENDENT SATURATION TRANSFER EXPERIMENTS ........................................................... 37

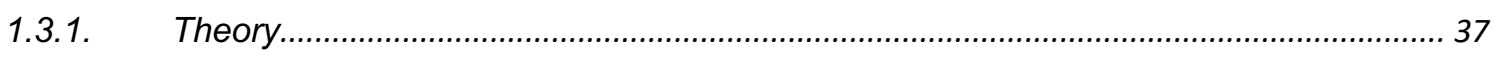

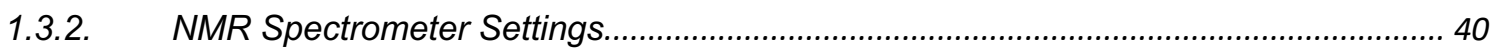

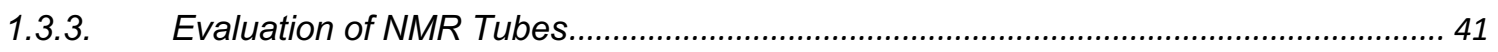

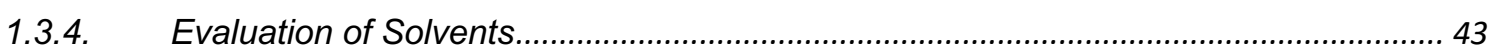

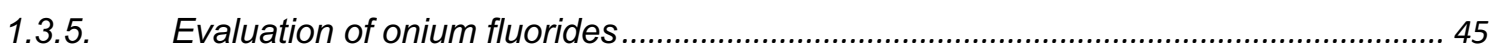

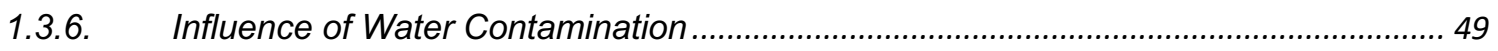

1.3.7. Evaluation of Substituent Effects of Aryl Fluorosulfates................................................ 51

1.3.8. Measurement of Second-Order Rate Constant ............................................................ 56

1.3.9. Correlation of Temperature and Fluoride Exchange Rate ........................................... 59 
2.1. Cell-free Assay for IC 50 Determination of Compound 35 against PARP1 .................... 62

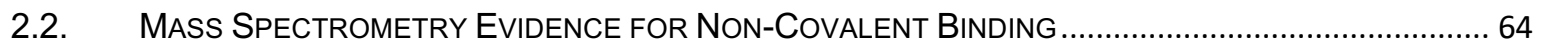

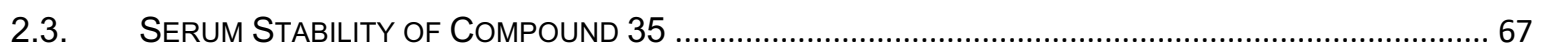

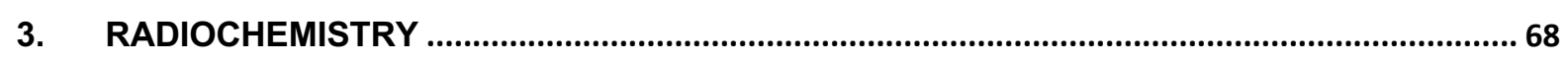

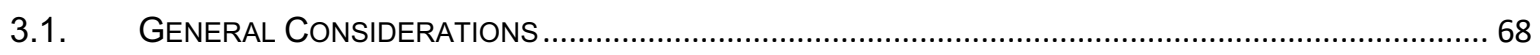

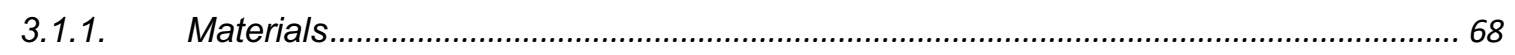

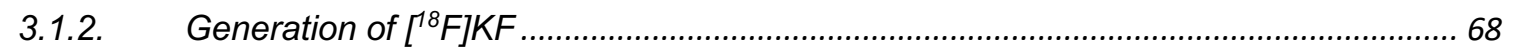

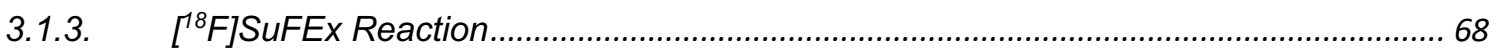

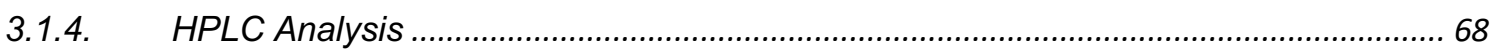

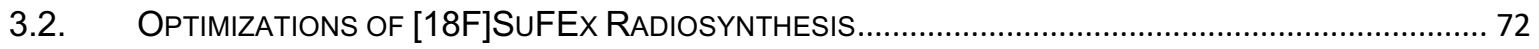

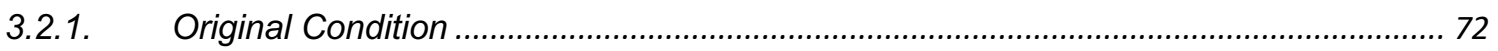

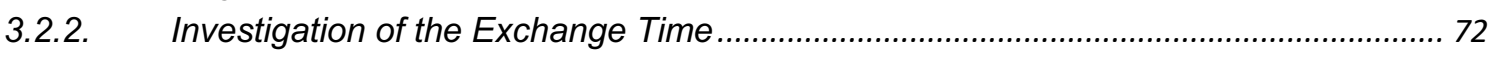

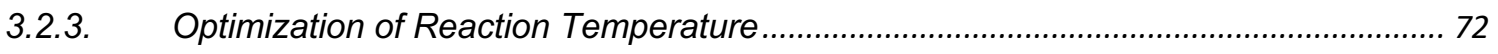

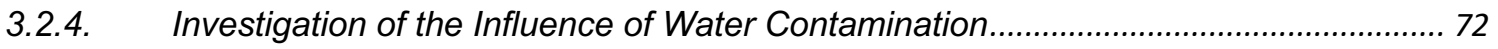

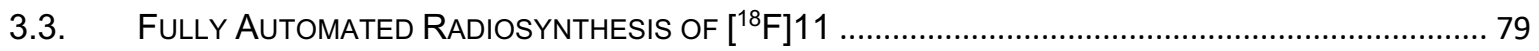

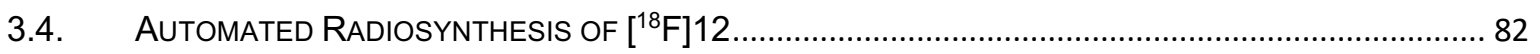

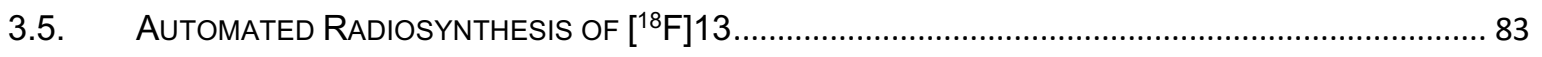

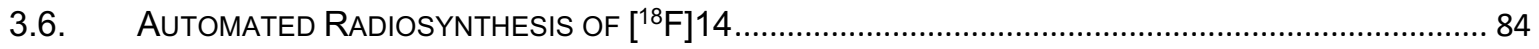

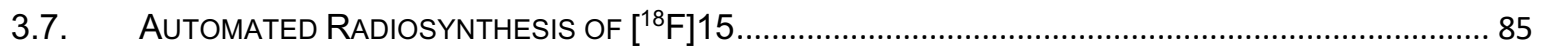

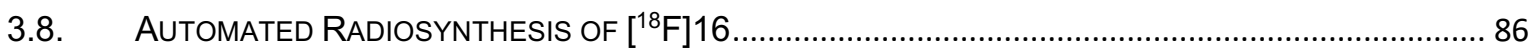

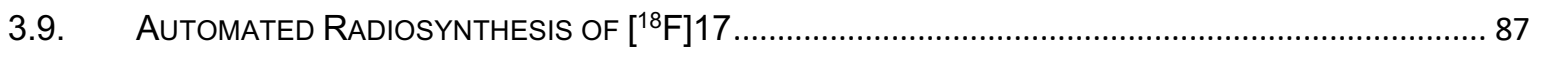

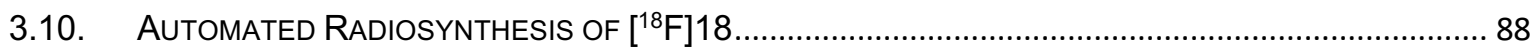

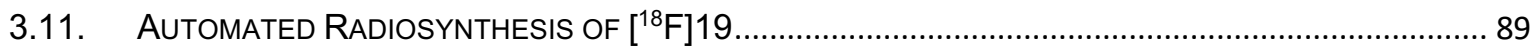

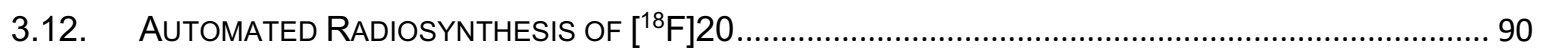

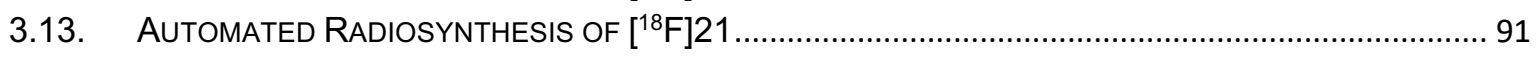

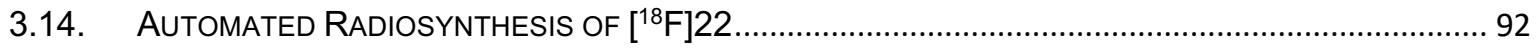

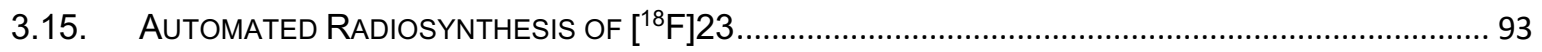

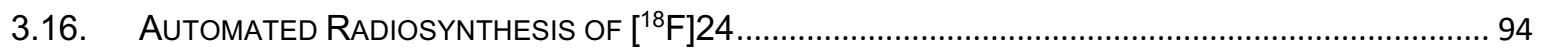

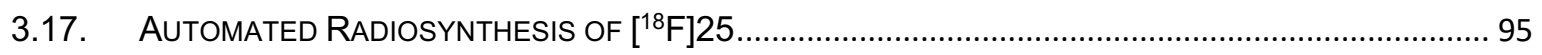

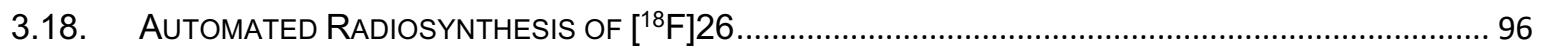

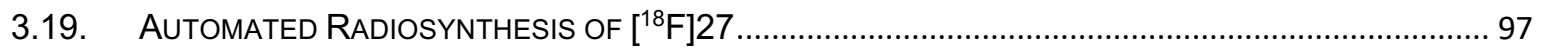

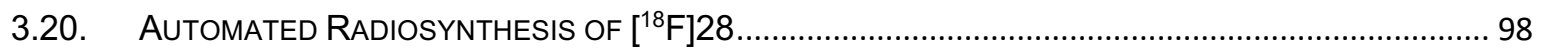

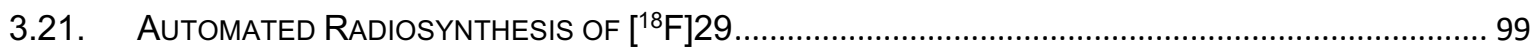

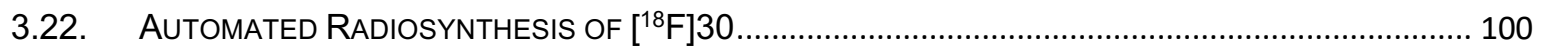

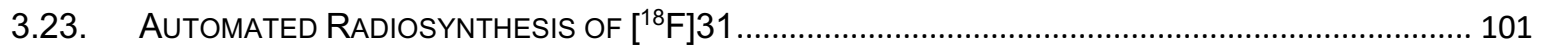

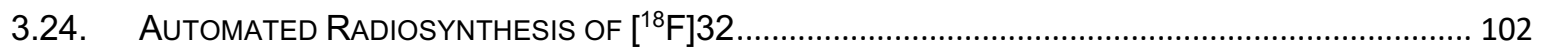

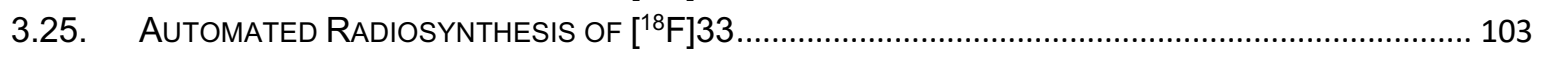

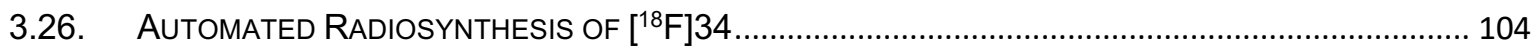

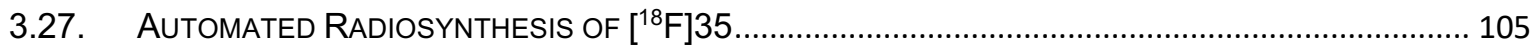

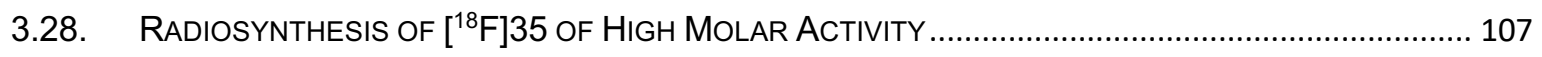

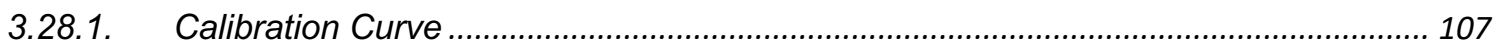

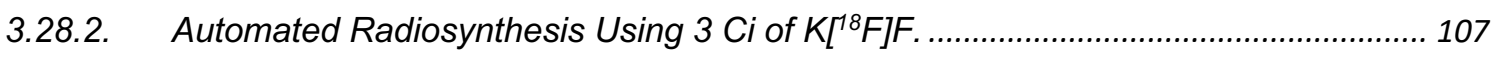

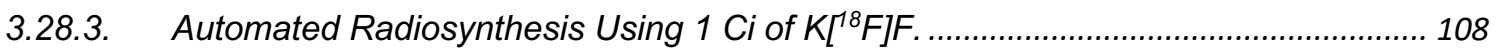

3.28.4. An example (Run \#3) of calculation of Specific Activity and Molar Activity of [ ${ }^{8}$ F]35108 
3.29. LeSS EfFECtIVE EXAMPLES OF $\left[{ }^{18} \mathrm{~F}\right]$ SuFEX RAdIOLABELING .................................................. 117

4. POSITRON EMISSION TOMOGRAPHY (PET) IMAGING .................................................... 120

4.1. Pet Imaging of Nude Mice CARRYIng SubCutaneous TUMOR ......................................... 120

4.2. BLOCKING EXPERIMENTS BY PRE-TREATMENT WITH OLAPARIB ............................................. 126

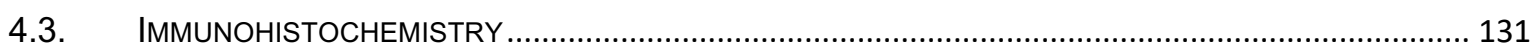

5. INHERITED STABILITY OF ARYL FLUOROSULFATE IN VIVO............................................. 133

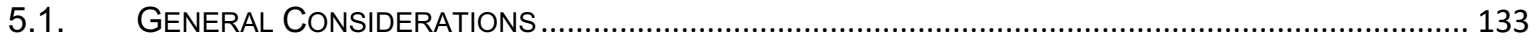

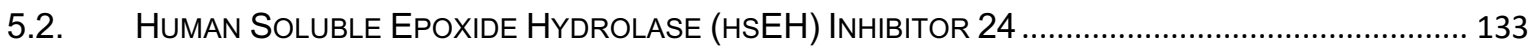

5.3. Selective Estrogen ReCEPTOR DegRAder (SERD) 28 ................................................. 133

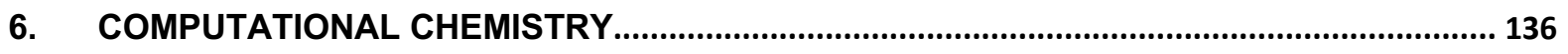

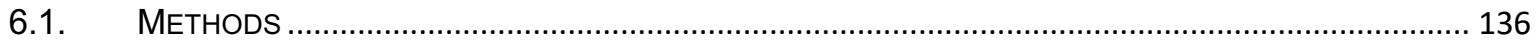

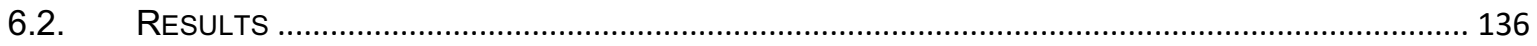

6.2.1. Substitution of Phenyl fluorosulfate by anionic fluoride ........................................................ 136

6.2.2. Substitution of phenyl fluorosulfate by anionic fluoride complexed by tetramethylammonium counterion. 136

6.2.3. Substitution of phenyl fluorosulfate by methyl amine or methanol........................................ 137

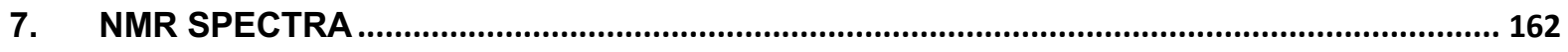

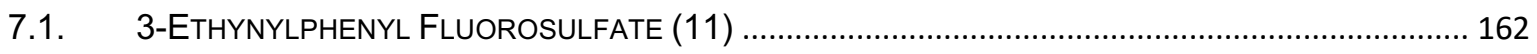

7.2. 2,5-DIOXOPYRROLIDIN-1-YL 4-((FLUOROSULFONYL)OXY)BENZOATE (15)................................ 162

7.3. 4-(2,5-DIOXO-2,5-DIHYDRO-1H-PYRROL-1-YL)PHENYL FLUOROSULFATE (16) ......................... 162

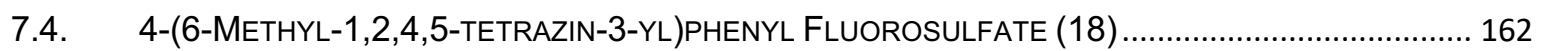

7.5. 3-(6-METHYL-1,2,4,5-TETRAZIN-3-YL)PHENYL FLUOROSULFATE (19) ......................................... 162

7.6. 4-(2-(3,4,5-TRIS(PROP-2-YN-1-YLOXY)BENZAMIDO)ETHYL)PHENYL FLUOROSULFATE (20)....... 162

7.7. 5-(((2S,3S,5R)-2-(HYDROXYMETHYL)-5-(5-METHYL-2,4-DIOXO-3,4-DIHYDROPYRIMIDIN-1(2H)-

YL)TETRAHYDROFURAN-3-YL)CARBAMOYL)-1,3-PHENYLENE BIS(FLUOROSULFATE) (21) ............................. 163

7.8. BENZYL (S)-2-(((BENZYLOXY)CARBONYL)AMINO)-3-(4-

((FLUOROSULFONYL)OXY)PHENYL)PROPANO-ATE (23)

7.9. (E)-4-(4-((TERT-BUTOXYCARBONYL)(METHYL)AMINO)STYRYL)PHENYL FLUOROSULFATE (29).. 163

7.10. (E)-5-(4-((TERT-BUTOXYCARBONYL)(METHYL)AMINO)STYRYL)PYRIDIN-2-YL FLUOROSULFATE (30) 163

7.11. 2-(4-(METHYLAMINO)PHENYL)BENZO[D]THIAZOL-5-YL FLUOROSULFATE (31) ........................... 163

7.12. 4-((2-(2-((2-(4-(METHYLAMINO)PHENYL)BENZO[D]THIAZOL-6-

YL)OXY)ETHOXY)ETHYL)CARBAMOYL)PHENYL FLUOROSULFATE (32)......................................................... 163

7.13. TERT-BUTYL (RS)-2-((RS)-(2-((FLUOROSULFONYL)OXY)PHENOXY)(PHENYL)METHYL)MORPH-

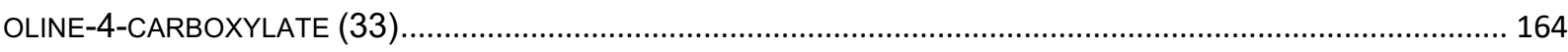

7.14. 4-(2-(4-(2-FLUORO-5-((4-OXO-3,4-DIHYDROPHTHALAZIN-1-YL)METHYL)BENZOYL)PIPERAZ-IN-1-

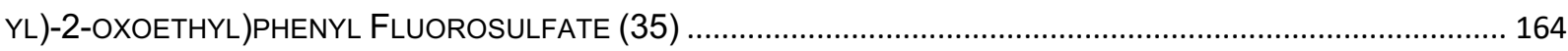

7.15. 2,5-DIOXOPYRROLIDIN-1-YL 3,5-BIS((FLUOROSULFONYL)OXY)BENZOATE (S10) ...................... 164

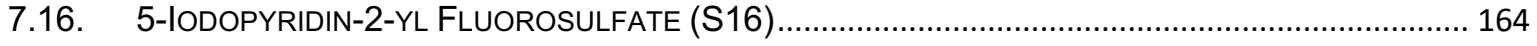

7.17. 2-(4-AMINOPHENYL)BENZO[D]THIAZOL-6-YL FLUOROSULFATE (S19) ...................................... 164

7.18. (RS)-6-((RS)-(2-HYDROXYPHENOXY)(PHENYL)METHYL)MORPHOLIN-3-ONE (S25).................. 164

7.19. (RS)-6-((RS)-(2-((TERT-BUTYLDIMETHYLSILYL)OXY)PHENOXY)(PHENYL)METHYL) MORPHOLIN-3ONE (S26) 165 
7.20. TERT-BUTYL (RS)-2-((RS)-(2-((TERT-BUTYLDIMETHYLSILYL)OXY)PHENOXY)(PHENYL)

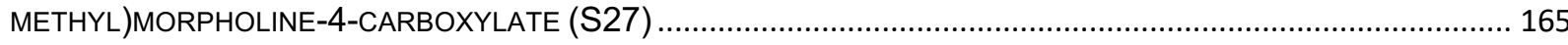

7.21. TERT-BUTYL 4-(2-(4-HYDROXYPHENYL)ACETYL)PIPERAZINE-1-CARBOXYLATE (S30)................ 165

7.22. 2-(4-HYDROXYPHENYL)-1-(PIPERAZIN-1-YL)ETHAN-1-ONE (S31) …........................................ 165

7.23. 4-(4-FLUORO-3-(4-(2-(4-HYDROXYPHENYL)ACETYL)PIPERAZINE-1-CARBONYL)BENZYL)

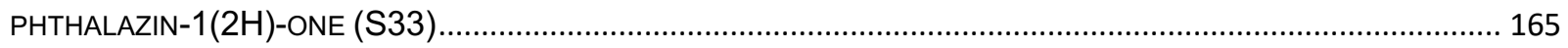

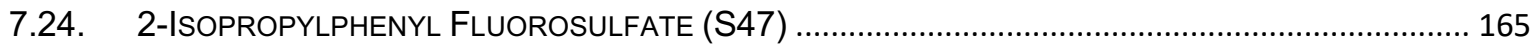

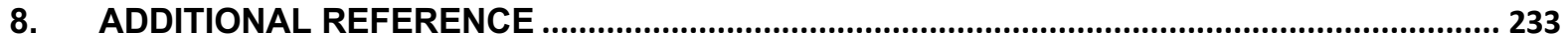




\section{Chemistry}

\subsection{Synthetic Procedures}

\subsubsection{General}

Synthetic reagents, catalysts, and solvents were used as purchased without further purification unless otherwise noted. The extent of chemical reaction was monitored by thin-layer chromatography (TLC), performed on $250 \mu \mathrm{m}$ silica gel $\mathrm{G}$ plates with $\mathrm{F}_{254}$ indicator. The TLC plates were visualized by ultraviolet light $(254 \mathrm{~nm})$. Flash chromatography was performed using 40-63 $\mu \mathrm{m}$ (230-400 mesh) silica gel.

Sulfuryl fluoride $\left(\mathrm{SO}_{2} \mathrm{~F}_{2}\right.$, Vikane $\left.{ }^{\circledR}\right)$ was purchased from SynQuest Labs, Inc. (Alachua, FL) and was used without further purification. (Caution! Sulfuryl fluoride is toxic to human through inhalation.) The use of this gas should be strictly limited in a well vented hood. A technical summary of the toxicity data is available online, at http://npic.orst.edu/factsheets/archive/sftech.html.

Anhydrous solvents were purchased from Acros Organics over $4 \AA$ molecular sieves and sealed with nitrogen. Before use, solvents were freshly distilled from $4 \AA$ molecular sieves pellets (activated according to Prof. David Collum's protocol, available online at https://cpb-use1.wpmucdn.com/blogs.cornell.edu/dist/1/3053/files/2019/10/Molecular sieves activation.pdf).

Unless otherwise noted, nuclear magnetic resonance (NMR) spectra were recorded on a Bruker AV-600 or a DRX-500 instrument $\left({ }^{1} \mathrm{H},{ }^{13} \mathrm{C}\right.$ at $600 \mathrm{MHz}, 151 \mathrm{MHz}$, or $500 \mathrm{MHz}, 126 \mathrm{MHz}$, respectively). ${ }^{19} \mathrm{~F}\left\{{ }^{1} \mathrm{H}\right\}$ and ${ }^{19} \mathrm{~F}\left\{{ }^{19} \mathrm{~F}\right\}$ NMR were recorded on a Bruker AV-400 instrument $\left({ }^{19} \mathrm{~F}\right.$ at $376 \mathrm{MHz}$ ). Data for ${ }^{1} \mathrm{H}$ NMR spectra is reported as follows: chemical shift (ppm, referenced to residual solvent peak), coupling constant $(\mathrm{Hz})$, and integration. Data for ${ }^{13} \mathrm{C} N M R$ is reported in terms of chemical shift (ppm) relative to solvent peak $\left(\mathrm{CDCl}_{3}\right.$ triplet at $77.0 \mathrm{ppm}$, DMSO-d6 multiplet at $39.5 \mathrm{ppm}$, MeOD-d4 multiplet at $49.2 \mathrm{ppm}$, acetone-d6 multiplet at 29.8). Data for ${ }^{19} \mathrm{~F} \mathrm{NMR}$ is reported in terms of chemical shift $(\mathrm{ppm})$ relative to the added internal standard $\left(\mathrm{CFCl}_{3} \text { at } 0.65 \mathrm{ppm}\right)^{1}$. Accurate mass spectrometry (MS) was performed using electrospray ionization (ESI) or atmosphere-pressure chemical ionization (APCl) with a time-of-flight (TOF) analyzer.

The liquid chromatography mass spectrometry (LC-MS) experiments were performed on an Agilent 1260 Infinity Liquid Chromatograph Mass Spectrometer and reported as time of retention $\left(t_{R}\right)$, and mass of the molecular ion(s). The ultra-performance liquid chromatography (UPLC) experiments were performed on a Waters Acquity UPLC H Class instrument with an Acquity UPLC PDA ed Detector.

The gas chromatography mass spectrometry (GC-MS) experiments were performed on an Agilent 5973 Gas Chromatograph Mass Spectrometer and reported as time of retention $\left(t_{R}\right)$, mass of major fragments and their corresponding relative percent abundance (in parentheses). GC Method: flow rate $2 \mathrm{~mL} / \mathrm{min}$; column temperature of $50{ }^{\circ} \mathrm{C}$ for $4 \mathrm{~min}$, then increased to 280 ${ }^{\circ} \mathrm{C}$ at a rate of $20^{\circ} \mathrm{C} / \mathrm{min}$, and then held for $2 \mathrm{~min}$. MS Method: electron ionization (EI, $70 \mathrm{eV}$ ); quadrupole $(\mathrm{Q})$ analyzer. MS data was reported as fragment peaks and the corresponding relative abundance (in parenthesis). 
Melting points (m.p.) were measured on a Barnstead Electrothermal 9300 digital capillary melting point apparatus and are uncorrected.

The characterizations of known compounds 1-10, 12-14, 17, 22, (S)-24, 25-28, S1-S5, S7, $\mathbf{S 9}, \mathbf{S 1 3}, \mathbf{S 1 4}, \mathbf{S 1 7}, \mathbf{S 2 1}, \mathbf{S 2 4}, \mathbf{S 4 3 - S 4 6}$, and S48 were reported in earlier works by us and the others ${ }^{2-13}$. The synthetic procedures and characterizations of new compounds, including the physical state, ${ }^{1} \mathrm{H},{ }^{13} \mathrm{C},{ }^{19} \mathrm{~F}$ NMR, TLC, m.p., and accurate MS and the synthetic procedures thereof were reported as follows. 


\subsubsection{3-Ethynylphenyl Fluorosulfate (11)}

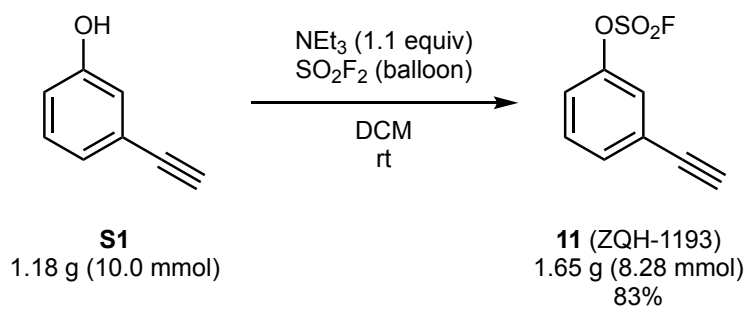

Preparation. A 100-mL round bottom flask equipped with a magnetic stir bar was charged with 3-ethynylphenol (S1, GFS Chemicals, CAS \# 10401-11-3, $1.18 \mathrm{~g}, 10.0 \mathrm{mmol})$. Methylene chloride (DCM, $10 \mathrm{~mL}, c \sim 1 \mathrm{~mol} \mathrm{~L}^{-1}$ ) was added, followed by triethylamine (TEA, $1.53 \mathrm{~mL}, 11.0$ $\mathrm{mmol}, 1.1$ equiv). Sealed by a rubber septum (14/24 joint), the flask was evacuated to vacuum (solvent gently bubbling, 10-20 mbar), and backfilled with sulfuryl fluoride gas (SynQuest Labs, Inc.) via a balloon. The resulting mixture was stirred at room temperature for $2 \mathrm{~h}$. Upon the full conversion of the reaction indicated by TLC, volatiles were removed in vacuo. The residue was diluted with $100 \mathrm{~mL}$ ethyl acetate (EA), washed sequentially with $100 \mathrm{~mL}$ aqueous $\mathrm{HCl}\left(1 \mathrm{~mol} \mathrm{~L}^{-1}\right)$, water, and brine. Dried over anhydrous sodium sulfate, the organic phase was concentrated. The crude product was purified by column chromatography $\left(\mathrm{SiO}_{2}\right)$ to give the title compound 11 (1.65 g, $8.28 \mathrm{mmol}, 83 \%$ isolated yield).

Characterizations. Physical state: Colorless oil (yellow oil after aging on bench top). ${ }^{1} \mathrm{H}$ $\operatorname{NMR}\left(500 \mathrm{MHz}, \mathrm{CDCl}_{3}\right) \delta 7.53(\mathrm{~d}, J=7.7 \mathrm{~Hz}, 1 \mathrm{H}), 7.49-7.41(\mathrm{~m}, 2 \mathrm{H}), 7.34$ (dd, $J=8.4,2.5$ $\mathrm{Hz}, 1 \mathrm{H}), 3.19$ (s, 1H). ${ }^{13} \mathrm{C} \mathrm{NMR}\left(126 \mathrm{MHz}, \mathrm{CDCl}_{3}\right) \delta 149.6,132.4,130.4,124.8,124.5,121.4$, 81.3, 79.7. ${ }^{19} \mathrm{~F} \mathrm{NMR}\left(376 \mathrm{MHz}, \mathrm{CDCl}_{3}\right) \delta 38.2$. TLC: $R_{\mathrm{f}}=0.48(10 \%$ EA in hexanes, UV, stained by $\mathrm{KMnO}_{4}$ ). Accurate $\mathrm{MS}$ (APCl-TOF): Calculated for $\mathrm{C}_{9} \mathrm{H}_{10} \mathrm{FO}_{4} \mathrm{~S}\left[\mathrm{M}+\mathrm{CH}_{3} \mathrm{OH}+\mathrm{H}\right]^{+} 233.0278$, found 233.0277 . 


\subsubsection{2,5-Dioxopyrrolidin-1-yl 4-((fluorosulfonyl)oxy)benzoate (15)}
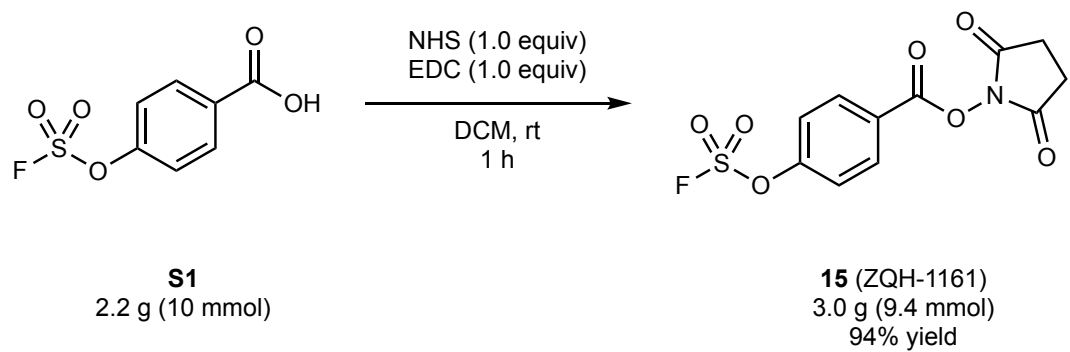

Preparation. The precursor S1 4-((fluorosulfonyl)oxy) benzoic acid was prepared from 4hydroxybenzoic acid according to the earlier report by Baranczak, A. et al. ${ }^{7}$ A $100-\mathrm{mL}$ round bottom flask equipped with a stir bar was charged with $\mathbf{S 1}(2.2 \mathrm{~g}, 10 \mathrm{mmol}), \mathrm{N}$ hydroxysuccinimide (NHS, $1.2 \mathrm{~g}, 10 \mathrm{mmol}, 1.0$ equiv), and 1-ethyl-3-(3-dimethylaminopropyl) carbodiimide hydrochloride (EDC, $1.9 \mathrm{~g}, 10 \mathrm{mmol}, 1.0$ equiv). The solid mixture was suspended on and, in $5 \mathrm{~min}$, dissolved in $25 \mathrm{~mL}$ DCM. The colorless solution was stirred at room temperature for $1 \mathrm{~h}$. The reaction mixture was diluted with $100 \mathrm{~mL}$ DCM and washed sequentially with water $(100 \mathrm{~mL} \times 3)$, and brine $(100 \mathrm{~mL})$. Dried over anhydrous sodium sulfate and filtered, the filtrate was concentrated in vacuo. The crude product was purified by flash chromatography $\left(\mathrm{SiO}_{2}\right.$, eluted by a gradient of $100 \% \mathrm{DCM}$ to $10 \% \mathrm{MeOH}$ in $\left.\mathrm{DCM}\right)$ to give the title compound 15 (3.0 g, $9.4 \mathrm{mmol}, 94 \%$ isolated yield).

Characterizations. Physical state: White crystalline. m.p. $181-182{ }^{\circ} \mathrm{C}$ (from DCM). ${ }^{1} \mathrm{H}$ NMR $\left(600 \mathrm{MHz}, \mathrm{CDCl}_{3}\right) \delta 8.31-8.25(\mathrm{~m}, 2 \mathrm{H}), 7.55-7.48(\mathrm{~m}, 2 \mathrm{H}), 2.92(\mathrm{~s}, 4 \mathrm{H}) .{ }^{13} \mathrm{C}$ NMR $(151 \mathrm{MHz}$, $\left.\mathrm{CDCl}_{3}\right) \delta 169.0,160.5,154.1,133.3,125.9,121.8,25.8 .{ }^{19} \mathrm{~F} \mathrm{NMR}\left(376 \mathrm{MHz}, \mathrm{CDCl}_{3}\right) \delta 39.5$. TLC: $R_{\mathrm{f}}=0.40$ (100\% DCM, UV). Accurate MS (APCI-TOF): Calculated for $\mathrm{C}_{12} \mathrm{H}_{13} \mathrm{FNO}_{8} \mathrm{~S}[\mathrm{M}+$ $\left.\mathrm{CH}_{3} \mathrm{OH}+\mathrm{H}\right]^{+} 350.0340$, found 350.0337. 


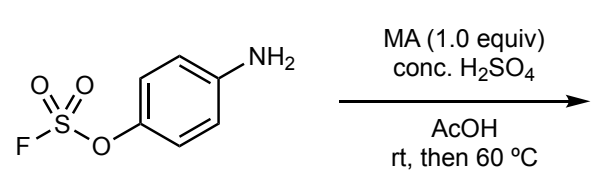

$$
\begin{gathered}
\mathbf{S 2} \\
1.9 \mathrm{~g}(10 \mathrm{mmol})
\end{gathered}
$$

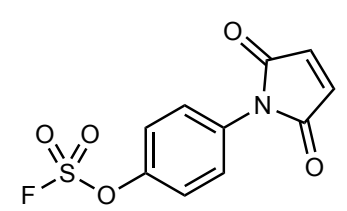

$$
\begin{gathered}
16 \text { (ZQH-1159) } \\
1.4 \mathrm{~g}(5.1 \mathrm{mmol}) \\
51 \% \text { yield }
\end{gathered}
$$

Preparation. The precursor S2 4-(fluorosulfonyl)oxy) aniline was prepared according to our earlier report ${ }^{3}$, and re-crystallized from ethanol before use. A $100-\mathrm{mL}$ round bottom flask, equipped with a stir bar, was charged with $\mathbf{S 2}(1.9 \mathrm{~g}, 10 \mathrm{mmol})$, maleic anhydride (MA, $0.98 \mathrm{~g}$, $10 \mathrm{mmol}, 1.0$ equiv), and $10 \mathrm{~mL}$ glacial acetic acid $(\mathrm{AcOH})$. The mixture was stirred at room temperature for $10 \mathrm{~min}$. Then, $25 \mathrm{~mL}$ concentrated sulfuric acid was added dropwise via a glass pipette while the mixture being vigorous stirred and occasional cooled by an external ice bath. The resulting black mixture was warmed to $60^{\circ} \mathrm{C}$ by an external oil bath for $60 \mathrm{~min}$. Cooled to room temperature, the mixture was poured onto crushed ice $(\sim 50 \mathrm{~g})$. Grey solid precipitated from the mixture, which was filtered and washed sequentially with aqueous sodium bicarbonate solution $(5 \% \mathrm{wt} \%)$ and water. The crude was purified by re-crystallization from ethanol to give the title compound $16(1.4 \mathrm{~g}, 5.1 \mathrm{mmol}, 51 \%$ isolated yield).

Characterizations. Physical state: White crystalline (brown crystalline after aging on bench top). m.p. $128-130{ }^{\circ} \mathrm{C}$ (from ethanol). ${ }^{1} \mathrm{H} \mathrm{NMR}\left(600 \mathrm{MHz}, \mathrm{CDCl}_{3}\right) \delta 7.57-7.52(\mathrm{~m}, 2 \mathrm{H}), 7.48-$ $7.43(\mathrm{~m}, 2 \mathrm{H}), 6.90(\mathrm{~s}, 2 \mathrm{H}) .{ }^{13} \mathrm{C} \mathrm{NMR}\left(151 \mathrm{MHz}, \mathrm{CDCl}_{3}\right) \delta 169.0,148.6,134.6,131.8,127.6$, 121.9. ${ }^{19} \mathrm{~F} \mathrm{NMR}\left(376 \mathrm{MHz}, \mathrm{CDCl}_{3}\right) \delta 38.0$. TLC: $R_{\mathrm{f}}=0.15(25 \% \mathrm{EA}$ in hexanes, faint upon both UV and $\mathrm{KMnO}_{4}$ ). Accurate MS (ESI-TOF): Calculated for $\mathrm{C}_{10} \mathrm{H}_{7} \mathrm{FNO}_{5} \mathrm{~S}\left[\mathrm{M}+\mathrm{H}^{+} 272.0023\right.$, found 272.0027 . 

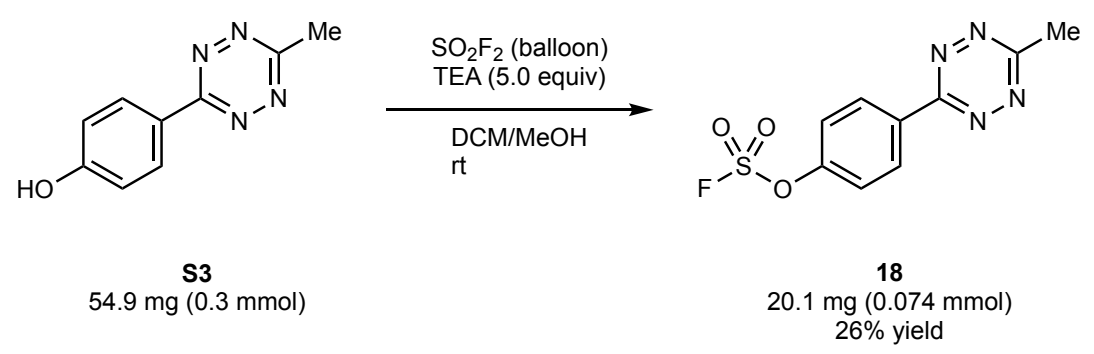

Preparation. The precursor S3 4-(6-methyl-1,2,4,5-tetrazin-3-yl)phenol was prepared according to an earlier report ${ }^{14}$. A $100 \mathrm{~mL}$ round bottom flask equipped with a magnetic stir bar was charged with $\mathbf{S} 3(54.9 \mathrm{mg}, 0.3 \mathrm{mmol})$ and TEA $(203 \mu \mathrm{L}, 1.5 \mathrm{mmol}, 5.0$ equiv) in $\mathrm{DCM} / \mathrm{methanol}(\mathrm{V} / \mathrm{V}=10: 1,10.0 \mathrm{~mL})$. Sealed by a rubber septum (14/24 joint), the flask was evacuated to vacuum (solvent gently bubbling, 10-20 mbar), and backfilled with sulfuryl fluoride gas (SynQuest Labs, Inc.) via a balloon. The resulting mixture was stirred at room temperature for 2 days. Upon the full conversion of the reaction indicated by TLC, volatiles were removed in vacuo. The residue was diluted with $100 \mathrm{~mL}$ ethyl acetate $(E A)$, washed sequentially with $100 \mathrm{~mL}$ aqueous $\mathrm{HCl}\left(1 \mathrm{~mol} \mathrm{~L}^{-1}\right)$, water, and brine. Dried over anhydrous sodium sulfate, the organic phase was concentrated. The crude product was purified by semi-preparative highperformance liquid chromatography (HPLC) to afford the title compound 18 (20.1 mg, 0.074 $\mathrm{mmol}, 26 \%$ yield).

Characterizations. Physical state: Red solid. ${ }^{1} \mathrm{H}$ NMR $\left(500 \mathrm{MHz}, \mathrm{DMSO}-d_{6}\right) \delta 8.66(\mathrm{~d}, \mathrm{~J}=$ $10 \mathrm{~Hz}, 2 \mathrm{H}), 7.91$ (d, $J=10 \mathrm{~Hz}, 2 \mathrm{H}), 3.03$ (s, 3H). ${ }^{13} \mathrm{C}$ NMR $(126 \mathrm{MHz}$, DMSO-d 6 ) $\delta$ 167.5, 162.3, 152.1, 132.9, 130.1, 122.3, 20.9. ${ }^{19} \mathrm{~F}$ NMR (471 MHz, DMSO- $\left.d_{6}\right): \delta 39.9$. TLC: $R_{\mathrm{f}}=0.48(10 \%$ $\mathrm{MeOH}$ in DCM, UV). Accurate MS (ESI-TOF): Calculated for $\mathrm{C}_{9} \mathrm{H}_{8} \mathrm{FN}_{4} \mathrm{O}_{3} \mathrm{~S}[\mathrm{M}+\mathrm{H}]^{+} 271.0301$, found 271.0167. 
<smiles>[M]c1nnc(-c2cccc(O)c2)nn1</smiles>

S4
$51.6 \mathrm{mg}(0.3 \mathrm{mmol})$

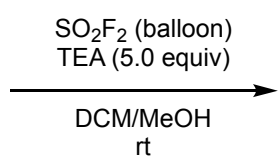

$\mathrm{rt}$<smiles>Cc1nnc(-c2cccc(OS(=O)(=O)F)c2)nn1</smiles>

19
$20.7 \mathrm{mg}(0.077 \mathrm{mmol})$
$28 \%$ yield

Preparation. The precursor S4 3-(6-methyl-1,2,4,5-tetrazin-3-yl)phenol was prepared according to an earlier report ${ }^{15}$. A $100 \mathrm{~mL}$ round bottom flask equipped with a magnetic stir bar was charged with $\mathbf{S 4}(51.6 \mathrm{mg}, 0.3 \mathrm{mmol})$ and TEA (203 $\mu \mathrm{L}, 1.5 \mathrm{mmol}, 5.0$ equiv) in $\mathrm{DCM} /$ methanol $(\mathrm{V} / \mathrm{V}=10: 1,10.0 \mathrm{~mL})$. Sealed by a rubber septum (14/24 joint), the flask was evacuated to vacuum (solvent gently bubbling, 10-20 mbar), and backfilled with sulfuryl fluoride gas (SynQuest Labs, Inc.) via a balloon. The resulting mixture was stirred at room temperature for 2 days. Upon the full conversion of the reaction indicated by TLC, volatiles were removed in vacuo. The residue was diluted with $100 \mathrm{~mL}$ ethyl acetate (EA), washed sequentially with $100 \mathrm{~mL}$ aqueous $\mathrm{HCl}\left(1 \mathrm{~mol} \mathrm{~L}^{-1}\right)$, water, and brine. Dried over anhydrous sodium sulfate, the organic phase was concentrated. The crude product was purified by semi-preparative highperformance liquid chromatography (HPLC) to afford the title compound 19 (20.7 mg, 0.077 $\mathrm{mmol}, 28 \%$ yield).

Characterizations. Physical state: Red solid. ${ }^{1} \mathrm{H}$ NMR $\left(500 \mathrm{MHz}, \mathrm{DMSO}-\mathrm{d}_{6}\right) \delta 8.61$ (d, $\mathrm{J}=5$ $\mathrm{Hz}, 1 \mathrm{H}), 8.59(\mathrm{~s}, 1 \mathrm{H}), 7.97-7.95(\mathrm{~m}, 1 \mathrm{H}), 7.91(\mathrm{t}, J=10 \mathrm{~Hz}, 1 \mathrm{H}), 3.04(\mathrm{~s}, 3 \mathrm{H}) .{ }^{13} \mathrm{C}$ NMR $(126$ $\left.\mathrm{MHz}, \mathrm{DMSO}-d_{6}\right) \delta 167.2,161.6,149.7,134.3,131.7,127.5,124.5,119.3,20.4 .{ }^{19} \mathrm{~F} \mathrm{NMR}(471$ MHz, DMSO- $\left.d_{6}\right): \delta$ 39.5. TLC: $R_{\mathrm{f}}=0.45(10 \% \mathrm{MeOH}$ in DCM, UV). Accurate MS (ESI-TOF): Calculated for $\mathrm{C}_{9} \mathrm{H}_{8} \mathrm{FN}_{4} \mathrm{O}_{3} \mathrm{~S}[\mathrm{M}+\mathrm{H}]^{+}$271.0301, found 271.0162 . 

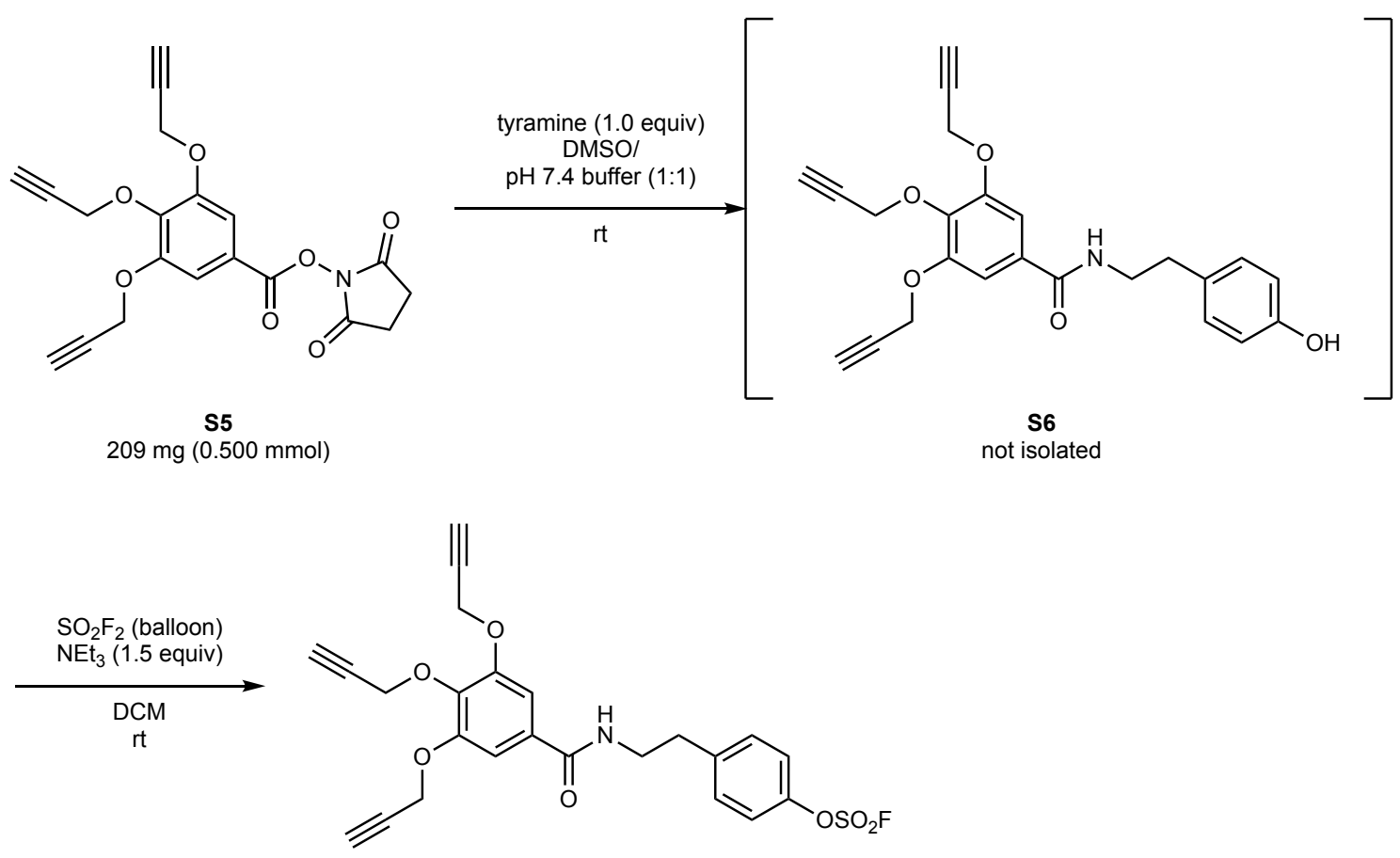

$20(\mathrm{ZQH}-1217)$
$222.8 \mathrm{mg}(0.458 \mathrm{mmol})$
$92 \%$

Preparation. A 20-mL vial equipped with a magnetic stir bar was charged with tyramine (69 $\mathrm{mg}, 0.50 \mathrm{mmol})$, NHS ester of tripropargyl gallic acid $(\mathbf{S} 5,209 \mathrm{mg}, 0.500 \mathrm{mmol}){ }^{16}$. Dimethyl sulfoxide (DMSO, $2.5 \mathrm{~mL})$, and $\mathrm{pH} 7.4$ phosphate buffer $(50 \mathrm{mM}, 2.5 \mathrm{~mL})$ were added. The homogenous mixture was stirred at room temperature for $100 \mathrm{~min}$. The reaction mixture was diluted with EA (50 mL), and sequentially washed with water $(50 \mathrm{~mL} \times 3)$, and brine. The organic phase was concentrated in vacuo to give the crude intermediate S6. Intermediate $\mathbf{S 6}$ was not purified and directly dissolved in DCM $(2 \mathrm{~mL})$. TEA $(0.1 \mathrm{~mL})$ was added. The flask was evacuated and backfilled with sulfuryl fluoride gas via a balloon. The reaction was stirred at room temperature for $2 \mathrm{~h}$. The reaction mixture was directly purified by column chromatography $\left(\mathrm{SiO}_{2}\right.$, eluted by a gradient of $10 \%$ to $60 \% \mathrm{EA}$ in hexanes) to give the title compound 20 (222.8 $\mathrm{mg}, 0.458 \mathrm{mmol}, 92 \%$ isolated yield over two steps).

Characterizations. Physical state: Brown solid. m.p. $105-107^{\circ} \mathrm{C}$ (from hexanes/DCM). ${ }^{1} \mathrm{H}$ NMR $\left(400 \mathrm{MHz}, \mathrm{CDCl}_{3}\right) \delta 7.09-7.04(\mathrm{~m}, 2 \mathrm{H}), 7.01(\mathrm{~d}, \mathrm{~J}=8.6 \mathrm{~Hz}, 2 \mathrm{H}), 6.82(\mathrm{~s}, 2 \mathrm{H}), 5.86(\mathrm{t}, \mathrm{J}=$ $5.8 \mathrm{~Hz}, 1 \mathrm{H}), 4.49(\mathrm{dd}, \mathrm{J}=4.6,2.4 \mathrm{~Hz}, 6 \mathrm{H}), 3.41(\mathrm{q}, \mathrm{J}=6.9 \mathrm{~Hz}, 2 \mathrm{H}), 2.69(\mathrm{t}, \mathrm{J}=7.0 \mathrm{~Hz}, 2 \mathrm{H})$, $2.23(\mathrm{t}, \mathrm{J}=2.4 \mathrm{~Hz}, 2 \mathrm{H}), 2.17(\mathrm{t}, \mathrm{J}=2.4 \mathrm{~Hz}, 1 \mathrm{H}) .{ }^{13} \mathrm{C} \operatorname{NMR}\left(151 \mathrm{MHz}, \mathrm{CDCl}_{3}\right) \delta$ 169.3, 166.9, 151.7, 148.9, 140.0, 130.9, 130.4, 121.3, 107.7, 78.8, 78.1, 76.4, 75.8, 60.5, 57.3, 41.2, 35.3, 25.8. ${ }^{19} \mathrm{~F} \mathrm{NMR}\left(376 \mathrm{MHz}, \mathrm{CDCl}_{3}\right) \delta 37.0$. TLC: $R_{\mathrm{f}}=0.50(60 \% \mathrm{EA}$ in hexanes, UV and stained by $\mathrm{KMnO}_{4}$ ). Accurate $\mathrm{MS}$ (ESI-TOF): Calculated for $\mathrm{C}_{24} \mathrm{H}_{21} \mathrm{FNO}_{7} \mathrm{~S}[\mathrm{M}+\mathrm{H}]^{+} 486.1017$, found 486.1035. 
1.1.8. 5-(((2S,3S,5R)-2-(Hydroxymethyl)-5-(5-methyl-2,4-dioxo-3,4-dihydropyrimidin-1(2H)yl)tetrahydrofuran-3-yl)carbamoyl)-1,3-phenylene Bis(fluorosulfate) (21)

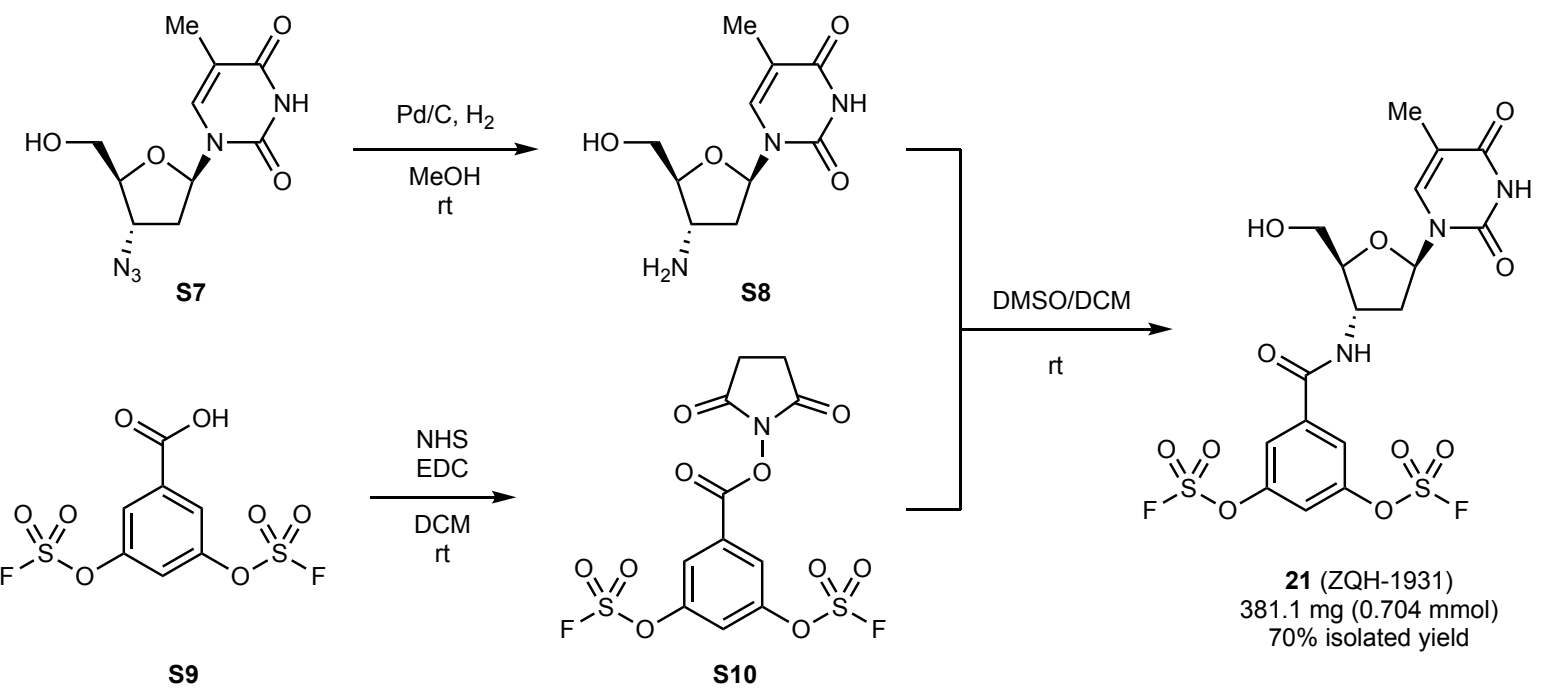

Preparation of Intermediate S8. A $100 \mathrm{~mL}$ round bottom flask equipped with a stir bar was charged with azidothymidine (S7, Acros Organics, $267 \mathrm{mg}, 1.00 \mathrm{mmol}$ ), palladium on carbon (Pd/C, Alfa Aesar, $27 \mathrm{mg}, 10 \mathrm{wt}$ \%). MeOH $\left(5.0 \mathrm{~mL}, c \sim 0.2 \mathrm{~mol} \mathrm{~L}^{-1}\right)$ was added. Hydrogen gas (Praxair) was bubbled through the solution for $10 \mathrm{~min}$. The reaction mixture, topped by hydrogen atmosphere ( $1 \mathrm{~atm})$, was stirred overnight. The mixture was filtered through a pad of Celite and concentrated to give crude S8. The crude was directly used in the preparation of Compound 21 without further purification.

Preparation of Intermediate $\mathbf{S 1 0}$. The preparation of precursor $\mathbf{S 9}$ was reported by us ${ }^{3}$. A $100 \mathrm{~mL}$ round bottom flask equipped with a stir bar was charged with carboxylic acid $\mathbf{S 9}$ (1.14 g, $3.58 \mathrm{mmol})$, NHS (0.412 g, $3.58 \mathrm{mmol}, 1.0$ equiv), and EDC (0.686 g, $3.58 \mathrm{mmol}, 1.0$ equiv). $\mathrm{DCM}\left(20 \mathrm{~mL}, c \sim 0.18 \mathrm{~mol} \mathrm{~L}^{-1}\right)$ was added. The resulting solution was stirred at room temperature for $2 \mathrm{~h}$. Volatiles were removed in vacuo. The residue was purified by column chromatography $\left(\mathrm{SiO}_{2}\right)$ to give the title compound $\mathbf{S} 10(1.29 \mathrm{~g}, 3.02 \mathrm{mmol}, 84 \%$ isolated yield). Physical state: White crystalline. m.p. $146-148^{\circ} \mathrm{C}$ (from hexanes/EA). ${ }^{1} \mathrm{H}$ NMR $(600 \mathrm{MHz}$, Acetone- $\left.d_{6}\right) \delta 8.50(\mathrm{~d}, J=2.3 \mathrm{~Hz}, 2 \mathrm{H}), 8.47(\mathrm{t}, J=2.3 \mathrm{~Hz}, 1 \mathrm{H}), 3.01(\mathrm{~s}, 4 \mathrm{H}) .{ }^{13} \mathrm{C}$ NMR (151 $\mathrm{MHz}$, Acetone- $\left.d_{6}\right) \delta 168.7,158.8,149.1,129.2,124.0,119.1,25.0 .{ }^{19} \mathrm{~F}$ NMR $(376 \mathrm{MHz}$, Acetone- $\left.d_{6}\right) \delta$ 38.6. TLC: $R_{\mathrm{f}}=0.76(67 \% \mathrm{EA}$ in hexanes, UV). MS (ESI-Q): Calculated for $\mathrm{C}_{11} \mathrm{H}_{8} \mathrm{~F}_{2} \mathrm{NO}_{10} \mathrm{~S}_{2}[\mathrm{M}+\mathrm{H}]^{+}$415.96, found 415.8.

Preparation of Compound 21. A $20 \mathrm{~mL}$ scintillation vial equipped by a stir bar was charged with the crude $\mathbf{S} 8$ ( $1.00 \mathrm{mmol}), \mathbf{S 1 0}(415 \mathrm{mg}, 1.00 \mathrm{mmol}, 1.0$ equiv). DMSO (5 mL) and DCM $(5 \mathrm{~mL})$ were added. The resulting solution was stirred for $2 \mathrm{~h}$. Diluted by DCM $(100 \mathrm{~mL})$, the solution was washed by water $(100 \mathrm{~mL} \times 2)$, brine, and dried over anhydrous sodium sulfate. The organic phase was concentrated in vacuo and purified by column chromatography to give the title compound 21 (381 mg, $0.704 \mathrm{mmol}, 70 \%$ isolated yield).

Characterizations of Compound 21. Physical state: White crystalline. m.p. $152-154^{\circ} \mathrm{C}$ (from DCM/MeOH). ${ }^{1} \mathrm{H}$ NMR $\left(600 \mathrm{MHz}, \mathrm{DMSO}-d_{6}\right) \delta 11.31(\mathrm{~s}, 1 \mathrm{H}), 9.13(\mathrm{~d}, J=7.2 \mathrm{~Hz}, 1 \mathrm{H}), 8.42$ 
(t, $J=2.3 \mathrm{~Hz}, 1 \mathrm{H}), 8.28(\mathrm{~d}, J=2.3 \mathrm{~Hz}, 2 \mathrm{H}), 7.82(\mathrm{~d}, J=1.4 \mathrm{~Hz}, 1 \mathrm{H}), 6.32(\mathrm{t}, J=6.9 \mathrm{~Hz}, 1 \mathrm{H})$, $5.15(\mathrm{t}, J=5.2 \mathrm{~Hz}, 1 \mathrm{H}), 4.63-4.56(\mathrm{~m}, 1 \mathrm{H}), 4.00(\mathrm{q}, J=3.8 \mathrm{~Hz}, 1 \mathrm{H}), 3.73-3.61(\mathrm{~m}, 2 \mathrm{H}), 2.37$ $-2.26(\mathrm{~m}, 2 \mathrm{H}), 1.80(\mathrm{~d}, J=1.2 \mathrm{~Hz}, 3 \mathrm{H}) .{ }^{13} \mathrm{C}$ NMR (151 MHz, DMSO) $\delta$ 163.8, 162.4, 150.5, 149.3, 138.5, 136.2, 121.4, 118.7, 109.6, 84.8, 83.7, 61.6, 50.6, 48.6, 40.4, 39.9, 39.8, 39.7,

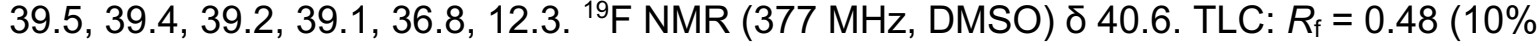
$\mathrm{MeOH}$ in DCM, UV). Accurate MS (ESI-TOF): Calculated for $\mathrm{C}_{17} \mathrm{H}_{18} \mathrm{~F}_{2} \mathrm{~N}_{3} \mathrm{O}_{11} \mathrm{~S}_{2}[\mathrm{M}+\mathrm{H}]^{+}$ 542.0345, found 542.0341. 
1.1.9. Benzyl (S)-2-(((benzyloxy)carbonyl)amino)-3-(4-((fluorosulfonyl)oxy)phenyl) propanoate (23)
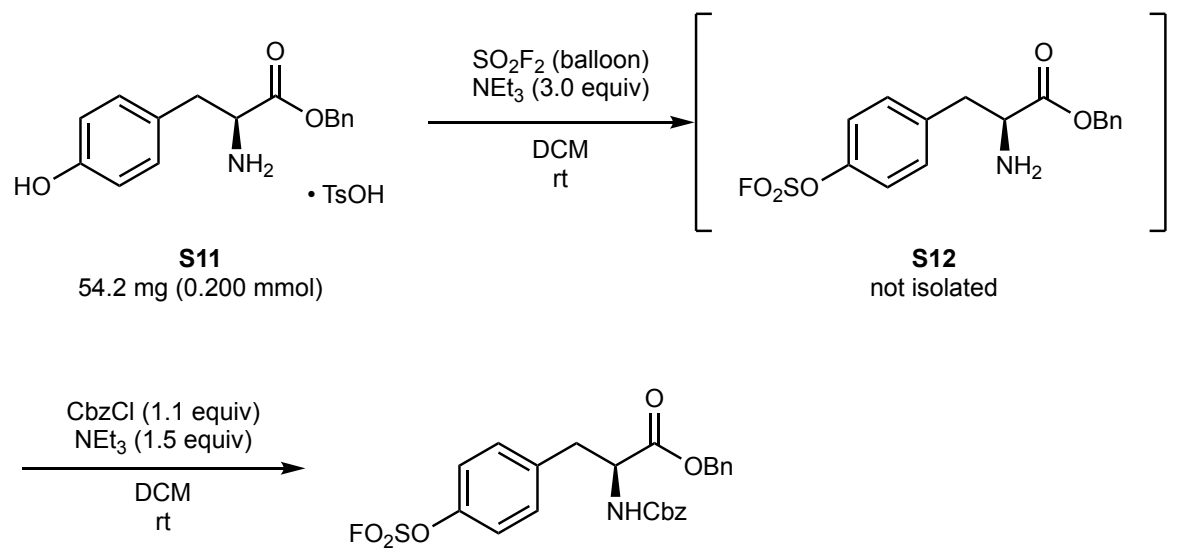

$$
\begin{gathered}
23(\mathrm{ZQH}-1162) \\
88.1 \mathrm{mg}(0.181 \mathrm{mmol}) \\
90 \% \text { for two steps }
\end{gathered}
$$

Preparation. A 4-mL vial equipped with a magnetic stir bar was charged with O-Bn tyrosine tosylate salt (S11, Alfa-Aesar, CAS \# 53587-11-4, $54.2 \mathrm{mg}, 0.200 \mathrm{mmol}$ ). TEA (84 $\mu \mathrm{L}, 0.600$ $\mathrm{mmol}, 3.0$ equiv), and $\mathrm{DCM}\left(1.0 \mathrm{~mL}, c \sim 0.2 \mathrm{~mol} \mathrm{~L}^{-1}\right)$ were added via syringes. The vial was evacuated and backfilled with sulfuryl fluoride gas via a balloon. The mixture was stirred at room temperature for $2 \mathrm{~h}$. Volatiles were removed in vacuo to give the crude Intermediate $\mathbf{S 1 2}$. The intermediate was used in the next step without further purification. The crude $\mathbf{S 1 2}$ was dissolved in DCM $(1.0 \mathrm{~mL})$. TEA $(41 \mu \mathrm{L}, 0.3 \mathrm{mmol}, 1.5$ equiv) and benzyl chloroformate $(\mathrm{CbzCl}$, Alfa Aesar, $38 \mathrm{mg}, 0.22 \mathrm{mmol}, 1.1$ equiv) were added sequentially. The resulting solution was stirred at room temperature for $2 \mathrm{~h}$ and directly purified by column chromatography $\left(\mathrm{SiO}_{2}\right.$, eluted by a gradient of hexanes to $25 \%$ EA in hexanes) to give the title compound 23 ( $88.1 \mathrm{mg}, 0.181$ $\mathrm{mmol}, 90 \%$ isolated yield over two steps).

Characterizations. Physical state: White crystalline. m.p. $78-80^{\circ} \mathrm{C}$ (from hexanes/EA). ${ }^{1} \mathrm{H}$ $\operatorname{NMR}\left(500 \mathrm{MHz}, \mathrm{CDCl}_{3}\right) \delta 7.43-7.27(\mathrm{~m}, 11 \mathrm{H}), 7.12(\mathrm{~d}, J=8.5 \mathrm{~Hz}, 2 \mathrm{H}), 7.04(\mathrm{~d}, J=8.7 \mathrm{~Hz}$, $2 \mathrm{H}), 5.34-5.16(\mathrm{~m}, 2 \mathrm{H}), 5.10(\mathrm{q}, J=11.9 \mathrm{~Hz}, 4 \mathrm{H}), 4.70(\mathrm{q}, J=6.0 \mathrm{~Hz}, 1 \mathrm{H}), 3.13$ (ddd, $J=40.9$, 13.9, $5.8 \mathrm{~Hz}, 2 \mathrm{H}) .{ }^{13} \mathrm{C} \mathrm{NMR}\left(126 \mathrm{MHz}, \mathrm{CDCl}_{3}\right) \delta 171.0,155.6,149.2,136.7,136.2,134.9$, $131.4,129.0,128.9,128.9,128.7,128.5,128.3,121.0,67.7,67.3,54.7,37.7 .{ }^{19} \mathrm{~F}$ NMR $(376$ $\left.\mathrm{MHz}, \mathrm{CDCl}_{3}\right) \delta 37.7$. TLC: $R_{\mathrm{f}}=0.42$ (25\% EA in hexanes, UV). Accurate MS (ESI-TOF): Calculated for $\mathrm{C}_{24} \mathrm{H}_{23} \mathrm{FNO}_{7} \mathrm{~S}[\mathrm{M}+\mathrm{H}]^{+} 488.1174$, found 488.1190 . 
1.1.10. (E)-4-(4-((tert-Butoxycarbonyl)(methyl)amino)styryl)phenyl Fluorosulfate (29)

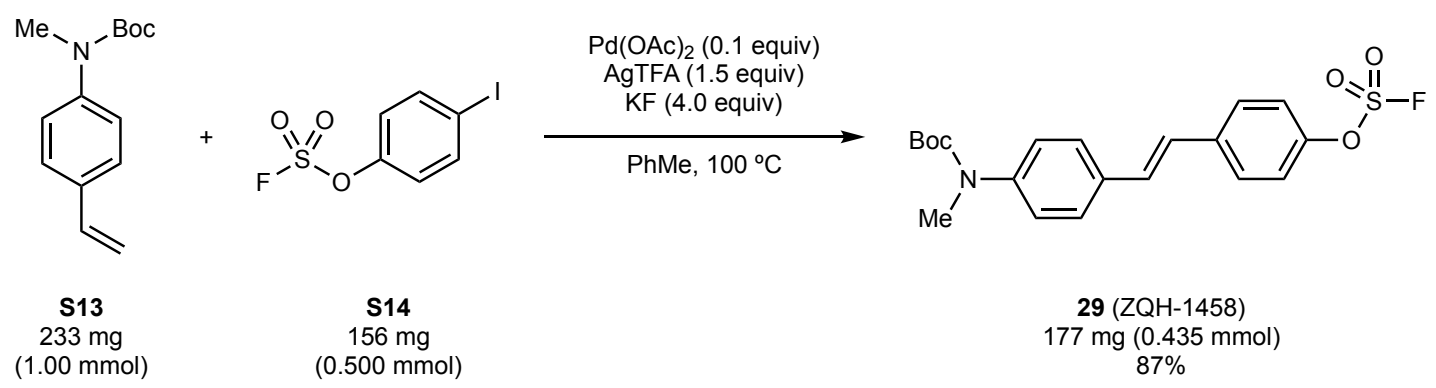

Preparation. A 4-mL vial equipped with a stir bar was charged with $\mathrm{N}$-Boc- $\mathrm{N}$-methyl-4amino styrene (S13, $233 \mathrm{mg}, 1.00 \mathrm{mmol}, 2.0$ equiv) ${ }^{17}$, 4-iodophenyl fluorosulfate (S14, 156 $\mathrm{mg}, 0.500 \mathrm{mmol}, 1.0$ equiv) ${ }^{18}$, palladium(II) acetate ( $\left.\mathrm{Pd}(\mathrm{OAc})_{2}, 11.4 \mathrm{mg}, 0.05 \mathrm{mmol}, 10 \mathrm{~mol} \%\right)$, silver(I) trifluoroacetate (AgTFA, $166.5 \mathrm{mg}, 0.75 \mathrm{mmol}, 1.5$ equiv), and anhydrous potassium fluoride (116.0 mg, $2.0 \mathrm{mmol}, 4.0$ equiv). The vial was sealed with a silicone septum, evacuated to vacuum and backfilled with nitrogen (3 times). Anhydrous toluene $\left(2.0 \mathrm{~mL}, c \sim 0.25 \mathrm{~mol} \mathrm{~L}^{-1}\right.$ for aryl iodide substrate) was added via a syringe. The reaction mixture was stirred in a heating mantle $\left(100^{\circ} \mathrm{C}\right)$ for $6 \mathrm{~h}$. The reaction mixture was diluted by EA and filtered under reduced pressure through a plug of Celite. Concentrated in vacuo, the crude was purified by column chromatography $\left(\mathrm{SiO}_{2}\right.$, eluted by a gradient of $10 \%$ to $25 \% \mathrm{EA}$ in hexanes) to give the title compound 29 ( $177 \mathrm{mg}, 0.435 \mathrm{mmol}, 87 \%$ isolated yield).

Characterizations. Physical state: white crystalline. m.p. 103-104 ${ }^{\circ} \mathrm{C}$ (from hexanes/EA). ${ }^{1} \mathrm{H} \mathrm{NMR}\left(500 \mathrm{MHz}, \mathrm{CDCl}_{3}\right) \delta 7.61-7.53(\mathrm{~m}, 2 \mathrm{H}), 7.50-7.45(\mathrm{~m}, 2 \mathrm{H}), 7.32(\mathrm{~d}, J=8.6 \mathrm{~Hz}, 2 \mathrm{H})$, $7.26(\mathrm{~d}, J=8.4 \mathrm{~Hz}, 2 \mathrm{H}), 7.12-7.00(\mathrm{~m}, 2 \mathrm{H}), 3.28(\mathrm{~s}, 3 \mathrm{H}), 1.47(\mathrm{~s}, 9 \mathrm{H}) .{ }^{13} \mathrm{C}$ NMR $(126 \mathrm{MHz}$, $\left.\mathrm{CDCl}_{3}\right) \delta 154.7,149.1,143.9,138.2,133.6,130.4,128.2,127.0,126.3,125.6,121.3,80.7$, 37.3, 28.5. ${ }^{19} \mathrm{~F} \mathrm{NMR}\left(376 \mathrm{MHz}, \mathrm{CDCl}_{3}\right) \delta 37.7$. TLC: $R_{\mathrm{f}}=0.20(10 \% \mathrm{EA}$ in hexanes, UV and stained by $\mathrm{KMnO}_{4}$ ). Accurate $\mathrm{MS}$ (ESI-TOF): Calculated for $\mathrm{C}_{20} \mathrm{H}_{23} \mathrm{FNO}_{5} \mathrm{~S}[\mathrm{M}+\mathrm{H}]^{+} 408.1275$, found 408.1262 . 

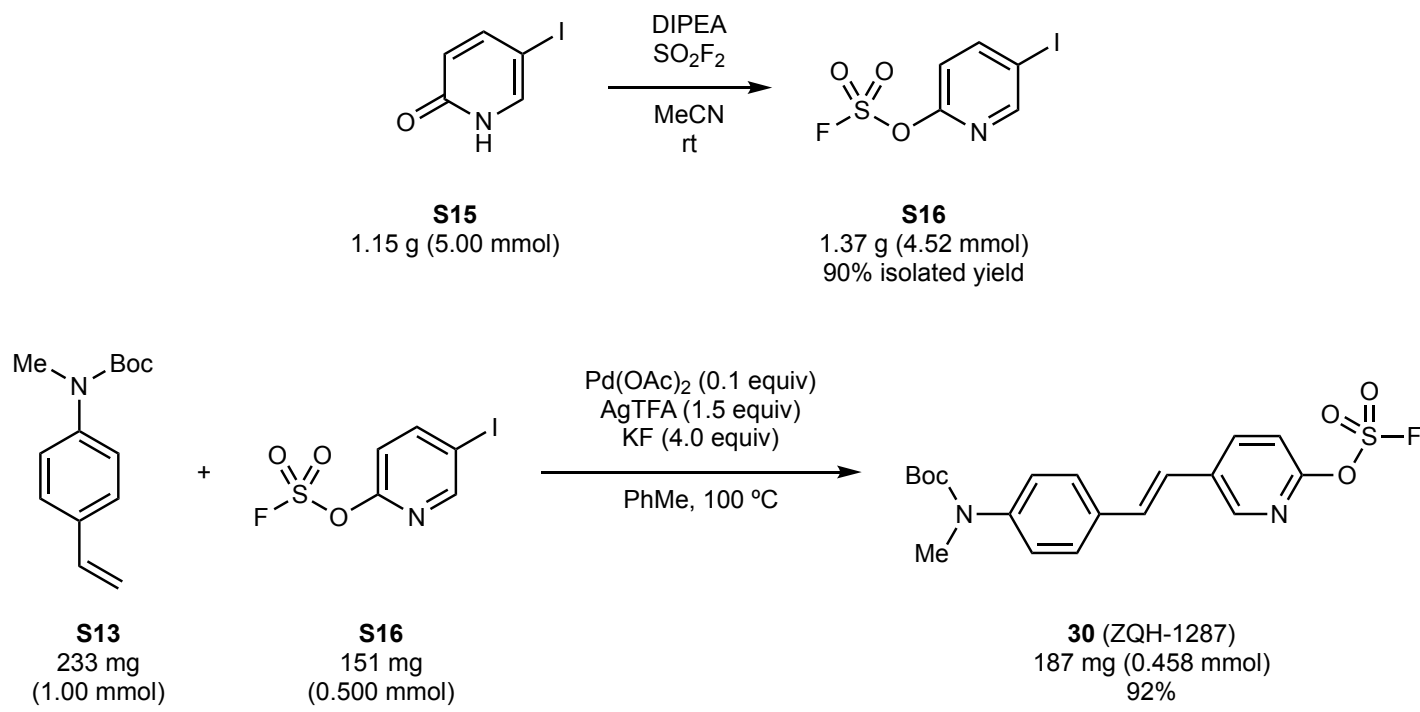

Preparation and characterizations of Intermediate S16. Heteroaryl fluorosulfate 5iodopyridin-2-yl fluorosulfate (S16) was prepared using the known procedure reported by $\mathrm{E}$. Zhang et al. ${ }^{6}$ The commercially available precursor 5-iodopyridin-2-one (S15, Combi-Blocks, CAS \# 13472-79-2, $1.15 \mathrm{~g}, 5.00 \mathrm{mmol}$ ), in the presence of diisopropylethylamine (DIPEA, 1.32 $\mathrm{mL}, 7.50 \mathrm{mmol}, 1.5$ equiv) and a $\mathrm{SO}_{2} \mathrm{~F}_{2}$ balloon, yielded $\mathbf{S} 16$ as an orange liquid $(1.37 \mathrm{~g}, 4.52$ mmol, $90 \%$ isolated yield). ${ }^{1} \mathrm{H}$ NMR $\left(500 \mathrm{MHz} \mathrm{CDCl}_{3}\right) \delta 8.61(\mathrm{~d}, \mathrm{~J}=2.3 \mathrm{~Hz}, 1 \mathrm{H}), 8.18(\mathrm{dd}, \mathrm{J}=$ 8.5, $2.3 \mathrm{~Hz}, 1 \mathrm{H}), 7.02(\mathrm{dd}, J=8.5,0.6 \mathrm{~Hz}, 1 \mathrm{H}) .{ }^{13} \mathrm{C}$ NMR $\left(126 \mathrm{MHz}, \mathrm{CDCl}_{3}\right) \delta 155.9$ (d, J = 1.3 $\mathrm{Hz}), 154.8,149.4,116.2(\mathrm{~d}, J=2.5 \mathrm{~Hz}), 92.1 .{ }^{19} \mathrm{~F} \mathrm{NMR}\left(377 \mathrm{MHz}, \mathrm{CDCl}_{3}\right) \delta 44.5$. TLC: $R_{\mathrm{f}}=0.52$ (16\% EA in hexanes, UV). MS (EI-Q): 302.9 (100, M+), 274.9 (50), 219.9 (12), 191.9 (56), 164.9 (50), 126.9 (18).

Preparation of Compound 30. A 4-mL vial equipped with a stir bar was charged with $\mathrm{N}$ Boc- $N$-methyl-4-amino styrene (S13, $233 \mathrm{mg}, 1.00 \mathrm{mmol}, 2.0$ equiv), Intermediate $\mathbf{S} 16$ (151 mg, $0.500 \mathrm{mmol}, 1.0$ equiv), $\mathrm{Pd}(\mathrm{OAc})_{2}$ (11.4 mg, $\left.0.05 \mathrm{mmol}, 10 \mathrm{~mol} \%\right)$, AgTFA (166.5 mg, 0.75 mmol, 1.5 equiv), and anhydrous KF (116.0 mg, $2.0 \mathrm{mmol}, 4.0$ equiv). The vial was sealed with a silicone septum, evacuated to vacuum and backfilled with nitrogen (3 times). Anhydrous toluene $(2.0 \mathrm{~mL}, c \sim 0.25 \mathrm{M}$ for aryl iodide) was added via a syringe. The reaction mixture was stirred in a heating mantle $\left(100^{\circ} \mathrm{C}\right)$ for $10 \mathrm{~h}$. Then, the reaction mixture was diluted with EA and filtered under reduced pressure through a plug of Celite. Concentrated in vacuo, the crude was purified by column chromatography $\left(\mathrm{SiO}_{2}\right.$, eluted by a gradient of $10 \%$ to $25 \%$ EA in hexanes) to give the title compound 30 (187 $\mathrm{mg}, 0.458 \mathrm{mmol}, 92 \%$ isolated yield).

Characterizations of Compound 30. Physical state: Off-white solid. m.p. $124-125^{\circ} \mathrm{C}$ (from hexanes/EA). ${ }^{1} \mathrm{H}$ NMR $\left(600 \mathrm{MHz}, \mathrm{CDCl}_{3}\right) \delta 8.46(\mathrm{~d}, J=2.4 \mathrm{~Hz}, 1 \mathrm{H}), 8.02$ (dd, $J=8.5,2.5$ $\mathrm{Hz}, 1 \mathrm{H}), 7.48(\mathrm{~d}, J=8.5 \mathrm{~Hz}, 2 \mathrm{H}), 7.28(\mathrm{~d}, J=8.4 \mathrm{~Hz}, 2 \mathrm{H}), 7.18(\mathrm{~d}, J=8.5 \mathrm{~Hz}, 1 \mathrm{H}), 7.14(\mathrm{~d}, J=$ $16.4 \mathrm{~Hz}, 1 \mathrm{H}), 7.02(\mathrm{~d}, J=16.4 \mathrm{~Hz}, 1 \mathrm{H}), 3.29(\mathrm{~s}, 3 \mathrm{H}), 1.48(\mathrm{~s}, 9 \mathrm{H}) .{ }^{13} \mathrm{C} \mathrm{NMR}\left(151 \mathrm{MHz}, \mathrm{CDCl}_{3}\right) \delta$ 155.1, 154.6, 146.7, 144.4, 137.6, 134.4, 132.9, 132.2, 127.1, 125.6, 122.4, 114.4, 80.8, 37.3, 28.5. ${ }^{19} \mathrm{~F} \mathrm{NMR}\left(376 \mathrm{MHz}, \mathrm{CDCl}_{3}\right) \delta$ 43.7. TLC: $R_{\mathrm{f}}=0.20$ (17\% EA in hexanes, UV). Accurate MS (ESI-TOF): Calculated for $\mathrm{C}_{19} \mathrm{H}_{22} \mathrm{FN}_{2} \mathrm{O}_{5} \mathrm{~S}[\mathrm{M}+\mathrm{H}]^{+} 409.1228$, found 409.1243. 


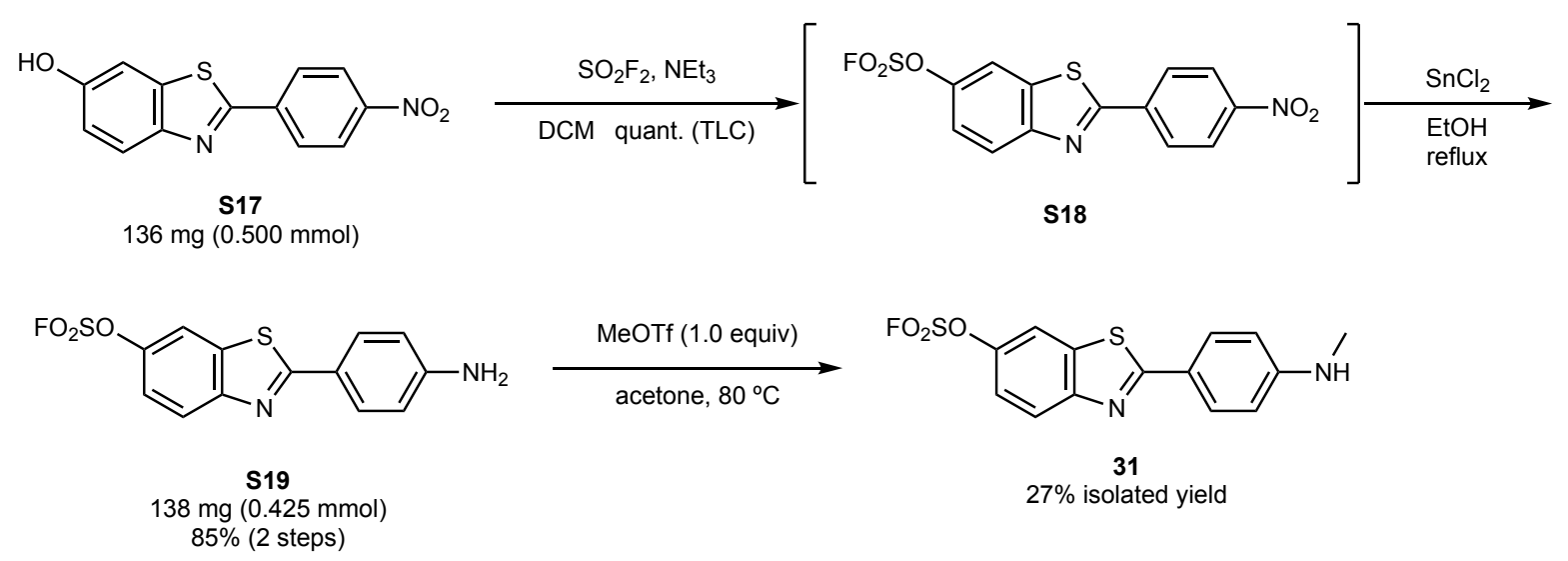

Preparation and characterizations of Intermediate S19. 6-Hydroxy-2-(4'-nitrophenyl)-1,3benzothiazole (S17, $136 \mathrm{mg}, 0.500 \mathrm{mmol}$ ), synthesized according to the earlier report by $\mathrm{K}$. Serdons et al. ${ }^{19}$, was suspended on DCM (yellow suspension). TEA (70 $\mu \mathrm{L}, 0.50 \mathrm{mmol}, 1.0$ equiv) was added, giving a bloody red suspension. Sulfuryl fluoride gas was introduced via a balloon, leading to the formation a dark maroon solution. The mixture was stirred at room temperature for $1 \mathrm{~h}$. Volatiles were removed in vacuo. The residue was diluted by EA and washed with water. The crude product $\mathbf{S 1 8}$ was dissolved in absolute ethanol $(2.0 \mathrm{~mL})$. Tin(II) chloride $\left(\mathrm{SnCl}_{2}, 237 \mathrm{mg}, 1.25 \mathrm{mmol}\right.$ ) was added and the mixture was heated to reflux (external oil bath $80^{\circ} \mathrm{C}$ ) for $2 \mathrm{~h}$. Cooled to room temperature, the solvent was removed in vacuo. Aqueous KF solution ( $2 \mathrm{~mol} \mathrm{~L}^{-1}, 5 \mathrm{~mL}$ ) was added to 'digest' tin(II/IV) species. followed by partitioning between EA $(50 \mathrm{~mL})$ and water $(50 \mathrm{~mL})$. The organic phase was sequentially washed by water and brine, and concentrated. The crude product was purified by column chromatography $\left(\mathrm{SiO}_{2}\right)$ to give the aniline $\mathbf{S} 19(138 \mathrm{mg}, 0.425 \mathrm{mmol}, 85 \%$ isolated yield over two steps). ${ }^{1} \mathrm{H}$ NMR $\left(600 \mathrm{MHz}, \mathrm{CDCl}_{3}\right) \delta 8.02(\mathrm{~d}, J=8.9 \mathrm{~Hz}, 1 \mathrm{H}), 7.92-7.85(\mathrm{~m}, 2 \mathrm{H}), 7.84(\mathrm{~d}, J$ $=2.5 \mathrm{~Hz}, 1 \mathrm{H}), 7.41(\mathrm{dd}, J=9.1,2.7 \mathrm{~Hz}, 1 \mathrm{H}), 6.77-6.72(\mathrm{~m}, 2 \mathrm{H}), 4.07(\mathrm{~s}, 2 \mathrm{H}) .{ }^{13} \mathrm{C}$ NMR $(151$ $\left.\mathrm{MHz}, \mathrm{CDCl}_{3}\right) \delta 171.0,154.1,150.0,146.6,135.9,129.6,123.7,123.3,119.4,114.9,114.3 .{ }^{19} \mathrm{~F}$ NMR (376 MHz, CDCl $\left.{ }_{3}\right) \delta 37.4$. TLC: $R_{\mathrm{f}}=0.1$ (25\% EA in hexanes, strong UV and $\mathrm{KMnO}_{4}$ ). MS (ESI-quadrupole): Calculated for $\mathrm{C}_{13} \mathrm{H}_{9} \mathrm{FN}_{2} \mathrm{O}_{3} \mathrm{~S}_{2} 325.00$, found 325.0.

Preparation of Compound 31. Precursor S19 (30.1 mg, $0.0929 \mathrm{mmol})$ was dissolved in acetone $(0.2 \mathrm{~mL})$. Into the vial, methyl triflate (MeOTf, $10.4 \mu \mathrm{L}, 0.0929 \mathrm{mmol}, 1.0$ equiv) was added via a syringe. The mixture instantly turned dark red from bright yellow. The solution was heated at $80^{\circ} \mathrm{C}$ in the sealed vial for $10 \mathrm{~min}$. Cooled to room temperature, the crude was purified by preparative TLC (pTLC, $20 \times 20 \mathrm{~cm}, 1000 \mu \mathrm{m}$ ) to give the title compound 31 (8.9 $\mathrm{mg}$, $0.025 \mathrm{mmol}, 27 \%$ isolated yield), along with $53 \%$ recovered aniline, and $18 \%$ dimethylated product.

Characterizations of Compound 31. Physical state: Off-white solid. ${ }^{1} \mathrm{H}$ NMR $(600 \mathrm{MHz}$, $\left.\mathrm{CDCl}_{3}\right) \delta 8.00(\mathrm{~d}, J=8.9 \mathrm{~Hz}, 1 \mathrm{H}), 7.91(\mathrm{~d}, J=8.6 \mathrm{~Hz}, 2 \mathrm{H}), 7.82(\mathrm{~d}, J=2.3 \mathrm{~Hz}, 1 \mathrm{H}), 7.40(\mathrm{dd}, J=$ 8.9, $2.3 \mathrm{~Hz}, 1 \mathrm{H}), 6.65(\mathrm{~d}, J=8.6 \mathrm{~Hz}, 2 \mathrm{H}), 4.26-4.12(\mathrm{~m}, 1 \mathrm{H}), 2.93(\mathrm{~d}, J=4.8 \mathrm{~Hz}, 3 \mathrm{H}) .{ }^{13} \mathrm{C}$ NMR $\left(151 \mathrm{MHz}, \mathrm{CDCl}_{3}\right) \delta 171.3,154.2,152.2,146.5,135.8,129.5,123.5,121.9,119.3,114.3$, 112.2, 30.4. $\left.{ }^{19} \mathrm{~F} \mathrm{NMR} \mathrm{(376} \mathrm{MHz,} \mathrm{CDCl}_{3}\right) \delta 37.4$. TLC: $R_{\mathrm{f}}=0.19(25 \% \mathrm{EA}$ in hexanes, strong UV 
and stained by $\mathrm{KMnO}_{4}$ ). Accurate $\mathrm{MS}$ (ESI-TOF): Calculated for $\mathrm{C}_{14} \mathrm{H}_{12} \mathrm{FN}_{2} \mathrm{O}_{3} \mathrm{~S}_{2}[\mathrm{M}+\mathrm{H}]^{+}$ 339.0268, found 339.0278. Fluorescence: $\lambda_{(\mathrm{ex}, \max )}=355 \mathrm{~nm}, \lambda_{(\mathrm{em}, \max )}=440 \mathrm{~nm}$ (Fig. S1).

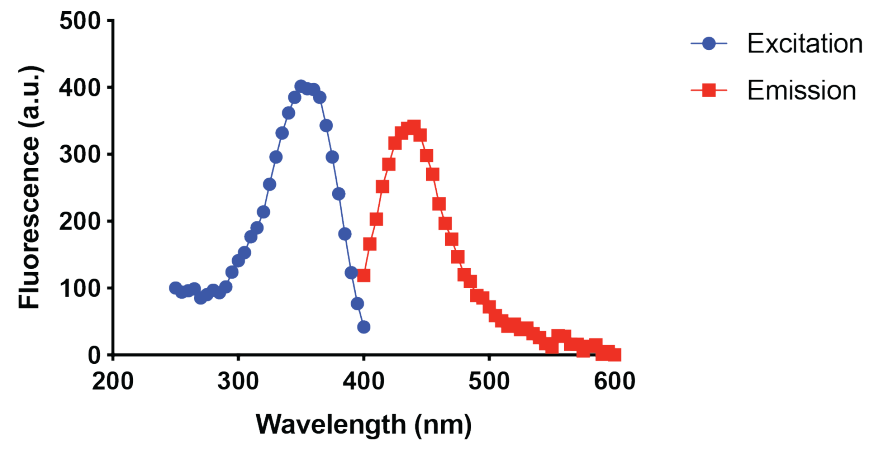

Fig. S1 | Fluorescence spectra of Compound 31. Blue curve, excitation, $\lambda_{\max }=355 \mathrm{~nm}$; red curve, emission, $\lambda_{\max }=440 \mathrm{~nm}$. 


\subsubsection{4-((2-(2-((2-(4-(Methylamino)phenyl)benzo[d]thiazol-6-yl)oxy)ethoxy)ethyl)}

carbamoyl) Phenyl Fluorosulfate (32)
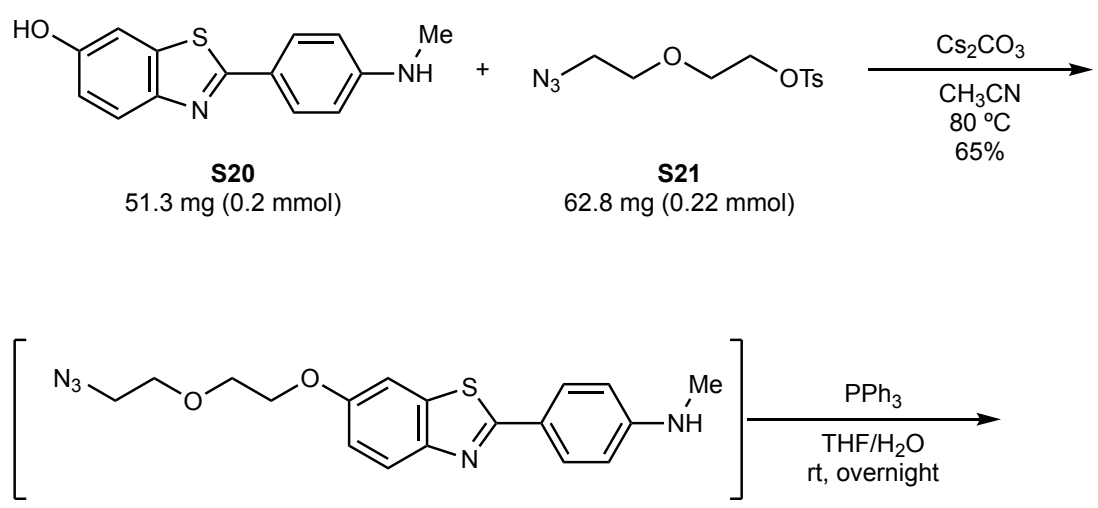

S22<smiles>CNc1ccc(-c2nc3ccc(OCCOCCN)cc3s2)cc1</smiles>

S23<smiles>O=C(ON1C(=O)CCC1=O)c1ccc(OS(=O)(=O)OF)cc1</smiles>

15

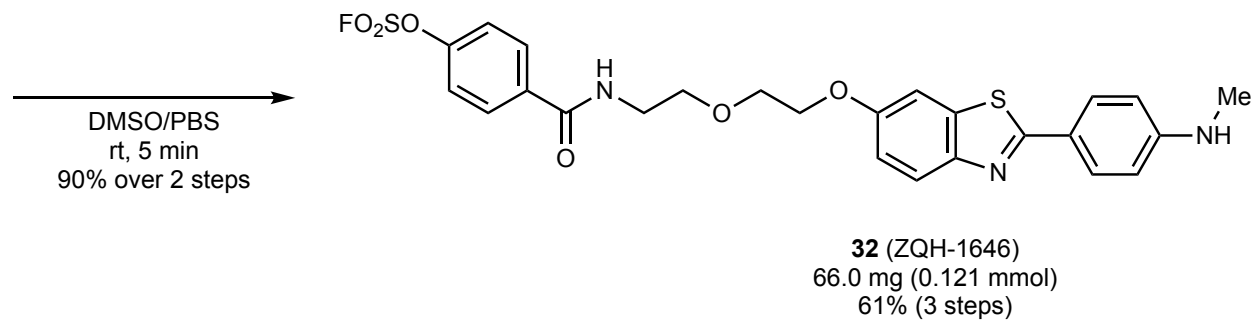

Preparation. Phenol S20 was purchased from a commercial source (Ark Pharm Inc., CAS \# 566169-93-5), tosylate $\mathbf{S} 21$ was synthesized using a procedure reported by I. Lundt et al. ${ }^{20} \mathrm{~A} 4$ $\mathrm{mL}$ vial equipped with a stir bar was charged with compound $\mathbf{S 2 0}(51.3 \mathrm{mg}, 0.2 \mathrm{mmol})$, cesium carbonate (97.7 mg, $0.3 \mathrm{mmol}, 1.5$ equiv), and $1.0 \mathrm{~mL} \mathrm{MeCN}\left(c \sim 0.2 \mathrm{~mol} \mathrm{~L}^{-1}\right)$. To this suspension, compound $\mathbf{S} 21$ (62.8 mg, $0.22 \mathrm{mmol}$ ) in $1.0 \mathrm{~mL} \mathrm{MeCN}$ was added. The mixture was stirred at $80^{\circ} \mathrm{C}$ for $4 \mathrm{~h}$ before partitioned between DCM $(20 \mathrm{~mL})$ and water $(20 \mathrm{~mL})$. The aqueous phase was extracted with DCM $(10 \mathrm{~mL} \times 3)$. The combined organic phase was then washed with brine and dried over anhydrous sodium sulfate. Concentrated in vacuo, the crude product $\mathbf{S 2 2}\left(\sim 80 \%\right.$ yield determined by ${ }^{1} \mathrm{H}$ NMR with $\mathrm{CH}_{2} \mathrm{Br}_{2}$ as internal standard) was dissolved in tetrahydrofuran (THF, $\left.2 \mathrm{~mL}, c \sim 0.1 \mathrm{~mol} \mathrm{~L}^{-1}\right)$. Triphenyl phosphine $(50.3 \mathrm{mg}, 0.192$ $\mathrm{mmol}, 1.2$ equiv) and water $(0.2 \mathrm{~mL})$ were added. The resulting emulsion was stirred at room temperature overnight. Volatiles were removed in vacuo, the residue crude $\mathbf{S 2 3}$ was dissolved in DMSO/PBS (0.5 mL/0.5 mL), and mixed with compound 15 (57 mg, $0.18 \mathrm{mmol}, 1.0$ equiv). The mixture was stirred for $5 \mathrm{~min}$, before directly purified by semi-preparative high-performance liquid chromatography (HPLC) to give the title compound $32(66.0 \mathrm{mg}, 0.121 \mathrm{mmol}, 61 \%$ isolated yield over three steps). 
Characterizations. Physical state: Viscous colorless oil. ${ }^{1} \mathrm{H}$ NMR $\left(500 \mathrm{MHz}\right.$, DMSO- $\left.\mathrm{d}_{6}\right) \delta$ $8.73(\mathrm{t}, J=5.5 \mathrm{~Hz}, 1 \mathrm{H}), 8.05-8.00(\mathrm{~m}, 1 \mathrm{H}), 7.76(\mathrm{dd}, J=8.8,3.3 \mathrm{~Hz}, 2 \mathrm{H}), 7.69(\mathrm{~d}, J=8.7 \mathrm{~Hz}$, $1 \mathrm{H}), 7.59(\mathrm{~d}, J=2.5 \mathrm{~Hz}, 1 \mathrm{H}), 7.03(\mathrm{dd}, J=8.9,2.6 \mathrm{~Hz}, 1 \mathrm{H}), 6.64(\mathrm{~d}, J=8.8 \mathrm{~Hz}, 1 \mathrm{H}), 4.20-4.14$ $(\mathrm{m}, 2 \mathrm{H}), 3.83-3.75(\mathrm{~m}, 2 \mathrm{H}), 3.64(\mathrm{t}, J=5.9 \mathrm{~Hz}, 1 \mathrm{H}), 3.47(\mathrm{q}, J=5.8 \mathrm{~Hz}, 2 \mathrm{H}), 2.75(\mathrm{~s}, 3 \mathrm{H}) .{ }^{13} \mathrm{C}$ NMR (126 MHz, DMSO-d 6 ) $\delta 165.7,164.9,155.9,152.1,151.1,148.4,135.2,135.0,129.9$, $128.3,122.2,121.1,120.3,115.4,111.5,105.7,68.9,68.7,67.7,29.3 .{ }^{19} \mathrm{~F} \mathrm{NMR}(471 \mathrm{MHz}$, DMSO- $\left.\mathrm{d}_{6}\right) \delta$ 39.3. Accurate MS (ESI-TOF): Calculated for $\mathrm{C}_{25} \mathrm{H}_{25} \mathrm{FN}_{3} \mathrm{O}_{6} \mathrm{~S}_{2}[\mathrm{M}+\mathrm{H}]^{+} 546.1169$, found 546.1175 . 
1.1.14. tert-Butyl (RS)-2-((RS)-(2-((fluorosulfonyl)oxy)phenoxy)(phenyl)methyl)morpho-line4-carboxylate ((士)-33)

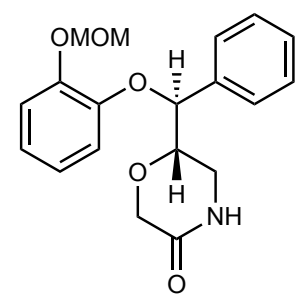

(士)-S24

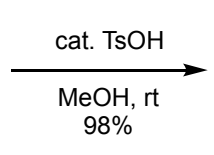

(士)-S27

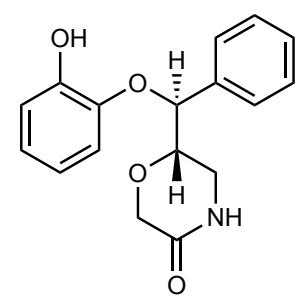

(士)-S25

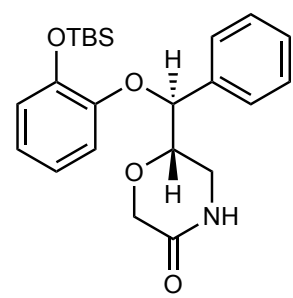

(士)-S26

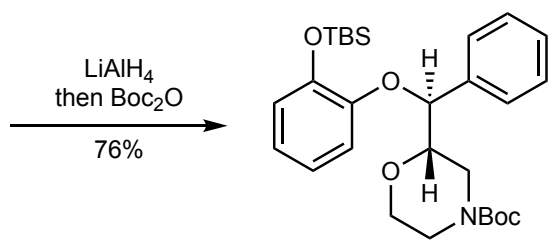

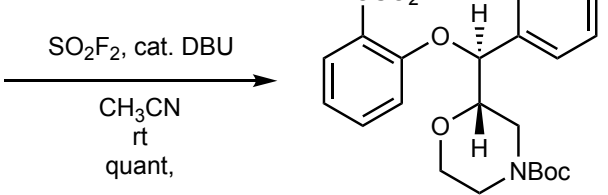

$( \pm)-33$ (ZQH-1522)

Preparation and characterizations of Intermediate ( \pm )-S25. Compound ( $\mathbf{\pm})$-S24 was prepared according to the earlier report by J. Prabhakaran et al. ${ }^{21}$ Compound ( $\left.\mathbf{\pm}\right)-\mathbf{S 2 4}$ (1.4 g, $4.0 \mathrm{mmol})$ was dissolved in methanol $\left(20 \mathrm{~mL}, c \sim 0.2 \mathrm{~mol} \mathrm{~L}^{-1}\right)$. A crystal of $p$-tolyl sulfonic acid $(\mathrm{TsOH}, \sim 50 \mathrm{mg})$ was added to the solution. The mixture was stirred at room temperature overnight. Solvent was removed in vacuo. The residue was dissolved in EA (100 mL) and washed by $100 \mathrm{~mL} \times 3$ aqueous $\mathrm{NaHCO}_{3}$ solution (10\% wt.\%). Compound ( $\left.\mathbf{\pm}\right)$-S25 was obtained as a white solid (1.2 g, $4.0 \mathrm{mmol}, 98 \%$ yield). ${ }^{1} \mathrm{H}$ NMR $\left(600 \mathrm{MHz}\right.$, Methanol- $\left.\mathrm{d}_{4}\right) \delta 7.49$ $-7.45(\mathrm{~m}, 2 \mathrm{H}), 7.40-7.32(\mathrm{~m}, 3 \mathrm{H}), 6.81(\mathrm{dd}, J=7.9,1.7 \mathrm{~Hz}, 1 \mathrm{H}), 6.77(\mathrm{td}, J=7.6,1.4 \mathrm{~Hz}, 1 \mathrm{H})$, $6.70(\mathrm{dd}, J=8.1,1.4 \mathrm{~Hz}, 1 \mathrm{H}), 6.59$ (ddd, $J=8.1,7.4,1.7 \mathrm{~Hz}, 1 \mathrm{H}), 5.22(\mathrm{~d}, J=6.7 \mathrm{~Hz}, 1 \mathrm{H}), 4.33$ $-4.23(\mathrm{~m}, 3 \mathrm{H}), 3.39-3.29(\mathrm{~m}, 3 \mathrm{H}), 2.90(\mathrm{dd}, J=12.3,3.0 \mathrm{~Hz}, 1 \mathrm{H}) .{ }^{13} \mathrm{C} N M R(151 \mathrm{MHz}$, Methanol-d $\left.\mathrm{d}_{4}\right) \delta 170.9,148.7,146.7,138.3,129.8,129.7,128.6,123.6,120.5,117.6,116.9$, 83.9, 77.0, 68.2, 43.6. LC-MS: $t_{R}=4.210 \mathrm{~min}, \mathrm{~m} / \mathrm{z}$ calculated for $[\mathrm{M}+\mathrm{H}]^{+} 300.12$, found 300.1 .

Preparation and characterizations of Intermediate ( \pm )-S26. A 4-mL vial equipped with a stir bar was charged with compound (士)-S25 (60.0 mg, $0.200 \mathrm{mmol})$, tert-butyldimethyl chlorosilane (TBSCl, $45.0 \mathrm{mg}, 0.300 \mathrm{mmol}, 1.5$ equiv), and imidazole ( $40.8 \mathrm{mg}, 0.600 \mathrm{mmol}, 3.0$ equiv). $N, N$-dimethylformamide (DMF, $0.5 \mathrm{~mL}, c \sim 0.4 \mathrm{~mol} \mathrm{~L}^{-1}$ ) was added. The resulting mixture was stirred at room temperature for 60 min before it was quenched with water $(50 \mathrm{~mL})$. Extracted by EA ( $50 \mathrm{~mL} \times 3)$, the organic phase was washed sequentially by water and brine. Compound ( $\mathbf{\pm})$-S26 was obtained as a white foam $\left(82.6 \mathrm{mg}, 0.200 \mathrm{mmol}\right.$, quantitative yield). ${ }^{1} \mathrm{H}$ $\operatorname{NMR}\left(500 \mathrm{MHz}, \mathrm{CDCl}_{3}\right) \delta 7.43-7.27(\mathrm{~m}, 5 \mathrm{H}), 6.83-6.63(\mathrm{~m}, 4 \mathrm{H}), 6.44-6.31(\mathrm{~m}, 1 \mathrm{H}), 5.21(\mathrm{~d}$, $J=6.4 \mathrm{~Hz}, 1 \mathrm{H}), 4.32(\mathrm{~d}, J=16.8 \mathrm{~Hz}, 1 \mathrm{H}), 4.20(\mathrm{~d}, J=16.8 \mathrm{~Hz}, 1 \mathrm{H}), 4.13$ (ddd, $J=10.1,6.4,3.0$ $\mathrm{Hz}, 1 \mathrm{H}), 3.32(\mathrm{t}, J=11.3 \mathrm{~Hz}, 1 \mathrm{H}), 2.94(\mathrm{dt}, J=11.8,3.7 \mathrm{~Hz}, 1 \mathrm{H}), 1.06(\mathrm{~s}, 9 \mathrm{H}), 0.24(\mathrm{~d}, J=3.1$ $\mathrm{Hz}, 6 \mathrm{H}) .{ }^{13} \mathrm{C}$ NMR $\left(151 \mathrm{MHz}, \mathrm{CDCl}_{3}\right) \delta 168.9,149.1,145.5,136.8,128.9,128.9,127.1,121.7$, 
121.6, 121.2, 115.6, 80.7, 75.9, 67.8, 43.2, 25.9, 18.5, -4.2, -4.4. LC-MS: $t_{\mathrm{R}}=5.732 \mathrm{~min}, \mathrm{~m} / \mathrm{z}$ calculated for $[\mathrm{M}+\mathrm{H}]^{+}$414.20, found 414.1.

Preparation and characterizations of Intermediate ( $\mathbf{\pm})-\mathbf{S 2 7}$. A 4-mL vial equipped with a stir bar was charged with ( \pm )-S26 $(20.7 \mathrm{mg}, 50 \mu \mathrm{mol})$. The vial was sealed with a silicone septum, evacuated and backfilled with nitrogen (3 times). Anhydrous THF $(0.5 \mathrm{~mL})$ was added, and the suspension was cooled to $0^{\circ} \mathrm{C}$ by an ice-bath. Lithium aluminum hydride (LAH, $1 \mathrm{~mol} \mathrm{~L}^{-}$ ${ }^{1}$ in THF, $50 \mu \mathrm{L}, 1.0$ equiv) was added dropwise via a syringe. The resulting mixture was then allowed to warm to room temperature slowly and stirred for $60 \mathrm{~min}$ at that temperature. Cooled to $0^{\circ} \mathrm{C}$, the reaction was carefully quenched by adding several drops of EA. The mixture was partitioned between saturated sodium potassium tartrate $\left(c \sim 2.4 \mathrm{~mol} \mathrm{~L}^{-1}, 10 \mathrm{~mL}\right)$, and EA (10 $\mathrm{mL}$ ). The emulsion was vigorously shaken until a clear boundary was formed. Aqueous phase was extracted by EA ( $10 \mathrm{~mL} \times 2)$, and the combined organic phase was washed by water and brine. The crude product of amide reduction was obtained. The amine crude was mixed with ditert-butyl dicarbonate $\left(\mathrm{Boc}_{2} \mathrm{O}, 22 \mathrm{mg}, 100 \mu \mathrm{mol}, 2.0\right.$ equiv) in water $(0.5 \mathrm{~mL})$. The suspension (turning to an emulsion as reaction proceeded) was stirred at $35^{\circ} \mathrm{C}$ for $2 \mathrm{~h}$. The desired product was extracted by EA, and purified by column chromatography $\left(\mathrm{SiO}_{2}\right.$, eluted by a gradient of hexanes to $33 \%$ EA in hexanes) to give the title compound ( $\mathbf{\pm})-\mathbf{S 2 7}$ as a colorless film (20.0 mg, $38 \mu \mathrm{mol}, 76 \%$ isolated yield for two steps). ${ }^{1} \mathrm{H}$ NMR $\left(600 \mathrm{MHz}, \mathrm{CDCl}_{3}\right) \delta 7.38(\mathrm{~d}, J=7.3 \mathrm{~Hz}$, $2 \mathrm{H}), 7.32(\mathrm{t}, J=7.4 \mathrm{~Hz}, 2 \mathrm{H}), 7.27(\mathrm{~d}, J=7.3 \mathrm{~Hz}, 1 \mathrm{H}), 6.82-6.77(\mathrm{~m}, 1 \mathrm{H}), 6.76-6.64(\mathrm{~m}, 3 \mathrm{H})$, $5.12(\mathrm{~d}, J=6.0 \mathrm{~Hz}, 1 \mathrm{H}), 3.92(\mathrm{~d}, J=12.7 \mathrm{~Hz}, 1 \mathrm{H}), 3.79(\mathrm{~s}, 2 \mathrm{H}), 3.67-3.44(\mathrm{~m}, 2 \mathrm{H}), 2.91(\mathrm{~s}$, $1 \mathrm{H}), 2.71(\mathrm{~s}, 1 \mathrm{H}), 1.40(\mathrm{~s}, 9 \mathrm{H}), 1.06(\mathrm{~s}, 9 \mathrm{H}), 0.24(\mathrm{~d}, J=3.1 \mathrm{~Hz}, 6 \mathrm{H}) .{ }^{13} \mathrm{C}$ NMR $(151 \mathrm{MHz}$, $\left.\mathrm{CDCl}_{3}\right) \delta 154.9,149.5,145.6,137.4,128.7,128.4,127.2,121.6,121.2,115.6,81.3,80.1,78.3$, 66.6, 45.9, 44.6, 44.0, 43.1, 28.5, 26.0, 18.6, -4.1, -4.3, -4.4. LC-MS: $t_{\mathrm{R}}=7.380 \mathrm{~min}, \mathrm{~m} / \mathrm{z}$ calculated for $[\mathrm{M}+\mathrm{H}]^{+} 500.28$, found 500.2. TLC: $R_{\mathrm{f}}=0.65$ (33\% EA in hexanes).

Preparation of Compound $(\mathbf{\pm})-33$. A 4-mL vial equipped with a stir bar was charged with ( \pm )-S27 $(20.0 \mathrm{mg}, 38 \mu \mathrm{mol})$. MeCN $(50 \mu \mathrm{L})$ was added and sulfuryl fluoride gas was introduced via a balloon into the vial. 1,8-Diazabicyclo[5.4.0]undec-7-ene (DBU, $0.6 \mathrm{mg}, 10 \mathrm{~mol} \%$ ) was added in $50 \mu \mathrm{L}$ of MeCN. The mixture was stirred for $60 \mathrm{~min}$. Volatiles were removed in vacuo. The crude was purified by preparative TLC (pTLC, 33\% EA in hexanes) to give the title compound ( \pm )-33.

Characterizations of Compound ( \pm )-33. Physical state: Colorless film. ${ }^{1} \mathrm{H}$ NMR $(600 \mathrm{MHz}$, $\left.\mathrm{CDCl}_{3}\right) \delta 7.41-7.27(\mathrm{~m}, 6 \mathrm{H}), 7.13(\mathrm{t}, J=8.6 \mathrm{~Hz}, 1 \mathrm{H}), 6.92(\mathrm{t}, J=7.8 \mathrm{~Hz}, 1 \mathrm{H}), 6.83(\mathrm{dd}, J=8.4$, $1.3 \mathrm{~Hz}, 1 \mathrm{H}), 5.19(\mathrm{~s}, 1 \mathrm{H}), 3.96-3.90(\mathrm{~m}, 1 \mathrm{H}), 3.86$ (ddd, $J=10.7,5.9,2.7 \mathrm{~Hz}, 2 \mathrm{H}), 3.69(\mathrm{~d}, J=$ 13.7 Hz, 1H), $3.57(\mathrm{t}, J=11.9 \mathrm{~Hz}, 1 \mathrm{H}), 2.86(\mathrm{~s}, 1 \mathrm{H}), 2.66(\mathrm{dd}, J=13.1,10.8 \mathrm{~Hz}, 1 \mathrm{H}), 1.42(\mathrm{~s}$, 9H). ${ }^{13} \mathrm{C}$ NMR $\left(151 \mathrm{MHz}, \mathrm{CDCl}_{3}\right) \delta 154.5,148.8,138.9,135.5,128.8,127.9,127.9,126.6$, 121.6, 120.6, 115.6, 80.9, 80.4, 79.7, 77.2, 65.8, 44.6, 43.6, 42.4, 26.7. ${ }^{19} \mathrm{~F} \mathrm{NMR}(376 \mathrm{MHz}$, $\left.\mathrm{CDCl}_{3}\right) \delta 40.3$, 39.6. Accurate MS (ESI-TOF): Calculated for $\mathrm{C}_{22} \mathrm{H}_{26} \mathrm{FNO}_{7} \mathrm{~S}[\mathrm{M}+\mathrm{H}]^{+} 468.1487$, found 468.1497. 
1.1.15. 4-(2-(4-(2-Fluoro-5-((4-oxo-3,4-dihydrophthalazin-1-yl)methyl)benzoyl) piperazin-1yl)-2-oxoethyl)phenyl Fluorosulfate (35)<smiles>CC(C)(C)C(=O)N1CCN(C(=O)Cc2ccc(O)cc2)CC1</smiles>

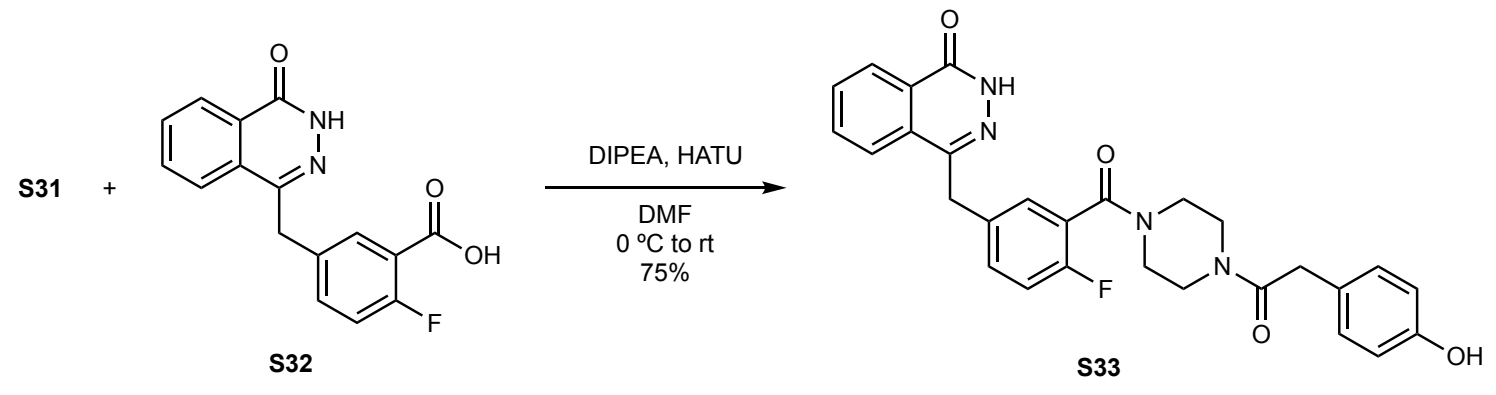<smiles>CN(C)C(N(C)C)n1n[n+](O)c2ccccc21</smiles>

Preparation and characterizations of Intermediate S30. To a stirred solution of 4hydroxyphenylacetic acid (S29, Sigma-Aldrich, CAS \# 156-38-7, $1.00 \mathrm{~g}, 6.57 \mathrm{mmol}$ ) in DMF (50 $\mathrm{mL}, c \sim 0.13 \mathrm{~mol} \mathrm{~L}^{-1}$ ), 1-[bis(dimethylamino)methylene]-1H-1,2,3-triazolo[4,5-b]pyridinium 3oxide hexafluorophosphate (HATU, $3.0 \mathrm{~g}, 7.88 \mathrm{mmol}, 1.2$ equiv) and DIPEA $(1.65 \mathrm{~mL}, 10 \mathrm{mmol}$, 1.5 equiv) were added at $0{ }^{\circ} \mathrm{C}$. The mixture was stirred for $15 \mathrm{~min}$. Then, 1-Boc-piperazine (S28, $1.47 \mathrm{~g}, 7.88 \mathrm{mmol}, 1.2$ equiv) was added. The resulting mixture was stirred at room temperature. Upon full conversion, the reaction mixture was quenched by water, extracted with $\mathrm{DCM}$, sequentially washed with aqueous $\mathrm{HCl}$ solution (5\% wt.\%), water, and brine.

Concentrated in vacuo, the crude was purified by column chromatography $\left(\mathrm{SiO}_{2}\right)$ to give the amide coupling product $\mathbf{S} 30$ (white solid, $1.83 \mathrm{~g}, 5.71 \mathrm{mmol}, 87 \%$ isolated yield). ${ }^{1} \mathrm{H}$ NMR (500 $\mathrm{MHz}$, DMSO-d $\left.\mathrm{d}_{6}\right) \delta 9.26(\mathrm{~s}, 1 \mathrm{H}), 7.01(\mathrm{~d}, J=8.1 \mathrm{~Hz}, 2 \mathrm{H}), 6.78-6.53(\mathrm{~m}, 2 \mathrm{H}), 3.59(\mathrm{~s}, 2 \mathrm{H}), 3.43$ $(\mathrm{t}, J=5.3 \mathrm{~Hz}, 4 \mathrm{H}), 3.26(\mathrm{t}, J=5.2 \mathrm{~Hz}, 2 \mathrm{H}), 3.19(\mathrm{t}, J=5.2 \mathrm{~Hz}, 2 \mathrm{H}), 1.40(\mathrm{~s}, 9 \mathrm{H}) \cdot{ }^{13} \mathrm{C} \mathrm{NMR}(126$ $\left.\mathrm{MHz}, \mathrm{DMSO}-d_{6}\right) \delta 170.0,156.3,154.2,130.2,126.1,115.6,79.6,45.6,41.4,39.3,28.5$. TLC: $R_{\mathrm{f}}$ $=0.65\left(10 \%\right.$ methanol in DCM). Accurate MS (ESI-TOF): Calculated for $\mathrm{C}_{17} \mathrm{H}_{25} \mathrm{~N}_{2} \mathrm{O}[\mathrm{M}+\mathrm{H}]^{+}$ 321.1814 , found 321.1810 . 
Preparation and characterizations of Intermediate S31. To a solution of Intermediate S30 (500 mg, $1.56 \mathrm{mmol}$ ) in $5 \mathrm{~mL}$ DCM, trifluoroacetic acid (TFA, $0.5 \mathrm{~mL}$ ) was added. The mixture was stirred at room temperature for $3 \mathrm{~h}$. Volatiles were removed in vacuo. The crude product S32 (presumably its TFA salt) was obtained (310 mg, $1.4 \mathrm{mmol}, 90 \%)$. ${ }^{1} \mathrm{H} \mathrm{NMR} \mathrm{(500} \mathrm{MHz,}$ DMSO-d $)) \delta 9.11(\mathrm{~s}, 1 \mathrm{H}), 7.10-6.97(\mathrm{~m}, 2 \mathrm{H}), 6.71(\mathrm{~d}, J=8.5 \mathrm{~Hz}, 2 \mathrm{H}), 3.66(\mathrm{dt}, J=10.9,5.2$ $\mathrm{Hz}, 4 \mathrm{H}), 3.62(\mathrm{~s}, 2 \mathrm{H}), 3.05(\mathrm{~d}, J=5.4 \mathrm{~Hz}, 2 \mathrm{H}), 3.01$ (t, $J=5.0 \mathrm{~Hz}, 2 \mathrm{H}) .{ }^{13} \mathrm{C}$ NMR $(126 \mathrm{MHz}$ DMSO) $\delta 170.1,156.4,130.3,125.7,115.7,43.2,43.1,42.8,38.9,38.5$. Accurate MS (ESITOF): Calculated for $\mathrm{C}_{12} \mathrm{H}_{17} \mathrm{~N}_{2} \mathrm{O}_{2}[\mathrm{M}+\mathrm{H}]^{+} 221.1290$, found 221.1289.

Preparation and characterizations of Intermediate S33. To a stirred solution of the commercially available compound S32 (AstaTech Inc., CAS \# 763114-26-7, 298 mg, 1.00 mmol) in DMF (10 ml), S31 (264 mg, 1.20 mmol, 1.2 equiv), HATU (758 mg, 2.00 mmol, 2.0 equiv) and DIPEA (348 $\mu \mathrm{L}, 2.00 \mathrm{mmol}, 2.0$ equiv) were added at $0^{\circ} \mathrm{C}$. The mixture was stirred at $0{ }^{\circ} \mathrm{C}$ for $15 \mathrm{~min}$ and then warmed to room temperature. Upon full conversion, the reaction mixture was quenched by water, extracted with DCM, sequentially washed with aqueous $\mathrm{HCl}$ solution (5\% wt.\%), water, and brine. Concentrated in vacuo, the crude was purified by column chromatography $\left(\mathrm{SiO}_{2}\right)$ to give the title compound S33. ${ }^{1} \mathrm{H}$ NMR (500 MHz, DMSO- $\left.d_{6}\right) \delta 12.61$ (s, 1H), $9.30(\mathrm{~d}, J=1.8 \mathrm{~Hz}, 1 \mathrm{H}), 8.27$ (dd, $J=7.4,2.4 \mathrm{~Hz}, 1 \mathrm{H}), 7.95(\mathrm{~d}, J=7.7 \mathrm{~Hz}, 1 \mathrm{H}), 7.90-$ $7.79(\mathrm{~m}, 2 \mathrm{H}), 7.43$ (ddd, J = 8.0, 5.1, $2.3 \mathrm{~Hz}, 1 \mathrm{H}), 7.39-7.34(\mathrm{~m}, 1 \mathrm{H}), 7.22(\mathrm{t}, J=9.0 \mathrm{~Hz}, 1 \mathrm{H})$, $7.02(\mathrm{dd}, J=13.3,8.0 \mathrm{~Hz}, 2 \mathrm{H}), 6.70(\mathrm{t}, J=7.6 \mathrm{~Hz}, 2 \mathrm{H}), 4.32(\mathrm{~s}, 2 \mathrm{H}), 3.68-3.48(\mathrm{~m}, 6 \mathrm{H}), 3.42-$ $3.37(\mathrm{~m}, 2 \mathrm{H}), 3.11(\mathrm{dt}, J=31.9,5.1 \mathrm{~Hz}, 2 \mathrm{H}) .{ }^{13} \mathrm{C}$ NMR (126 MHz, DMSO-d6) $\delta$ 170.1, 170.0, $164.6,164.5,159.9,156.3,155.9,145.3,135.2,133.9,132.2,132.0,130.3,130.2,129.5,129.4$, $129.4,128.3,126.5,126.0,125.9,124.0,123.9,116.5,116.3,115.7,47.0,46.7,45.9,45.5$, 42.0, 41.8, 41.7, 41.3, 36.9. ${ }^{19} \mathrm{~F}$ NMR (376 MHz, DMSO-d6) $\delta-119.5$.

Preparation of Compound 35. A 25-mL round bottom flask equipped with a magnetic stir bar was charged with $\mathbf{S} 25$ (50.0 mg, $0.1 \mathrm{mmol})$, TEA (28 $\mu \mathrm{L}, 0.2 \mathrm{mmol}, 2.0$ equiv), and DCM (10 $\left.\mathrm{mL}, c \sim 10 \mathrm{mmol} \mathrm{L}^{-1}\right)$. Sealed with a rubber septum (14/24 joint), the flask was evacuated to vacuum (solvent gently bubbling, 10-20 mbar), and backfilled with sulfuryl fluoride gas via a balloon. The resulting mixture was stirred at room temperature for $12 \mathrm{~h}$. Upon full conversion, volatiles were removed in vacuo. The crude product was purified by column chromatography $\left(\mathrm{SiO}_{2}\right)$ to give the title compound $35(43 \mathrm{mg}, 0.074 \mathrm{mmol}, 74 \%$ isolated yield).

Characterizations of Compound 35. Physical state: White solid. ${ }^{1} \mathrm{H} \mathrm{NMR}(500 \mathrm{MHz}$, DMSO-d $)) \delta 12.59(\mathrm{~s}, 1 \mathrm{H}), 8.26(\mathrm{~d}, J=7.3 \mathrm{~Hz}, 1 \mathrm{H}), 7.96(\mathrm{~d}, J=8.0 \mathrm{~Hz}, 1 \mathrm{H}), 7.88(\mathrm{t}, J=7.0 \mathrm{~Hz}$, $1 \mathrm{H}), 7.83(\mathrm{t}, J=7.5 \mathrm{~Hz}, 1 \mathrm{H}), 7.52(\mathrm{dt}, J=7.8,4.1 \mathrm{~Hz}, 1 \mathrm{H}), 7.45(\mathrm{t}, J=9.6 \mathrm{~Hz}, 3 \mathrm{H}), 7.37(\mathrm{t}, J=$ $7.2 \mathrm{~Hz}, 2 \mathrm{H}), 7.23(\mathrm{t}, J=9.0 \mathrm{~Hz}, 1 \mathrm{H}), 4.33(\mathrm{~s}, 2 \mathrm{H}), 3.88(\mathrm{~s}, 1 \mathrm{H}), 3.82(\mathrm{~s}, 1 \mathrm{H}), 3.64-3.52(\mathrm{~m}, 4 \mathrm{H})$, $3.48-3.38(\mathrm{~m}, 2 \mathrm{H}), 3.20-3.13(\mathrm{~m}, 2 \mathrm{H}) .{ }^{13} \mathrm{C} \mathrm{NMR}(126 \mathrm{MHz}, \mathrm{DMSO}) \delta 168.4(\mathrm{~d}, J=3.8 \mathrm{~Hz})$, 164.1 (d, $J=8.8 \mathrm{~Hz}$ ), 159.4, 157.3 (d, $J=7.6 \mathrm{~Hz}$ ), 155.4 (d, $J=7.6 \mathrm{~Hz}$ ), 149.5, 144.8, 139.3 (d, $J=10.1 \mathrm{~Hz}), 134.8,133.5,131.8(\mathrm{~d}, J=7.6 \mathrm{~Hz}), 131.6,130.4(\mathrm{~d}, J=13.7 \mathrm{~Hz}), 129.1,128.9$ (d, $J=3.8 \mathrm{~Hz}), 126.1,125.4,123.5(\mathrm{~d}, J=25.2 \mathrm{~Hz}), 121.8,119.0,116.0(\mathrm{~d}, J=22.7 \mathrm{~Hz}), 46.4(\mathrm{~d}, J$ $=39 \mathrm{~Hz}), 45.1(\mathrm{~d}, J=59 \mathrm{~Hz}), 41.5,41.1(\mathrm{~d}, J=30 \mathrm{~Hz}), 38.6(\mathrm{~d}, J=8.8 \mathrm{~Hz}), 36.4 .{ }^{19} \mathrm{~F} \mathrm{NMR}(471$ $\mathrm{MHz}, \mathrm{DMSO}) \delta 38.8,-119.5$. TLC: $R_{\mathrm{f}}=0.4(10 \% \mathrm{MeOH}$ in DCM). Accurate MS (ESI-TOF): Calculated for $\mathrm{C}_{28} \mathrm{H}_{25} \mathrm{~F}_{2} \mathrm{~N}_{4} \mathrm{O}_{6} \mathrm{~S}[\mathrm{M}+\mathrm{H}]^{+}$583.1463, found, 583.1479. 


\subsubsection{2-Isopropylphenyl Fluorosulfate (S48)}

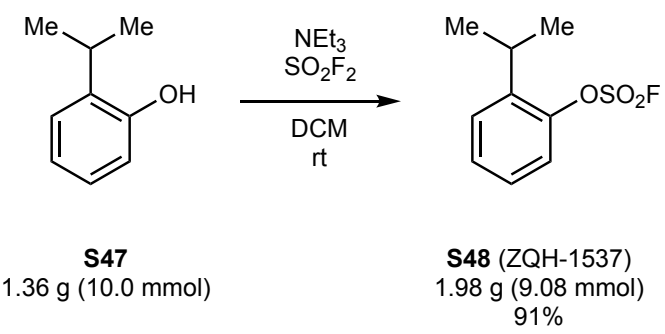

Preparation. A $100 \mathrm{~mL}$ round bottom flask equipped with a magnetic stir bar was charged with 2-isopropylphenol (S47, Sigma-Aldrich, CAS \# 88-69-7, $1.36 \mathrm{~g}, 10.0 \mathrm{mmol}$ ) and TEA (4.2 $\mathrm{mL}, 30.0 \mathrm{mmol}, 1.5$ equiv) in DCM (10.0 mL). Sealed by a rubber septum (14/24 joint), the flask was evacuated to vacuum (solvent gently bubbling, 10-20 mbar), and backfilled with sulfuryl fluoride gas (SynQuest Labs, Inc.) via a balloon. The resulting mixture was stirred at room temperature for 12 hours. Upon the full conversion of the reaction indicated by TLC, volatiles were removed in vacuo. The residue was diluted with $100 \mathrm{~mL}$ ethyl acetate (EA), washed sequentially with $100 \mathrm{~mL}$ aqueous $\mathrm{HCl}\left(1 \mathrm{~mol} \mathrm{~L}^{-1}\right)$, water, and brine. Dried over anhydrous sodium sulfate, the organic phase was concentrated. The crude product was purified by column chromatography $\left(\mathrm{SiO}_{2}\right)$ to afford the title compound $\mathbf{S 4 8}(1.98 \mathrm{~g}, 9.08 \mathrm{mmol}, 91 \%$ yield).

Characterizations. Physical state: Colorless liquid. ${ }^{1} \mathrm{H}$ NMR $\left(500 \mathrm{MHz}, \mathrm{CDCl}_{3}\right) \delta 7.41$ (dd, J $=7.8,1.5 \mathrm{~Hz}, 1 \mathrm{H}), 7.38-7.33(\mathrm{~m}, 1 \mathrm{H}), 7.33-7.20(\mathrm{~m}, 2 \mathrm{H}), 3.31$ (hept, $J=6.8 \mathrm{~Hz}, 1 \mathrm{H}), 1.27(\mathrm{~d}$, $J=6.9 \mathrm{~Hz}, 6 \mathrm{H}) .{ }^{13} \mathrm{C} \mathrm{NMR}\left(126 \mathrm{MHz} \mathrm{CDCl}_{3}\right) \delta 148.1,140.9,129.0,128.1,127.6,120.8,27.1$, 23.2. ${ }^{19} \mathrm{~F}$ NMR (376 MHz, $\left.\mathrm{CDCl}_{3}\right) \delta$ 39.5. MS (EI-Q): Calculated for $\mathrm{C}_{9} \mathrm{H}_{11} \mathrm{FO}_{3} \mathrm{~S}[\mathrm{M}]^{+} 218.04$, found 218 (42), 203 (100), 120 (23), 103 (85), 91 (50), 77 (23), 65 (15), 51 (8). TLC: $R_{\mathrm{f}}=0.48$ (100\% hexanes). 

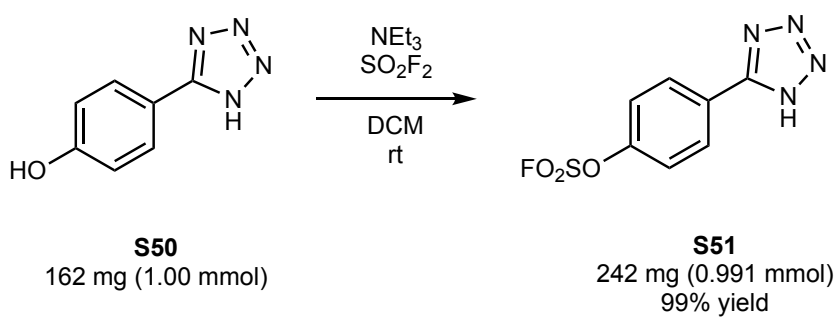

Preparation. Phenol precursor $\mathbf{S 5 0}$ was prepared according to the earlier report by $\mathbf{Z}$. Demko et al. ${ }^{22}$ A $25 \mathrm{~mL}$ round bottom flask equipped with a magnetic stir bar was charged with S50 (162 mg, $1.00 \mathrm{mmol}$ ) and TEA (0.42 mL, $3.00 \mathrm{mmol}, 3.0$ equiv) in DCM (10.0 mL). Sealed by a rubber septum (14/24 joint), the flask was evacuated to vacuum (solvent gently bubbling, 10-20 mbar), and backfilled with sulfuryl fluoride gas (SynQuest Labs, Inc.) via a balloon. The resulting mixture was stirred at room temperature for 1 hours. Upon the full conversion of the reaction indicated by TLC, volatiles were removed in vacuo. The residue was diluted with 100 $\mathrm{mL}$ ethyl acetate (EA), washed sequentially with $100 \mathrm{~mL}$ aqueous $\mathrm{HCl}\left(1 \mathrm{~mol} \mathrm{~L}^{-1}\right)$, water, and brine. Dried over anhydrous sodium sulfate, the organic phase was concentrated. The crude product was purified by column chromatography $\left(\mathrm{SiO}_{2}\right)$ to afford the title compound $\mathbf{S 5 1}$ (242 $\mathrm{mg}, 0.991 \mathrm{mmol}, 99 \%$ yield).

Characterizations. Physical state: White crystalline. m.p. $=195^{\circ} \mathrm{C}$ (decomposed to a brown tar). ${ }^{1} \mathrm{H}$ NMR (400 MHz, Acetone-d6) $\delta 8.37$ (d, J = 8.9 Hz, 2H), 7.80 (d, J = $8.5 \mathrm{~Hz}$, $2 \mathrm{H}) .{ }^{13} \mathrm{C}$ NMR (151 MHz, Acetone-d6) $\delta 157.6,152.4,130.4,127.3,123.1 .{ }^{19} \mathrm{~F} \mathrm{NMR}(377 \mathrm{MHz}$, Acetone-d6) $\delta$ 37.1. Accurate MS (ESI-TOF): Calculated for $\mathrm{C}_{7} \mathrm{H}_{6} \mathrm{FN}_{4} \mathrm{O}_{3} \mathrm{~S}[\mathrm{M}+\mathrm{H}]^{+} 245.0139$, found 245.0130. TLC: $R_{\mathrm{f}}=0.21(17 \% \mathrm{MeOH}$ in DCM). 


\subsection{Stability of Aryl Fluorosulfates}

\subsection{1. "Refluxing Aniline" Test}

The "refluxing aniline" test was originally reported by W. Steinkopf ${ }^{23-24}$ and documented in C. Suter's book chapter on sulfonyl fluoride ${ }^{25}$ - benzenesulfonyl fluoride $\left(\mathrm{PhSO}_{2} \mathrm{~F}\right)$ did not react with neat aniline at its boiling point $\left(184^{\circ} \mathrm{C}\right)$. It was further shown by $\mathrm{Q}$. Zheng et al. ${ }^{26}$ that nearly all commonly used electrophilic groups for drug discovery cannot stay intact under the same condition of "refluxing aniline".

Phenyl fluorosulfate $\left(1, \mathrm{PhOSO}_{2} \mathrm{~F}, 0.1 \mathrm{~mL}\right)$ was heated in refluxing aniline $(1.1 \mathrm{~mL}$, freshly distilled) for $3 \mathrm{~h}$. The mixture was analyzed by GC-MS, and it was found that no reaction took place. Both reactants remained intact. The GC trace was shown in Fig. S2. This experiment demonstrated the inherited stability of the functional group, aryl fluorosulfate in an extreme condition of refluxing aniline.

The same test was performed for the imaging agent used in this study, Compound 35. No apparent reaction took place, the starting material fluorosulfate remained intact (Fig. S3).

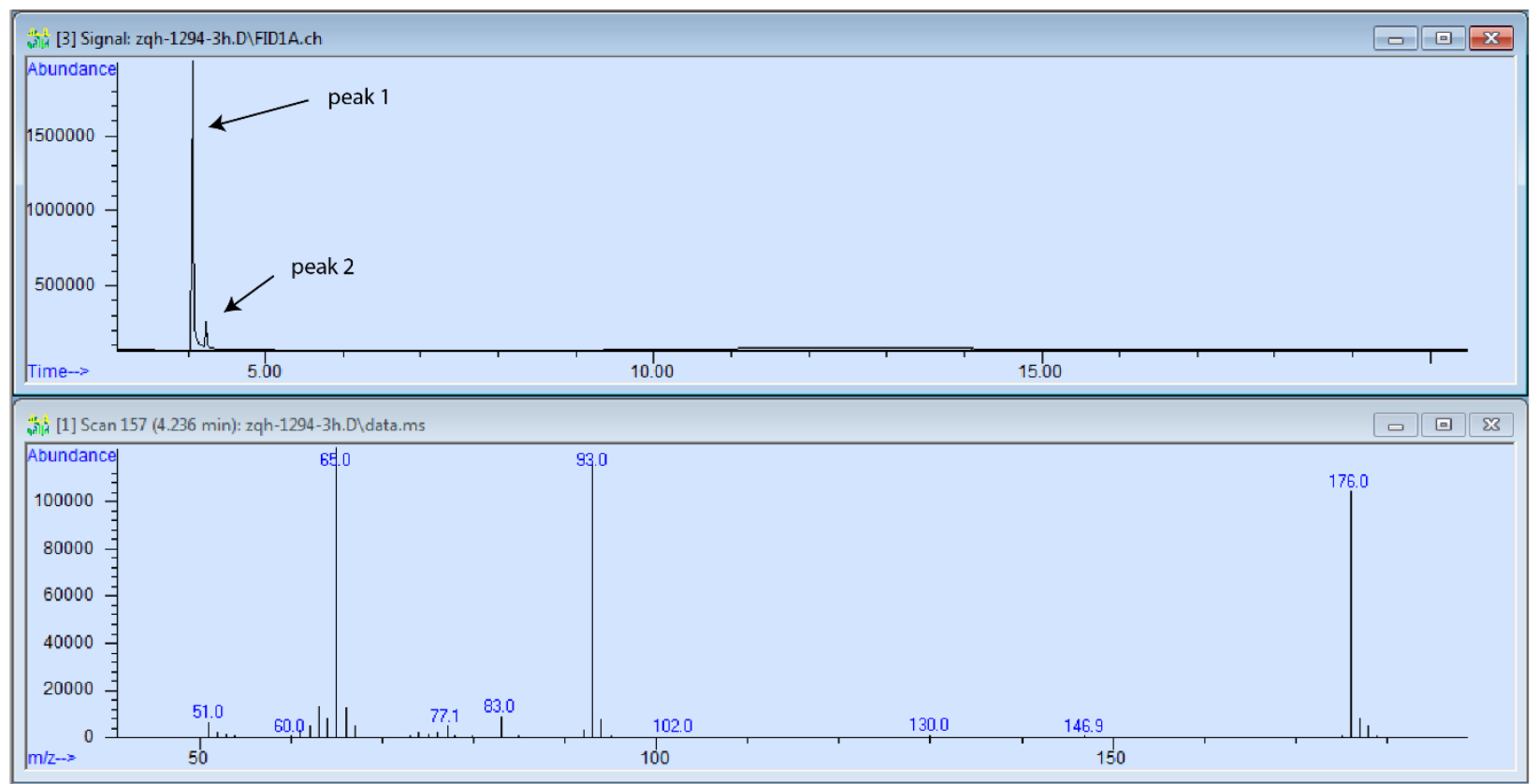

Fig. S2 | Stability of phenyl fluorosulfate in refluxing aniline. GC chromatogram of crude mixture of phenyl fluorosulfate in refluxing aniline for $3 \mathrm{~h}$. Peak 1 (aniline): $t_{\mathrm{R}}=4.053 \mathrm{~min}, \mathrm{El}-\mathrm{Q}$ MS m/z calculated for $\mathrm{C}_{6} \mathrm{H}_{7} \mathrm{~N}^{+}$93.1, found 93.1. Peak 2 (phenyl fluorosulfate): $t_{\mathrm{R}}=4.236 \mathrm{~min}$, El-Q MS m/z calculated for $\mathrm{C}_{6} \mathrm{H}_{5} \mathrm{O}_{3} \mathrm{SF}^{+} 176.0$, found 176.0. 
A

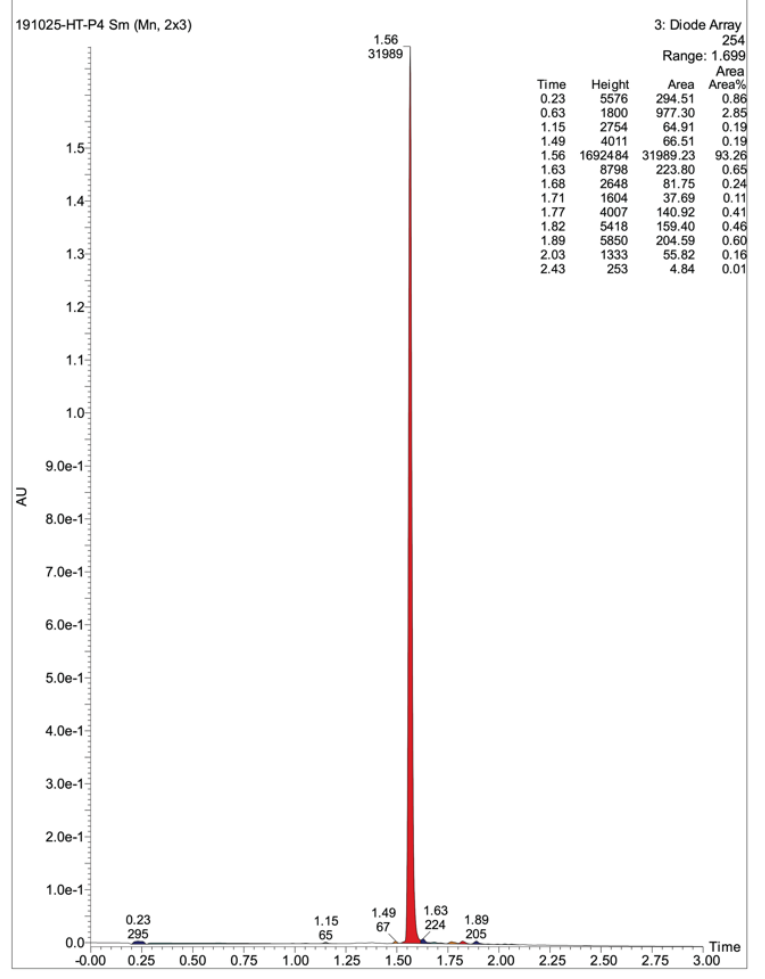

B

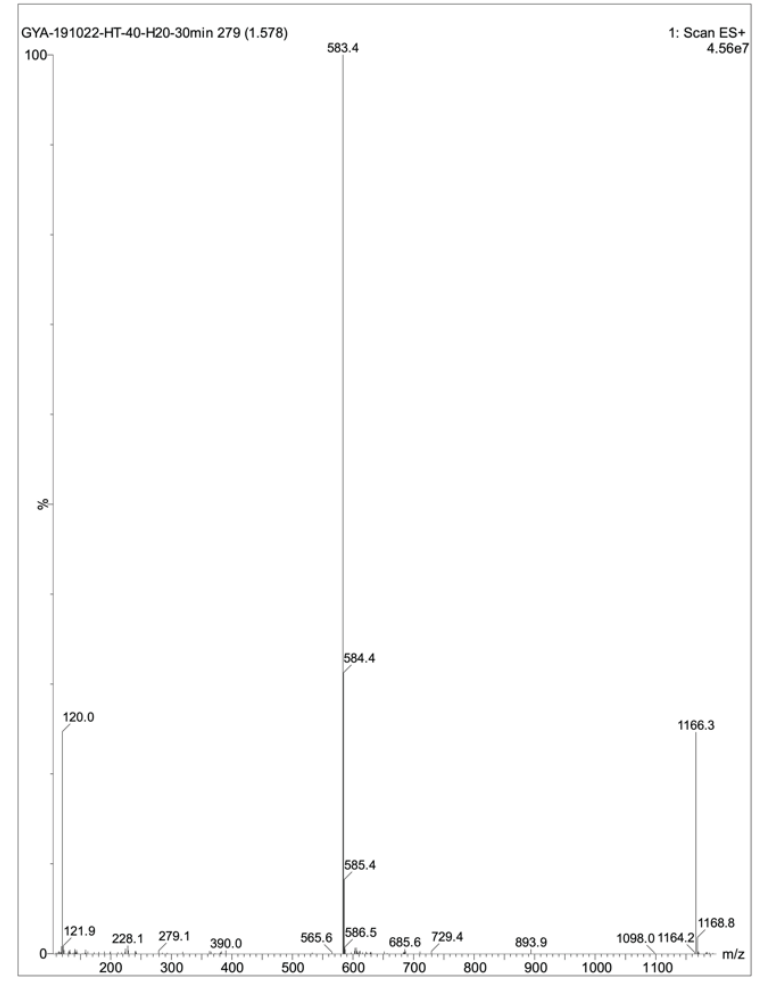

Fig. S3 | Stability of Compound 35 in refluxing aniline. UPLC chromatogram of crude mixture of Compound $35 \mathrm{in}$ refluxing aniline for $3 \mathrm{~h}$. Peak (35): $t_{\mathrm{R}}=1.56 \mathrm{~min}$, ESI-Q MS m/z calculated for $\mathrm{C}_{28} \mathrm{H}_{25} \mathrm{~F}_{2} \mathrm{~N}_{4} \mathrm{O}_{6} \mathrm{~S}^{+}[\mathrm{M}+\mathrm{H}]^{+}$583.1, found 583.4. 


\subsubsection{Stability against Aqueous Solutions}

General. The in vitro stability of aryl fluorosulfate against hydrolysis was examined using phenyl fluorosulfate (1) in various buffer systems, as well as strong acid and base solutions. Stock solution of phenyl fluorosulfate $\left(1,10 \mathrm{mmol} \mathrm{L}^{-1}\right)$ in acetonitrile was prepared. Mix $0.5 \mathrm{~mL}$ of the stock solution with $0.5 \mathrm{~mL}$ of respective aqueous buffer solutions in a 2-mL HPLC vial, thus the final concentration of the analyte being $5 \mathrm{mmol} \mathrm{L}^{-1}$. Aliquots $(1 \mu \mathrm{L})$ were taken from the shaken mixture, diluted by methanol and analyzed by LC-MS. Remaining of the starting material was determined based on HPLC analysis (UV $254 \mathrm{~nm}$ channel).

Stability in aqueous buffers. Commercially available pH 4.00 (potassium acid phthalate, 50 mmol L ${ }^{-1}$ ), $\mathrm{pH} 7.00$ (potassium phosphate monobasic/sodium hydroxide, $50 \mathrm{mmol} \mathrm{L}^{-1}$ ), $\mathrm{pH} 7.40$ (potassium phosphate monobasic/sodium hydroxide, $50 \mathrm{mmol} \mathrm{L}^{-1}$ ), and $\mathrm{pH} 10.00$ (potassium carbonate/potassium borate/potassium hydroxide, $50 \mathrm{mmol} \mathrm{L}^{-1}$ ) buffers were tested in this section. Phenyl fluorosulfate (1) showed great stability in all buffer/acetonitrile mixed solutions. No apparent hydrolysis was observed in buffer/acetonitrile solutions other than $\mathrm{pH} 10.00$, where only less than $10 \%$ of 1 was hydrolyzed after 24 hours (Fig. 4, Fig. S4a). The imaging agent Compound 35 was tested using the same protocol. Compound 35 was stable at neutral pH but degraded in $\mathrm{pH} 10.00$ buffer (Fig. S4b).

Stability under physiological conditions. Phenyl fluorosulfate (1) was incubated in phosphate-buffered saline (PBS, $1 \mathrm{x}, \mathrm{pH} \sim 7.4$ ) at $37^{\circ} \mathrm{C}$. It was observed that 1 was stable (>95\% remaining) for at least 6 days with no apparent hydrolysis (Fig. 4, Fig. S4c).

Stability in Borax solution. We incubated phenyl fluorosulfate with saturated Borax solution $\left(\mathrm{Na}_{2} \mathrm{~B}_{4} \mathrm{O}_{7}\right.$, initial $\left.\mathrm{pH} \sim 10\right)$, phenyl fluorosulfate was slowly hydrolyzed, however, to an extent that less than $5 \%$ converted to monophenyl sulfate $\left(\mathbf{S 3 4}, \mathrm{PhOSO}_{2} \mathrm{O}^{-}\right.$) after $4 \mathrm{~h}$ (Fig. $\mathbf{S 4 d}$ ).

Stability in strong basic solution. In basic sodium hydroxide solution with concentration of 25 $\mathrm{mmol} \mathrm{L}^{-1}$ (initial $\mathrm{pH} 12.4$ ), phenyl fluorosulfate rapidly hydrolyzed into sodium monophenyl sulfate S34, half-life being approximately $18 \mathrm{~min}$ (Fig. S4e). This experiment showed that aryl fluorosulfate is not stable in aqueous solution in the presence of a strong base. 
a

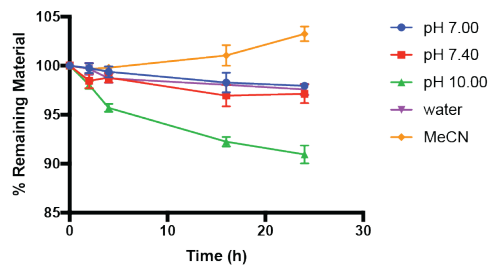

C

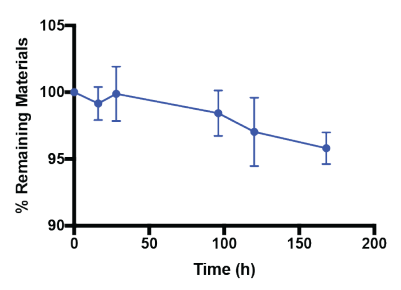

b
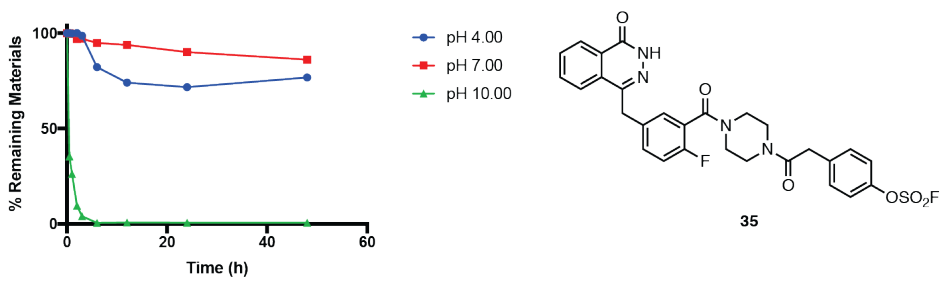

35

d

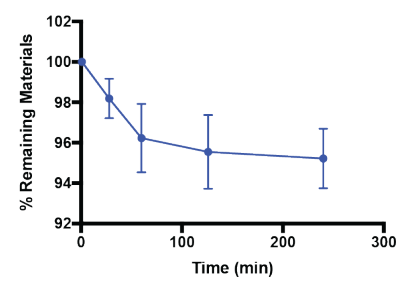

e

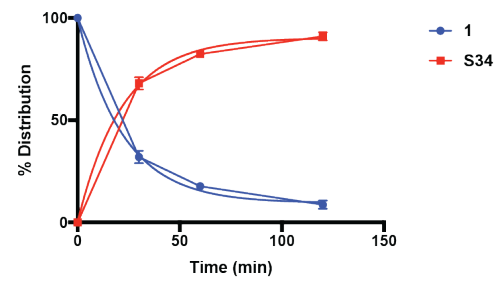

Fig. S4 | Stability of fluorosulfates in aqueous solution. a, Compound 1 in various aqueous buffers. The percentage of remaining materials was determined by HPLC $(n=3)$. b, Compound 35 in various aqueous buffers. The percentage of remaining materials was determined by HPLC. c, Stability of Compound 1 under physiological conditions $(n=3)$. d, Stability of Compound 1 in Borax solution $(\mathrm{pH} \sim 10, n=3)$. d, Hydrolysis of Compound 1 in $25 \mathrm{mmol} \mathrm{L}^{-1}$ $\mathrm{NaOH}$ solution $(n=3)$. 


\subsubsection{Stability against Reactive Amino Acids in Aqueous Buffers}

Compound 1 with Serine. Stock solution Aqser was prepared by dissolving L-serine (S35, Sigma-Aldrich, CAS \# 56-45-1, $10.5 \mathrm{mg}, 0.100 \mathrm{mmol})$ in $\mathrm{pH} 7.40$ buffer $\left(10 \mathrm{~mL}, C_{\text {ser }} \sim 10 \mathrm{mmol}\right.$ $\left.\mathrm{L}^{-1}\right)$. Following the general method described in Section 1.2.2., phenyl fluorosulfates (1) was incubated with $\mathrm{Aqser}$ in a $\mathrm{MeCN} / \mathrm{H}_{2} \mathrm{O}$ mixed solvent at room temperature. The percentage of remaining compound 1 was monitored by HPLC in the following $48 \mathrm{~h}$ by aliquoting from the mother liquor. No apparent consumption of compound 1 by either water or serine was apparent (Fig. 4, Fig. S5).

Compound 1 with Threonine. Stock solution $\mathrm{Aq}_{\mathrm{Thr}}$ was prepared by dissolving L-threonine (S36, Sigma-Aldrich, CAS \# 72-19-5, $12.0 \mathrm{mg}, 0.100 \mathrm{mmol}$ ) in pH 7.40 buffer $\left(10 \mathrm{~mL}, c_{\text {Thr }} \sim 10\right.$ $\mathrm{mmol} \mathrm{L}{ }^{-1}$ ). Following the general method described in Section 1.2.2., phenyl fluorosulfates (1) was incubated with $\mathrm{Aq}_{\mathrm{Thr}}$ in a $\mathrm{MeCN} / \mathrm{H}_{2} \mathrm{O}$ mixed solvent at room temperature. The percentage of remaining compound 1 was monitored by HPLC in the following $48 \mathrm{~h}$ by aliquoting from the mother liquor. No apparent consumption of compound 1 by either water or threonine was apparent.

Compound 1 with Lysine. Stock solution $\mathrm{Aq}_{\text {Lys }}$ was prepared by dissolving L-lysine monohydrochloride (S37, Sigma-Aldrich, CAS \# 657-27-2, $18.2 \mathrm{mg}, 0.100 \mathrm{mmol}$ ) in pH 7.40 buffer $\left(10 \mathrm{~mL}, C_{\mathrm{Lys}} \sim 10 \mathrm{mmol} \mathrm{L}^{-1}\right)$. The $\mathrm{pH}$ of this $A_{\mathrm{L}_{\mathrm{Lys}}}$ solution remained between 7.0 and 8.0 (pH strip). Following the general method described in Section 1.2.2., phenyl fluorosulfates (1) was incubated with $\mathrm{Aq}_{\text {Lys }}$ in a $\mathrm{MeCN} / \mathrm{H}_{2} \mathrm{O}$ mixed solvent at room temperature. The percentage of remaining compound 1 was monitored by HPLC in the following $48 \mathrm{~h}$ by aliquoting from the mother liquor. No apparent consumption of compound 1 by either water or lysine was apparent.

Compound 1 with Tyrosine. Stock solution $\mathrm{Aq}_{\mathrm{Tyr}}$ was prepared by dissolving L-tyrosine (S38, Sigma-Aldrich, CAS \# 60-18-4, $18.1 \mathrm{mg}, 0.100 \mathrm{mmol}$ ) in pH 7.40 buffer $\left(10 \mathrm{~mL}, c_{\text {Tyr }} \sim 10 \mathrm{mmol}\right.$ $\left.\mathrm{L}^{-1}\right)$. The $\mathrm{pH}$ of this $\mathrm{Aq}_{\mathrm{Tyr}}$ solution remained between 7.0 and 8.0 ( $\mathrm{pH}$ strip). Following the general method described in Section 1.2.2., phenyl fluorosulfates (1) was incubated with $\mathrm{Aq}_{\mathrm{Tyr}}$ in a $\mathrm{MeCN} / \mathrm{H}_{2} \mathrm{O}$ mixed solvent at room temperature. The percentage of remaining compound 1 was monitored by HPLC in the following $48 \mathrm{~h}$ by aliquoting from the mother liquor. No apparent consumption of compound 1 by either water or tyrosine was apparent.

Compound 1 with Cysteine (Glutathione). Stock solution $\mathrm{Aq}_{\mathrm{GSH}}$ was prepared by dissolving glutathione (S39, reduced form, Sigma-Aldrich, CAS \# 70-18-8) in PBS ( $\left.C_{G S H} \sim 10 \mathrm{mmol} \mathrm{L}^{-1}\right)$. PBS solution containing $10 \mathrm{mmol} \mathrm{L}^{-1}$ of $\mathrm{GSH}$ was prepared. The PBS solution was mixed with equivolume of $10 \mathrm{mmol} \mathrm{L}^{-1}$ DMSO solution of phenyl fluorosulfate (1), the final concentration of GSH being $5 \mathrm{mmol} \mathrm{L}^{-1}$ that mimics the total free thiol group concentration in animal cells. Aliquots $(2 \mu \mathrm{L})$ were taken out occasionally and analyzed by HPLC. The time course of percentage remaining of phenyl fluorosulfate (1) was plotted, which indicated the high stability of aryl fluorosulfates in aqueous environment in the presence of free thiol groups (i.e., cysteines).

Compound 35. See above procedures. Results were summarized in Fig. S4e. Compound 35 was stable at $\mathrm{pH}$ lower than 10.00 . 
a

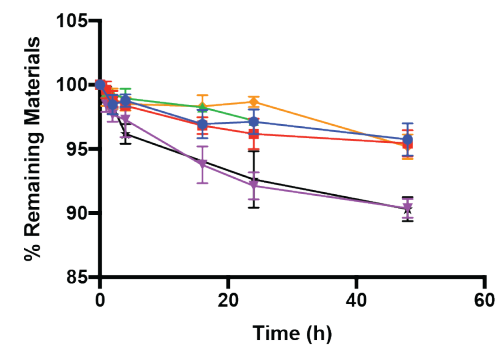

b

$\rightarrow$ Control $\left(+\mathrm{H}_{2} \mathrm{O}\right)$

-+ Serine $(\mathbf{S} 35)$

\pm+ Threonine $(\mathbf{S 3 6})$

++ Lysine $(\mathbf{S} 37)$

$\rightarrow+$ Tyrosine $(\mathbf{S 3 8})$

* + Glutathione

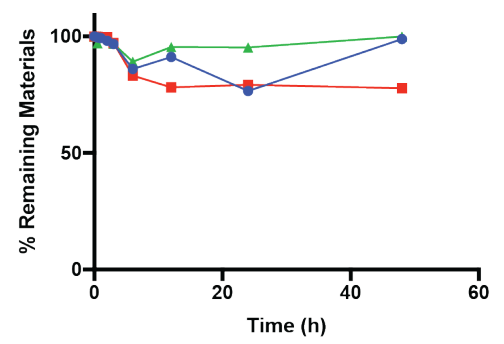

-+ Lysine $(\mathbf{S} 37)$

-+ Serine $(\mathbf{S} 35)$

$₫-+$ Tyrosine $(\mathbf{S} 38)$

Fig. S5 | Stability of fluorosulfates in aqueous solution. a, Stability of Compound 1 in $\mathrm{pH} 7.4$ buffer in the presence of various amino acids $(n=3)$. $\mathbf{b}$, Stability of Compound $35 \mathrm{in} \mathrm{pH} 7.4$ buffer in the presence of various amino acids. 


\subsubsection{Stability against Acids and Bases}

Stability in strong acids. Phenyl fluorosulfate $\left(1,100 \mathrm{mmol} \mathrm{L}^{-1}\right)$ was incubated with or without strong Brønsted acid, $1 \mathrm{mmol} \mathrm{L}{ }^{-1} \mathrm{HCl}$ aqueous solution and Lewis acid, $13 \mathrm{mmol} \mathrm{L}^{-1}$ TFA in $\mathrm{DCM}$ at its boiling point $\left(\sim 45^{\circ} \mathrm{C}\right.$, b.p. of the mixture), respectively. The remaining material was quantified by HPLC. No apparent degradation was found in both cases (Fig. S6).

Stability with bases. Phenyl fluorosulfate $\left(1,100 \mathrm{mmol} \mathrm{L}^{-1}\right)$ was incubated with or without bases (triethylamine, pyridine, or potassium carbonate, $5 \mathrm{eq}$ ) in $\mathrm{MeCN}$ at room temperature for $2 \mathrm{~h}$. The remaining material was quantified by HPLC. No significant degradation was found in these three commonly used bases.

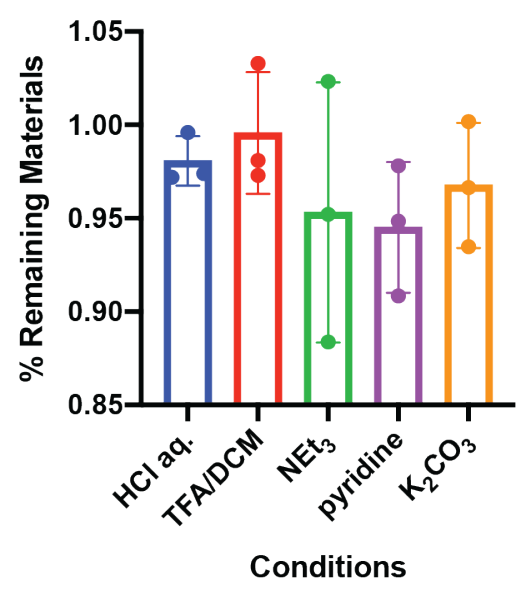

Fig. S6 | Stability of fluorosulfate under acidic or basic conditions. Conditions: Column 1 (left to right), Compound $1\left(100 \mathrm{mmol} \mathrm{L}^{-1}\right), \mathrm{HCl}$ aq. $\left(1 \mathrm{~mol} \mathrm{~L}^{-1}\right), \mathrm{rt}, 24 \mathrm{~h}$ (relative to control, $n=$ 3); Column 2, Compound $1\left(100 \mathrm{mmol} \mathrm{L}^{-1}\right)$, trifluoroacetic acid $\left(13 \mathrm{mmol} \mathrm{L}^{-1}\right), \mathrm{DCM}, 45^{\circ} \mathrm{C}, 24 \mathrm{~h}$ (relative to control, $n=3)$; Column 3, Compound $1\left(100 \mathrm{mmol} \mathrm{L}^{-1}\right)$, triethylamine $\left(500 \mathrm{mmol} \mathrm{L}^{-1}\right)$, MeCN, rt, $2 \mathrm{~h}$ (relative to control, $n=3$ ); Column 4, Compound $1\left(100 \mathrm{mmol} \mathrm{L}^{-1}\right)$, pyridine $(500$ mmol L $\left.{ }^{-1}\right), \mathrm{MeCN}, \mathrm{rt}, 2 \mathrm{~h}$ (relative to control, $n=3$ ); Column 5, Compound $1\left(100 \mathrm{mmol} \mathrm{L}^{-1}\right)$, $\mathrm{K}_{2} \mathrm{CO}_{3}$ (5 eq.), $\mathrm{MeCN}$, rt, $2 \mathrm{~h}$ (relative to control, $n=3$ ). 


\subsubsection{Stability against Redox Reagents}

Oxidants in organic solvents. Phenyl fluorosulfate (1) was treated with $\mathrm{CrO}$ (2 eq) in $\mathrm{CCl}_{4}$ (100 mmol L ${ }^{-1}$ ), and mCPBA (5 eq) in DCM (100 $\left.\mathrm{mmol} \mathrm{L}^{-1}\right)$, respectively, at room temperature for $12 \mathrm{~h}$. The remaining material was analyzed by HPLC. No apparent change was observed in both cases (Fig. S7).

Reductants in organic solvents. On the other hand, the stability of aryl fluorosulfate against redox reagents was examined by the incubation experiments with various representative reductants, including triphenyl phosphine (S40), diphenyl phosphine (S41), and phenylsilane (S42). Under all entries examined here, no apparent hydrolysis/decomposition of 4-biphenyl fluorosulfates (12) was observed by either ${ }^{19} \mathrm{~F}-\mathrm{NMR}$ or LC-MS. The experiments were summarized in Fig. S7.

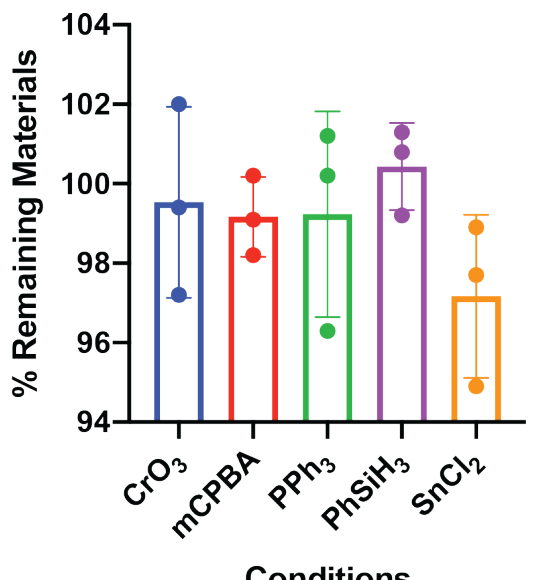

Fig. S7 | Stability of fluorosulfates against oxidants and reductants. Three replicates. 


\subsubsection{Stability against Nucleophiles and Electrophiles.}

Aniline. See Supplementary Information Section 1.2.1 for "refluxing aniline" test.

Thiol. Phenyl fluorosulfate $\left(\mathbf{1}, 100 \mathrm{mmol} \mathrm{L}^{-1}\right)$ was incubated with 1-hexanethiol $(200 \mathrm{mmol} \mathrm{L}$ ${ }^{1}$ ) in $\mathrm{MeCN}$ at room temperature for $16 \mathrm{~h}$. No conversion of starting material was confirmed by HPLC analysis.

Phenyl lithium. Gao et al. ${ }^{27}$ reported in a previous paper that substitution of fluorosulfation occurred when treated with phenyl lithium at $-78^{\circ} \mathrm{C}$ in THF, resulting in a aryl sulfonate ester.

Nitronium $\left(\mathrm{NO}_{2}{ }^{+}\right)$. It is shown that nitronium acts as an electrophile to the aromatic ring leaving the fluorosulfate group untouched. A 2-L Erlenmeyer flask equipped with overhead stirring was charged with $440 \mathrm{~mL}$ concentrated sulfuric acid $(95 \% \mathrm{w} / \mathrm{w})$. Cooled to $5^{\circ} \mathrm{C}$ internal temperature using an ice bath, phenyl fluorosulfate $(1,176 \mathrm{~g}, 1 \mathrm{mmol})$ was added dropwise via a syringe. By end of addition of phenyl fluorosulfate, a colorless solution formed. Into the solution, a mixture of $130 \mathrm{~mL}$ ( $68 \% \mathrm{w} / \mathrm{w}, 2 \mathrm{mmol}, 2$ equiv) nitric acid and $130 \mathrm{~mL}$ sulfuric acid was added via a dropping funnel slowly, which took about $1 \mathrm{~h}$. After the nitric acid was added, the resulting mixture was poured onto crushed ice with care. White flake precipitated on the surface of ice water, which turned into an emulsion on standing at room temperature. The crude was partitioned between water and ether. The upper ether phase was collected, washed sequentially with water, sodium bicarbonate, brine, dried $\left(\mathrm{Na}_{2} \mathrm{SO}_{4}\right)$ and concentrated to give a yellow oily crude. The crude product was found $\sim 95 \%$ purity. Upon distillation under reduced pressure (b.p. $108^{\circ} \mathrm{C}, 1.5 \mathrm{mbar}$ ), the purified compound was obtained as a pale oil ( $201 \mathrm{~g}, 0.91$ $\mathrm{mmol}, 91 \%$ isolated yield). Characterizations including NMR and MS were consistent to those reported by Dong, J. et al. ${ }^{3}$ TLC: $R_{\mathrm{f}}=0.49$ (17\% ethyl acetate in hexanes, UV).

Methyl triflate. Phenyl fluorosulfate $\left(\mathbf{1}, 100 \mathrm{mmol} \mathrm{L}^{-1}\right)$ was incubated with methyl triflate (200 $\mathrm{mmol} \mathrm{L}^{-1}$ ) in DCM first at $0^{\circ} \mathrm{C}$, then at room temperature for $16 \mathrm{~h}$. No conversion of starting material was confirmed by HPLC analysis. 
a<smiles>Nc1ccccc1Oc1ccc(OC(=O)OF)cc1</smiles>

C<smiles>[R]c1ccc(OC(=O)Oc2ccc([R])cc2)cc1</smiles>

e

$$
\text { Me-OTf }
$$

b<smiles>O=[W]Oc1ccc(OC(=O)OCc2ccccc2)cc1</smiles>

d<smiles>O=C(OF)Oc1ccc([N+](=O)[O-])cc1</smiles>

Fig. S8 | Stability of fluorosulfates against nucleophiles and electrophiles. See Section 1.2.6 for respective conditions. 


\subsubsection{Stability in the Most Frequently Used Reactions in Medicinal Chemistry}

The most frequently used reactions were identified by Brown, D. G. and Boström, J. ${ }^{28}$ by extracting all archived publications in the Journal of Medicinal Chemistry. The top ten constructive reactions by occurrence were examined here (Fig. S9) and summarized in Fig. 1c. The degrative reactions were excluded from this list though some of the has been confirmed elsewhere, e.g. TFA-enabled Boc-deprotection.

Amide synthesis. The inertness of fluorosulfate group to various amide coupling conditions have been validated in the syntheses of Compounds 16, 21, 23, and 32 in this work. This group is compatible to amide synthesis from acyl chloride, anhydride, and NHS-ester.

Suzuki-Miyaura coupling. Zhang, E.-X. et al. ${ }^{6}$ has shown the reactivity of commonly used electrophile, aryl bromide much higher than fluorosulfate in competition experiments. When an aryl bromide is present, the fluorosulfate will stay intact; On the other hand, Jiang, B. ${ }^{11}$ et al. has developed a reliable method to activate fluorosulfate by the enhanced reactivity at the aqueous/organic interface. Thus, fluorosulfate is categorized conditional stable to the SuzukiMiyaura coupling conditions.

$\underline{S}_{N} A r$. On one hand, Sanford, M. et al. ${ }^{29}$ has shown fluorosulfate with electron withdrawing group could be substituted via $S_{N} A r$ by highly reactive anionic fluoride at elevated temperature; On the other hand, we found that in a competition with common $S_{N} A r$ substrate, e.g. 2,4dichloropyrimidine, fluorosulfate remained completely intact in 1,4-dioxane (Fig. S9a). Thus, fluorosulfate is categorized conditional stable to the $S_{N} A r$ conditions.

Electrophile with amines. On one hand, Dong, J. et al. has reported a harsh condition including a combo of MgO/DMAP and refluxing temperature to force the activation of fluorosulfate toward secondary amines; Ball, N. D. et al. ${ }^{30}$ has recently reported a $\mathrm{Ca}\left(\mathrm{NTf}_{2}\right)_{2-}$ mediated SuFEx reaction of fluorosulfate; One the other hand, in our experiences with fluorosulfate, we found that its reactivity toward amine nucleophiles regarding either substitution or addition is low (Fig. S9b,c).

Peptide synthesis. Chen, W. et al. ${ }^{31}$ has shown tyrosine fluorosulfate is completely compatible to solid-phase peptide synthesis; Wang, L. et al. ${ }^{32}$ has shown tyrosine fluorosulfate is even compatible to the enzymic machinery to synthesized unnatural protein that contains fluorosulfate handle. Thus, fluorosulfate is considered completely inert to peptide synthesis.

Heterocycle synthesis. The synthesis of heterocycles like triazoles have been used in routine protein fishing in proteomes ${ }^{33}$ and preparation of iterative polymers ${ }^{34}$. Thus, fluorosulfate is considered completely inert

Reductive amination. Compound $\mathbf{1 7}$ has been used in reductive amination in unpublished works. The coupling of it with primary amine, e.g. propargyl amine, was efficient (Fig. S9d). And thus, fluorosulfate is considered compatible to reductive amination.

Buchwald-Hartwig amination. This palladium-catalyzed process often requires a strong base, e.g. KOtBu or DBU, and refluxing temperature. These could be detrimental to the stability of fluorosulfate. However, we found that with robust catalysts ${ }^{35}$, a typical Buchwald-Hartwig amination process could occur at room temperature without affecting aryl fluorosulfate in the 
same milieu (Fig. S9e). Thus, fluorosulfate is considered conditional stable under BuchwaldHartwig conditions.

Phenol alkylation. The substitution of fluorosulfate with phenolates (or silyl ethers) is considered the most reliable process of SuFEx click chemistry ${ }^{3}$. However, the electrophilicity of fluorosulfate is much lower compared to a common alkylating reagent. For example, when methyl triflate and phenyl fluorosulfate were present in the same mixture, only methylation of phenol was observed (Fig. S9f). Therefore, we concluded fluorosulfate is conditional stable to phenol alkylation.

Sulfonamide synthesis. Sulfur fluorides including sulfonyl fluoride and aryl fluorosulfates are known inert to the synthesis of sulfonamide from sulfonyl chloride and amines ${ }^{36}$. In addition, Zheng, Q. et al. has shown the rate for a SuFEx substitution of sulfonyl fluoride is about 30 relative to aryl fluorosulfate ${ }^{26}$. With this regard, it can be concluded that fluorosulfate is stable to sulfonamide synthesis.

a

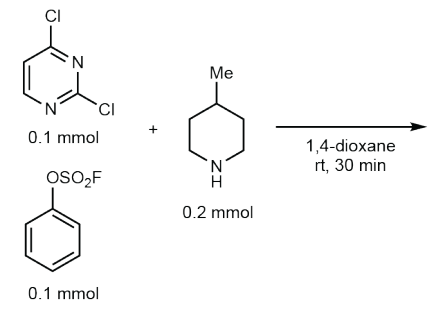

C

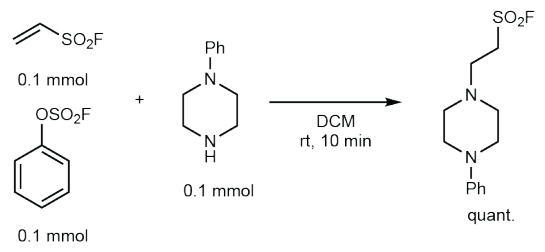

e

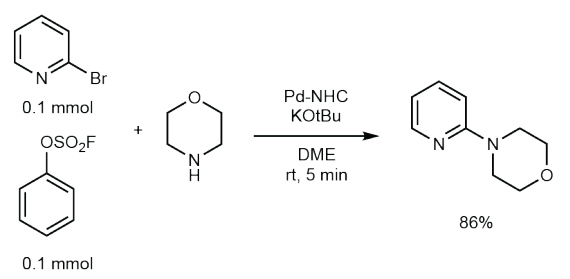

b

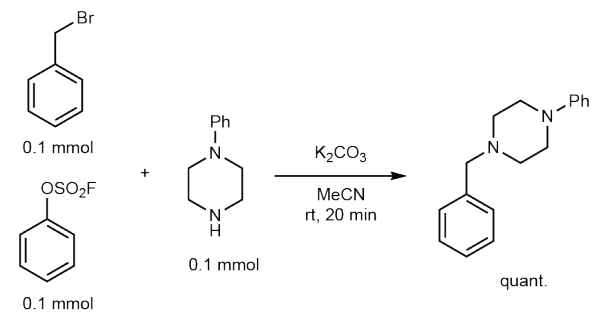

d

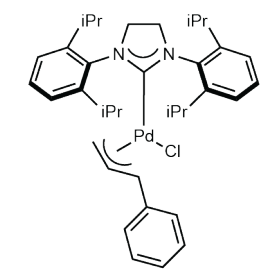

f
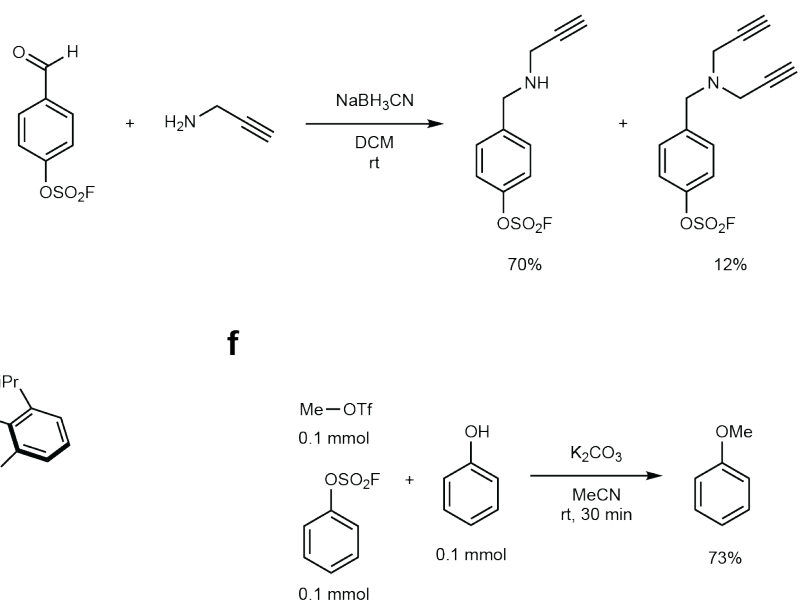

Fig. S9 I Compatibility of fluorosulfates in the most commonly used medicinal chemistry reactions. 


\subsubsection{Stability against bovine serum albumin}

Bovine serum albumin (BSA, $50 \mu \mathrm{M})$ was incubated with the simplest aryl fluorosulfate, phenyl fluorosulfate (main text compound 1, $1 \mathrm{eq}, 5 \mathrm{eq}, 10 \mathrm{eq}$ or $100 \mathrm{eq}$ ) in 1x phosphate buffered saline (PBS). No covalent irreversible labeling (apo $+\mathrm{PhOSO}_{2} \mathrm{~F}-\mathrm{HF}$ or apo $+n$ * $\left(\mathrm{PhOSO}_{2} \mathrm{~F}-\mathrm{HF}\right)$ ) was found in the intact protein mass spec analysis after $24 \mathrm{~h}$ at room temperature (Fig. S10).
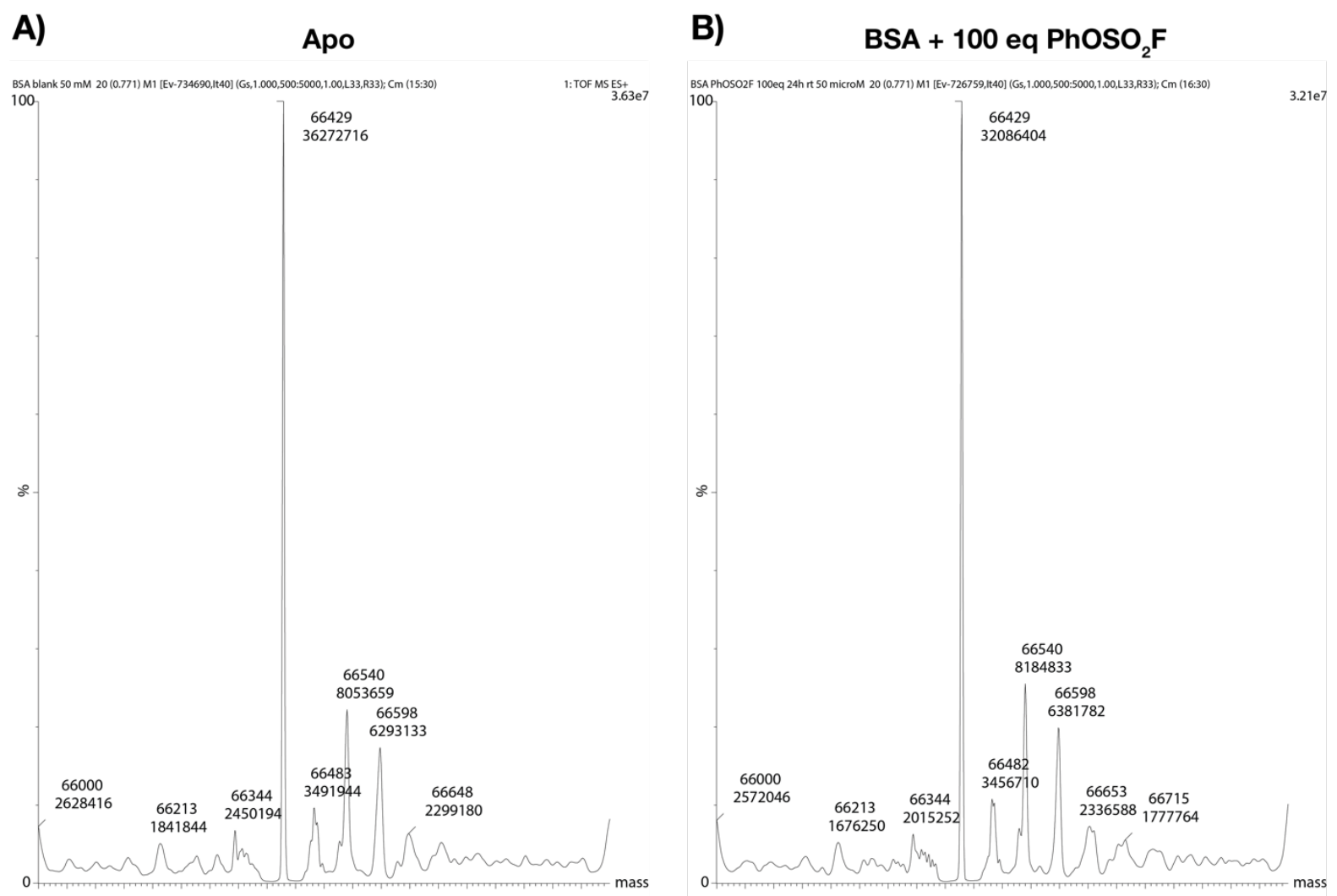

Fig. S10 I BSA did not form covalent adduct in the presence of excess amount of phenyl fluorosulfate. 


\subsection{Time-Dependent Saturation Transfer experiments}

\subsubsection{Theory}

The pulse sequence of the time-dependent saturation transfer (TDST) experiments is illustrated in Fig. S11, which is adapted from G. Weiss and R. Spencer's original report in 1994 37. The TDST experiment is defined in terms of a constant cycle time $\left(T_{\mathrm{c}}\right)$, a constant acquisition time $A C$ and a set of saturation times $T S_{i}$ and recycle delays $\mathrm{RD}_{i}$, where the subscript $i$ refers to the ith measurement.

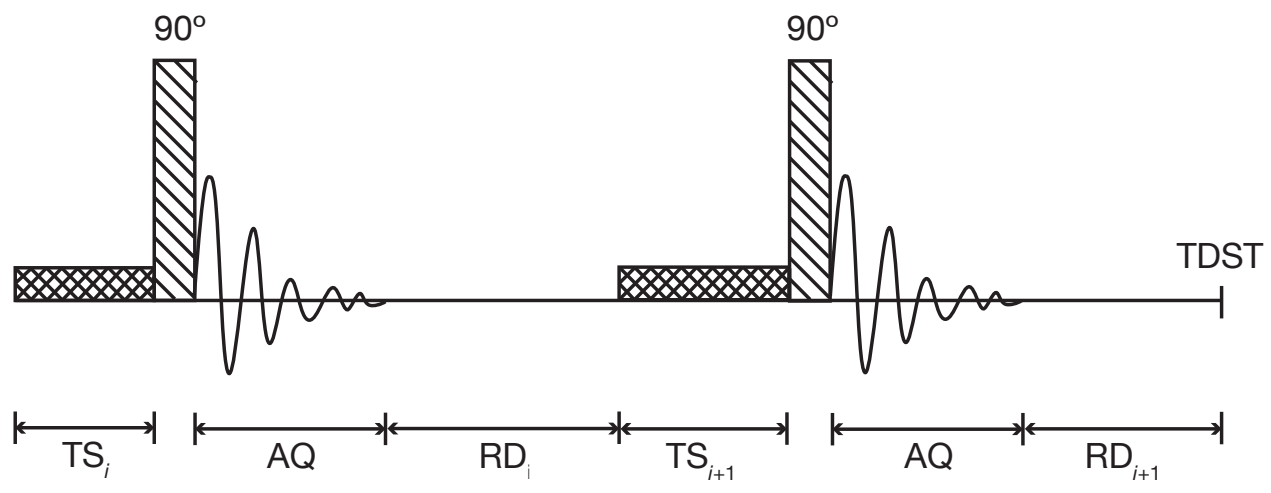

Fig. S11 | TDST pulse sequence. $A Q=$ acquisition; $R D_{i}=$ recycle delay; $T S_{i}=$ saturation time at the ith measurement.

In the experiments, it is assumed that the fluoride exchange process is first order regarding both aryl fluorosulfate and anionic fluoride species. Let the forwards rate constant be $k_{\mathrm{f}}$, and the backwards one be $k_{b}$. It is also assumed that the irradiated species (i.e., nucleophilic fluoride donor ' $\mathrm{F} \ominus$ ' in the following experiments) is saturated, thus the backwards reaction rate being neglected in context of NMR measurement.

$$
\begin{gathered}
\mathrm{PhOSO}_{2} \mathrm{~F}+{ }^{\prime} \mathrm{F}^{-\prime *} \stackrel{k_{\mathrm{f}}}{\leftrightarrow} \mathrm{PhOSO}_{2} \mathrm{~F}^{*}+\mathrm{F}^{-\prime} \\
\mathrm{PhOSO}_{2} \mathrm{~F}^{*} \stackrel{\frac{1}{T_{1}}}{\rightarrow} \mathrm{PhOSO}_{2} \mathrm{~F}
\end{gathered}
$$

Considering the two equations that involve the species of aryl fluorosulfate $\left(\mathrm{PhOSO}_{2} \mathrm{~F}, 1\right)$, where fluorine with an asterisk superscript is a saturated nucleus, we can write the reaction rate equation in terms of the magnetization $M(\mathrm{t})$. 


$$
\frac{d M(t)}{d t}=\frac{M_{0}-M(t)}{T_{1}}-k_{\mathrm{f}}\left[\mathrm{F}^{-\prime}\right] M(t)
$$

In the experiments, we intentionally made fluoride species over 10-fold than aryl fluorosulfate to reach a pseudo-first order condition. Let the obvious rate constant (pseudo-firstorder rate constant) be $k_{\text {obs, }}$ thus, we have

$$
\frac{d M(t)}{d t}=\frac{M_{0}-M(t)}{T_{1}}-k_{\mathrm{obs}} M(t)
$$

Solving the equation using the initial condition $M(0)=M_{0}$ leads to a fully deterministic system (Eq. S5, instrumental error is neglected here)

$$
M(t)=\frac{M_{0}}{1+k_{\mathrm{obs}} T_{1}}\left\{1+k_{\mathrm{obs}} T_{1} e^{-\frac{\left(1+k_{\mathrm{obs}} T_{1}\right) t}{T_{1}}}\right\}
$$

A series of $T S_{i}\left(t_{i}\right)$ and $M_{i}$ could be obtained from TDST NMR experiments. The relationship between $T S_{\mathrm{i}}\left(t_{\mathrm{i}}\right)$ and $M_{\mathrm{i}}$ is given below.

$$
\begin{gathered}
t=\left\{t_{1}, t_{2}, t_{3}, \ldots, t_{i}\right\} \\
M=\left\{M_{1}, M_{2}, M_{3}, \ldots, M_{i}\right\} \\
M_{i}=M\left(t_{i}\right)
\end{gathered}
$$

Plotting $M_{\mathrm{i}}$ versus $t_{\mathrm{i}}$, followed by curve fitting, should give the desired $k_{\text {obs. }}$. Execute nonlinear regression on the data points $\left(t_{\mathrm{i}}, M_{\mathrm{i}}\right)$ according to Eq. S9. The coefficients, $(a, b$, and $c)$ can be solved by least-squares. And the three constants including the pseudo-first order rate constant $\left(k_{\text {obs }}\right)$ in Eq. S5 can be solved from Eq. S10, Eq. S11, Eq. S12.

$$
\begin{gathered}
M(t)=c+a \cdot e^{-t / b} \\
M_{0}=a+c
\end{gathered}
$$




$$
\begin{aligned}
& k_{o b s}=\frac{a}{b(a+c)} \\
& T_{1}=\frac{b(a+c)}{(a+c-1)}
\end{aligned}
$$

Eq. $\$ 12$ 


\subsubsection{NMR Spectrometer Settings}

Instrument Bruker AV-400 (NMR Facility, The Scripps Research Institute).

Parameters $\quad \mathrm{RD}$ (recycle delay): set to $3-5$-fold to $T_{1}(15 \mathrm{~s})$;

D11 (saturation time, TS): variable, (0.01 to $25 \mathrm{~s})$;

DS (dummy scan): 0 ;

NS (number of scans): 32 ;

SW (sweep width): 301.848 ppm;

O1 (channel 1, center of spectrum): -79.980 ppm;

$\mathrm{O} 2$ (channel 2, nucleus of saturation): chemical shift of ' $\mathrm{F}$ '.

NMR Tubes $\quad 5 \mathrm{~mm}$ diam., $\mathrm{L} 7$ in., borosilicate glass tube, argon purged;

or $5 \mathrm{~mm}$ diam., L 7 in., glass tube with FEP liner and PTFE cap, argon purged.

Temperature $\quad 298.0 \mathrm{~K}$, unless otherwise noted. 


\subsubsection{Evaluation of NMR Tubes}

Experimental. In the experiments of examining the influence of the material of NMR tubes, the same outer tube ( $5 \mathrm{~mm}$, borosilicate glass) was used. The inner liner was made of either borosilicate glass or fluorinated ethylene propylene copolymer (FEP, Wilmad-LabGlass \#6005). The latter was considered resistant towards corrosive fluoride-containing solution.

Phenyl fluorosulfate $(1,1.7 \mathrm{mg}, 0.010 \mathrm{mmol})$ was dissolved in $0.5 \mathrm{~mL}$ MeCN-d3 stock solution of tetrabutylammonium bifluoride (TBABF, 2, $c=0.2 \mathrm{~mol} \mathrm{~L}^{-1}$ ). Into an NMR inner liner (borosilicate or FEP), $0.3 \mathrm{~mL}$ of the freshly prepared solution was added. The inner liner was then inserted into an outer borosilicate tube (5 mm diam.). NMR spectra were taken using the aforementioned configurations (see Section 1.3.2). The results were shown in Fig. S12.

Data analysis. Unpaired $t$-test (GraphPad Prism 8) showed no statistical significance $(P=$ 0.70 ) between the two groups using either a FEP liner or a borosilicate glass inner tube (Fig. S12c, Table S1). We concluded that the possible "etching" effect of fluoride ion to glass did not influence the measurement of the fluoride exchange reaction rate during the period of data acquisition ( $\sim 2 \mathrm{~h}$ for each sample), neither apparent acceleration nor apparent inhibition was observed. Taking the standard deviation (SD) into account, we ruled out the use of FEP liners for its nearly doubled SD. A possible cause of the large SD is that the FEP material itself contains fluorine, leading to a much poorer baseline (signal-to-noise ratio) of the spectra. Thus, in all of the following experiments, we used borosilicate glass NMR tubes.

Table S1 | Evaluation of the materials of NMR tubes.

\begin{tabular}{ccc}
\hline \multirow{2}{*}{ Entry } & \multicolumn{2}{c}{$\boldsymbol{k}_{\text {obs }}\left(\mathbf{s}^{-1}\right)$} \\
& Borosilicate glass & FEP \\
\hline 1 & 0.155 & 0.175 \\
2 & 0.164 & 0.115 \\
3 & 0.136 & 0.141 \\
Mean \pm SD & $0.152 \pm 0.008(n=3)$ & $0.144 \pm 0.017(n=3)$ \\
\hline
\end{tabular}


a
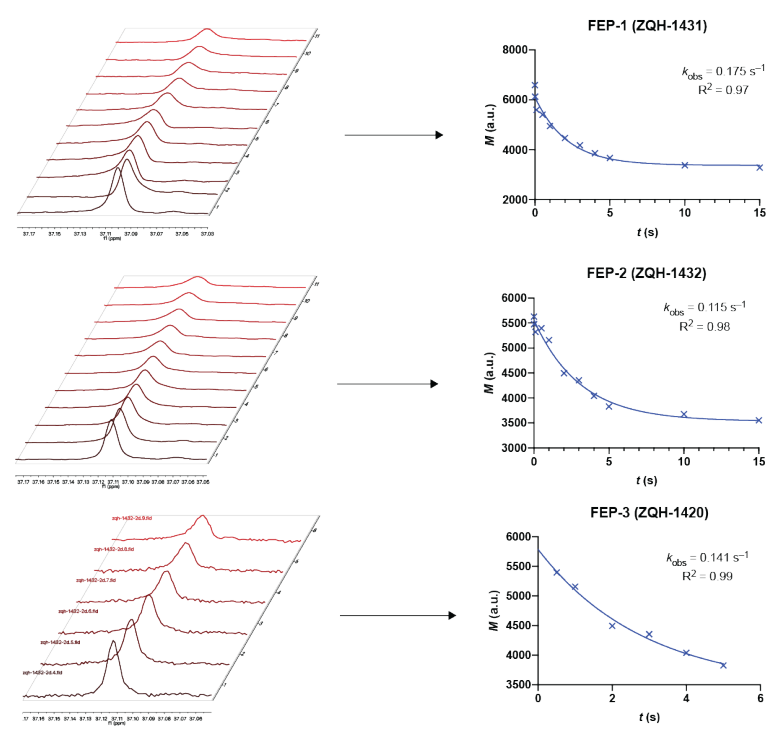

b
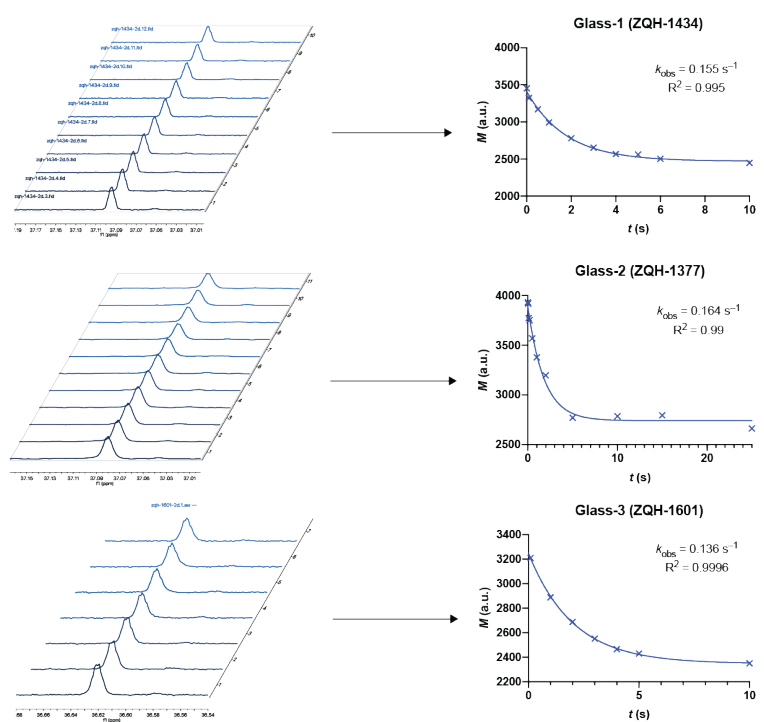

Glass-3 (ZQH-1601)

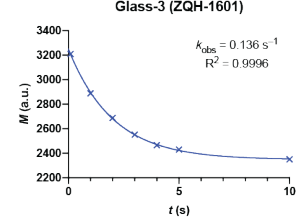

c

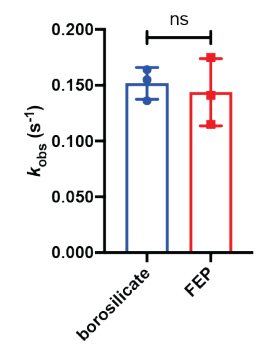

Fig. S12 | TDST-NMR experiments in FEP or borosilicate glass NMR tubes. a, Overlaid NMR spectra with curve fitting, three replicates. Conditions: Phenyl fluorosulfate $\left(1,0.02 \mathrm{~mol} \mathrm{~L}^{-}\right.$ $\left.{ }^{1}\right)$, TBABF $\left(2,0.2 \mathrm{~mol} \mathrm{~L}^{-1}\right), \mathrm{MeCN}-\mathrm{d} 3,298.0 \mathrm{~K}$, FEP liner. b, Overlaid NMR spectra with curve fitting, three replicates. Conditions: Phenyl fluorosulfate $\left(1,0.02 \mathrm{~mol} \mathrm{~L}^{-1}\right), \operatorname{TBABF}\left(2,0.2 \mathrm{~mol} \mathrm{~L}^{-}\right.$ ${ }^{1}$ ), MeCN-d3, $298.0 \mathrm{~K}$, borosilicate liner. c, Comparison of FEP and borosilicate NMR tube. Unpaired $t$-test (GraphPad Prism 8) suggested no significance between two groups using the indicated material for NMR tubes $(P=0.70)$. 


\subsubsection{Evaluation of Solvents}

Experimental. All solvents were dried by distillation over $4 \AA$ molecular sieves (activated at $150^{\circ} \mathrm{C}$ under high vacuum for 1 day then stored under argon atmosphere) before use. In general, deuterated solvents were used in the TDST-NMR experiments. Due to the less accessibility of the deuterium-labeled sulfolane (2,3,4,5-tetrahydrothiophene-1,1-dioxide), 1,4dioxane, and DMF, non-deuterated solvents were used in these cases, in the presence of deuterium oxide $\left(D_{2} \mathrm{O}\right)$ in an outer tube for instrument phase lock.

Phenyl fluorosulfate $(1,1.7 \mathrm{mg}, 10 \mu \mathrm{mol})$ was dissolved in $0.5 \mathrm{~mL}$ respective solution of $\operatorname{TBABF}\left(2, c=0.2 \mathrm{~mol} \mathrm{~L}^{-1}\right)$ and vortexed. Into an NMR liner (borosilicate), $0.3 \mathrm{~mL}$ of the new solution was added. The inner liner was then inserted into a borosilicate outer NMR tube (5 $\mathrm{mm}$ diam.). TDST-NMR experiments were performed using the aforementioned configurations (see Section 1.3.2). The results were shown in Table $\mathbf{S} 2$ and Fig. $\mathbf{2 h}$.

\section{Table S2 | Evaluation of solvents.}

\begin{tabular}{ccc}
\hline Entry & Solvent & $\boldsymbol{k}_{\text {obs }}\left(\mathbf{s}^{-1}\right)$ \\
\hline 1 & MeCN & $0.152 \pm 0.008(n=3)$ \\
3 & DMF & 0.314 \\
4 & Sulfolane & $\mathrm{N}^{\mathrm{a}} \mathrm{A}^{\mathrm{a}}$ \\
5 & $\mathrm{NMP}$ & 0.384 \\
6 & DMSO & 0.213 \\
7 & Toluene & 0.013 \\
8 & Methanol & $0^{b}$ \\
9 & DCM & $0^{b}$ \\
\hline
\end{tabular}

aSulfolane solidified in NMR tube at the acquisition temperature $(298.0 \mathrm{~K})$. ' In the case where observed rated constant equals "zero", non-linear curve fitting using Bloch Equation failed, which resulted from very slow, if any, exchange. 
a
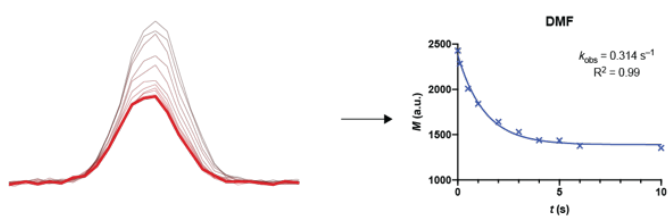

b

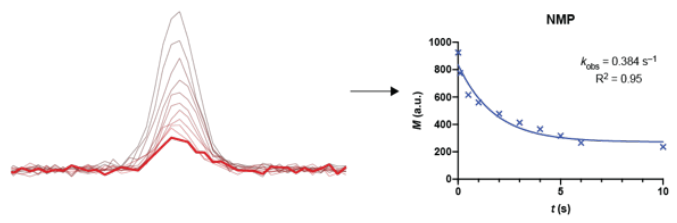

c

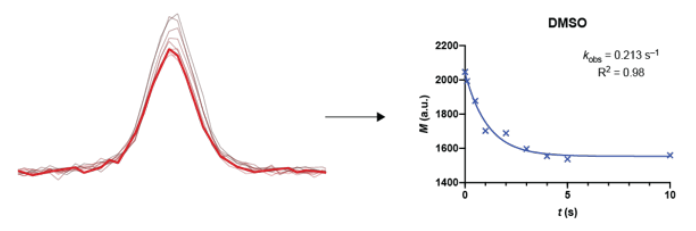

d

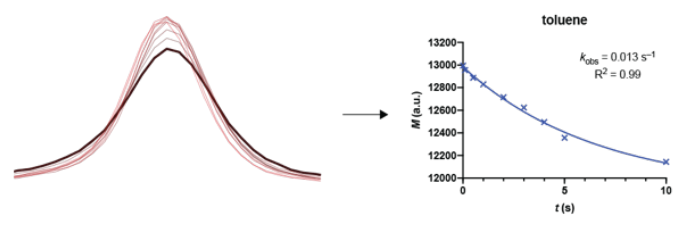

e

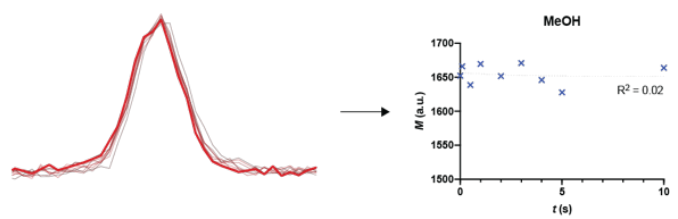

f

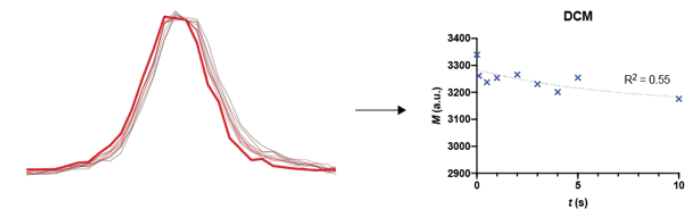

g

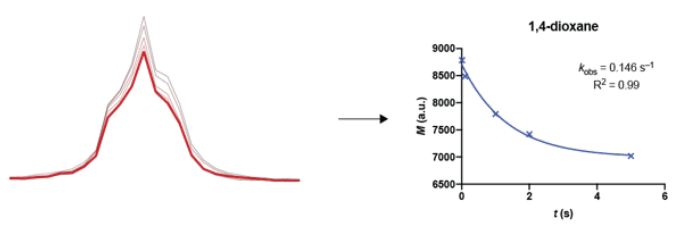

Fig. S13 | TDST experiments in different solvents. Overlaid NMR spectra with curve fitting. Fluoride exchange conditions: Phenyl fluorosulfate (1, $\left.0.02 \mathrm{~mol} \mathrm{~L}^{-1}\right)$, TBABF $\left(2,0.2 \mathrm{~mol} \mathrm{~L}^{-1}\right)$, indicated solvent, $298.0 \mathrm{~K}$, borosilicate NMR tube. a, DMF-d7. b, NMP. c, DMSO-d6. d, Toluene-d8. e, MeOD-d4. f, DCM-d2. g, 1,4-Dioxane. 


\subsubsection{Evaluation of onium fluorides}

Preparation of stock solutions of onium fluorides.

Procedure I (commercially available salts). Onium fluorides $2-\mathbf{5}, \mathbf{6} \cdot 3 \mathrm{H}_{2} \mathrm{O}$, and $6\left(1.0 \mathrm{~mol} \mathrm{~L}^{-1}\right.$ THF solution), are commercially available in near pure form ( $\geq 95 \%)$. These salts are very hygroscopic, and thus stored in a glove box with nitrogen or argon atmosphere. Weigh the salts into 15-mL corning centrifuge tubes (clear PP), which was topped with a rubber Suba-Seal ${ }^{\circ}$ septum (14/20 joint) and further sealed by 3M Electric tape and Parafilm. A balloon filled with nitrogen or argon was used to maintain a slightly positive pressure. Dissolve the salts with dry $\mathrm{MeCN}-\mathrm{d} 3$ to a final concentration of $0.2 \mathrm{~mol} \mathrm{~L}^{-1}$.

Procedure II (onium fluorides prepared from inorganic fluoride with phase transfer reagents). Fluorides 7 and $\mathbf{8}$ were prepared from potassium bifluoride in the presence of phase transfer reagents, 18-crown-6 and 2.2.2-cryptand, respectively. The procedure was exemplified by preparing $\mathrm{K} \subset(18-\mathrm{crown}-6)(\mathrm{FHF})$. Crown ether $(1.0 \mathrm{mmol})$, and potassium bifluoride $(5.0 \mathrm{mmol}$, excess) were suspended on acetonitrile-d3. The suspension was warmed to $50^{\circ} \mathrm{C}$ in an ultrasound bath for $30 \mathrm{~min}$ to result in a stock solution. Note: The concentrations for fluoride 7 and 8 refer to approximate concentrations of the phase transfer reagents, but not the bifluoride anion, which can hardly be determined. The actual concentration of fluoride anion was not determined. According to previous study, the actual concentrations of bifluoride should be no higher than $0.004 \mathrm{~mol} \mathrm{~L}^{-1}$ (Cf. potassium fluoride, a more soluble salt in organic solvents).

Procedure III (onium fluorides prepared via halide exchange [HalEx]). The stock solution of 9 was prepared from silver bifluoride (AgFHF) and an onium chloride/bromide according to known procedures and our earlier report ${ }^{10}$. In this context, we found that, generally speaking, onium bromide is a much better HalEx precursor compared to its onium chloride counterpart.

$$
\begin{aligned}
& \mathrm{Q}^{+} \mathrm{X}^{-}+\mathrm{AgFHF} \underset{\mathrm{rt}}{\stackrel{\mathrm{MeCN}}{\longrightarrow}} \mathrm{Q}^{+} \mathrm{FHF}^{-}+\mathrm{AgX} \downarrow \\
& \text { Q: onium } \\
& \text { X: } \mathrm{Cl}, \mathrm{Br}
\end{aligned}
$$

Procedure IV (onium fluoride prepared via chemical reaction). The stock solution of TAS bifluoride (10) was prepared according to known procedures and our earlier report ${ }^{10}$.

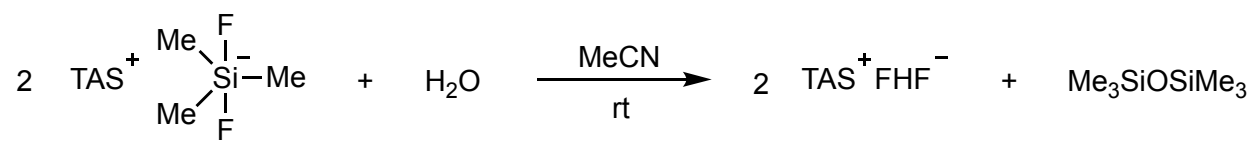

Using TDST-NMR to evaluate the effectiveness of fluoride salts in fluoride exchange. The TDST-NMR study was carried out using the same protocol (see Section 1.3.2). In the cases that the concentration of fluoride was lower than $0.2 \mathrm{~mol} \mathrm{~L}^{-1}$, adjust the corresponding concentration of phenyl fluorosulfate (1) to a final ratio of 1:10 substrate:fluoride (7 and $\mathbf{8}$ not applicable because of solubility issue). Unless otherwise noted, the conditions for the TDST-NMR experiments were: phenyl fluorosulfate $\left(1,0.02 \mathrm{~mol} \mathrm{~L}^{-1}\right)$, indicated fluoride salt $\left(0.2 \mathrm{~mol} \mathrm{~L}^{-1}\right.$, or 
indicated concentration), MeCN-d3, $298 \mathrm{~K}$. The results of NMR experiments were shown in Table S3 and Fig. S14.

Unexpected reaction of 1 catalyzed by TBAF. Upon the contact of phenyl fluorosulfate (1) with excess amount of "anhydrous" $\operatorname{TBAF}(\mathbf{6}$, from commercially available TBAF solution in THF), it was observed that 1 rapidly decomposed. Thus, the TDST-NMR measurement is not applicable to this fluoride source. To understand the side-reaction pathways taken place other than fluoride exchange, we proposed a defluorosulfation process (Fig. S15A), and compared the HPLC traces and NMR spectra of reaction mixture with authentic samples of some key species presumably involved. The results were shown in Fig. S15, which were supportive to the defluorosulfation pathway proposed. A similar phenomenon was observed by Sanford and coworkers $^{29}$.

Table S3 | Evaluation of onium fluoride salts. Conditions: phenyl fluorosulfate (1, $0.02 \mathrm{~mol} \mathrm{~L}^{-}$ $\left.{ }^{1}\right)$, indicated fluoride salt $\left(0.2 \mathrm{~mol} \mathrm{~L}^{-1}\right.$, or indicated concentration), $\mathrm{MeCN}-d 3,298.0 \mathrm{~K}$.

\begin{tabular}{ccc}
\hline Entry & Fluorides $\left(\#, c\right.$ in mol L $\left.{ }^{-1}\right)$ & $\boldsymbol{k}_{\text {obs }}\left(\mathbf{s}^{-1}\right)$ \\
\hline 1 & {$\left[n-\mathrm{Bu}_{4} \mathrm{~N}\right](\mathrm{FHF})(2,0.2)$} & $0.152 \pm 0.008(n=3)$ \\
3 & {$\left[n-\mathrm{Bu}_{4} \mathrm{~N}\right](\mathrm{FHFHF})(3,0.2)$} & 0.073 \\
4 & {$\left[n-\mathrm{Bu}_{4} \mathrm{~N}\right]\left(\mathrm{Ph}_{3} \mathrm{SiF}_{2}\right)(4,0.18)$} & 0.067 \\
5 & {$\left[n-\mathrm{Bu}_{4} \mathrm{~N}\right]\left(\mathrm{Ph}_{3} \mathrm{SnF}_{2}\right)(5,0.2)$} & $\mathrm{N} / \mathrm{A}^{b}$ \\
6 & {$\left[n-\mathrm{Bu}{ }_{4} \mathrm{~N}\right] \mathrm{F}(6,0.2)$} & 8.33 \\
7 & {$\left[n-\mathrm{Bu}_{4} \mathrm{~N}\right] \mathrm{F} \cdot 3 \mathrm{H}_{2} \mathrm{O}\left(6 \cdot 3 \mathrm{H}{ }_{2} \mathrm{O}, 0.2\right)$} & 0.008 \\
8 & $\mathrm{~K} \subset(18-\mathrm{crown}-6)(\mathrm{FHF})(7,0.1)$ & 0.019 \\
9 & $\mathrm{~K} \subset(2.2 .2-\mathrm{Cryptand})(\mathrm{FHF})(8,0.15)$ & $0^{a}$ \\
10 & {$\left[(\mathrm{PPh})_{2} \mathrm{~N}\right](\mathrm{FHF})(9,0.1)$} & 1.16 \\
\hline
\end{tabular}

${ }^{a}$ Exchange process was too slow to measure using TDST-NMR method with the corresponding onium fluoride. ${ }^{b}$ Exchange process, as well as a defluorosulfation process (see below), was too fast for TDST-NMR measurement. Note: Protected by a $\mathrm{N}_{2}$ balloon, the stock solution was found good for NMR experiments after 3 days. However, it is recommended that the corresponding NMR experiment should be carried out as soon as the solution being prepared freshly. 
a
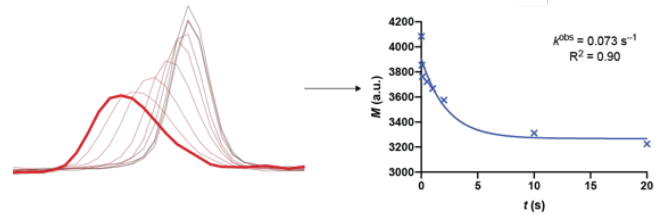

b

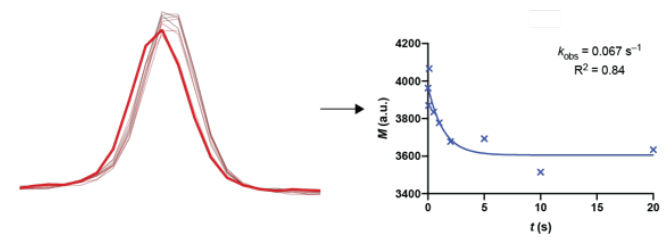

c

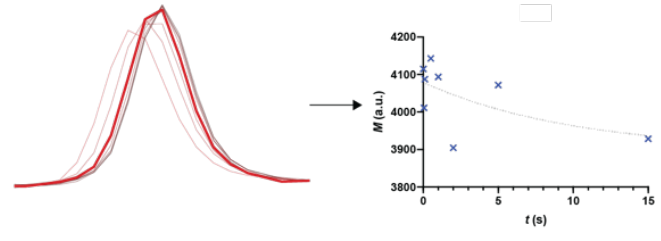

d

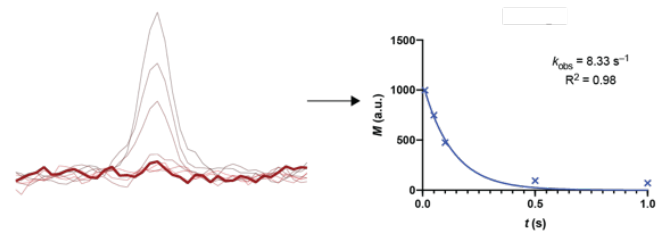

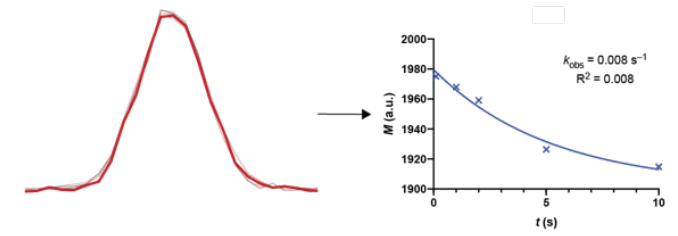

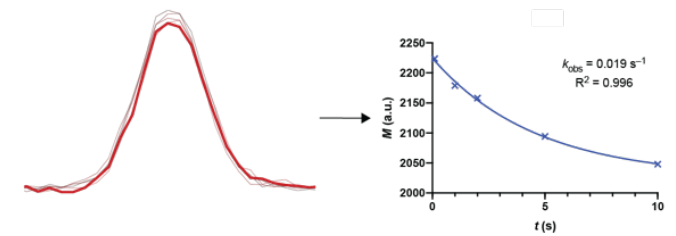

g

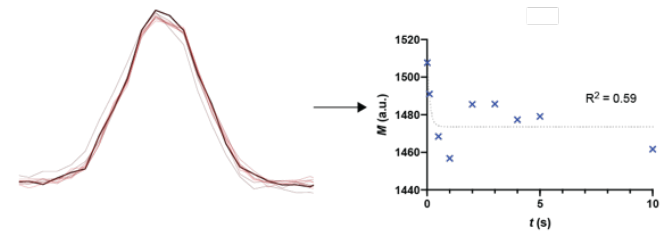

h

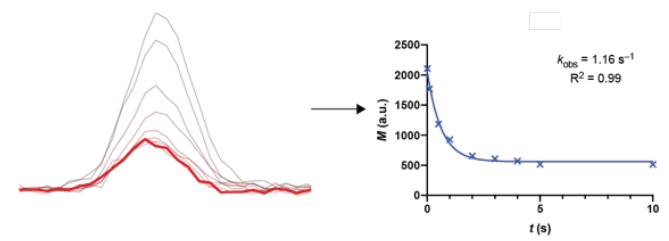

Fig. S14 | TDST experiments with different fluoride salts. Overlaid NMR spectra with curve fitting. Conditions: See above. a, $\left[n-\mathrm{Bu}_{4} \mathrm{~N}\right](\mathrm{FHFHF}) . \mathbf{b},\left[n-\mathrm{Bu}_{4} \mathrm{~N}\right]\left(\mathrm{Ph}_{3} \mathrm{SiF}_{2}\right) . \mathbf{c},\left[n-\mathrm{Bu}_{4} \mathrm{~N}\right]\left(\mathrm{Ph}_{3} \mathrm{SnF}_{2}\right)$. d, $\left[n-\mathrm{Bu}_{4} \mathrm{~N}\right] \mathrm{F} \cdot 3 \mathrm{H}_{2} \mathrm{O} . \mathbf{e}, \mathrm{K} \subset(18-c r o w n-6)(\mathrm{FHF}) . \mathbf{f}, \mathrm{K} \subset(2.2 .2-c r y p t a n d)(\mathrm{FHF}) . \mathbf{g},\left[\left(\mathrm{PPh}_{3}\right)_{2} \mathrm{~N}\right](\mathrm{FHF}) . \mathbf{h}$, $\left[\left(\mathrm{Me}_{2} \mathrm{~N}\right)_{3} \mathrm{~S}\right](\mathrm{FHF})$. 
a

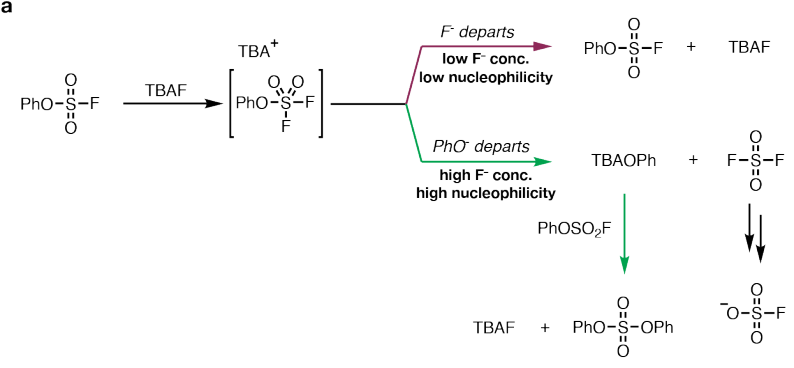

c

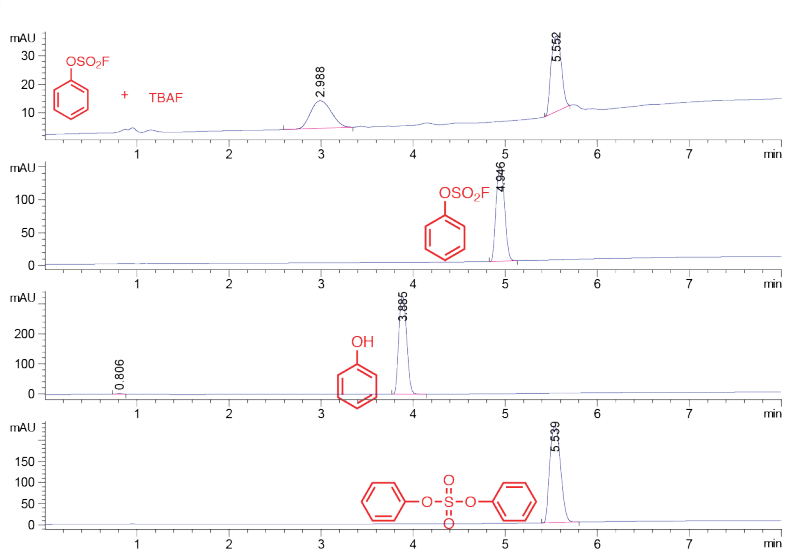

b

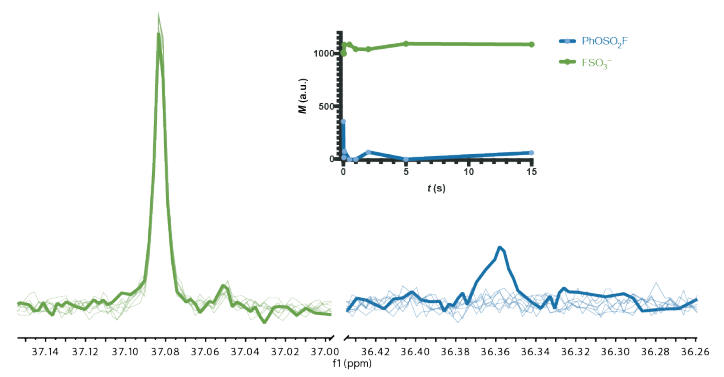

d

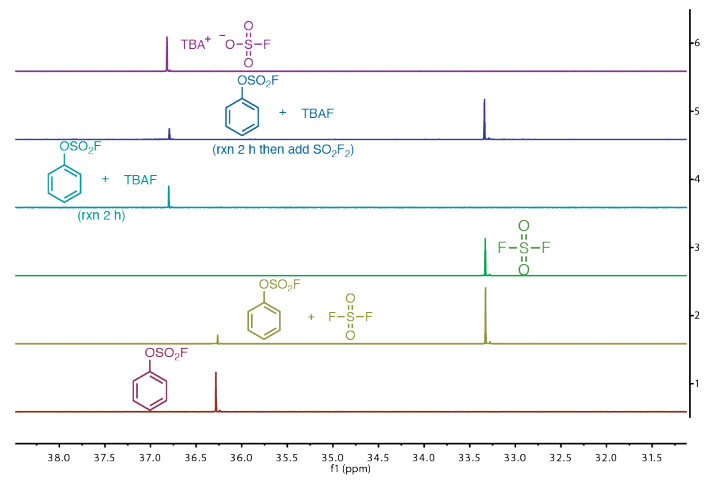

Fig. S15 | Discovery and evidence for the defluorosulfation of aryl fluorosulfate under basic fluoride conditions. a, Possible mechanism of fluoride-mediated defluorosulfation. $\mathbf{b}$, Fast defluorosulfation monitored by ${ }^{19} \mathrm{~F}$ NMR. The decomposition process was monitored by ${ }^{19} \mathrm{~F}$ NMR of aliquots taken out of the reaction mixture at the stated time points quenched with $1 \mathrm{~mol}$ $\mathrm{L}^{-1} \mathrm{HCl}$. c, HPLC evidence of formation of biphenyl sulfate. LC Trace 1 (from top to bottom): crude of TBAF and phenyl fluorosulfate mixed in acetonitrile for $3 \mathrm{~h}$. LC Trace 2: authentic sample of phenyl fluorosulfate. LC Trace 3: authentic sample of phenol. LC Trace 4: authentic sample of diphenyl sulfate. $\mathbf{d},{ }^{19} \mathrm{~F}$ NMR evidence of formation of fluorosulfate anion. NMR Spectrum 1 (from bottom to top): authentic sample of phenyl fluorosulfate. Spectrum 2: mixture of phenyl fluorosulfate with $\mathrm{SO}_{2} \mathrm{~F}_{2}$. Spectrum 3: authentic sample of $\mathrm{SO}_{2} \mathrm{~F}_{2}$. Spectrum 4: reaction mixture of phenyl fluorosulfate and TBAF for $2 \mathrm{~h}$. Spectrum 5: same reaction mixture added with $\mathrm{SO}_{2} \mathrm{~F}_{2}$; Spectrum 6: mixture of tetrabutylammonium bromide and potassium fluorosulfate. 


\subsubsection{Influence of Water Contamination}

Although the contamination of water in the commercially available fluoride source is often inevitable (and so is the fluoride source for nucleophilic fluorination in radiosynthesis), we studied the trend of exchange rate change versus the amount of exogenous water added using the same batch of purchased fluoride salt.

Into $1.0 \mathrm{~mL}$ TBABF solution (0.2 mol L $\mathrm{L}^{-1}$ in $\left.\mathrm{MeCN}-\mathrm{d} 3\right)$, water $(0.9 \mu \mathrm{L}$ for 0.5 equiv, or $1.8 \mu \mathrm{L}$ for 1.0 equiv, respectively) was added via a syringe. The TDST-NMR experiments were carried out according to aforementioned protocol (see NMR Spectrometer Settings). The results were shown in Table S4 and Fig. S16.

Table S4 | Evaluation of water contamination. Conditions: phenyl fluorosulfate $\left(1,0.02 \mathrm{~mol} \mathrm{~L}^{-}\right.$ $\left.{ }^{1}\right)$, indicated fluoride salt $\left(0.2 \mathrm{~mol} \mathrm{~L}^{-1}\right), \mathrm{MeCN}-d 3,298 \mathrm{~K}$.

\begin{tabular}{ccc}
\hline Entry & Fluoride & $\boldsymbol{k}_{\text {obs }}\left(\mathbf{s}^{-1}\right)$ \\
\hline 1 & {$\left[n-\mathrm{Bu}_{4} \mathrm{~N}\right](\mathrm{FHF})$} & $0.152 \pm 0.008(n=3)$ \\
2 & {$\left[n-\mathrm{Bu}_{4} \mathrm{~N}\right](\mathrm{FHF})\left(\mathrm{H}_{2} \mathrm{O}\right)_{0.5}$} & 0.065 \\
3 & {$\left[n-\mathrm{Bu}_{4} \mathrm{~N}\right](\mathrm{FHF})\left(\mathrm{H}_{2} \mathrm{O}\right)$} & 0.024 \\
\hline
\end{tabular}


a

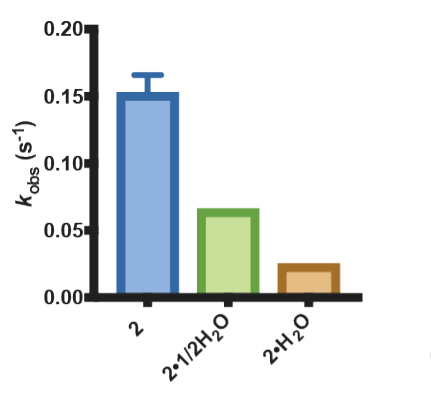

b
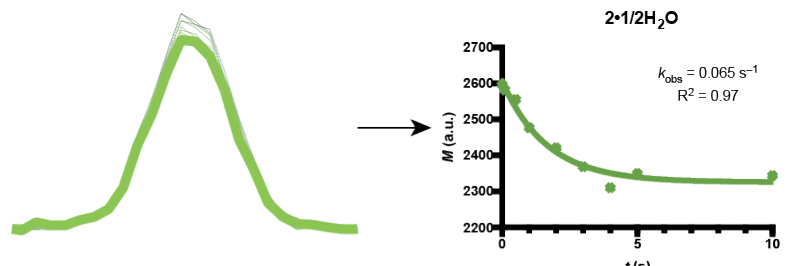

$t(s)$

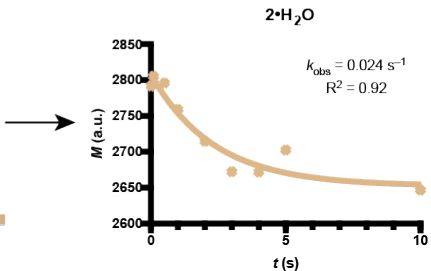

Fig. S16 | TDST experiments with different water contamination. Overlaid NMR spectra with curve fitting. a, Pseudo-first-order rate of the fluoride exchange process under various water contamination levels. b, $2 \cdot 1 / 2 \mathrm{H}_{2} \mathrm{O}$. c, $2 \cdot \mathrm{H}_{2} \mathrm{O}$. Conditions: See above. 


\subsubsection{Evaluation of Substituent Effects of Aryl Fluorosulfates}

Electronic effects. All relative rate constants $\left(k_{\text {rel }}\right)$ were measured via competition experiments. Equimolar amount of para-substituted phenyl flourosulfate S2, S43-S46 and phenyl fluorosulfate 1 (final concentration $0.02 \mathrm{~mol} \mathrm{~L}^{-1}$, respectively) were dissolved in $\mathrm{MeCN}$ d3 containing $0.2 \mathrm{~mol} \mathrm{~L}^{-1} \mathrm{TBABF}$. The exchange rate of either compounds was indepedently calculated using the same method (see Section 1.3.2). The relative rate $\left(k_{\mathrm{rel}}=k_{\mathrm{X}} / k_{\mathrm{H}}\right)$ was calculated using the data obtained from the same run of TDST-NMR experiment. The results were shown in Table S5 and Fig. S17.

Steric effects. Aryl fluorosulfates with bulky substituent (i.e., isopropyl) at one (S48) or both (S49) of its ortho-positions were tested in the context of competition TDST-NMR experiments with phenyl fluorosulfate (1). The results were shown in Table S6 and Fig. S18. Bulky orthosubstitution leads to decreased fluoride exchange rate. 
Table S5 | Evaluation of substituent effects. Conditions: phenyl fluorosulfate $\left(1,0.02 \mathrm{~mol} \mathrm{~L}^{-}\right.$ $\left.{ }^{1}\right)$, 4-substituted phenyl fluorosulfate (S2, S43-S46, $\left.0.02 \mathrm{~mol} \mathrm{~L}^{-1}\right)$, TBABF $\left(0.2 \mathrm{~mol} \mathrm{~L}^{-1}\right), \mathrm{MeCN}-$ d3, 298.0 K. ${ }^{a} \sigma$-values adapted from Hammett, L. P. ${ }^{38}$ and Hansch, C. et al. ${ }^{39}$.

\begin{tabular}{|c|c|c|c|c|c|}
\hline Entry & $\begin{array}{l}\text { Compound } \\
\text { Structure }\end{array}$ & $\begin{array}{c}\text { Substituent } \\
(\mathrm{X})\end{array}$ & $\sigma_{x^{a}}^{a}$ & $k_{\text {rel }}$ & $\log \left(k_{x} / k_{H}\right)$ \\
\hline 1 & & $\mathrm{NH}_{2}$ & -0.660 & 0.221 & -0.655 \\
\hline 2 & & OMe & -0.270 & 0.786 & -0.145 \\
\hline \multirow[t]{2}{*}{3} & & $\mathrm{Me}$ & -0.170 & 0.870 & -0.060 \\
\hline & S44 & & & & \\
\hline 4 & 1 & $\mathrm{H}$ & 0 & 1.000 & 0 \\
\hline 5 & & $\mathrm{Cl}$ & 0.227 & 3.34 & 0.520 \\
\hline \multirow[t]{2}{*}{6} & & $\mathrm{CO}_{2} \mathrm{Et}$ & 0.450 & 14.97 & 1.175 \\
\hline & 46 & & & & \\
\hline
\end{tabular}


a
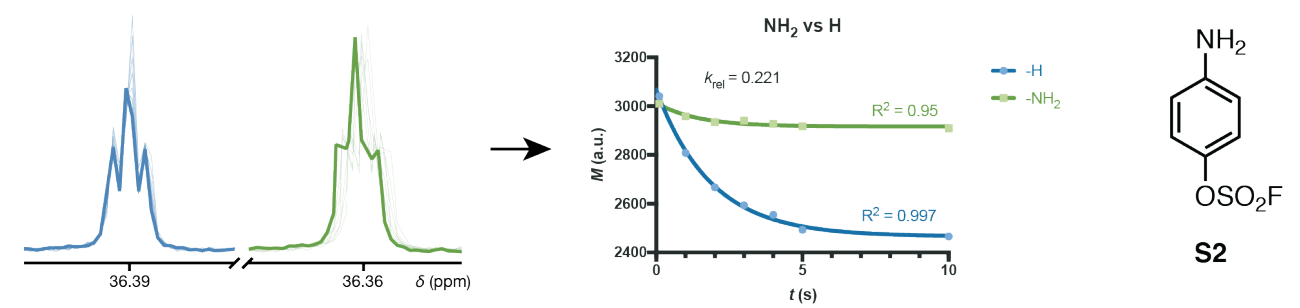

b
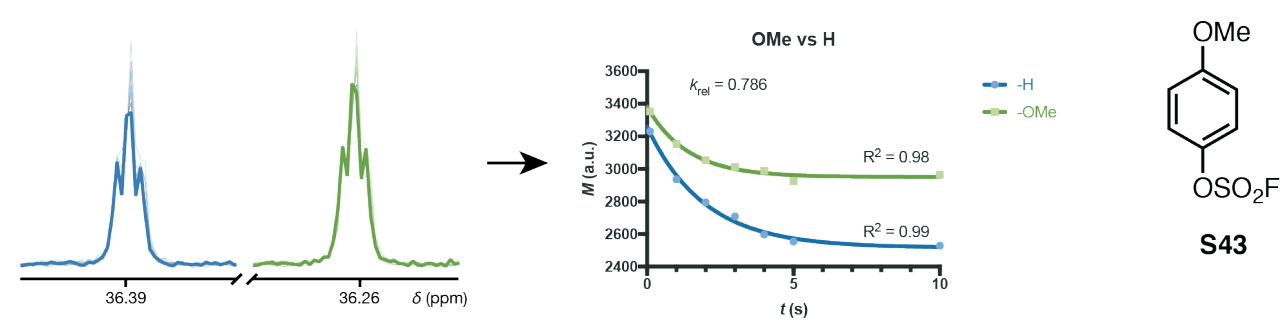

C
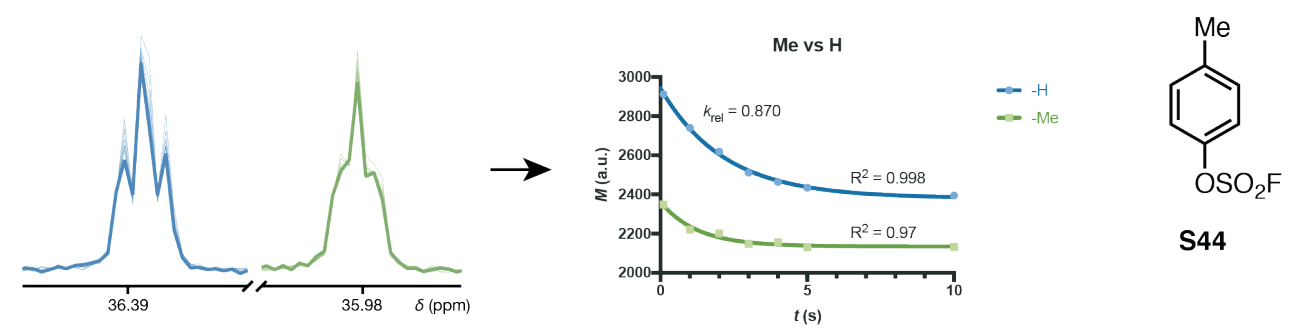

\$44

d
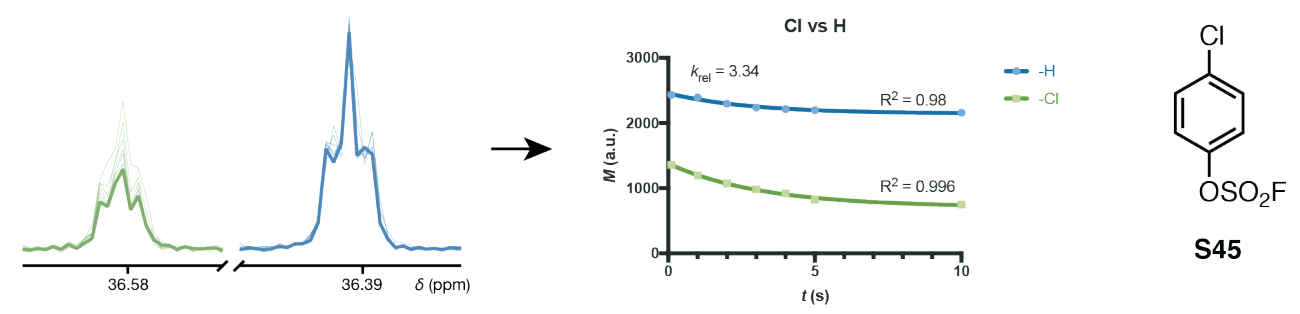

e
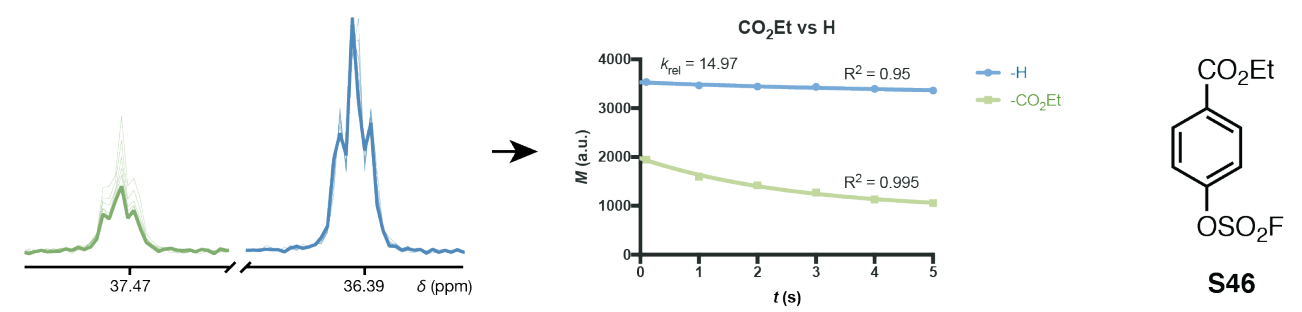

Fig. S17 | TDST-NMR experiments of competition experiments between phenyl fluorosulfate and substrates with different para-substituent. Overlaid NMR spectra with curve fitting. a, S2 $\left(X=N_{2}\right)$ vs 1. b, S43 $(X=O M e)$ vs 1. c, S44 $(X=M e)$ vs 1. d, S45 $(X=C l)$ vs 1. e, $\mathbf{S} 46\left(X=\mathrm{CO}_{2} \mathrm{Et}\right)$ vs 1. Conditions: See above. 
Table S6 | Influence of steric hindrance.

\begin{tabular}{|c|c|c|c|}
\hline Entry & Aryl Fluorosulfates & $k_{\text {obs }}\left(\mathrm{s}^{-1}\right)$ & $k_{\text {rel }}^{a}$ \\
\hline 1 & 1 & $0.152 \pm 0.008(n=3)$ & 1.00 \\
\hline 2 & S48 & 0.074 & 0.49 \\
\hline 3 & S49 & 0.018 & 0.12 \\
\hline
\end{tabular}

Conditions: phenyl fluorosulfate $\left(\mathbf{1}, 0.02 \mathrm{~mol} \mathrm{~L}^{-1}\right)$, ortho-substituted phenyl fluorosulfate (S48 or $\mathbf{S 4 9}$,

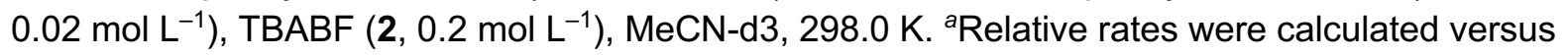
phenyl fluorosulfate 1. 
a

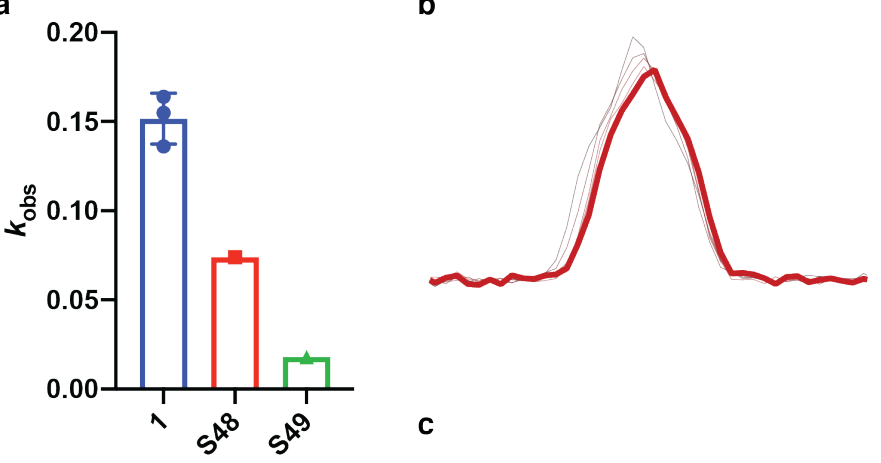

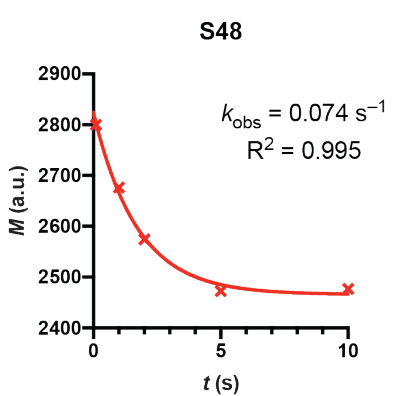

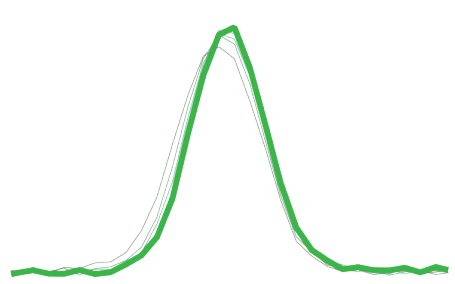

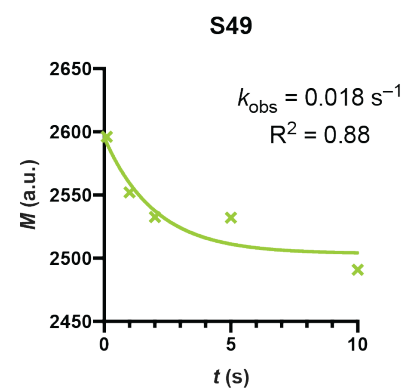

Fig. S18 | TDST experiments of substrates with steric hindrance. Overlaid NMR spectra with curve fitting. a, Fluoride exchange rate decreases as the sulfur center is surrounded by a more hindered environment. b, S48. c, S49. Conditions: see above. 


\subsubsection{Measurement of Second-Order Rate Constant}

Experimental. Stock solutions of TBABF (2) in MeCN-d3 were prepared, concentration of which being $0.2 \mathrm{~mol} \mathrm{~L}^{-1}, 0.35 \mathrm{~mol} \mathrm{~L}^{-1}, 0.5 \mathrm{~mol} \mathrm{~L}^{-1}, 1.0 \mathrm{~mol} \mathrm{~L}^{-1}$, or $1.5 \mathrm{~mol} \mathrm{~L}^{-1}$, respectively. Weigh $1.7 \mathrm{mg}(\sim 1.5 \mu \mathrm{L})$ phenyl fluorosulfate (1) and dilute it with $0.5 \mathrm{~mL}$ respective stock solution. Thus, all solutions shared the same concentration of $1,0.02 \mathrm{~mol} \mathrm{~L}^{-1}$. The TDST-NMR experiments were carried out according to aforementioned protocol (see Section 1.3.2). The results were shown in Table S7 and Fig. S19.

Data analysis. Plot Inkobs versus In[2], a linear trend was apparent (Fig. 2E, main text). The equation was solved

$$
\ln k_{o b s}=(0.707 \pm 0.034) \ln [2]-(0.849 \pm 0.031)
$$

Eq. $\mathbf{S 1 3}$

Under the assumption that the reaction was a bimolecular reaction, we have the secondorder rate constant

$$
k_{298 K}=\frac{k_{o b s}}{[2]}
$$

Then, we have

$$
\ln k_{o b s}=\ln k_{298 K}+\ln [2]
$$

That is the second-order rate at $298 \mathrm{~K}$ equal to the natural exponentiation of the $\mathrm{y}$-intercept of the linear regression. Compare Eq. S13 and Eq. S15, the second-order rate constant was solved.

$$
k_{298 K}=0.428 \pm 0.037 \mathrm{M}^{-1} \mathrm{~s}^{-1}
$$

Eq. $\mathbf{S 1 6}$ 
Table S7 | Measurement of second-order rate constant. In $k_{\text {obs }}$ vs $\ln [2]$.

\begin{tabular}{ccccc}
\hline Entry & {$[2]\left(\mathrm{mol} \mathrm{L}^{-1}\right)$} & $\ln [2]$ & $\boldsymbol{k}_{\text {obs }}\left(\mathbf{s}^{-1}\right)$ & $\ln k_{\text {obs }}$ \\
\hline 1 & 0.20 & -1.609 & 0.138 & -1.980 \\
2 & 0.35 & -1.050 & 0.192 & -1.652 \\
3 & 0.50 & -0.693 & 0.281 & -1.269 \\
4 & 1.00 & 0.000 & 0.428 & -0.849 \\
5 & 1.50 & 0.405 & 0.561 & -0.578 \\
\hline
\end{tabular}

Conditions: phenyl fluorosulfate (1, $\left.0.02 \mathrm{~mol} \mathrm{~L}^{-1}\right), \operatorname{TBABF}(\mathbf{2}$, indicated concentration), MeCN-d3, $298.0 \mathrm{~K}$. 
a
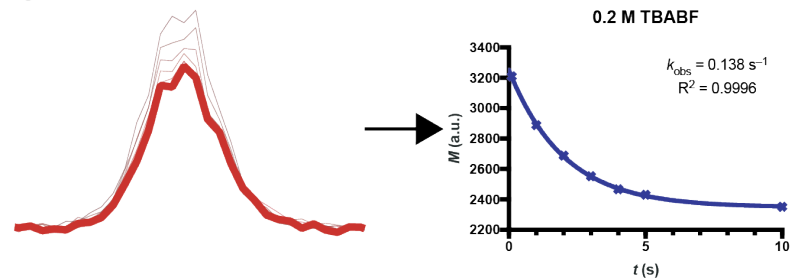

C
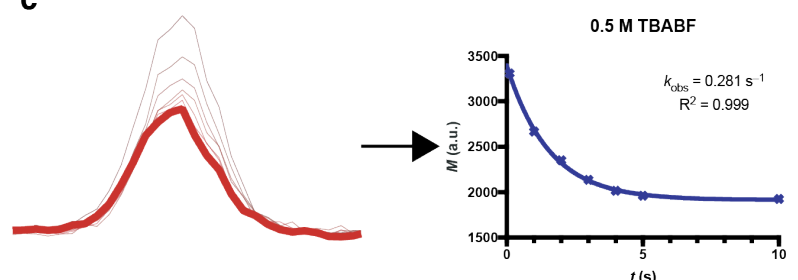

e
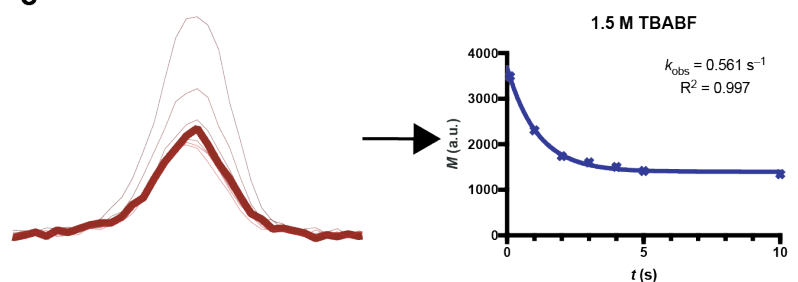

b

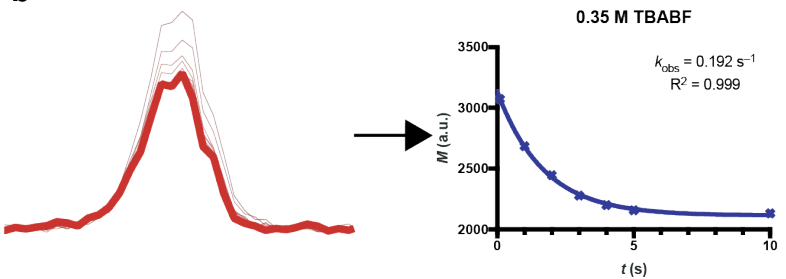

d

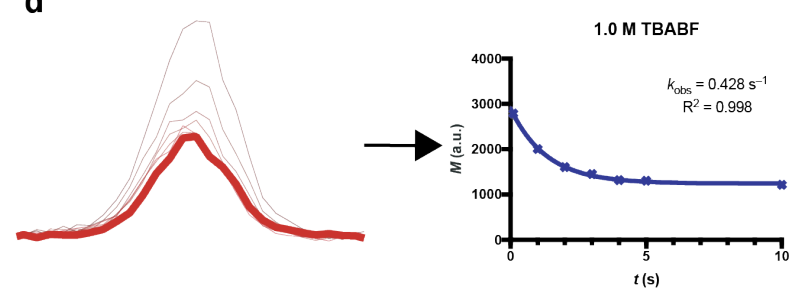

Fig. S19 | TDST experiments of phenyl fluorosulfate with TBABF at different concentrations. Overlaid NMR spectra with curve fitting. a, $0.2 \mathrm{~mol} \mathrm{~L}^{-1} \mathbf{2}$ in MeCN-d3. b, 0.35 mol L-1. c, $0.5 \mathrm{~mol} \mathrm{~L}^{-1}$. d, $1.0 \mathrm{~mol} \mathrm{~L}^{-1}$. e, $1.5 \mathrm{~mol} \mathrm{~L}^{-1}$. Conditions: See above. 


\subsubsection{Correlation of Temperature and Fluoride Exchange Rate}

Experimental. The concentration of phenyl fluorosulfate $\left(1,0.02 \mathrm{~mol} \mathrm{~L}^{-1}\right)$ and $\operatorname{TBABF}(2,0.2$ $\left.\mathrm{mol} \mathrm{L}^{-1}\right)$ were fixed. The temperature of the fluoride exchange process was set to change within a range between $278.0 \mathrm{~K}$ to $303.0 \mathrm{~K}$ in $5.0 \mathrm{~K}$ step length (6 data points). Before each acquisition, the NMR tube was left in field for $5 \mathrm{~min}$ to reach the set temperature (probe temperature). The probe temperature was stable $( \pm 0.1 \mathrm{~K})$ during all acquisitions. The results of the temperature change experiments were shown in Table S8, and Fig. S20.

Data analysis. In Eyring Equation, assume the transmission coefficient $(\kappa)$ equals unity, then we have

$$
k=\frac{k_{\mathrm{obs}}}{[2]}=\frac{k_{\mathrm{B}} T}{h} e^{-\frac{\Delta G^{\ddagger}}{R T}}
$$

Considering $\Delta G^{\ddagger} / T=\Delta H^{\ddagger} / T-\Delta S^{\ddagger}$, Eq. S17 can also be written as Eq. S18 or Eq. S19, where $\Delta H^{\ddagger}$ and $\Delta S^{\ddagger}$ are solvable by plotting $\ln \left(k_{\mathrm{obs}} / T\right)$ versus $T^{-1}$ and carrying out linear fit of the two variants.

$$
\begin{gathered}
k_{\mathrm{obs}}=[2] \frac{k_{\mathrm{B}} T}{h} e^{-\frac{\left(\Delta H^{\ddagger}-T \Delta S^{\ddagger}\right)}{R T}} \\
\ln \frac{k_{\mathrm{obs}}}{T}=-\frac{\Delta H^{\ddagger}}{R} T^{-1}+\ln \frac{k_{\mathrm{B}}}{h}+\frac{\Delta S^{\ddagger}}{R}+\ln [2]
\end{gathered}
$$

Plotting $\ln \left(k_{\text {obs }} / T\right)$ versus $T^{-1}$, we were able to obtain a linear trend (Fig. 2F, Main Text). The slope and $y$-intercept were calculated to be -5697 and 11.35 , respectively. Thus, the enthalpy $\left(\Delta H^{\ddagger}\right)$ and entropy of activation $\left(\Delta S^{\ddagger}\right)$ can be solved by Eq. S20 and Eq. S21.

$$
\begin{gathered}
\Delta H^{\ddagger}=-8.314 \mathrm{~J} \mathrm{~mol}^{-1} \mathrm{~K}^{-1} \times-5697 \mathrm{~K}=4.74 \times 10^{4} \mathrm{~J} \mathrm{~mol}^{-1} \\
=11.3 \mathrm{kcal} \mathrm{mol}^{-1} \\
\begin{array}{c}
\Delta S^{\ddagger}=[(11.35-23.76+1.61) \times 8.314] \mathrm{J} \mathrm{mol}^{-1} \mathrm{~K}^{-1} \\
=-89.8 \mathrm{~J} \mathrm{~mol}^{-1} \mathrm{~K}^{-1}
\end{array}
\end{gathered}
$$

At $298 \mathrm{~K}, \Delta G^{\ddagger}$ can be solved by $\Delta G^{\ddagger}=\Delta H^{\ddagger}-T \Delta S^{\ddagger}$ 


$$
\begin{aligned}
\Delta G^{\ddagger}(298 \mathrm{~K})= & 4.74 \times 10^{4} \mathrm{~J} \mathrm{~mol}^{-1}-298 \mathrm{~K} \times\left(-89.8 \mathrm{~J} \mathrm{~mol}^{-1} \mathrm{~K}^{-1}\right) \\
& =7.42 \times 10^{4} \mathrm{~J} \mathrm{~mol}^{-1}=17.7 \mathrm{kcal} \mathrm{mol}^{-1}
\end{aligned}
$$

Eq. $\mathbf{S 2 2}$

Table S8 | Temperature change TDST-NMR experiments.

\begin{tabular}{ccccc}
\hline Entry & Temperature $^{\mathbf{a}}(\mathrm{K})$ & $\mathbf{1 0 0 0 T}^{-\mathbf{1}}\left(\mathbf{1 0 0 0} \mathbf{K}^{-1}\right)$ & $\boldsymbol{K}_{\text {obs }}\left(\mathbf{s}^{-1}\right)$ & $\ln \left(\boldsymbol{K}_{\text {obs }} / \boldsymbol{T}\right)$ \\
\hline 1 & 278.0 & 3.597 & 0.0299 & -9.14 \\
2 & 283.0 & 3.534 & 0.0445 & -8.76 \\
3 & 288.0 & 3.472 & 0.0645 & -8.40 \\
4 & 293.0 & 3.413 & 0.0809 & -8.19 \\
5 & 298.0 & 3.356 & 0.1383 & -7.68 \\
6 & 303.0 & 3.300 & 0.1741 & -7.46 \\
\hline
\end{tabular}

Conditions: phenyl fluorosulfate (1, $\left.0.02 \mathrm{~mol} \mathrm{~L}^{-1}\right), \operatorname{TBABF}\left(2,0.2 \mathrm{~mol} \mathrm{~L}^{-1}\right), \mathrm{MeCN}-\mathrm{d} 3$, indicated temperature. ${ }^{a}$ NMR probe temperature. 
a

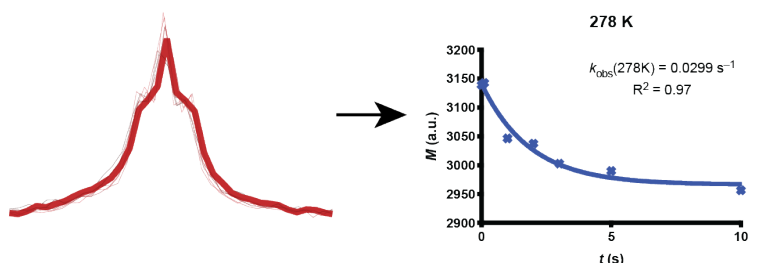

C

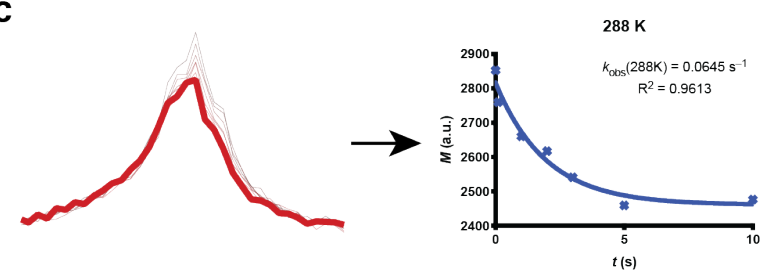

e

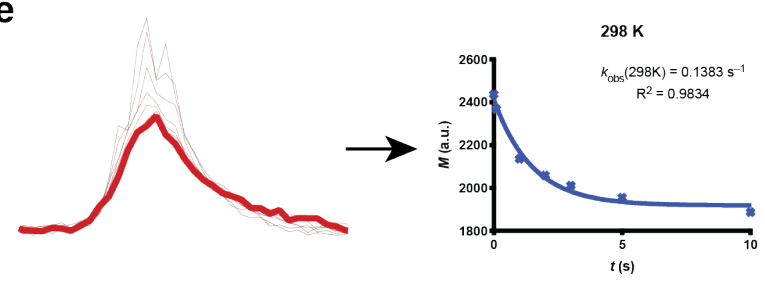

b
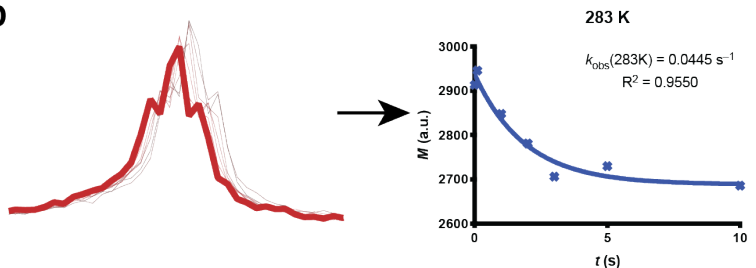

d

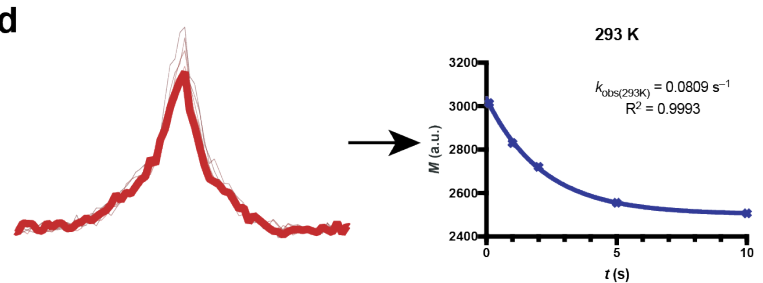

f

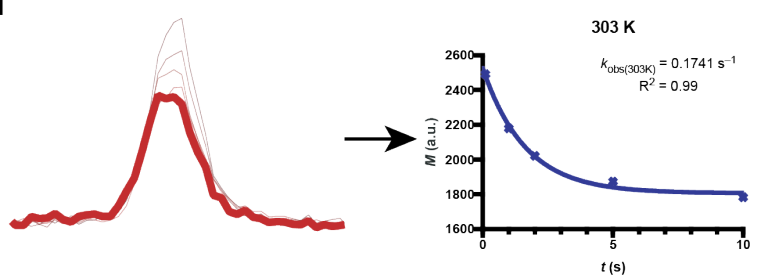

Fig. S20 | TDST-NMR experiments of phenyl fluorosulfate with TBABF at indicated temperature. Overlaid NMR spectra with curve fitting. Conditions: see above. a, $278.0 \mathrm{~K}$. b, 283.0 K. c, 288.0 K. d, 293.0 K. e, 298.0 K. f, 303.0 K. 


\section{Biochemistry}

\subsection{Cell-free Assay for $I C_{50}$ Determination of Compound 35 against PARP1}

Materials. A commercially available PARP1 (poly(ADP-ribose) polymerase 1) chemiluminescent assay kit (\#80551, BPS Bioscience) was used to test the inhibitory effect of the synthesized PARP1 inhibitor (35) and the assay was performed following the manufacturer's protocol (http://bpsbioscience.com/media/wysiwyg/80551_2.pdf).

Experimental. Compound $\mathbf{3 5}$ was dissolved in DMSO and diluted to the assay concentrations with $1 \times$ PARP buffer. Briefly, $50 \mu \mathrm{l}$ of histone mixture was added to each well of a 96-well plate (\#6005299, PerkinElmer) and incubated at $4{ }^{\circ} \mathrm{C}$ overnight. Being washed 3 times with PBST buffer ( 1 x PBS containing $0.05 \%$ Tween 20 ), the wells were blocked by blocking buffer and incubated at room temperature for 60-90 min, after which the plate was washed by PBST buffer. The "master mixture" $(25 \mu \mathrm{l})$ prepared following the protocol was added to each well, followed by addition of inhibitor solution $(5 \mu \mathrm{l})$ to the wells labeled as "inhibitor" and $1 \mathrm{x}$ PARP buffer ( $5 \mu \mathrm{l})$ to wells designated as "positive control" and "blank". Then $20 \mu \mathrm{l}$ of 1 x PARP buffer was added to the wells labeled as "blank", and $20 \mu$ of diluted PARP1 enzyme was added to the wells designated as "positive control" and "inhibitor". The plate was incubated at room temperature for $1 \mathrm{~h}$. Next, the reaction mixture was discarded, and the wells were washed 3 times with PBST buffer. Diluted Streptavidin-HRP (1:50 in blocking buffer, $50 \mu \mathrm{l})$ was added to each well and incubated for $30 \mathrm{~min}$ at room temperature, after which the wells were washed with PBST buffer three times. HRP chemiluminescent substrate A and HRP chemiluminescent substrate $B$ were mixed by $1: 1$ on ice and added to the wells $(100 \mu l$ per well). The chemiluminescence signals were immediately read in a micro titer-plate reader (Envision, PerkinElmer). The average value of "blank" wells was subtracted from values of all other wells. The dose-response curve was shown in Fig. S21. As a positive control, parent drug compound, olaparib (S49) was assayed using the same protocol in parallel. 


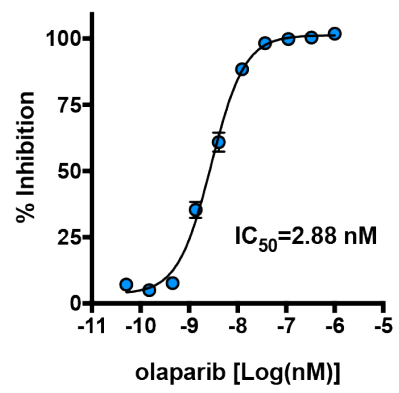

b

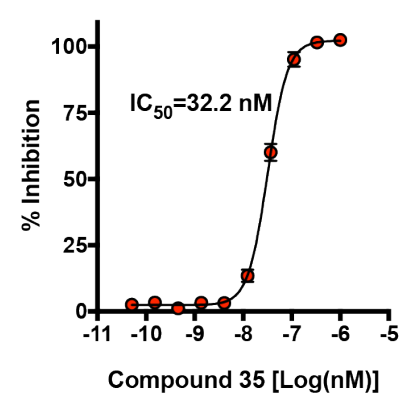

C

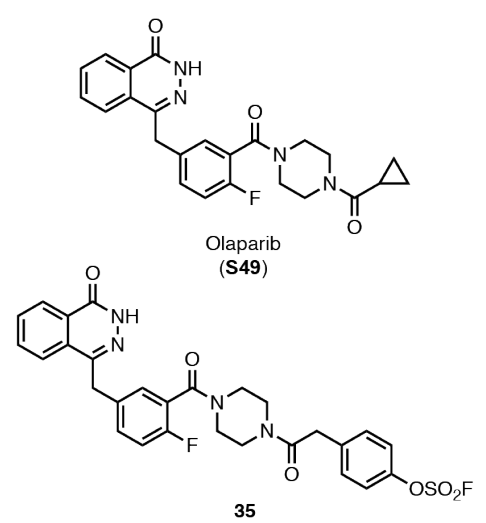

Fig. S21. Dose-response curves of olaparib (S49) and Compound 35 using the PARP1 chemiluminescent assay. a, Half-inhibition dose curve of S49. b, Half-inhibition dose curve of compound 35. c, Chemical structures of $\mathbf{S 4 9}$ and compound 35. 


\subsection{Mass Spectrometry Evidence for Non-Covalent Binding}

Protocol for LC-MS/MS analysis was adapted from Q. Zhao et al. ${ }^{40}$ PARP1-His fusion protein (\#11040-H08B, Sino Biological) was dissolved and diluted to $5 \mu \mathrm{M} / \mathrm{L}$ with reaction buffer

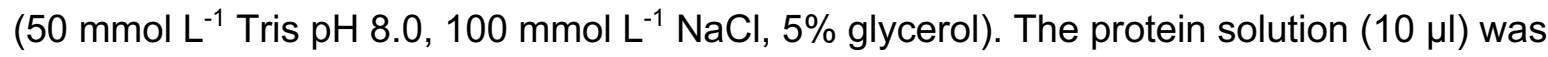
mixed with $1 \mu \mathrm{l}$ of reaction buffer-diluted PARP1 inhibitor solution $\left(500 \mu \mathrm{mol} \mathrm{L}^{-1}\right)$ and rotated at room temperature for $1 \mathrm{~h}$. Another $10 \mu \mathrm{l}$ of the protein solution was mixed with $1 \mu \mathrm{l}$ of reaction buffer and rotated at room temperature for $1 \mathrm{~h}$ as control. To the two samples, $10 \mu \mathrm{l}$ of quench buffer $(0.1 \%$ formic acid in MeCN) were added to quench the reaction. Samples were digested and then analyzed by a nano LC-MS/MS system (Orbitrap Fusion ${ }^{\mathrm{TM}}$ Tribrid $^{\mathrm{TM}}$ and EASY-nLC 1000, Thermo Fisher Scientific) with PepMap ${ }^{T M}$ RSLC C18 column (P/N ES803, Thermo Fisher Scientific). Data analysis (Modification: $\mathrm{C}_{28} \mathrm{H}_{23} \mathrm{FN}_{4} \mathrm{O}_{6} \mathrm{~S}$, mass shift: 562.1328 ) was performed using PD2.2 software (Thermo Fisher Scientific). Non-covalent interaction between PARP1 and compound $\mathbf{3 5}$ was evidenced by the mass spectrometry experiments (Table S9, Table S10). 
Table S9 | LC-MS/MS analysis of PARP1 Apo.

\begin{tabular}{cc}
\hline PARP1 & parp1 \\
\hline Accession & parp1 \\
Description & 67 \\
Coverage [\%] & 104 \\
\# Peptides & 416 \\
\# PSMs & 104 \\
\# Unique Peptides & 1 \\
\# Protein Groups & 1013 \\
\# AAs & 112.9 \\
MW [kDa] & 8.88 \\
calc. pl & 1734.87 \\
\hline Score Sequest HT: Sequest HT & 104 \\
\hline Peptides (by Search Engine): Sequest HT & \\
\hline
\end{tabular}


Table S10 | LC-MS/MS analysis of PARP1 treated with compound 35.

\begin{tabular}{|c|c|}
\hline PARP1 + Compound 35 & \\
\hline Checked & FALSE \\
\hline Master & Master Protein \\
\hline Accession & parp1 \\
\hline Description & parp1 \\
\hline Coverage $[\%]$ & 63 \\
\hline \# Peptides & 96 \\
\hline \# PSMs & 393 \\
\hline \# Unique Peptides & 96 \\
\hline \# Protein Groups & 1 \\
\hline \# AAs & 1013 \\
\hline $\mathrm{MW}[\mathrm{kDa}]$ & 112.9 \\
\hline calc. pl & 8.88 \\
\hline Score Sequest HT: Sequest HT & 1645.37 \\
\hline \# Peptides (by Search Engine): Sequest HT & 96 \\
\hline
\end{tabular}




\subsection{Serum Stability of Compound 35}

Compound 35 was dissolved in DMSO $\left(1 \mathrm{mmol} \mathrm{L}^{-1}\right)$. The resulting stock solution $(50 \mu \mathrm{L})$ was diluted by human serum $\left(450 \mu \mathrm{L}\right.$, pre-warmed to $\left.37^{\circ} \mathrm{C}\right)$ and incubated at $37^{\circ} \mathrm{C}$ with gentle agitation. During the incubation, aliquots $(50 \mu \mathrm{L})$ were withdrawn at $0,5,10,15,30,45,60,120$, $180 \mathrm{~min}$ time plots and diluted by MeCN $(150 \mu \mathrm{L})$. The quenched aliquots were centrifuged (2,500 rpm, $5 \mathrm{~min})$ and supernatant $(10 \mu \mathrm{L})$ was withdrawn for analysis by UPLC-MS. The remaining material percentages were calculated by area of the peak of interest by the original peak area at $t_{0}$. The serum stability assay was performed with three replicates (Fig. $\mathbf{5 b}$ ). The serum stability of the parent medicine olaparib was performed using the same protocol for comparison. The assay was performed with three replicates. 


\section{Radiochemistry}

\subsection{General Considerations}

\subsubsection{Materials}

Solvents and reagents for radiochemical synthesis were purchased from commercial sources and used as received: MeCN (Merck, HPLC grade), potassium carbonate (Huayi Isotopes Co., AR grade), 2.2.2-cryptand (Huayi Isotopes Co., AR grade), $\left[{ }^{18} \mathrm{O}\right]$ water (Huayi Isotopes Co., AR grade). Starting materials were prepared according to known procedures or reported procedures here.

\subsubsection{Generation of $\left[{ }^{18} F\right] K F$}

Preconditioning. The QMA column was eluted with potassium bicarbonate solution $(0.5 \mathrm{~mol}$ $\left.\mathrm{L}^{-1}, 10 \mathrm{~mL}\right)$ and water $(10 \mathrm{~mL})$, then purged to dry with air.

Preparation of Stock Solution A1. Potassium carbonate $\left(\mathrm{K}_{2} \mathrm{CO}_{3}, 3.5 \mathrm{mg}\right), 2.2 .2$-cryptand (7 $\mathrm{mg})$, were dissolved in $\mathrm{MeCN}(5 \mathrm{~mL})$ and $\mathrm{H}_{2} \mathrm{O}(2 \mathrm{~mL})$.

Preparation of Stock Solution A2. MeCN.

lon exchange. No-carrier-added (n.c.a.) hydrogen $\left[{ }^{18} \mathrm{~F}\right]$ fluoride $\left(\mathrm{H}\left[{ }^{18} \mathrm{~F}\right] \mathrm{F}\right)$ was produced from $\left[{ }^{18} \mathrm{O}\right]$ oxygen enriched water by nuclear reaction ${ }^{18} \mathrm{O}(\mathrm{p}, \mathrm{n}){ }^{18} \mathrm{~F}$ with an IBA Cyclone ${ }^{18} \mathrm{Twin}$ cyclotron and a silver-bodied target at Huayi Isotopes Co. The produced $\mathrm{H}\left[{ }^{18} \mathrm{~F}\right] \mathrm{F}$ in water was transferred from the cyclotron to a Synthra RNplus radiosynthesis system (Fig. S22), and trapped onto the QMA column (Waters, WAT023525). Valves V1-V13-V13-V14 were opened, $\left[{ }^{18}\right.$ F]fluoride was eluted into Stirrer 1 by Stock SolutionA1 $(1 \mathrm{~mL})$. Valves V2-V14 were opened, and Stock Solution A2 (1 mL) was added to Stirrer 1. The mixture was dried under nitrogen flow at $120^{\circ} \mathrm{C}$ for $3 \mathrm{~min}$. Cooled to $40^{\circ} \mathrm{C}$, Stock Solution $\mathrm{A} 2(1 \mathrm{~mL})$ was added, the solution was dried under nitrogen flow at $120^{\circ} \mathrm{C}$ for $3 \mathrm{~min}$. The resulting mixture containing potassium $\left[{ }^{18} \mathrm{~F}\right]$ fluoride $\left(\mathrm{K}\left[{ }^{18} \mathrm{~F}\right] \mathrm{F}\right)$ was re-dissolved in $\mathrm{MeCN}$ to make a stock solution with measurable activity.

\subsection{3. $\left[{ }^{18} F\right]$ SuFEx Reaction}

Desired amount (activity, 3.7 to $37 \mathrm{GBq}$ ) of $\mathrm{K}\left[{ }^{18} \mathrm{~F}\right] \mathrm{F}$ stock solution was transferred to a reaction vessel. Respective aryl fluorosulfate in $\mathrm{MeCN}$ was added. The $\left[{ }^{18} \mathrm{~F}\right] \mathrm{SuFEx}$ reaction was carried out at room temperature for $30 \mathrm{~s}$ without stirring. Water $(0.1 \mathrm{~mL})$ was added to quench the reaction if needed.

\subsubsection{HPLC Analysis}

The quenched reaction mixture was analyzed by HPLC with UV and radioactivity detectors. Radiochemical yields (RCYs) were determined by dividing the peak area of target product by the integrated peak area of all the regions of interest (R.O.I.) ${ }^{41}$. Note: radioactivity 
chromatographs are offset by 0.3 min regarding the delay introduced by the spatial separation between the diode array detector and the radioactivity detector.

Conditions for HPLC analysis are stated below:

Column: Waters SunFire C18 column, $100 \AA$ Å, $5.0 \mu \mathrm{m}, 4.6 \mathrm{~mm}$ x $150 \mathrm{~mm}$.

UV Wavelength of detection: $254 \mathrm{~nm} / 214 \mathrm{~nm}$.

Column temperature: $30^{\circ} \mathrm{C}$.

Flow rate: $1.0 \mathrm{~mL} / \mathrm{min}$.

Injection volume: $20 \mu \mathrm{L}$.

Elution gradient: see Table S11. 
Table S11 | Gradient elution conditions.

\begin{tabular}{|c|c|c|c|}
\hline \multicolumn{4}{|c|}{ Elution I } \\
\hline Time (min) & $A(\%)^{a}$ & $\mathrm{~B}(\%)^{b}$ & Elution \\
\hline 0 & 90 & 10 & isocratic \\
\hline 18 & 0 & 100 & linear gradient \\
\hline 20 & 0 & 100 & isocratic \\
\hline \multicolumn{4}{|c|}{ Elution II } \\
\hline Time (min) & $A(\%)^{a}$ & $\mathrm{~B}(\%)^{b}$ & Elution \\
\hline 0 & 90 & 10 & isocratic \\
\hline 13 & 0 & 100 & linear gradient \\
\hline 15 & 0 & 100 & isocratic \\
\hline \multicolumn{4}{|c|}{ Elution III } \\
\hline Time (min) & $A(\%)^{a}$ & $\mathrm{~B}(\%)^{b}$ & Elution \\
\hline 0 & 90 & 10 & isocratic \\
\hline 18 & 0 & 100 & linear gradient \\
\hline 25 & 0 & 100 & isocratic \\
\hline
\end{tabular}

${ }^{a} \mathrm{~A}$ : Water containing $0.5 \%$ TFA. ${ }^{b} \mathrm{~B}$ : MeCN. 


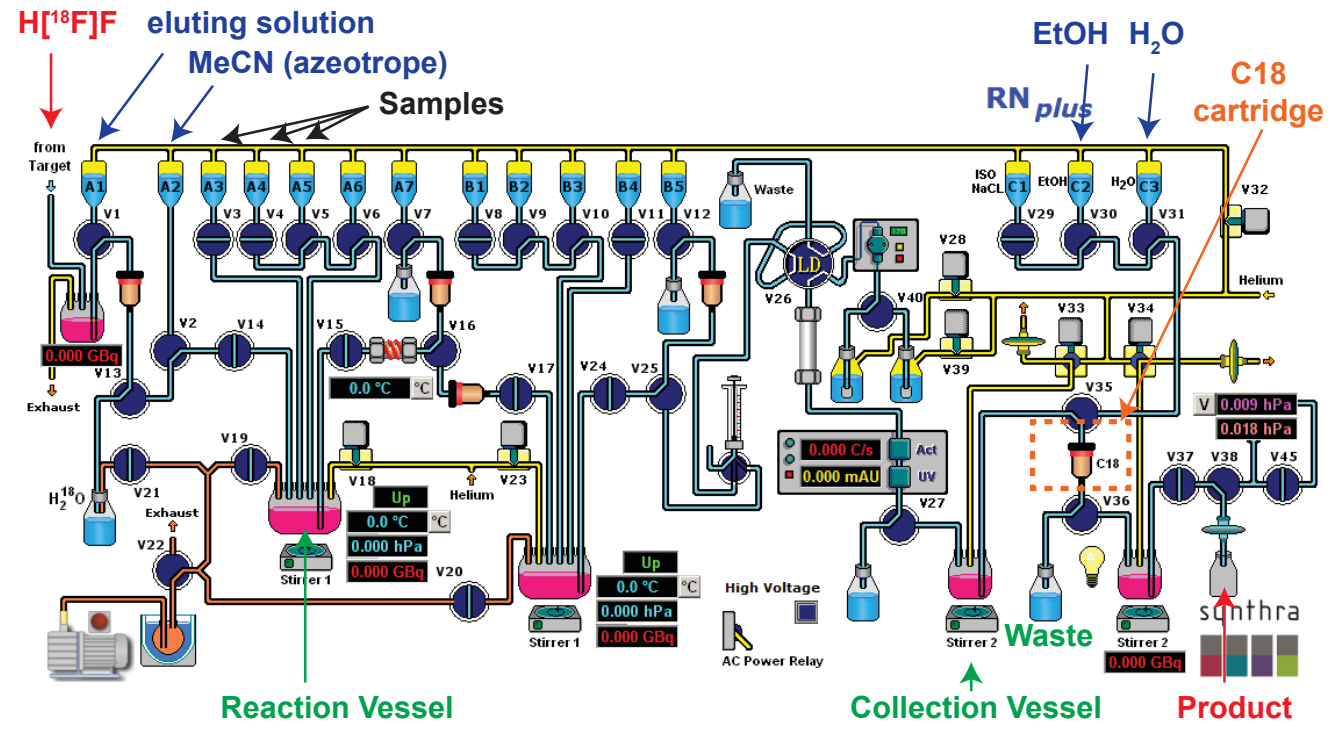

Fig. S22. Fully automated Synthra RNplus radiosynthesis system. Adapted from http://www.synthra.com/. 


\subsection{Optimizations of [18F]SuFEx Radiosynthesis}

\subsubsection{Original Condition}

3-Ethynylphenyl fluorosulfate 11 (1 mg), $\mathrm{K}\left[{ }^{18} \mathrm{~F}\right] \mathrm{F}$ (3.7 GBq), 2.2.2-cryptand were mixed in $\operatorname{MeCN}(0.5 \mathrm{~mL})$ in a radiosynthesizer at $50^{\circ} \mathrm{C}$ for $10 \mathrm{~min}$. It was found that under this condition the fluoride exchange reaction was extremely clean based on HPLC analysis (Fig. S23).

\subsubsection{Investigation of the Exchange Time}

Shorter incubation time was tried. It was found that 30-second incubation with other conditions unchanged was adequate for the "complete" conversion $\left(\left[{ }^{18} \mathrm{~F}\right]\right.$ SuFEx reached equilibrium). The UV and gamma chromatographs showed equally excellent results as those of 10-min incubation (Fig. S24).

\subsubsection{Optimization of Reaction Temperature}

Lower temperature, e.g. room temperature $\left(23^{\circ} \mathrm{C}\right)$ was tried. Compound 11 was incubated with same activity $\mathrm{K}\left[{ }^{18} \mathrm{~F}\right] \mathrm{F}$ for $5 \mathrm{~min}, 1 \mathrm{~min}$, and $30 \mathrm{~s}$. After indicated incubation time, the reactions were quenched by adding water $(0.1 \mathrm{~mL})$. In all three parallel experiments (Fig. S25, Fig. S26, Fig. S27), the $\left[{ }^{18} \mathrm{~F}\right]$ SuFEx reactions were clean, giving near pure aryl $\left[{ }^{18} \mathrm{~F}\right]$ fluorosulfate as the only peak on gamma chromatographs. Thus, reaction at room temperature $\left(23^{\circ} \mathrm{C}\right)$ for 30 $\mathrm{s}$ was considered the optimal conditions for the $\left[{ }^{18} \mathrm{~F}\right] \mathrm{SuFEx}$ radiolabeling.

\subsubsection{Investigation of the Influence of Water Contamination}

In the TDST-NMR experiment, we have showed that by adding exogenous water to the SuFEx system, the fluoride exchange rate would dramatically decrease. Although, it was known that during the preparation of radioactive $\mathrm{K}\left[{ }^{18} \mathrm{~F}\right] \mathrm{F}$, the contamination of water is usually inevitable even after three times of azeotropic evaporation with anhydrous acetonitrile ${ }^{42}$. We have run a parallel experiment with or without external introduced water. It was apparent that in the presence of exogenous water, the conversion of $\left[{ }^{18} \mathrm{~F}\right]$ fluoride to aryl fluorosulfate was very much impaired, evidenced by an RCY decrease from 99\% to 14\% (Fig. S28). At the same time, the UV trace showed no obvious hydrolysis/reaction of 11, indicating that the inhibition does stem from decomposition of the starting material. 
a

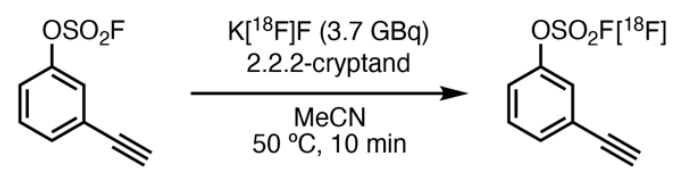

11

$\left[{ }^{18} \mathrm{~F}\right] 11$

b

Chromatogram: ${ }^{18} \mathrm{~F}$

Counts

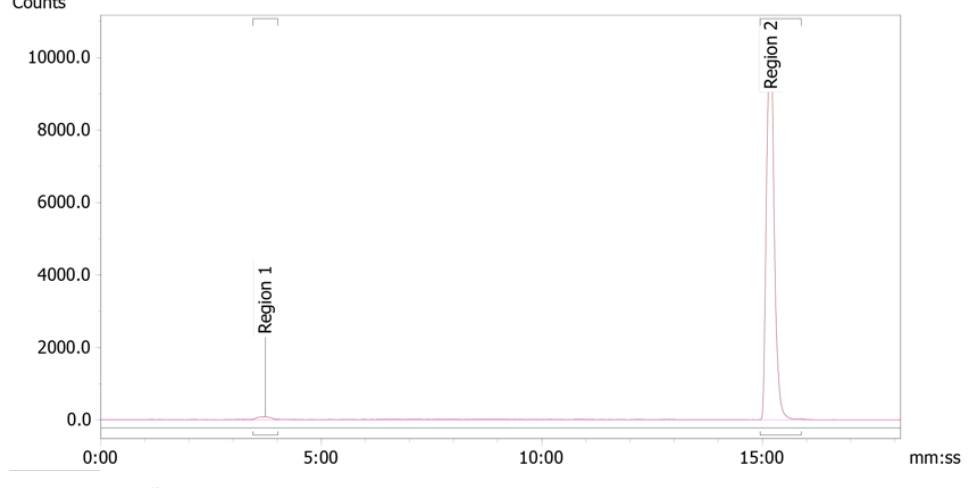

\begin{tabular}{|c|c|c|c|c|c|c|c|}
\hline Regions: & & Detector: & PMT & & & & \\
\hline Name & $\begin{array}{r}\text { Start } \\
(\mathrm{mm}: \mathrm{ss})\end{array}$ & $\begin{array}{r}\text { End } \\
(\mathrm{mm}: \mathrm{ss})\end{array}$ & $\begin{array}{r}\text { Retention } \\
\text { (mm:ss) }\end{array}$ & $\begin{array}{r}\text { Area } \\
\text { (Counts) }\end{array}$ & $\begin{array}{r}\% \text { ROI } \\
(\%)\end{array}$ & $\begin{array}{r}\begin{array}{r}\text { \%Total } \\
(\%)\end{array} \\
\end{array}$ & $\begin{array}{r}\text { Height } \\
\text { (Counts) }\end{array}$ \\
\hline $\begin{array}{l}\text { Region } 1 \\
\text { Region } 2\end{array}$ & $\begin{array}{r}3: 27 \\
14: 57\end{array}$ & $\begin{array}{r}4: 01 \\
15: 53\end{array}$ & $\begin{array}{r}3: 44 \\
15: 12\end{array}$ & $\begin{array}{r}2027.0 \\
130070.0\end{array}$ & $\begin{array}{r}1.53 \\
98.47\end{array}$ & $\begin{array}{r}1.42 \\
90.82\end{array}$ & $\begin{array}{r}99.0 \\
10955.0\end{array}$ \\
\hline 2 Peaks & & & & 132097.0 & 100.00 & 92.24 & \\
\hline $\begin{array}{l}\text { Total Area: } \\
\text { Average Background: }\end{array}$ & & $\begin{array}{l}143216.0 \\
0.0 \text { Count }\end{array}$ & & & & & \\
\hline
\end{tabular}

C

Chromatogram: UV

mAU

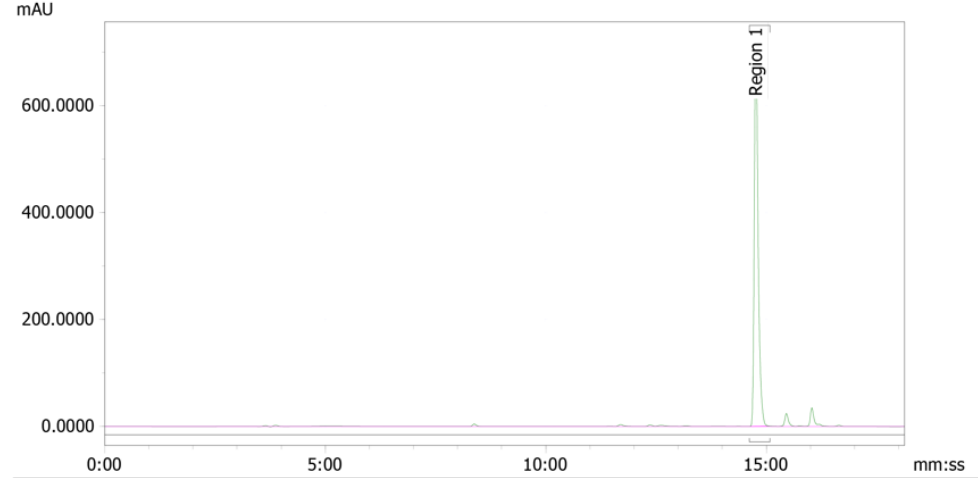

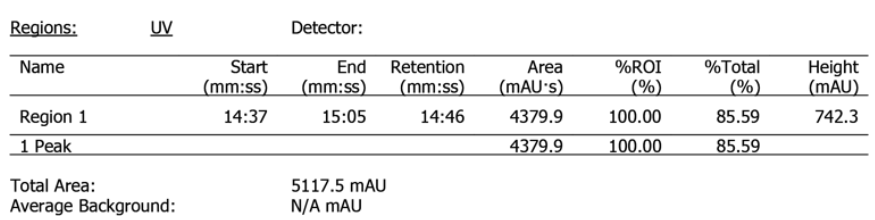

Fig. S23 | Chromatographs of crude mixture of 11 and $\mathrm{K}\left[{ }^{18} \mathrm{~F}\right] \mathrm{F}$ at $50{ }^{\circ} \mathrm{C}$ for $10 \mathrm{~min}$. a, Reaction. b, Gamma trace. c, UV trace $(254 \mathrm{~nm})$. Conditions: $11(50 \mu \mathrm{g}, 250 \mathrm{nmol}), \mathrm{K}\left[{ }^{18} \mathrm{~F}\right] \mathrm{F}$ $(\sim 3.7 \mathrm{GBq}), \mathrm{MeCN}(0.5 \mathrm{~mL}), 50^{\circ} \mathrm{C}, 10 \mathrm{~min} . \mathrm{RCY}=98 \%$. HPLC Elution I. 
a

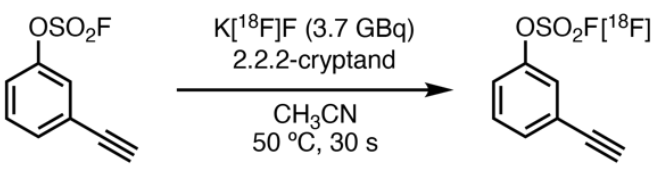

11

$\left[{ }^{18} \mathrm{~F}\right] 11$

b

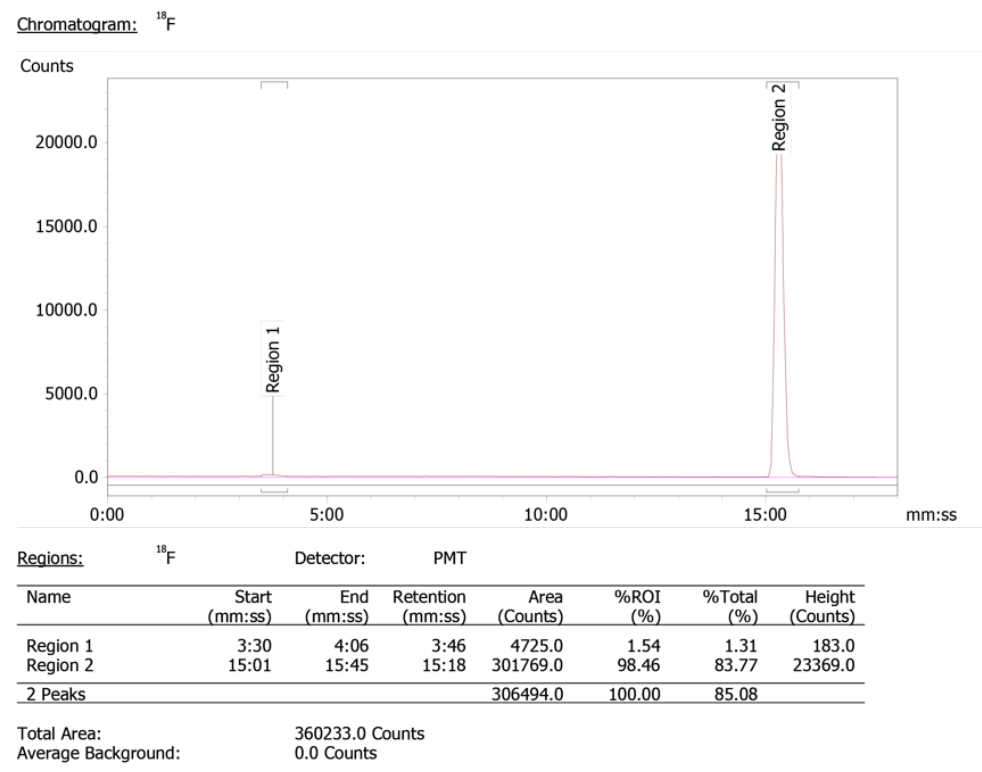

.

Chromatogram: UV

mAU

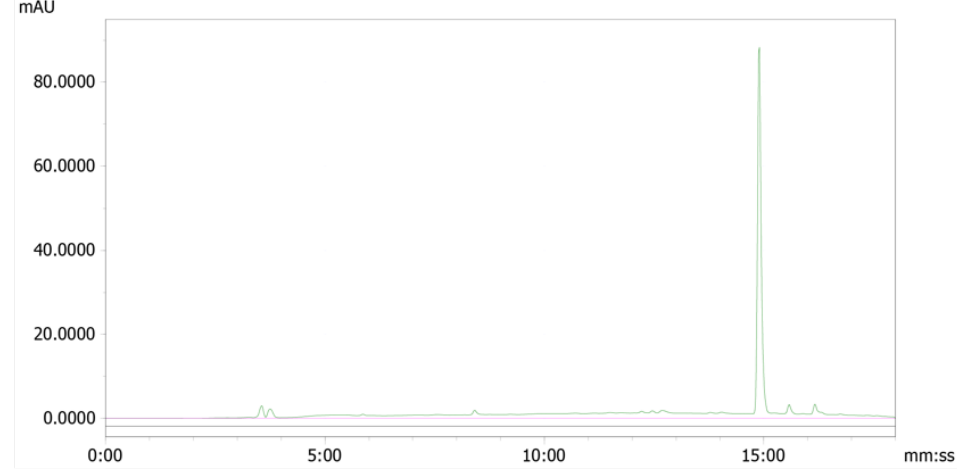

Regions:

$\underline{\text { UV }}$

Detector:

\begin{tabular}{rrrrrrrr}
\hline Name & $\begin{array}{r}\text { Start } \\
(\mathrm{mm}: \mathrm{ss})\end{array}$ & $\begin{array}{r}\text { End } \\
(\mathrm{mm}: \mathrm{ss})\end{array}$ & $\begin{array}{r}\text { Retention } \\
(\mathrm{mm}: \mathrm{ss})\end{array}$ & $\begin{array}{r}\text { Area } \\
(\mathrm{mAU} \cdot \mathrm{s})\end{array}$ & $\begin{array}{r}\% \text { ROI } \\
(\%)\end{array}$ & $\begin{array}{r}\% \text { Total } \\
(\%)\end{array}$ & $\begin{array}{r}\text { Height } \\
(\mathrm{mAU})\end{array}$ \\
\hline
\end{tabular}

No ROIs allocated.

0 Peaks

$0.0 \quad 100.00 \quad 0.00$

Total Area: $\quad 1410.8 \mathrm{mAU}$

Fig. S24 | Crude gamma and UV HPLC traces of $\left[{ }^{18} \mathrm{~F}\right]$ SuFEx reaction. a, Reaction. $b$, Gamma trace. c, UV trace (254 nm). Conditions: $11(50 \mu \mathrm{g}, 250 \mathrm{nmol}), \mathrm{K}\left[{ }^{18} \mathrm{~F}\right] \mathrm{F}(\sim 3.7 \mathrm{GBq})$, $\mathrm{MeCN}(0.5 \mathrm{~mL}), 50^{\circ} \mathrm{C}, 30 \mathrm{~s}$. RCY $=98 \%$. HPLC Elution I. 
a

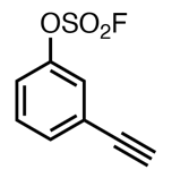

11

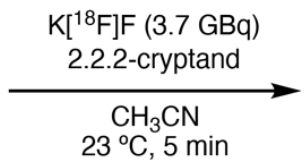

$23^{\circ} \mathrm{C}, 5 \mathrm{~min}$

b

Chromatogram: ${ }^{18} \mathrm{~F}$

Counts 25000.0

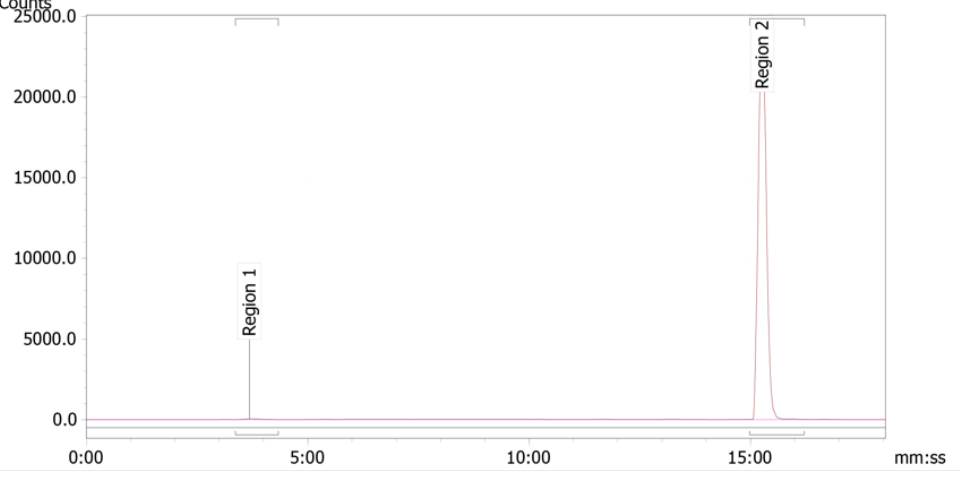

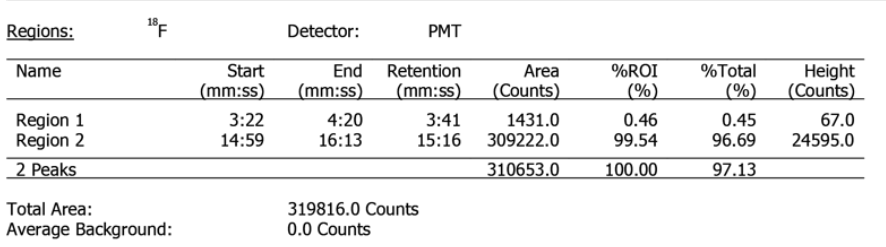

C

Chromatogram: UV

mAU

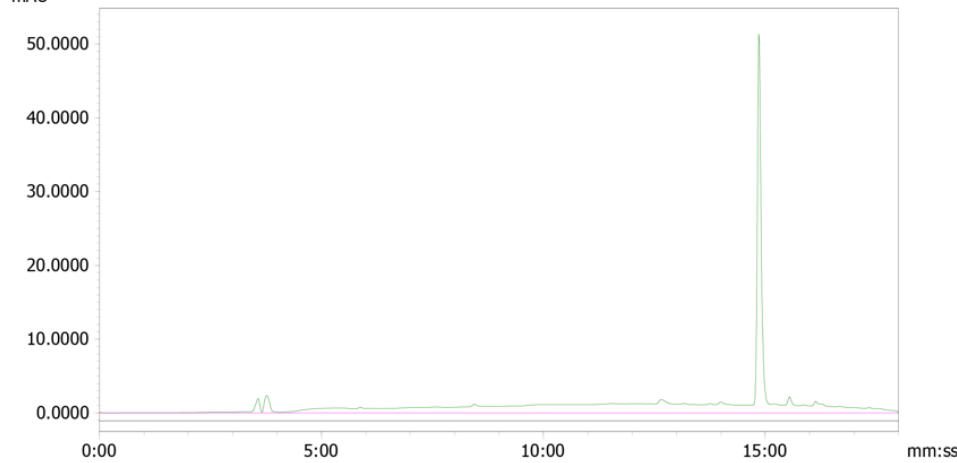

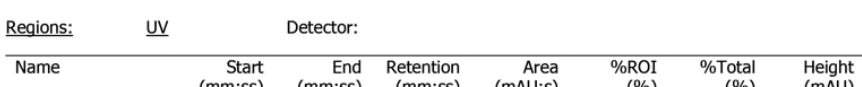

No ROIs allocated

\begin{tabular}{llll}
\hline 0 Peaks & 0.0 & 100.00 & 0.00 \\
\hline
\end{tabular}

Total Area:

Average Background

$1094.6 \mathrm{mAU}$
N/A mAU

Fig. S25 | Crude gamma and UV HPLC traces of $\left[{ }^{18} \mathrm{~F}\right]$ SuFEx reaction. $a$, Reaction. $b$, Gamma trace. c, UV trace (254 nm). Conditions: 11 (0.05 mg, $250 \mathrm{nmol}), \mathrm{K}\left[{ }^{18} \mathrm{~F}\right] \mathrm{F}(\sim 3.7 \mathrm{GBq})$, $\operatorname{MeCN}(0.5 \mathrm{~mL}), 23^{\circ} \mathrm{C}, 5 \mathrm{~min}$. RCY $=100 \%$. HPLC Elution I. 
a

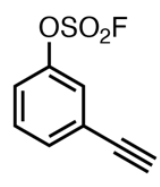

11

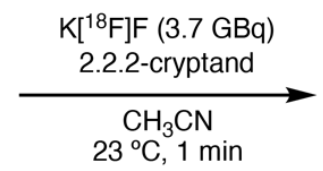

$23^{\circ} \mathrm{C}, 1 \mathrm{~min}$

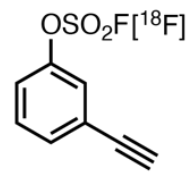

$\left[{ }^{18} \mathrm{~F}\right] 11$

b

Chromatogram: ${ }^{18} \mathrm{~F}$

Counts 2500.0

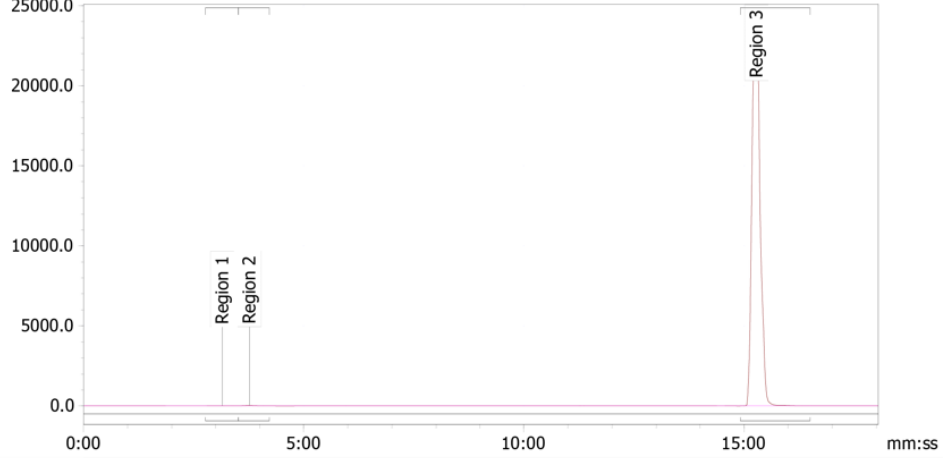

\begin{tabular}{|c|c|c|c|c|c|c|c|}
\hline Regions: & & Detector: & PMT & & & & \\
\hline Name & $\begin{array}{r}\text { Start } \\
(\mathrm{mm}: \mathrm{ss})\end{array}$ & $\begin{array}{r}\text { End } \\
(\mathrm{mm}: \mathrm{ss})\end{array}$ & $\begin{array}{r}\text { Retention } \\
\text { (mm:ss) }\end{array}$ & $\begin{array}{r}\text { Area } \\
\text { (Counts) }\end{array}$ & $\begin{array}{r}\text { \%ROI } \\
(\%) \\
\end{array}$ & $\begin{array}{r}\text { \%Total } \\
(\%)\end{array}$ & $\begin{array}{r}\text { Height } \\
\text { (Counts) }\end{array}$ \\
\hline $\begin{array}{l}\text { Region } 1 \\
\text { Region } 2\end{array}$ & $\begin{array}{l}2: 46 \\
3: 31\end{array}$ & $\begin{array}{l}3: 31 \\
4: 13\end{array}$ & $\begin{array}{r}3: 09 \\
3: 46\end{array}$ & $\begin{array}{r}321.0 \\
755.0\end{array}$ & $\begin{array}{r}0.10 \\
0.24\end{array}$ & $\begin{array}{r}0.10 \\
0.23 \\
0777\end{array}$ & $\begin{array}{r}13.0 \\
38.0\end{array}$ \\
\hline Region 3 & $14: 55$ & $16: 30$ & $15: 17$ & 318239.0 & 99.66 & 97.77 & \\
\hline 3 Peaks & & & & 319315.0 & 100.00 & 98.10 & \\
\hline
\end{tabular}

Total Area: $\quad 325509.0$ Counts

Average Background: $\quad 0.0$ Counts

Chromatogram: UV

mAU

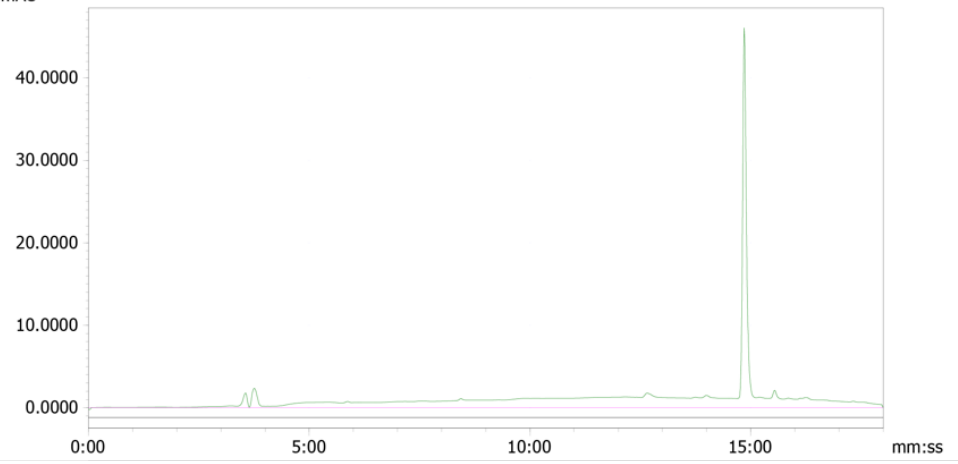

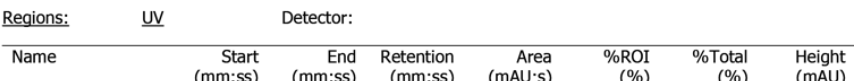

No ROIs allocated.

o Peaks

Total Area: $\quad 1099.0 \mathrm{mAU}$

Fig. S26 | Crude gamma and UV HPLC traces of $\left[{ }^{18} \mathrm{~F}\right]$ SuFEx reaction. $\mathbf{a}$, Reaction. $\mathbf{b}$, Gamma trace. c, UV trace (254 nm). Conditions: 11 (0.05 mg, $250 \mathrm{nmol}), \mathrm{K}\left[{ }^{18} \mathrm{~F}\right] \mathrm{F}(\sim 3.7 \mathrm{GBq})$, $\operatorname{MeCN}(0.5 \mathrm{~mL}), 23^{\circ} \mathrm{C}, 1 \mathrm{~min} . \mathrm{RCY}=100 \%$. HPLC Elution I. 
a
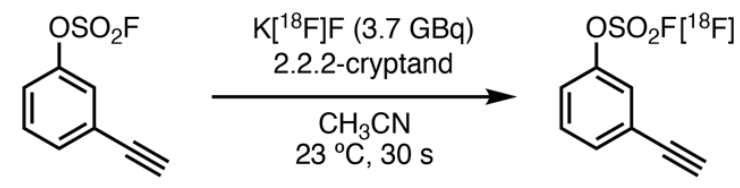

11

$\left[{ }^{18} \mathrm{~F}\right] 11$

b

Chromatogram: ${ }^{18} \mathrm{~F}$

Counts

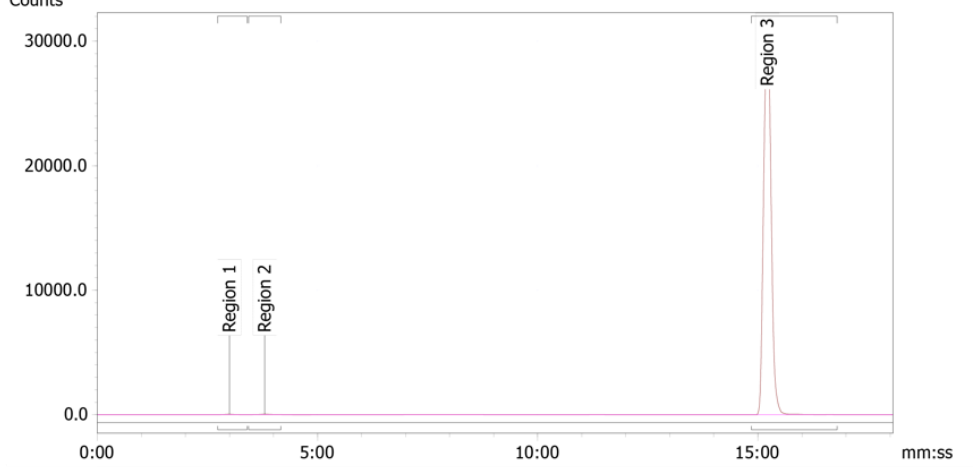

Regions: $\quad{ }^{18} \mathrm{~F} \quad$ Detector: $\quad$ PMT

\begin{tabular}{lrrrrrrr}
\hline Name & $\begin{array}{r}\text { Start } \\
(\mathrm{mm}: \mathrm{ss})\end{array}$ & $\begin{array}{r}\text { End } \\
(\mathrm{mm}: \mathrm{ss})\end{array}$ & $\begin{array}{r}\text { Retention } \\
(\mathrm{mm} \text { m:ss }\end{array}$ & $\begin{array}{r}\text { Area } \\
\text { (Counts) }\end{array}$ & $\begin{array}{r}\% \text { ROI } \\
(\%)\end{array}$ & $\begin{array}{r}\% \text { Total } \\
(\%)\end{array}$ & $\begin{array}{r}\text { Height } \\
(\text { Counts) }\end{array}$ \\
\hline Region 1 & $2: 44$ & $3: 24$ & $3: 00$ & 694.0 & 0.19 & 0.18 & 50.0
\end{tabular}

\begin{tabular}{lrrrrrrr} 
Region 1 & $2: 44$ & $3: 24$ & $3: 00$ & 694.0 & 0.19 & 0.18 & 50.0 \\
Region 2 & $3: 26$ & $4: 10$ & $3: 48$ & 998.0 & 0.26 & 0.26 & 56.0 \\
Region 3 & $14: 51$ & $16: 48$ & $15: 13$ & 372576.0 & 99.56 & 98.49 & 31658.0 \\
\hline
\end{tabular}

\begin{tabular}{llllllll} 
Region 3 & $14: 51$ & $16: 48$ & $15: 13$ & 372576.0 & 99.56 & 98.49 & 31658.0 \\
\hline 3 Pens & & & & 37438.0 & 1000 & 98.93 &
\end{tabular}

\begin{tabular}{ll}
\hline 3 Peaks & \\
\hline Total Area: & 378300.0 Counts \\
Average Background: & 0.0 Counts
\end{tabular}

Average Background: $\quad 0.0$ Counts

C

Chromatogram: $\underline{\mathrm{UV}}$

mAU

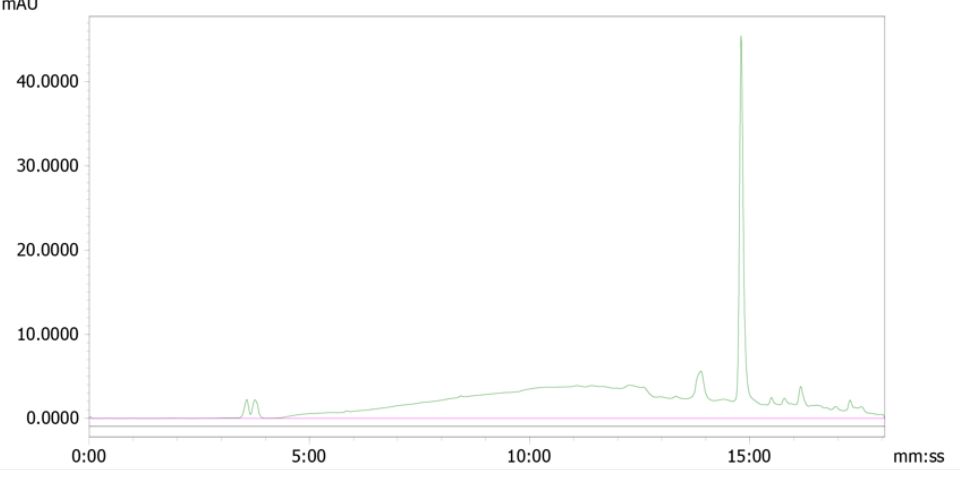

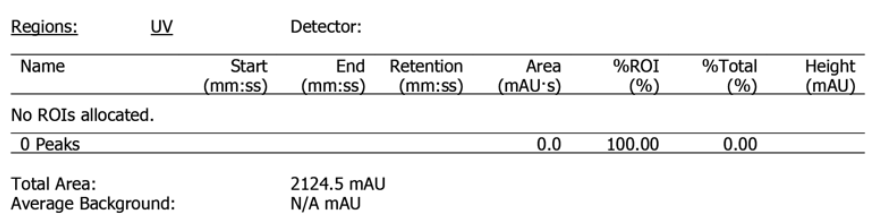

Fig. S27 | Crude gamma and UV HPLC traces of $\left[{ }^{18} \mathrm{~F}\right]$ SuFEx reaction. a, Reaction. $\mathbf{b}$, Gamma trace. c, UV trace $(254 \mathrm{~nm})$. Conditions: $11(0.05 \mathrm{mg}, 250 \mathrm{nmol}), \mathrm{K}\left[{ }^{18} \mathrm{~F}\right] \mathrm{F}(\sim 3.7 \mathrm{GBq})$, $\operatorname{MeCN}(0.5 \mathrm{~mL}), 23^{\circ} \mathrm{C}, 30 \mathrm{~s} . \mathrm{RCY}=100 \%$. HPLC Elution I. 
a

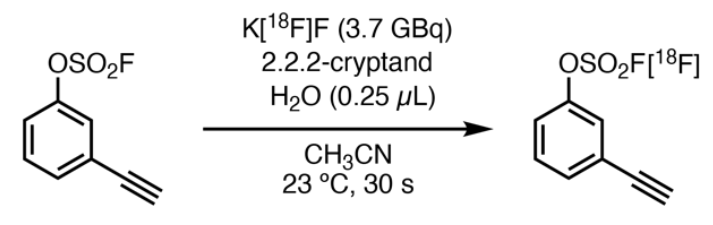

11

b

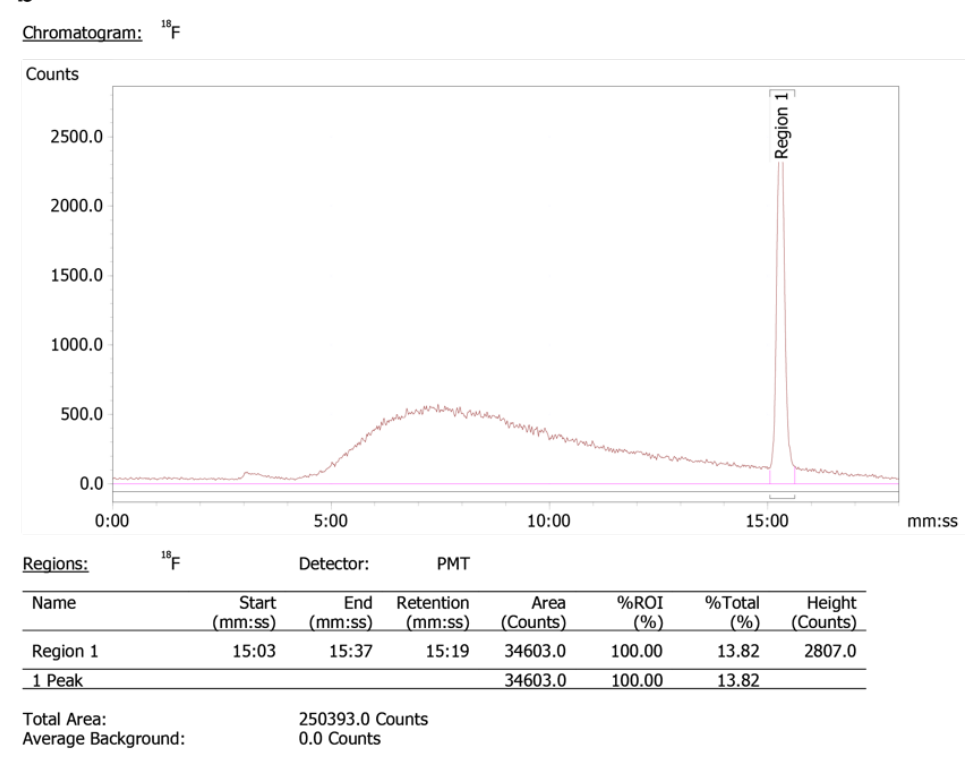

c

Chromatogram: $\underline{u v}$

maU

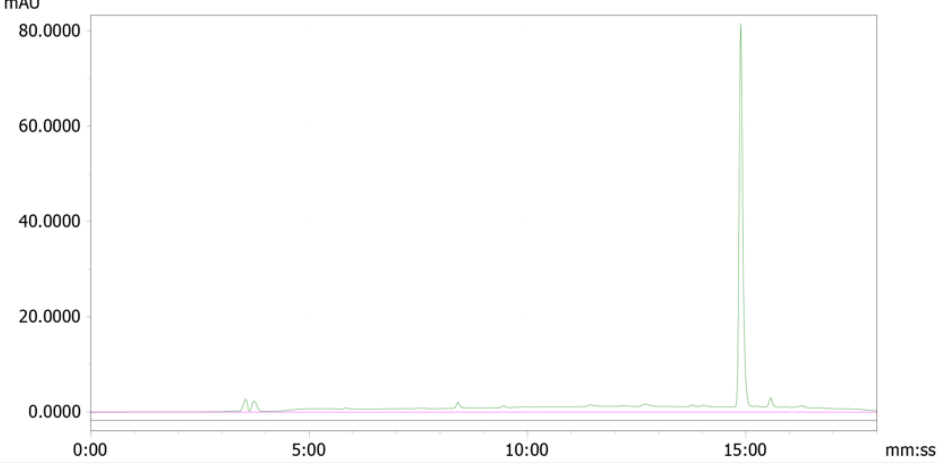

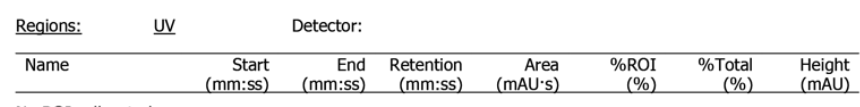

No ROIs allocated.

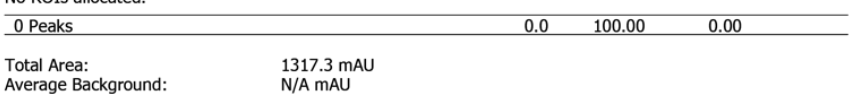

Fig. S28. Influence of water contamination to $\left[{ }^{18} \mathrm{~F}\right]$ SuFEx. a, Reaction. $\mathbf{b}$, Gamma trace, $\mathrm{RCY} \sim 14 \%$. c, UV trace $(254 \mathrm{~nm})$. Conditions: $11(0.05 \mathrm{mg}, 250 \mathrm{nmol}), \mathrm{K}\left[{ }^{18} \mathrm{~F}\right] \mathrm{F}(\sim 3.7 \mathrm{GBq})$, water $(0.25 \mu \mathrm{L}, 14 \mu \mathrm{mol}), \mathrm{MeCN}(0.25 \mathrm{~mL}), 50^{\circ} \mathrm{C}, 5 \mathrm{~min}$. RCY $\sim 14 \%$. HPLC Elution I. 


\subsection{Fully Automated Radiosynthesis of $\left[{ }^{18} \mathrm{~F}\right] 11$}<smiles>C#Cc1cccc(OC(F)(F)F)c1</smiles>

11

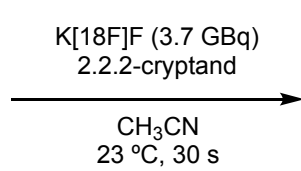

$23^{\circ} \mathrm{C}, 30 \mathrm{~s}$

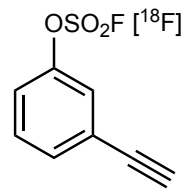

$\left[{ }^{18} \mathrm{~F}\right] 11$

$\mathrm{RCY}=99.3 \pm 0.6 \%$

General procedures for radiosynthesis, exemplified by $\left[{ }^{18} \mathrm{~F}\right] 11$. Desired amount (based on radioactivity, $\sim 3.7 \mathrm{GBq}$ ) of potassium $\left[{ }^{18} \mathrm{~F}\right]$ fluoride stock solution was transferred to a conical vial. 3-Ethynylphenyl fluorosulfates (11, $0.05 \mathrm{mg}, 250 \mu \mathrm{mol})$ in $\mathrm{MeCN}(0.5 \mathrm{~mL})$ was added. The exchange was carried out at room temperature for $30 \mathrm{~s}$. Water $(0.1 \mathrm{~mL})$ was added to quench the fluoride exchange. The diluted mixture was analyzed by HPLC with UV and radioactivity probes. Note: radioactivity chromatographs are offset by 0.3 min regarding the delay introduced by the spatial separation between the diode array detector and the radioactivity detector.

Four replicates of experiments were performed for the synthesis of $\left[{ }^{18} \mathrm{~F}\right] 11$, shown in Fig. S29. The radiochemical yield based on crude HPLC were shown in Table S12. 


\section{a}

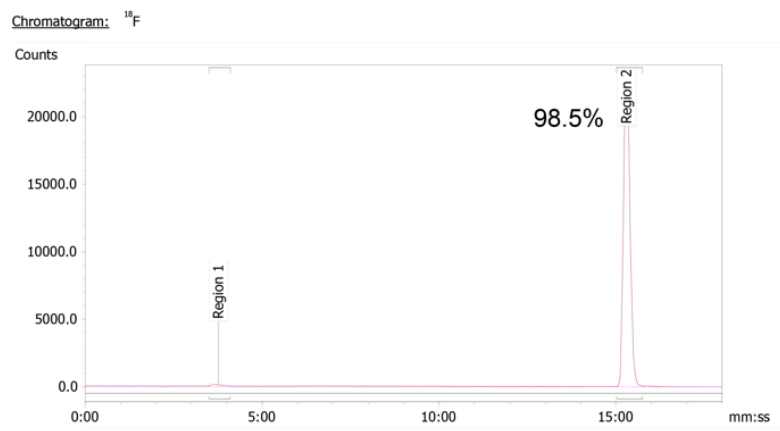

b

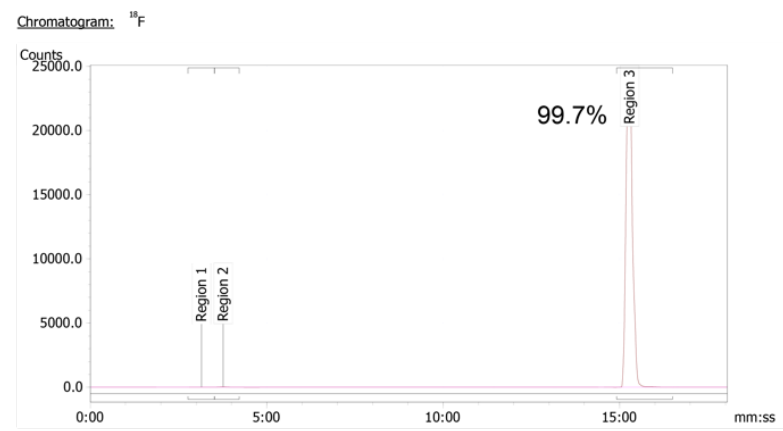

C

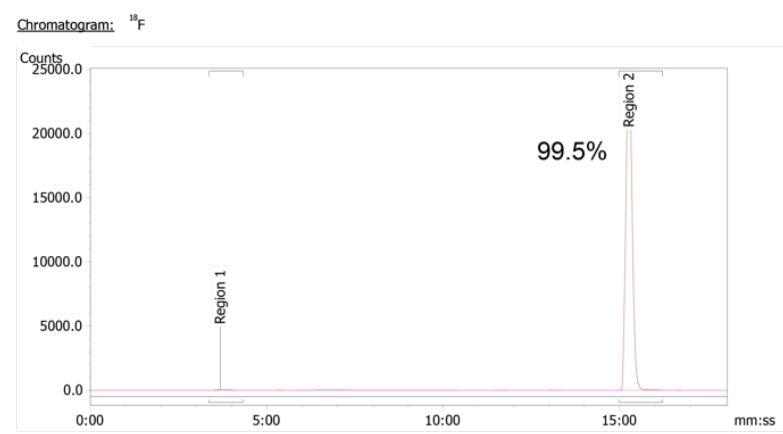

d

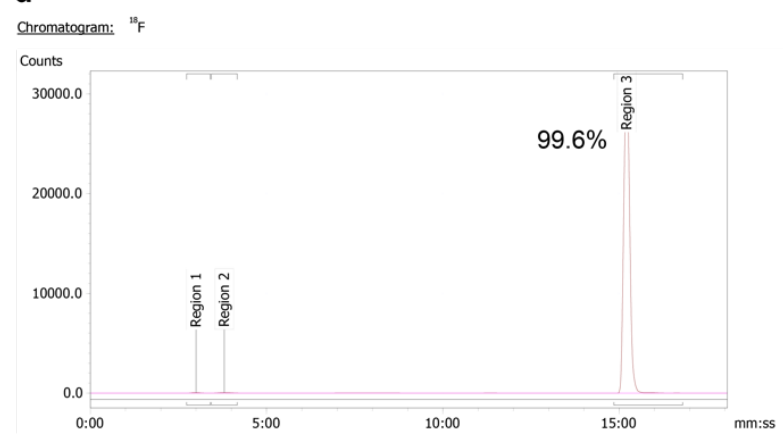

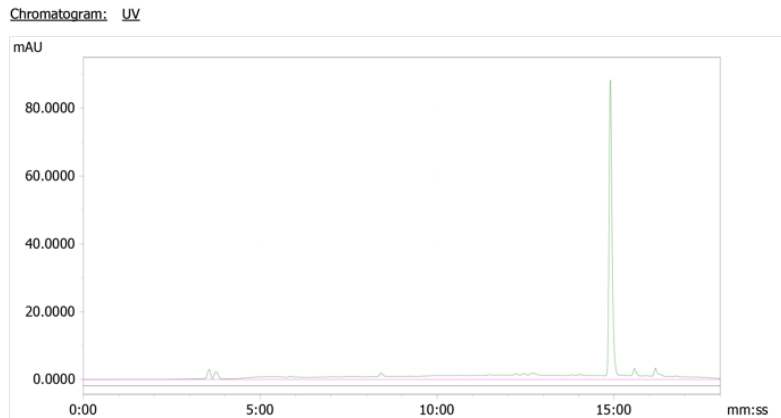

Chromatogram: UV

MAU

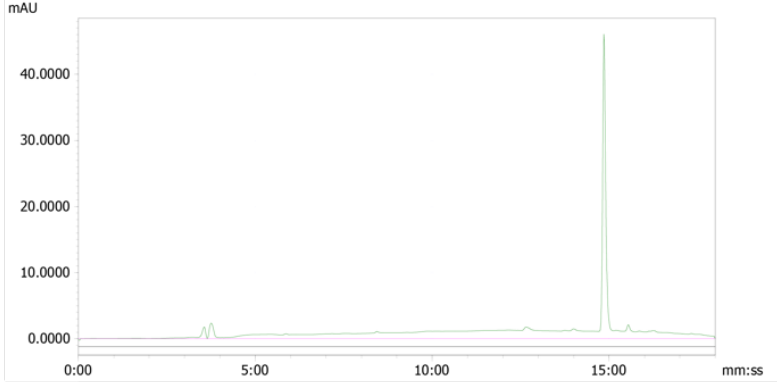

Chromatogram: UV

MAU

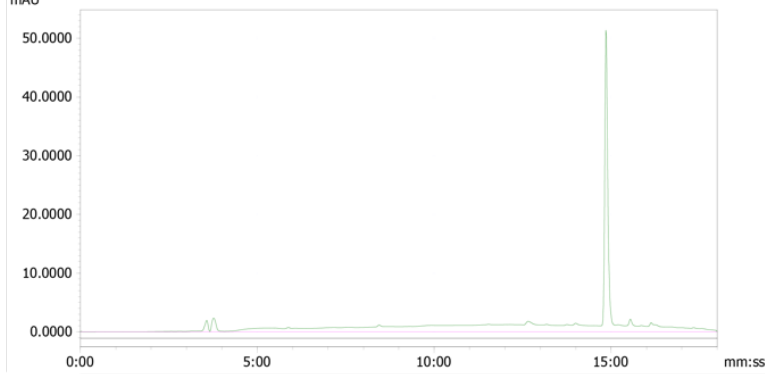

Chromatogram: UV

mAU

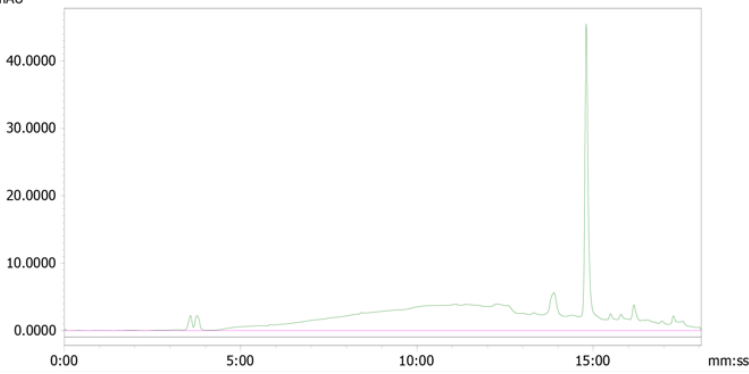

Fig. S29 | Radiosynthesis of $\left[{ }^{18} \mathrm{~F}\right] 11$ and determination of radiochemical yield by crude chromatogram. a, Run 1, 98.5\% RCY. b, Run 2, 99.7\% RCY. c, Run 3, 99.5\% RCY. d, Run 4, 99.6\% RCY. Conditions: 11 (0.05 $\mu \mathrm{g}, 250 \mathrm{nmol}), \mathrm{K}\left[{ }^{18} \mathrm{~F}\right] \mathrm{F}(\sim 3.7 \mathrm{GBq}), \mathrm{MeCN}(0.5 \mathrm{~mL}), 2{ }^{\circ} \mathrm{C}, 30$ s. HPLC Elution I. 


\section{Table S12 | RCY of $\left[{ }^{18} \mathrm{~F}\right] 11$.}

\begin{tabular}{cc}
\hline Run \# & \% RCY $^{a}$ \\
\hline 1 & 98.5 \\
2 & 99.7 \\
3 & 99.5 \\
4 & 99.6 \\
Mean \pm SD & $99.3 \pm 0.6$ \\
\hline
\end{tabular}

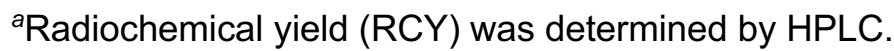




\subsection{Automated Radiosynthesis of $\left[{ }^{18} \mathrm{~F}\right] 12$}

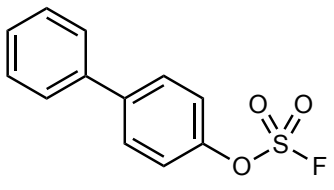

12
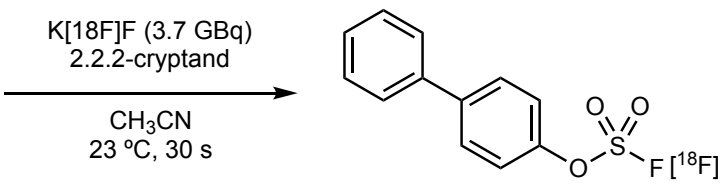

$\left[{ }^{18} \mathrm{~F}\right] 12$

Following the General Procedure of Radiosynthesis (vide supra), the radiolabeling of compound $12(0.1 \mathrm{mg})$ was achieved in $97 \%$ radiochemical yield. The gamma and UV chromatograms were shown in Fig. $\mathbf{S 3 0}$, respectively. $t_{R}$ (gamma) $=17: 00$ (mm:ss).

a

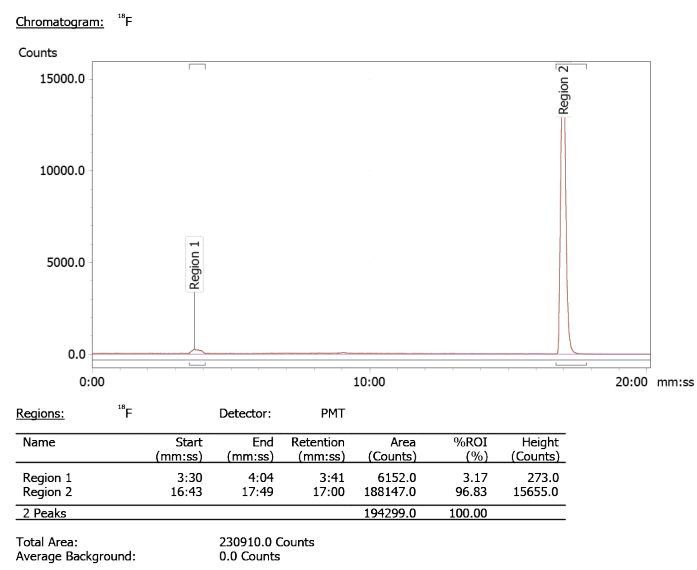

b

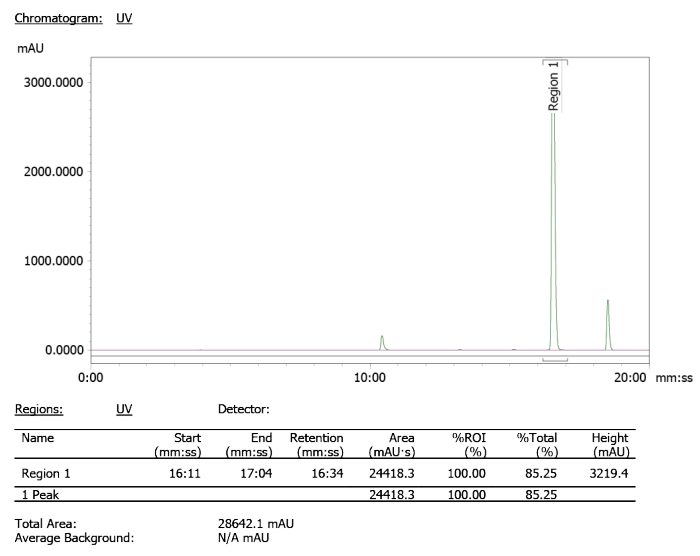

Fig. S30 | HPLC chromatograms of the reaction crude for the synthesis of $\left[{ }^{18} \mathrm{~F}\right] 12$. a, Gamma-trace. b, UV trace. RCY $=97 \%$. HPLC Elution I. 


\subsection{Automated Radiosynthesis of $\left[{ }^{18} \mathrm{~F}\right] 13$}<smiles>O=S(=O)(F)Oc1cccnc1</smiles>

13

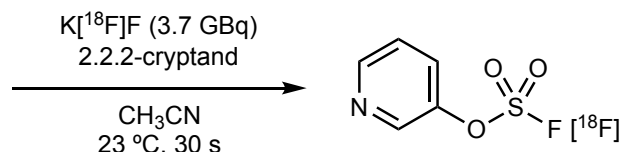

$\left[{ }^{18} \mathrm{~F}\right] 13$

$\mathrm{RCY}=98 \%$

Following the General Procedure of Radiosynthesis (vide supra), the radiolabeling of compound $13(0.1 \mathrm{mg})$ was achieved in $98 \%$ radiochemical yield. The gamma and UV chromatograms were shown in Fig. S31, respectively. $t_{\mathrm{R}}$ (gamma) $=11: 22$ (mm:ss).

a

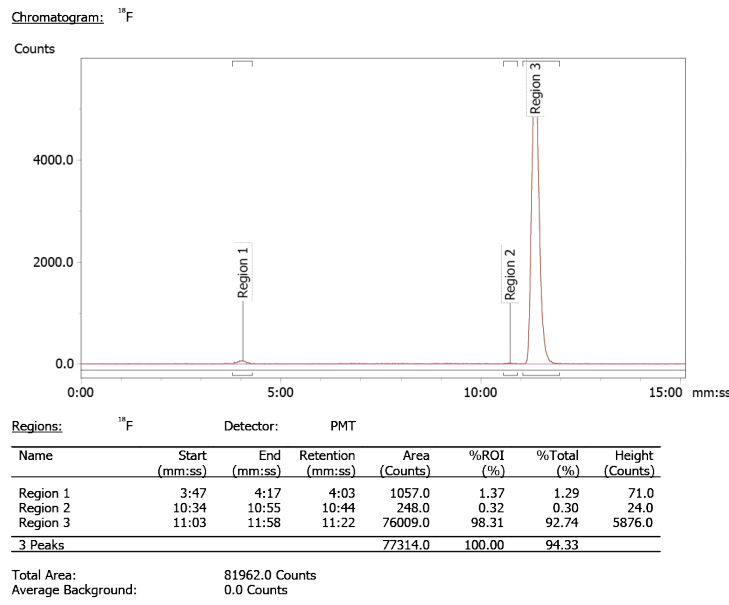

b

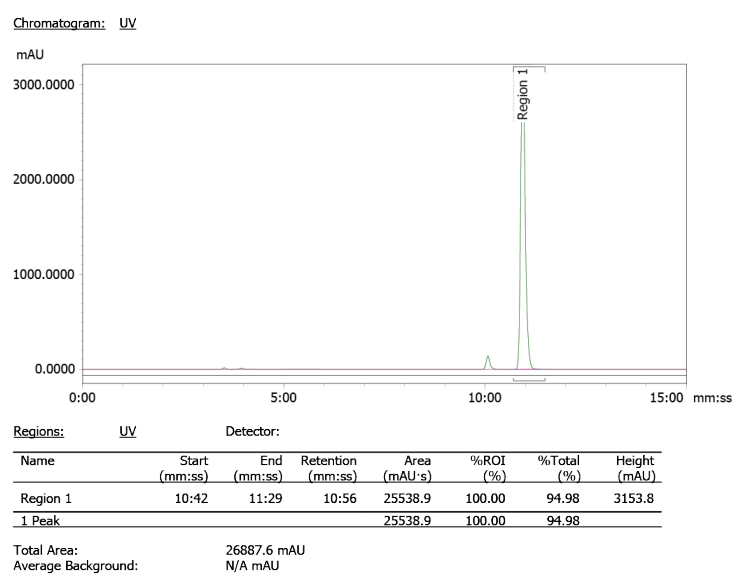

Fig. S31 | HPLC chromatograms of the reaction crude for the synthesis of $\left[{ }^{18} \mathrm{~F}\right] 13$. a, Gamma trace. b, UV trace. RCY $=98 \%$. HPLC Elution II. 


\subsection{Automated Radiosynthesis of $\left[{ }^{18} \mathrm{~F}\right] 14$}

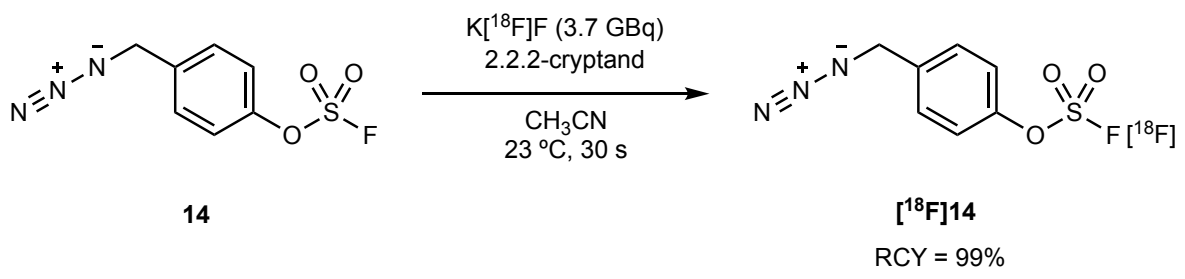

Following the General Procedure of Radiosynthesis (vide supra), the radiolabeling of compound $14(0.1 \mathrm{mg})$ was achieved in $99 \%$ radiochemical yield. The gamma and UV chromatograms were shown in Fig. S32, respectively. $t_{\mathrm{R}}$ (gamma) $=15: 21$ (mm:ss).

a

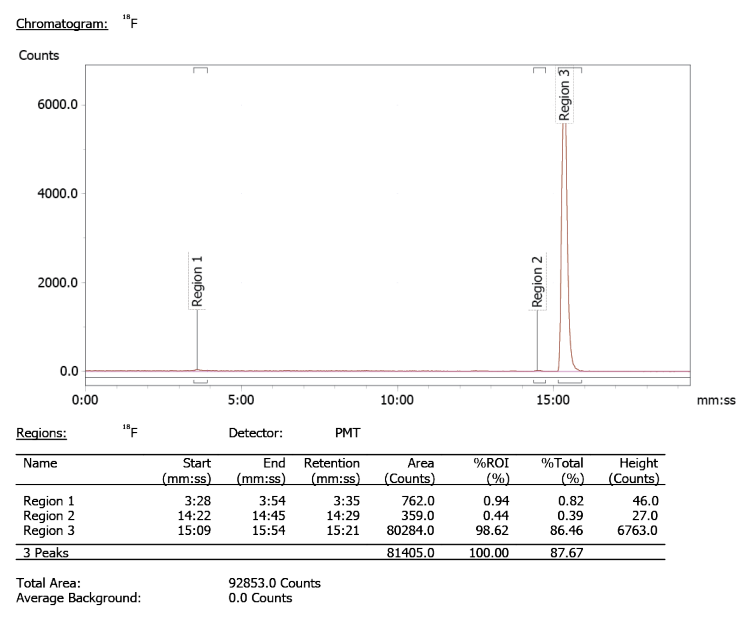

b

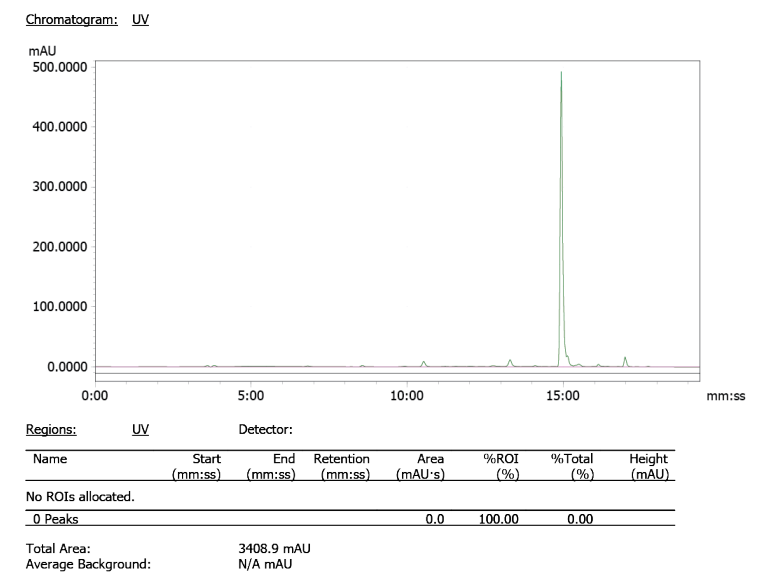

Fig. S32 | HPLC chromatograms of the reaction crude for the synthesis of $\left[{ }^{18} \mathrm{~F}\right] 14$. a, Gamma trace. b, UV trace. RCY $=99 \%$. HPLC Elution I. 


\subsection{Automated Radiosynthesis of $\left[{ }^{18} \mathrm{~F}\right] 15$}<smiles>O=C(ON1C(=O)CCC1=O)c1ccc(OS(=O)(=O)F)cc1</smiles>

15

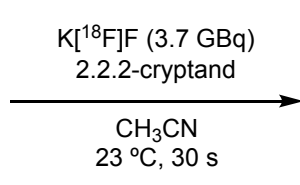

$23^{\circ} \mathrm{C}, 30 \mathrm{~s}$

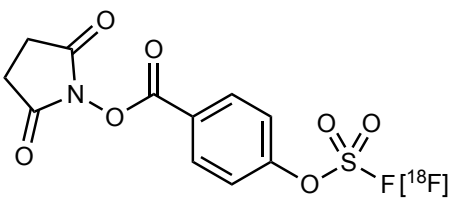

$\left[{ }^{18} \mathrm{~F}\right] 15$ $\mathrm{RCY}=85 \%$

Following the General Procedure of Radiosynthesis (vide supra), the radiolabeling of compound $15(0.1 \mathrm{mg})$ was achieved in $85 \%$ radiochemical yield. The gamma and UV chromatograms were shown in Fig. S33, respectively. $t_{\mathrm{R}}$ (gamma) $=4: 41$ (mm:ss).

a

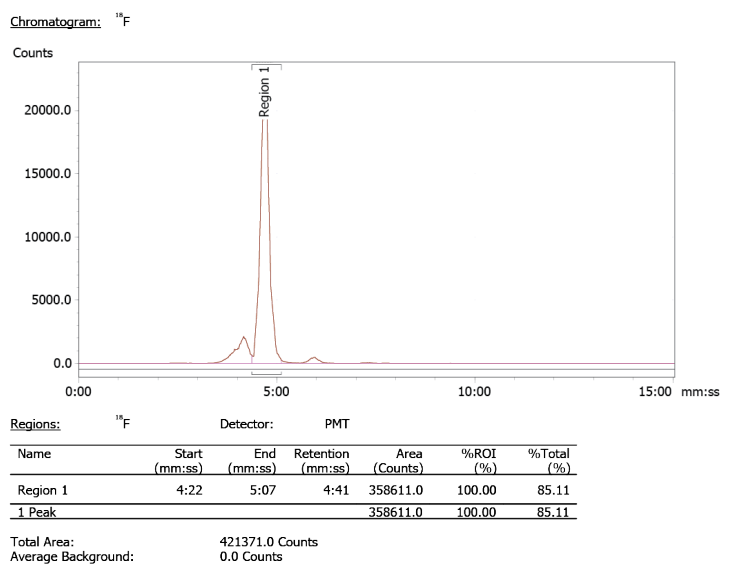

b

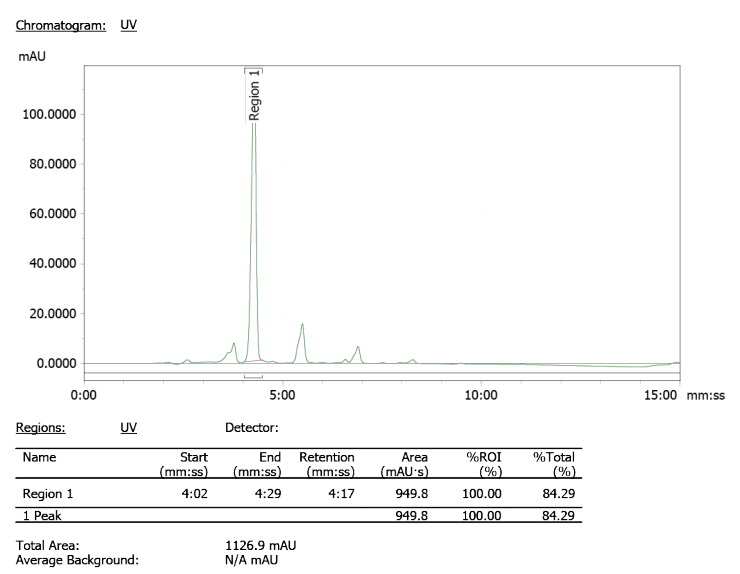

Fig. S33 | HPLC chromatograms of the reaction crude for the synthesis of $\left[{ }^{18} \mathrm{~F}\right] 15$. $a$, Gamma trace. b, UV trace. RCY $=85 \%$. HPLC Elution II. 


\subsection{Automated Radiosynthesis of $\left[{ }^{18} \mathrm{~F}\right] 16$}

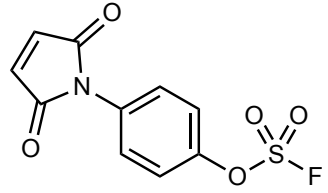

16

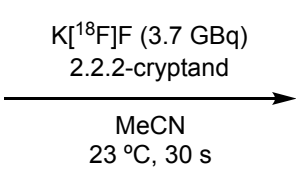

$23^{\circ} \mathrm{C}, 30 \mathrm{~s}$

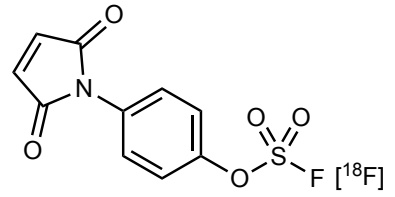

$\left[{ }^{18} \mathrm{~F}\right] 16$

Following the General Procedure of Radiosynthesis (vide supra), the radiolabeling of compound $16(0.1 \mathrm{mg})$ was achieved in $99 \%$ radiochemical yield. The gamma and UV chromatograms were shown in Fig. S34, respectively. $t_{\mathrm{R}}$ (gamma) $=13: 35$ (mm:ss).

a

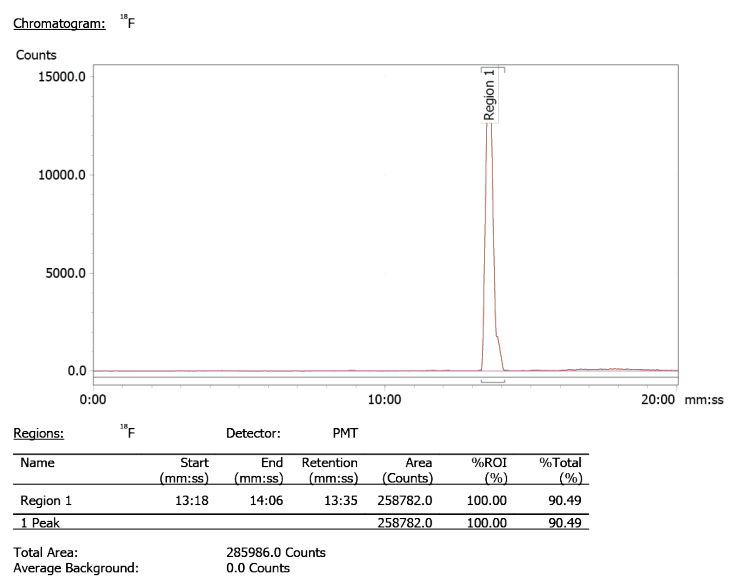

b

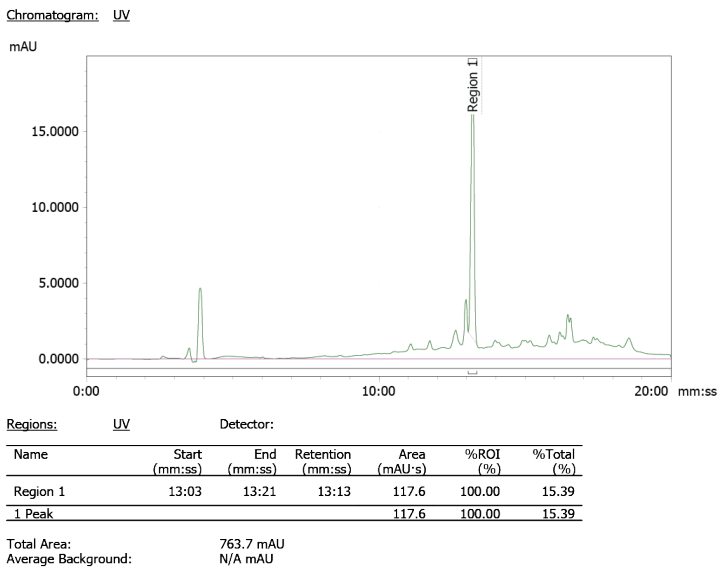

Fig. S34 | HPLC chromatograms of the reaction crude for the synthesis of $\left[{ }^{18} \mathrm{~F}\right] 16$. a, Gamma trace. b, UV trace. RCY $=100 \%$. HPLC Elution I. 


\subsection{Automated Radiosynthesis of $\left[{ }^{18} \mathrm{~F}\right] 17$}<smiles>O=Cc1ccc(OS(=O)(=O)F)cc1</smiles>

17

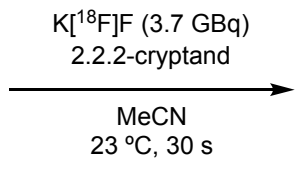

$23^{\circ} \mathrm{C}, 30 \mathrm{~s}$<smiles></smiles>

$\left[{ }^{18} \mathrm{~F}\right] 17$

$\mathrm{RCY}=95 \%$

Following the General Procedure of Radiolabeling (vide supra), the radiolabeling of compound 17 was achieved in 95\% radiochemical yield. The gamma and UV chromatograms were shown in Fig. S35, respectively. $t_{\mathrm{R}}$ (gamma) $=10: 42$ (mm:ss).

a

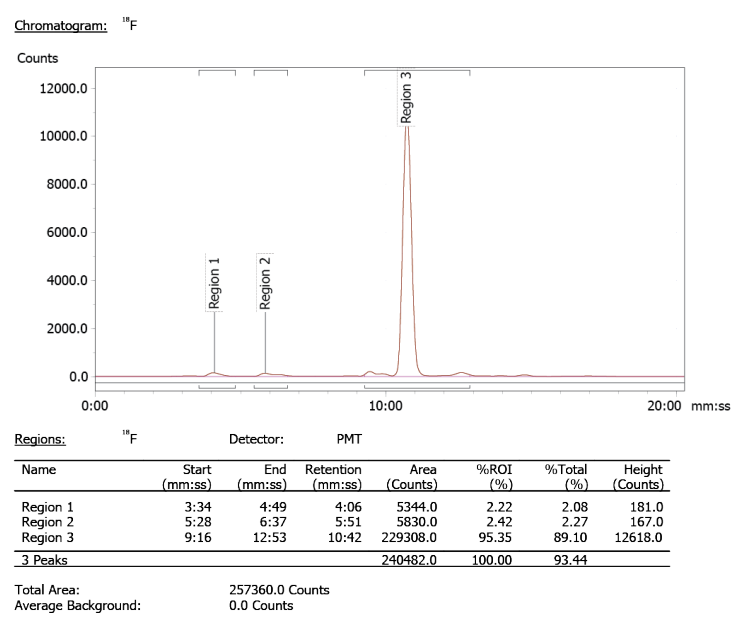

b

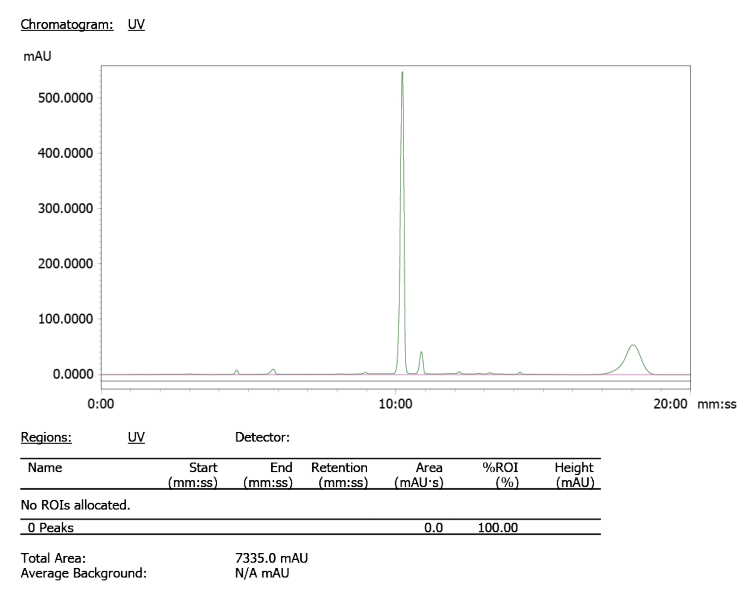

Fig. S35 | HPLC chromatograms of the reaction crude for the synthesis of $\left[{ }^{18} \mathrm{~F}\right] 17$. a, Gamma trace. b, UV trace. RCY $=95 \%$. HPLC Elution I. 


\subsection{Automated Radiosynthesis of $\left[{ }^{18} \mathrm{~F}\right] 18$}

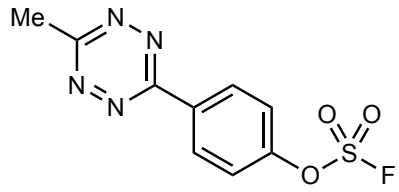

18

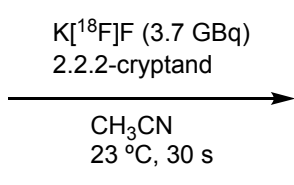

$23^{\circ} \mathrm{C}, 30 \mathrm{~s}$

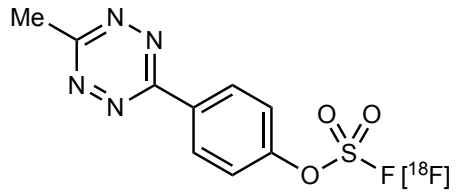

$\left[{ }^{18} \mathrm{~F}\right] 18$

$\mathrm{RCY}=83 \%$

Following the General Procedure of Radiosynthesis (vide supra), the radiolabeling of compound 18 was achieved in $83 \%$ radiochemical yield. The gamma and UV chromatograms were shown in Fig. S36, respectively. $t_{R}$ (gamma) $=14: 55$ (mm:ss).

a

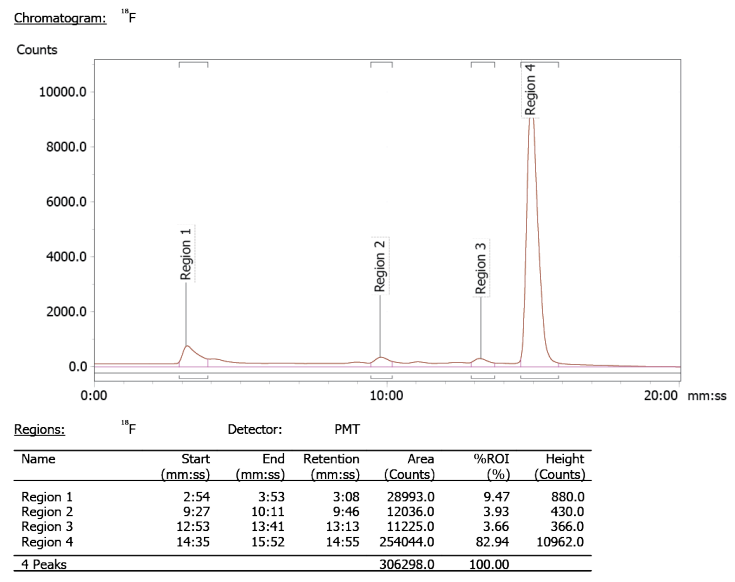

b

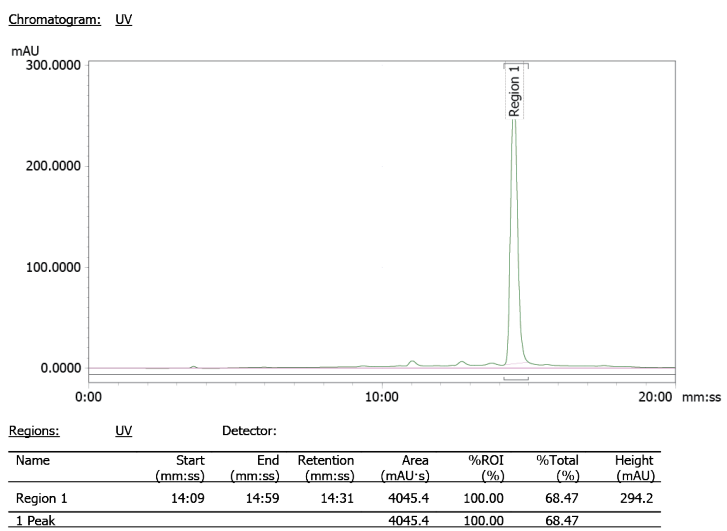

Fig. S36 | HPLC chromatograms of the reaction crude for the synthesis of $\left[{ }^{18} \mathrm{~F}\right] 18$. a, Gamma trace. b, HPLC, trace. RCY $=83 \%$. HPLC Elution I. 


\subsection{Automated Radiosynthesis of $\left[{ }^{18} \mathrm{~F}\right] 19$}<smiles>Cc1nnc(-c2cccc(OS(=O)(=O)F)c2)nn1</smiles>

19

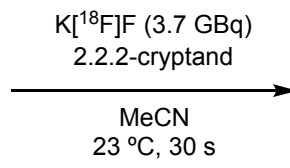

$23^{\circ} \mathrm{C}, 30 \mathrm{~s}$

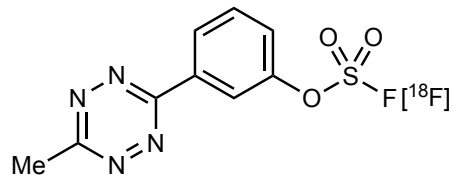

$\left[{ }^{18} \mathrm{~F}\right] 19$
$\mathrm{RCY}=100 \%$

Following the General Procedure of Radiosynthesis (vide supra), the radiolabeling of compound 19 was achieved in 100\% radiochemical yield. The gamma and UV chromatograms were shown in Fig. S37, respectively. $t_{\mathrm{R}}$ (gamma) $=15: 09$ (mm:ss).

a

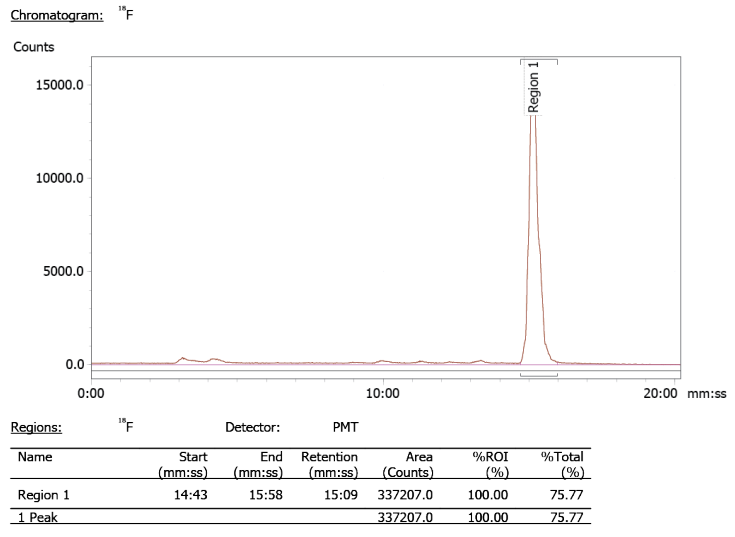

b

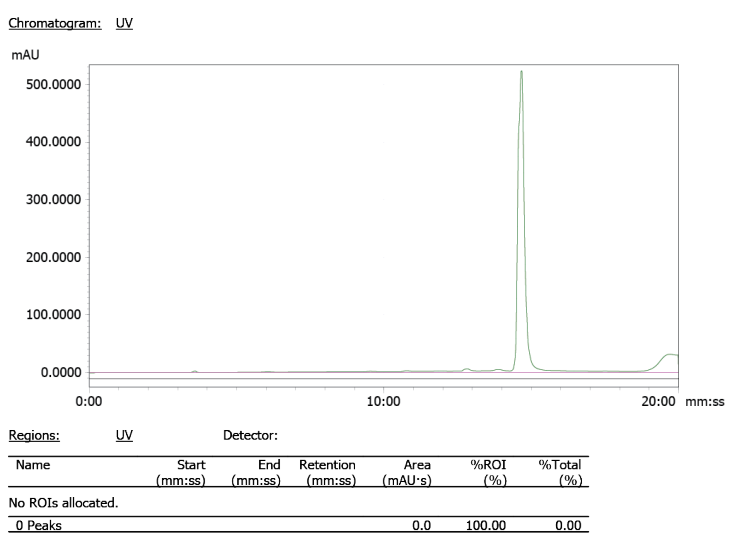

Fig. S37 | HPLC chromatograms of the reaction crude for the synthesis of $\left[{ }^{18} \mathrm{~F}\right] 19$. a, Gamma trace. b, UV trace. RCY $=100 \%$. HPLC Elution I. 


\subsection{Automated Radiosynthesis of $\left[{ }^{18} \mathrm{~F}\right] 20$}<smiles>C#CCOc1cc(C(=O)NCCc2ccc(OS(=O)(=O)F)cc2)cc(OCC#C)c1OCC#C</smiles>

20

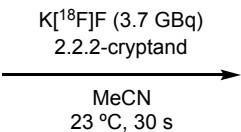

$23^{\circ} \mathrm{C}, 30 \mathrm{~s}$

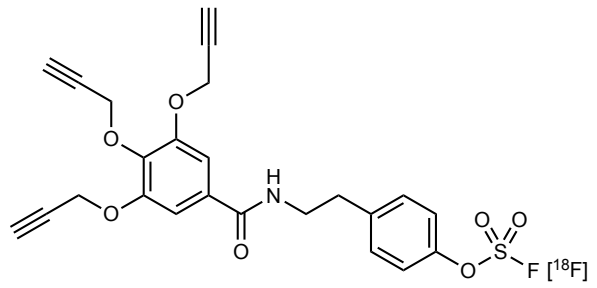

$\left[{ }^{18} \mathrm{~F}\right] 20$

Following the General Procedure of Radiosynthesis (vide supra), the radiolabeling of compound $20(0.1 \mathrm{mg})$ was achieved in 96\% radiochemical yield. The gamma and UV chromatograms were shown in Fig. $\mathbf{S 3 8}$, respectively. $t_{R}$ (gamma) $=6: 13$ (mm:ss).

a

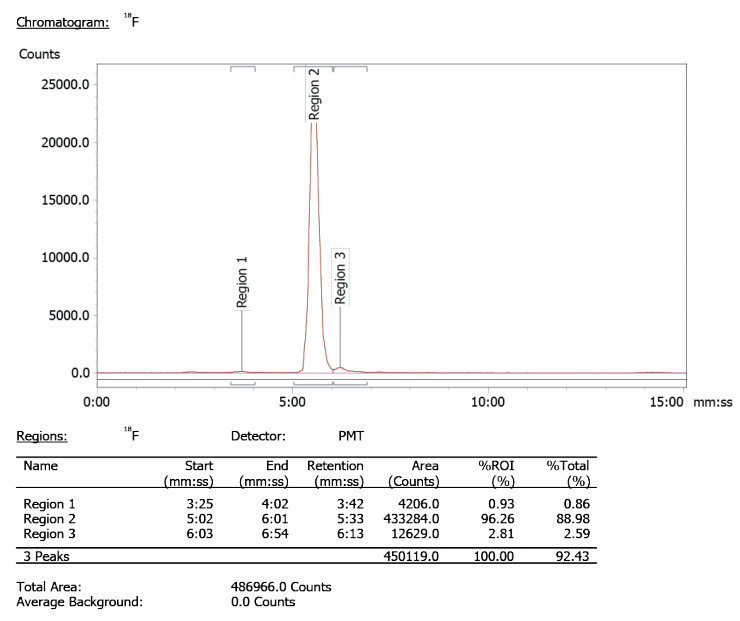

b

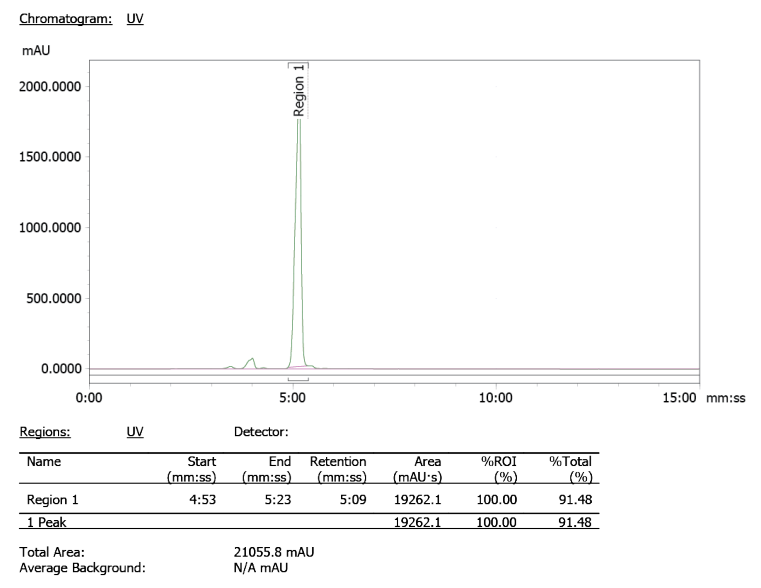

Fig. S38 | HPLC chromatograms of the reaction crude for the synthesis of $\left[{ }^{18} \mathrm{~F}\right] 20$. $a$, Gamma trace. b, UV trace. RCY $=96 \%$. HPLC Elution II. 


\subsection{Automated Radiosynthesis of $\left[{ }^{18} \mathrm{~F}\right] 21$}

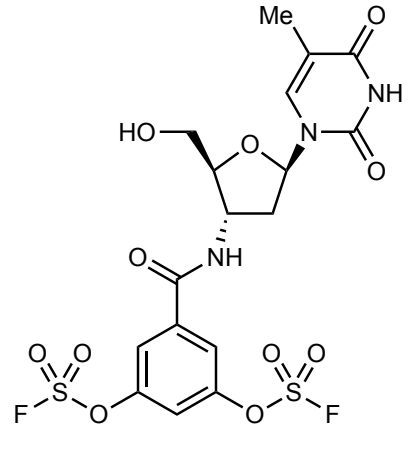

21

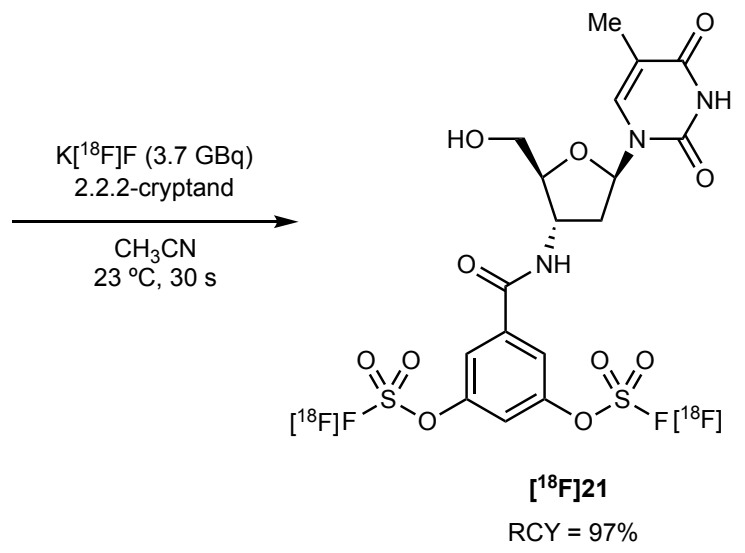

Following the General Procedure of Radiosynthesis (vide supra), the radiolabeling of compound $21(0.1 \mathrm{mg})$ was achieved in $97 \%$ radiochemical yield. The gamma and UV chromatograms were shown in Fig. $\mathbf{S 4 2}$, respectively. $t_{R}$ (gamma) $=12: 24$ (mm:ss).

a

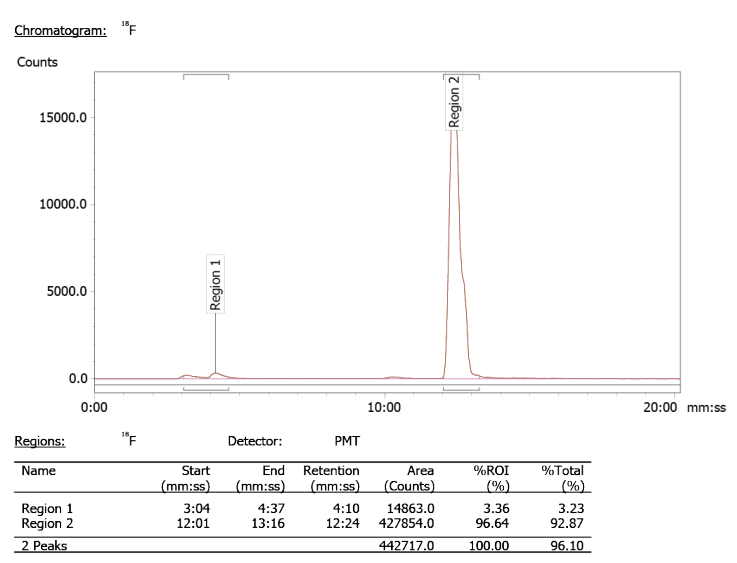

b

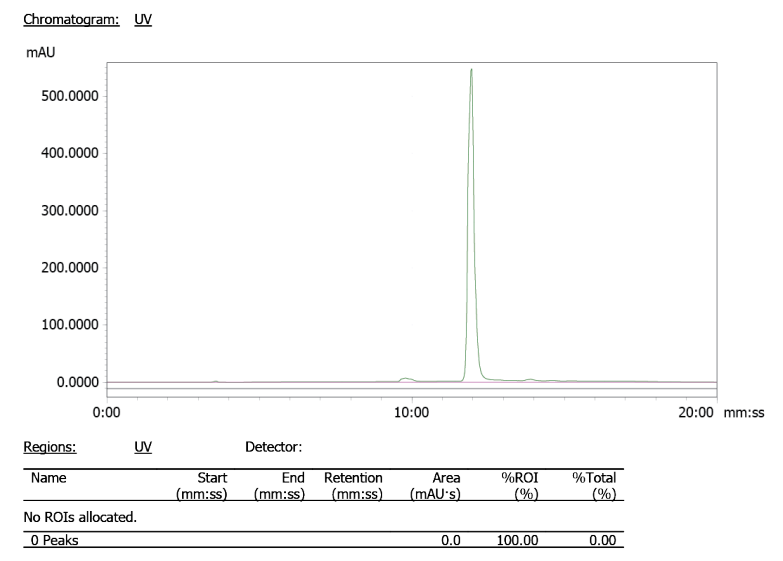

Fig. S39 | HPLC chromatograms of the reaction crude for the synthesis of $\left[{ }^{18} \mathrm{~F}\right] 21$. a, Gamma trace. b, UV trace. RCY $=97 \%$. HPLC Elution I. 


\subsection{Automated Radiosynthesis of $\left[{ }^{18} \mathrm{~F}\right] 22$}

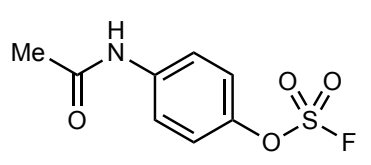

22

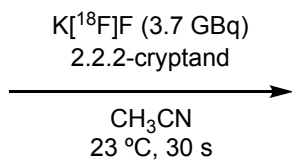

$23^{\circ} \mathrm{C}, 30 \mathrm{~s}$

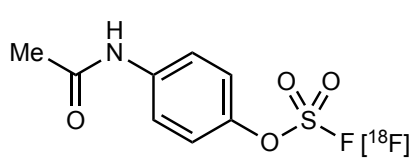

$\left[{ }^{18} \mathrm{~F}\right] 22$

Following the General Procedure of Radiosynthesis (vide supra), the radiolabeling of compound 22 was achieved in 99\% radiochemical yield. The gamma and UV chromatograms were shown in Fig. S40, respectively. $t_{\mathrm{R}}$ (gamma) $=11: 55$ (mm:ss).

a

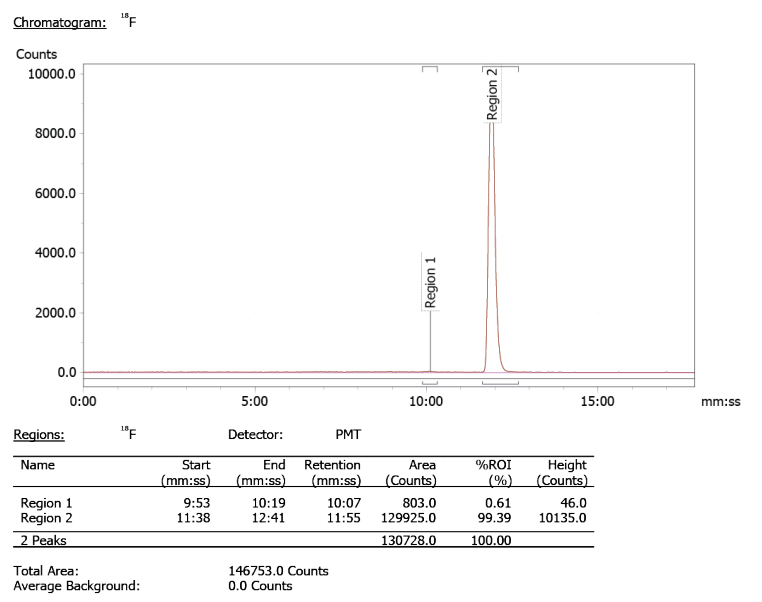

b

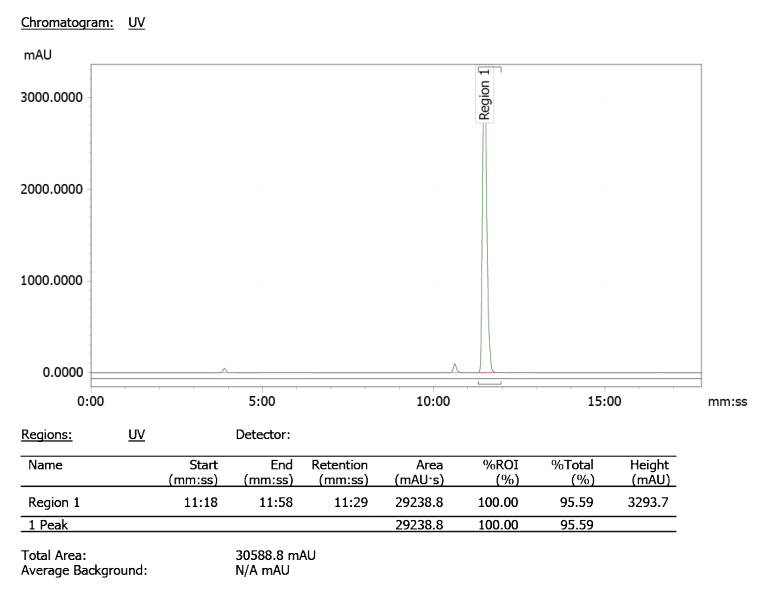

Fig. S40 | HPLC chromatogram of the reaction crude for the synthesis of $\left[{ }^{18} \mathrm{~F}\right] 22$. $a$, Gamma trace. b, UV trace. RCY $=99 \%$. HPLC Elution I. 


\subsection{Automated Radiosynthesis of $\left[{ }^{18} \mathrm{~F}\right] 23$}

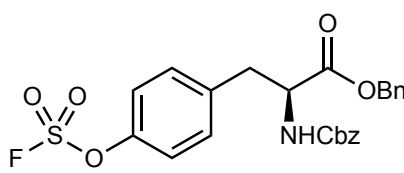

23

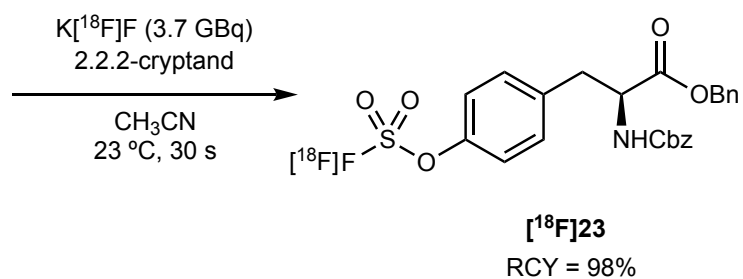

$\mathrm{RCY}=98 \%$

Following the General Procedure of Radiosynthesis (vide supra), the radiolabeling of compound $23(0.1 \mathrm{mg})$ was achieved in $98 \%$ radiochemical yield. The gamma and UV chromatograms were shown in Fig. S41, respectively. $t_{\mathrm{R}}$ (gamma) = 8:25 (mm:ss).

a

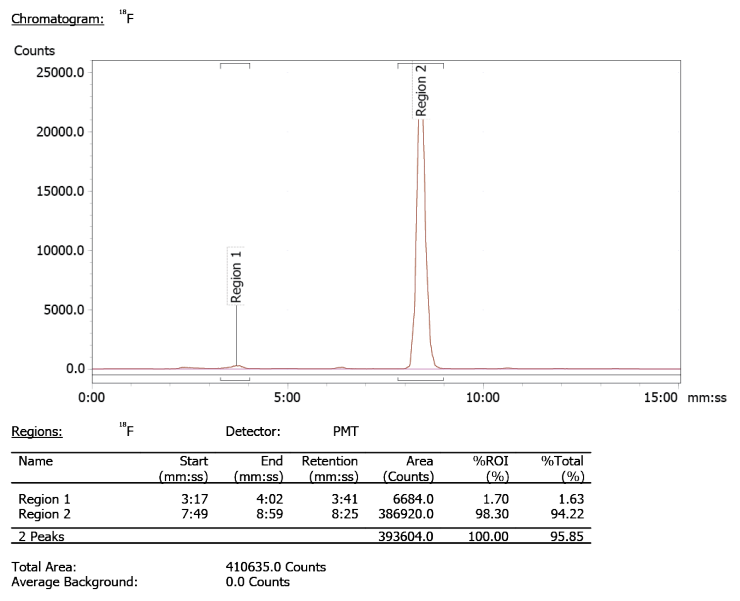

b

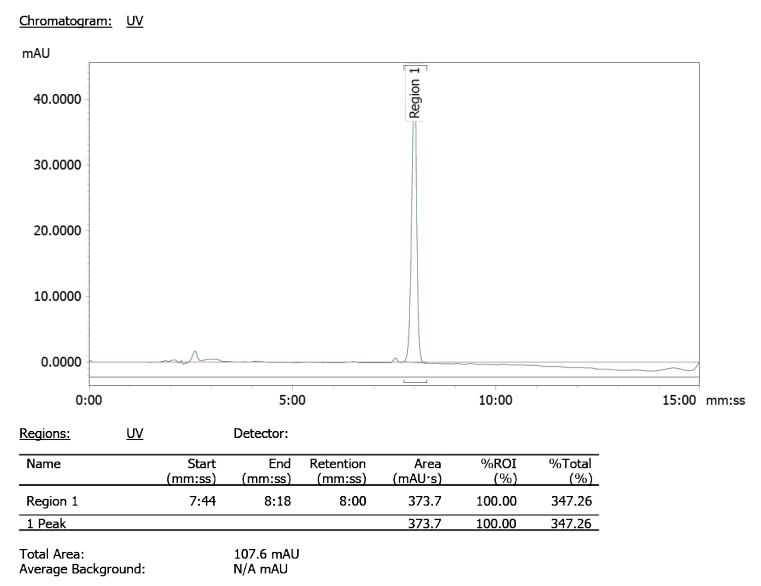

Fig. S41 | HPLC chromatograms of the reaction crude for the synthesis of $\left[{ }^{18} \mathrm{~F}\right] 23$. a, Gamma trace. b, UV trace. RCY $=98 \%$. HPLC Elution II. 


\subsection{Automated Radiosynthesis of $\left[{ }^{18} \mathrm{~F}\right] 24$}<smiles>CC[C@H](C)C(=O)N1CCC(NC(=O)Nc2ccc(OS(=O)(=O)F)cc2)CC1</smiles>

24

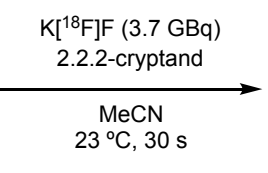

\section{.}

Following the General Procedure of Radiosynthesis (vide supra), the radiolabeling of compound $24(0.1 \mathrm{mg})$ was achieved in $100 \%$ radiochemical yield. The gamma and UV chromatograms were shown in Fig. $\mathbf{S 4 2}$, respectively. $t_{R}($ gamma $)=13: 06$ (mm:ss).

a

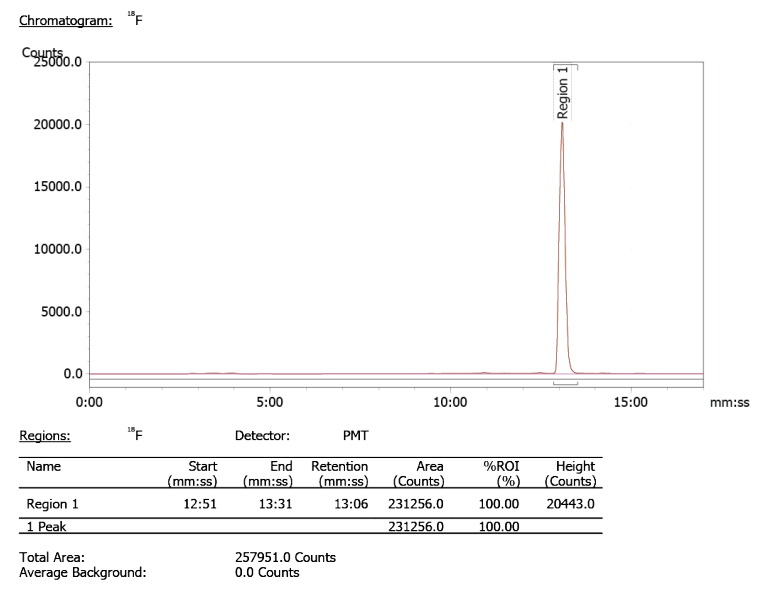

b

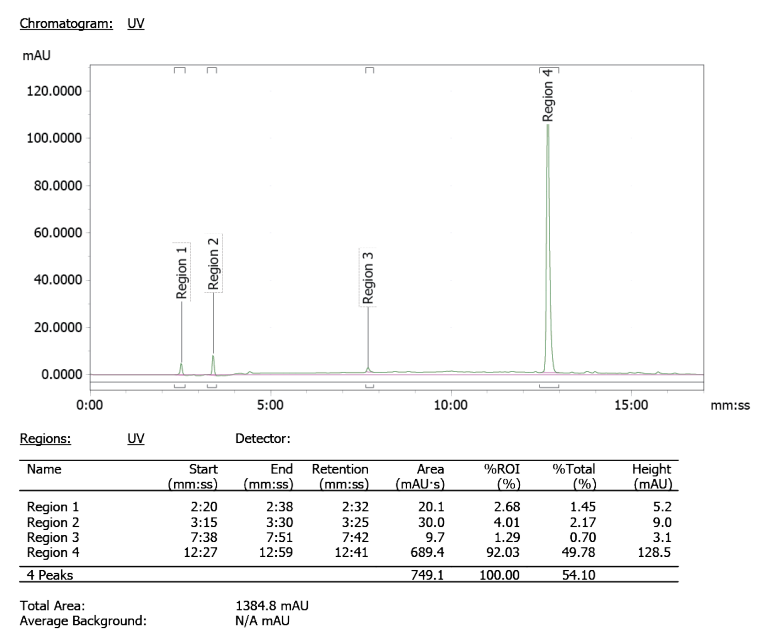

Fig. S42 | HPLC chromatograms of the reaction crude for the synthesis of $\left[{ }^{18} \mathrm{~F}\right] 24$. a, Gamma trace. $\mathbf{b}$, UV trace. RCY $=100 \%$. HPLC Elution I. 


\subsection{Automated Radiosynthesis of $\left[{ }^{18} \mathrm{~F}\right] 25$}

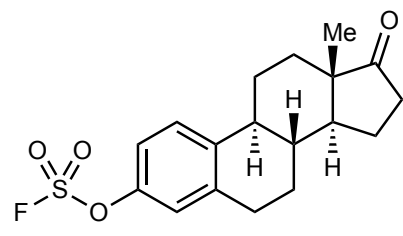

25

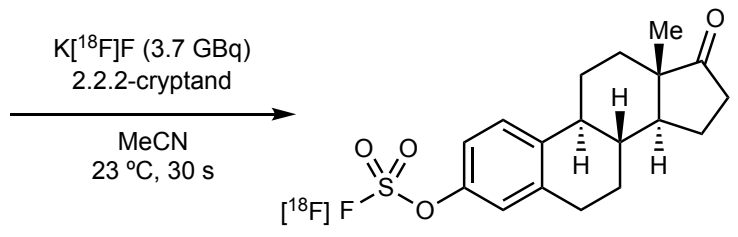

$\left[{ }^{18} \mathrm{~F}\right] 25$

$\mathrm{RCY}=100 \%$

Following the General Procedure of Radiosynthesis (vide supra), the radiolabeling of compound $25(0.1 \mathrm{mg})$ was achieved in $100 \%$ radiochemical yield. The gamma and UV chromatograms were shown in Fig. S43, respectively. $t_{\mathrm{R}}$ (gamma) $=17: 47$ (mm:ss).

a

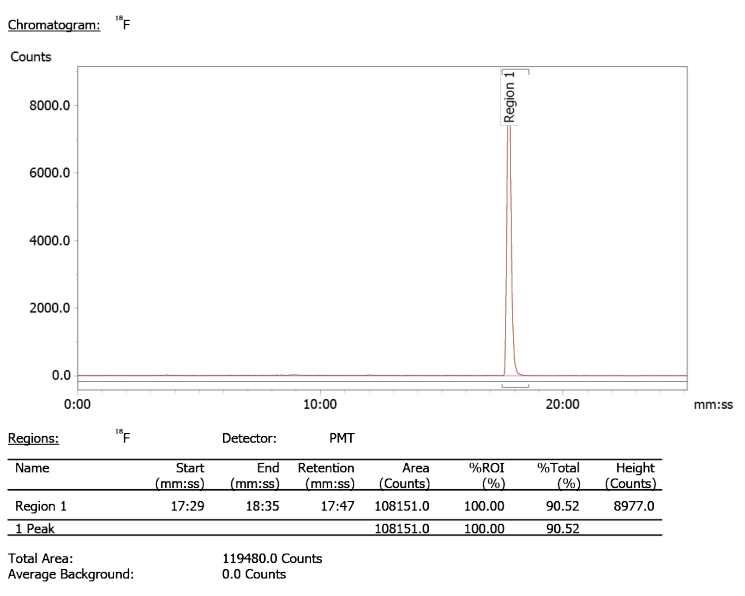

b

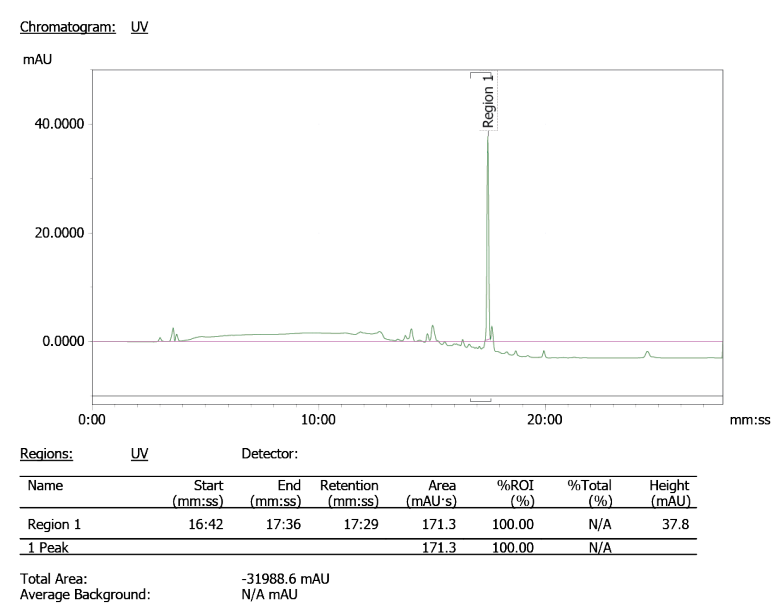

Fig. S43 | HPLC chromatograms of the reaction crude for the synthesis of $\left[{ }^{18} \mathrm{~F}\right] 25$. a, Gamma trace. b, UV trace. RCY $=100 \%$. HPLC Elution III. 


\subsection{Automated Radiosynthesis of $\left[{ }^{18} \mathrm{~F}\right] 26$}

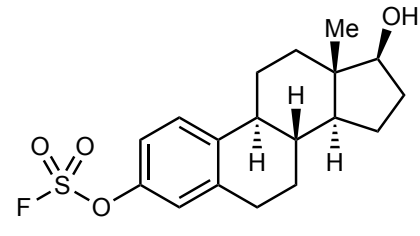

26

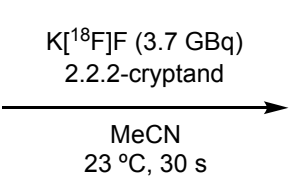

$23^{\circ} \mathrm{C}, 30 \mathrm{~s}$

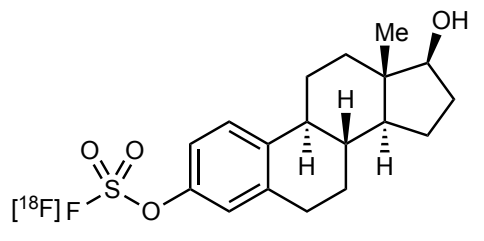

$\left[{ }^{18} \mathrm{~F}\right] 26$

$\mathrm{RCY}=98 \%$

Following the General Procedure of Radiosynthesis (vide supra), the radiolabeling of compound $26(0.1 \mathrm{mg})$ was achieved in $98 \%$ radiochemical yield. The gamma and UV chromatograms were shown in Fig. S44, respectively. $t_{\mathrm{R}}$ (gamma) $=8: 21$ (mm:ss).

a

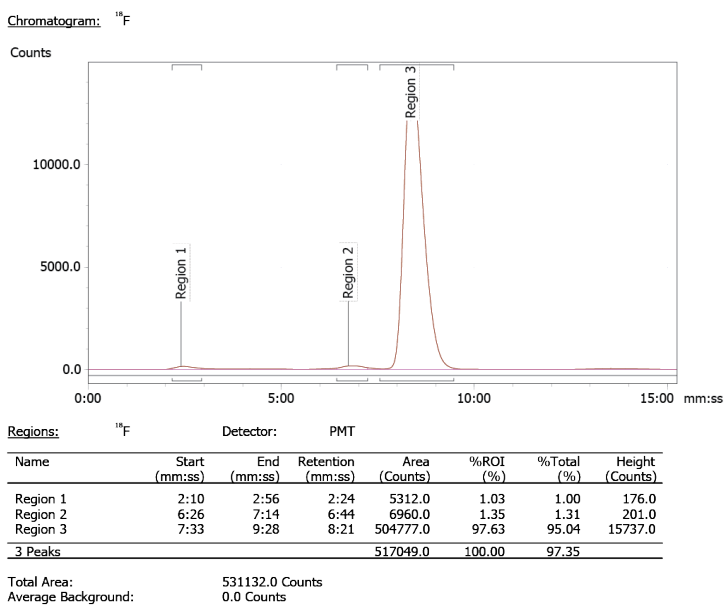

b

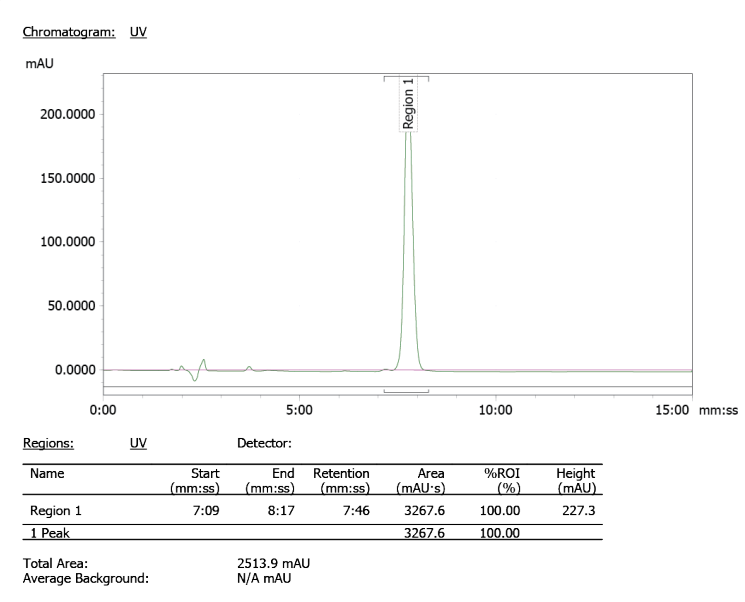

Fig. S44 | HPLC chromatograms of the reaction crude for the synthesis of $\left[{ }^{18} \mathrm{~F}\right] 26$. a, Gamma trace. b, UV trace. RCY $=98 \%$. HPLC Elution II. 


\subsection{Automated Radiosynthesis of $\left[{ }^{18} \mathrm{~F}\right] 27$}

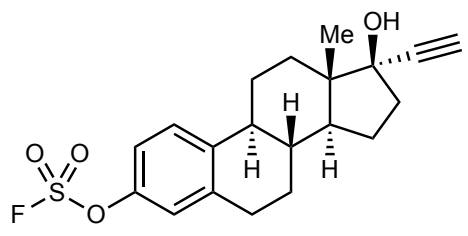

27

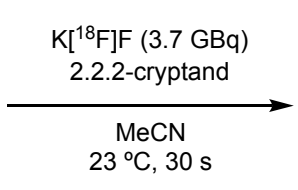

$23^{\circ} \mathrm{C}, 30 \mathrm{~s}$

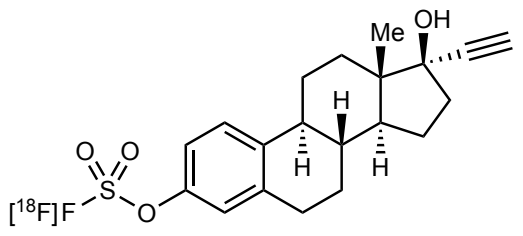

$\left[{ }^{18} \mathrm{~F}\right] 27$

Following the General Procedure of Radiosynthesis (vide supra), the radiolabeling of compound $27(0.1 \mathrm{mg})$ was achieved in $94 \%$ radiochemical yield. The gamma and UV chromatograms were shown in Fig. S45, respectively. $t_{R}$ (gamma) $=17: 33$ (mm:ss).

a

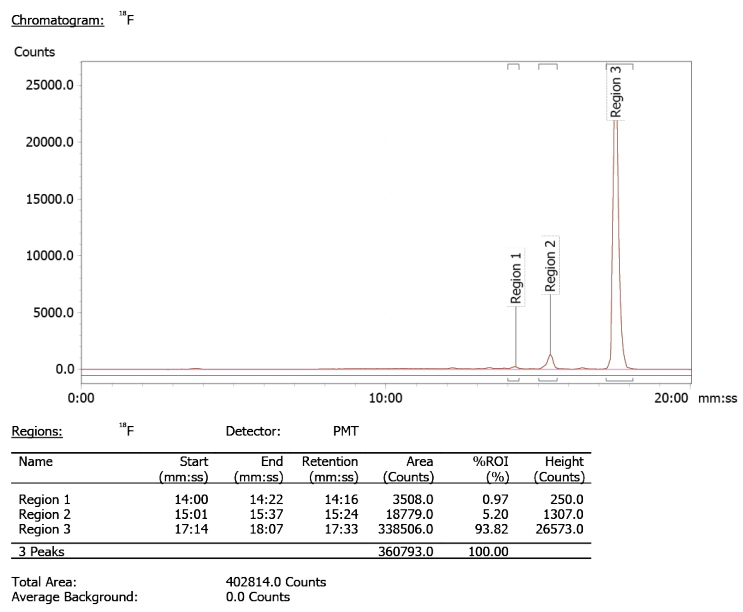

b

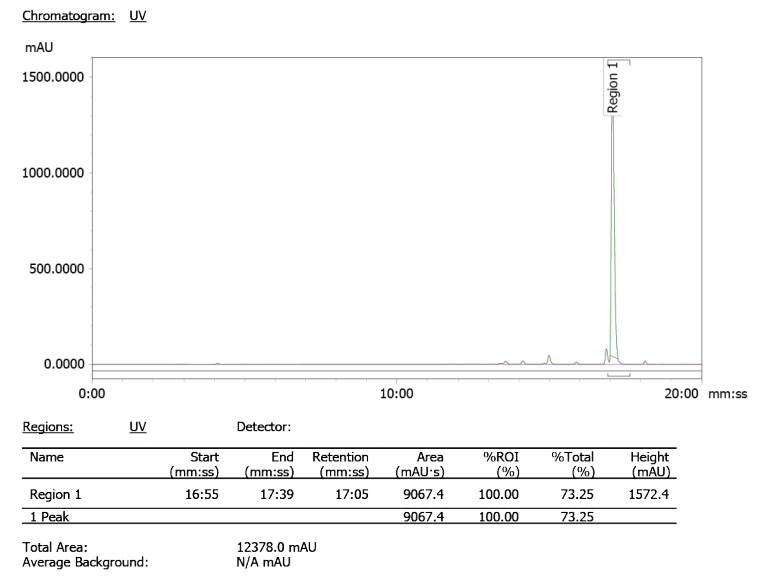

Fig. S45 | HPLC chromatograms of the reaction crude for the synthesis of $\left[{ }^{18} \mathrm{~F}\right] 27$. $a$, Gamma trace. b, UV trace. RCY $=94 \%$. HPLC Elution I. 


\subsection{Automated Radiosynthesis of $\left[{ }^{18} \mathrm{~F}\right] 28$}

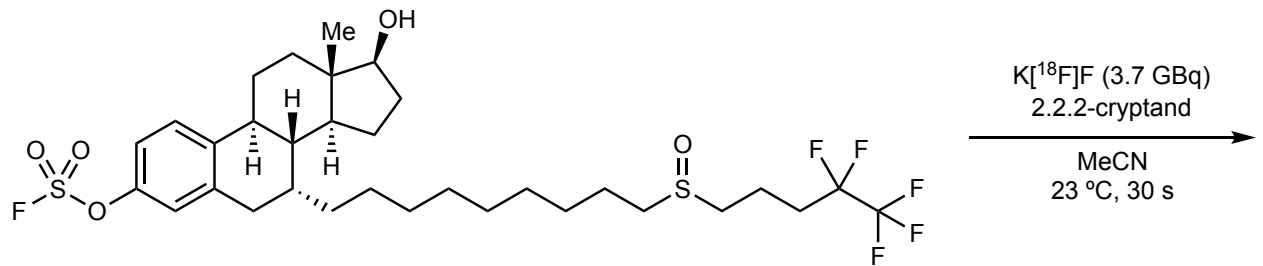

28

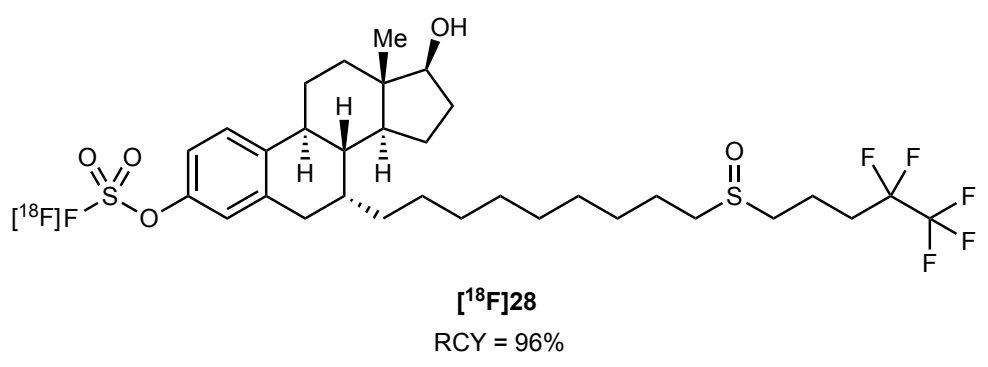

Following the General Procedure of Radiosynthesis (vide supra), the radiolabeling of compound $28(0.1 \mathrm{mg})$ was achieved in $96 \%$ radiochemical yield. The gamma and UV chromatograms were shown in Fig. S46, respectively. $t_{R}($ gamma $)=8: 04$ (mm:ss).

a

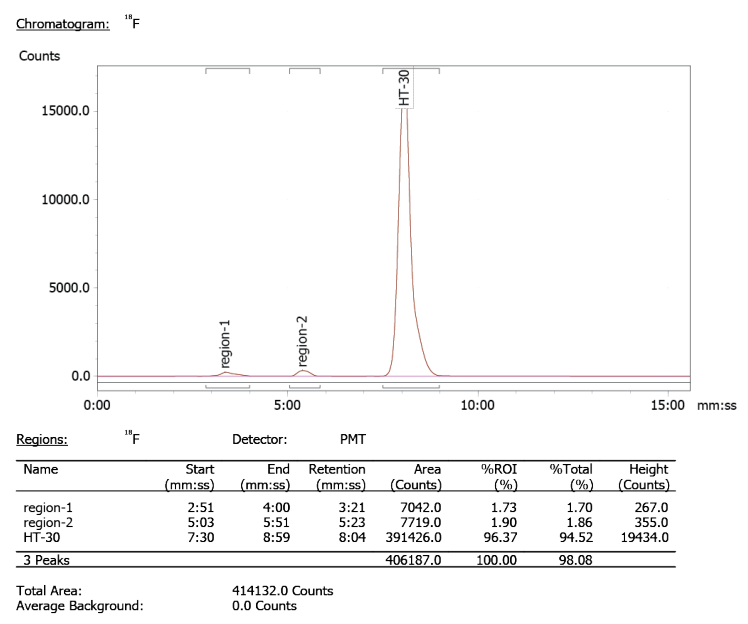

b

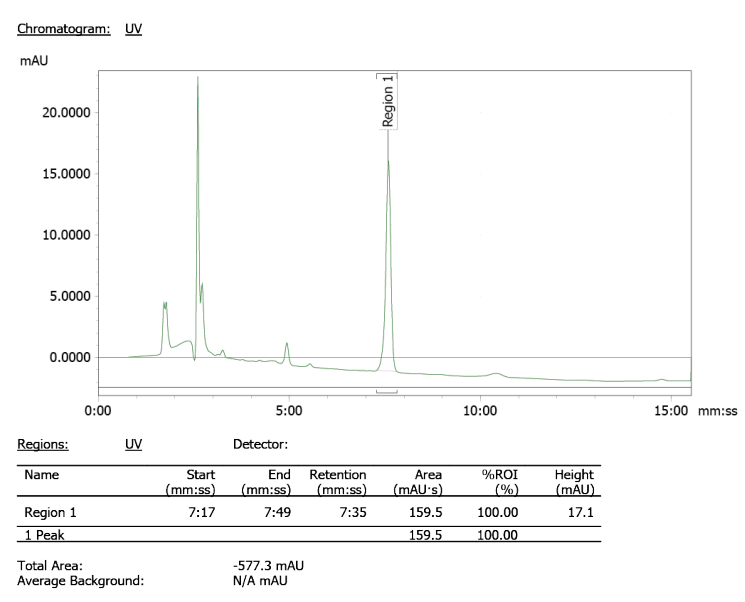

Fig. S46 | HPLC chromatograms of the reaction crude for the synthesis of $\left[{ }^{18} \mathrm{~F}\right] 28$. a, Gamma trace. b, UV trace. RCY $=96 \%$. HPLC Elution II. 


\subsection{Automated Radiosynthesis of $\left[{ }^{18} \mathrm{~F}\right] 29$}

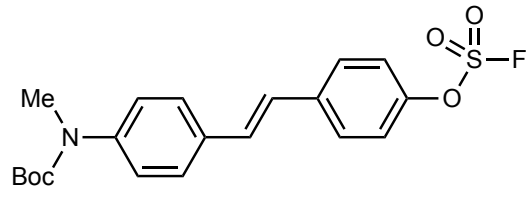

29

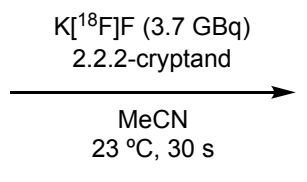

$23^{\circ} \mathrm{C}, 30 \mathrm{~s}$

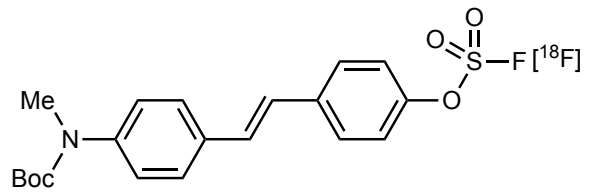

$\left[{ }^{18} \mathrm{~F}\right] 29$

$\mathrm{RCY}=95 \%$

Following the General Procedure of Radiosynthesis (vide supra), the radiolabeling of compound $29(0.1 \mathrm{mg})$ was achieved in $95 \%$ radiochemical yield. The gamma and UV chromatograms were shown in Fig. S47, respectively. $t_{\mathrm{R}}$ (gamma) $=10: 50$ (mm:ss).

a

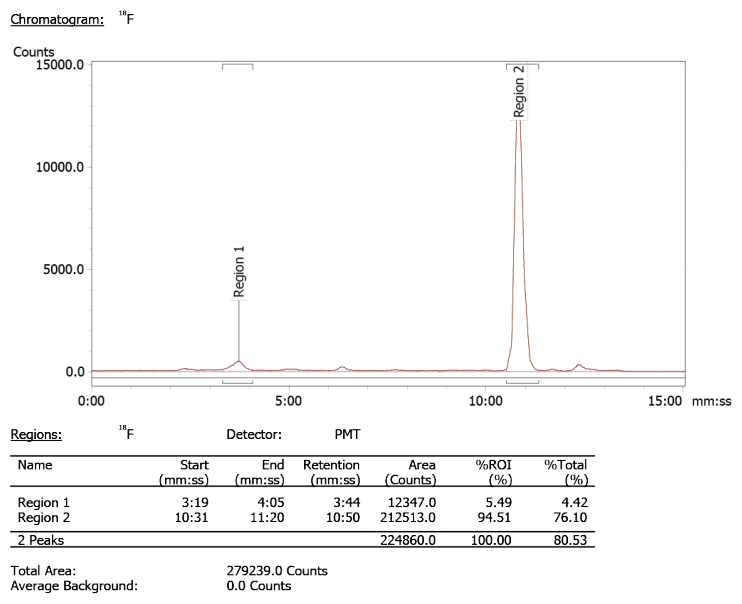

b

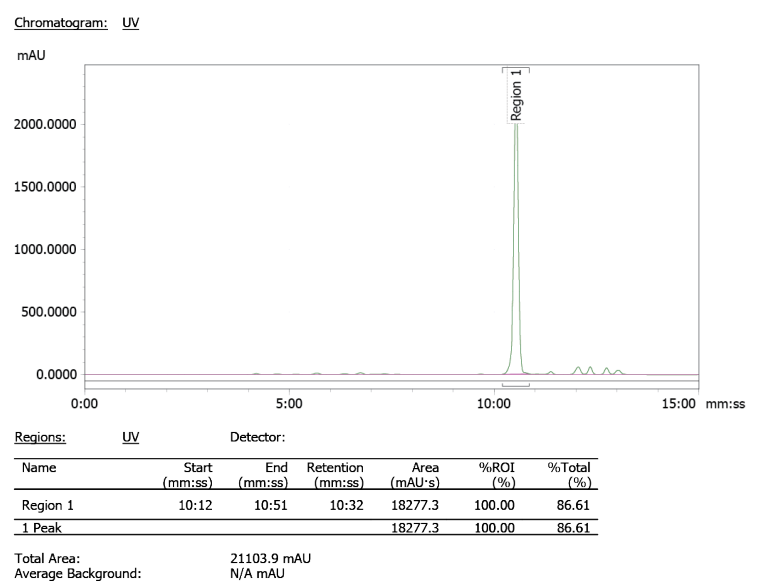

Fig. S47 | HPLC chromatograms of the reaction crude for the synthesis of $\left[{ }^{18} \mathrm{~F}\right] 29$. a, Gamma trace. b, UV trace. RCY $=95 \%$. HPLC Elution II. 


\subsection{Automated Radiosynthesis of $\left[{ }^{18} \mathrm{~F}\right] 30$}

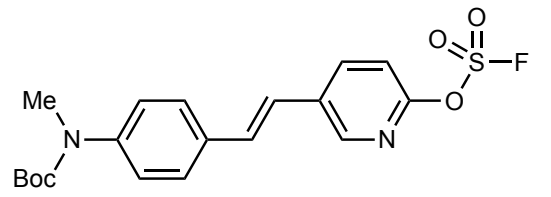

30

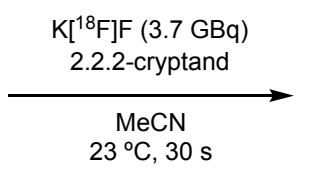

$23^{\circ} \mathrm{C}, 30 \mathrm{~s}$<smiles>[3H]S(=O)(=O)Oc1ccc(/C=C/c2ccc(C(=O)OC(C)(C)C)cc2)cn1</smiles>

$\left[{ }^{18} \mathrm{~F}\right] 30$

$\mathrm{RCY}=100 \%$

Following the General Procedure of Radiosynthesis (vide supra), the radiolabeling of compound $30(0.1 \mathrm{mg})$ was achieved in $100 \%$ radiochemical yield. The gamma and UV chromatograms were shown in Fig. S48, respectively. $t_{R}$ (gamma) $=9: 41$ (mm:ss).

a

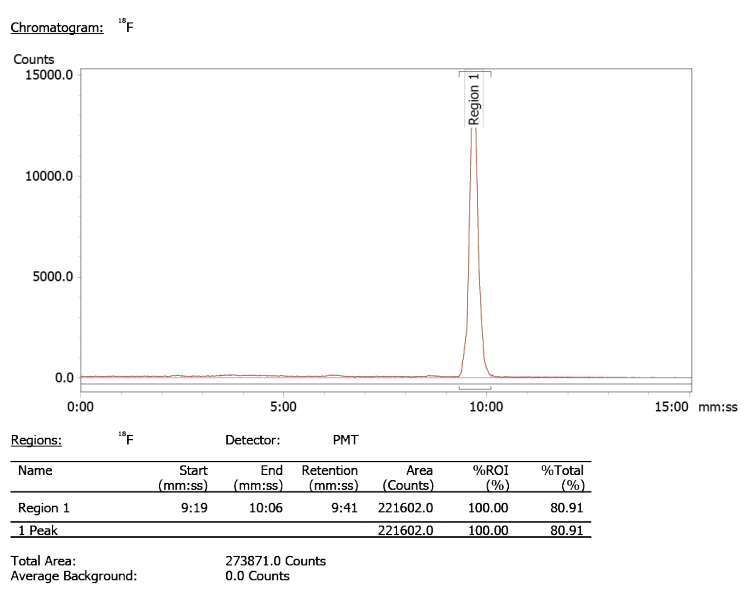

b

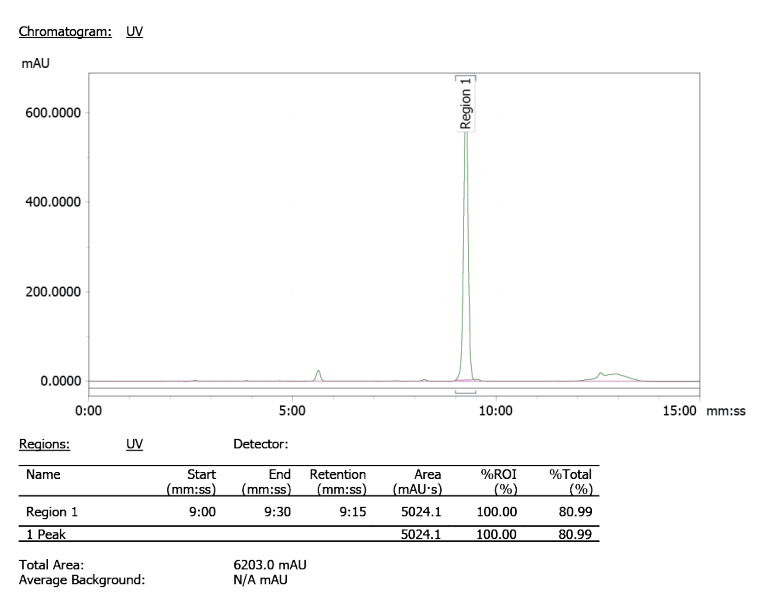

Fig. S48 | HPLC chromatograms of the reaction crude for the synthesis of $\left[{ }^{18} \mathrm{~F}\right] 30$. a, Gamma trace. b, UV trace. RCY $=100 \%$. HPLC Elution II. 


\subsection{Automated Radiosynthesis of $\left[{ }^{18} \mathrm{~F}\right] 31$}

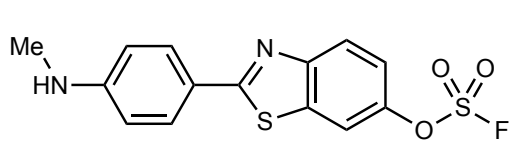

31

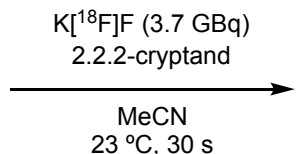

$23^{\circ} \mathrm{C}, 30 \mathrm{~s}$

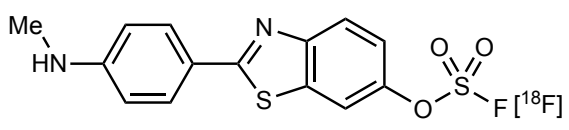

$\left[{ }^{18} \mathrm{~F}\right] 31$

Following the General Procedure of Radiosynthesis (vide supra), the radiolabeling of compound $31(0.1 \mathrm{mg})$ was achieved in $91 \%$ radiochemical yield. The gamma and UV chromatograms were shown in Fig. S49, respectively. $t_{\mathrm{R}}$ (gamma) $=10: 42$ (mm:ss).

a

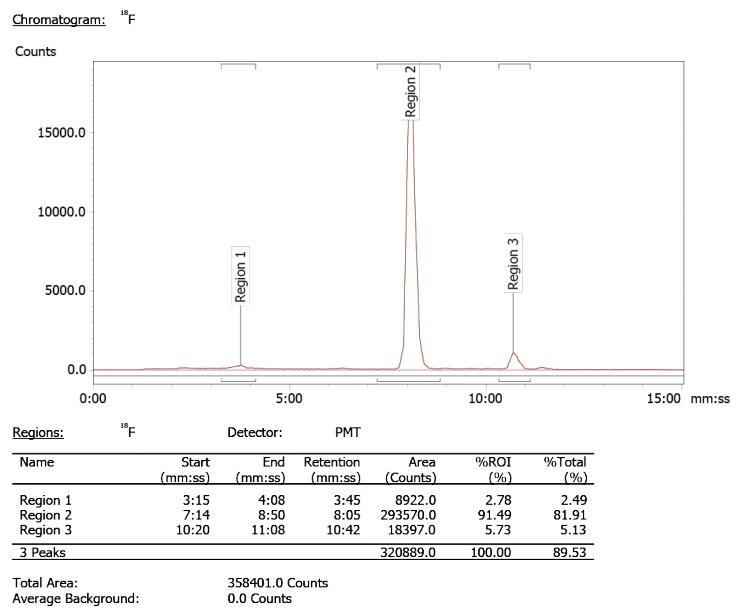

b

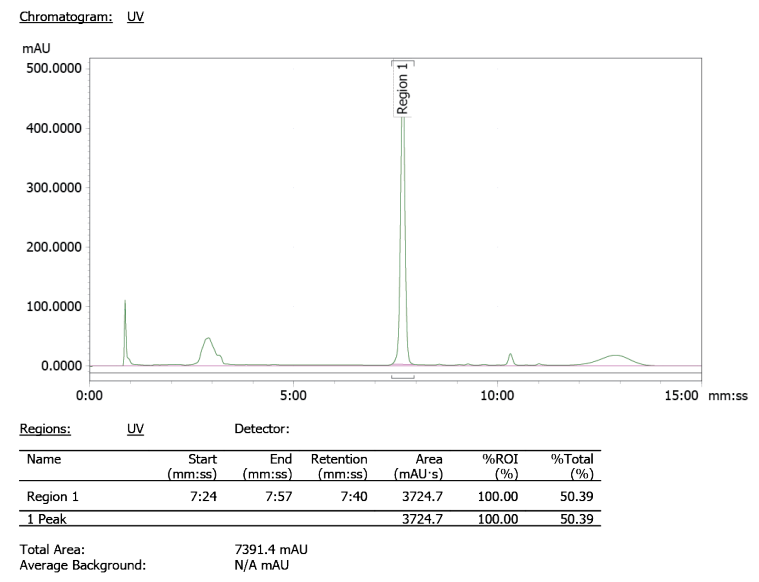

Fig. S49 | HPLC chromatograms of the reaction crude for the synthesis of $\left[{ }^{18} \mathrm{~F}\right] 31$. a, Gamma trace. b, UV trace. RCY $=91 \%$. HPLC Elution II. 


\subsection{Automated Radiosynthesis of $\left[{ }^{18} \mathrm{~F}\right] 32$}

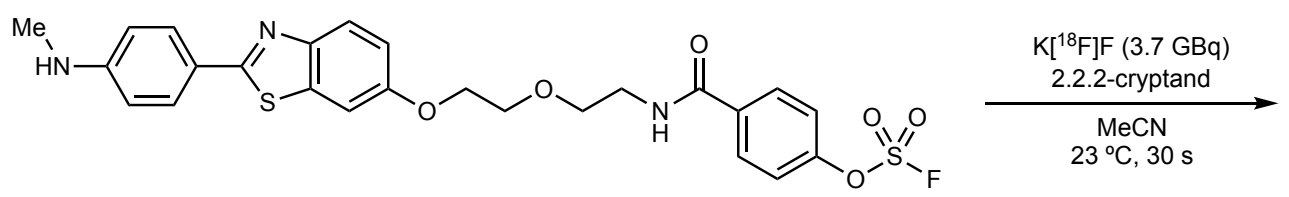

32<smiles>CNc1ccc(-c2nc3ccc(OCCOCCNC(=O)c4ccc(OS(=O)(=O)[In])cc4)cc3s2)cc1</smiles>

$\left[{ }^{18} \mathrm{~F}\right] 32$

$\mathrm{RCY}=98 \%$

Following the General Procedure of Radiosynthesis (vide supra), the radiolabeling of compound $32(0.1 \mathrm{mg})$ was achieved in $98 \%$ radiochemical yield. The gamma and UV chromatograms were shown in Fig. S50, respectively. $t_{\mathrm{R}}$ (gamma) $=11: 19$ (mm:ss).

a

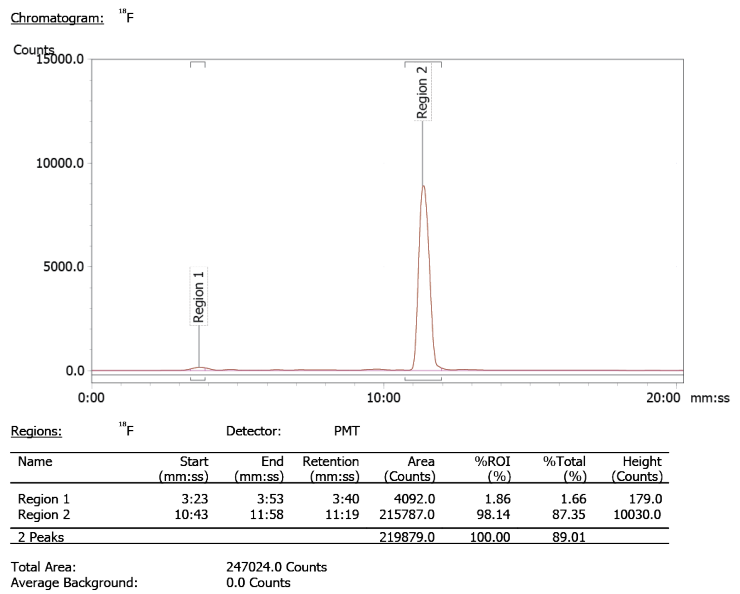

b

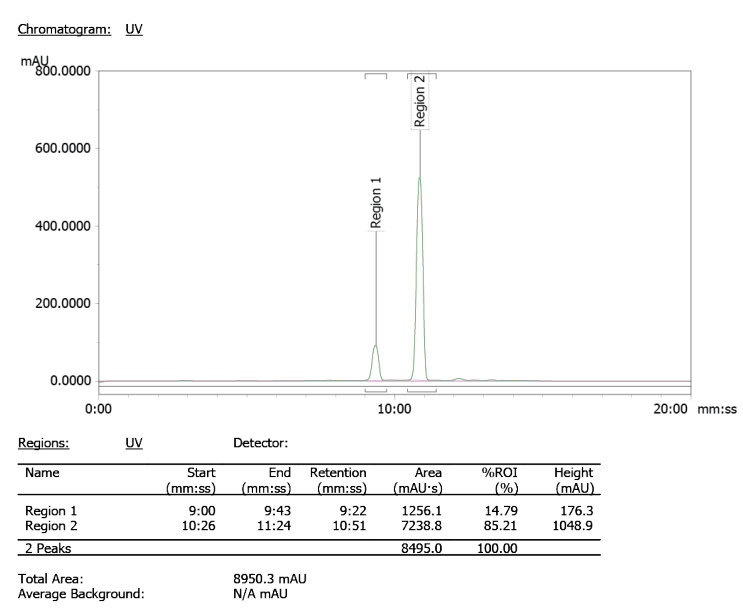

Fig. S50 | HPLC chromatograms of the reaction crude for the synthesis of $\left[{ }^{18} \mathrm{~F}\right] 32$. a, Gamma trace. b, UV trace. RCY $=98 \%$. HPLC Elution I. 


\subsection{Automated Radiosynthesis of $\left[{ }^{18} \mathrm{~F}\right] 33$}<smiles>O=C1NCCOC1(c1ccccc1)C(Oc1ccccc1OS(=O)(=O)F)c1ccccc1</smiles>

$( \pm)-33$

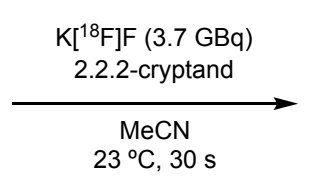

$23^{\circ} \mathrm{C}, 30 \mathrm{~s}$

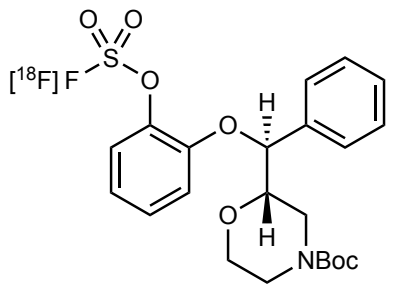

$( \pm)-\left[{ }^{18} \mathrm{~F}\right] 33$

$\mathrm{RCY}=93 \%$

Following the General Procedure of Radiosynthesis (vide supra), the radiolabeling of compound $33(0.1 \mathrm{mg})$ was achieved in $93 \%$ radiochemical yield. The gamma and UV chromatograms were shown in Fig. S51, respectively. $t_{\mathrm{R}}$ (gamma) = 9:43 (mm:ss).

a

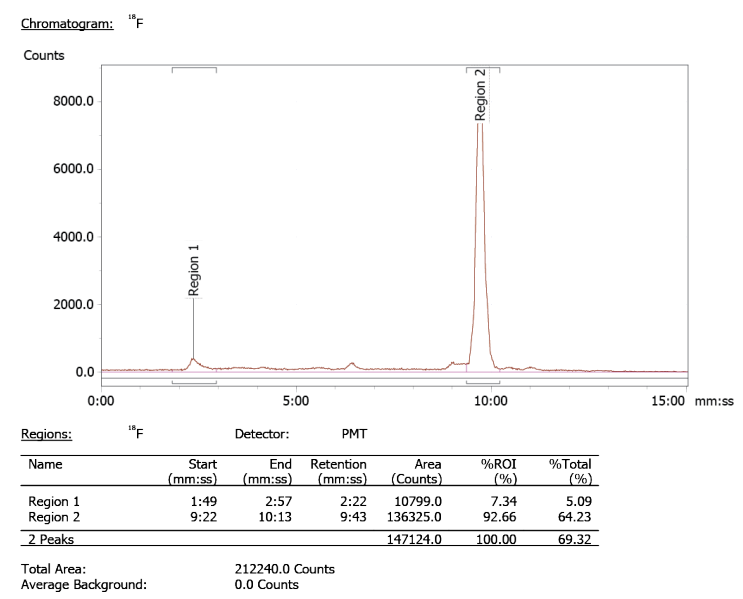

b

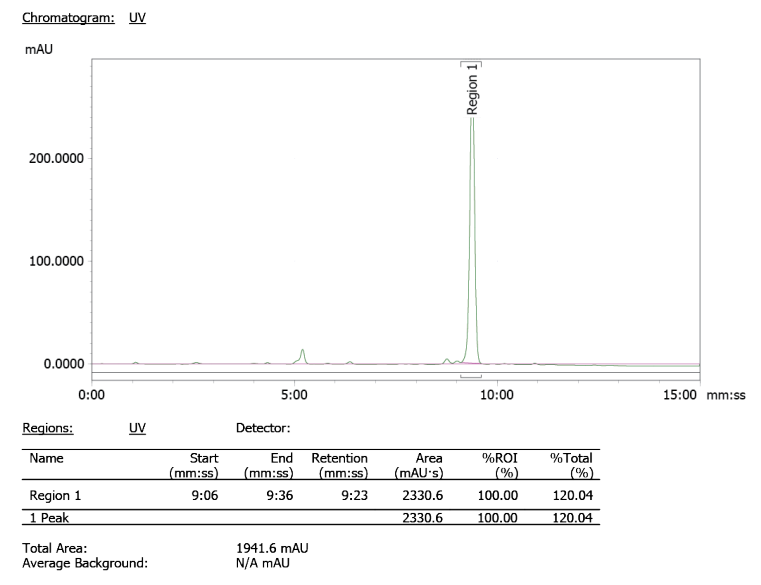

Fig. S51 | HPLC chromatograms of the reaction crude for the synthesis of $\left[{ }^{18} \mathrm{~F}\right] 33$. a, Gamma trace. b, UV trace. RCY $=93 \%$. HPLC Elution II. 


\subsection{Automated Radiosynthesis of $\left[{ }^{18} \mathrm{~F}\right] 34$}

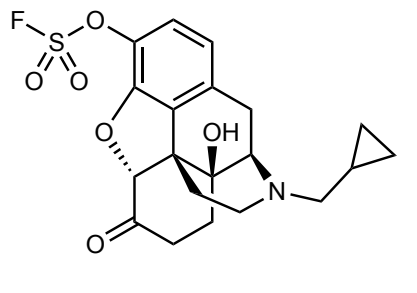

34

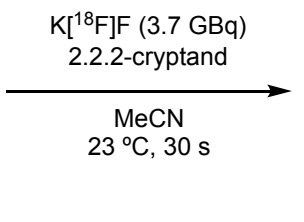

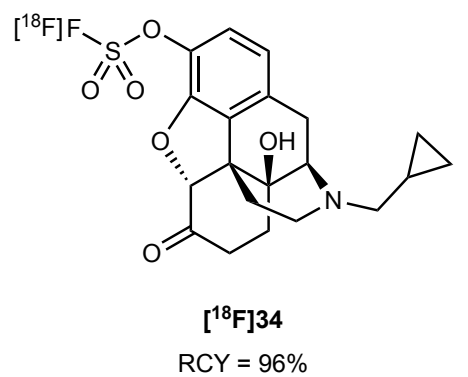

$\mathrm{RCY}=96 \%$

Following the General Procedure of Radiosynthesis (vide supra), the radiolabeling of compound $34(0.1 \mathrm{mg})$ was achieved in $96 \%$ radiochemical yield. The gamma and UV chromatograms were shown in Fig. S52, respectively. $t_{\mathrm{R}}$ (gamma) $=8: 51$ (mm:ss).

a

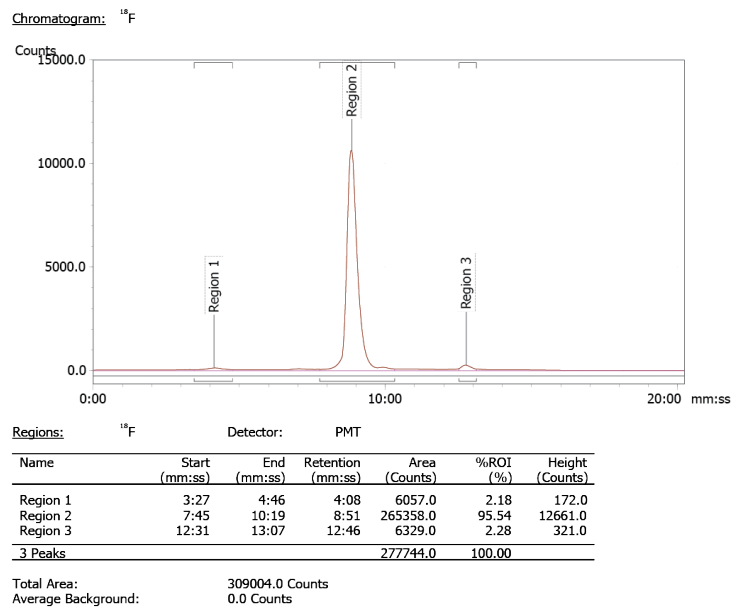

b

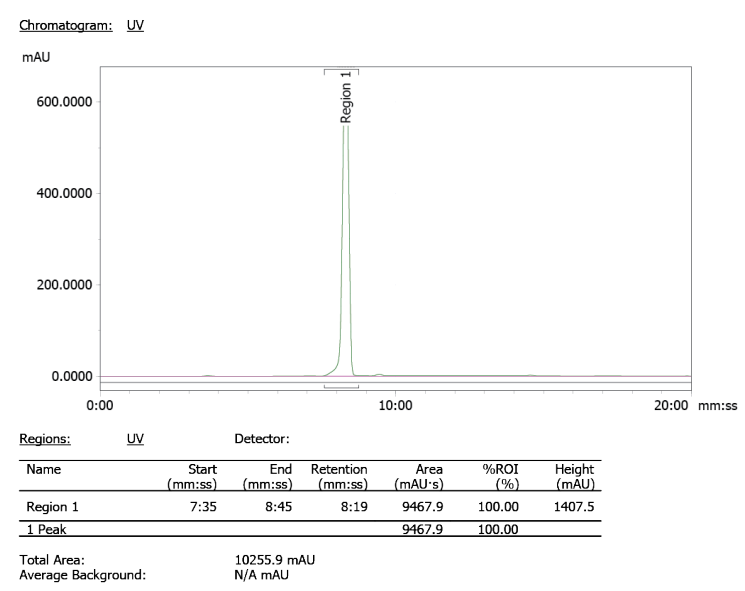

Fig. S52 | HPLC chromatograms of the reaction crude for the synthesis of $\left[{ }^{18} \mathrm{~F}\right] 34$. $a$, Gamma trace. b, UV trace. RCY $=96 \%$. HPLC Elution I. 


\subsection{Automated Radiosynthesis of $\left[{ }^{18} \mathrm{~F}\right] 35$}

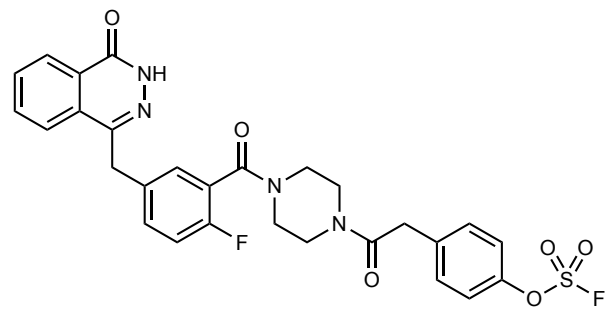

35

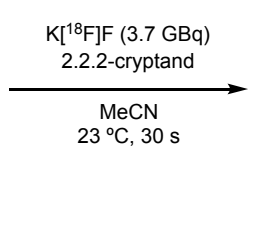

$\mathrm{MeCN}$
$23^{\circ} \mathrm{C}, 30$

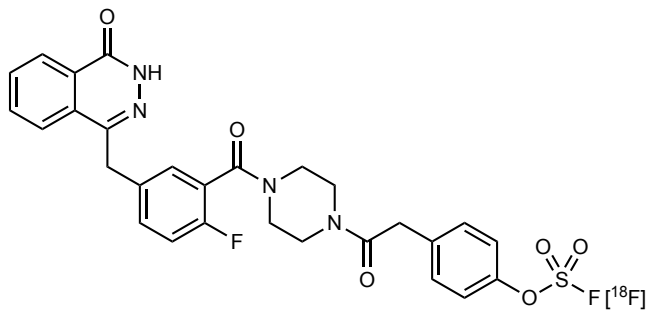

$\left[{ }^{18} \mathrm{~F}\right] 35$

Un 1: RCY $=96 \%$ Run 2: RCY $=95 \%$

Following the General Procedure of Radiosynthesis (vide supra), the radiolabeling of compound $35(0.1 \mathrm{mg})$ was achieved in $95 \%$ and $96 \%$ radiochemical yield in two independent runs. The gamma and UV chromatograms were shown in Fig. S53, respectively. $t_{R}$ (gamma) = 7:55-8:01(mm:ss). 
a

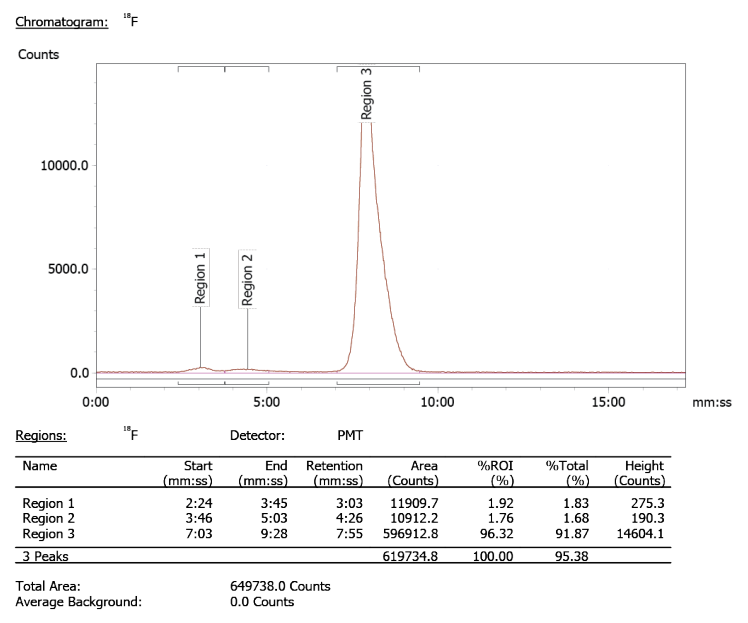

Chromatooram: $1 \mathrm{k} F$

Counts 12000.0
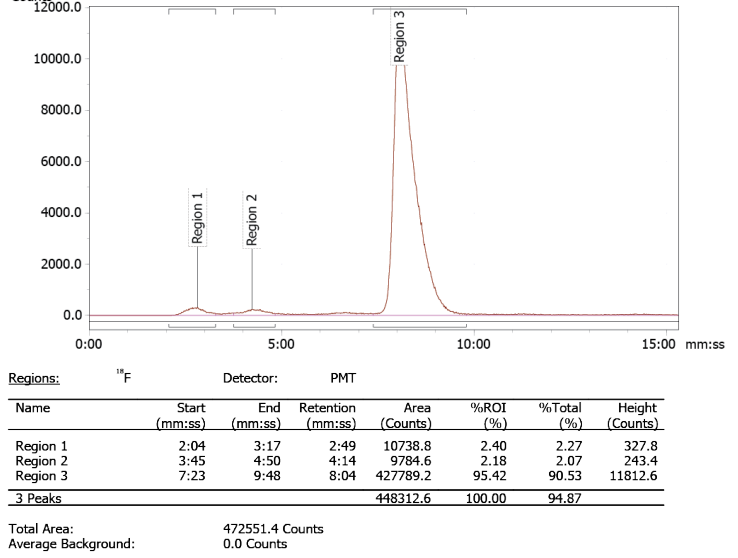

b

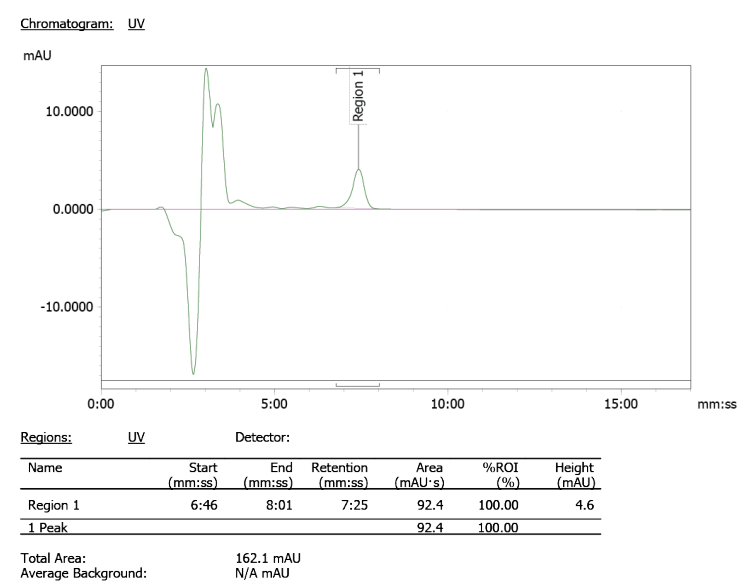

Chromatogram: UV

mAL

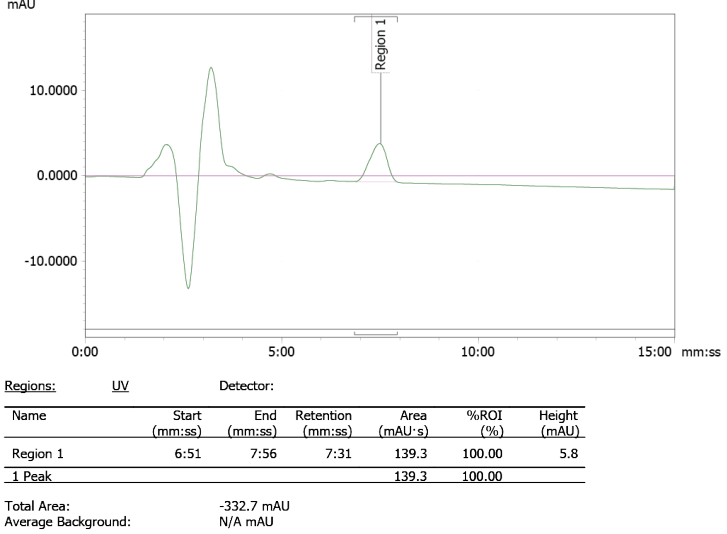

Fig. S53 | HPLC chromatograms of the reaction crude for the synthesis of $\left[{ }^{18} \mathrm{~F}\right] 35$. $a$, Gamma traces, Run 1 (top, RCY =96\%), Run 2 (bottom, RCY = 95\%). b, Gamma traces, Run 1 (top), Run 2 (bottom). HPLC Elution II. 


\subsection{Radiosynthesis of $\left[{ }^{18} \mathrm{~F}\right] 35$ of High Molar Activity}

\subsubsection{Calibration Curve}

To obtain the molar concentration of total compound 35 (including SuFEx product $\left[{ }^{18} \mathrm{~F}\right] 35$ and unreacted $\left.\left[{ }^{19} \mathrm{~F}\right] 35\right)$, the calibration curve of HPLC peak area (254 nm UV channel) versus concentration [35] was plotted (Fig. S54). The injected concentration (injection volume: $20 \mu \mathrm{L}$ ) for calibration ranged from 0.2 to $10 \mu \mathrm{g} \mathrm{mL}^{-1}$. The estimated concentration of the sample used for molar activity measurement should be around $1 \mu \mathrm{g} \mathrm{mL}^{-1}$, which lies within the range of the calibration curve.

3.28.2. Automated Radiosynthesis Using $3 \mathrm{Ci}$ of $\left.\mathrm{K} \Gamma^{18} \mathrm{~F}\right] \mathrm{F}$.

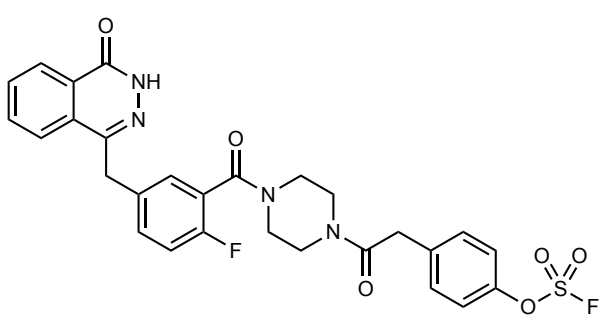

35

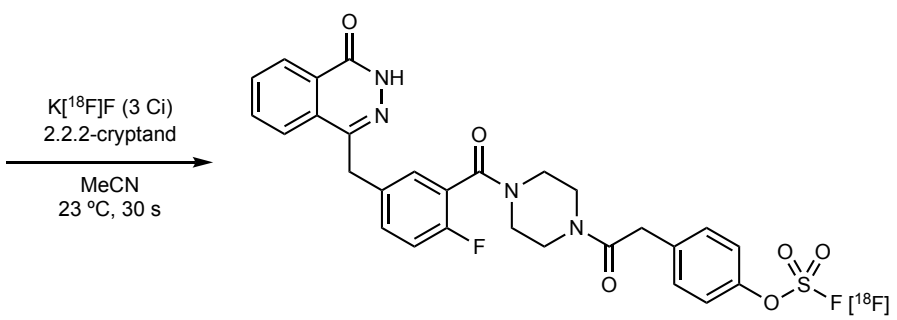

$\left[{ }^{18} \mathrm{~F}\right] 35$

Run \#1
RCY $_{\text {HPLC }}=89 \%, A m=281 \mathrm{GBq} / \mu \mathrm{mol}$ (decay corrected to E.O.S.);

Experimental. $\left[{ }^{18} \mathrm{~F}\right] \mathrm{Fluoride}$ was trapped on the QMA column (Waters, WAT023525, preconditioned by $\mathrm{KHCO}_{3}$ ). Valves $\mathrm{V} 1-\mathrm{V} 13-\mathrm{V} 13-\mathrm{V} 14$ were opened, and $\left[{ }^{18} \mathrm{~F}\right]$ fluoride was eluted into Stirrer 1 by Stock Solution A1 (MeCN/water). Valves V2-V14 were opened, and Stock Solution A2 $(1 \mathrm{~mL})$ was added to the Reaction Vessel (on Stirrer 1). The mixture was dried under nitrogen flow at $120^{\circ} \mathrm{C}$ for $3 \mathrm{~min}$. Cooled to $40^{\circ} \mathrm{C}$, one more portion of Stock Solution A2 (1 mL) was added, the solution was dried under nitrogen flow at $120^{\circ} \mathrm{C}$ for $3 \mathrm{~min}$. The residue containing $\mathrm{K}\left[{ }^{18} \mathrm{~F}\right] \mathrm{F}$ was re-dissolved in $\mathrm{MeCN}(0.5 \mathrm{~mL})$ to make a stock solution with approximately $37 \mathrm{GBq}(\sim 1 \mathrm{Ci}$, see Table $\mathbf{S} 13$ for accurate value) activity.

Valve V3 was opened and Stock Solution A3 (10 mL, $100 \mu \mathrm{g}$ of Compound 35, $172 \mathrm{nmol}$ ) was added to the Reaction Vessel. The $\left[{ }^{18} \mathrm{~F}\right]$ SuFEx reaction was carried out at room temperature for $30 \mathrm{~s}$. Valve $\mathrm{V} 15$ was opened, the reaction mixture was transferred to the Collecting Vessel containing $30 \mathrm{~mL} \mathrm{H}_{2} \mathrm{O}$ (on Stirrer 2). The crude mixtures were analyzed by HPLC, and the results are shown in Fig. S55. The HPLC RCYs are $93 \%$ and $85 \%$, respectively.

Valve 35 was opened; Solution in the Collecting Vessel was passed through C18 cartridge and the elution was collected in the Waste bottle. Valves 31 was opened, the $\mathrm{C} 18$ cartridge was eluted with $\mathrm{H}_{2} \mathrm{O}(10 \mathrm{~mL})$, the elution collected in the Waste bottle. Valve 30 was opened, the $\mathrm{C} 18$ cartridge was eluted with ethanol $(1 \mathrm{~mL})$, the elution collected in the Connecting Bottle. The resulting solution was diluted by $0.9 \% \mathrm{NaCl}$ solution and used without further purification. The HPLC chromatograms of $\left[{ }^{18} \mathrm{~F}\right] 35$ after $\mathrm{C} 18$ purification were shown in Fig. S56. The molar activity of final purified product $\left[{ }^{18} \mathrm{~F}\right] 35$ was 103 and $103 \mathrm{GBq} \mathrm{\mu mol}^{-1}$, respectively. 
3.28.3. Automated Radiosynthesis Using 1 Ci of $\left.K{ }^{18} \mathrm{~F}\right] \mathrm{F}$.

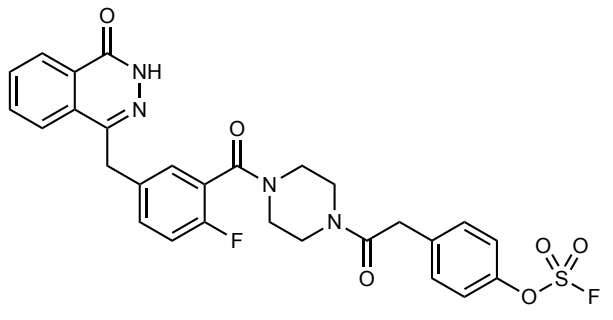

35

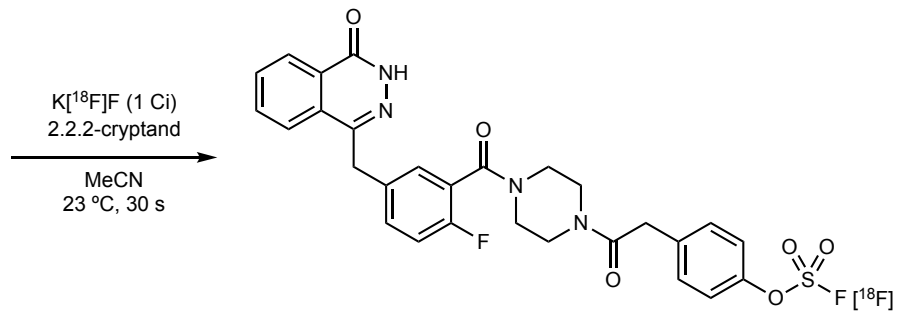

$\left[{ }^{18} \mathrm{~F}\right] 35$

Run \#2

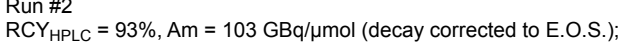

Run \#3

$\mathrm{RCY}_{\mathrm{HPLC}}=85 \%, \mathrm{Am}=103 \mathrm{GBq} / \mu \mathrm{mol}$ (decay corrected to E.O.S.);

Experimental. $\left[{ }^{18} \mathrm{~F}\right] \mathrm{Fluoride}$ was trapped on the QMA column (Waters, WAT023525, preconditioned by $\mathrm{KHCO}_{3}$ ). Valves $\mathrm{V} 1-\mathrm{V} 13-\mathrm{V} 13-\mathrm{V} 14$ were opened, and $\left[{ }^{18} \mathrm{~F}\right]$ fluoride was eluted into Stirrer 1 by Stock Solution A1 (MeCN/water). Valves V2-V14 were opened, and Stock Solution A2 $(1 \mathrm{~mL})$ was added to the Reaction Vessel (on Stirrer 1). The mixture was dried under nitrogen flow at $120^{\circ} \mathrm{C}$ for $3 \mathrm{~min}$. Cooled to $40^{\circ} \mathrm{C}$, one more portion of Stock Solution A2 (1 mL) was added, the solution was dried under nitrogen flow at $120^{\circ} \mathrm{C}$ for $3 \mathrm{~min}$. The residue containing $\mathrm{K}\left[{ }^{18} \mathrm{~F}\right] \mathrm{F}$ was re-dissolved in $\mathrm{MeCN}(0.5 \mathrm{~mL})$ to make a stock solution with approximately $108 \mathrm{GBq}(\sim 3 \mathrm{Ci}$, see Table $\mathbf{S} 13$ for accurate value) activity.

Valve V3 was opened and Stock Solution A3 (10 mL, $100 \mu \mathrm{g}$ of Compound 35, $172 \mathrm{nmol}$ ) was added to the Reaction Vessel. The $\left[{ }^{18} \mathrm{~F}\right]$ SuFEx reaction was carried out at room temperature for $30 \mathrm{~s}$. Valve $\mathrm{V} 15$ was opened, the reaction mixture was transferred to the Collecting Vessel containing $30 \mathrm{~mL} \mathrm{H}_{2} \mathrm{O}$ (on Stirrer 2). The crude mixtures were analyzed by HPLC, and the results are shown in Fig. S59. The HPLC RCY is $89 \%$.

Valve 35 was opened; Solution in the Collecting Vessel was passed through C18 cartridge and the elution was collected in the Waste bottle. Valves 31 was opened, the $\mathrm{C} 18$ cartridge was eluted with $\mathrm{H}_{2} \mathrm{O}(10 \mathrm{~mL})$, the elution collected in the Waste bottle. Valve 30 was opened, the C18 cartridge was eluted with ethanol $(1 \mathrm{~mL})$, the elution collected in the Connecting Bottle. The resulting solution was diluted by $0.9 \% \mathrm{NaCl}$ solution and used without further purification. The HPLC chromatograms of $\left[{ }^{18} \mathrm{~F}\right] 35$ after $\mathrm{C} 18$ purification were shown in Fig. S58. The molar

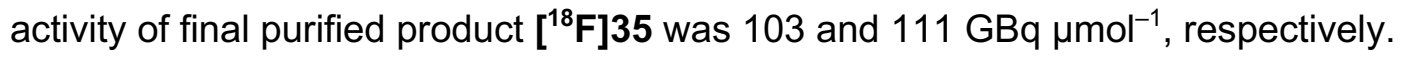

\subsubsection{An example (Run \#3) of calculation of Specific Activity and Molar Activity of $\left[{ }^{8} F\right] 35$}

Total concentration of 35 , that is the sum of $\left[{ }^{19} \mathrm{~F}\right] 35$ (unexchanged starting material), and $\left[{ }^{18} \mathrm{~F}\right] 35$ (exchanged product), in the diluted sample was determined by calibration curve (Fig. S54). The mass concentration $\left(\rho_{35, \text { total }}\right)$ and molar concentration $\left(c_{35, \text { total }}\right)$ are calculated by Eq. S23, and Eq. S24. 


$$
\begin{gathered}
\rho_{35, \text { total }}=\frac{12.9+4.618}{56.25\left(\mu \mathrm{g} \mathrm{mL}^{-1}\right)^{-1}}=0.311 \mu \mathrm{g} \mathrm{mL}^{-1} \\
c_{35, \text { total }}=\frac{\rho_{35, \text { total }}}{M_{35}}=\frac{0.311 \mu \mathrm{g} \mathrm{mL}^{-1}}{582.58 \mathrm{~g} \mathrm{~mol}^{-1}}=0.533(8) \mathrm{nmol} \mathrm{mL}^{-1}
\end{gathered}
$$

The whole (radio)activity per milliliter of the analyzed (diluted) sample was $49.2 \mathrm{MBq} \mathrm{mL}^{-1}$ $\left(1.33 \mathrm{mCi} \mathrm{mL}^{-1}\right.$ ). Decay correction (gap between the E.O.S. and the time of analysis is $194 \mathrm{~min}$; 11:11 E.O.S.; 14:25 time of analysis) gave the whole (radio)activity per milliliter of the analyzed sample at the E.O.S. was $0.168 \mathrm{GBq} \mathrm{mL}^{-1}\left(4.53 \mathrm{mCi} \mathrm{mL}^{-1}\right)$ (Eq. S25).

$$
\begin{aligned}
A_{\text {EOS }, \text { whole,per mL }}= & \frac{A_{\text {whole,per mL }}}{e^{-\frac{0.693 \times t}{\lambda}}}=\frac{49.2(1) \times 10^{-3} \mathrm{GBq} \mathrm{mL}^{-1}}{e^{-\frac{0.693 \times 194 \mathrm{~min}}{109.77 \mathrm{~min}}}} \\
& =0.167(5) \mathrm{GBq} \mathrm{mL}^{-1}
\end{aligned}
$$

Eq. $\mathbf{S 2 5}$

Thus, the (radio)activity per milliliter of $\left[{ }^{18} \mathrm{~F}\right] 35$ was calculated by multiplying the whole (radio)activity of the sample by the peak proportion (\%Total) of Region 2 (desired product peak, $\left.t_{R}=7.56 \mathrm{~min}\right)$ in Fig. $\mathbf{S 5 5}$.

$$
A_{\left[{ }^{18} \mathrm{~F}\right] 35, \text { per mL }}=0.167(5) \mathrm{GBq} \mathrm{mL}^{-1} \times 89.13 \%=0.149(3) \mathrm{GBq} \mathrm{mL}^{-1} \quad \text { Eq. } \mathbf{S 2 6}
$$

The specific activity $\left(A_{s}\right)$ and molar activity $\left(A_{m}\right)$ of $\left[{ }^{18} \mathrm{~F}\right] 35$ can be calculated ${ }^{41}$ based on Eq. S23, Eq. S24, and Eq. S26.

$$
\begin{gathered}
A_{\mathrm{S}}\left(\left[{ }^{18} \mathrm{~F}\right] 35\right)=\frac{A_{\left[{ }^{18} \mathrm{~F}\right] 35, \text { per mL }}}{\rho_{35, \text { total }}}=\frac{0.149(3) \mathrm{GBq} \mathrm{mL}^{-1}}{0.311 \mu \mathrm{gL}^{-1}} \\
=0.480 \mathrm{GBq}_{\mu \mathrm{g}}^{-1}
\end{gathered}
$$




$$
\begin{gathered}
A_{m}\left(\left[{ }^{18} \mathrm{~F}\right] 35\right)=\frac{A_{\left[{ }^{18} \mathrm{~F}\right] 35, \text { per mL }}}{c_{35} \text { total }}=\frac{0.149(3) \mathrm{GBq} \mathrm{mL}^{-1}}{0.533(8) \times 10^{-3} \mu \mathrm{mol} \mathrm{mL}^{-1}} \\
=280 \mathrm{GBq} \mu \mathrm{mol}^{-1}
\end{gathered}
$$




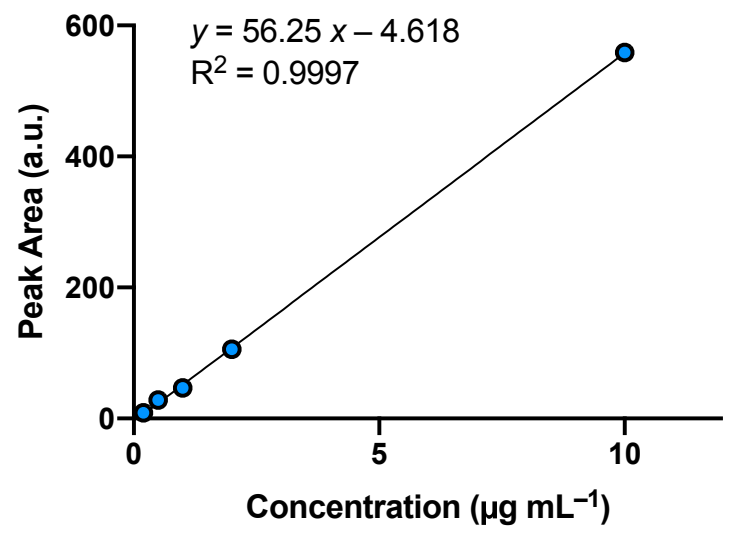

Fig. S54 | Calibration curve acquired with authentic standard (35) at $254 \mathrm{~nm}$. 
Table S13 | Key experimental data regarding high molar activity radiosynthesis.

\begin{tabular}{|c|c|c|c|c|}
\hline & & Run \#1 & Run \#2 & Run \#3 \\
\hline \multicolumn{2}{|l|}{$\begin{array}{l}\text { Activity of } \\
{\left[{ }^{18} \mathrm{~F}\right] \text { fluoride }}\end{array}$} & $2.91 \mathrm{Ci}$ & $1.01 \mathrm{Ci}$ & $1.04 \mathrm{Ci}$ \\
\hline \multirow{3}{*}{ Time } & End-of-synthesis & $11: 11$ & $10: 30$ & 9:23 \\
\hline & Crude HPLC & $14: 25$ & $12: 12$ & $11: 38$ \\
\hline & Final product HPLC & $\mathrm{N} / \mathrm{A}$ & $11: 55$ & $12: 38$ \\
\hline \multirow{2}{*}{ Gamma HPLC } & Crude & $89.13 \%$ & $92.80 \%$ & $84.78 \%$ \\
\hline & Purified & $\mathrm{N} / \mathrm{A}$ & $100 \%$ & $100 \%$ \\
\hline \multirow{3}{*}{$\begin{array}{l}\text { Activity per } \\
\text { milliliter } \\
\text { (GBq/mL) }\end{array}$} & Crude HPLC & 0.04921 & 0.06179 & 0.05661 \\
\hline & Final product HPLC & $(0.04386)$ & 0.04292 & 0.06327 \\
\hline & $\begin{array}{c}\text { Final product } \\
\text { corrected to E.O.S. }\end{array}$ & 0.1493 & 0.07341 & 0.2168 \\
\hline \multirow{3}{*}{$\begin{array}{l}\text { Final product } \\
\text { total } \\
\text { concentration }\end{array}$} & UV area & 12.9 & 18.7 & 59.1 \\
\hline & $\begin{array}{l}\text { Concentration } \\
(\mu \mathrm{g} / \mathrm{mL})\end{array}$ & 0.311 & 0.414 & 1.133 \\
\hline & $\begin{array}{l}\text { Molar concentration } \\
\qquad(\mathrm{nmol} / \mathrm{mL})\end{array}$ & 0.5338 & 0.7116 & 1.9445 \\
\hline \multicolumn{2}{|c|}{ C18 recovery rate } & N/A & $69 \%$ & $73 \%$ \\
\hline \multicolumn{2}{|c|}{ 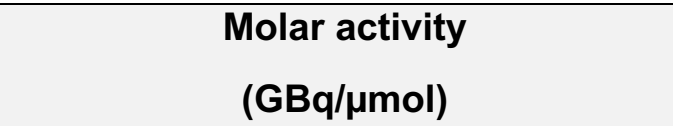 } & 280 & 103 & 111 \\
\hline
\end{tabular}


a

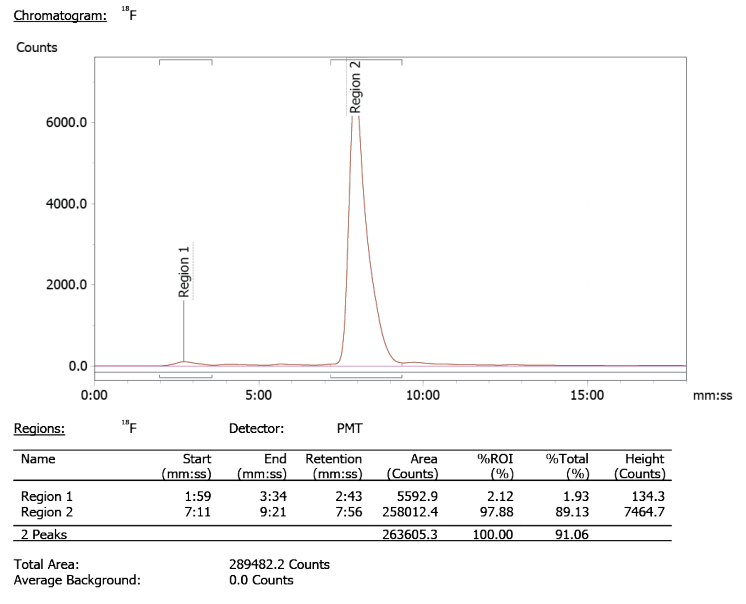

b

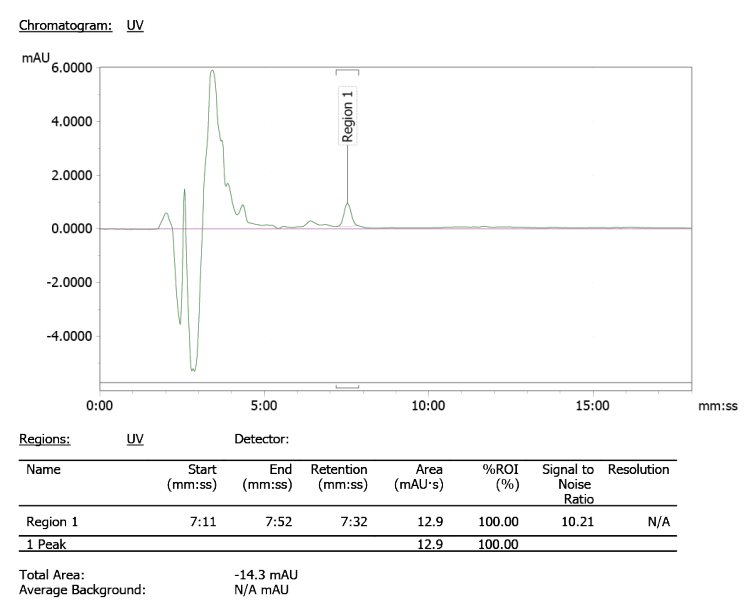

Fig. S55 | HPLC chromatograms of the reaction crude for the 3-Ci high activity radiosynthesis of $\left[{ }^{18} \mathrm{~F}\right] 35$. $\mathbf{a}$, Gamma trace. $\mathbf{b}$, UV trace. RCY $=89 \%$. HPLC Elution I. 
a

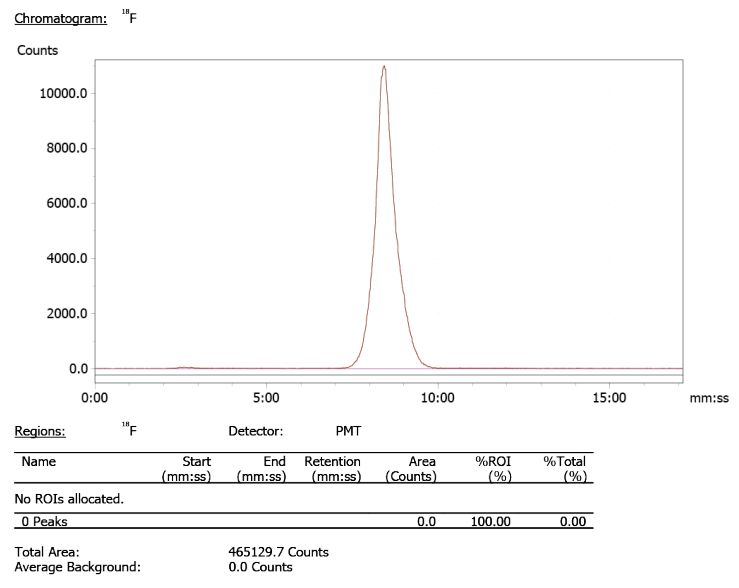

b

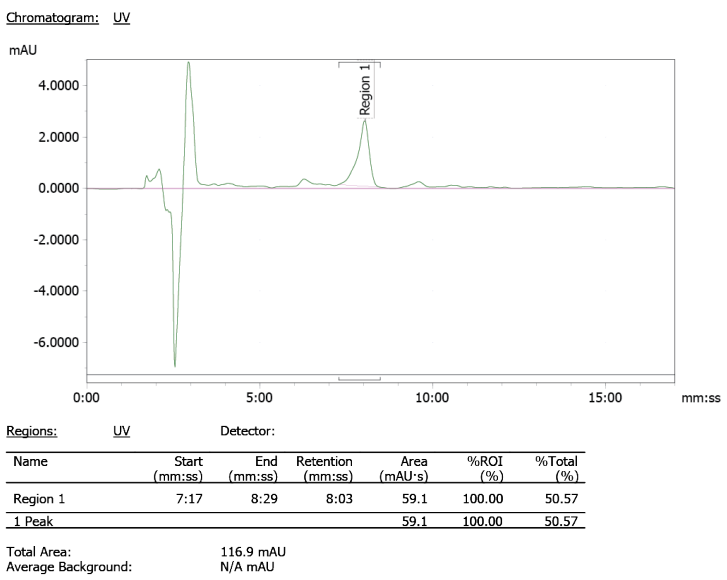

Fig. S56 | HPLC chromatograms of the $\mathbf{C 1 8}$ cartridge purified product for the 3-Ci high activity radiosynthesis of $\left[{ }^{18} \mathrm{~F}\right] 35$. a, Gamma trace (radiochemical purity $=100 \%$ ). b, UV trace. HPLC Elution I. 
a

Chromatooram: ${ }^{\mathrm{F}} \mathrm{F}$

Counts

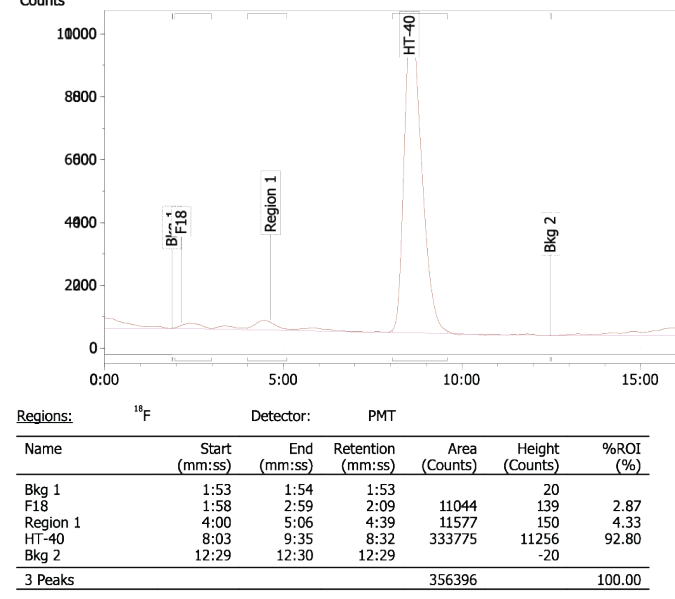

C

Chromatogram: ${ }^{10} \mathrm{~F}$

Counts

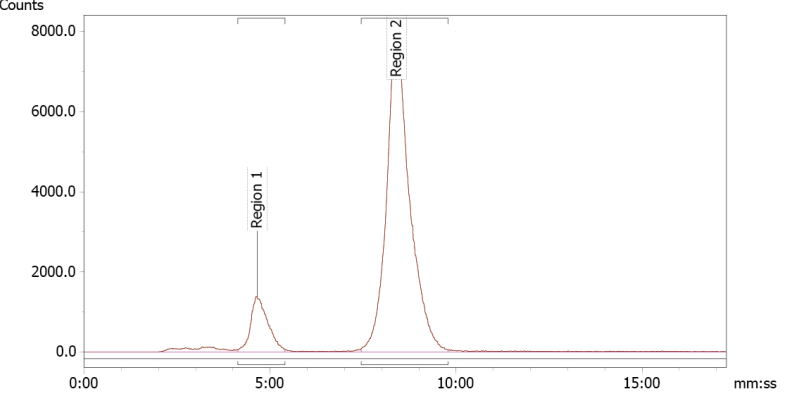

b

Chromatogram: UV

mAU

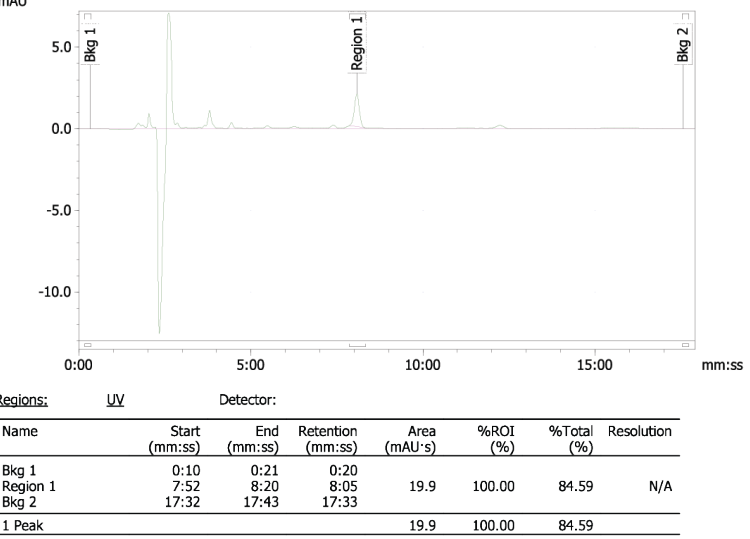

d

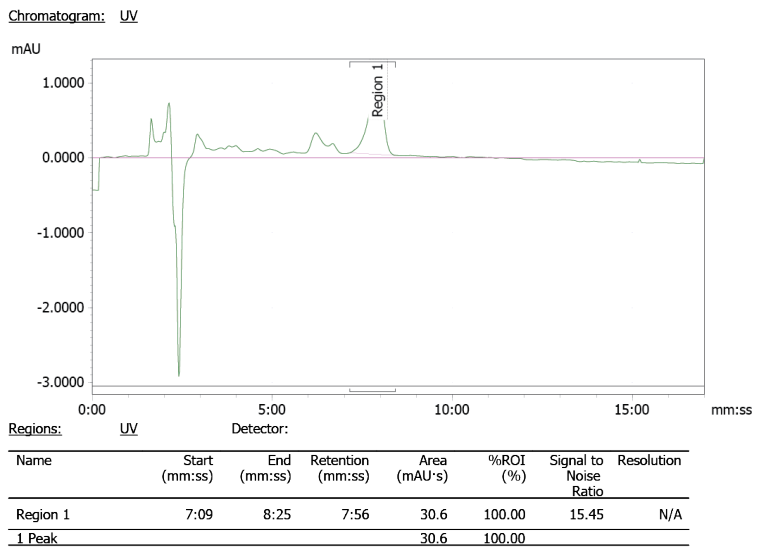

Fig. S57 | HPLC chromatograms of the reaction crude for the 1-Ci high activity radiosynthesis of $\left[{ }^{18} \mathrm{~F}\right] 35$. a, Gamma trace of Run \#2, RCY $=93 \%$. HPLC Elution I. b, UV trace of Run \#2. c, Gamma trace of Run \#3, RCY = 85\%. HPLC Elution I. d, UV trace of Run \#3. 
a

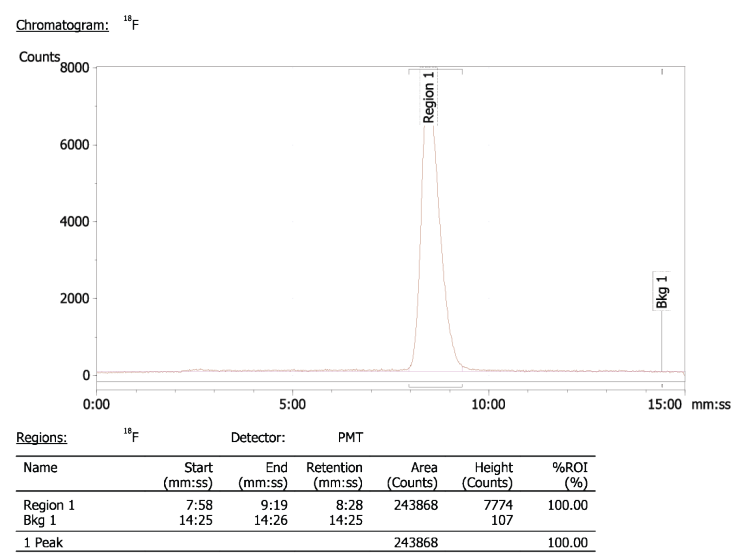

C

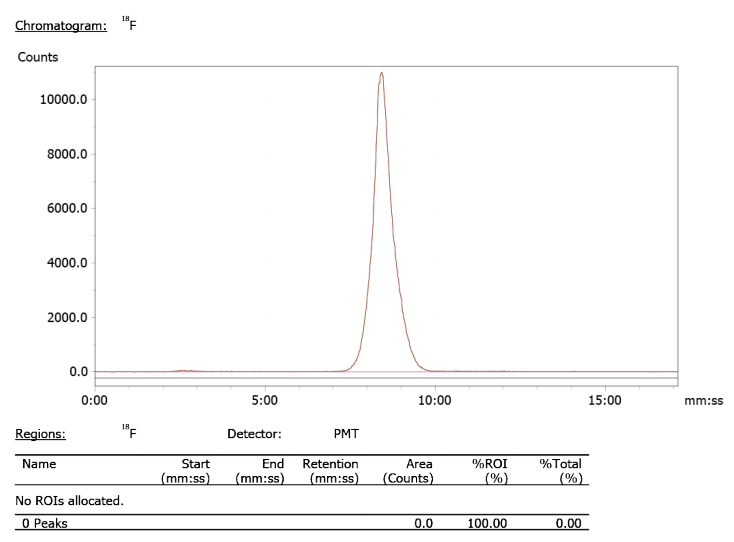

b

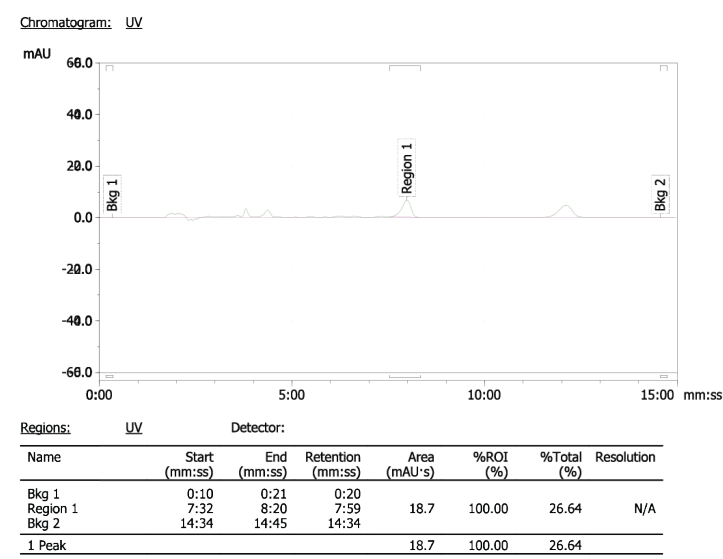

d

Chromatogram: $\underline{\text { UV }}$

mAU

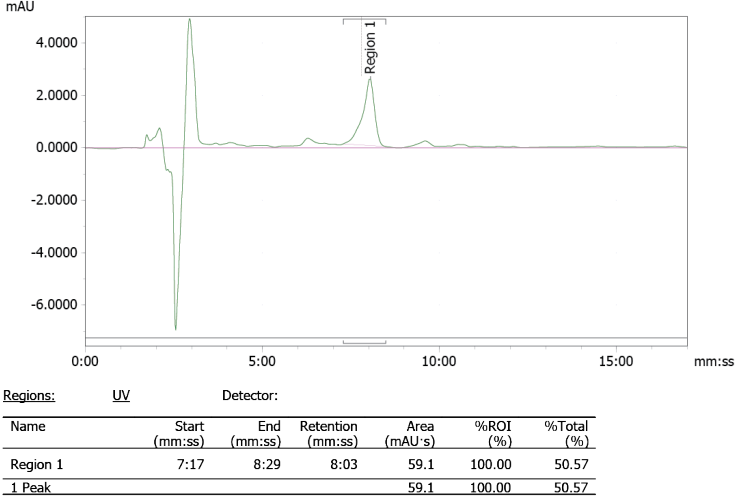

Fig. S58 | HPLC chromatograms of the C18 cartridge purified product for the 3-Ci high activity radiosynthesis of $\left[{ }^{18} \mathrm{~F}\right] 35$. a, Gamma trace of Run \#2, radiochemical purity $=100 \%$, HPLC Elution I. b, UV trace of Run \#2. c, Gamma trace of Run \#3, radiochemical purity = $100 \%$, HPLC Elution I. d, UV trace of Run \#3. 


\subsection{Less Effective Examples of $\left[{ }^{18} \mathrm{~F}\right]$ SuFEx Radiolabeling}<smiles>O=C(O)c1ccc(OC(F)(F)F)cc1</smiles>

s1<smiles>O=C(F)Oc1ccc(-c2nnn[nH]2)cc1</smiles>

S51
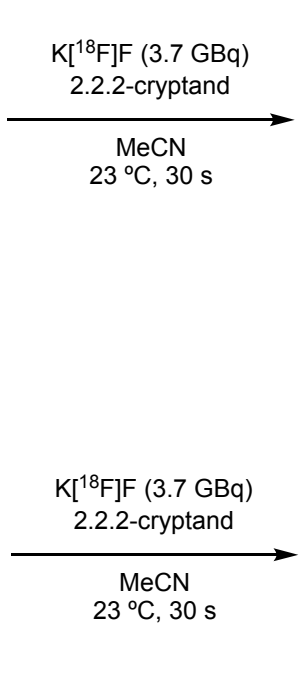

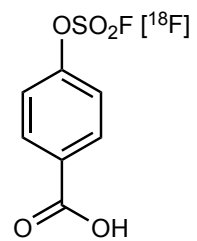

$\left[{ }^{18} \mathrm{~F}\right] \mathrm{S} 1$

$\mathrm{RCY} \sim 50 \%$<smiles>Oc1ccc(-c2nnn[nH]2)cc1</smiles>

$\left[{ }^{18} \mathrm{~F}\right] \mathrm{S} 51$

RCY 28\%

Substrates containing an acidic group yielded much lower RCY. Aryl fluorosulfate $\mathbf{S 1}\left(\mathrm{pK}_{\mathrm{a}}{ }^{25}\right.$ ${ }^{\circ} \mathrm{C}=3.50 \pm 0.04$ ) with a carboxylic acid group, and aryl fluorosulfate $\mathbf{S 5 1}$ with a $\mathrm{NH}$-tetrazole group under the same radiolabeling conditions only gave desired product in less than $50 \%$ RCY (Fig. S59, and Fig. S60,). This observation was in consistence with the NMR experiments that fluoride salts complexed with Brønsted or Lewis acids are much less effective for the fluoride exchange process. 
a

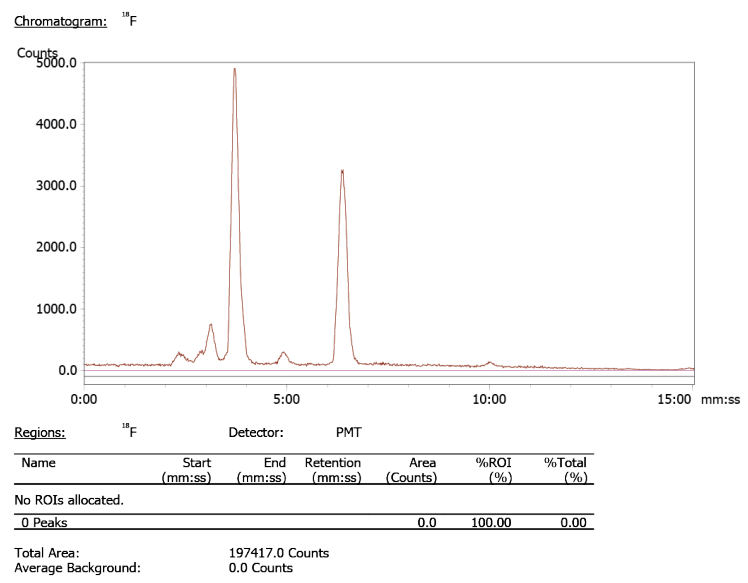

b

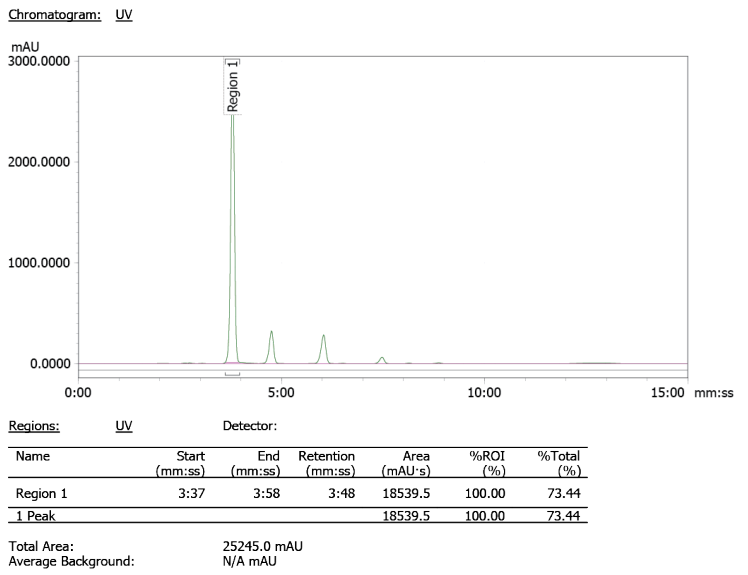

Fig. S59 | HPLC chromatograms of the reaction crude for the radiosynthesis of $\left[{ }^{18} \mathrm{~F}\right] \mathrm{S} 1 . \mathrm{a}$, Gamma trace. b, UV trace. RCY $\sim 50 \%, t_{\mathrm{R}}=3: 48$ (mm:ss). HPLC Elution II. 
a

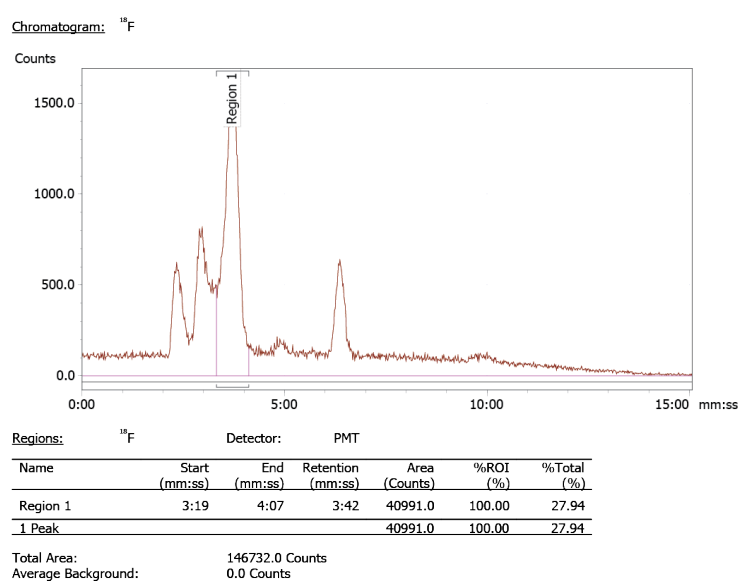

b

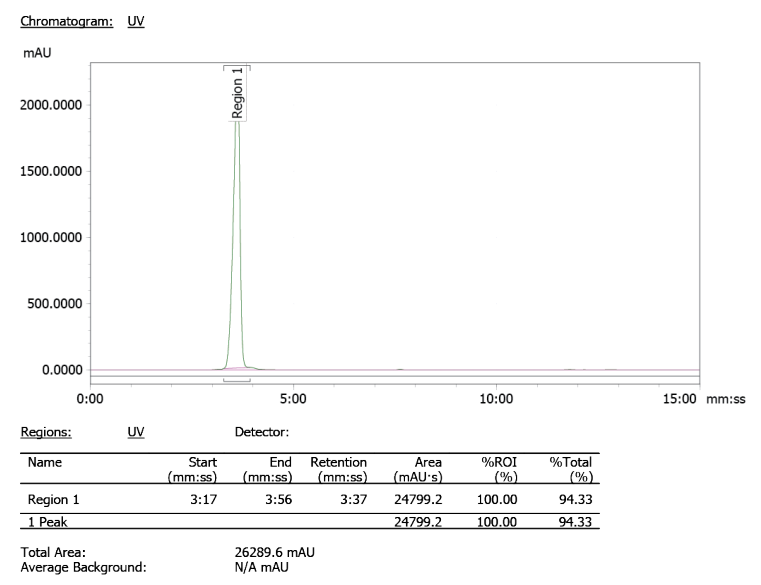

Fig. S60 | HPLC chromatograms of the reaction crude for the radiosynthesis of $\left[{ }^{18} \mathrm{~F}\right] \mathrm{S} 51$. a, Gamma trace. b, UV trace. RCY $=28 \%, t_{R}=3: 42$ (mm:ss). HPLC Elution II. 


\section{Positron Emission Tomography (PET) Imaging}

\subsection{PET Imaging of Nude Mice Carrying Subcutaneous Tumor}

All PET/CT images were performed on an Inveon PET/CT scanner (Siemens) and the reconstructed PET data and CT were analyzed using the Inveon Research Workplace Software (Siemens).

Female nude mice (8 weeks old) were supplemented with estradiol pellet each prior to inoculated with MCF-7 cancer cells ( $5 \times 10^{6}$ in $200 \mu \mathrm{L}$ PBS) subcutaneously. Two weeks following tumor implantation, the mice were used for in vivo imaging.

Subcutaneous MCF-7 tumor bearing female nude mice $(n=3)$ were anesthetized using inhaled $2 \%$ isoflurane and placed on the PET/CT scanner bed. The mouse received a bolus tailvein injection of $3.7 \mathrm{MBq}$ of $\left[{ }^{18} \mathrm{~F}\right] 35\left(A_{\mathrm{m}} \sim 19 \mathrm{GBq} \mu \mathrm{mol}^{-1}\right)$ in $2 \% \mathrm{v} / \mathrm{v} \mathrm{EtOH}$ in $0.9 \%$ saline, and a 60 min dynamic PET scan (continuous list mode) was initiated immediately. The reconstructed PET data were automatically co-registered with the MRI data, and they were subsequently analyzed using the Inveon Research Workplace software.

The uptake value versus time plots in tumor and normal tissues in three mice were summarized in Table S14, Table S15, Table S16, respectively. The time plots were shown in Fig. S62, respective PET images were summarized in Fig. S61. 

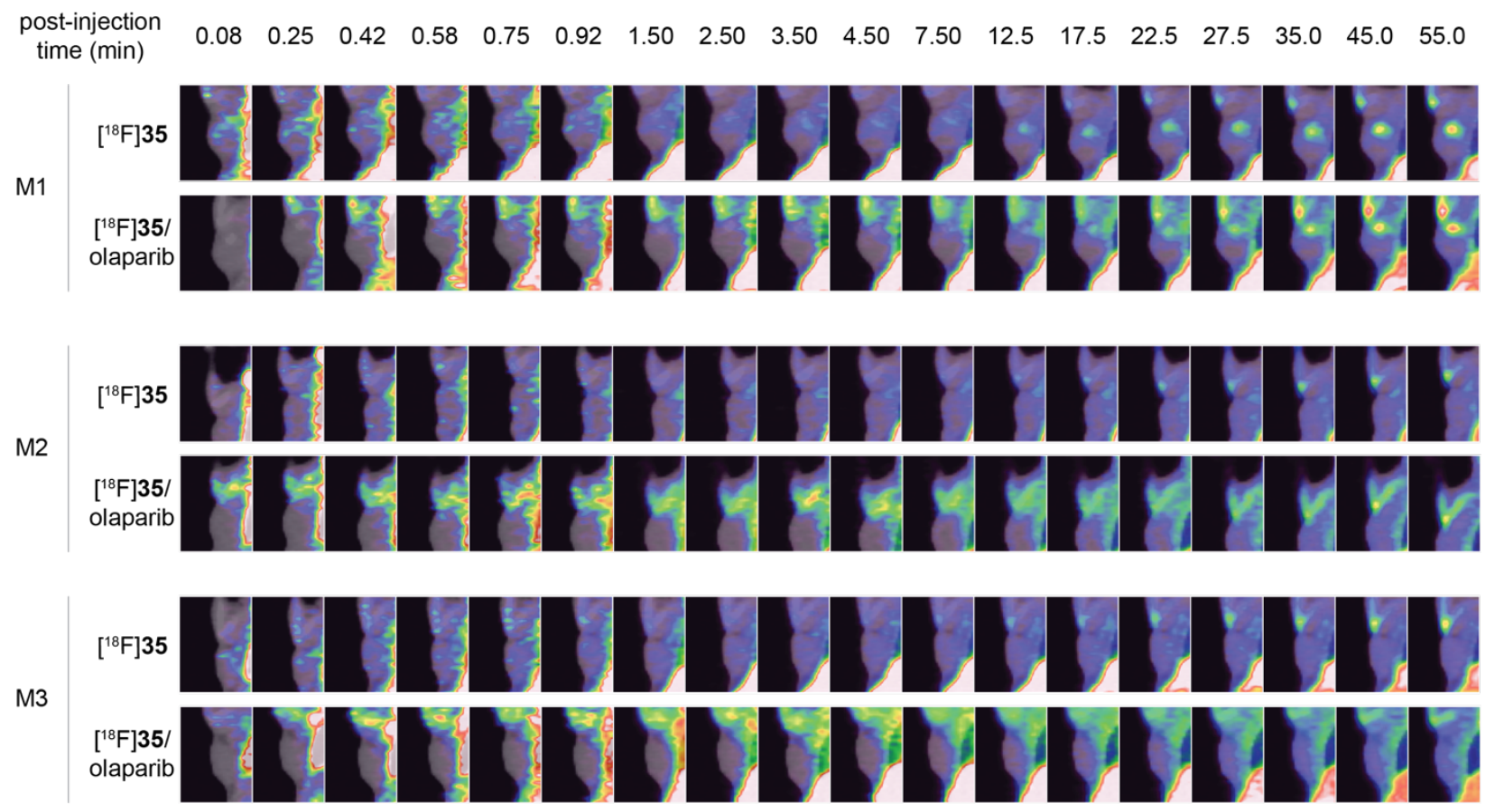

Fig. S61 | PET images of tumor region of three mice treated by either $\left[{ }^{18} \mathrm{~F}\right] 35$ or olaparib then $\left[{ }^{18} \mathrm{~F}\right] 35$. Coronal views are given where the left-side of picture corresponds to the right arm of mouse. 
Table S14 | Uptake values versus time in Mouse 1 (data shown in two decimals).

\begin{tabular}{|c|c|c|c|c|c|c|c|c|c|}
\hline \multicolumn{5}{|c|}{ Tumor } & \multicolumn{5}{|c|}{ Muscle } \\
\hline \multirow[b]{2}{*}{$\begin{array}{c}t \\
(\min )\end{array}$} & \multirow[b]{2}{*}{ mean } & \multicolumn{2}{|c|}{$\%$ ID/g } & \multirow[b]{2}{*}{ SD } & \multirow[b]{2}{*}{$\begin{array}{c}t \\
(\min )\end{array}$} & \multirow[b]{2}{*}{ mean } & \multicolumn{2}{|c|}{$\%$ ID/g } & \multirow[b]{2}{*}{ SD } \\
\hline & & $\begin{array}{l}\text { upper } \\
\text { bound }\end{array}$ & $\begin{array}{l}\text { lower } \\
\text { bound }\end{array}$ & & & & $\begin{array}{l}\text { upper } \\
\text { bound }\end{array}$ & $\begin{array}{l}\text { lower } \\
\text { bound }\end{array}$ & \\
\hline 0.08 & 2.82 & 6.63 & 0.59 & 1.15 & 0.08 & 0.34 & 0.62 & 0.11 & 0.17 \\
\hline 0.25 & 2.73 & 5.84 & 1.01 & 1.00 & 0.25 & 1.17 & 1.80 & 0.53 & 0.38 \\
\hline 0.42 & 2.60 & 4.77 & 1.07 & 0.77 & 0.42 & 0.39 & 0.62 & 0.20 & 0.14 \\
\hline 0.58 & 2.47 & 4.17 & 1.03 & 0.70 & 0.58 & 0.94 & 1.56 & 0.34 & 0.39 \\
\hline 0.75 & 2.49 & 3.94 & 0.89 & 0.66 & 0.75 & 1.07 & 1.51 & 0.58 & 0.31 \\
\hline 0.92 & 2.33 & 3.84 & 0.69 & 0.64 & 0.92 & 1.08 & 1.48 & 0.51 & 0.33 \\
\hline 1.50 & 1.91 & 3.12 & 0.74 & 0.58 & 1.50 & 0.82 & 0.95 & 0.71 & 0.09 \\
\hline 2.50 & 1.94 & 3.02 & 0.94 & 0.55 & 2.50 & 0.73 & 0.80 & 0.60 & 0.06 \\
\hline 3.50 & 2.04 & 3.34 & 0.89 & 0.60 & 3.50 & 0.75 & 0.89 & 0.63 & 0.08 \\
\hline 4.50 & 2.07 & 3.30 & 0.80 & 0.58 & 4.50 & 0.95 & 1.11 & 0.79 & 0.09 \\
\hline 7.50 & 2.19 & 3.84 & 0.85 & 0.67 & 7.50 & 0.88 & 1.04 & 0.74 & 0.10 \\
\hline 12.50 & 2.45 & 4.30 & 0.77 & 0.77 & 12.50 & 1.02 & 1.15 & 0.83 & 0.10 \\
\hline 17.50 & 2.64 & 4.89 & 1.08 & 0.87 & 17.50 & 1.08 & 1.26 & 0.85 & 0.13 \\
\hline 22.50 & 2.81 & 5.53 & 1.17 & 0.96 & 22.50 & 1.18 & 1.31 & 0.98 & 0.11 \\
\hline 27.50 & 2.92 & 6.01 & 1.20 & 1.09 & 27.50 & 1.04 & 1.26 & 0.88 & 0.10 \\
\hline 35.00 & 3.03 & 6.85 & 1.27 & 1.27 & 35.00 & 1.11 & 1.24 & 0.90 & 0.12 \\
\hline 45.00 & 3.17 & 7.66 & 1.24 & 1.42 & 45.00 & 1.03 & 1.15 & 0.85 & 0.11 \\
\hline 55.00 & 3.22 & 8.15 & 1.14 & 1.54 & 55.00 & 1.01 & 1.16 & 0.87 & 0.08 \\
\hline
\end{tabular}


Table S15 | Uptake values versus time in Mouse 2 (data shown in two decimals).

\begin{tabular}{|c|c|c|c|c|c|c|c|c|c|}
\hline \multicolumn{5}{|c|}{ Tumor } & \multicolumn{5}{|c|}{ Muscle } \\
\hline \multirow[b]{2}{*}{$\begin{array}{c}t \\
(\min )\end{array}$} & \multirow[b]{2}{*}{ mean } & \multicolumn{2}{|c|}{$\%$ ID/g } & \multirow[b]{2}{*}{ SD } & \multirow[b]{2}{*}{$\begin{array}{c}t \\
(\min )\end{array}$} & \multicolumn{4}{|c|}{$\%$ ID/g } \\
\hline & & $\begin{array}{l}\text { upper } \\
\text { bound }\end{array}$ & $\begin{array}{l}\text { lower } \\
\text { bound }\end{array}$ & & & mean & $\begin{array}{l}\text { upper } \\
\text { bound }\end{array}$ & $\begin{array}{l}\text { lower } \\
\text { bound }\end{array}$ & SD \\
\hline 0.08 & 1.18 & 2.64 & 0.45 & 0.41 & 0.08 & 0.05 & 0.32 & 0.00 & 0.08 \\
\hline 0.25 & 1.58 & 3.86 & 0.70 & 0.57 & 0.25 & 0.78 & 1.33 & 0.26 & 0.33 \\
\hline 0.42 & 1.75 & 3.92 & 0.67 & 0.57 & 0.42 & 0.78 & 1.40 & 0.22 & 0.37 \\
\hline 0.58 & 1.62 & 4.29 & 0.70 & 0.55 & 0.58 & 1.15 & 2.30 & 0.40 & 0.48 \\
\hline 0.75 & 1.70 & 3.82 & 0.82 & 0.49 & 0.75 & 1.10 & 1.77 & 0.50 & 0.38 \\
\hline 0.92 & 1.59 & 2.95 & 0.89 & 0.40 & 0.92 & 1.57 & 2.34 & 0.86 & 0.50 \\
\hline 1.50 & 1.35 & 2.66 & 0.76 & 0.35 & 1.50 & 1.15 & 1.35 & 0.92 & 0.12 \\
\hline 2.50 & 1.39 & 2.85 & 0.59 & 0.38 & 2.50 & 1.05 & 1.32 & 0.79 & 0.16 \\
\hline 3.50 & 1.48 & 3.11 & 0.77 & 0.40 & 3.50 & 1.17 & 1.45 & 0.91 & 0.17 \\
\hline 4.50 & 1.53 & 2.81 & 0.87 & 0.31 & 4.50 & 1.20 & 1.38 & 0.99 & 0.13 \\
\hline 7.50 & 1.60 & 2.82 & 0.89 & 0.35 & 7.50 & 1.18 & 1.26 & 1.05 & 0.06 \\
\hline 12.50 & 1.80 & 2.97 & 1.01 & 0.36 & 12.50 & 1.25 & 1.41 & 1.06 & 0.08 \\
\hline 17.50 & 1.88 & 3.20 & 0.97 & 0.36 & 17.50 & 1.18 & 1.40 & 0.97 & 0.13 \\
\hline 22.50 & 2.04 & 3.05 & 1.20 & 0.33 & 22.50 & 1.41 & 1.68 & 1.26 & 0.12 \\
\hline 27.50 & 2.01 & 2.92 & 1.01 & 0.31 & 27.50 & 1.21 & 1.45 & 1.06 & 0.11 \\
\hline 35.00 & 1.99 & 2.99 & 1.00 & 0.30 & 35.00 & 1.40 & 1.64 & 1.04 & 0.17 \\
\hline 45.00 & 1.94 & 2.88 & 1.09 & 0.25 & 45.00 & 1.30 & 1.52 & 1.00 & 0.16 \\
\hline 54.99 & 1.86 & 2.81 & 0.98 & 0.28 & 54.99 & 1.22 & 1.42 & 0.99 & 0.16 \\
\hline
\end{tabular}


Table S16 | Uptake values versus time in Mouse 3 (data shown in two decimals).

\begin{tabular}{|c|c|c|c|c|c|c|c|c|c|}
\hline \multicolumn{5}{|c|}{ Tumor } & \multicolumn{5}{|c|}{ Muscle } \\
\hline \multirow[b]{2}{*}{$t(\min )$} & \multicolumn{4}{|c|}{$\% \mathrm{ID} / \mathrm{g}$} & \multirow[b]{2}{*}{$t(\min )$} & \multicolumn{4}{|c|}{$\% \mathrm{ID} / \mathrm{g}$} \\
\hline & mean & $\begin{array}{l}\text { upper } \\
\text { bound }\end{array}$ & $\begin{array}{l}\text { lower } \\
\text { bound }\end{array}$ & SD & & mean & $\begin{array}{l}\text { upper } \\
\text { bound }\end{array}$ & $\begin{array}{l}\text { lower } \\
\text { bound }\end{array}$ & SD \\
\hline 0.08 & 1.70 & 3.35 & 0.25 & 0.83 & 0.08 & 0.30 & 0.91 & 0.02 & 0.31 \\
\hline 0.25 & 2.00 & 3.14 & 0.75 & 0.64 & 0.25 & 1.03 & 1.67 & 0.29 & 0.40 \\
\hline 0.42 & 2.22 & 3.05 & 1.43 & 0.37 & 0.42 & 2.07 & 2.70 & 1.40 & 0.43 \\
\hline 0.58 & 2.09 & 3.50 & 0.88 & 0.46 & 0.58 & 1.48 & 2.07 & 1.10 & 0.27 \\
\hline 0.75 & 2.25 & 2.93 & 1.17 & 0.36 & 0.75 & 1.40 & 1.76 & 0.77 & 0.29 \\
\hline 0.92 & 2.21 & 3.18 & 1.30 & 0.37 & 0.92 & 1.38 & 1.79 & 1.01 & 0.29 \\
\hline 1.50 & 1.89 & 2.44 & 1.00 & 0.35 & 1.50 & 1.45 & 1.64 & 1.25 & 0.12 \\
\hline 2.50 & 1.90 & 2.56 & 0.69 & 0.40 & 2.50 & 1.45 & 1.58 & 1.22 & 0.10 \\
\hline 3.50 & 1.89 & 2.58 & 0.93 & 0.35 & 3.50 & 1.52 & 1.71 & 1.22 & 0.17 \\
\hline 4.50 & 2.00 & 2.72 & 0.89 & 0.36 & 4.50 & 1.39 & 1.54 & 1.27 & 0.07 \\
\hline 7.50 & 1.97 & 2.67 & 1.18 & 0.31 & 7.50 & 1.46 & 1.56 & 1.33 & 0.08 \\
\hline 12.50 & 2.17 & 2.79 & 1.16 & 0.36 & 12.50 & 1.45 & 1.63 & 1.33 & 0.09 \\
\hline 17.50 & 2.34 & 3.06 & 1.25 & 0.35 & 17.50 & 1.37 & 1.50 & 1.29 & 0.06 \\
\hline 22.50 & 2.35 & 3.04 & 1.51 & 0.30 & 22.50 & 1.38 & 1.50 & 1.19 & 0.10 \\
\hline 27.50 & 2.43 & 2.94 & 1.55 & 0.26 & 27.50 & 1.54 & 1.67 & 1.40 & 0.10 \\
\hline 35.00 & 2.34 & 2.89 & 1.38 & 0.24 & 35.00 & 1.42 & 1.55 & 1.31 & 0.08 \\
\hline 45.00 & 2.26 & 2.72 & 1.33 & 0.24 & 45.00 & 1.26 & 1.32 & 1.15 & 0.05 \\
\hline 55.00 & 2.12 & 2.81 & 1.17 & 0.24 & 55.00 & 1.23 & 1.33 & 1.13 & 0.07 \\
\hline 65.00 & 2.05 & 2.59 & 1.20 & 0.23 & 65.00 & 1.19 & 1.40 & 1.01 & 0.11 \\
\hline 75.00 & 1.94 & 2.56 & 1.13 & 0.22 & 75.00 & 1.19 & 1.28 & 1.09 & 0.06 \\
\hline 85.00 & 1.78 & 2.39 & 1.03 & 0.21 & 85.00 & 1.07 & 1.15 & 0.87 & 0.09 \\
\hline 95.00 & 1.77 & 2.20 & 0.95 & 0.24 & 95.00 & 1.05 & 1.11 & 0.95 & 0.05 \\
\hline 105.00 & 1.73 & 2.44 & 0.95 & 0.23 & 105.00 & 1.13 & 1.20 & 1.01 & 0.07 \\
\hline 114.99 & 1.69 & 2.40 & 0.88 & 0.26 & 114.99 & 0.95 & 1.05 & 0.81 & 0.07 \\
\hline
\end{tabular}


a

Mouse 1

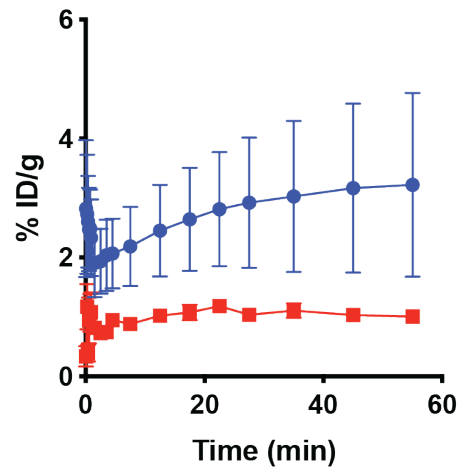

C

Mouse 3

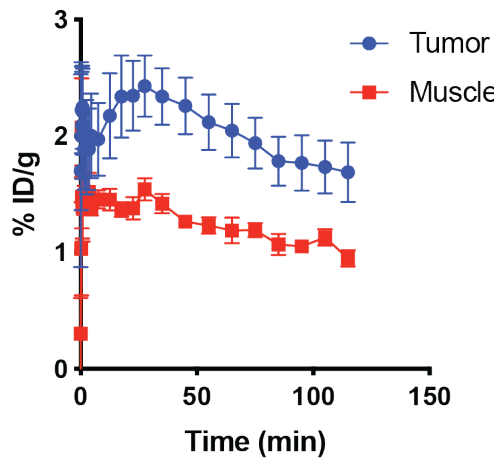

b

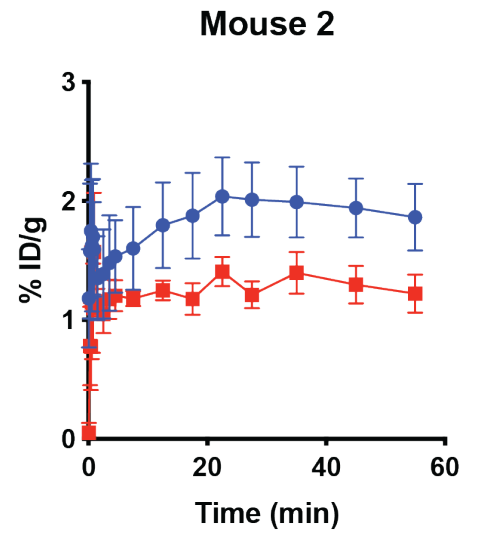

d

Mouse 1,2,3

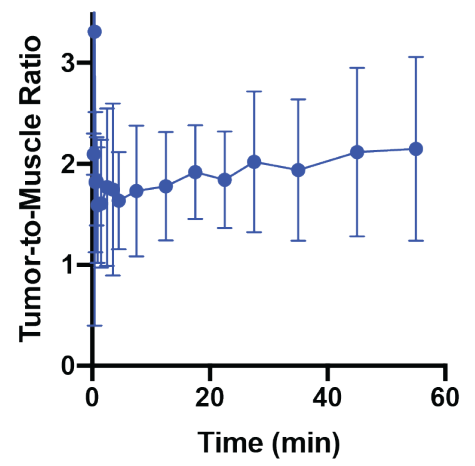

Fig. S62 | Uptake value versus time plots and tumor-to-muscle ratio versus time plot. a, Mouse 1, monitored for $60 \mathrm{~min}$. b, Mouse 2, monitored for $60 \mathrm{~min}$. c, Mouse 3, monitored for $120 \mathrm{~min}$. d, Tumor-to-muscle ratio versus time plot of Mouse 1,2,3. 


\subsection{Blocking Experiments by Pre-Treatment with Olaparib}

Female nude mice ( 8 weeks old) were supplemented with estradiol pellet each prior to inoculated with MCF-7 cancer cells (5 x $10^{6}$ in $200 \mu \mathrm{L}$ PBS) subcutaneously. Two weeks following tumor implantation, the mice were used for in vivo imaging.

Subcutaneous MCF-7 tumor bearing female nude mice $(n=3)$ were anesthetized using inhaled $2 \%$ isoflurane and placed on the PET/CT scanner bed. The mouse received a bolus tail-

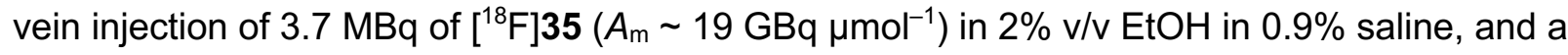
60 min dynamic PET scan (continuous list mode) was initiated immediately. The reconstructed PET data were automatically co-registered with the MRI data, and they were subsequently analyzed using the Inveon Research Workplace software.

The uptake value versus time plots in tumor and normal tissues in three mice were summarized in Table S17, Table S18, Table S19, respectively. The time plots were shown in Fig. 563. 
Table S17 | Uptake values versus time in mouse 1 pre-treated with olaparib (data shown in two decimals).

\begin{tabular}{|c|c|c|c|c|c|c|c|c|c|}
\hline \multicolumn{5}{|c|}{ Tumor } & \multicolumn{5}{|c|}{ Muscle } \\
\hline \multirow[b]{2}{*}{$\begin{array}{c}t \\
(\min )\end{array}$} & \multirow[b]{2}{*}{ mean } & \multicolumn{2}{|c|}{$\%$ ID/g } & \multirow[b]{2}{*}{ SD } & \multirow[b]{2}{*}{$\begin{array}{c}t \\
(\min )\end{array}$} & \multicolumn{4}{|c|}{$\% \mathrm{ID} / \mathrm{g}$} \\
\hline & & $\begin{array}{l}\text { upper } \\
\text { bound }\end{array}$ & $\begin{array}{l}\text { lower } \\
\text { bound }\end{array}$ & & & mean & $\begin{array}{l}\text { upper } \\
\text { bound }\end{array}$ & $\begin{array}{l}\text { lower } \\
\text { bound }\end{array}$ & SD \\
\hline 0.08 & 0.01 & 0.36 & 0.00 & 0.04 & 0.08 & 0.00 & 0.00 & 0.00 & 0.00 \\
\hline 0.25 & 0.23 & 2.03 & 0.00 & 0.38 & 0.25 & 0.42 & 0.87 & 0.02 & 0.27 \\
\hline 0.42 & 0.76 & 2.80 & 0.00 & 0.71 & 0.42 & 1.22 & 1.80 & 0.48 & 0.37 \\
\hline 0.58 & 0.99 & 2.90 & 0.00 & 0.85 & 0.58 & 1.84 & 2.37 & 1.10 & 0.40 \\
\hline 0.75 & 0.99 & 3.30 & 0.00 & 0.82 & 0.75 & 2.13 & 2.87 & 1.50 & 0.46 \\
\hline 0.92 & 1.14 & 3.38 & 0.00 & 0.81 & 0.92 & 2.57 & 3.18 & 1.68 & 0.45 \\
\hline 1.50 & 0.93 & 3.04 & 0.19 & 0.60 & 1.50 & 2.08 & 2.70 & 1.36 & 0.35 \\
\hline 2.50 & 1.05 & 2.84 & 0.17 & 0.58 & 2.50 & 2.19 & 2.59 & 1.76 & 0.25 \\
\hline 3.50 & 1.26 & 3.46 & 0.18 & 0.70 & 3.50 & 2.38 & 2.82 & 1.93 & 0.26 \\
\hline 4.50 & 1.33 & 3.33 & 0.34 & 0.66 & 4.50 & 2.24 & 2.73 & 1.62 & 0.31 \\
\hline 7.50 & 1.51 & 3.44 & 0.29 & 0.74 & 7.50 & 2.58 & 3.00 & 2.10 & 0.28 \\
\hline 12.50 & 1.86 & 3.85 & 0.40 & 0.86 & 12.50 & 3.13 & 3.67 & 2.53 & 0.38 \\
\hline 17.50 & 2.21 & 4.35 & 0.57 & 0.92 & 17.50 & 3.06 & 3.43 & 2.53 & 0.26 \\
\hline 22.50 & 2.50 & 4.95 & 0.76 & 1.08 & 22.50 & 3.23 & 3.80 & 2.91 & 0.30 \\
\hline 27.50 & 2.73 & 5.75 & 0.81 & 1.18 & 27.50 & 3.29 & 3.64 & 2.80 & 0.26 \\
\hline 35.00 & 2.99 & 6.69 & 1.26 & 1.29 & 35.00 & 2.99 & 3.28 & 2.68 & 0.17 \\
\hline 45.00 & 3.19 & 7.73 & 1.43 & 1.43 & 45.00 & 2.87 & 3.11 & 2.53 & 0.17 \\
\hline 54.99 & 3.26 & 8.67 & 1.53 & 1.61 & 54.99 & 2.60 & 2.86 & 2.33 & 0.14 \\
\hline
\end{tabular}


Table S18 | Uptake values versus time in mouse 2 pre-treated with olaparib (data shown in two decimals).

\begin{tabular}{|c|c|c|c|c|c|c|c|c|c|}
\hline \multicolumn{5}{|c|}{ Tumor } & \multicolumn{5}{|c|}{ Muscle } \\
\hline \multirow[b]{2}{*}{$\begin{array}{c}t \\
(\min )\end{array}$} & \multirow[b]{2}{*}{ mean } & \multicolumn{2}{|c|}{$\%$ ID/g } & \multirow[b]{2}{*}{ SD } & \multirow[b]{2}{*}{$\begin{array}{c}t \\
(\min )\end{array}$} & \multirow[b]{2}{*}{ mean } & \multicolumn{2}{|c|}{$\% \mathrm{ID} / \mathrm{g}$} & \multirow[b]{2}{*}{ SD } \\
\hline & & $\begin{array}{l}\text { upper } \\
\text { bound }\end{array}$ & $\begin{array}{l}\text { lower } \\
\text { bound }\end{array}$ & & & & $\begin{array}{l}\text { upper } \\
\text { bound }\end{array}$ & $\begin{array}{l}\text { lower } \\
\text { bound }\end{array}$ & \\
\hline 0.08 & 0.33 & 2.23 & 0.00 & 0.43 & 0.08 & 0.14 & 0.43 & 0.00 & 0.16 \\
\hline 0.25 & 0.45 & 2.00 & 0.00 & 0.49 & 0.25 & 0.76 & 1.35 & 0.37 & 0.36 \\
\hline 0.42 & 0.69 & 2.53 & 0.01 & 0.53 & 0.42 & 1.47 & 3.07 & 0.72 & 0.80 \\
\hline 0.58 & 0.69 & 3.35 & 0.05 & 0.53 & 0.58 & 1.18 & 1.41 & 0.78 & 0.20 \\
\hline 0.75 & 0.79 & 3.63 & 0.06 & 0.54 & 0.75 & 1.29 & 1.74 & 1.03 & 0.27 \\
\hline 0.92 & 0.86 & 3.08 & 0.16 & 0.49 & 0.92 & 1.58 & 1.97 & 1.00 & 0.32 \\
\hline 1.50 & 0.74 & 3.19 & 0.32 & 0.41 & 1.50 & 1.48 & 1.77 & 1.24 & 0.20 \\
\hline 2.50 & 0.72 & 3.44 & 0.16 & 0.46 & 2.50 & 1.51 & 1.66 & 1.39 & 0.09 \\
\hline 3.50 & 0.83 & 3.64 & 0.25 & 0.47 & 3.50 & 1.84 & 2.23 & 1.40 & 0.33 \\
\hline 4.50 & 0.89 & 2.96 & 0.30 & 0.44 & 4.50 & 1.98 & 2.43 & 1.56 & 0.35 \\
\hline 7.50 & 1.03 & 3.21 & 0.29 & 0.49 & 7.50 & 2.12 & 2.25 & 1.95 & 0.10 \\
\hline 12.50 & 1.31 & 3.59 & 0.48 & 0.54 & 12.50 & 2.44 & 2.68 & 2.25 & 0.13 \\
\hline 17.50 & 1.58 & 3.61 & 0.54 & 0.56 & 17.50 & 2.58 & 2.76 & 2.37 & 0.12 \\
\hline 22.50 & 1.79 & 3.74 & 0.86 & 0.52 & 22.50 & 2.75 & 2.93 & 2.60 & 0.11 \\
\hline 27.50 & 2.01 & 4.00 & 1.18 & 0.48 & 27.50 & 2.65 & 3.04 & 2.34 & 0.21 \\
\hline 35.00 & 2.13 & 4.33 & 1.26 & 0.45 & 35.00 & 2.63 & 2.71 & 2.49 & 0.07 \\
\hline 45.00 & 2.25 & 3.95 & 1.61 & 0.38 & 45.00 & 2.40 & 2.58 & 2.17 & 0.13 \\
\hline 55.00 & 2.24 & 4.17 & 1.66 & 0.34 & 55.00 & 2.21 & 2.31 & 2.03 & 0.11 \\
\hline
\end{tabular}


Table S19 | Uptake values versus time in mouse 3 pre-treated with olaparib (data shown in two decimals).

\begin{tabular}{|c|c|c|c|c|c|c|c|c|c|}
\hline \multicolumn{5}{|c|}{ Tumor } & \multicolumn{5}{|c|}{ Muscle } \\
\hline \multirow[b]{2}{*}{$\begin{array}{c}t \\
(\min )\end{array}$} & \multicolumn{4}{|c|}{$\% \mathrm{ID} / \mathrm{g}$} & \multirow[b]{2}{*}{$\begin{array}{c}t \\
(\min )\end{array}$} & \multicolumn{4}{|c|}{$\% \mathrm{ID} / \mathrm{g}$} \\
\hline & mean & $\begin{array}{l}\text { upper } \\
\text { bound }\end{array}$ & $\begin{array}{l}\text { lower } \\
\text { bound }\end{array}$ & SD & & mean & $\begin{array}{l}\text { upper } \\
\text { bound }\end{array}$ & $\begin{array}{l}\text { lower } \\
\text { bound }\end{array}$ & SD \\
\hline 0.08 & 0.22 & 1.40 & 0.00 & 0.32 & 0.08 & 0.20 & 0.85 & 0.00 & 0.27 \\
\hline 0.25 & 0.74 & 2.91 & 0.00 & 0.65 & 0.25 & 1.99 & 2.64 & 1.19 & 0.47 \\
\hline 0.42 & 1.00 & 3.15 & 0.01 & 0.75 & 0.42 & 2.09 & 2.65 & 1.37 & 0.32 \\
\hline 0.58 & 1.11 & 3.08 & 0.02 & 0.77 & 0.58 & 2.72 & 3.36 & 2.09 & 0.41 \\
\hline 0.75 & 1.16 & 3.50 & 0.07 & 0.73 & 0.75 & 2.88 & 3.56 & 2.09 & 0.48 \\
\hline 0.92 & 1.25 & 4.03 & 0.10 & 0.78 & 0.92 & 2.88 & 3.69 & 1.76 & 0.56 \\
\hline 1.50 & 1.13 & 3.82 & 0.27 & 0.74 & 1.50 & 3.09 & 4.13 & 1.88 & 0.66 \\
\hline 2.50 & 1.36 & 3.99 & 0.39 & 0.76 & 2.50 & 3.41 & 4.15 & 2.65 & 0.48 \\
\hline 3.50 & 1.39 & 3.98 & 0.40 & 0.79 & 3.50 & 3.52 & 4.13 & 2.71 & 0.43 \\
\hline 4.50 & 1.41 & 3.79 & 0.54 & 0.70 & 4.50 & 3.50 & 4.71 & 2.29 & 0.80 \\
\hline 7.50 & 1.80 & 4.19 & 0.79 & 0.77 & 7.50 & 3.78 & 4.64 & 2.69 & 0.59 \\
\hline 12.50 & 2.23 & 4.48 & 1.11 & 0.77 & 12.50 & 3.90 & 4.55 & 3.09 & 0.47 \\
\hline 17.50 & 2.54 & 4.45 & 1.31 & 0.74 & 17.50 & 4.08 & 4.58 & 3.33 & 0.40 \\
\hline 22.50 & 2.78 & 4.85 & 1.53 & 0.72 & 22.50 & 3.82 & 4.25 & 3.24 & 0.30 \\
\hline 27.50 & 2.99 & 4.41 & 1.90 & 0.62 & 27.50 & 3.84 & 4.32 & 2.92 & 0.41 \\
\hline 35.00 & 3.13 & 4.25 & 2.17 & 0.50 & 35.00 & 3.73 & 4.13 & 3.08 & 0.31 \\
\hline 45.00 & 3.14 & 4.10 & 2.33 & 0.43 & 45.00 & 3.38 & 3.64 & 2.93 & 0.19 \\
\hline 55.00 & 3.13 & 4.15 & 2.39 & 0.39 & 55.00 & 3.33 & 3.91 & 2.81 & 0.34 \\
\hline
\end{tabular}


a

Mouse 1 blocked

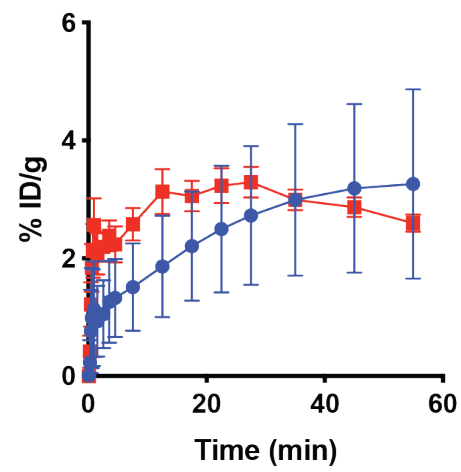

C

Mouse 3 blocked

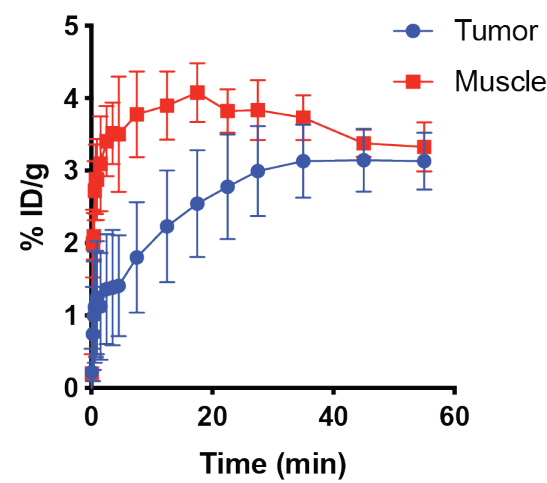

b

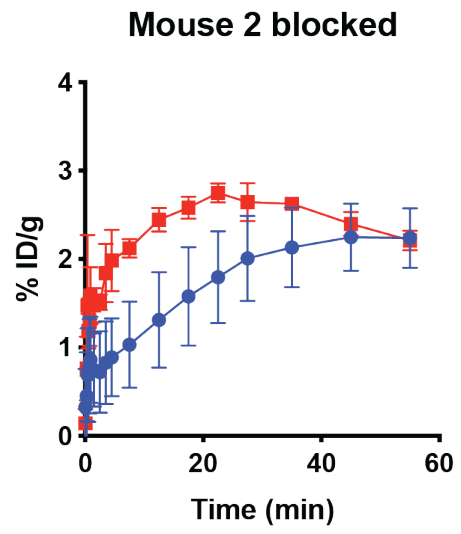

d

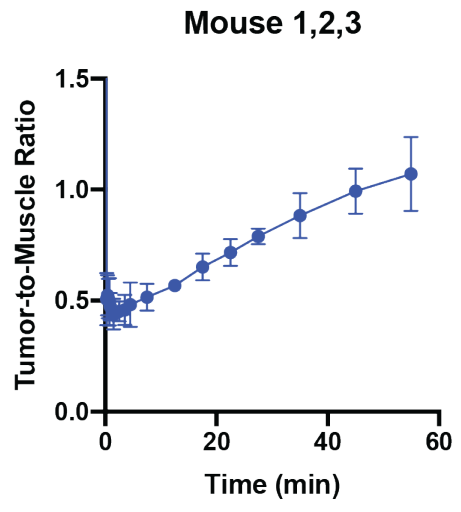

Fig. S63 | Uptake value versus time plots and tumor-to-muscle versus time plot of mice pre-treated with olaparib. a, Mouse 1 pre-treated with olaparib, monitored for $60 \mathrm{~min}$. b, Mouse 2 pre-treated with olaparib, monitored for $60 \mathrm{~min}$. c, Mouse 3 pre-treated with olaparib, monitored for 120 min. d, Tumor-to-muscle versus time plot of Mouse 1,2,3 pre-treated with olaparib. 


\subsection{Immunohistochemistry}

Tissue samples of tumor and muscle preserved in $4 \%$ formaldehyde were dehydrated and embedded in paraffin following routine methods, and $4 \mu \mathrm{m}$ sections were cut. Paraffin was removed by incubating sections in xylene $(2 \times 10 \mathrm{~min}$ ) followed by anhydrous $\mathrm{EtOH}(5 \mathrm{~min})$, $95 \% \mathrm{EtOH}$ (5 min), 70\% EtOH (2 $\times 5 \mathrm{~min}$ ), and $\mathrm{H}_{2} \mathrm{O}$ (5 min). Immunohistochemistry was performed using a Dako EnVision kits. Briefly, after antigen retrieval and blocking, sections were incubated at $4{ }^{\circ} \mathrm{C}$ in 1:100 anti-PARP-1 antibody (rabbit anti-human and rabbit antibody; ab227244; abcam) overnight. Afterwards, sections were washed with $0.1 \%$ Tween 20 in TBS (3 $\times 5 \mathrm{~min}$ ), and a secondary $1 \mathrm{~h}$ incubation at room temperature was performed using Dako horseradish-peroxidase labeled anti-rabbit polymer. The sections were once again washed using $0.1 \%$ Tween 20 TBS $(3 \times 5 \mathrm{~min})$, and the presence of antibody was colored with a 3,3'diaminobenzidine (DAB) solution (10 min). Afterwards, the sections were hematoxylin stained, dehydrated, cleared and mounted with neutral gum. The representative immunohistochemistry images were shown in Fig. S64. 
a

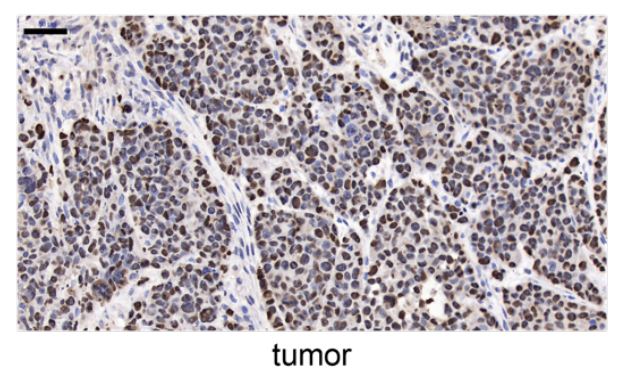

b

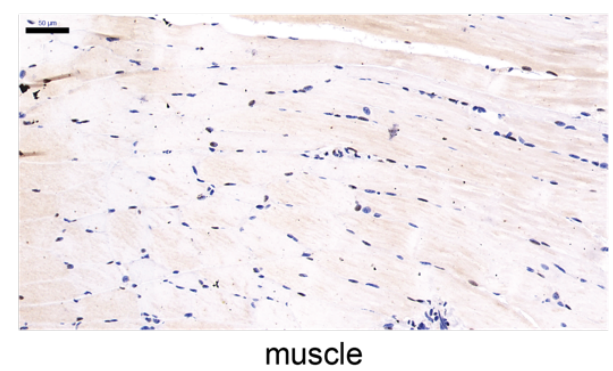

Fig. S64 | Representative immunohistochemistry images. a, Human MCF-7 subcutaneous tumor. b, muscle tissue. Both tissues were isolated from nude mice stained for PARP1 and counter-stained with hematoxylin (brown staining signifies the presence of PARP1, dark blue staining indicates cellular nuclei). Scale bar shown is $50 \mu \mathrm{m}$. 


\section{Inherited Stability of Aryl Fluorosulfate in vivo}

\subsection{General Considerations}

The main concern of using a heteroatom-based $\left[{ }^{18} \mathrm{~F}\right]$ fluoride labeling protocol is the often lower stability compared with a carbon-fluoride linker. Even though we have shown the in vitro stability of the aryl fluorosulfate functional group, it is more convincing to demonstrate its inherited in vivo stability.

If the fluorosulfate group was hydrolyzed in the aqueous solution and, likewise, in a biological fluid, free $\left[{ }^{18} \mathrm{~F}\right] \mathrm{F}^{-}$anion was generated. The free $\left[{ }^{18} \mathrm{~F}\right] \mathrm{F}^{-}$anion was known to enrich in the spine and bones of the animal ${ }^{43}$. Thus the "lightening-up" of the spine/bones in a PET scan is considered the consequence of the instability of the $S^{V I}-F$ link.

We have showcased the PET imaging of subcutaneous tumor with an aryl fluorosulfate derivative of PARP1 inhibitor olaparib. In this case, we observed the high uptake of fluorine-18 signal in the spine marrow. However, we cannot simply attribute the reason of the enrichment of fluorine-18 in the spine/bone tissues to the result of deposit of free $\left[{ }^{18} \mathrm{~F}\right]$ fluoride. In fact, PARP1 expression level in bone marrow is very high even in healthy human/mouse (see, The Human Protein Atlas, www.proteinatlas.org).

To clearly demonstrate the in vivo stability regarding the $S^{\mathrm{VI}-F}$ link of aryl fluorosulfate, we performed the following two experiments using two known biologically active compounds.

\subsection{Human Soluble Epoxide Hydrolase (hsEH) Inhibitor 24}

Aryl fluorosulfate 24 was radiolabeled using $\left[{ }^{18} \mathrm{~F}\right]$ SuFEx and injected via tail vein to healthy mouse. PET scans were performed in the following $60 \mathrm{~min}$. No apparent deposit of fluorine-18 signal on bones was observed. (Fig. S65)

\subsection{Selective Estrogen Receptor Degrader (SERD) 28}

Aryl fluorosulfate 28 was radiolabeled using $\left[{ }^{18} \mathrm{~F}\right]$ SuFEx and injected via tail vein to subcutaneous tumor bearing mice. PET scans were performed in the following $60 \mathrm{~min}$. No apparent deposit of fluorine-18 signal on bones was observed. (Fig. S66) 


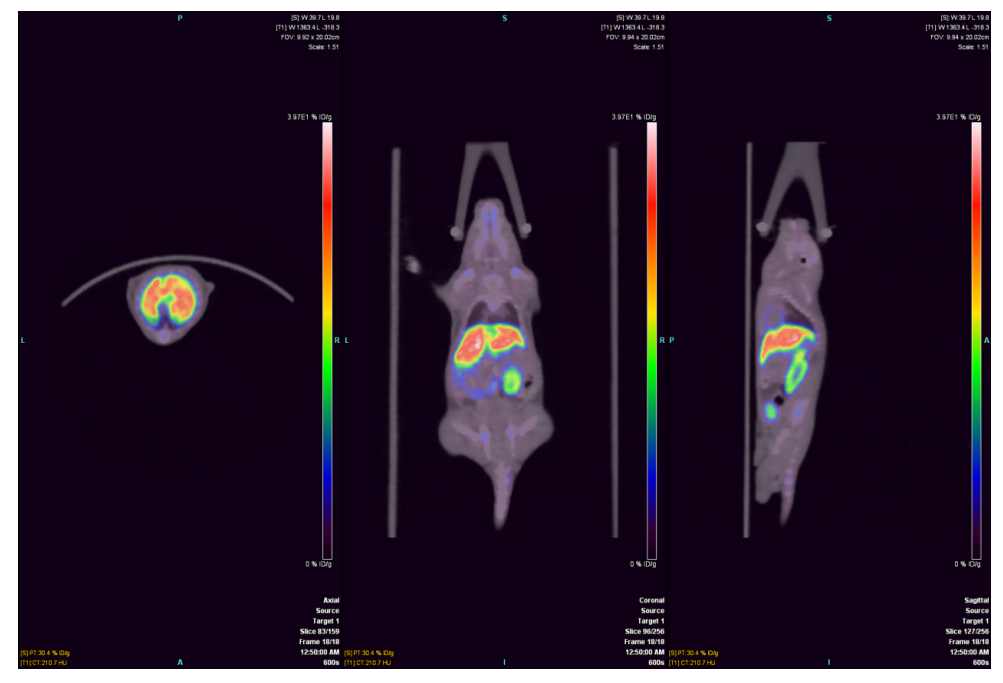

Fig. S65 | Representative PET Image of Mouse Administrated with $\left[{ }^{18} \mathrm{~F}\right] 24$. Scan was performed 60 min after administration of the ${ }^{18} \mathrm{~F}$-tracer. 


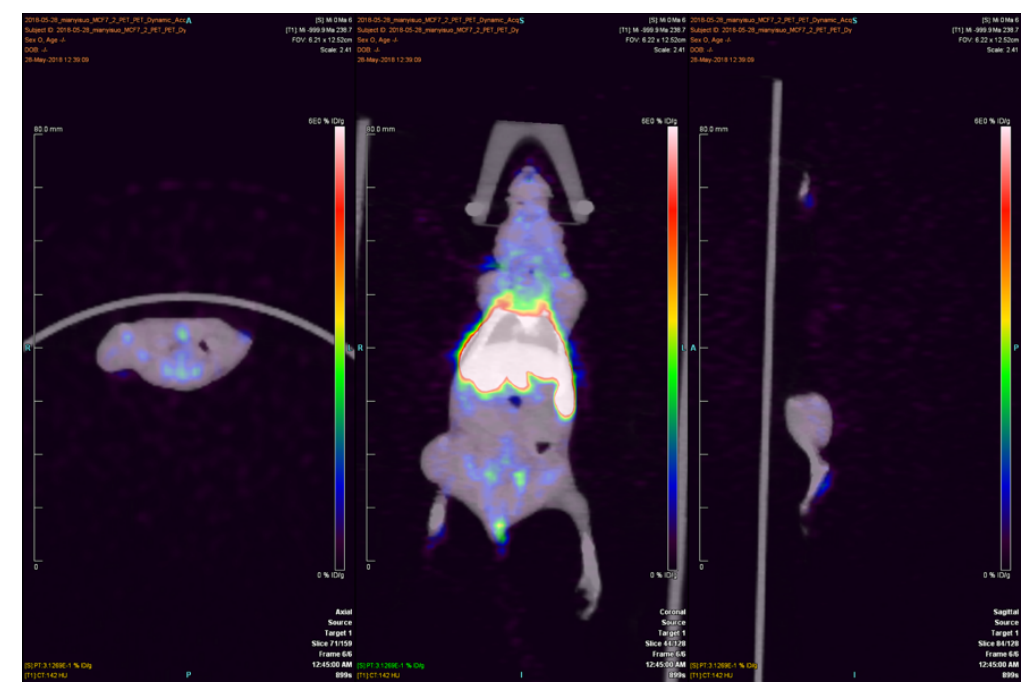

Fig. S66 | Representative PET Image of Mouse Administrated with $\left[{ }^{18} \mathrm{~F}\right] 28$. Scan was performed 60 min after administration of ${ }^{18} \mathrm{~F}$-tracer. 


\section{Computational Chemistry}

\subsection{Methods}

All calculations are performed using Amsterdam Density Functional Package (ADF2017) ${ }^{44-}$ 46. The B3LYP functional plus Grimme's latest dispersion corrections (D3-BJ) ${ }^{47}$ are used within the conductor like screening (COSMO) solvation model with the dielectric constant of acetonitrile $(\varepsilon=18.5)^{48-51}$. The triple- $\zeta$ plus double polarization (TZ2P) Slater-type basis set is applied to all the atoms.

\subsection{Results}

\subsubsection{Substitution of Phenyl fluorosulfate by anionic fluoride.}

Starting from the fully optimized structure $\mathbf{A}$ (starting material), the $\mathrm{F}^{\mathrm{Nu}}$ - was gradually brought toward the $\mathrm{S}$ center. With fixed $\mathrm{F}^{\mathrm{Nu}}$-S distance at each point, the geometry was optimized to get the energy at respective point. The system goes over the barrier at Transition State B (TS1) to afford an Intermediate State C.

Starting from State $\mathbf{C}$, the $\mathrm{F}^{\mathrm{Lg}}$ was gradually moved away from the $\mathbf{S}$ center. Again, at each point, the geometry was optimized with fixed $\mathrm{F}^{\mathrm{Lg}}$-S distance. The system then goes over the second barrier at Transition State $\mathbf{D}$ (TS2) to Point $\mathbf{E}$ where the final structure set with $\mathrm{F}^{\mathrm{Lg}}$ dissociated.

Point $\mathbf{A}$ is the fully geometry optimized structure with $\mathrm{F}^{\mathrm{Nu}-}$ far away from the sulfur atom $\left(R_{\mathrm{FNu}-\mathrm{S}}=4.228 \AA, \mathrm{R}_{\mathrm{FLg}-\mathrm{S}}=1.579 \AA\right)$. As $\mathrm{F}^{\mathrm{Nu}-}$ is getting closer to the $\mathrm{S}$ atom, Point $\mathrm{B}$ was found to be the $1^{\text {st }}$ transition state (confirmed by vibrational frequency calculations). In the structure of $\mathbf{B}$, $\mathrm{R}_{\mathrm{FNu}-\mathrm{S}}=2.100 \AA$ and $\mathrm{R}_{\mathrm{FLg}-\mathrm{S}}=1.684 \AA$ ). After going over the barrier of the transition state $\mathrm{B}$, as $\mathrm{F}^{\mathrm{Nu}-}$ is further approaching the $\mathrm{S}$ center and $\mathrm{F}^{\mathrm{Lg}}-\mathrm{S}$ distance is getting longer, an intermediate state $\mathbf{C}$ formed, where $R_{\mathrm{FNu}-\mathrm{S}}=1.790 \AA$ and $\mathrm{R}_{\mathrm{FLg}-\mathrm{S}}=1.787 \AA$. From the Intermediate, the $\mathrm{F}^{\mathrm{Lg}}$ atom departs from the $S$ with the energy of the system going up, and after reaching the highest point $D$, where $R_{\mathrm{FNu}-\mathrm{S}}=1.585 \AA$ and $R_{\mathrm{FLg}-\mathrm{S}}=1.915 \AA, \mathrm{F}^{\mathrm{Lg}}$ dissociates from the $S$ center and the system essentially proceeds to a new ground state $\mathbf{E}$ with the bonded atom switched from $\mathrm{F}^{\mathrm{Lg}}$ to

$\mathrm{F}^{\mathrm{Nu}}$. The calculated relative energies for the states $A$ to $\mathbf{D}$ are: $\Delta E_{\mathrm{BA}}=E_{\mathrm{B}}-E_{\mathrm{A}}=8.43 \mathrm{kcal} \mathrm{mol}^{-1}$, $\Delta E_{\mathrm{CB}}=-1.22 \mathrm{kcal} \mathrm{mol}^{-1}$, and $\Delta E_{\mathrm{DC}}=1.63 \mathrm{kcal} \mathrm{mol}^{-1}$. Vibrational entropy and vibrational internal energy (mainly zero-point energy) corrections gave the relative free energies (the green triangles in the figure above) of the four structures are given below: $\Delta G_{\mathrm{BA}}=9.10 \mathrm{kcal} \mathrm{mol}^{-1}$, $\Delta G_{\mathrm{CB}}=-0.11 \mathrm{kcal} \mathrm{mol}^{-1}$, and $\Delta G_{\mathrm{DC}}=1.54 \mathrm{kcal} \mathrm{mol}^{-1}$.

\subsubsection{Substitution of phenyl fluorosulfate by anionic fluoride complexed by tetramethylammonium counter ion.}

The substitution process by tetramethylammonium fluoride was calculated using the same protocol, rendering a slightly higher activation barrier (Fig. S68). Starting from the fully optimized structure $\mathbf{A}^{\prime}$ (starting material), the $\mathrm{F}^{\mathrm{Nu}}{ }^{-}$was gradually brought toward the $\mathrm{S}$ center. With fixed $\mathrm{F}^{\mathrm{Nu}}$-S distance at each point, the geometry was optimized to get the energy at respective point. 
The system goes over the barrier at Transition State B' (TS1') to afford an Intermediate State C'.

Starting from State C', the $\mathrm{F}^{\mathrm{Lg}}$ was gradually moved away from the S center. Again, at each point, the geometry was optimized with fixed $\mathrm{F}^{\mathrm{Lg}}$-S distance. The system then goes over the second barrier at Transition State D' (TS2') to Point E' where the final structure set with F'. $^{\mathrm{Lg}}$ dissociated.

Point A' is the fully geometry optimized structure with $\mathrm{F}^{\mathrm{Nu}-}$ far away from the sulfur atom $\left(R_{\mathrm{FNu}-\mathrm{S}}=3.604 \AA, \mathrm{R}_{\mathrm{FLg}-\mathrm{S}}=1.582 \AA\right)$. As $\mathrm{F}^{\mathrm{Nu}-}$ is getting closer to the $\mathrm{S}$ atom, Point $\mathrm{B}^{\prime}$ ' was found to be the $1^{\text {st }}$ transition state. In the structure of $B^{\prime}, R_{F N u-S}=2.080 \AA$ and $R_{F L g-S}=1.690 \AA$ ). After going over the barrier of the transition state $\mathbf{B}^{\prime}$, as $\mathrm{F}^{\mathrm{Nu}-}$ is further approaching the $\mathrm{S}$ center and $\mathrm{F}^{\mathrm{Lg}}$-S distance is getting longer, an intermediate state $\mathbf{C}^{\prime}$ formed, where $\mathrm{R}_{\mathrm{FNu}-\mathrm{S}}=1.830 \AA$ and $R_{\mathrm{FLg}-\mathrm{S}}=1.768 \AA$. From the Intermediate, the $\mathrm{F}^{\mathrm{Lg}}$ atom departs from the $\mathrm{S}$ with the energy of the system going up, and after reaching the second-high point $D^{\prime}$, where $R_{F N u-S}=1.688 \AA$ and $R_{F L g-S}$ $=2.120 \AA, F^{L g}$ dissociates from the $S$ center and the system essentially proceeds to a new ground state $E^{\prime}$ with the bonded atom switched from $\mathrm{F}^{\mathrm{Lg}}$ to $\mathrm{F}^{\mathrm{Nu}}$. The calculated relative energies for the states $\mathbf{A}^{\prime}$ to $\mathbf{B}^{\prime}$ are: $\Delta E_{\mathbf{B}^{\prime} \mathrm{A}^{\prime}}=E_{\mathrm{B}^{\prime}}-E_{\mathrm{A}^{\prime}}=7.16 \mathrm{kcal} \mathrm{mol}^{-1}, \Delta E_{\mathrm{C}^{\prime} \mathrm{B}^{\prime}}=-0.68 \mathrm{kcal} \mathrm{mol}^{-1}$, and $\Delta E_{\mathrm{D}^{\prime} \mathrm{C}^{\prime}}=2.05 \mathrm{kcal} \mathrm{mol}^{-1}$. Vibrational entropy and vibrational internal energy (mainly zero-point energy) corrections gave the relative free energies (the green triangles in the figure above) of the four structures are given below: $\Delta G_{B^{\prime} A^{\prime}}=11.75 \mathrm{kcal} \mathrm{mol}^{-1}, \Delta G_{C^{\prime} B^{\prime}}=-2.33 \mathrm{kcal} \mathrm{mol}^{-1}$, and $\Delta G_{D^{\prime} \mathrm{C}^{\prime}}=1.63 \mathrm{kcal} \mathrm{mol}^{-1}$.

\subsubsection{Substitution of phenyl fluorosulfate by methyl amine or methanol.}

The counterpart substitution process by methyl amine or methanol was calculated using the same protocol, rendering a much higher activation barrier (Fig. S70). 


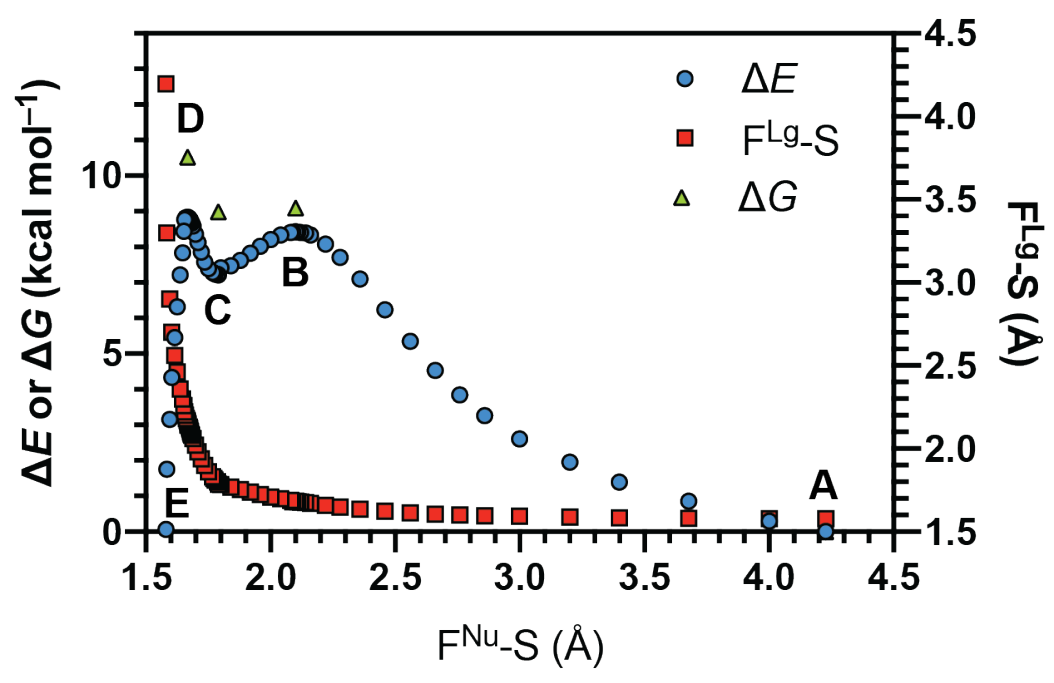

Fig. S67 | Interaction of $\mathrm{F}^{-}$with phenyl fluorosulfate (1). 
Table S20 I Cartesian coordinates of starting material (Point A).

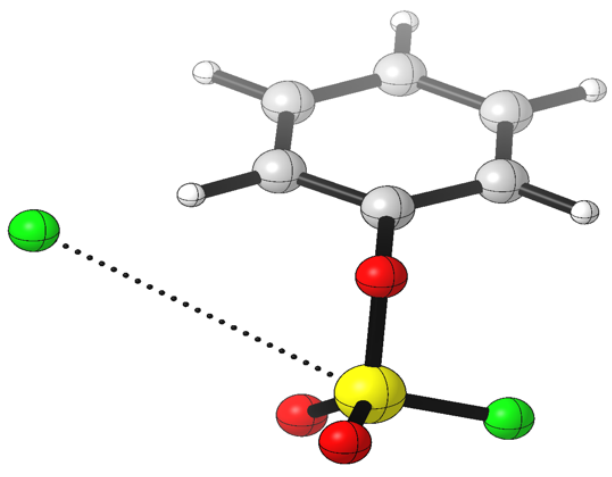

\begin{tabular}{ccccc}
\hline \multirow{2}{*}{ Center Number } & Atomic Number & \multicolumn{3}{c}{ Cartesian Coordinates $(\AA)$} \\
\hline 1 & 6 & 0.342285 & 0.397219 & -0.467436 \\
2 & 6 & 0.982913 & -0.825269 & -0.427994 \\
3 & 6 & 0.962484 & 1.607218 & -0.220853 \\
4 & 6 & 2.319982 & 1.587251 & 0.087750 \\
5 & 6 & 3.005841 & 0.376497 & 0.139586 \\
6 & 6 & 2.341039 & -0.819869 & -0.117114 \\
7 & 1 & 0.435934 & -1.744898 & -0.646788 \\
8 & 1 & 0.408010 & 2.533122 & -0.274809 \\
9 & 1 & 2.836370 & 2.517214 & 0.282577 \\
10 & 1 & 2.879272 & -1.757700 & -0.078685 \\
11 & 1 & 4.061290 & 0.366506 & 0.376763 \\
12 & 8 & -1.040789 & 0.413799 & -0.858391 \\
13 & 16 & -2.159752 & 0.270340 & 0.221338 \\
14 & 9 & -2.161470 & 1.740153 & 0.797788 \\
15 & 8 & -3.389780 & 0.104715 & -0.470051 \\
16 & 8 & -1.768694 & -0.567797 & 1.302109 \\
17 & 9 & -0.464193 & -3.369750 & -1.100879 \\
\hline
\end{tabular}


Table S21 | Cartesian coordinates of TS1 (Point B).

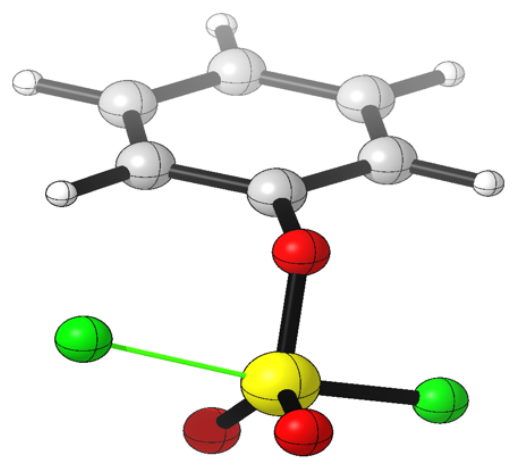

\begin{tabular}{ccccc}
\hline \multirow{2}{*}{ Center Number } & Atomic Number & \multicolumn{3}{c}{ Cartesian Coordinates $(\AA)$} \\
\hline 1 & 6 & 0.403149 & 0.419171 & -0.476892 \\
2 & 6 & 1.116829 & -0.762296 & -0.364198 \\
3 & 6 & 0.968466 & 1.660685 & -0.243338 \\
4 & 6 & 2.310875 & 1.719260 & 0.118181 \\
5 & 6 & 3.052764 & 0.548293 & 0.243625 \\
6 & 6 & 2.457135 & -0.687394 & 0.002056 \\
7 & 1 & 0.617320 & -1.701244 & -0.551520 \\
8 & 1 & 0.368514 & 2.553215 & -0.346071 \\
9 & 1 & 2.771440 & 2.680110 & 0.304044 \\
10 & 1 & 3.035139 & -1.596707 & 0.098715 \\
11 & 1 & 4.094833 & 0.598786 & 0.529778 \\
12 & 8 & -0.944801 & 0.381742 & -0.910823 \\
13 & 16 & -2.084010 & 0.020678 & 0.143500 \\
14 & 9 & -2.158132 & 1.626067 & 0.645568 \\
15 & 8 & -3.371621 & -0.032607 & -0.482259 \\
16 & 8 & -1.686674 & -0.527381 & 1.408161 \\
17 & 9 & -1.765097 & -1.904755 & -0.631744 \\
\hline
\end{tabular}


Table S22 | Cartesian coordinates of intermediate (Point C).

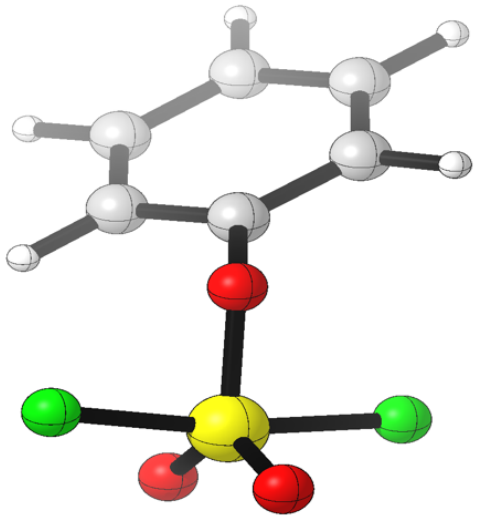

\begin{tabular}{ccccc}
\hline \multirow{2}{*}{ Center Number } & Atomic Number & \multicolumn{3}{c}{ Cartesian Coordinates $(\AA)$} \\
& & $X$ & $Y$ & $Z$ \\
\hline 1 & 6 & 0.407008 & 0.433939 & -0.450819 \\
2 & 6 & 1.135018 & -0.710793 & -0.163880 \\
3 & 6 & 0.967890 & 1.698888 & -0.379711 \\
4 & 6 & 2.304234 & 1.819097 & -0.012320 \\
5 & 6 & 3.053493 & 0.684565 & 0.288598 \\
6 & 6 & 2.467691 & -0.576175 & 0.213342 \\
7 & 1 & 0.667715 & -1.681829 & -0.237904 \\
8 & 1 & 0.364529 & 2.565035 & -0.610011 \\
9 & 1 & 2.755629 & 2.800544 & 0.043351 \\
10 & 1 & 3.048025 & -1.460161 & 0.441302 \\
11 & 1 & 4.091320 & 0.782429 & 0.578328 \\
12 & 8 & -0.915340 & 0.329627 & -0.917053 \\
13 & 16 & -2.089202 & -0.184893 & 0.075214 \\
14 & 9 & -1.816603 & 1.325026 & 0.992143 \\
15 & 8 & -3.398159 & 0.241832 & -0.356824 \\
16 & 8 & -1.744072 & -0.992122 & 1.222290 \\
17 & 9 & -2.138100 & -1.623670 & -0.989376 \\
\hline
\end{tabular}


Table S23 | Cartesian coordinates of TS2 (Point D).

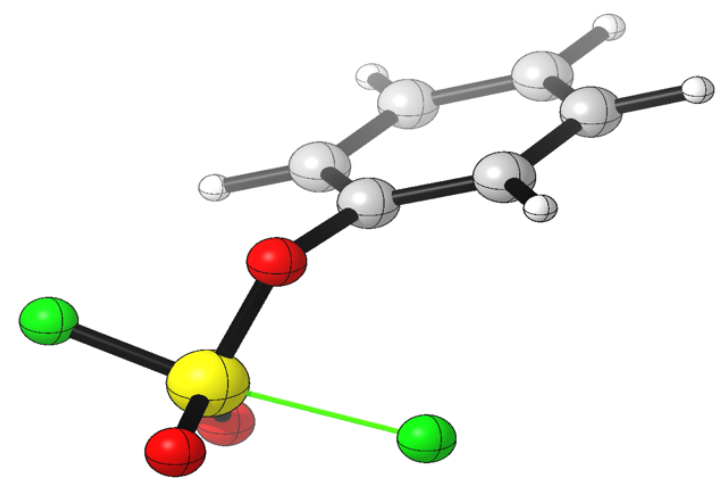

\begin{tabular}{ccccc}
\hline \multirow{2}{*}{ Center Number } & Atomic Number & \multicolumn{3}{c}{ Cartesian Coordinates $(\AA)$} \\
& & $X$ & $Y$ & $Z$ \\
\hline 1 & 6 & 0.400685 & 0.450079 & -0.417122 \\
2 & 6 & 1.121112 & -0.699268 & 0.138743 \\
3 & 6 & 0.967118 & 1.711655 & -0.360080 \\
4 & 6 & 2.310792 & 1.821994 & -0.017932 \\
5 & 6 & 3.057054 & 0.683129 & 0.275098 \\
6 & 6 & 2.460517 & -0.572754 & 0.218020 \\
7 & 1 & 0.650431 & -1.669294 & -0.201213 \\
8 & 1 & 0.363766 & 2.579830 & -0.578983 \\
9 & 1 & 2.771465 & 2.799830 & 0.023773 \\
10 & 1 & 3.036328 & -1.460640 & 0.441364 \\
11 & 1 & 4.101054 & 0.774136 & 0.543951 \\
12 & 8 & -0.930414 & 0.364376 & -0.879337 \\
13 & 16 & -2.089240 & -0.273700 & 0.004364 \\
14 & 9 & -1.778441 & 1.543133 & 1.130473 \\
15 & 8 & -3.369214 & 0.270503 & -0.332977 \\
16 & 8 & -1.718458 & -0.948451 & 1.212216 \\
17 & 9 & -2.136872 & -1.608510 & -0.995044 \\
\hline
\end{tabular}


Table S24 | Cartesian coordinates of product.

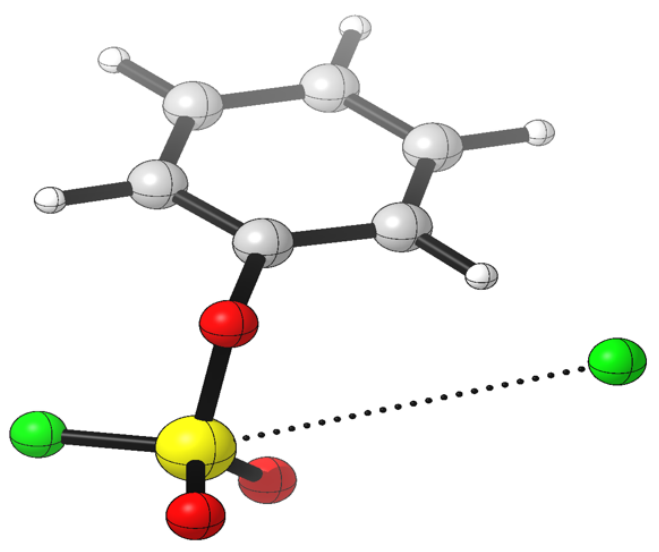

\begin{tabular}{|c|c|c|c|c|}
\hline \multirow{2}{*}{ Center Number } & \multirow{2}{*}{ Atomic Number } & \multicolumn{3}{|c|}{ Cartesian Coordinates (A) } \\
\hline & & $\mathrm{X}$ & $\mathrm{Y}$ & Z \\
\hline 1 & 6 & 0.361446 & 0.337234 & -0.471201 \\
\hline 2 & 6 & 1.238085 & -0.646991 & -0.886555 \\
\hline 3 & 6 & 0.720395 & 1.416923 & 0.310771 \\
\hline 4 & 6 & 2.054800 & 1.501724 & 0.701653 \\
\hline 5 & 6 & 2.970837 & 0.528086 & 0.312087 \\
\hline 6 & 6 & 2.565670 & -0.542625 & -0.480772 \\
\hline 7 & 1 & 0.896806 & -1.465593 & -1.504700 \\
\hline 8 & 1 & -0.025285 & 2.165274 & 0.589310 \\
\hline 9 & 1 & 2.376707 & 2.334018 & 1.314539 \\
\hline 10 & 1 & 3.277387 & -1.298537 & -0.783040 \\
\hline 11 & 1 & 4.003818 & 0.604730 & 0.624587 \\
\hline 12 & 8 & -1.000509 & 0.273737 & -0.922697 \\
\hline 13 & 16 & -2.057704 & -0.526514 & -0.096834 \\
\hline 14 & 9 & -1.367753 & 3.475463 & 0.960490 \\
\hline 15 & 8 & -3.337923 & -0.173078 & -0.601794 \\
\hline 16 & 8 & -1.758867 & -0.546918 & 1.293937 \\
\hline 17 & 9 & -1.756833 & -1.985592 & -0.623111 \\
\hline
\end{tabular}


Table S25 | Interaction of $\mathrm{F}^{-}$with phenyl fluorosulfate.

\begin{tabular}{|c|c|c|c|c|c|}
\hline $\begin{array}{c}\mathrm{F}^{\mathrm{Nu}}-\mathrm{S} \\
(\AA)\end{array}$ & $\begin{array}{c}E \\
\left(\mathrm{kcal} \mathrm{mol}^{-1}\right)\end{array}$ & $\begin{array}{c}\Delta E \\
\left(\mathrm{kcal} \mathrm{mol}^{-1}\right)\end{array}$ & $\begin{array}{c}\mathrm{F}^{\mathrm{Lg}}-\mathrm{S} \\
(\mathrm{A})\end{array}$ & $\begin{array}{c}G \\
\left(\mathrm{kcal} \mathrm{mol}^{-1}\right)\end{array}$ & $\begin{array}{c}\Delta G \\
\left.\left(k^{2}\right)^{-1} \mathrm{~mol}^{-1}\right)\end{array}$ \\
\hline 1.580 & -2929.59 & 0.06 & 4.196 & & \\
\hline 1.585 & -2927.90 & 1.75 & 3.300 & & \\
\hline 1.596 & -2926.50 & 3.15 & 2.900 & & \\
\hline 1.605 & -2925.31 & 4.34 & 2.700 & & \\
\hline 1.616 & -2924.20 & 5.45 & 2.560 & & \\
\hline 1.626 & -2923.33 & 6.32 & 2.460 & & \\
\hline 1.637 & -2922.43 & 7.22 & 2.360 & & \\
\hline 1.647 & -2921.82 & 7.83 & 2.300 & & \\
\hline 1.652 & -2921.21 & 8.44 & 2.260 & & \\
\hline 1.655 & -2920.88 & 8.77 & 2.220 & & \\
\hline 1.660 & -2920.84 & 8.81 & 2.200 & & \\
\hline 1.662 & -2920.82 & 8.83 & 2.180 & & \\
\hline 1.665 & -2920.82 & 8.83 & 2.168 & & \\
\hline $\begin{array}{l}1.668 \\
\text { (TS2) }\end{array}$ & -2920.81 & 8.84 & 2.160 & -2856.77 & 10.53 \\
\hline 1.669 & -2920.83 & 8.82 & 2.150 & & \\
\hline 1.670 & -2920.84 & 8.81 & 2.140 & & \\
\hline 1.674 & -2920.85 & 8.80 & 2.130 & & \\
\hline 1.675 & -2920.87 & 8.78 & 2.120 & & \\
\hline 1.677 & -2920.89 & 8.76 & 2.110 & & \\
\hline 1.679 & -2920.91 & 8.74 & 2.100 & & \\
\hline 1.681 & -2920.94 & 8.71 & 2.090 & & \\
\hline 1.684 & -2920.98 & 8.67 & 2.080 & & \\
\hline 1.689 & -2921.06 & 8.59 & 2.060 & & \\
\hline 1.700 & -2921.29 & 8.36 & 2.020 & & \\
\hline 1.710 & -2921.52 & 8.13 & 1.980 & & \\
\hline
\end{tabular}


(continued, Table S24)

\begin{tabular}{|c|c|c|c|c|c|}
\hline $\begin{array}{c}\mathrm{F}^{\mathrm{Nu}}-\mathrm{S} \\
(\mathrm{A})\end{array}$ & $\begin{array}{c}E \\
\left(\mathrm{kcal} \mathrm{mol}^{-1}\right)\end{array}$ & $\begin{array}{c}\Delta E \\
\left(\mathrm{kcal} \mathrm{mol}^{-1}\right)\end{array}$ & $\begin{array}{c}F^{\mathrm{Lg}}-\mathrm{S} \\
(\AA)\end{array}$ & $\begin{array}{c}\mathbf{G} \\
\left(\mathrm{kcal} \mathrm{mol}^{-1}\right)\end{array}$ & $\begin{array}{c}\Delta G \\
\left(\mathrm{kcal} \mathrm{mol}^{-1}\right)\end{array}$ \\
\hline 1.723 & -2921.79 & 7.86 & 1.940 & & \\
\hline 1.736 & -2922.07 & 7.58 & 1.900 & & \\
\hline 1.750 & -2922.26 & 7.39 & 1.860 & & \\
\hline 1.767 & -2922.36 & 7.29 & 1.830 & & \\
\hline 1.772 & -2922.39 & 7.26 & 1.820 & & \\
\hline 1.777 & -2922.41 & 7.24 & 1.810 & & \\
\hline 1.788 & -2922.42 & 7.23 & 1.800 & & \\
\hline $\begin{array}{c}1.790 \\
\text { (Intermediate) }\end{array}$ & -2922.44 & 7.21 & 1.787 & -2858.31 & 8.99 \\
\hline 1.800 & -2922.24 & 7.41 & 1.784 & & \\
\hline 1.840 & -2922.18 & 7.47 & 1.768 & & \\
\hline 1.880 & -2922.03 & 7.62 & 1.754 & & \\
\hline 1.920 & -2921.83 & 7.82 & 1.739 & & \\
\hline 1.960 & -2921.63 & 8.02 & 1.724 & & \\
\hline 2.000 & -2921.44 & 8.21 & 1.710 & & \\
\hline 2.040 & -2921.32 & 8.33 & 1.699 & & \\
\hline 2.080 & -2921.25 & 8.40 & 1.688 & & \\
\hline 2.090 & -2921.23 & 8.42 & 1.682 & & \\
\hline $\begin{array}{l}2.100 \\
\text { (TS1) }\end{array}$ & -2921.22 & 8.43 & 1.684 & -2858.20 & 9.10 \\
\hline 2.110 & -2921.23 & 8.42 & 1.681 & & \\
\hline 2.120 & -2921.24 & 8.41 & 1.678 & & \\
\hline 2.140 & -2921.26 & 8.39 & 1.675 & & \\
\hline 2.160 & -2921.26 & 8.33 & 1.671 & & \\
\hline 2.220 & -2921.57 & 8.08 & 1.659 & & \\
\hline 2.280 & -2921.94 & 7.71 & 1.648 & & \\
\hline 2.360 & -2922.55 & 7.10 & 1.636 & & \\
\hline
\end{tabular}


(continued, Table S24)

\begin{tabular}{|c|c|c|c|c|c|}
\hline $\begin{array}{c}\mathrm{F}^{\mathrm{Nu}}-\mathrm{S} \\
(\mathrm{A})\end{array}$ & $\begin{array}{c}E \\
\left(\text { kcal mol }^{-1}\right)\end{array}$ & $\begin{array}{c}\Delta E \\
\left(\mathrm{kcal} \mathrm{mol}^{-1}\right)\end{array}$ & $\begin{array}{c}\text { F }^{\mathrm{Lg}}-\mathrm{S} \\
(\AA)\end{array}$ & $\begin{array}{c}G \\
\left(\text { kcal mol }^{-1}\right)\end{array}$ & $\begin{array}{c}\Delta G \\
\left(\mathrm{kcal} \mathrm{mol}^{-1}\right)\end{array}$ \\
\hline 2.460 & -2923.41 & 6.24 & 1.624 & & \\
\hline 2.560 & -2924.30 & 5.35 & 1.614 & & \\
\hline 2.660 & -2925.12 & 4.53 & 1.607 & & \\
\hline 2.760 & -2925.81 & 3.84 & 1.601 & & \\
\hline 2.860 & -2926.39 & 3.26 & 1.597 & & \\
\hline 3.000 & -2927.04 & 2.61 & 1.593 & & \\
\hline 3.200 & -2927.70 & 1.95 & 1.588 & & \\
\hline 3.400 & -2928.26 & 1.39 & 1.584 & & \\
\hline 3.677 & -2928.79 & 0.86 & 1.580 & & \\
\hline 4.000 & -2929.35 & 0.30 & 1.579 & & \\
\hline $\begin{array}{c}4.228 \\
\text { (ground state) }\end{array}$ & -2929.65 & 0.00 & 1.579 & -2867.30 & 0.00 \\
\hline
\end{tabular}




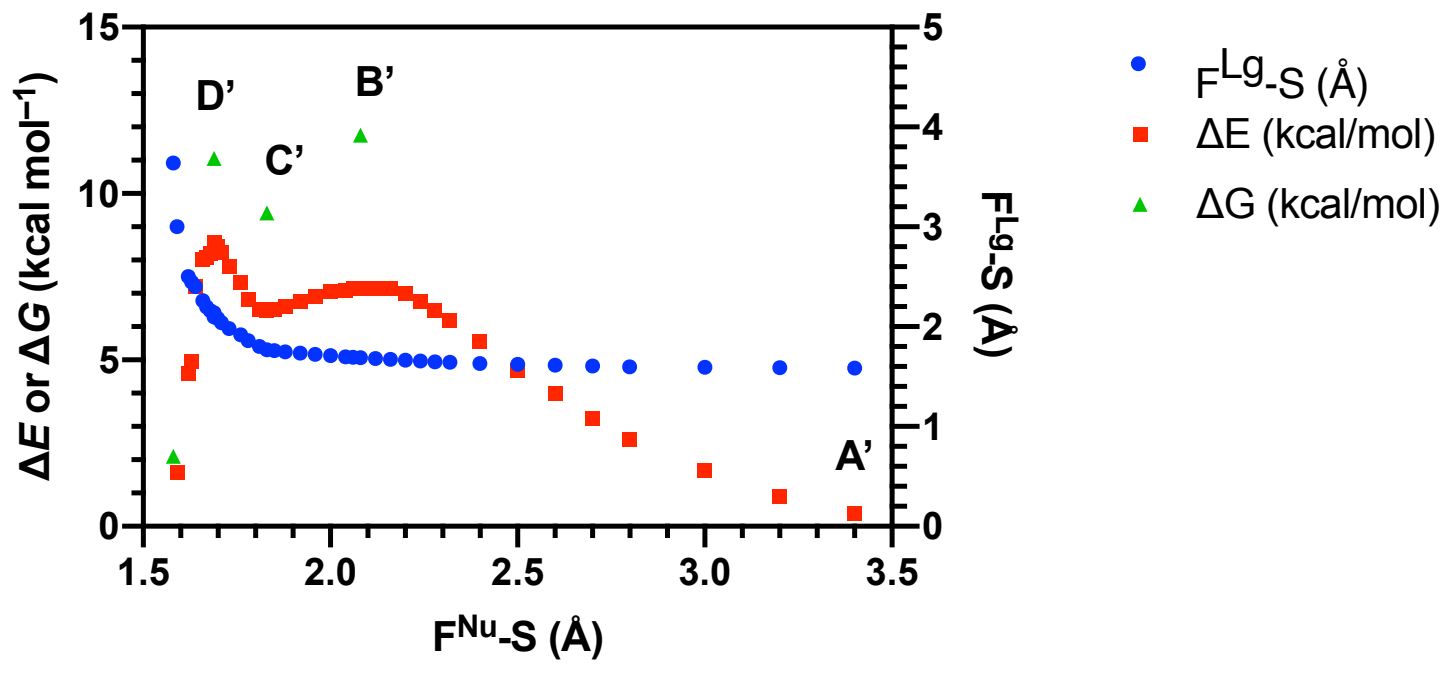

Fig. S68 | Interaction of $\mathrm{F}^{-}$complexed by TMA counter ion with phenyl fluorosulfate (1). 
Table S26 I Cartesian coordinates of starting material (Point A') with TMA counter ion.

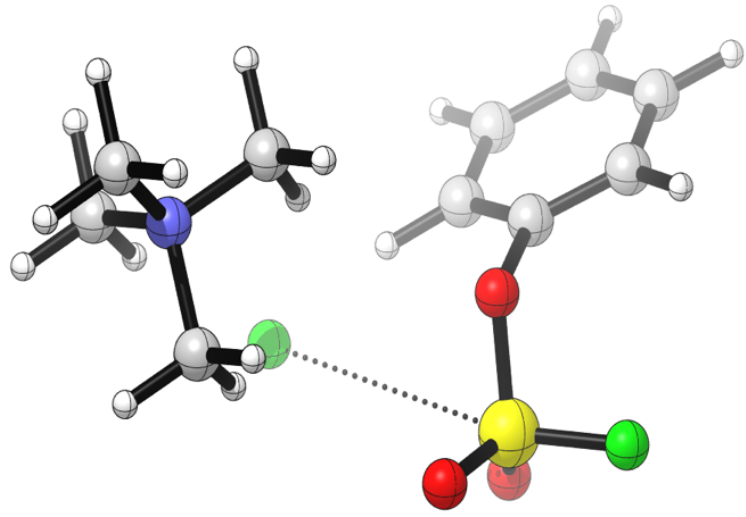

\begin{tabular}{|c|c|c|c|c|}
\hline \multirow{2}{*}{ Center Number } & \multirow{2}{*}{ Atomic Number } & \multicolumn{3}{|c|}{ Cartesian Coordinates $(\AA)$} \\
\hline & & $x$ & $Y$ & Z \\
\hline 1 & 6 & 0.124749 & -0.418527 & -0.512686 \\
\hline 2 & 6 & 0.788 & -1.500311 & 0.033071 \\
\hline 3 & 6 & 0.690858 & 0.82893 & -0.689793 \\
\hline 4 & 6 & 2.014161 & 0.999917 & -0.291684 \\
\hline 5 & 6 & 2.720536 & -0.064873 & 0.26124 \\
\hline 6 & 6 & 2.111105 & -1.307213 & 0.421728 \\
\hline 7 & 1 & 0.257603 & -2.44606 & 0.141679 \\
\hline 8 & 1 & 0.120474 & 1.635732 & -1.12745 \\
\hline 9 & 1 & 2.488322 & 1.963576 & -0.417471 \\
\hline 10 & 1 & 2.665595 & -2.131 & 0.851202 \\
\hline 11 & 1 & 3.749253 & 0.074149 & 0.566103 \\
\hline 12 & 8 & -1.211449 & -0.627745 & -0.989744 \\
\hline 13 & 16 & -2.42755 & -0.497742 & -0.020182 \\
\hline 14 & 9 & -2.649156 & 1.06678 & -0.101328 \\
\hline 15 & 8 & -3.545388 & -1.093428 & -0.662856 \\
\hline 16 & 8 & -2.08219 & -0.765828 & 1.332786 \\
\hline 17 & 9 & -1.10423 & -3.846764 & 0.134479 \\
\hline 18 & 7 & -1.69871 & -4.451144 & -3.050625 \\
\hline 19 & 6 & -1.112773 & -5.654055 & -2.366385 \\
\hline
\end{tabular}


(continued, Table S25)

\begin{tabular}{ccccc}
\hline Center Number & Atomic Number & \multicolumn{3}{c}{ Cartesian Coordinates $(\AA)$} \\
& & $X$ & $Y$ & $Z$ \\
\hline 20 & 6 & -1.992986 & -4.7653 & -4.483192 \\
21 & 6 & -2.959193 & -4.049577 & -2.336781 \\
23 & 6 & -0.715764 & -3.320743 & -2.958776 \\
24 & 1 & -3.371407 & -3.17794 & -2.8357 \\
25 & 1 & -3.659495 & -4.878306 & -2.38681 \\
26 & 1 & -2.679851 & -3.823113 & -1.310265 \\
27 & 1 & -1.150697 & -2.446301 & -3.433272 \\
28 & 1 & -0.538116 & -3.146998 & -1.901957 \\
29 & 1 & 0.195443 & -3.613295 & -3.47231 \\
30 & 1 & -1.830079 & -6.467193 & -2.428852 \\
31 & 1 & -0.193636 & -5.924793 & -2.878266 \\
32 & 1 & -0.92597 & -5.364283 & -1.333923 \\
33 & 1 & -2.414814 & -3.882606 & -4.954134 \\
34 & 1 & -1.066413 & -5.047158 & -4.974483 \\
\hline & 1 & -2.702455 & -5.586273 & -4.519946 \\
\hline & 1 & & &
\end{tabular}


Table S27 I Cartesian coordinates of transition state 1 (Point B') with TMA counter ion.

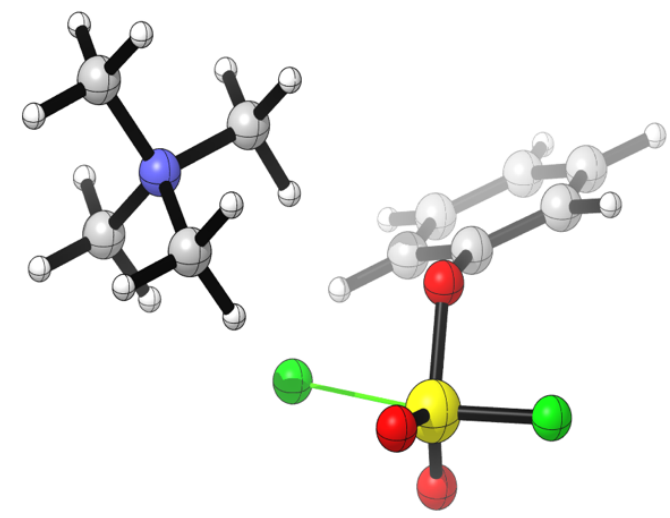

\begin{tabular}{ccccc}
\hline Center Number & Atomic Number & \multicolumn{3}{c}{ Cartesian Coordinates $(\AA)$} \\
& & $X$ & $Y$ & $Z$ \\
\hline 1 & 6 & 0.224013 & 0.037703 & -0.185049 \\
2 & 6 & 0.979119 & -1.077645 & 0.140302 \\
3 & 6 & 0.778136 & 1.299473 & -0.321172 \\
4 & 6 & 2.148565 & 1.446223 & -0.127426 \\
5 & 6 & 2.931714 & 0.343351 & 0.201352 \\
6 & 6 & 2.346668 & -0.913228 & 0.336131 \\
7 & 1 & 0.490527 & -2.03521 & 0.239252 \\
8 & 1 & 0.149831 & 2.140018 & -0.578459 \\
9 & 1 & 2.600627 & 2.423078 & -0.233747 \\
10 & 1 & 2.954927 & -1.771023 & 0.59005 \\
11 & 1 & 3.996526 & 0.462529 & 0.350761 \\
12 & 8 & -1.15204 & -0.105752 & -0.483719 \\
13 & 16 & -2.206187 & -0.352755 & 0.689115 \\
14 & 9 & -2.342993 & 1.315866 & 0.921794 \\
15 & 8 & -3.521863 & -0.564023 & 0.164189 \\
16 & 8 & -1.705262 & -0.650326 & 2.00004 \\
17 & 9 & -1.818206 & -2.34412 & 0.230488 \\
18 & 7 & -2.092648 & -3.496263 & -2.960831 \\
19 & 6 & -1.678129 & -4.603253 & -2.034091 \\
\hline
\end{tabular}


(continued, Table S26)

\begin{tabular}{ccccc}
\hline Center Number & Atomic Number & \multicolumn{3}{c}{ Cartesian Coordinates $(\AA)$} \\
& & $X$ & $Y$ & $Z$ \\
\hline 20 & 6 & -2.225771 & -4.022103 & -4.356524 \\
21 & 6 & -3.4076 & -2.934834 & -2.498483 \\
23 & 6 & -1.055389 & -2.412161 & -2.922102 \\
24 & 1 & -3.695229 & -2.137385 & -3.177014 \\
25 & 1 & -4.145615 & -3.73106 & -2.521374 \\
26 & 1 & -3.269148 & -2.556072 & -1.490121 \\
27 & 1 & -1.367116 & -1.612925 & -3.588006 \\
28 & 1 & -0.991837 & -2.058229 & -1.899378 \\
29 & 1 & -0.109492 & -2.829318 & -3.254326 \\
30 & 1 & -2.433881 & -5.382121 & -2.069613 \\
31 & 1 & -0.72198 & -4.992379 & -2.371317 \\
32 & 1 & -1.598248 & -4.18193 & -1.036445 \\
33 & 1 & -2.527856 & -3.206417 & -5.006002 \\
34 & 1 & -1.265184 & -4.417786 & -4.671621 \\
\hline & 1 & -2.976707 & -4.806012 & -4.362321 \\
\hline & 1 & & &
\end{tabular}


Table S28 I Cartesian coordinates of intermediate (Point C') with TMA counter ion.

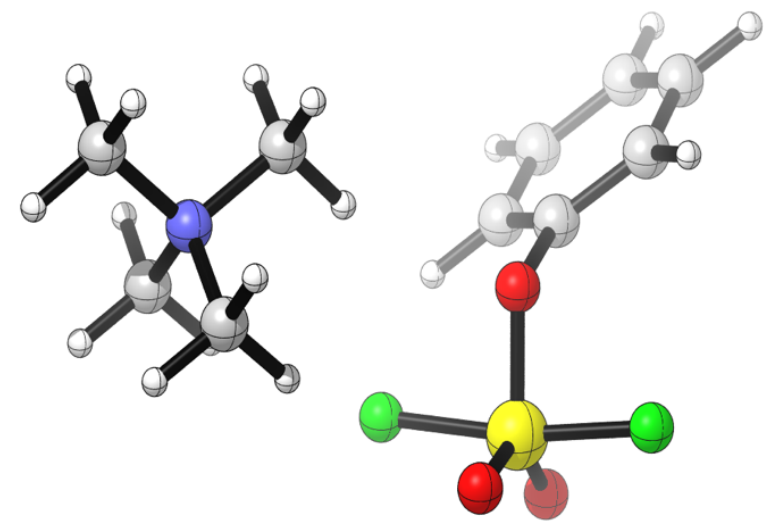

\begin{tabular}{|c|c|c|c|c|}
\hline \multirow{2}{*}{ Center Number } & \multirow{2}{*}{ Atomic Number } & \multicolumn{3}{|c|}{ Cartesian Coordinates (A) } \\
\hline & & $\mathrm{X}$ & $\mathrm{Y}$ & Z \\
\hline 1 & 6 & 0.186296 & 0.077321 & -0.09028 \\
\hline 2 & 6 & 0.963541 & -1.005009 & 0.295463 \\
\hline 3 & 6 & 0.725971 & 1.335247 & -0.304442 \\
\hline 4 & 6 & 2.095525 & 1.511633 & -0.133237 \\
\hline 5 & 6 & 2.896561 & 0.442088 & 0.257003 \\
\hline 6 & 6 & 2.329477 & -0.81106 & 0.472792 \\
\hline 7 & 1 & 0.503084 & -1.968699 & 0.453221 \\
\hline 8 & 1 & 0.082495 & 2.150137 & -0.603376 \\
\hline 9 & 1 & 2.53324 & 2.486238 & -0.30299 \\
\hline 10 & 1 & 2.950049 & -1.644359 & 0.774027 \\
\hline 11 & 1 & 3.96051 & 0.584119 & 0.390902 \\
\hline 12 & 8 & -1.182664 & -0.093879 & -0.37146 \\
\hline 13 & 16 & -2.215747 & -0.434408 & 0.823625 \\
\hline 14 & 9 & -2.282153 & 1.307892 & 1.116782 \\
\hline 15 & 8 & -3.574032 & -0.487358 & 0.345537 \\
\hline 16 & 8 & -1.706572 & -0.695421 & 2.148578 \\
\hline 17 & 9 & -1.939362 & -2.180918 & 0.351468 \\
\hline 18 & 7 & -2.097797 & -3.322496 & -2.985067 \\
\hline 19 & 6 & -1.723789 & -4.43151 & -2.044146 \\
\hline
\end{tabular}


(continued, Table S27)

\begin{tabular}{ccccc}
\hline \multirow{2}{*}{ Center Number } & Atomic Number & \multicolumn{3}{c}{ Cartesian Coordinates $(\AA)$} \\
& & $X$ & $Y$ & $Z$ \\
\hline 21 & 6 & -2.204197 & -3.858959 & -4.380862 \\
22 & 6 & -3.41731 & -2.738103 & -2.566961 \\
23 & 6 & -1.044323 & -2.255123 & -2.935296 \\
24 & 1 & -3.670943 & -1.940036 & -3.257594 \\
25 & 1 & -4.166584 & -3.522406 & -2.607151 \\
26 & 1 & -3.315761 & -2.3544 & -1.557071 \\
27 & 1 & -1.324752 & -1.461763 & -3.621071 \\
28 & 1 & -0.99481 & -1.877445 & -1.920968 \\
29 & 1 & -0.096605 & -2.691887 & -3.234302 \\
30 & 1 & -2.490922 & -5.197669 & -2.093808 \\
31 & 1 & -0.766093 & -4.837251 & -2.355272 \\
32 & 1 & -1.659825 & -4.0177 & -1.043364 \\
33 & 1 & -2.480091 & -3.044642 & -5.043216 \\
34 & 1 & -1.241221 & -4.269324 & -4.668211 \\
\hline 25 & -2.964778 & -4.632978 & -4.397052 \\
\hline & 1 & & &
\end{tabular}


Table S29 I Cartesian coordinates of transition state 2 (Point D') with TMA counter ion.

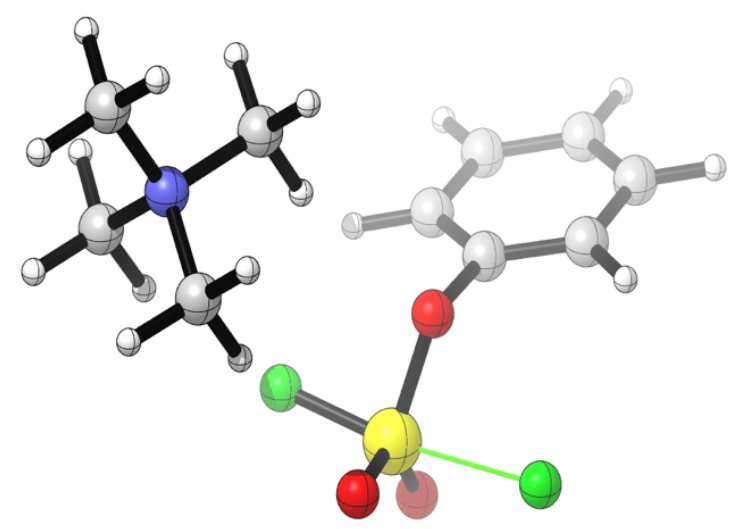

\begin{tabular}{|c|c|c|c|c|}
\hline \multirow{2}{*}{ Center Number } & \multirow{2}{*}{ Atomic Number } & \multicolumn{3}{|c|}{ Cartesian Coordinates (A) } \\
\hline & & $x$ & Y & Z \\
\hline 1 & 6 & 0.343095 & 0.036677 & -0.0237 \\
\hline 2 & 6 & 1.244355 & -0.958972 & 0.313693 \\
\hline 3 & 6 & 0.703778 & 1.367817 & -0.132472 \\
\hline 4 & 6 & 2.030791 & 1.712148 & 0.104133 \\
\hline 5 & 6 & 2.958545 & 0.733662 & 0.451417 \\
\hline 6 & 6 & 2.565665 & -0.597679 & 0.557055 \\
\hline 7 & 1 & 0.918843 & -1.986362 & 0.387066 \\
\hline 8 & 1 & -0.044641 & 2.102855 & -0.386748 \\
\hline 9 & 1 & 2.3361 & 2.746558 & 0.021476 \\
\hline 10 & 1 & 3.284773 & -1.359246 & 0.825783 \\
\hline 11 & 1 & 3.987675 & 1.00841 & 0.639681 \\
\hline 12 & 8 & -0.989254 & -0.313313 & -0.351614 \\
\hline 13 & 16 & -2.0112 & -0.711421 & 0.803526 \\
\hline 14 & 9 & -2.279979 & 1.39048 & 0.868082 \\
\hline 15 & 8 & -3.349156 & -0.785486 & 0.298893 \\
\hline 16 & 8 & -1.571329 & -0.602817 & 2.161918 \\
\hline 17 & 9 & -1.625956 & -2.342124 & 0.598977 \\
\hline 18 & 7 & -2.226918 & -3.351378 & -3.067896 \\
\hline 19 & 6 & -2.001938 & -4.43753 & -2.055658 \\
\hline
\end{tabular}


(continued, Table S28)

\begin{tabular}{ccccc}
\hline \multirow{2}{*}{ Center Number } & Atomic Number & \multicolumn{3}{c}{ Cartesian Coordinates $(\AA)$} \\
& & $X$ & $Y$ & $Z$ \\
\hline 20 & 6 & -2.353039 & -3.958045 & -4.434336 \\
21 & 6 & -3.486633 & -2.60641 & -2.730673 \\
23 & 6 & -1.063691 & -2.403199 & -3.049772 \\
24 & 1 & -3.631237 & -1.824404 & -3.469394 \\
25 & 1 & -4.316149 & -3.3057 & -2.755622 \\
26 & 1 & -3.384341 & -2.176041 & -1.739577 \\
27 & 1 & -1.238181 & -1.628417 & -3.789488 \\
28 & 1 & -0.988931 & -1.9665 & -2.060304 \\
29 & 1 & -0.162621 & -2.957484 & -3.291968 \\
30 & 1 & -2.846843 & -5.117778 & -2.08756 \\
31 & 1 & -1.086466 & -4.961325 & -2.312011 \\
32 & 1 & -1.918462 & -3.980845 & -1.07534 \\
33 & 1 & -2.517637 & -3.160394 & -5.151691 \\
34 & 1 & -1.433508 & -4.487315 & -4.662661 \\
\hline & 1 & -3.193885 & -4.644031 & -4.431381 \\
\hline & 1 & & &
\end{tabular}


Table S30 I Cartesian coordinates of product with TMA counter ion.

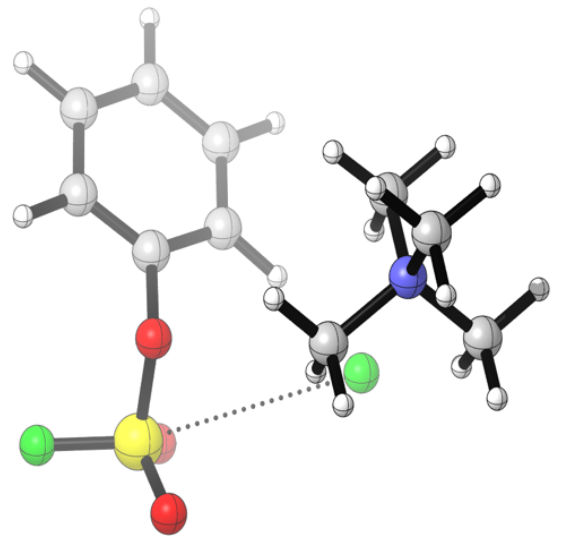

\begin{tabular}{|c|c|c|c|c|}
\hline \multirow{2}{*}{ Center Number } & \multirow{2}{*}{ Atomic Number } & \multicolumn{3}{|c|}{ Cartesian Coordinates ( $(\mathbf{A})$} \\
\hline & & $\mathrm{x}$ & $\mathrm{Y}$ & Z \\
\hline 1 & 6 & 0.537729 & -1.291582 & 0.537276 \\
\hline 2 & 6 & 1.805265 & -1.685153 & 0.920594 \\
\hline 3 & 6 & 0.268885 & -0.14433 & -0.182699 \\
\hline 4 & 6 & 1.35035 & 0.659576 & -0.533153 \\
\hline 5 & 6 & 2.645041 & 0.300702 & -0.165179 \\
\hline 6 & 6 & 2.872783 & -0.867264 & 0.557547 \\
\hline 7 & 1 & 1.954321 & -2.600071 & 1.476047 \\
\hline 8 & 1 & -0.761766 & 0.074968 & -0.456839 \\
\hline 9 & 1 & 1.179077 & 1.566213 & -1.098181 \\
\hline 10 & 1 & 3.878505 & -1.147256 & 0.839096 \\
\hline 11 & 1 & 3.479054 & 0.930804 & -0.444209 \\
\hline 12 & 8 & -0.558431 & -2.166629 & 0.836067 \\
\hline 13 & 16 & -1.506999 & -1.881961 & 2.04449 \\
\hline 14 & 9 & -2.649191 & -0.114573 & -0.924545 \\
\hline 15 & 8 & -2.675625 & -2.665914 & 1.849472 \\
\hline 16 & 8 & -1.551945 & -0.50541 & 2.397121 \\
\hline 17 & 9 & -0.680023 & -2.591618 & 3.18897 \\
\hline 18 & 7 & -2.291488 & -2.393727 & -3.286909 \\
\hline 19 & 6 & -2.354703 & -3.053631 & -1.938113 \\
\hline
\end{tabular}


(continued, Table S29)

\begin{tabular}{ccccc}
\hline Center Number & Atomic Number & \multicolumn{3}{c}{ Cartesian Coordinates $(\AA)$} \\
& & $X$ & $Y$ & $Z$ \\
\hline 20 & 6 & -2.161865 & -3.424805 & -4.363558 \\
21 & 6 & -3.544389 & -1.588946 & -3.491153 \\
23 & 6 & -1.11039 & -1.466648 & -3.316555 \\
24 & 1 & -3.482075 & -1.097976 & -4.457932 \\
25 & 1 & -4.392968 & -2.266487 & -3.468773 \\
26 & 1 & -3.587185 & -0.866957 & -2.678029 \\
27 & 1 & -1.063796 & -0.999031 & -4.295359 \\
28 & 1 & -1.26865 & -0.731169 & -2.533146 \\
29 & 1 & -0.211488 & -2.048886 & -3.136117 \\
30 & 1 & -3.215711 & -3.715644 & -1.922066 \\
31 & 1 & -1.442019 & -3.62406 & -1.792639 \\
32 & 1 & -2.448188 & -2.259176 & -1.201059 \\
33 & 1 & -2.125237 & -2.919951 & -5.324188 \\
34 & 1 & -1.248157 & -3.987702 & -4.199351 \\
\hline & 1 & -3.02325 & -4.084233 & -4.319272 \\
\hline & 1 & & &
\end{tabular}


Table S31 | Interaction of $\mathrm{F}^{-}$complexed by TMA counter ion with phenyl fluorosulfate.

\begin{tabular}{|c|c|c|c|}
\hline $\begin{array}{c}\mathrm{F}^{\mathrm{Nu}}-\mathrm{S} \\
(\AA)\end{array}$ & $\begin{array}{c}\mathrm{F}^{\mathrm{Lg}}-\mathrm{S} \\
(\mathrm{A})\end{array}$ & $\begin{array}{c}\Delta E \\
\left(\mathrm{kcal} \mathrm{mol}^{-1}\right)\end{array}$ & $\begin{array}{c}\Delta G \\
\left(\mathrm{kcal} \mathrm{mol}^{-1}\right)\end{array}$ \\
\hline $3.604\left(A^{\prime}\right)$ & 1.582 & 0 & 0 \\
\hline 3.400 & 1.584 & 0.39 & \\
\hline 3.200 & 1.588 & 0.91 & \\
\hline 3.000 & 1.593 & 1.67 & \\
\hline 2.800 & 1.600 & 2.62 & \\
\hline 2.700 & 1.606 & 3.26 & \\
\hline 2.600 & 1.613 & 4 & \\
\hline 2.500 & 1.622 & 4.69 & \\
\hline 2.400 & 1.632 & 5.54 & \\
\hline 2.320 & 1.643 & 6.18 & \\
\hline 2.280 & 1.649 & 6.48 & \\
\hline 2.240 & 1.657 & 6.75 & \\
\hline 2.200 & 1.664 & 7 & \\
\hline 2.160 & 1.672 & 7.14 & \\
\hline 2.120 & 1.681 & 7.15 & \\
\hline $2.080\left(B^{\prime}\right)$ & 1.690 & 7.16 & 11.75 \\
\hline 2.060 & 1.695 & 7.14 & \\
\hline 2.040 & 1.699 & 7.09 & \\
\hline 2.000 & 1.710 & 7.07 & \\
\hline 1.960 & 1.721 & 6.91 & \\
\hline 1.920 & 1.734 & 6.75 & \\
\hline 1.880 & 1.749 & 6.59 & \\
\hline 1.850 & 1.760 & 6.51 & \\
\hline $1.830\left(C^{\prime}\right)$ & 1.768 & 6.48 & 9.42 \\
\hline 1.809 & 1.800 & 6.53 & \\
\hline 1.779 & 1.860 & 6.82 & \\
\hline
\end{tabular}


(Continued Fig. S30)

\begin{tabular}{|c|c|c|c|}
\hline $\begin{array}{c}\mathrm{F}^{\mathrm{Nu}}-\mathrm{S} \\
(\AA)\end{array}$ & $\begin{array}{c}F^{\text {Lg-S }} \\
(\AA)\end{array}$ & $\begin{array}{c}\Delta E \\
\left(\mathrm{kcal} \mathrm{mol}^{-1}\right)\end{array}$ & $\begin{array}{c}\Delta G \\
\left(k^{\prime} c a l \mathrm{~mol}^{-1}\right)\end{array}$ \\
\hline 1.756 & 1.920 & 7.33 & \\
\hline 1.733 & 1.980 & 7.81 & \\
\hline 1.712 & 2.040 & 8.22 & \\
\hline 1.699 & 2.080 & 8.42 & \\
\hline 1.694 & 2.100 & 8.47 & \\
\hline 1.688 (D’) & 2.120 & 8.53 & 11.05 \\
\hline 1.685 & 2.140 & 8.33 & \\
\hline 1.677 & 2.160 & 8.19 & \\
\hline 1.668 & 2.200 & 8.09 & \\
\hline 1.657 & 2.260 & 8 & \\
\hline 1.636 & 2.400 & 7.22 & \\
\hline 1.625 & 2.450 & 4.96 & \\
\hline 1.621 & 2.500 & 4.61 & \\
\hline 1.593 & 3.000 & 1.63 & \\
\hline 1.580 (product) & 3.639 & -0.21 & 2.1 \\
\hline
\end{tabular}




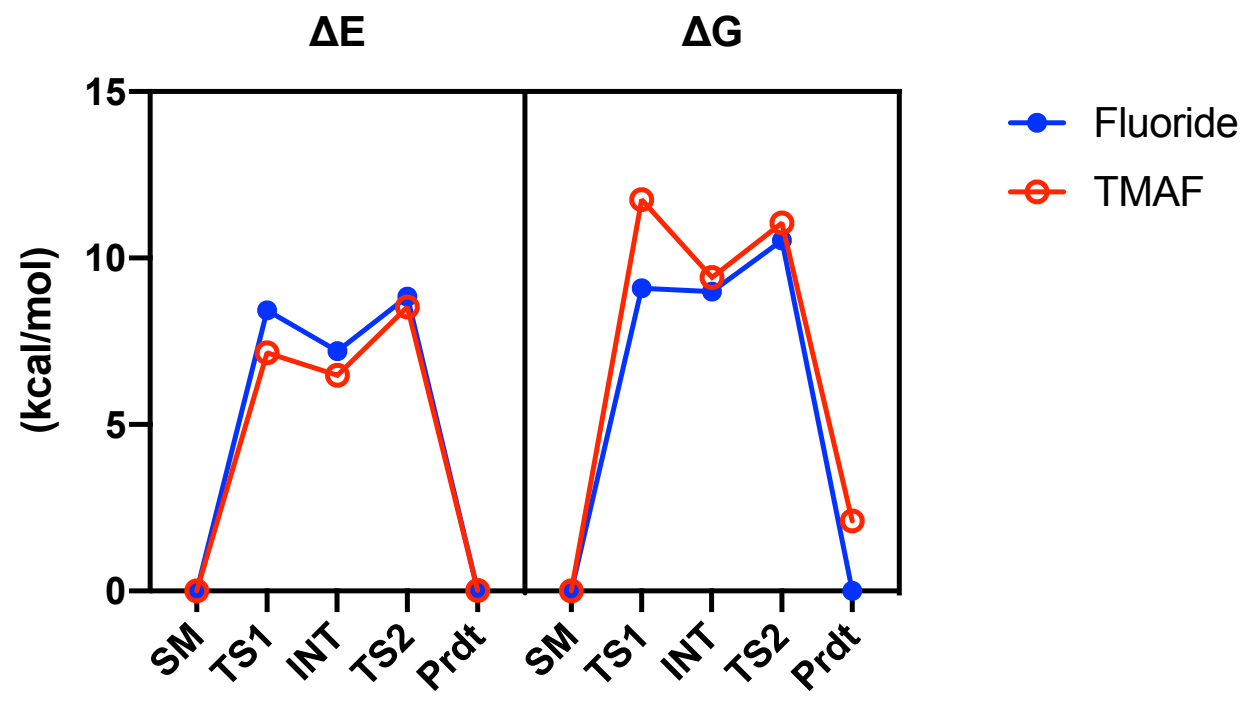

Fig. S69 I Reaction profile comparison of calculation methods using either "naked" fluoride or complexed tetramethylammonium fluoride. 
a

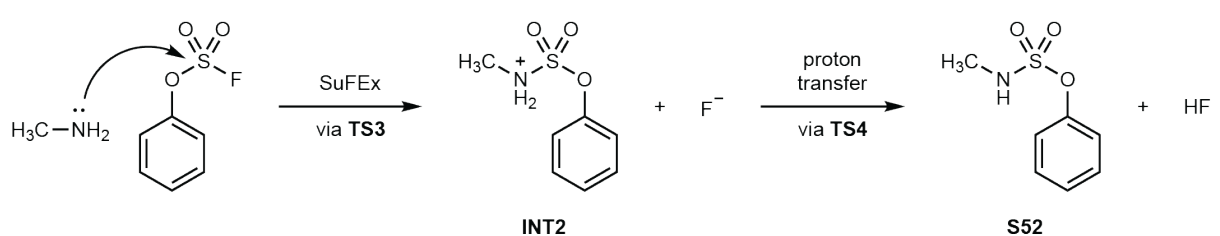

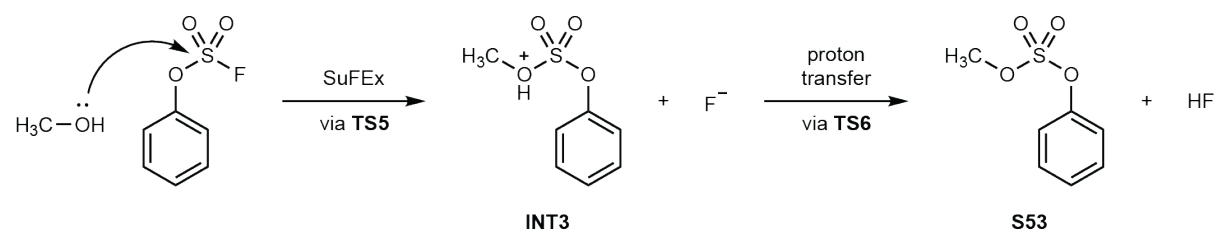

b

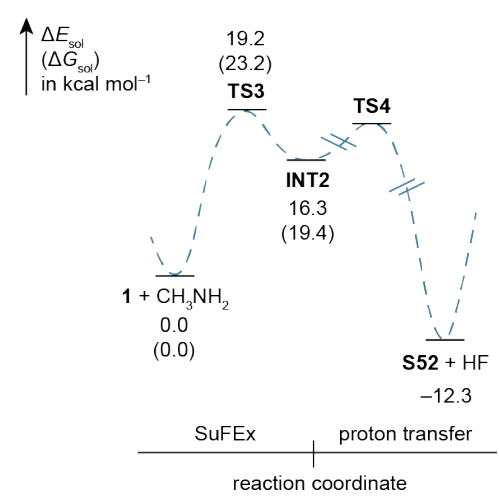

d

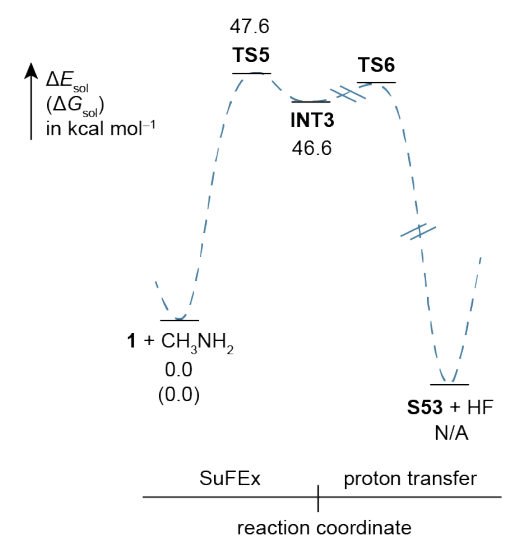

C
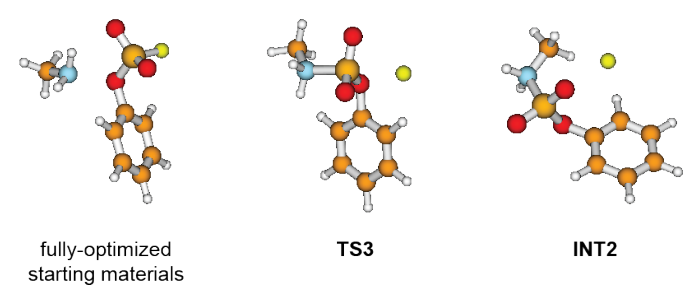

INT2

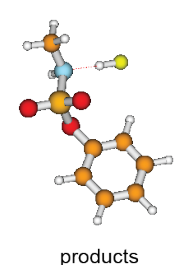

e
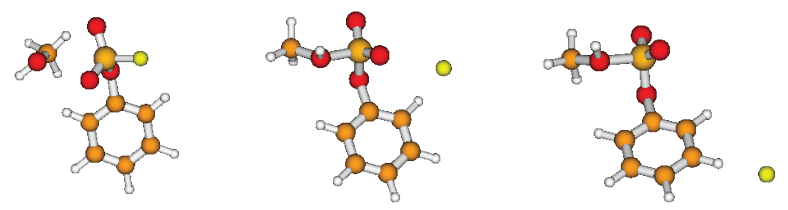

fully-optimized

TS5

INT3

Fig. S70 I Substitution of phenyl fluorosulfate by methyl amine or methanol. a, Proposed reaction pathway. b, Energy diagram calculated by DFT. c, Structures of full-optimized starting materials, transition states, intermediate and products. 


\section{NMR Spectra}

7.1. 3-Ethynylphenyl Fluorosulfate (11)

${ }^{1} \mathrm{H}$ NMR

Fig. $\mathbf{S 7 1}$

${ }^{13} \mathrm{C}$ NMR

Fig. $\mathbf{S 7 2}$

${ }^{19} \mathrm{~F}$ NMR

Fig. $\mathbf{S 7 3}$

7.2. 2,5-Dioxopyrrolidin-1-yl 4-((fluorosulfonyl)oxy)benzoate (15)

${ }^{1} \mathrm{H}$ NMR

Fig. $\mathbf{S 7 4}$

${ }^{13} \mathrm{C}$ NMR

Fig. $\mathbf{S 7 5}$

${ }^{19}$ F NMR

Fig. $\mathbf{S 7 6}$

7.3. 4-(2,5-Dioxo-2,5-dihydro-1H-pyrrol-1-yl)phenyl Fluorosulfate (16)

${ }^{1} \mathrm{H}$ NMR

Fig. $\mathbf{S 7 7}$

${ }^{13} \mathrm{C}$ NMR

Fig. $\mathbf{S 7 8}$

${ }^{19} \mathrm{~F}$ NMR

Fig. $\mathbf{S 7 9}$

7.4. 4-(6-Methyl-1,2,4,5-tetrazin-3-yl)phenyl Fluorosulfate (18)

${ }^{1} \mathrm{H}$ NMR

Fig. $\mathbf{S 8 0}$

${ }^{13} \mathrm{C}$ NMR

Fig. 581

${ }^{19} \mathrm{~F}$ NMR

Fig. $\mathbf{8 2}$

\subsection{3-(6-Methyl-1,2,4,5-tetrazin-3-yl)phenyl Fluorosulfate (19)}

${ }^{1} \mathrm{H}$ NMR

Fig. $\mathbf{8 8 3}$

${ }^{13} \mathrm{C}$ NMR

Fig. 584

${ }^{19} \mathrm{~F}$ NMR

Fig. $\mathbf{8 8 5}$

7.6. 4-(2-(3,4,5-Tris(prop-2-yn-1-yloxy)benzamido)ethyl)phenyl Fluorosulfate (20)

${ }^{1} \mathrm{H}$ NMR

${ }^{13} \mathrm{C}$ NMR

${ }^{19} \mathrm{~F}$ NMR
Fig. $\mathbf{8 8 6}$

Fig. 587

Fig. $\mathbf{S 8 8}$ 
7.7. 5-(((2S,3S,5R)-2-(Hydroxymethyl)-5-(5-methyl-2,4-dioxo-3,4-dihydropyrimidin1(2H)-yl)tetrahydrofuran-3-yl)carbamoyl)-1,3-phenylene Bis(fluorosulfate) (21)

${ }^{1} \mathrm{H}$ NMR

Fig. $\mathbf{S 8 9}$

${ }^{13}$ C NMR

Fig. $\$ 90$

${ }^{19}$ F NMR

Fig. $\mathbf{S 9 1}$

7.8. Benzyl (S)-2-(((Benzyloxy)carbonyl)amino)-3-(4-

((fluorosulfonyl)oxy)phenyl)propano-ate (23)

${ }^{1} \mathrm{H}$ NMR

Fig. $\mathbf{S 9 2}$

${ }^{13} \mathrm{C}$ NMR

Fig. $\$ 93$

${ }^{19}$ F NMR

Fig. $\$ 94$

7.9. (E)-4-(4-((Tert-butoxycarbonyl)(methyl)amino)styryl)phenyl Fluorosulfate (29)

${ }^{1} \mathrm{H}$ NMR

Fig. $\mathbf{S 9 5}$

${ }^{13} \mathrm{C}$ NMR

Fig. $\mathbf{S 9 6}$

${ }^{19} \mathrm{~F}$ NMR

Fig. $\$ 97$

7.10. (E)-5-(4-((Tert-butoxycarbonyl)(methyl)amino)styryl)pyridin-2-yl Fluorosulfate (30)

${ }^{1} \mathrm{H}$ NMR

Fig. $\mathbf{5 9 8}$

${ }^{13} \mathrm{C}$ NMR

Fig. $\$ 99$

${ }^{19}$ F NMR

Fig. $\mathbf{S 1 0 0}$

7.11. 2-(4-(Methylamino)phenyl)benzo[d]thiazol-5-yl Fluorosulfate (31)

${ }^{1} \mathrm{H} N M R \quad$ Fig. $\mathbf{S 1 0 1}$

${ }^{13} \mathrm{C}$ NMR $\quad$ Fig. $\mathbf{S 1 0 2}$

${ }^{19}$ F NMR $\quad$ Fig. $\mathbf{S 1 0 3}$

7.12. 4-((2-(2-((2-(4-(Methylamino)phenyl)benzo[d]thiazol-6yl)oxy)ethoxy)ethyl)carbamoyl)phenyl Fluorosulfate (32)

${ }^{1} \mathrm{H}$ NMR

Fig. S104

${ }^{13} \mathrm{C}$ NMR

Fig. $\mathbf{S 1 0 5}$

${ }^{19}$ F NMR

Fig. $\mathbf{S 1 0 6}$ 
7.13. Tert-butyl (RS)-2-((RS)-(2-

((Fluorosulfonyl)oxy)phenoxy)(phenyl)methyl)morph-oline-4-carboxylate (33)

${ }^{1} \mathrm{H} N M R$

Fig. S107

${ }^{13} \mathrm{C}$ NMR

Fig. $\mathbf{S 1 0 8}$

${ }^{19} \mathrm{~F} \mathrm{NMR}$

Fig. $\mathbf{S 1 0 9}$

7.14. 4-(2-(4-(2-Fluoro-5-((4-oxo-3,4-dihydrophthalazin-1yl)methyl)benzoyl)piperaz-in-1-yl)-2-oxoethyl)phenyl Fluorosulfate (35)

${ }^{1} \mathrm{H} N M R$

Fig. S110

${ }^{13} \mathrm{C}$ NMR

Fig. $\mathbf{S 1 1}$

${ }^{19} \mathrm{~F}$ NMR

Fig. S112

7.15. 2,5-Dioxopyrrolidin-1-yl 3,5-Bis((fluorosulfonyl)oxy)benzoate (S10)

${ }^{1} \mathrm{H}$ NMR

${ }^{13} \mathrm{C}$ NMR

${ }^{19} \mathrm{~F}$ NMR
Fig. $\mathbf{S 1 1 3}$

Fig. $\mathbf{S 1 1 4}$

Fig. $\mathbf{S 1 1 5}$

7.16. 5-lodopyridin-2-yl Fluorosulfate (S16)

${ }^{1} \mathrm{H} N M R$

Fig. $\mathbf{S 1 1 6}$

${ }^{13} \mathrm{C}$ NMR

Fig. $\mathbf{S 1 1 7}$

${ }^{19} \mathrm{~F}$ NMR

Fig. $\mathbf{S 1 1 8}$

7.17. 2-(4-Aminophenyl)benzo[d]thiazol-6-yl Fluorosulfate (S19)

${ }^{1} \mathrm{H} N M R \quad$ Fig. $\mathbf{S 1 1 9}$

${ }^{13} \mathrm{C}$ NMR Fig. $\mathbf{S 1 2 0}$

${ }^{19}$ F NMR $\quad$ Fig. S121

7.18. (RS)-6-((RS)-(2-Hydroxyphenoxy)(phenyl)methyl)morpholin-3-one (S25)

${ }^{1} \mathrm{H} N M R$

Fig. $\mathbf{S} 122$

${ }^{13} \mathrm{C}$ NMR

Fig. $\mathbf{S 1 2 3}$ 
7.19. (RS)-6-((RS)-(2-((Tert-butyldimethylsilyl)oxy)phenoxy)(phenyl)methyl) morpholin-3-one (S26)

${ }^{1} \mathrm{H} N M R$

Fig. $\mathbf{S 1 2 4}$

${ }^{13} \mathrm{C}$ NMR

Fig. $\mathbf{S} 125$

7.20. Tert-butyl (RS)-2-((RS)-(2-((tert-butyldimethylsilyl)oxy)phenoxy)(phenyl) methyl)morpholine-4-carboxylate (S27)

${ }^{1} \mathrm{H} N M R \quad$ Fig. $\mathbf{S 1 2 6}$

${ }^{13} \mathrm{C}$ NMR $\quad$ Fig. $\mathbf{S 1 2 7}$

7.21. Tert-butyl 4-(2-(4-Hydroxyphenyl)acetyl)piperazine-1-carboxylate (S30)

${ }^{1} \mathrm{H} N M R \quad$ Fig. $\mathbf{S 1 2 8}$

${ }^{13} \mathrm{C}$ NMR $\quad$ Fig. $\mathbf{S 1 2 9}$

7.22. 2-(4-Hydroxyphenyl)-1-(piperazin-1-yl)ethan-1-one (S31)

${ }^{1} \mathrm{H}$ NMR $\quad$ Fig. $\mathbf{S 1 3 0}$

${ }^{13} \mathrm{C}$ NMR $\quad$ Fig. $\mathbf{S 1 3 1}$

7.23. 4-(4-Fluoro-3-(4-(2-(4-hydroxyphenyl)acetyl)piperazine-1-carbonyl)benzyl) phthalazin-1(2H)-one (S33)

${ }^{1} \mathrm{H}$ NMR

Fig. $\mathbf{S} 132$

${ }^{13} \mathrm{C}$ NMR

Fig. $\mathbf{S 1 3 3}$

${ }^{13} \mathrm{C} N M R$

Fig. $\mathbf{S 1 3 4}$

7.24. 2-Isopropylphenyl Fluorosulfate (S47)

${ }^{1} \mathrm{H} N M R$

Fig. $\mathbf{S 1 3 5}$

${ }^{13} \mathrm{C}$ NMR

Fig. $\mathbf{S 1 3 6}$

${ }^{19} \mathrm{~F}$ NMR

Fig. $\mathbf{S 1 3 7}$ 
zqh-1193-500-20171018.1.fid - 50 mM cyclosporine

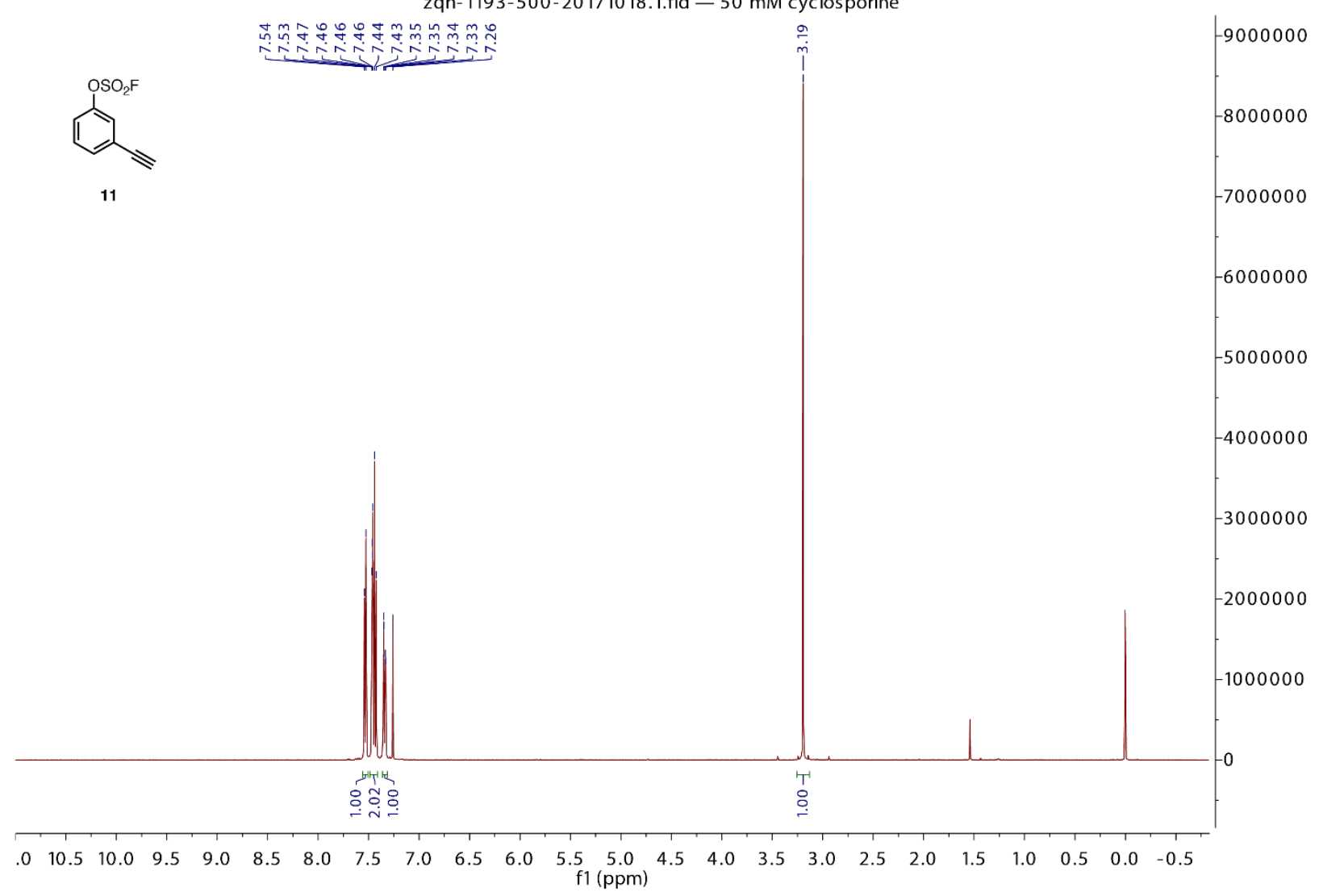

Fig. S71 | ${ }^{1} \mathrm{H}$ NMR of Compound 11. Solvent: $\mathrm{CDCl}_{3}$; Frequency: $500 \mathrm{MHz}$; Temperature: 298 $\mathrm{K}$. 
zqh-1193-500-201710 18.2.fid - AV NEO 500, C-13 Routine, 5-25-2017

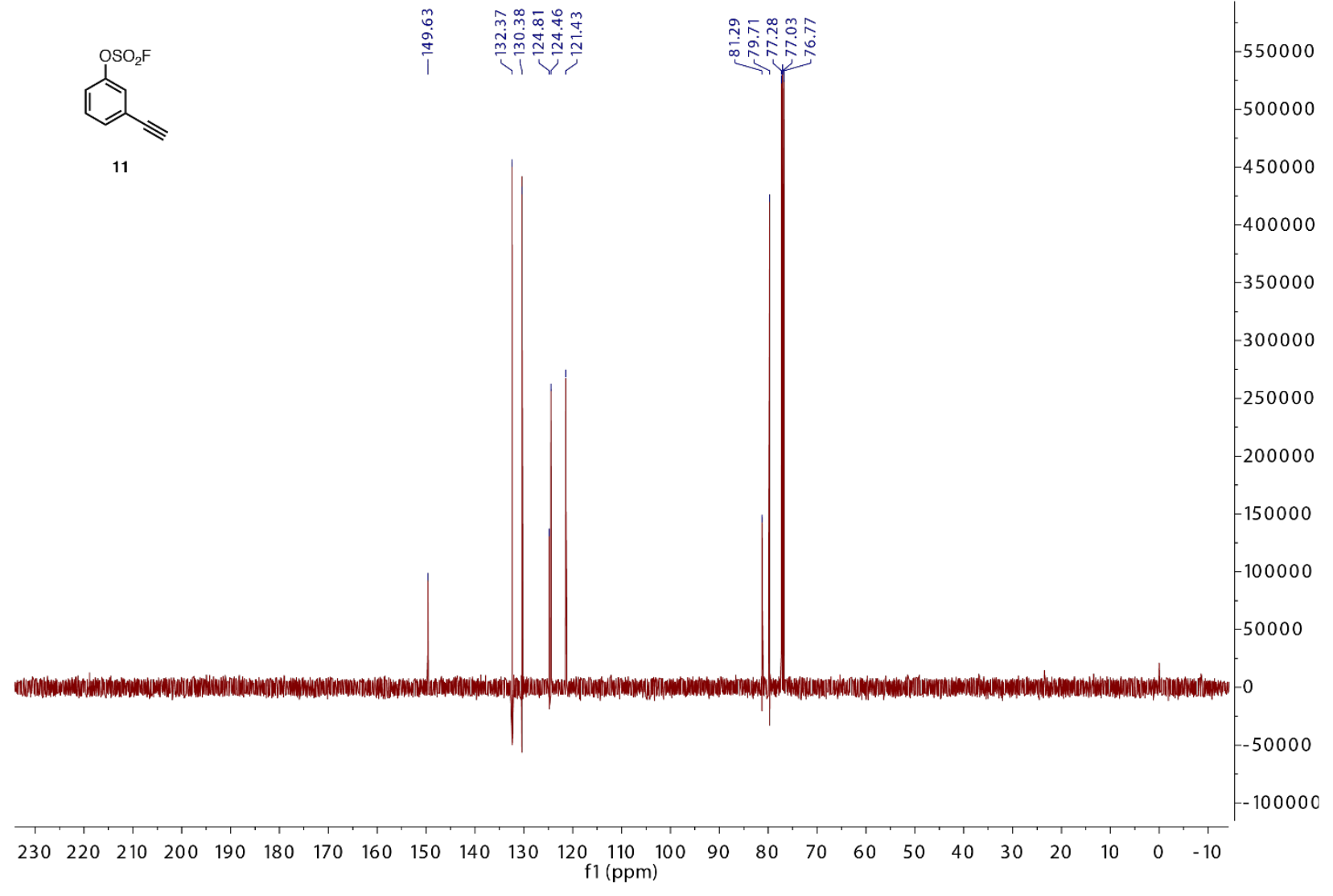

Fig. S72 | ${ }^{13} \mathrm{C}$ NMR of Compound 11. Solvent: $\mathrm{CDCl}_{3}$; Frequency: $126 \mathrm{MHz}$; Temperature: 298 $\mathrm{K}$. 


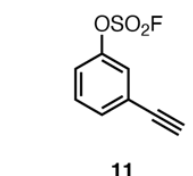

zqh-1193-400-F-20171018.1.fid - AV400 BBOF Probe, F-19 in CDCl3, CFCl3=0 ppm.

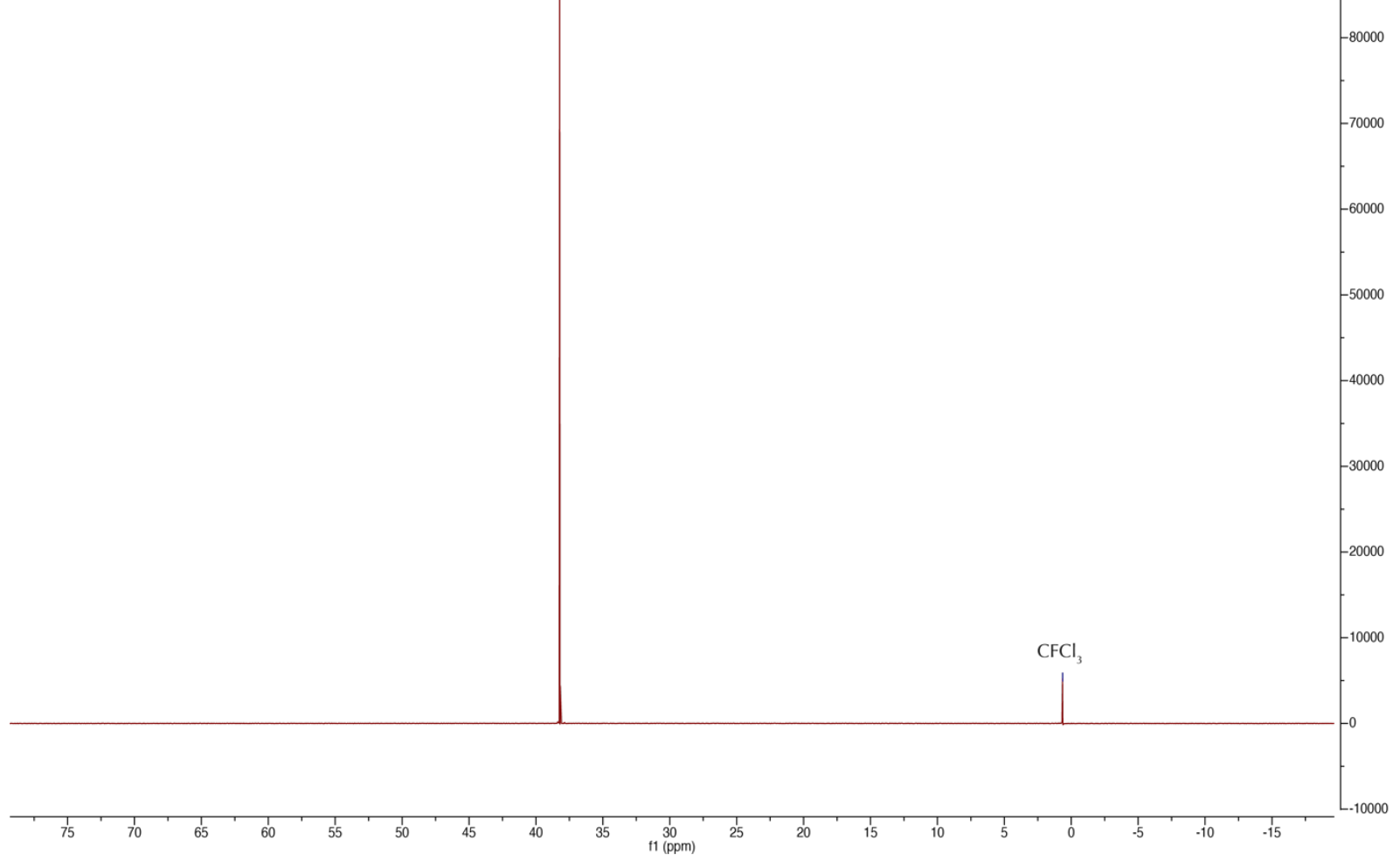

Fig. S73 | ${ }^{19}$ F NMR of Compound 11. Solvent: $\mathrm{CDCl}_{3}$, internal standard $\mathrm{CFCl} 3(\delta 0.65 \mathrm{ppm})$; Frequency: 376 MHz; Temperature: $298 \mathrm{~K}$. 


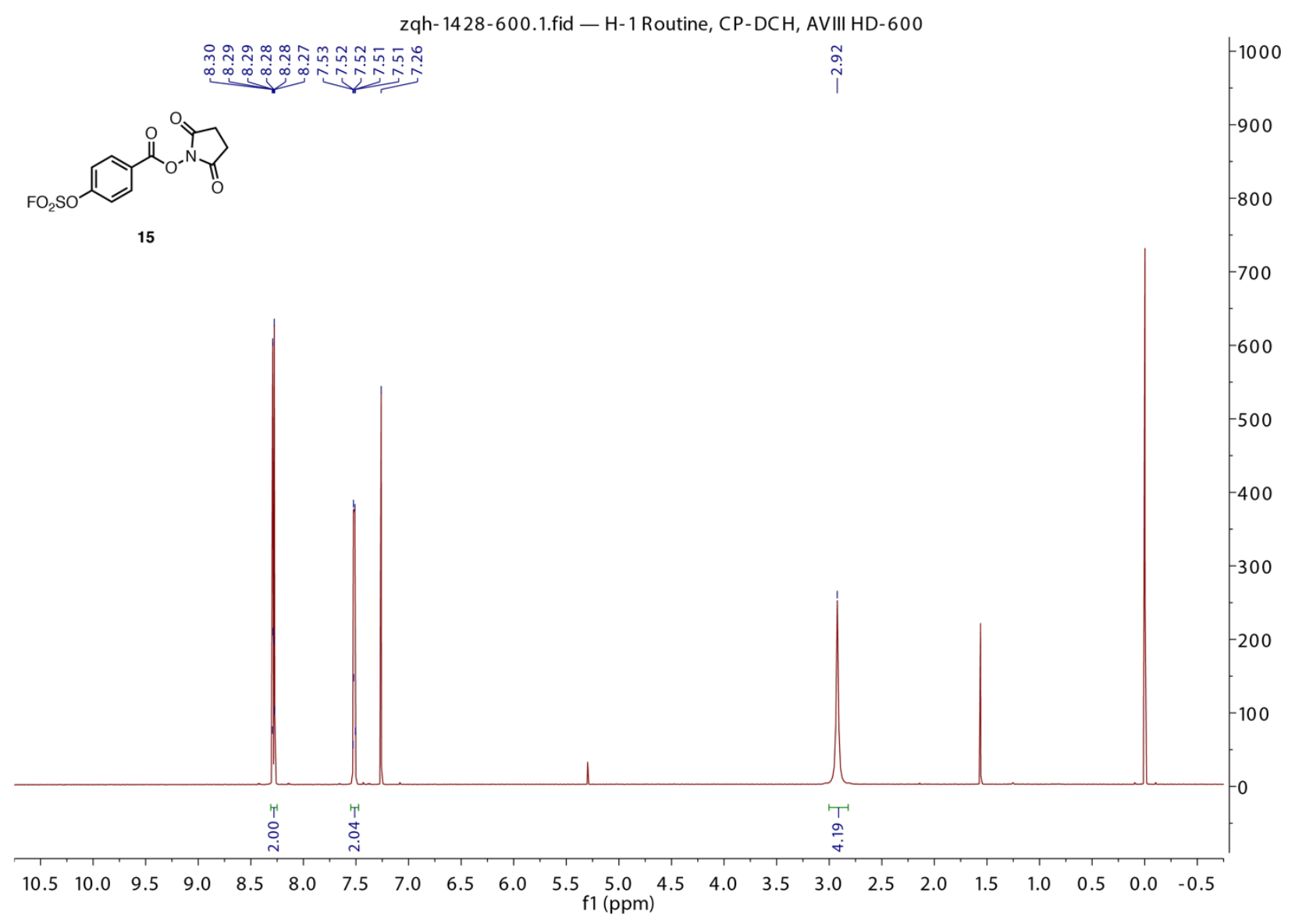

Fig. S74 | ${ }^{1} \mathrm{H}$ NMR of Compound 15. Solvent: $\mathrm{CDCl}_{3}$; Frequency: $600 \mathrm{MHz}$; Temperature: 298 K. 


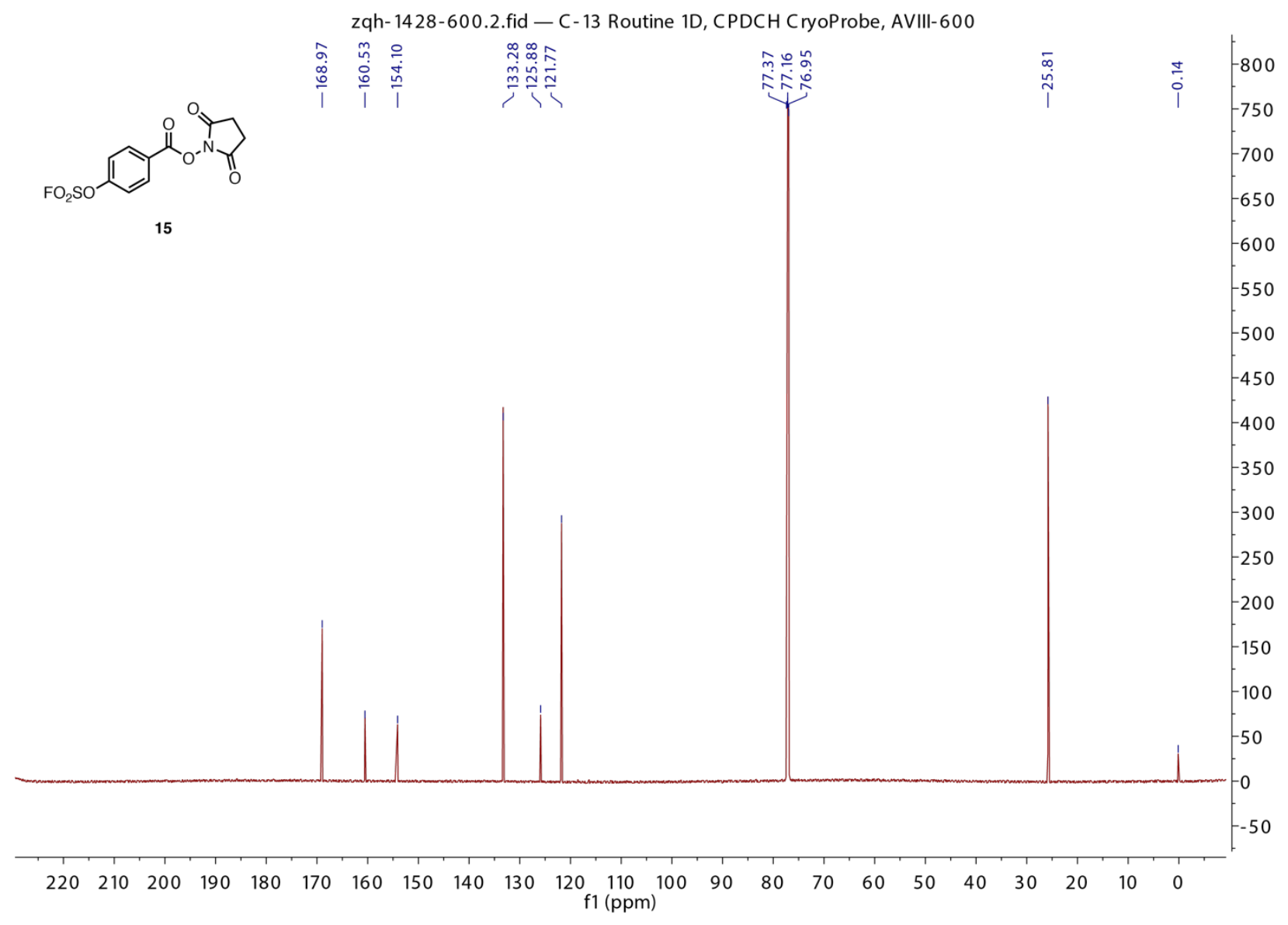

Fig. S75 $\mid{ }^{13} \mathrm{C}$ NMR of Compound 15. Solvent: $\mathrm{CDCl} 3$; Frequency: $151 \mathrm{MHz}$; Temperature: $298 \mathrm{~K}$. 


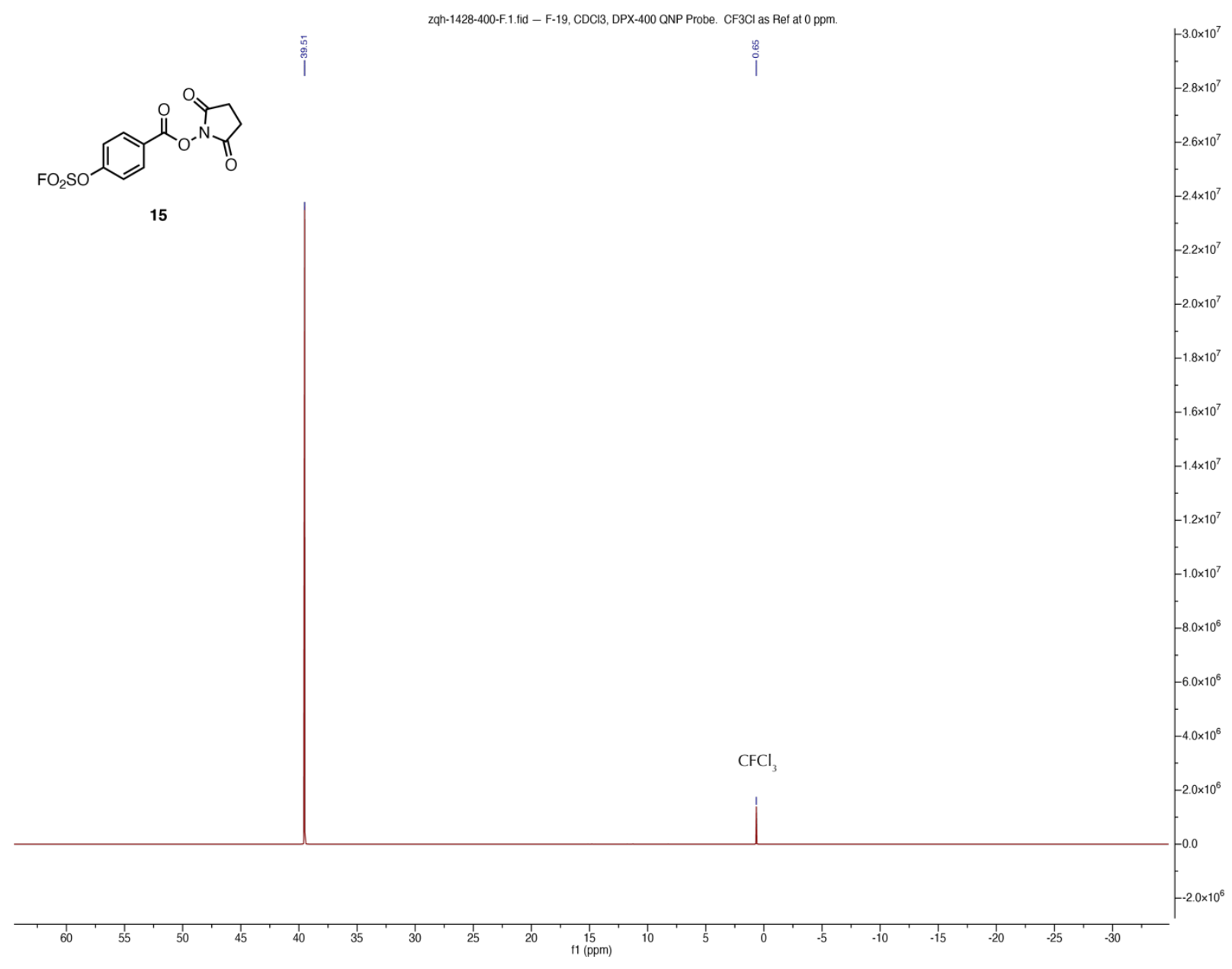

Fig. S76 | ${ }^{19} \mathrm{~F}$ NMR of Compound 15. Solvent: $\mathrm{CDCl}_{3}$, internal standard $\mathrm{CFCl} 3$ ( $\delta 0.65 \mathrm{ppm}$ ); Frequency: $376 \mathrm{MHz}$; Temperature: $298 \mathrm{~K}$. 


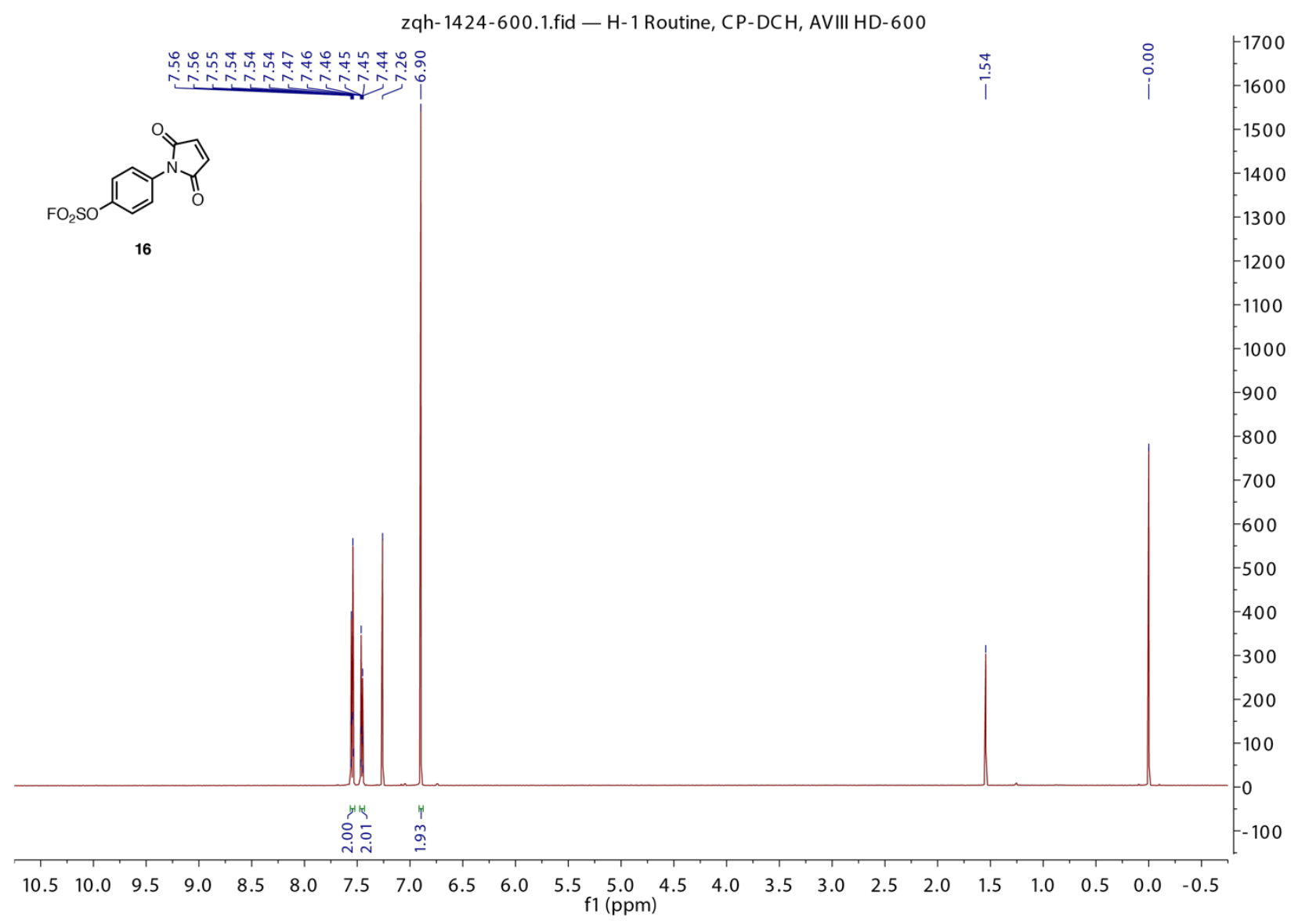

Fig. S77 | ${ }^{1} \mathrm{H}$ NMR of Compound 16. Solvent: $\mathrm{CDCl}_{3}$; Frequency: $600 \mathrm{MHz}$; Temperature: 298 $\mathrm{K}$. 


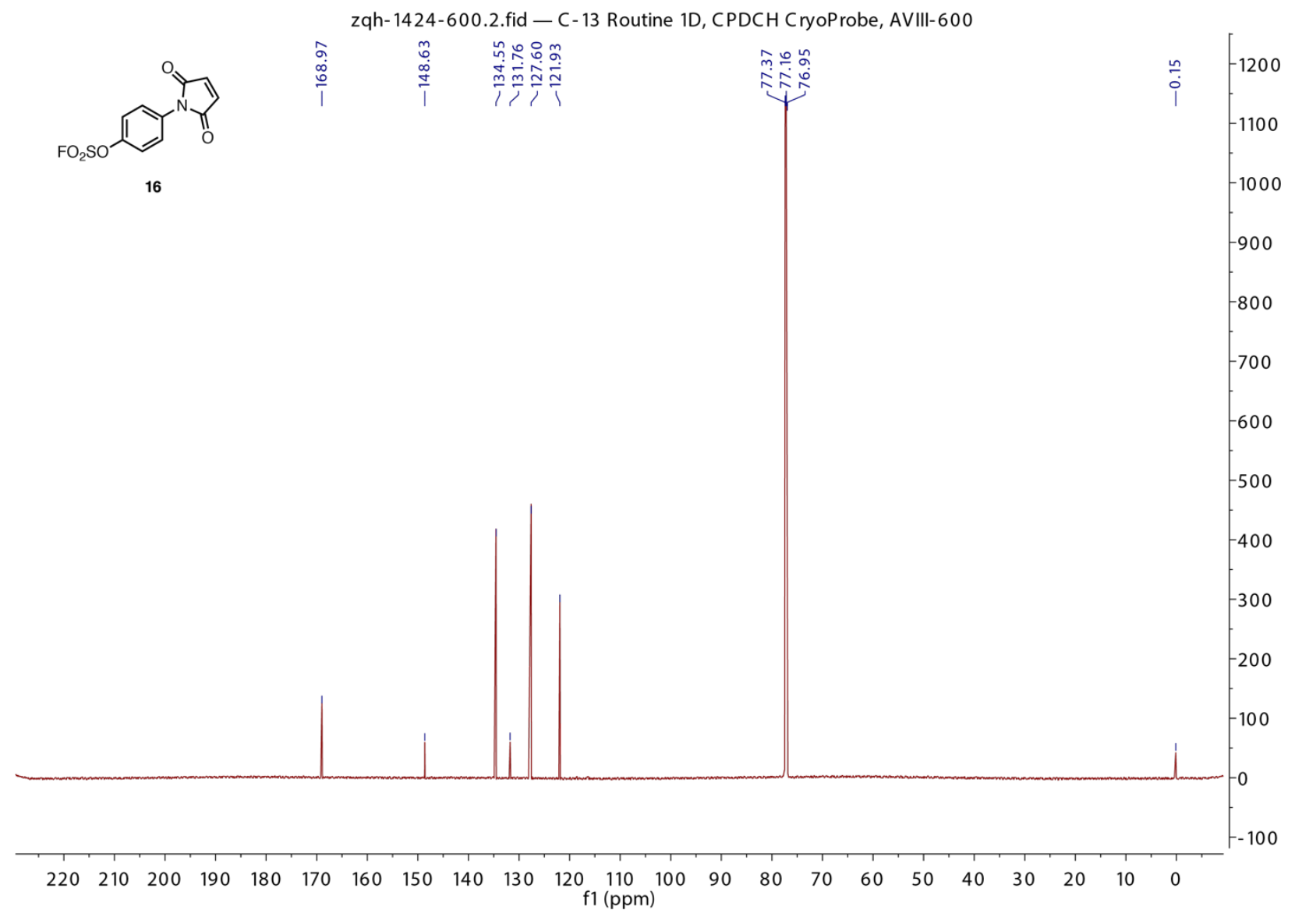

Fig. S78 | ${ }^{13} \mathrm{C}$ NMR of Compound 16. Solvent: $\mathrm{CDCl}_{3}$; Frequency: $151 \mathrm{MHz}$; Temperature: 298 K. 


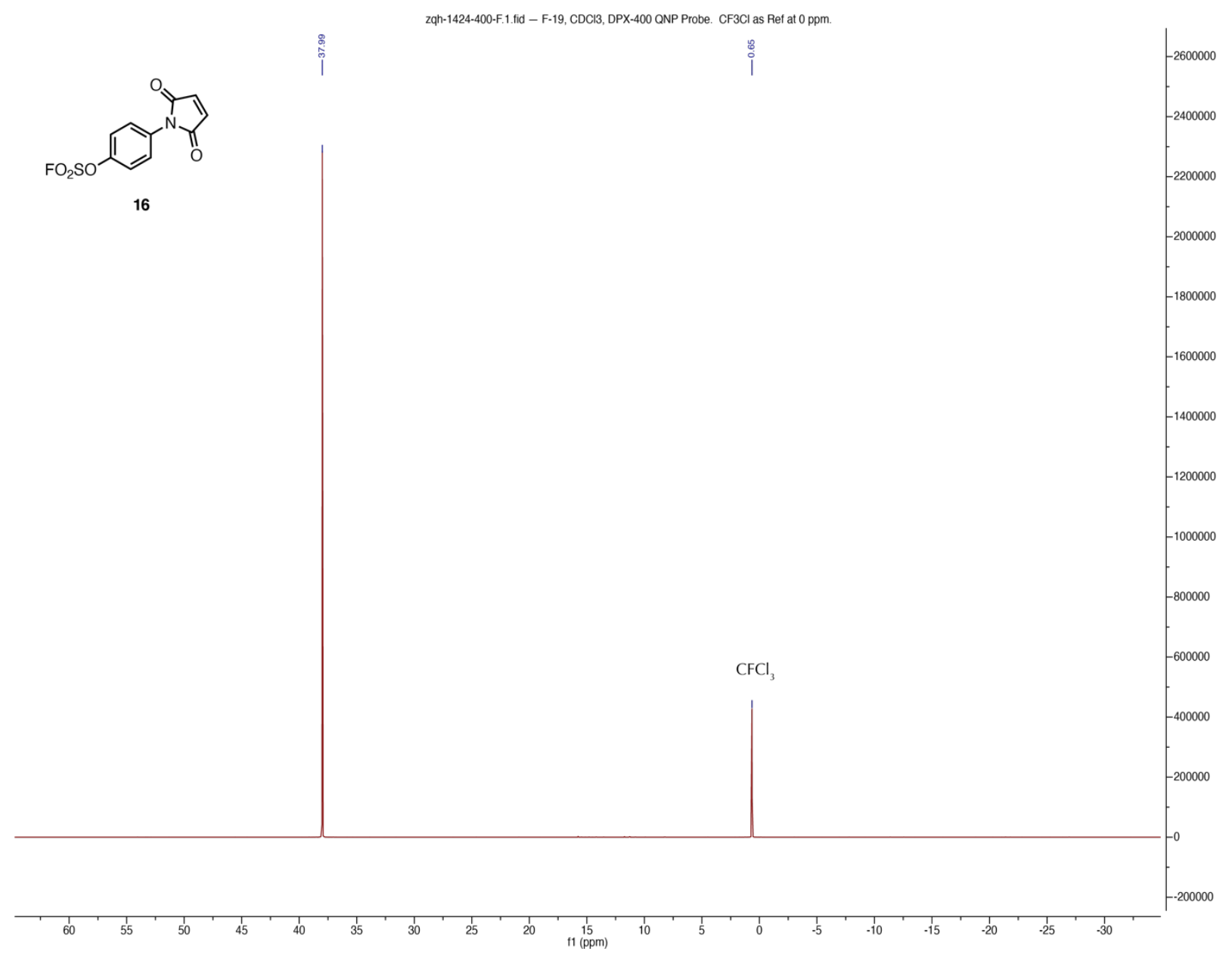

Fig. S79 | ${ }^{19} \mathrm{~F}$ NMR of Compound 16. Solvent: $\mathrm{CDCl}_{3}$, internal standard $\mathrm{CFCl} 3$ ( $\delta 0.65$ ppm); Frequency: $376 \mathrm{MHz}$; Temperature: $298 \mathrm{~K}$. 


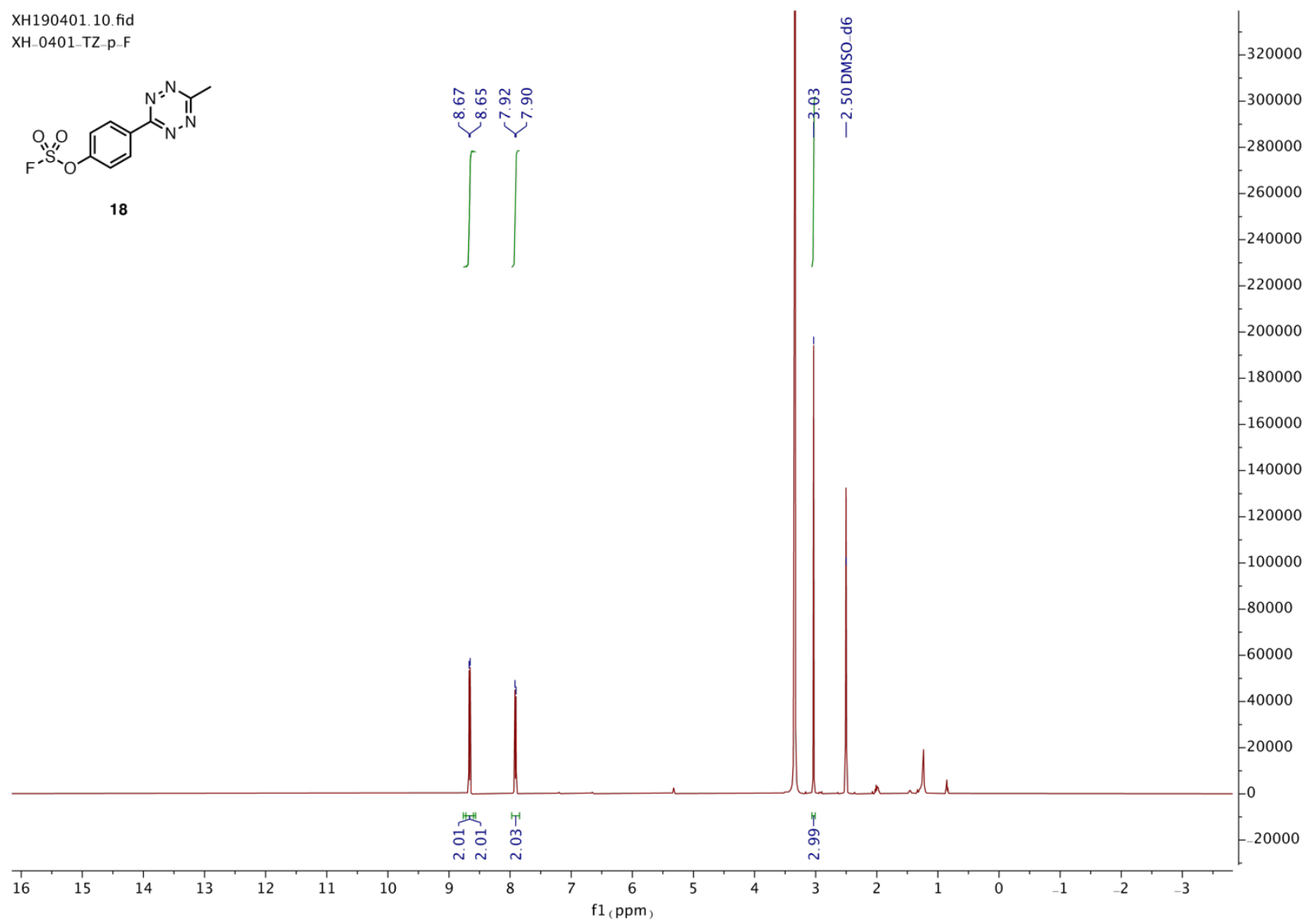

Fig. S80 | ${ }^{1} \mathrm{H}$ NMR of Compound 18. Solvent: DMSO-d6; Frequency: $500 \mathrm{MHz}$; Temperature: $298 \mathrm{~K}$. 


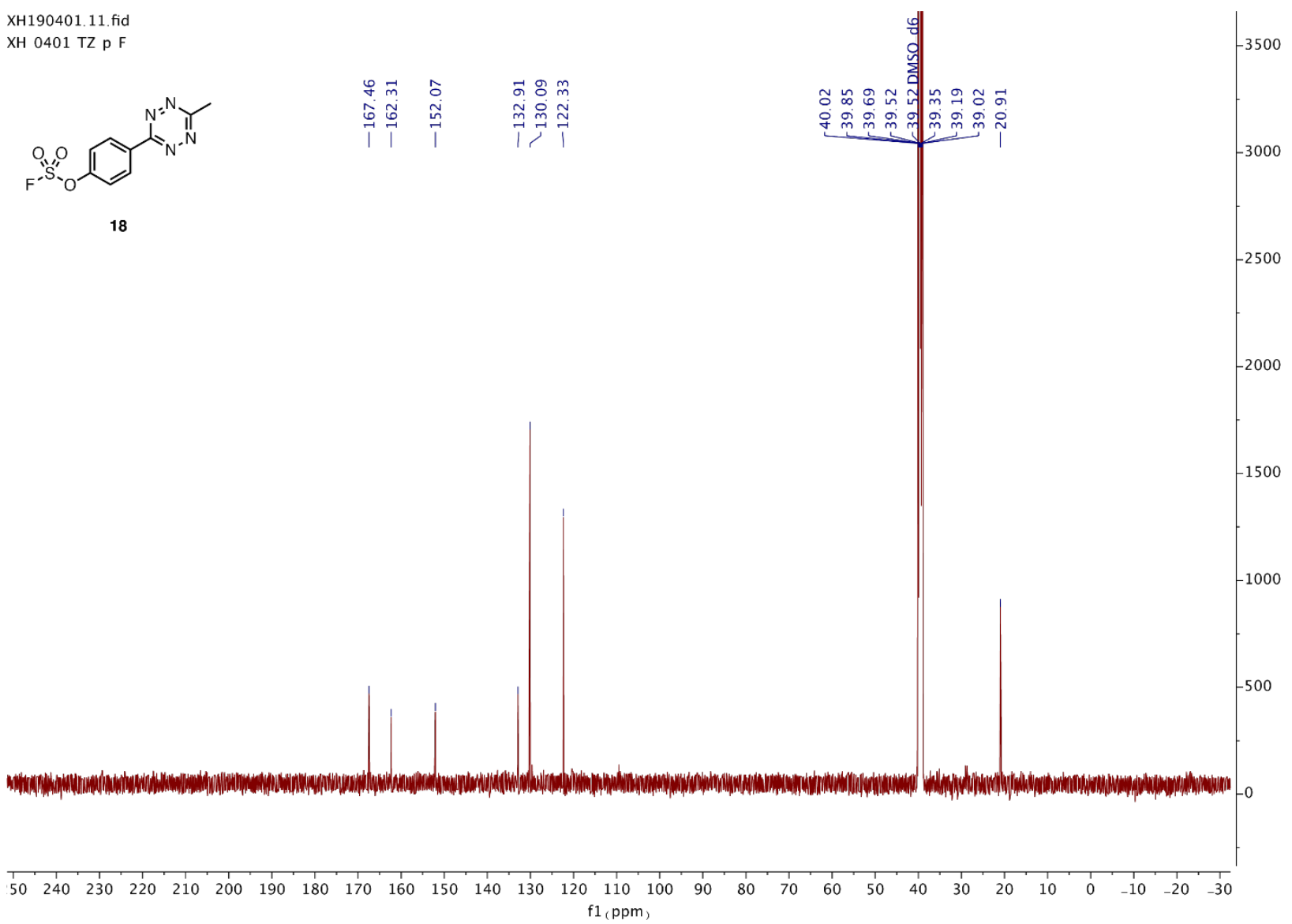

Fig. S81 | ${ }^{13} \mathrm{C}$ NMR of Compound 18. Solvent: DMSO-d6; Frequency: $126 \mathrm{MHz}$; Temperature: $298 \mathrm{~K}$. 


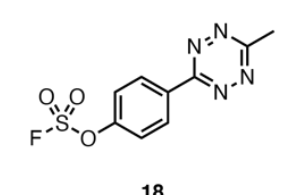

18

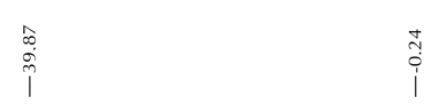

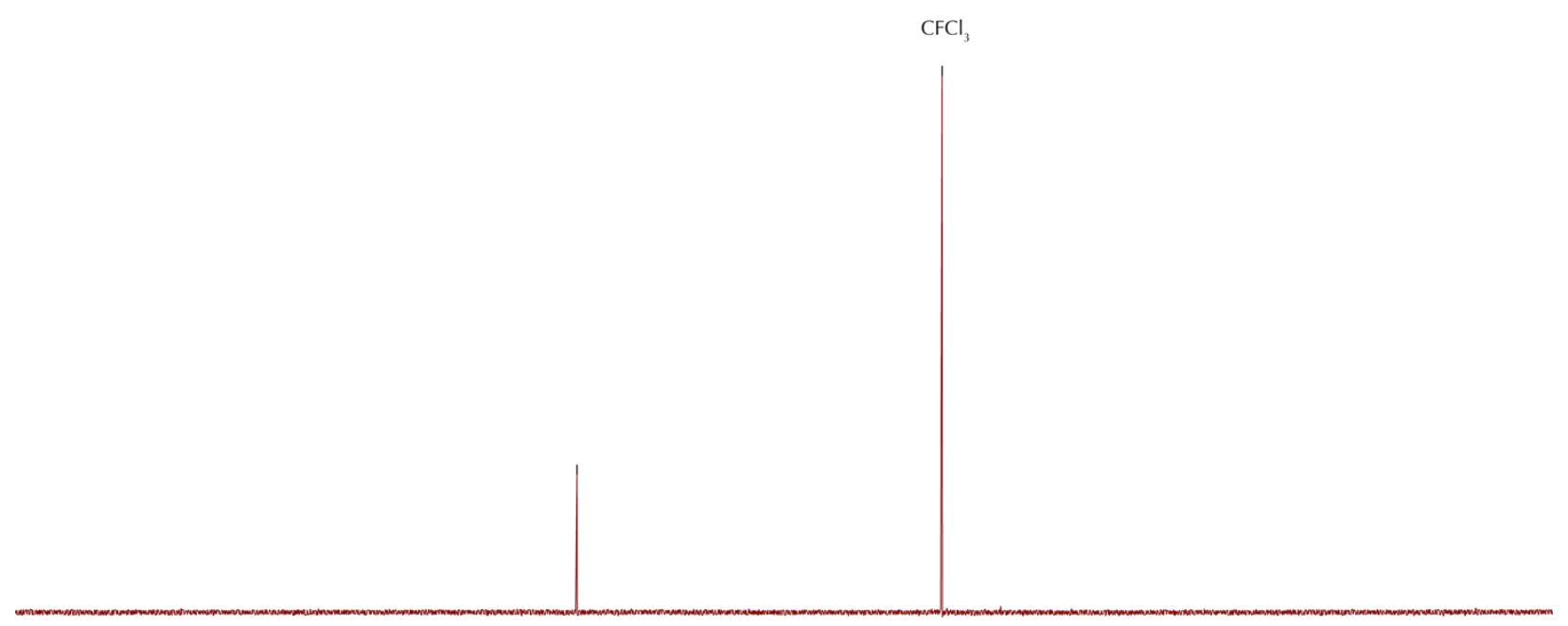

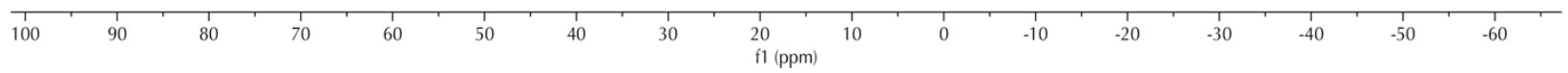

Fig. S82 | ${ }^{19} \mathrm{~F}$ NMR of Compound 18. Solvent: DMSO-d6, internal standard $\mathrm{CFCl}_{3}(\delta-0.24$ ppm); Frequency: $471 \mathrm{MHz}$; Temperature: $298 \mathrm{~K}$. 


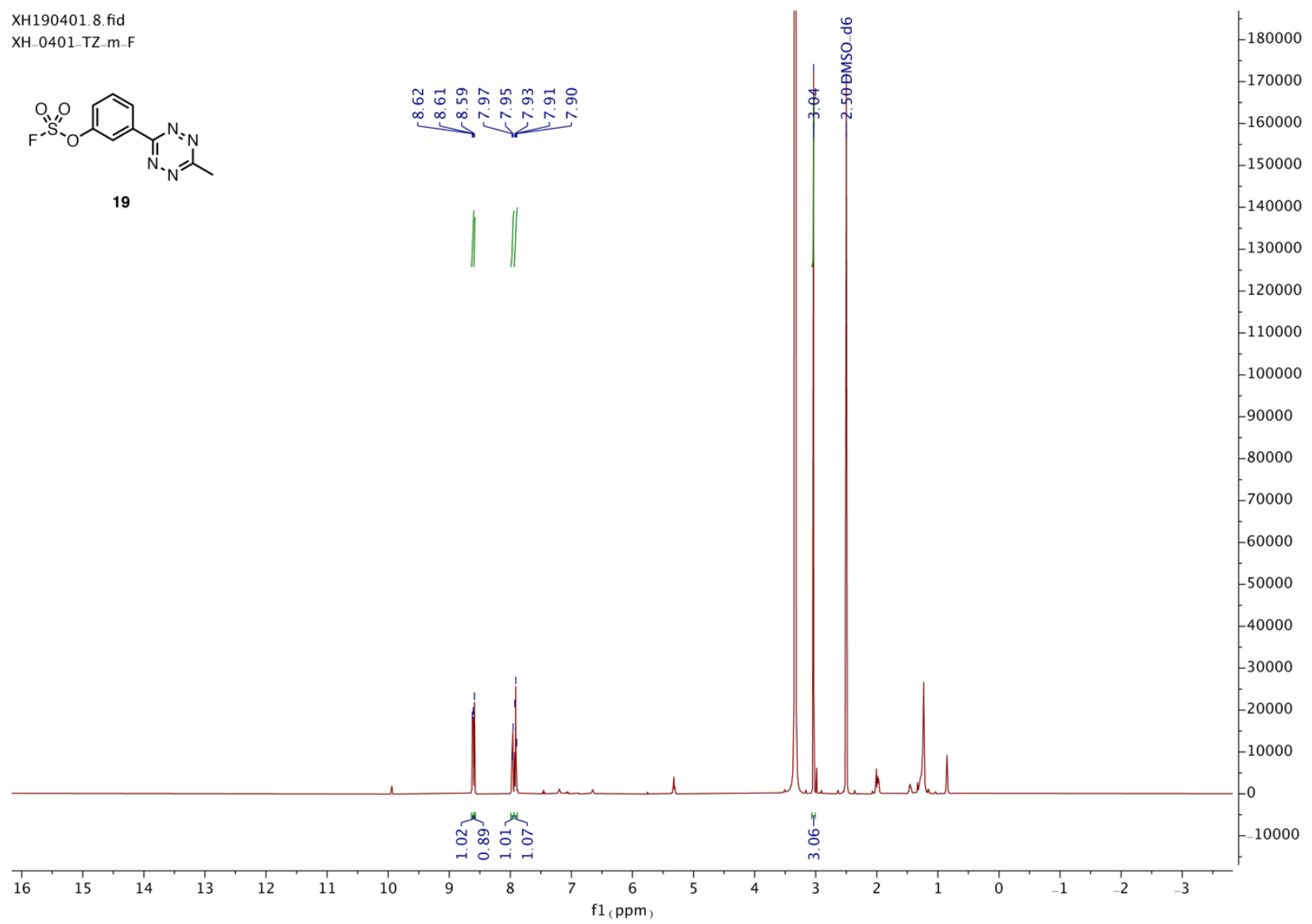

Fig. S83 | ${ }^{1} \mathrm{H}$ NMR of Compound 19. Solvent: DMSO-d6; Frequency: $500 \mathrm{MHz}$; Temperature: $298 \mathrm{~K}$. 


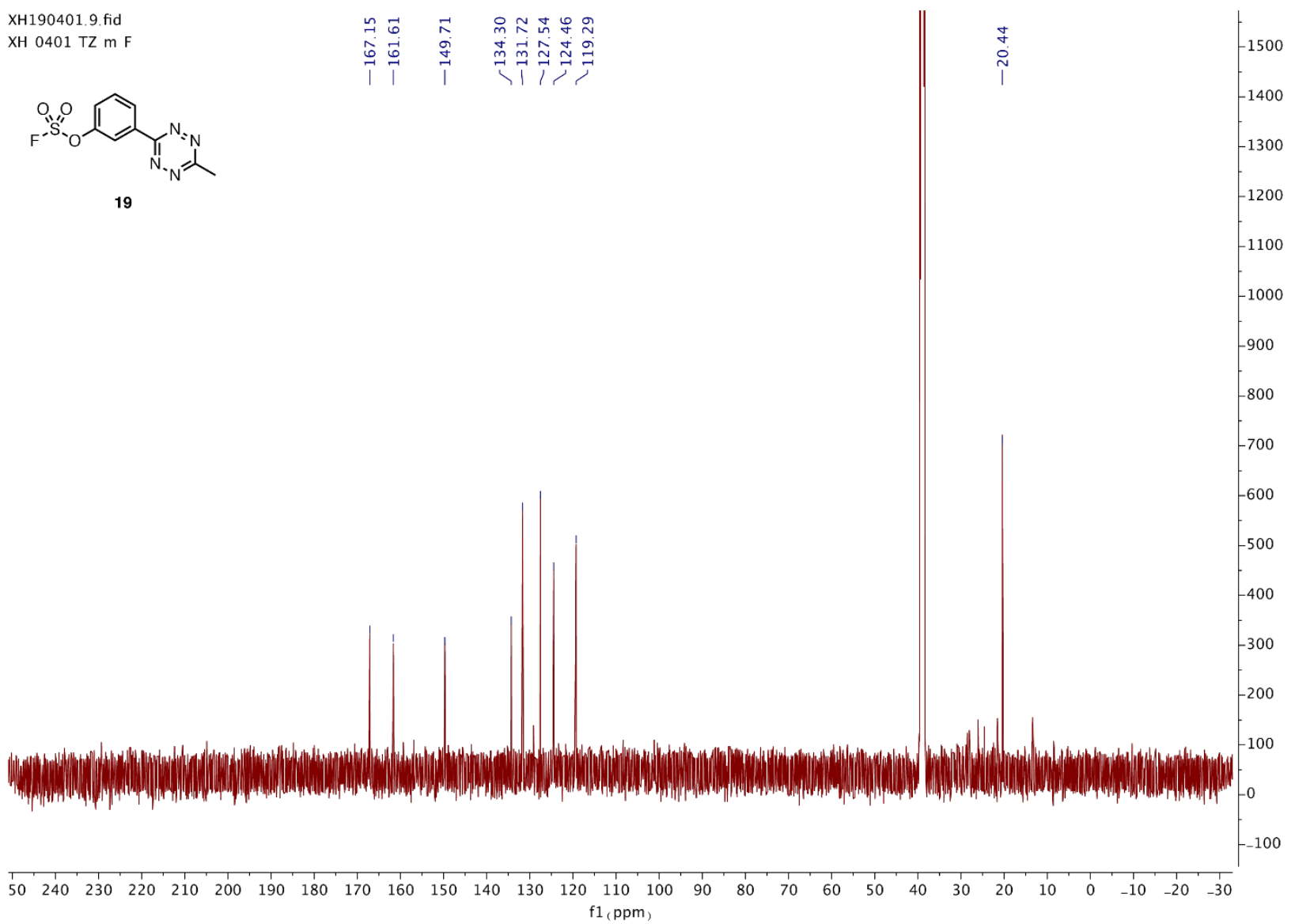

Fig. S84 | ${ }^{13} \mathrm{C}$ NMR of Compound 19. Solvent: DMSO-d6; Frequency: $126 \mathrm{MHz}$; Temperature: $298 \mathrm{~K}$. 

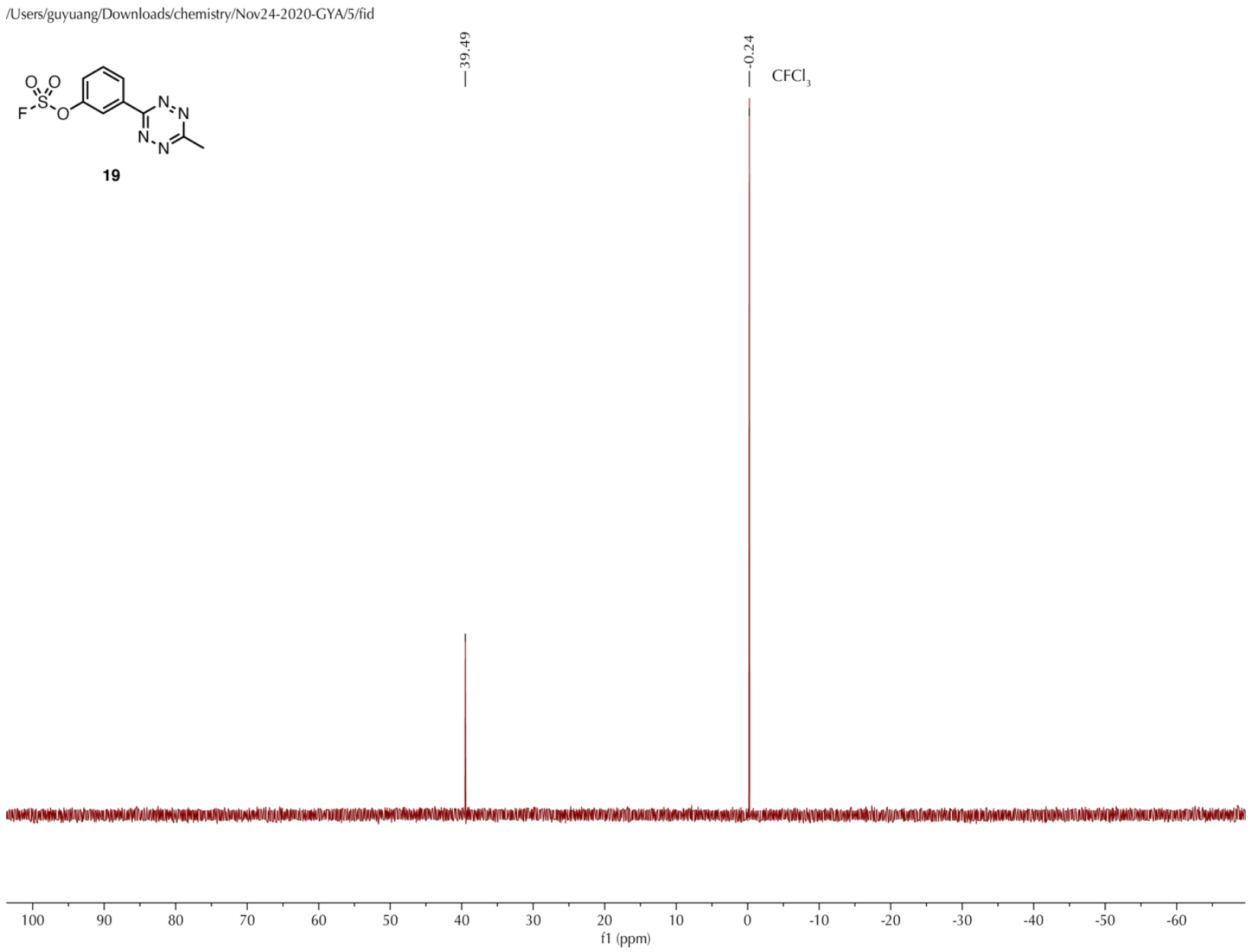

Fig. S85 | ${ }^{19} \mathrm{~F}$ NMR of Compound 19. Solvent: DMSO-d6, internal standard $\mathrm{CFCl}_{3}(\delta-0.24$ ppm); Frequency: $471 \mathrm{MHz}$; Temperature: $298 \mathrm{~K}$. 


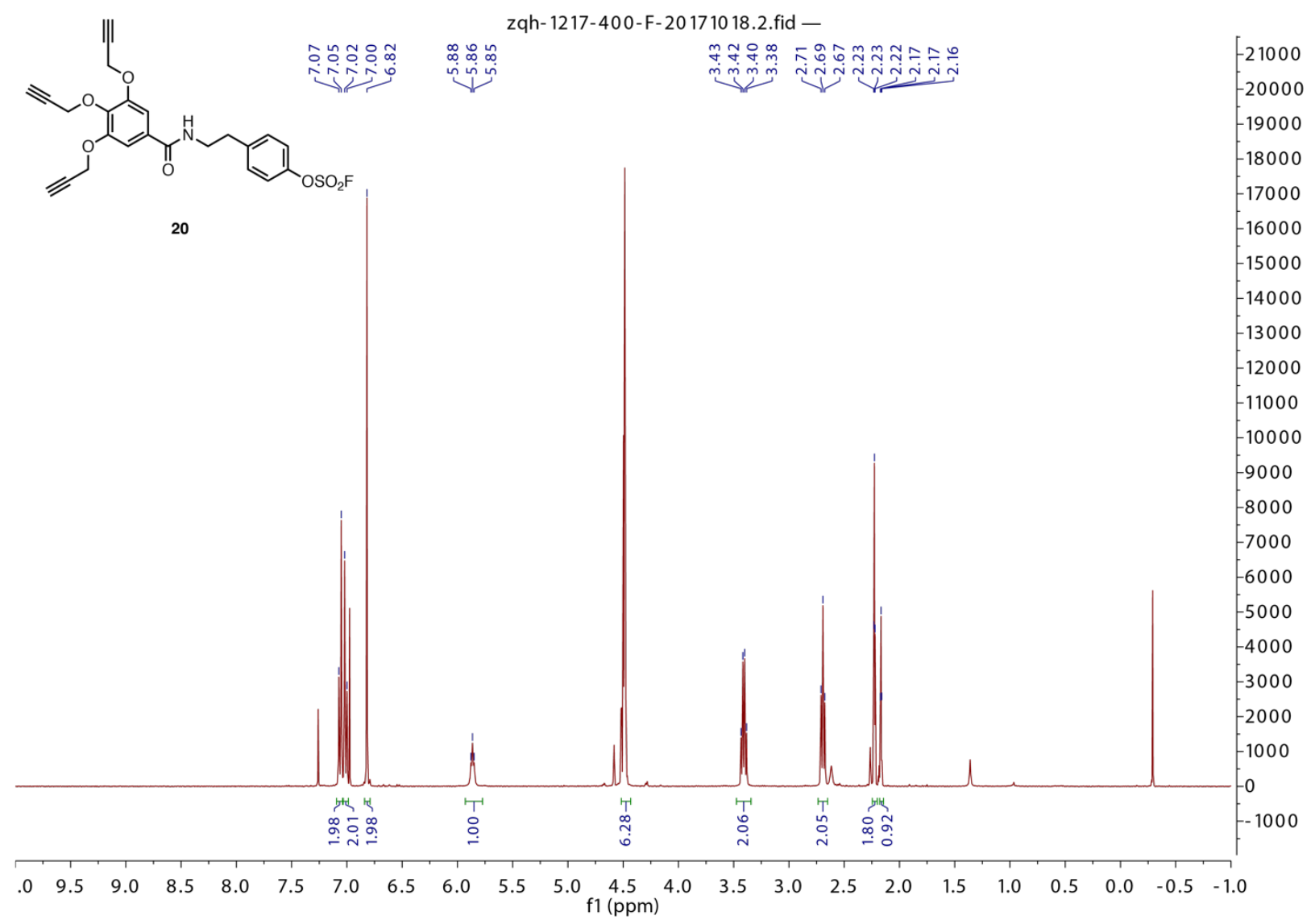

Fig. S86 | ${ }^{1} \mathrm{H}$ NMR of Compound 20. Solvent: $\mathrm{CDCl}_{3}$; Frequency: $400 \mathrm{MHz}$; Temperature: 298 $\mathrm{K}$. 


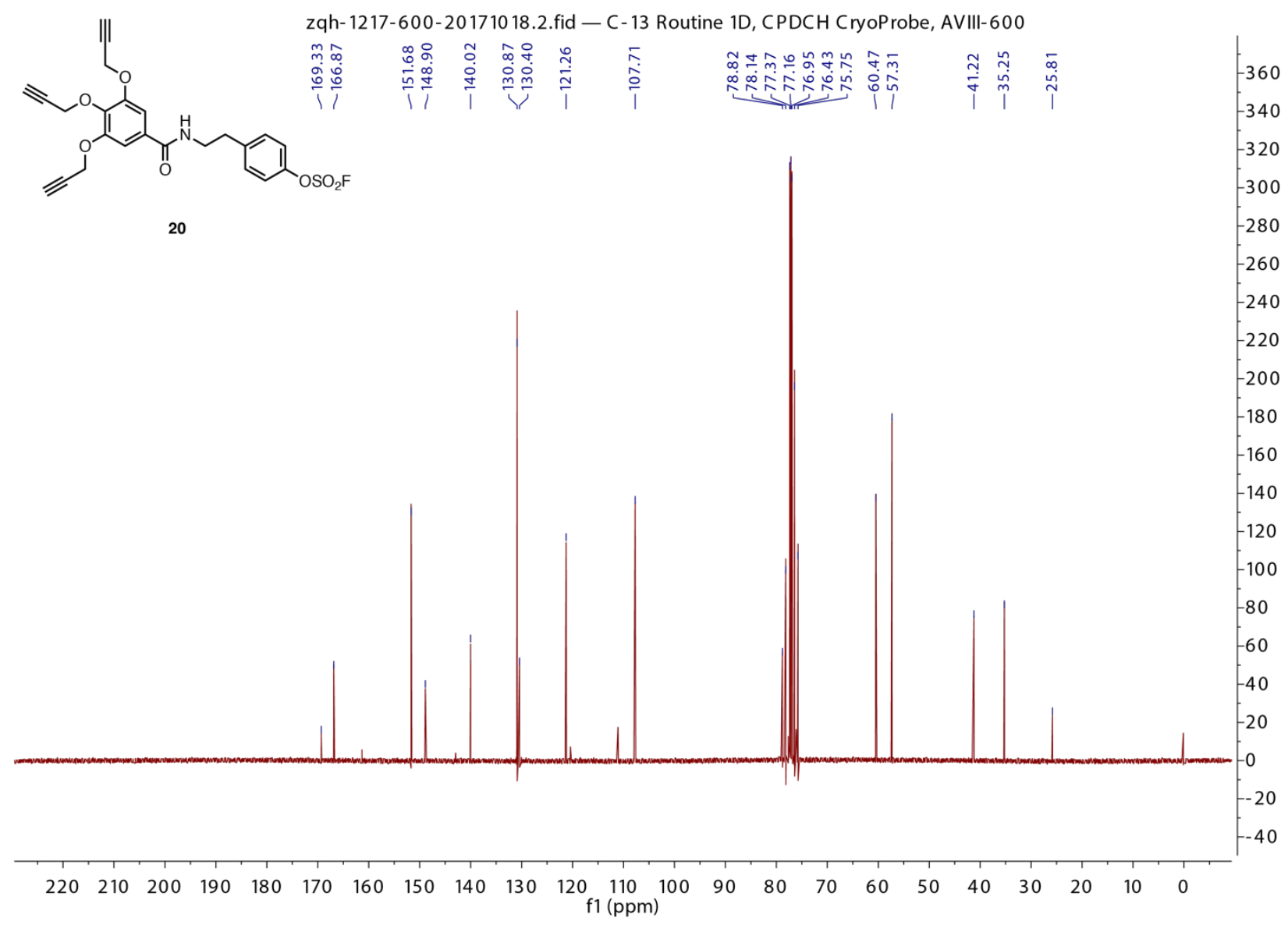

Fig. S87 | ${ }^{13} \mathrm{C}$ NMR of Compound 20. Solvent: $\mathrm{CDCl}_{3}$; Frequency: $151 \mathrm{MHz}$; Temperature: 298 $\mathrm{K}$. 


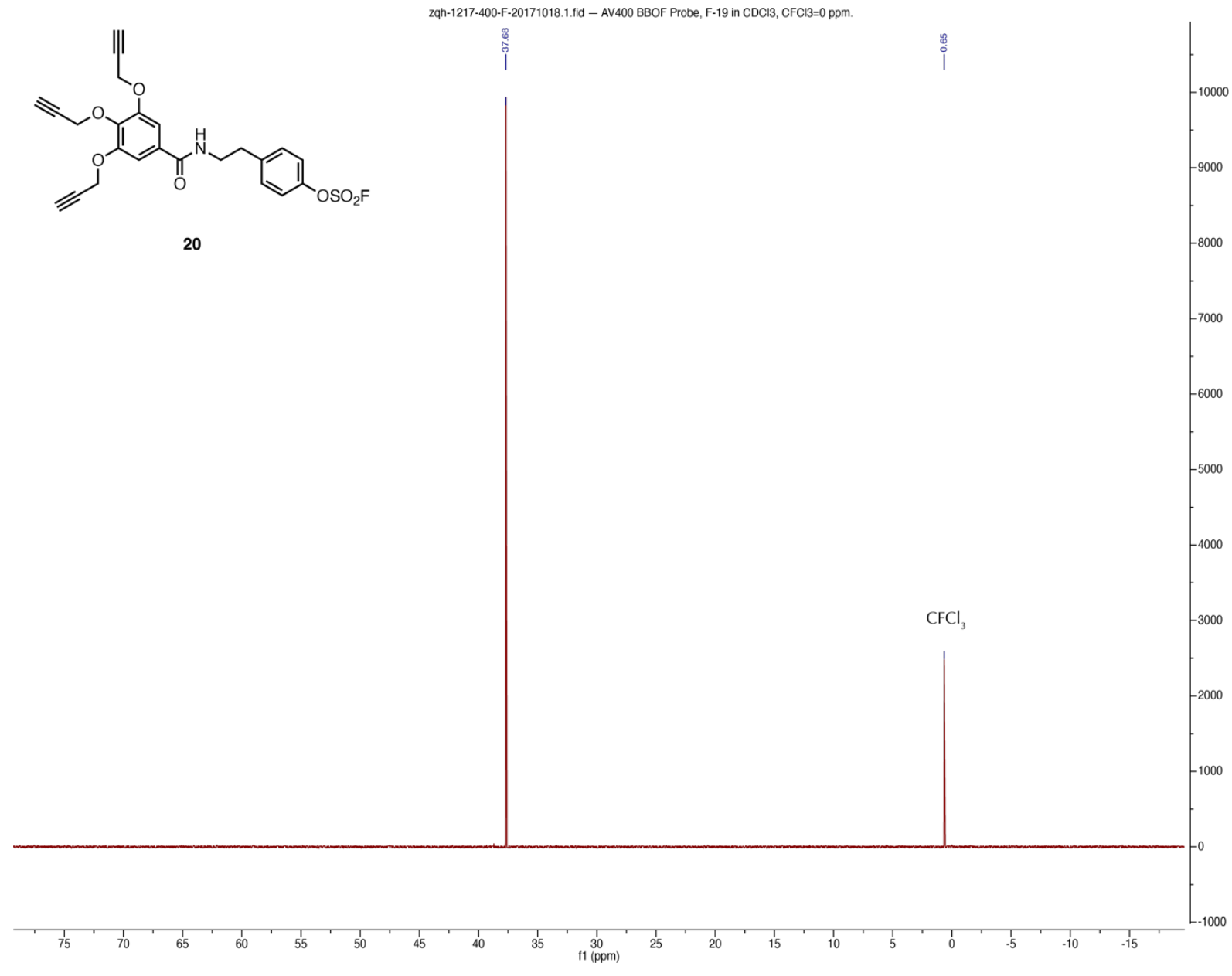

Fig. S88 | ${ }^{19}$ F NMR of Compound 20. Solvent: $\mathrm{CDCl}_{3}$, internal standard $\mathrm{CFCl}_{3}(\delta 0.65 \mathrm{ppm})$; Frequency: 376 MHz; Temperature: $298 \mathrm{~K}$. 


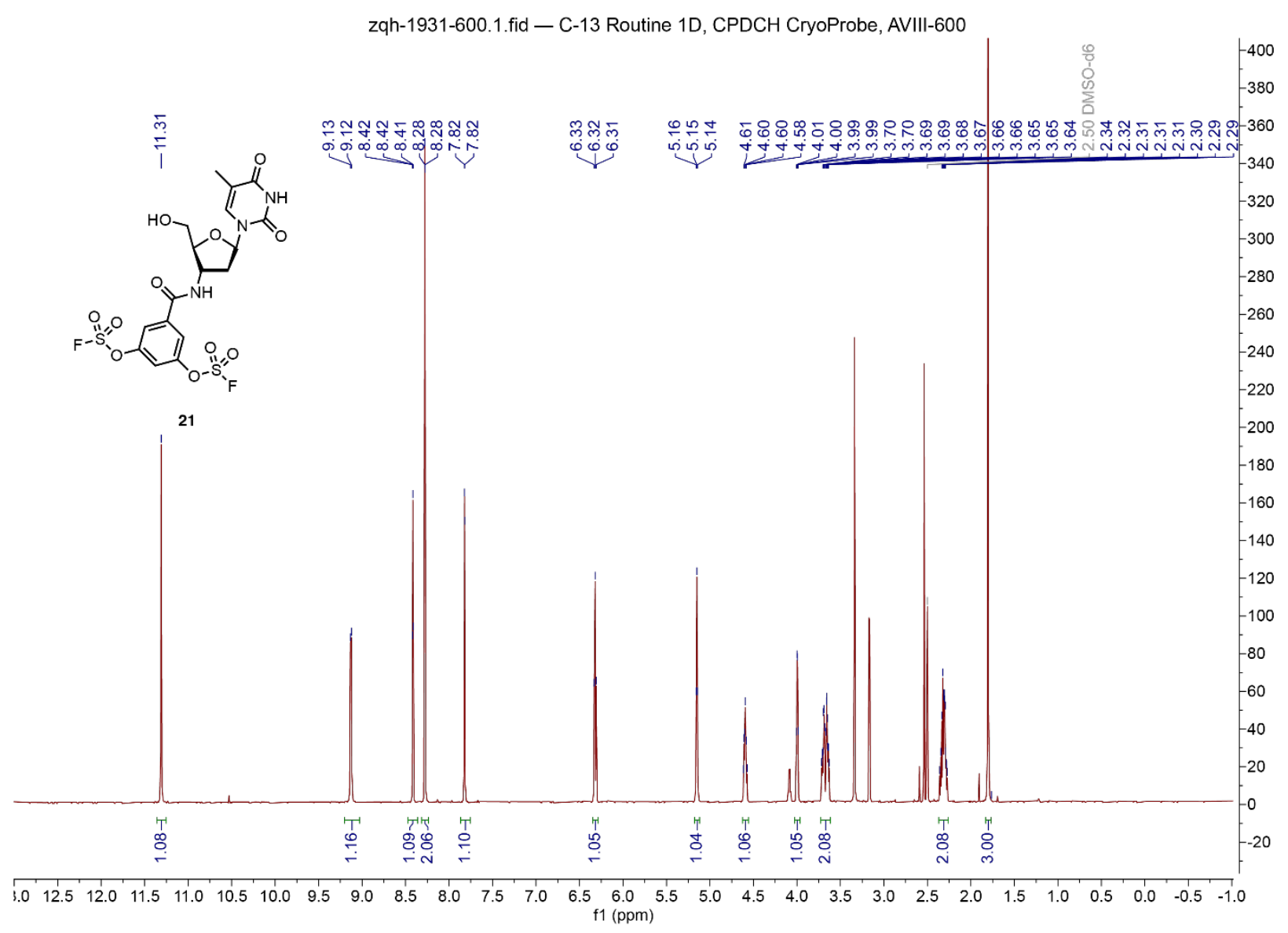

Fig. S89 | ${ }^{1} \mathrm{H}$ NMR of Compound 21. Solvent: DMSO-d6; Frequency: $600 \mathrm{MHz}$; Temperature: $298 \mathrm{~K}$. 

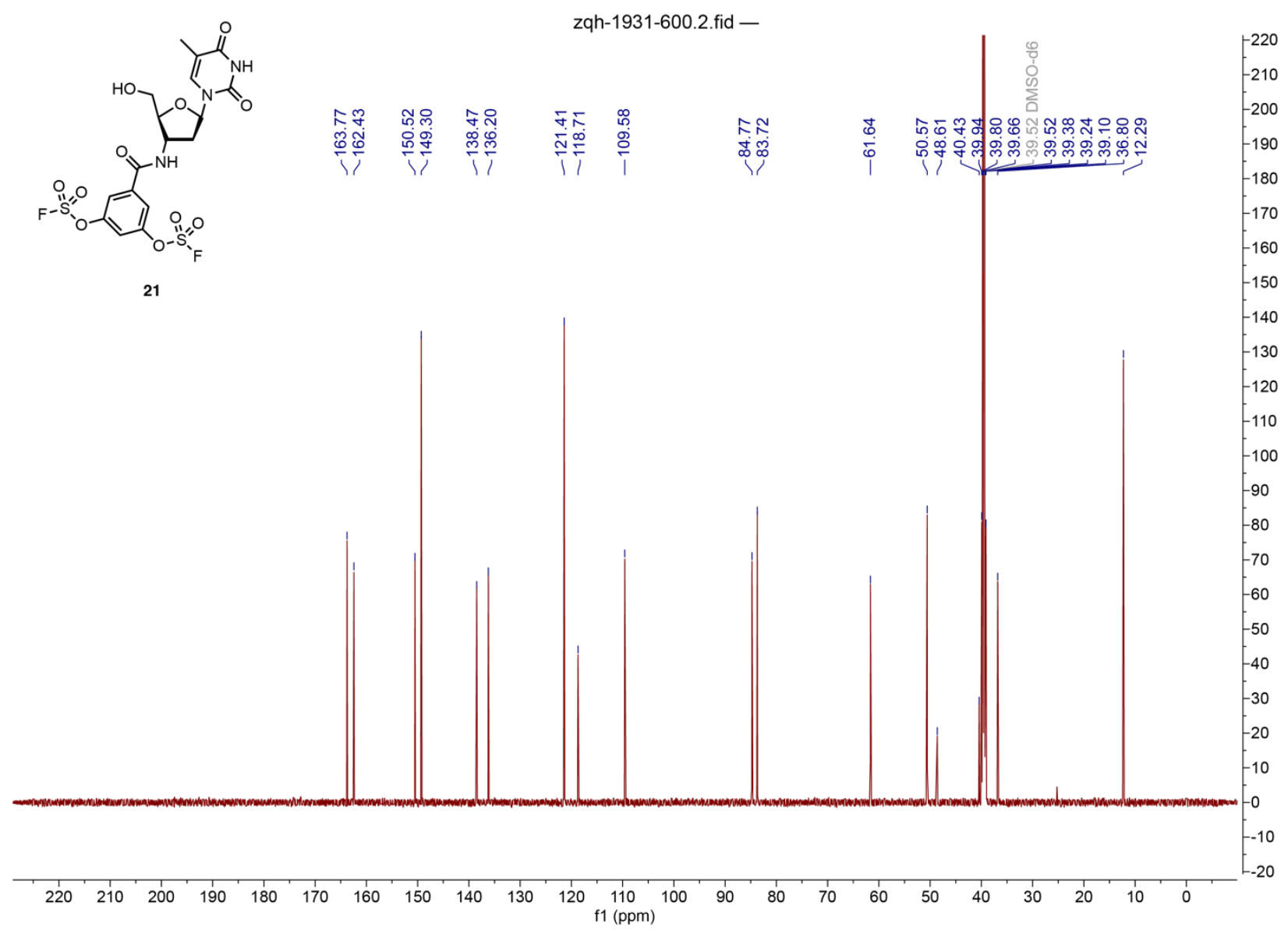

Fig. S90 | ${ }^{13} \mathrm{C}$ NMR of Compound 21. Solvent: DMSO-d6; Frequency: $151 \mathrm{MHz}$; Temperature: $298 \mathrm{~K}$. 
/Users/guyuang/Downloads/chemistry/Nov24-2020-GYA/6/fid

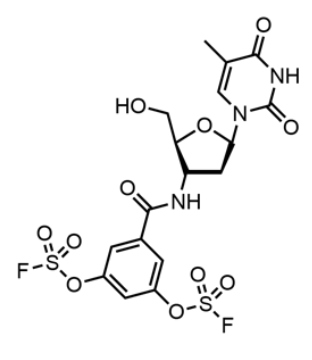

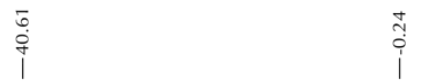

21

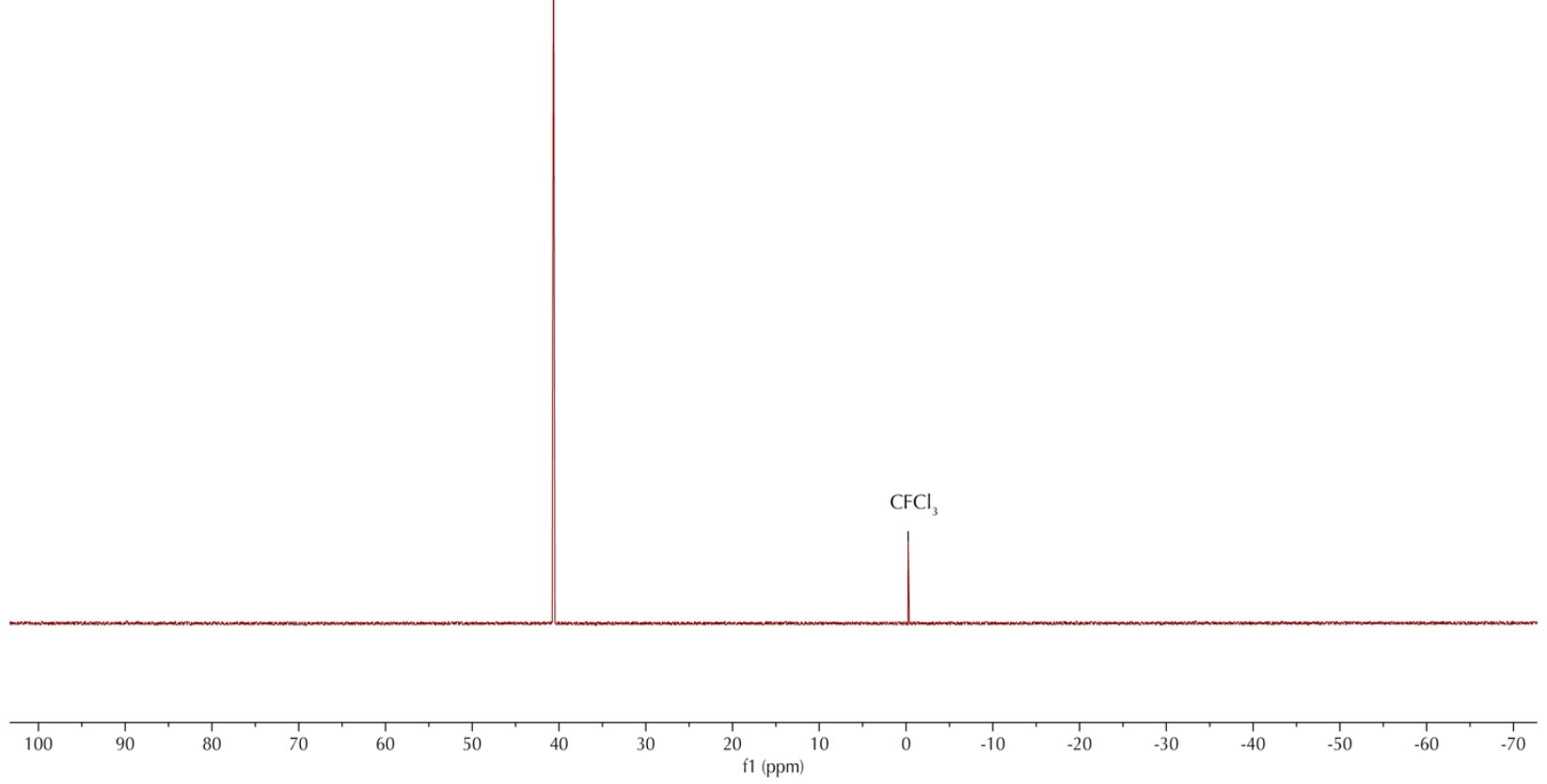

Fig. S91 | ${ }^{19} \mathrm{~F}$ NMR of Compound 21. Solvent: DMSO-d6, internal standard $\mathrm{CFCl}_{3}(\delta-0.24$ ppm); Frequency: $376 \mathrm{MHz}$; Temperature: $298 \mathrm{~K}$. 


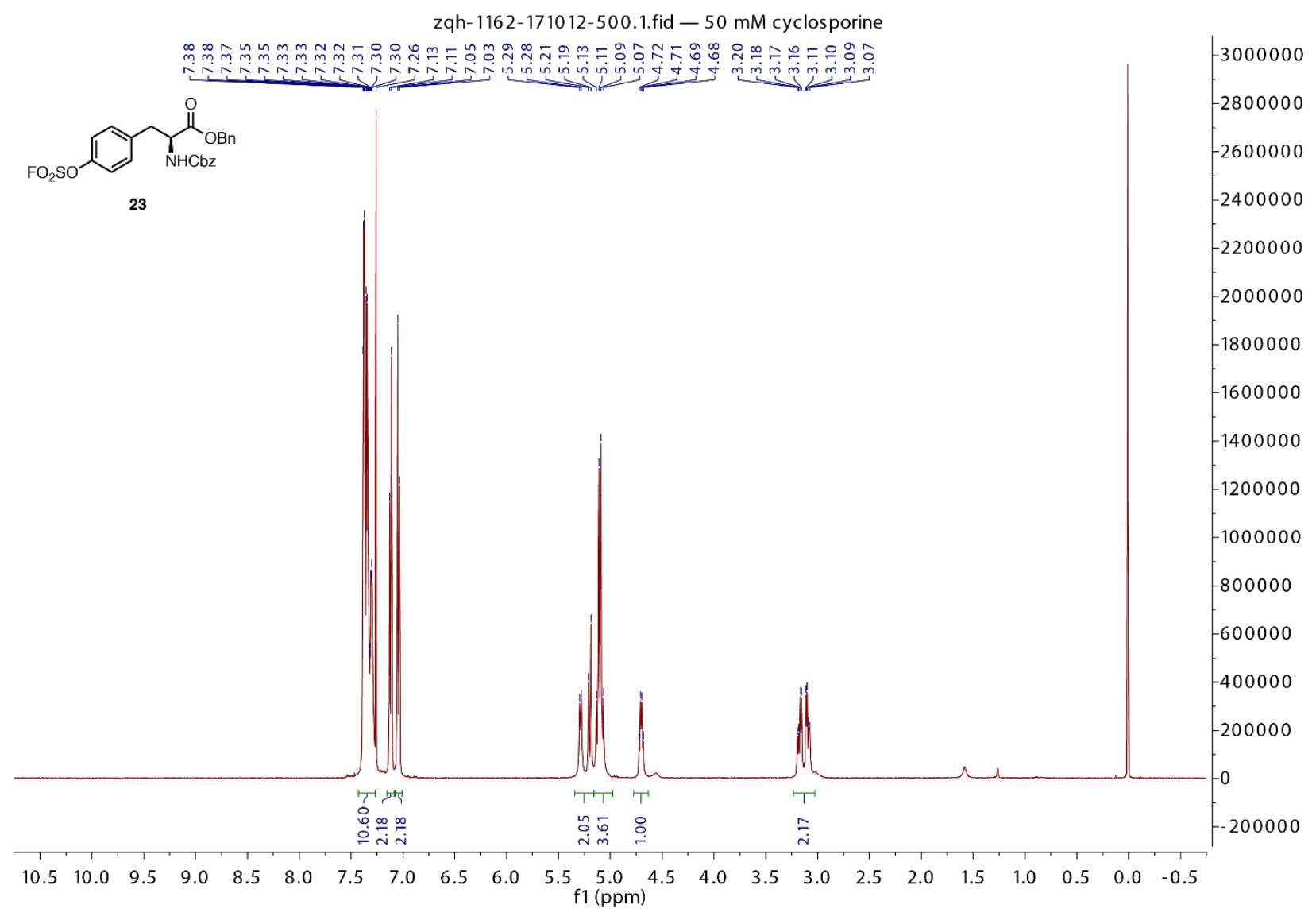

Fig. S92 | ${ }^{1} \mathrm{H}$ NMR of Compound 23. Solvent: $\mathrm{CDCl}_{3}$; Frequency: $500 \mathrm{MHz}$; Temperature: 298 $\mathrm{K}$. 


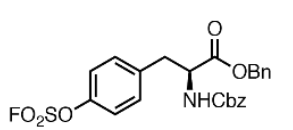

23

zqh-1162-171012-500.2.fid - AV NEO 500, C-13 Routine, 5-25-2017

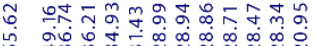

望

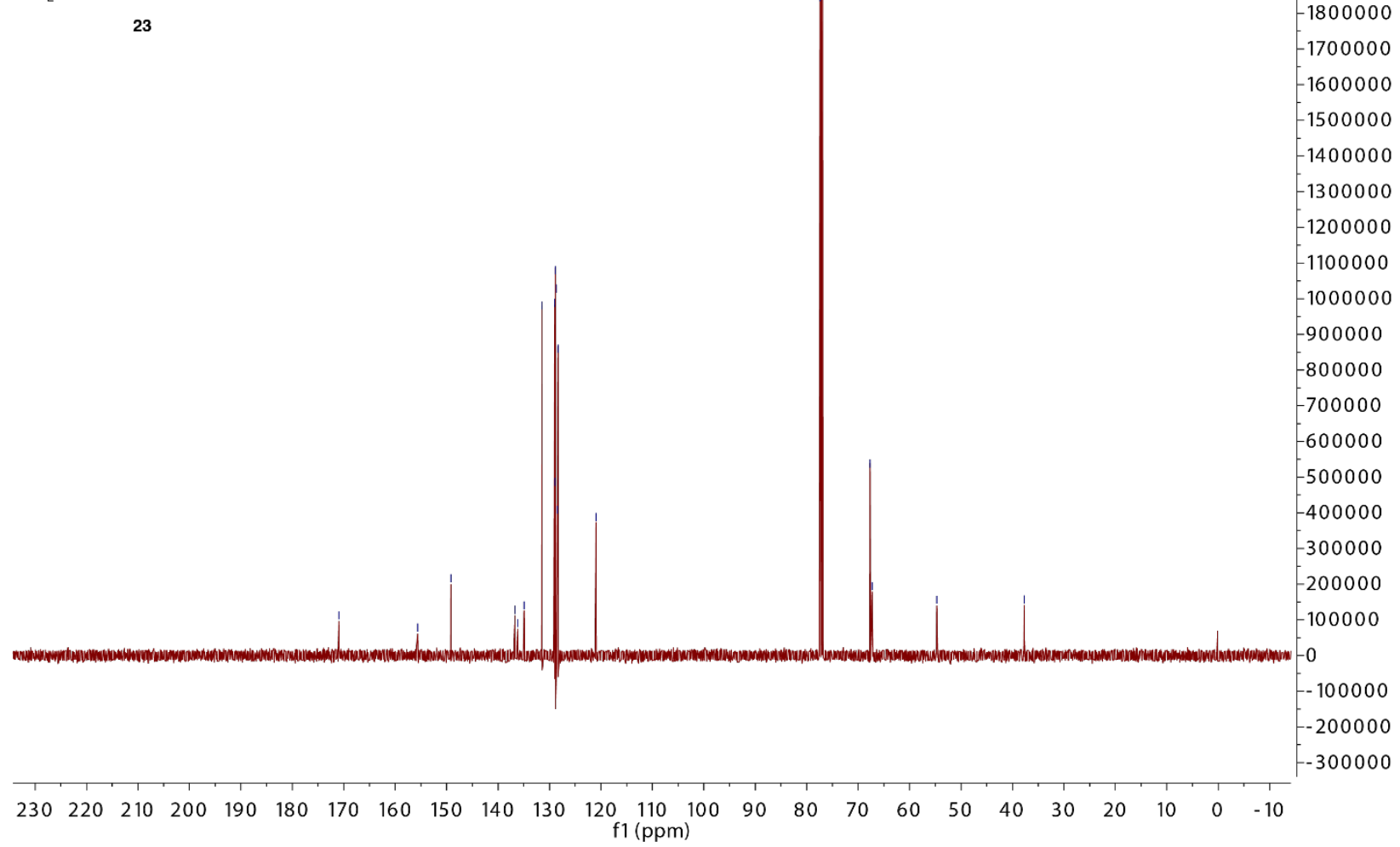

Fig. S93 $\mid{ }^{13} \mathrm{C}$ NMR of Compound 23. Solvent: $\mathrm{CDCl}_{3}$; Frequency: $126 \mathrm{MHz}$; Temperature: 298 $\mathrm{K}$. 

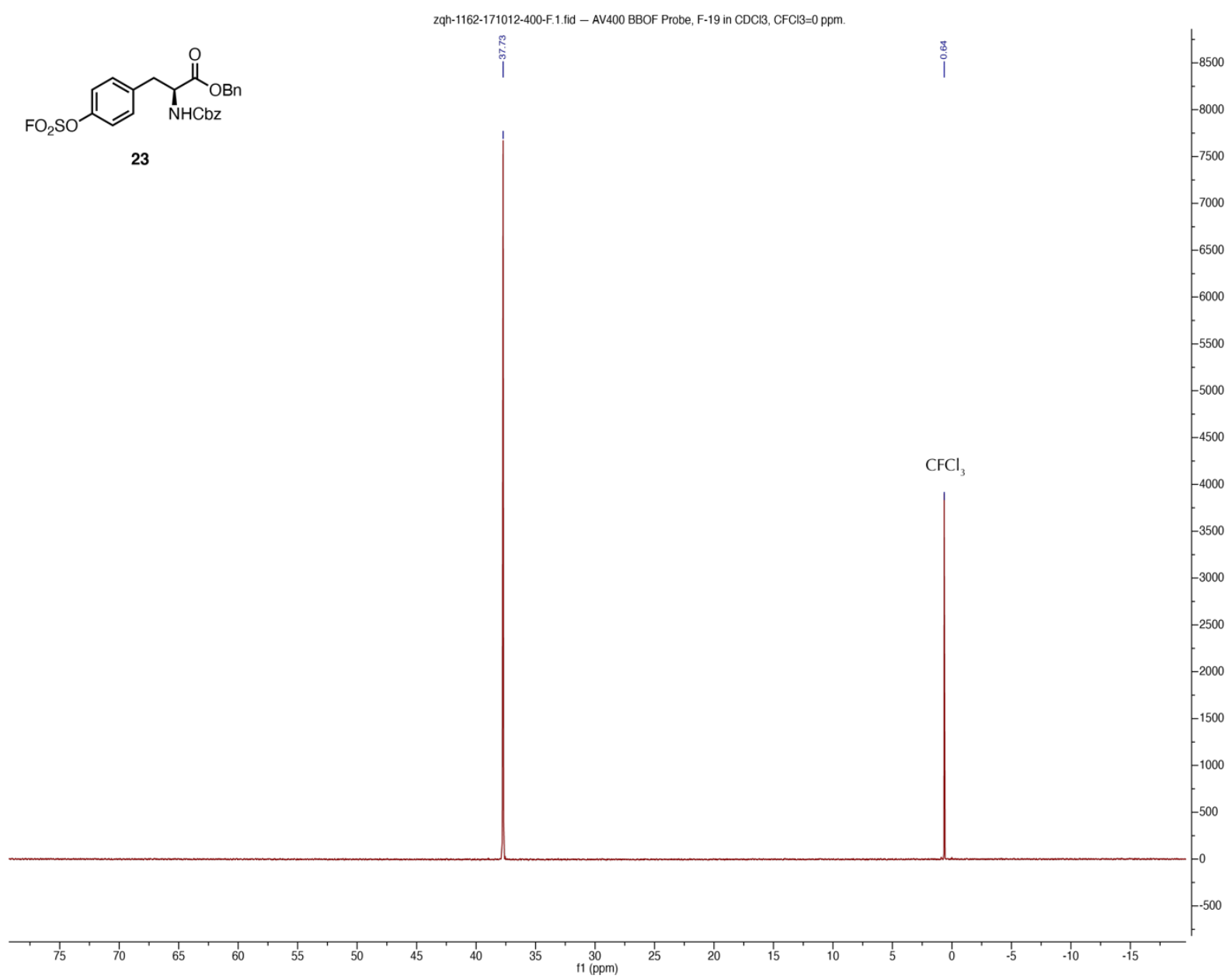

Fig. S94 | ${ }^{19} \mathrm{~F}$ NMR of Compound 23. Solvent: $\mathrm{CDCl}_{3}$, internal standard $\mathrm{CFCl}_{3}$ ( $\left.\delta 0.65 \mathrm{ppm}\right)$; Frequency: 376 MHz; Temperature: $298 \mathrm{~K}$. 
zqh-1458-500.1.fid - $50 \mathrm{mM}$ cyclosporine

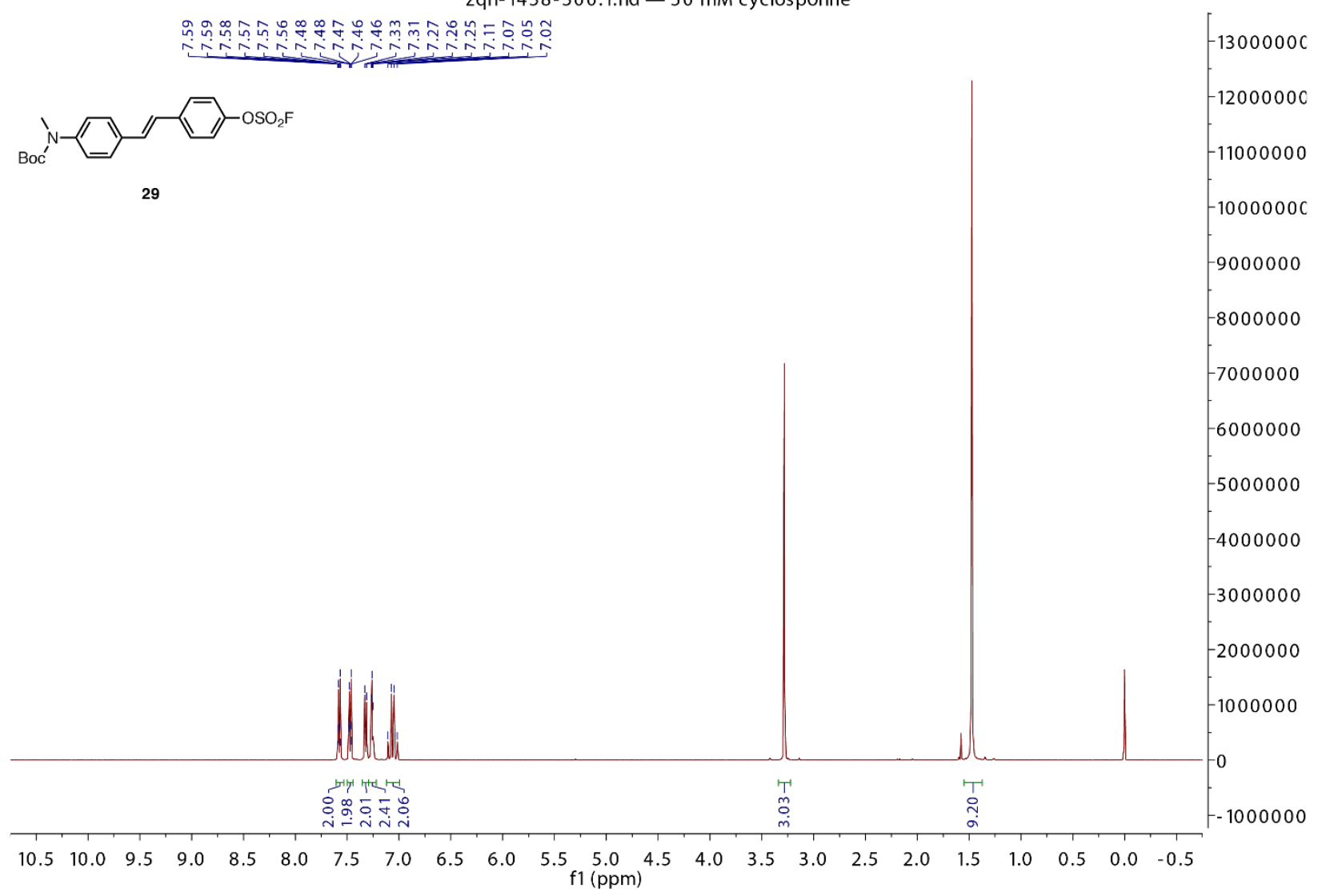

Fig. S95 | ${ }^{1} \mathrm{H}$ NMR of Compound 29. Solvent: $\mathrm{CDCl}_{3}$; Frequency: $500 \mathrm{MHz}$; Temperature: 298 $\mathrm{K}$. 
zqh-1458-500.2.fid - AV NEO 500, C-13 Routine, 5-25-2017

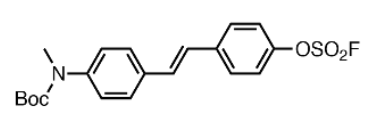

29

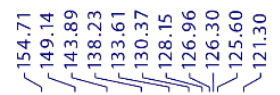

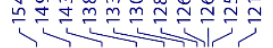

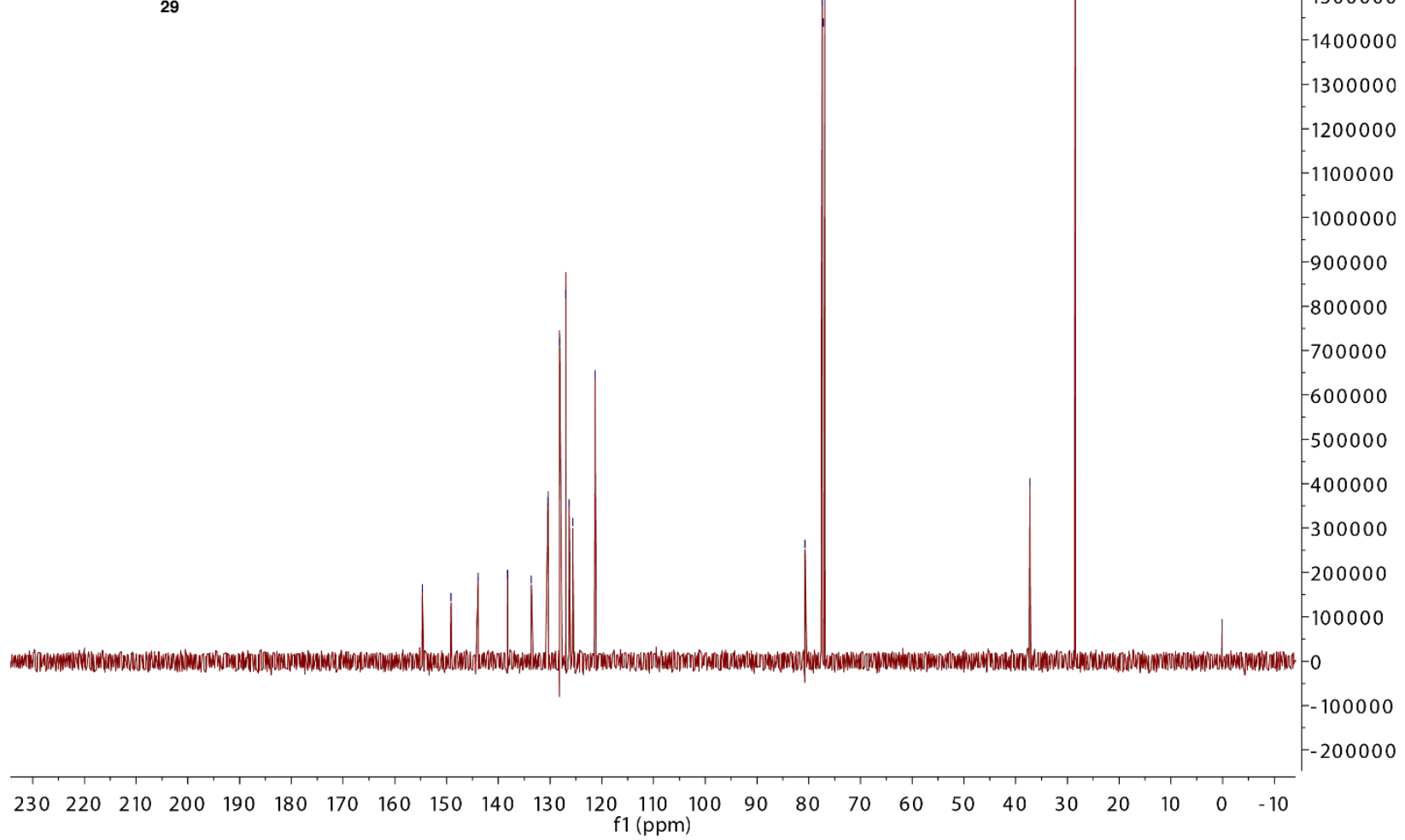

Fig. S96 $\mid{ }^{13} \mathrm{C}$ NMR of Compound 29. Solvent: $\mathrm{CDCl}_{3}$; Frequency: $126 \mathrm{MHz}$; Temperature: 298 $\mathrm{K}$. 


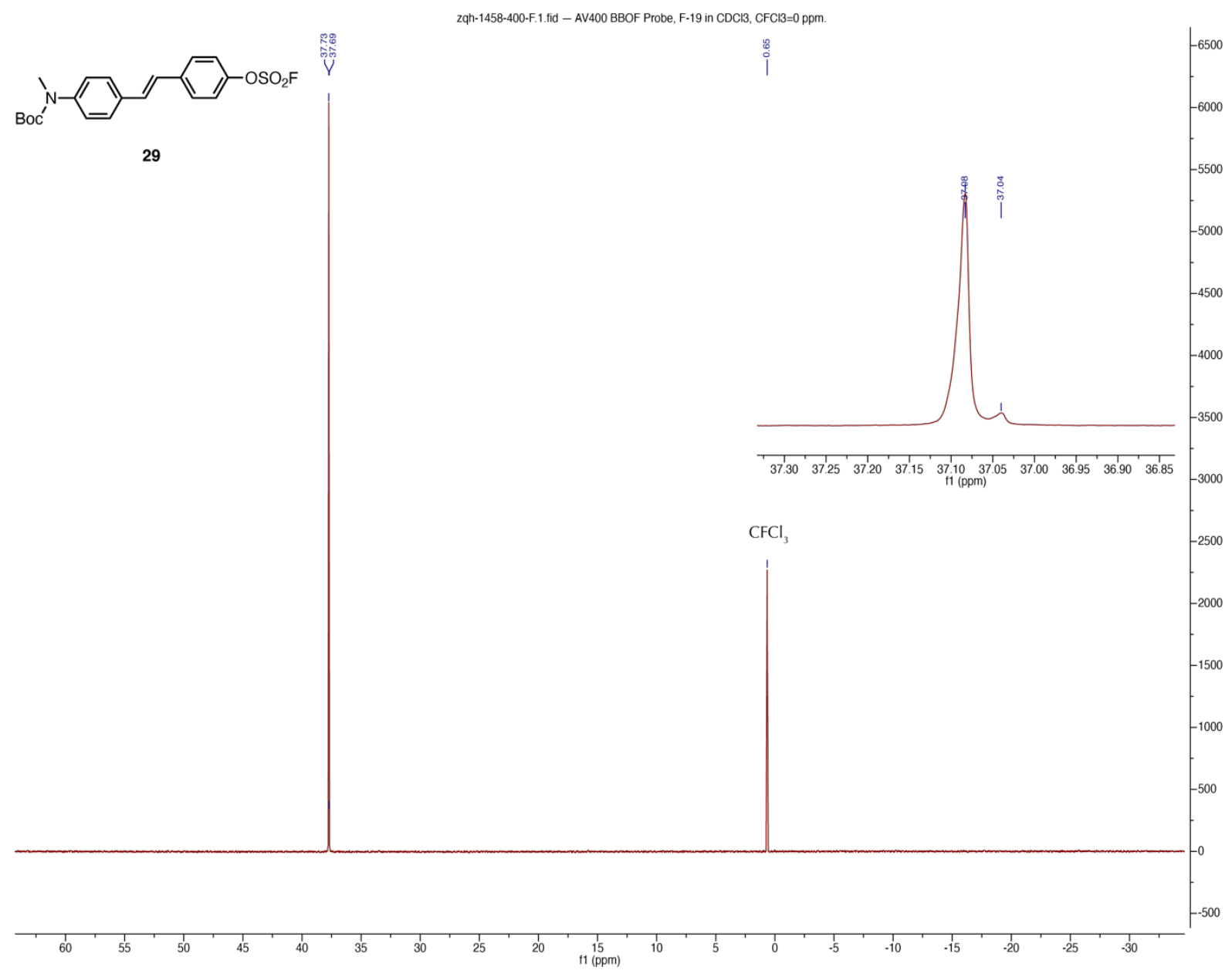

Fig. S97 | ${ }^{19}$ F NMR of Compound 29. Solvent: $\mathrm{CDCl}_{3}$, internal standard $\mathrm{CFCl}_{3}(\delta 0.65 \mathrm{ppm})$; Frequency: $376 \mathrm{MHz}$; Temperature: $298 \mathrm{~K}$. 
zqh-1287-600.1.fid - H-1 Routine, CP-DCH, AVIII HD-600 $\underbrace{0}$

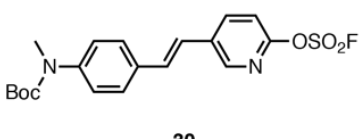

30

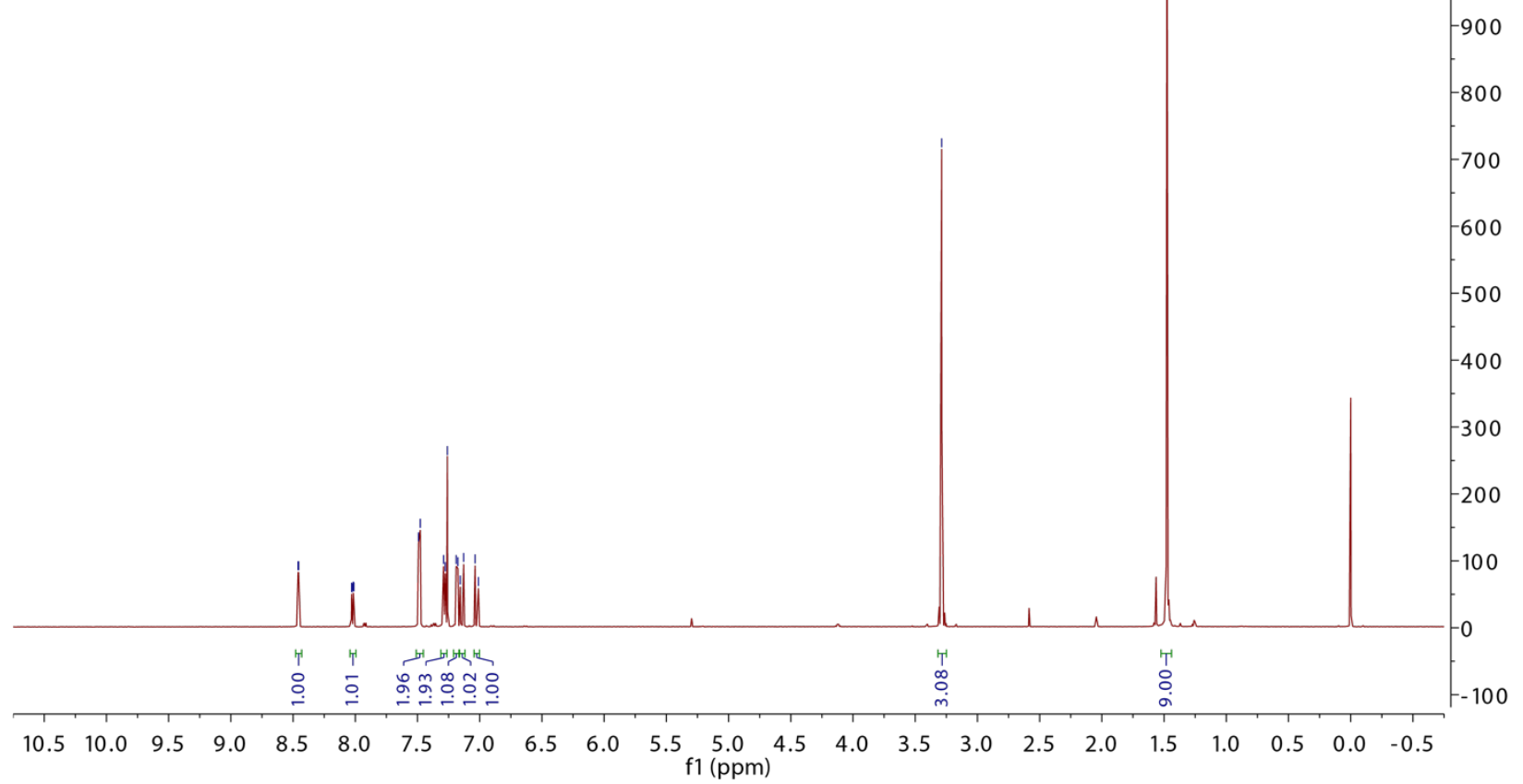

Fig. S98 | ${ }^{1} \mathrm{H}$ NMR of Compound 30. Solvent: $\mathrm{CDCl}_{3}$; Frequency: $600 \mathrm{MHz}$; Temperature: 298 $\mathrm{K}$. 


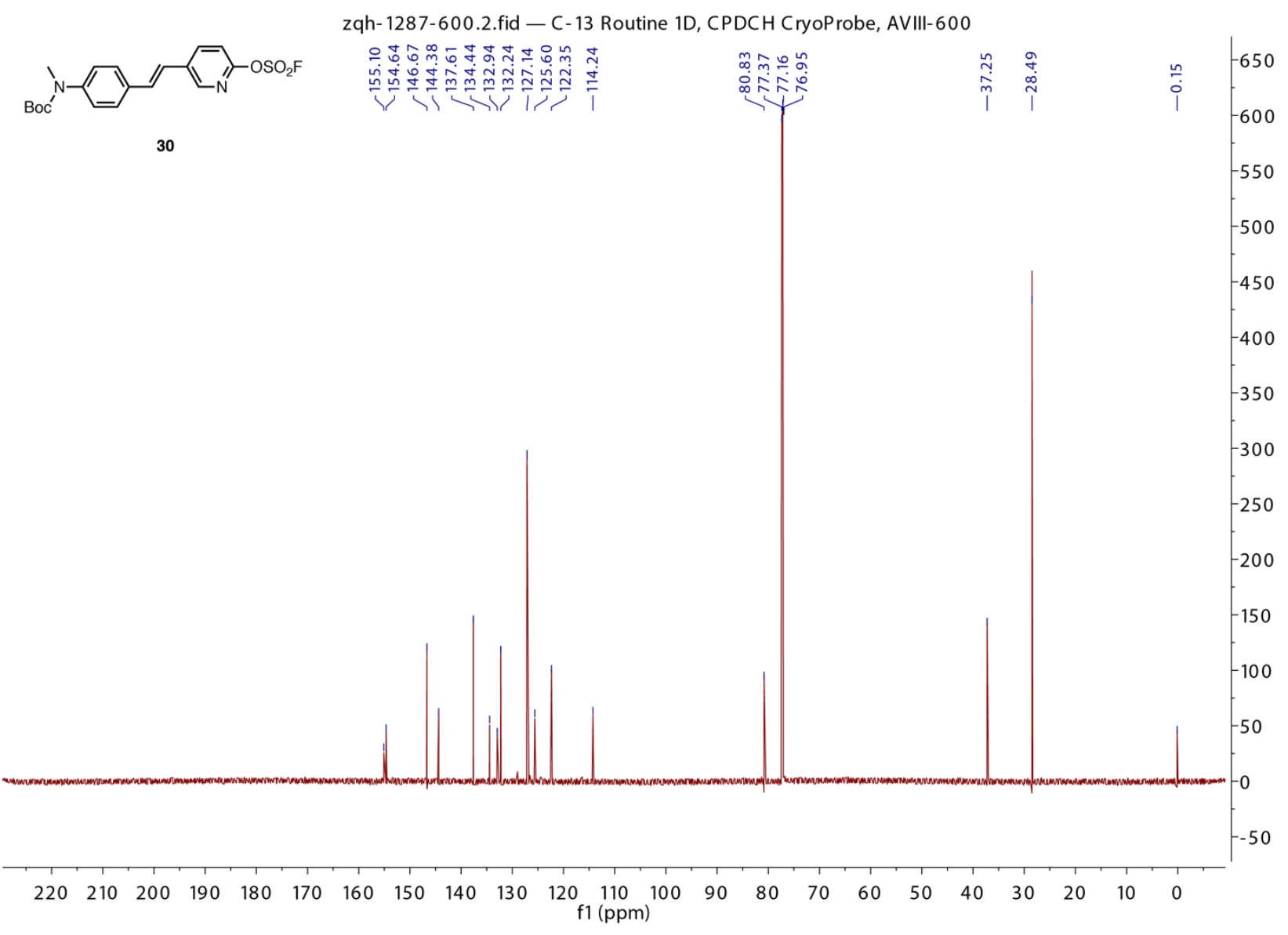

Fig. S99 | ${ }^{13} \mathrm{C}$ NMR of Compound 30. Solvent: $\mathrm{CDCl}_{3}$; Frequency: $151 \mathrm{MHz}$; Temperature: 298 $\mathrm{K}$. 


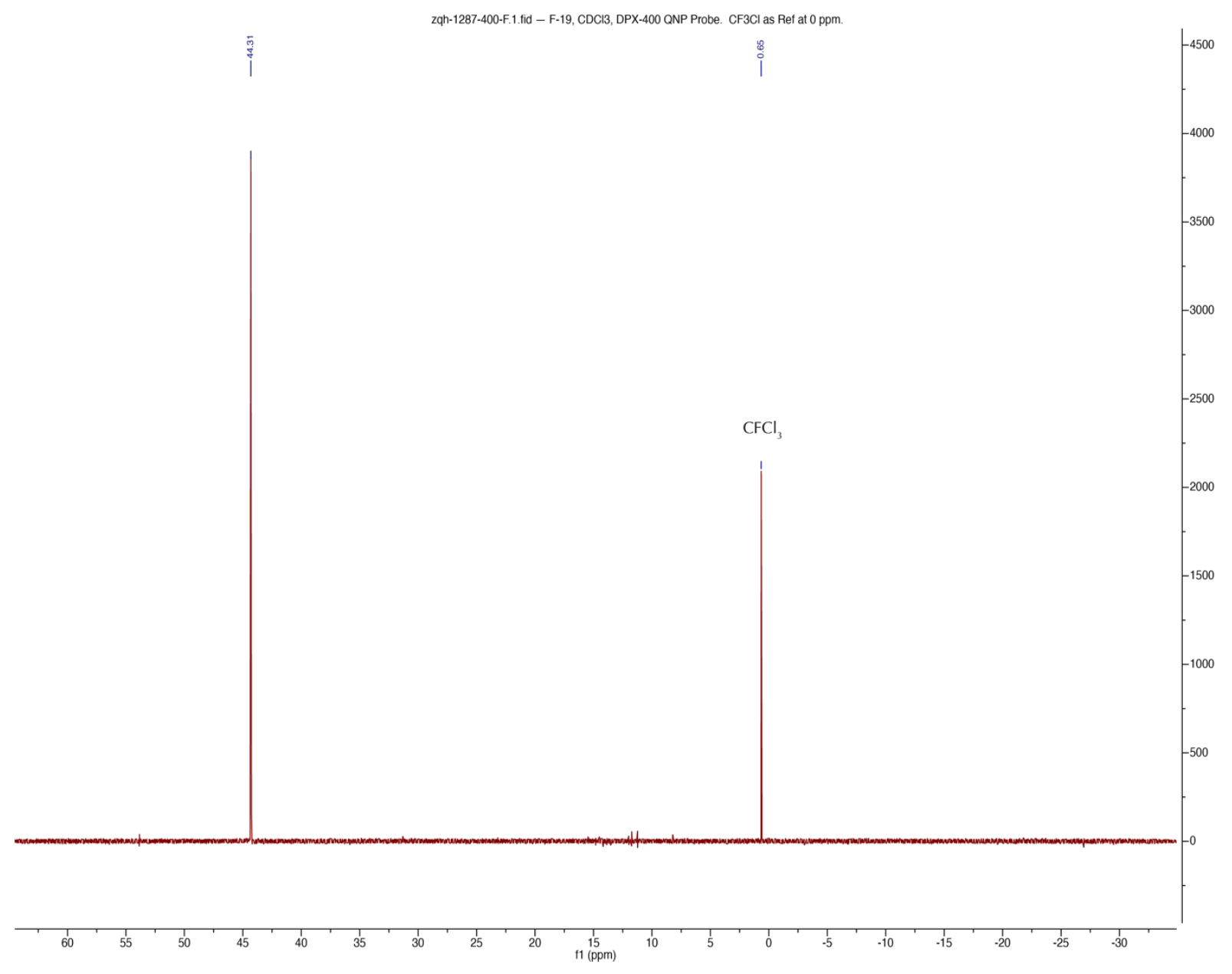

Fig. S100 | ${ }^{19} \mathrm{~F}$ NMR of Compound 30. Solvent: $\mathrm{CDCl}_{3}$, internal standard $\mathrm{CFCl}_{3}$ ( $\left.\delta 0.65 \mathrm{ppm}\right)$; Frequency: $376 \mathrm{MHz}$; Temperature: $298 \mathrm{~K}$. 


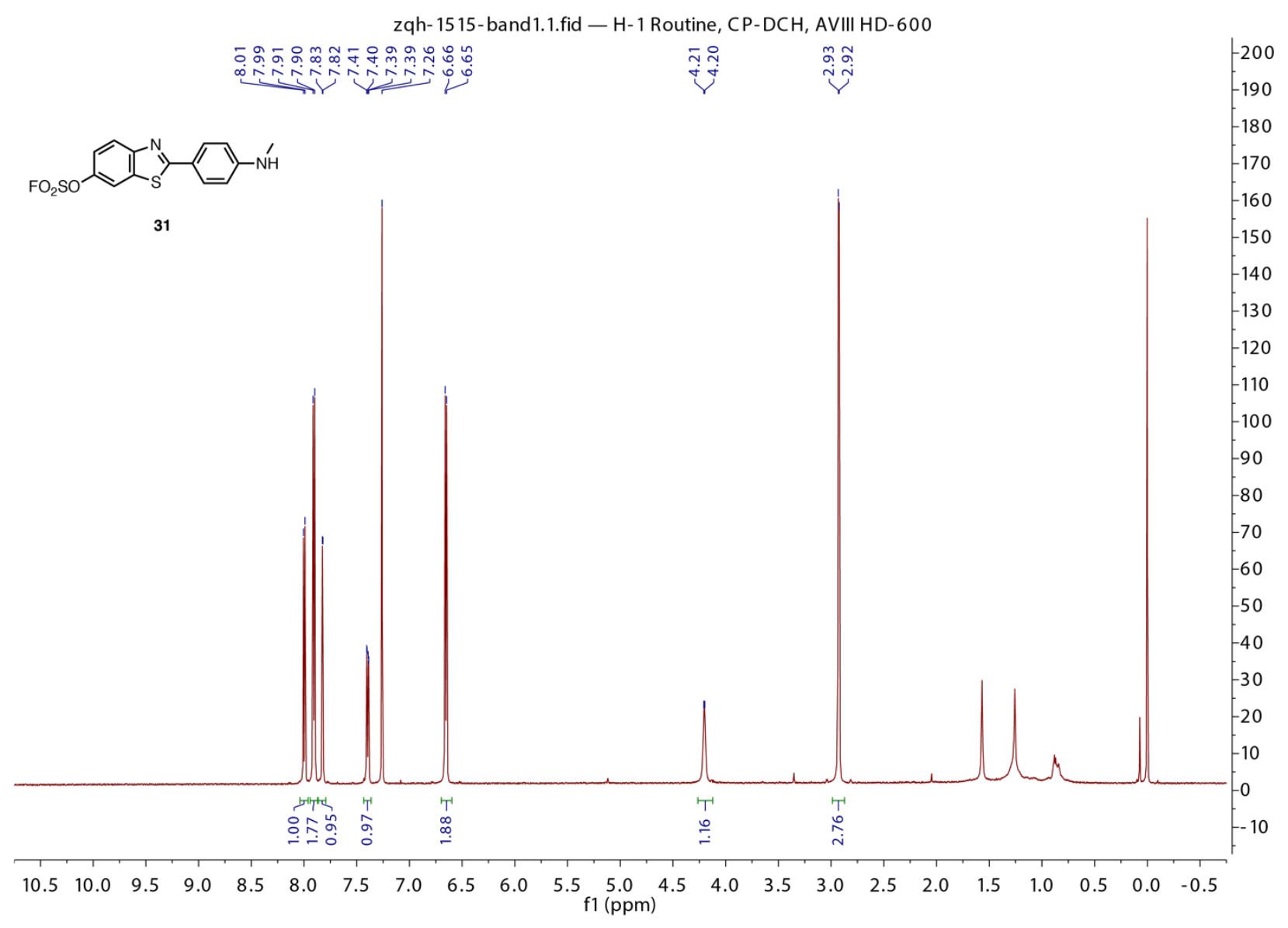

Fig. S101 | ${ }^{1} \mathrm{H}$ NMR of Compound 31. Solvent: $\mathrm{CDCl}_{3}$; Frequency: $600 \mathrm{MHz}$; Temperature: $298 \mathrm{~K}$. 


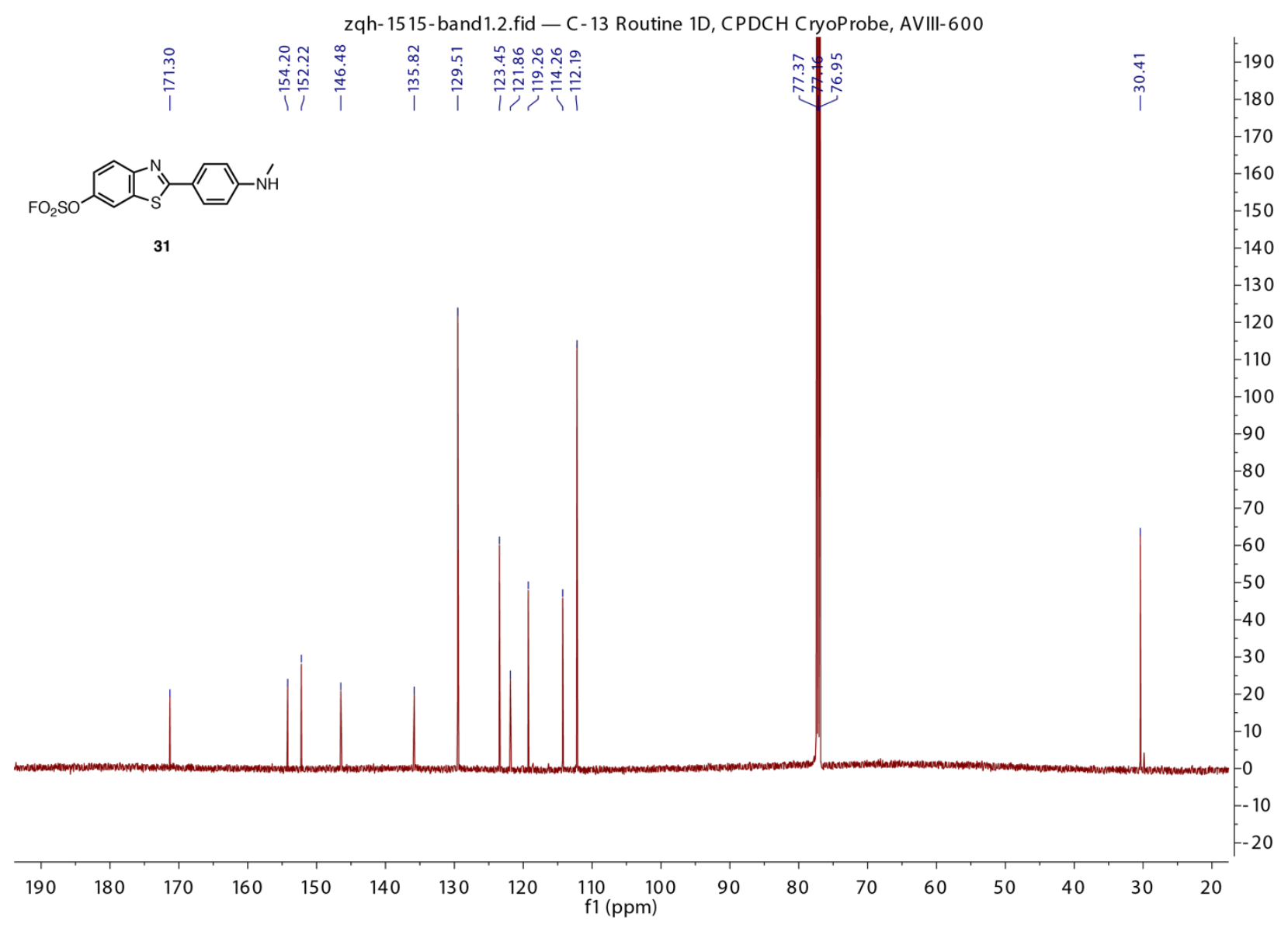

Fig. S102 | ${ }^{13} \mathrm{C}$ NMR of Compound 31. Solvent: $\mathrm{CDCl}_{3}$; Frequency: $151 \mathrm{MHz}$; Temperature: $298 \mathrm{~K}$. 


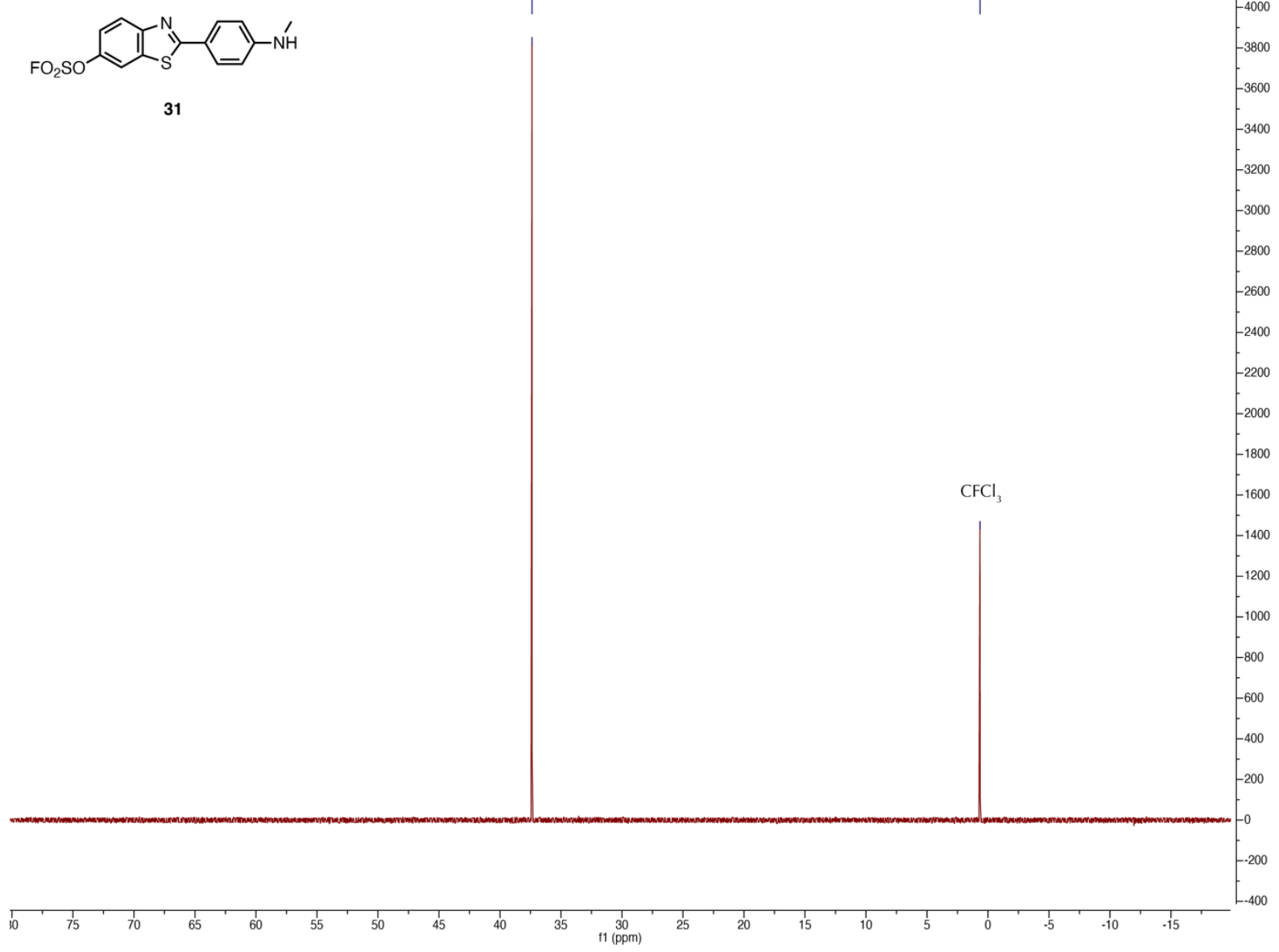

Fig. S103 | ${ }^{19} \mathrm{~F}$ NMR of Compound 31. Solvent: $\mathrm{CDCl}_{3}$, internal standard $\mathrm{CFCl}_{3}$ ( $\left.\delta 0.65 \mathrm{ppm}\right)$; Frequency: $376 \mathrm{MHz}$; Temperature: $298 \mathrm{~K}$. 


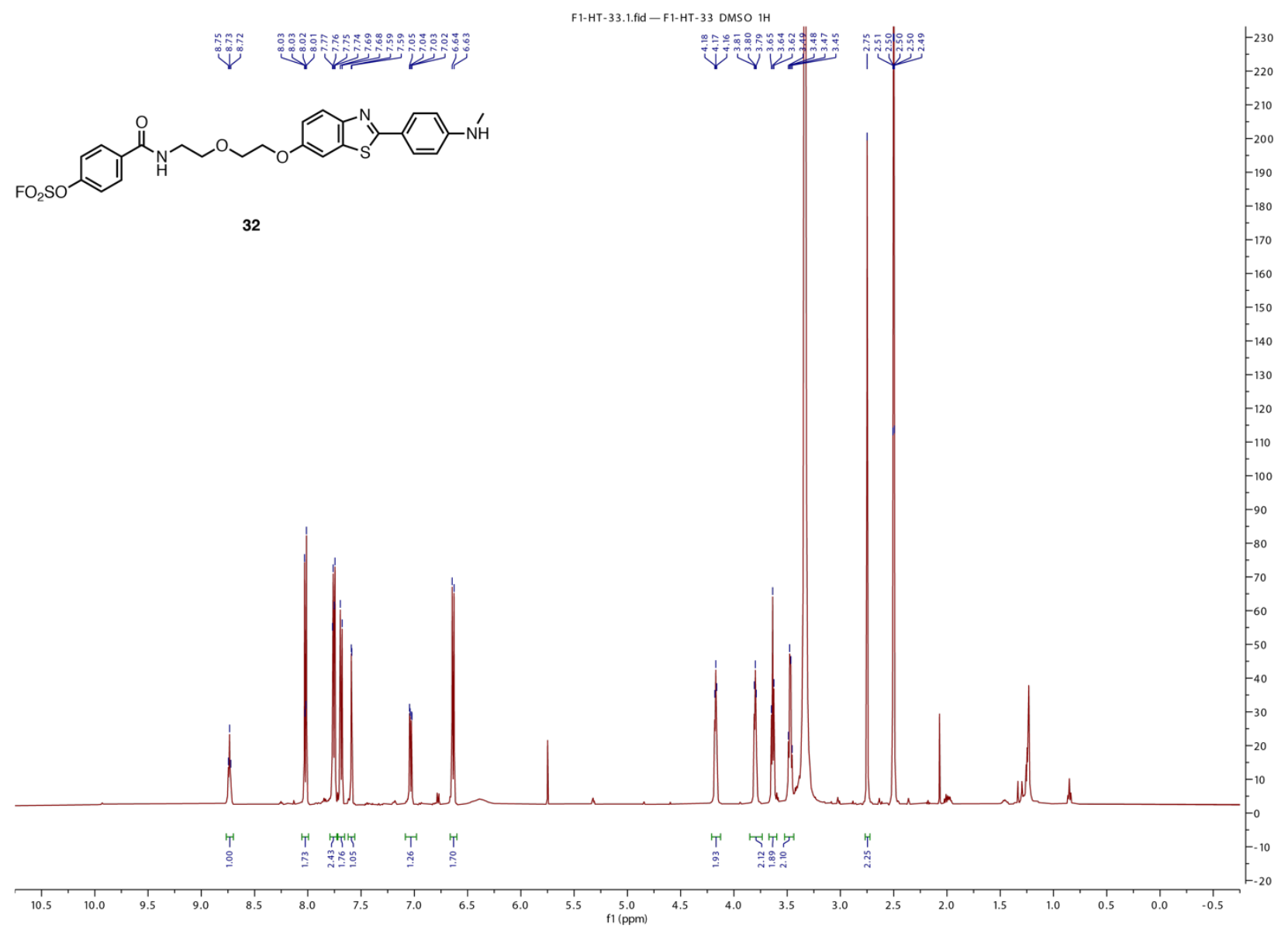

Fig. S104 | ${ }^{1} \mathrm{H}$ NMR of Compound 32. Solvent: DMSO-d6; Frequency: $600 \mathrm{MHz}$; Temperature: $298 \mathrm{~K}$. 


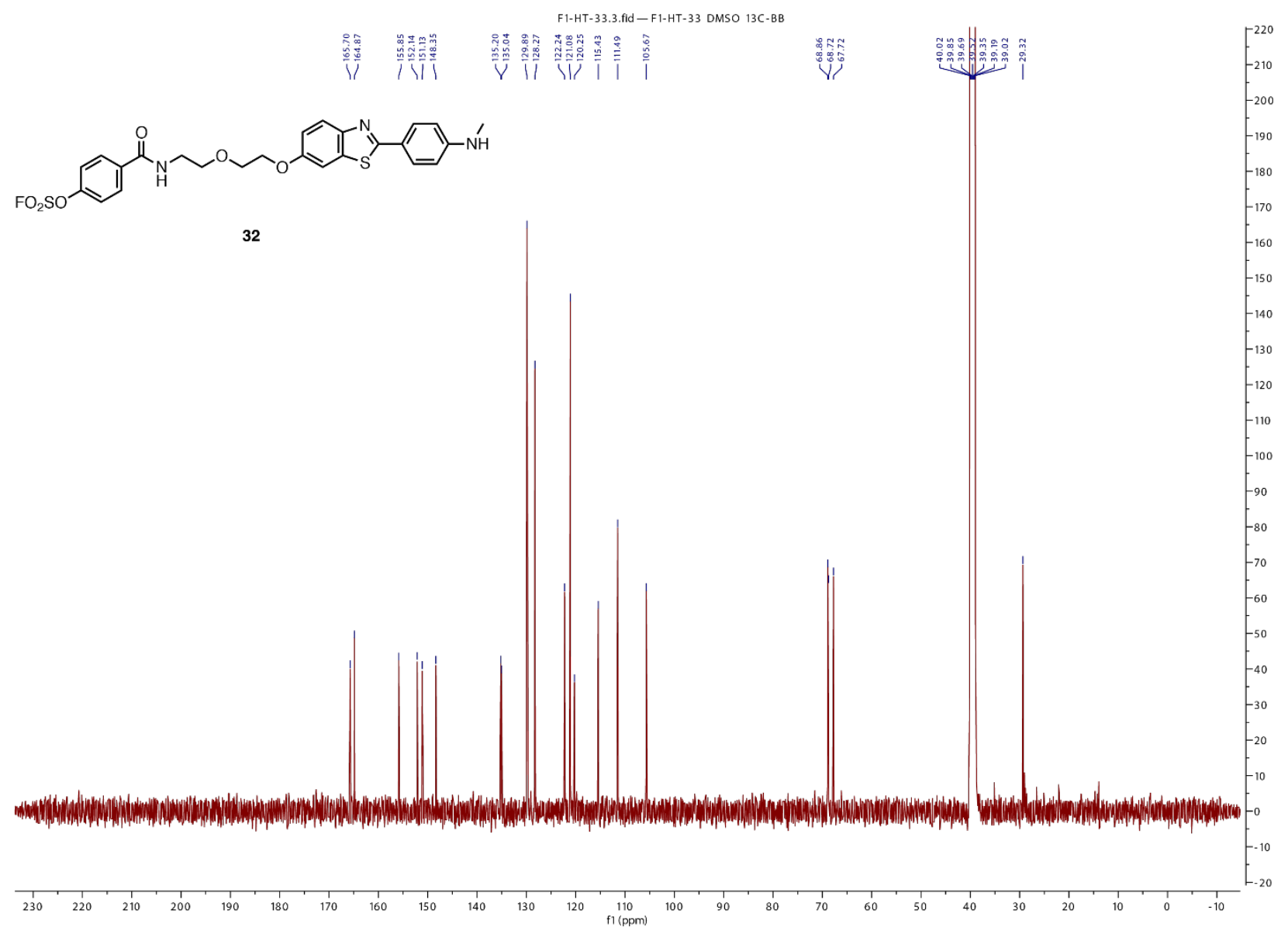

Fig. S105 | ${ }^{13} \mathrm{C}$ NMR of Compound 32. Solvent: DMSO-d6; Frequency: $151 \mathrm{MHz}$;

Temperature: $298 \mathrm{~K}$. 


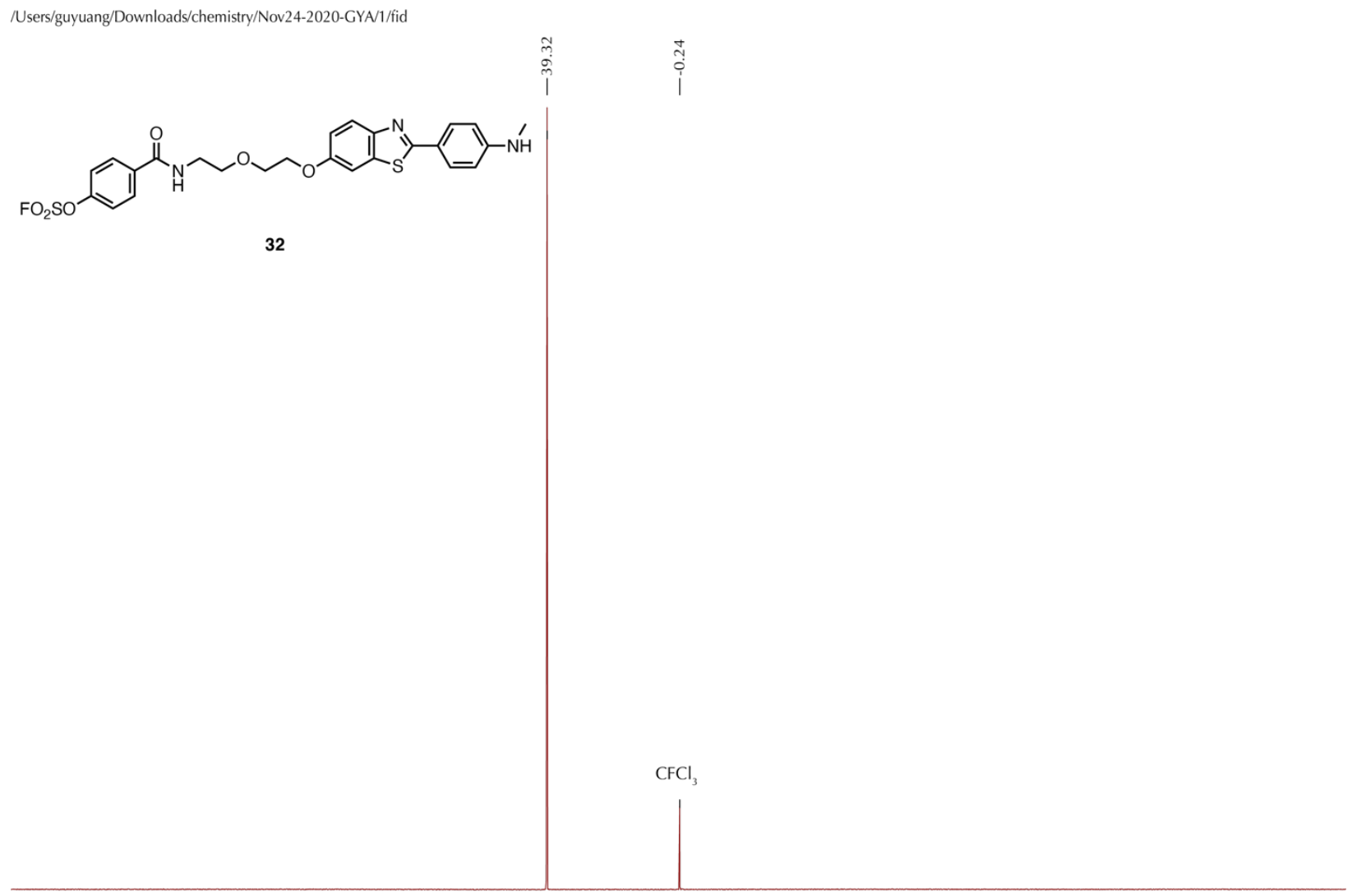

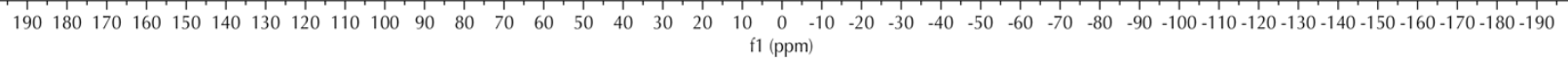

Fig. S106 | ${ }^{19} \mathrm{~F}$ NMR of Compound 32. Solvent: DMSO-d6, internal standard $\mathrm{CFCl}_{3}(\delta-0.24$ ppm); Frequency: $376 \mathrm{MHz}$; Temperature: $298 \mathrm{~K}$. 


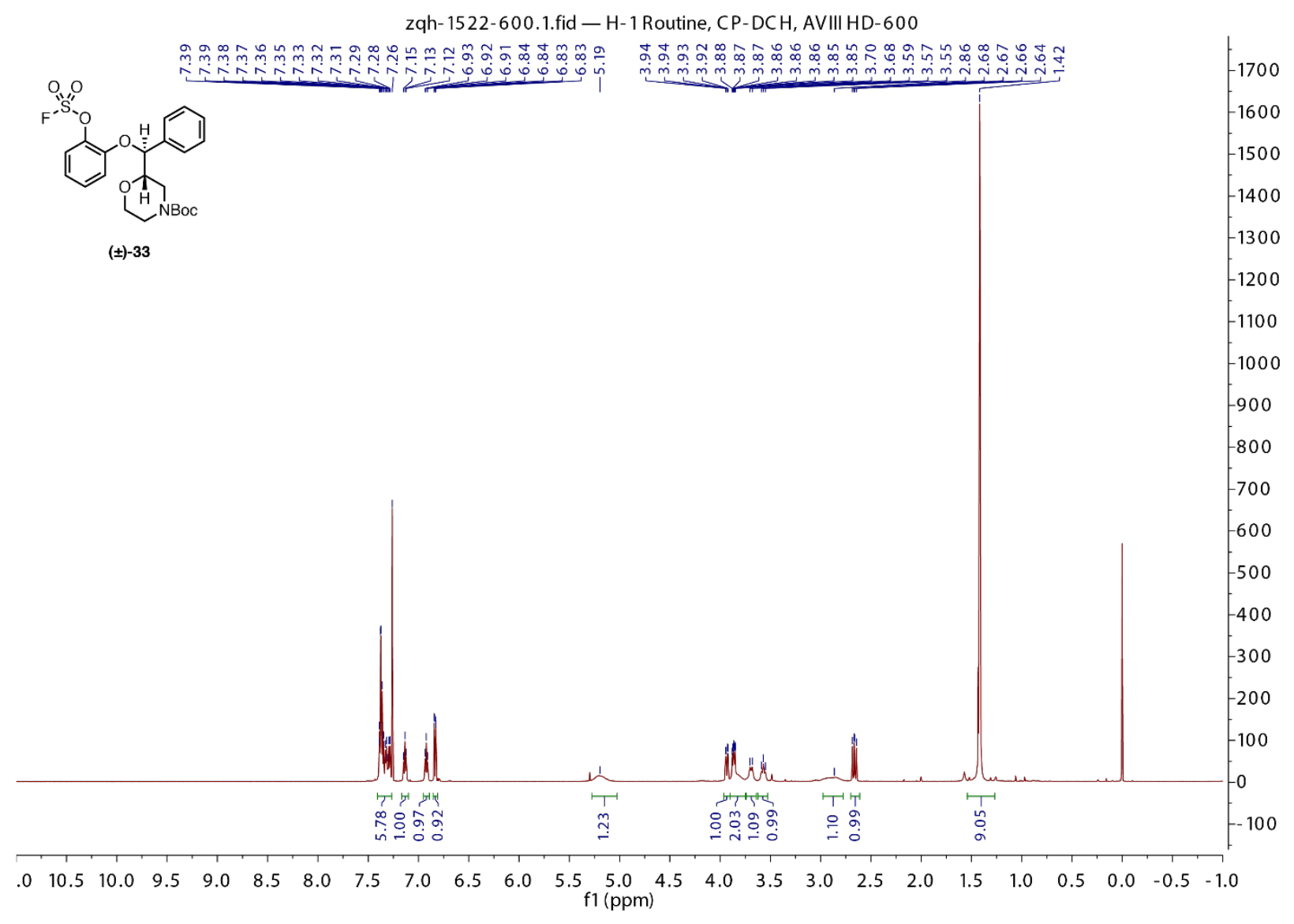

Fig. S107 | ${ }^{1} \mathrm{H}$ NMR of Compound 33. Solvent: $\mathrm{CDCl}_{3}$; Frequency: $600 \mathrm{MHz}$; Temperature: $298 \mathrm{~K}$. 


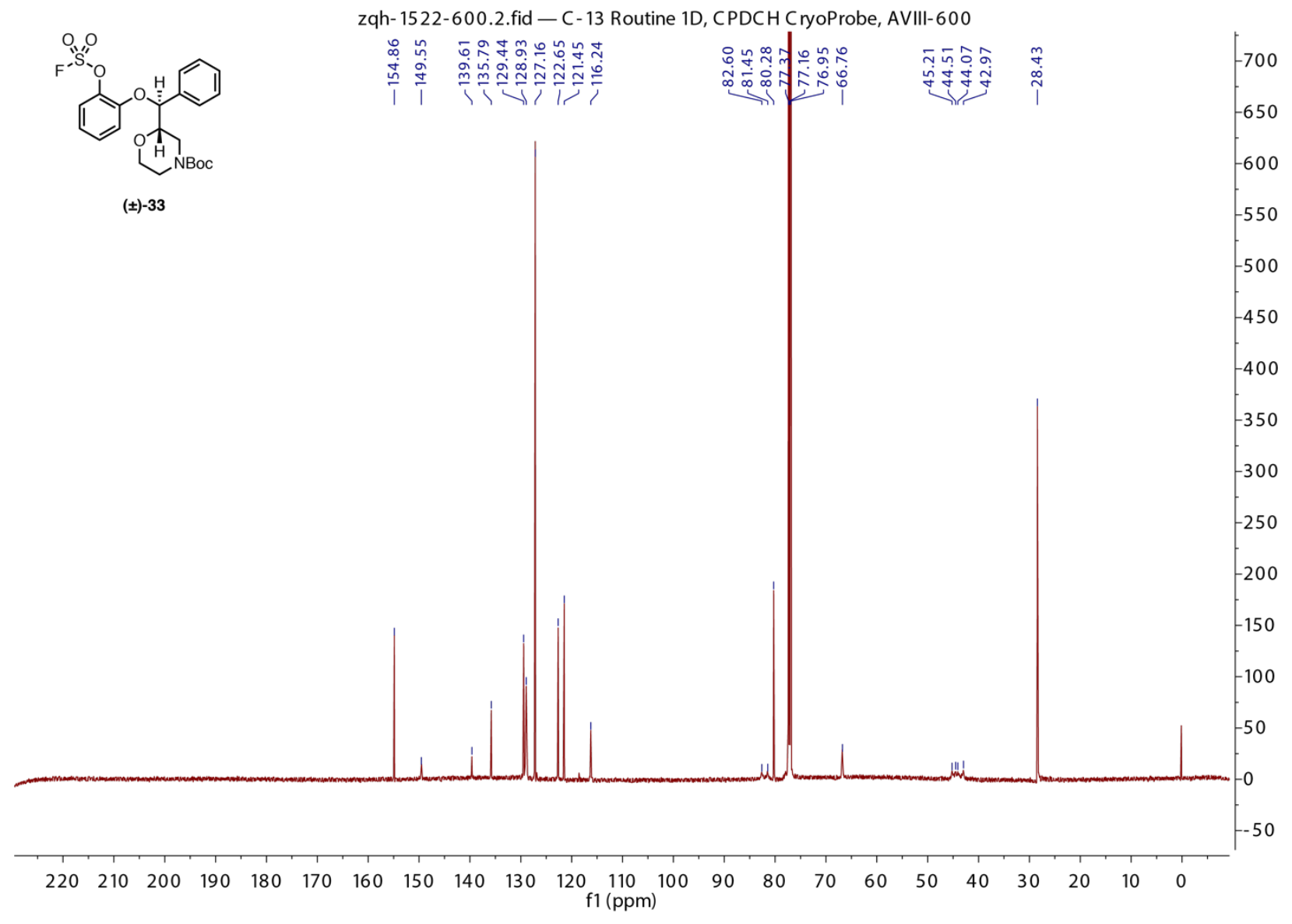

Fig. S108 | ${ }^{13} \mathrm{C}$ NMR of Compound 33. Solvent: $\mathrm{CDCl}_{3}$; Frequency: $151 \mathrm{MHz}$; Temperature: $298 \mathrm{~K}$. 


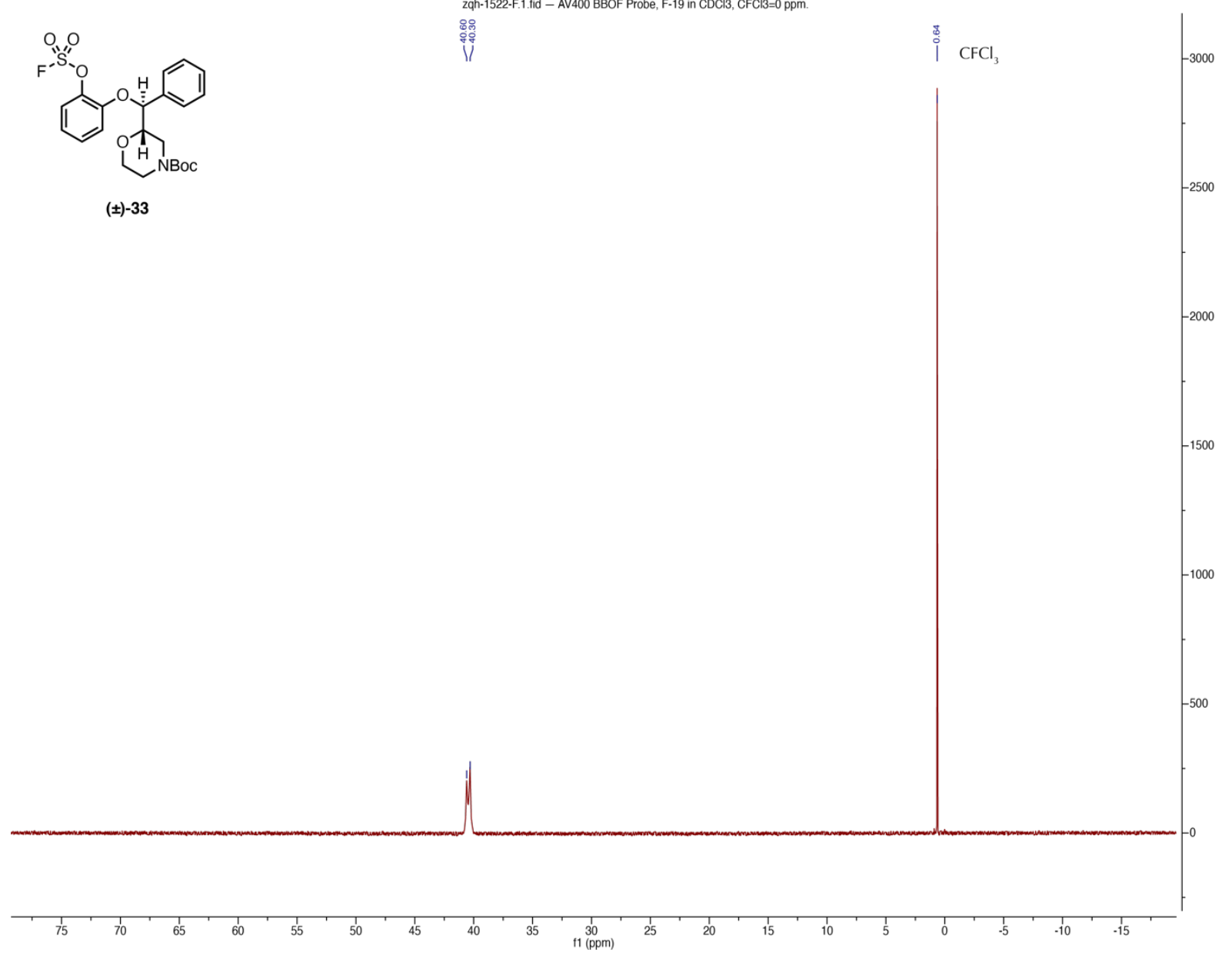

Fig. S109 | ${ }^{19} \mathrm{~F}$ NMR of Compound 33. Solvent: $\mathrm{CDCl}_{3}$, internal standard $\mathrm{CFCl}_{3}$ ( $\left.\delta 0.65 \mathrm{ppm}\right)$; Frequency: 376 MHz; Temperature: $298 \mathrm{~K}$. 


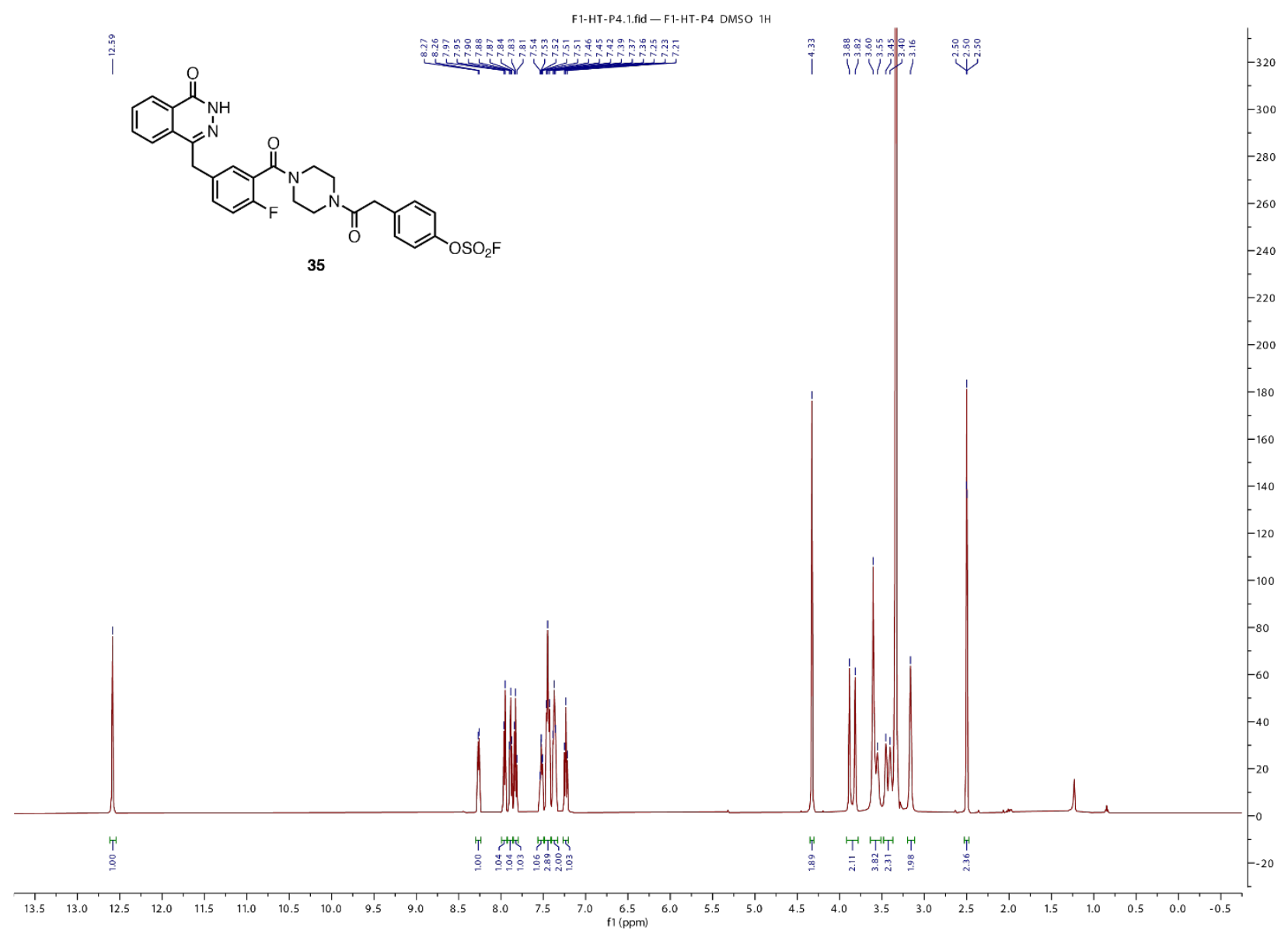

Fig. S110 | ${ }^{1} \mathrm{H}$ NMR of Compound 35. Solvent: DMSO-d6; Frequency: $500 \mathrm{MHz}$; Temperature: $298 \mathrm{~K}$. 


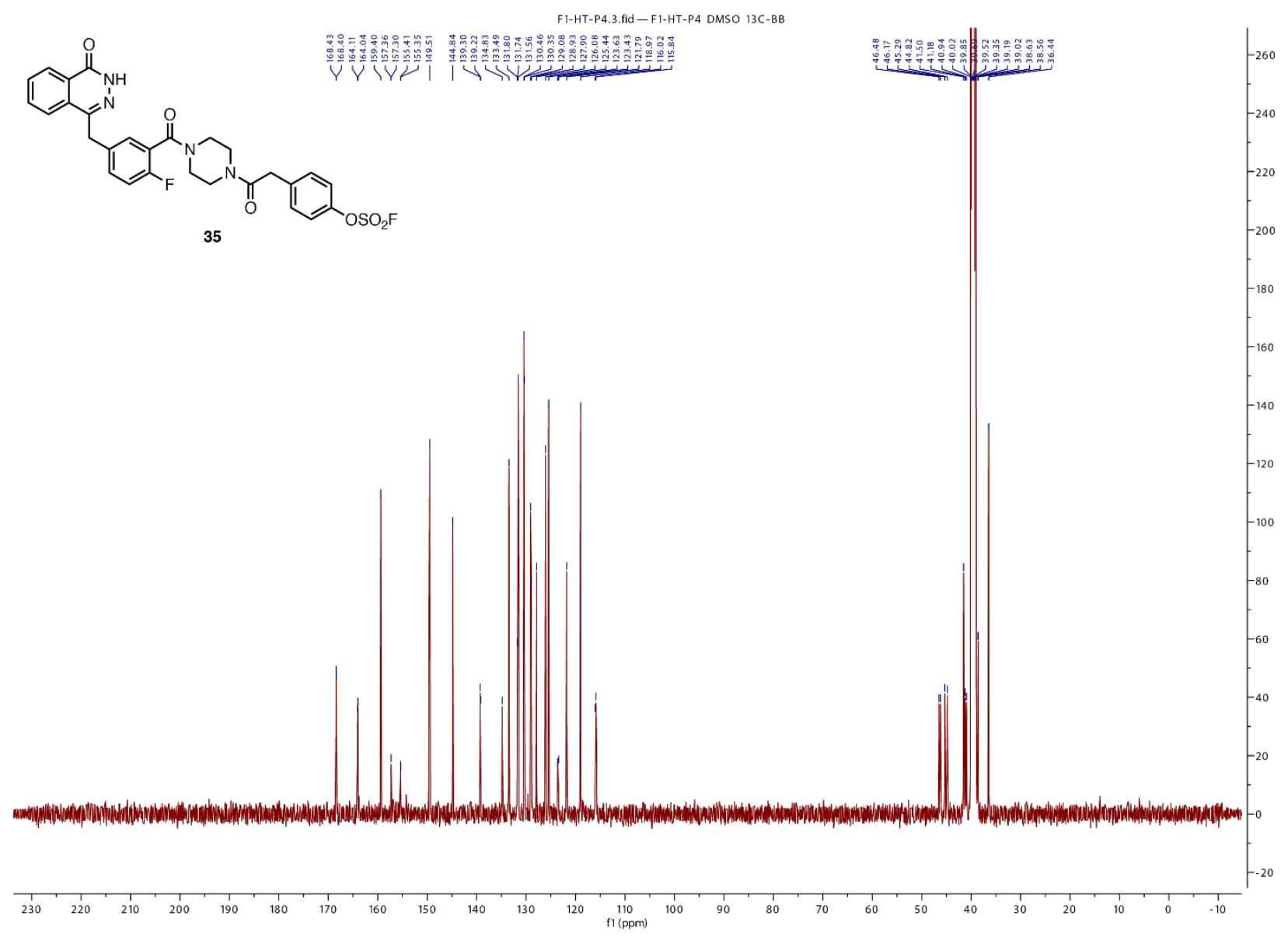

Fig. S111 | ${ }^{13} \mathrm{C}$ NMR of Compound 35. Solvent: DMSO-d6; Frequency: $126 \mathrm{MHz}$;

Temperature: $298 \mathrm{~K}$. 
/Users/guyuang/Downloads/chemistry/Nov24-2020-GYA/3/fid

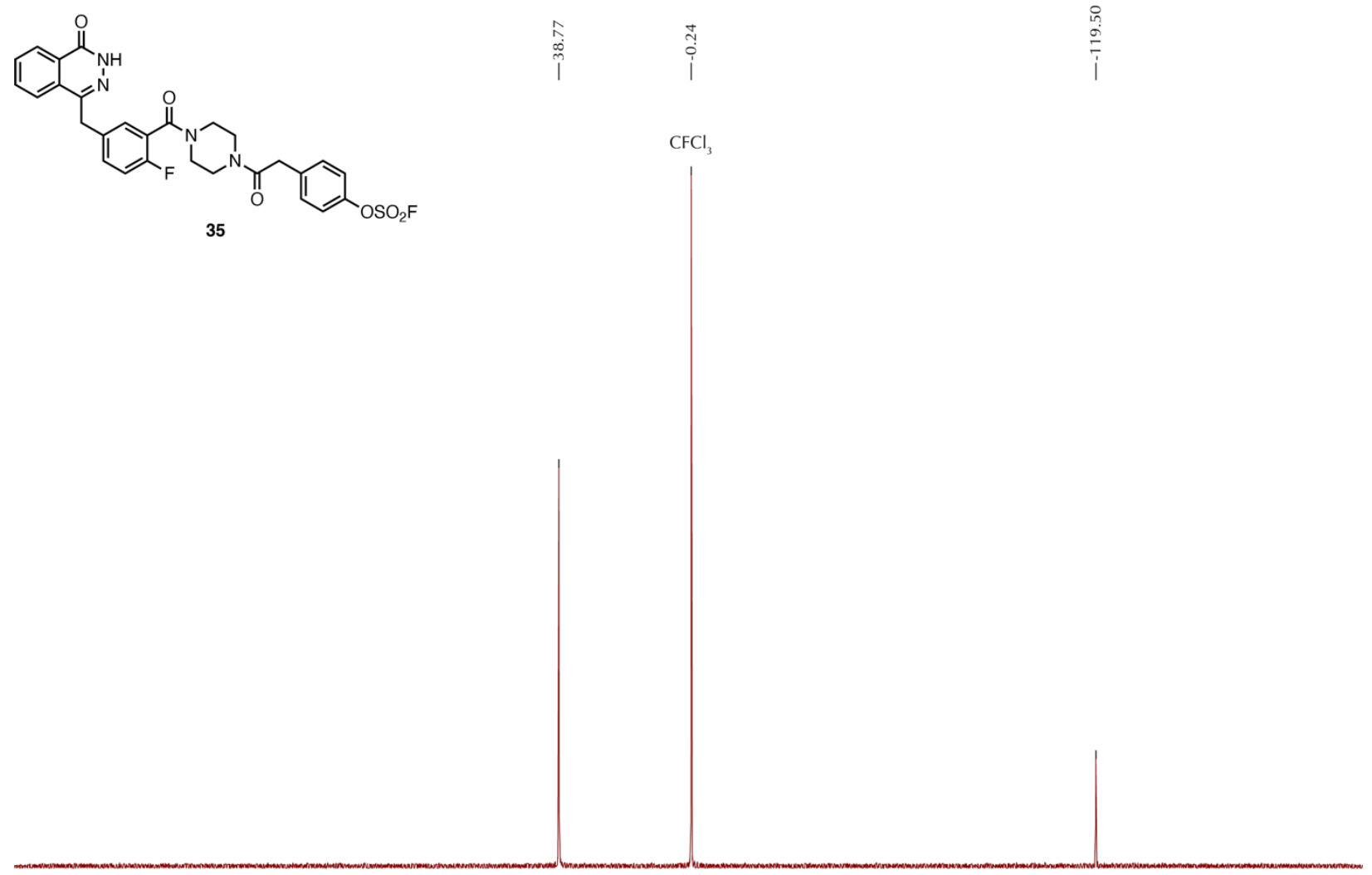

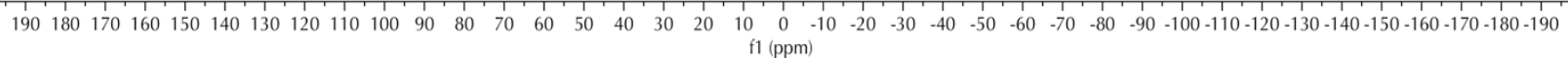

Fig. S112 $\mid{ }^{19} \mathrm{~F}$ NMR of Compound 35. Solvent: DMSO-d6, internal standard $\mathrm{CFCl}_{3}(\delta-0.24$ ppm); Frequency: $471 \mathrm{MHz}$; Temperature: $298 \mathrm{~K}$. 


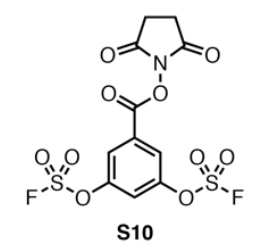

zqh-1927-600.1. fid - C-13 Routine 1D, CPDCH CryoProbe, AVIII-600

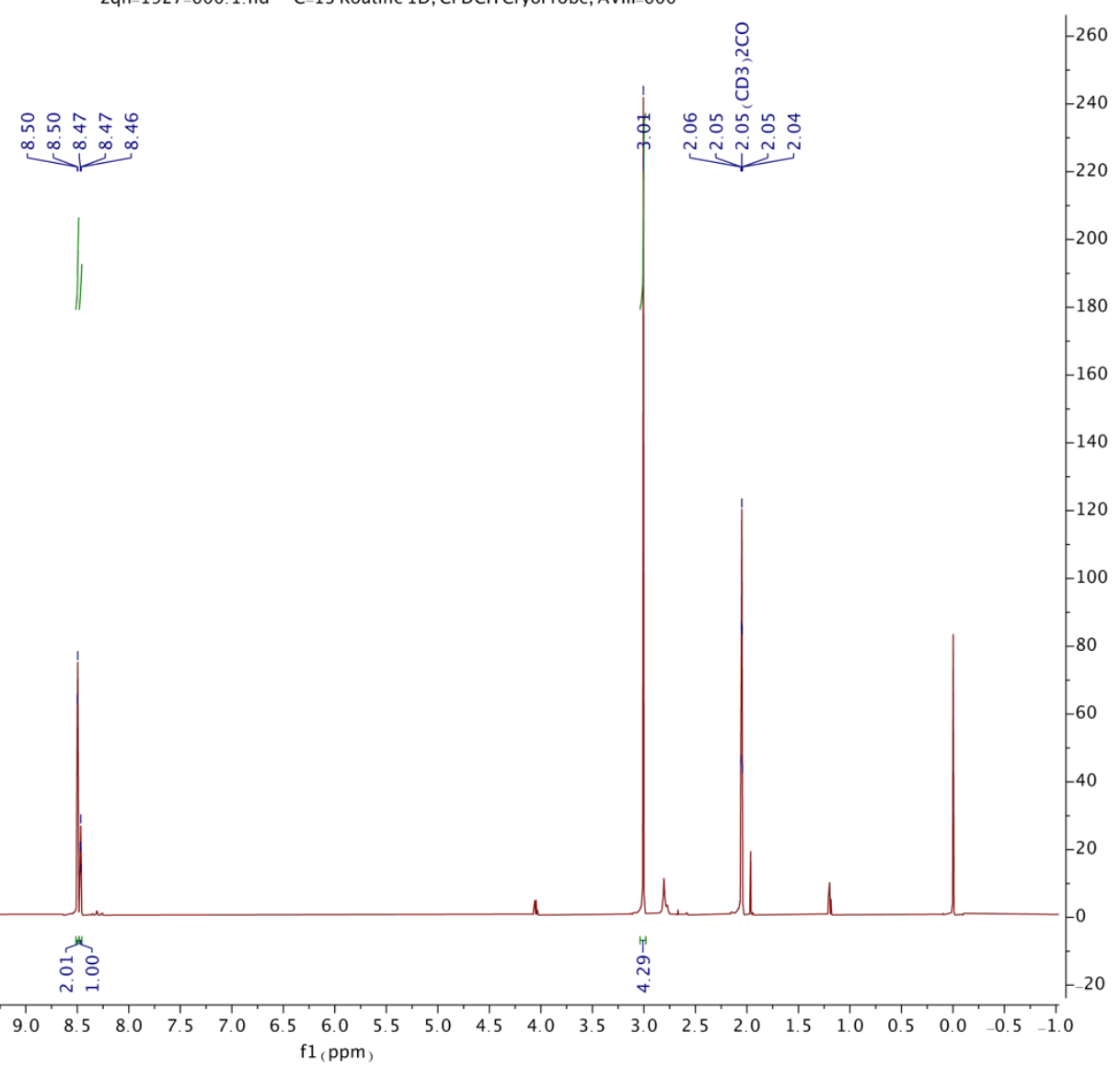

Fig. S113 | ${ }^{1} \mathrm{H}$ NMR of Compound S10. Solvent: acetone-d6; Frequency: $600 \mathrm{MHz}$; Temperature: $298 \mathrm{~K}$. 


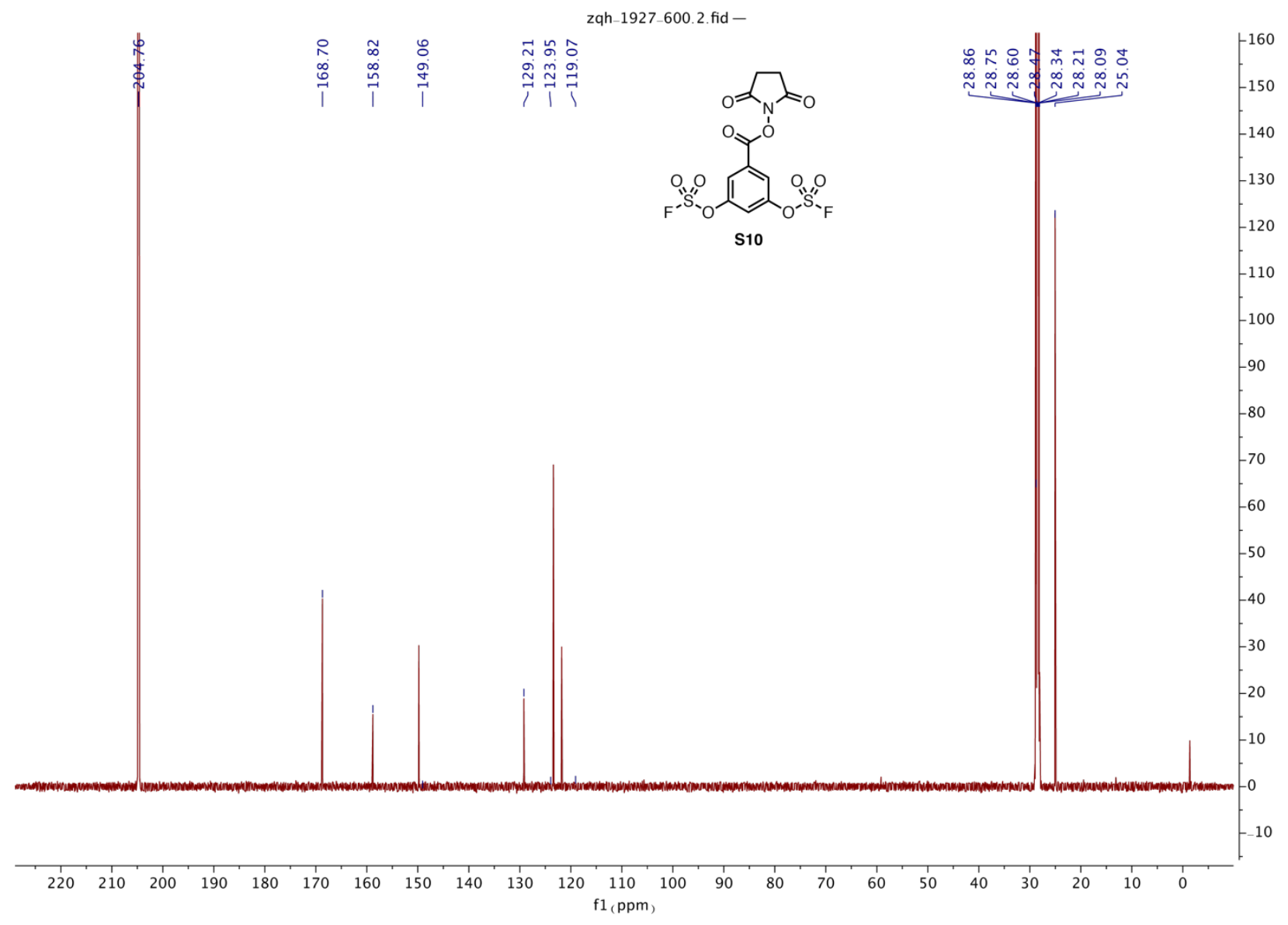

Fig. S114 | ${ }^{13} \mathrm{C}$ NMR of Compound S10. Solvent: acetone-d6; Frequency: $151 \mathrm{MHz}$; Temperature: $298 \mathrm{~K}$. 


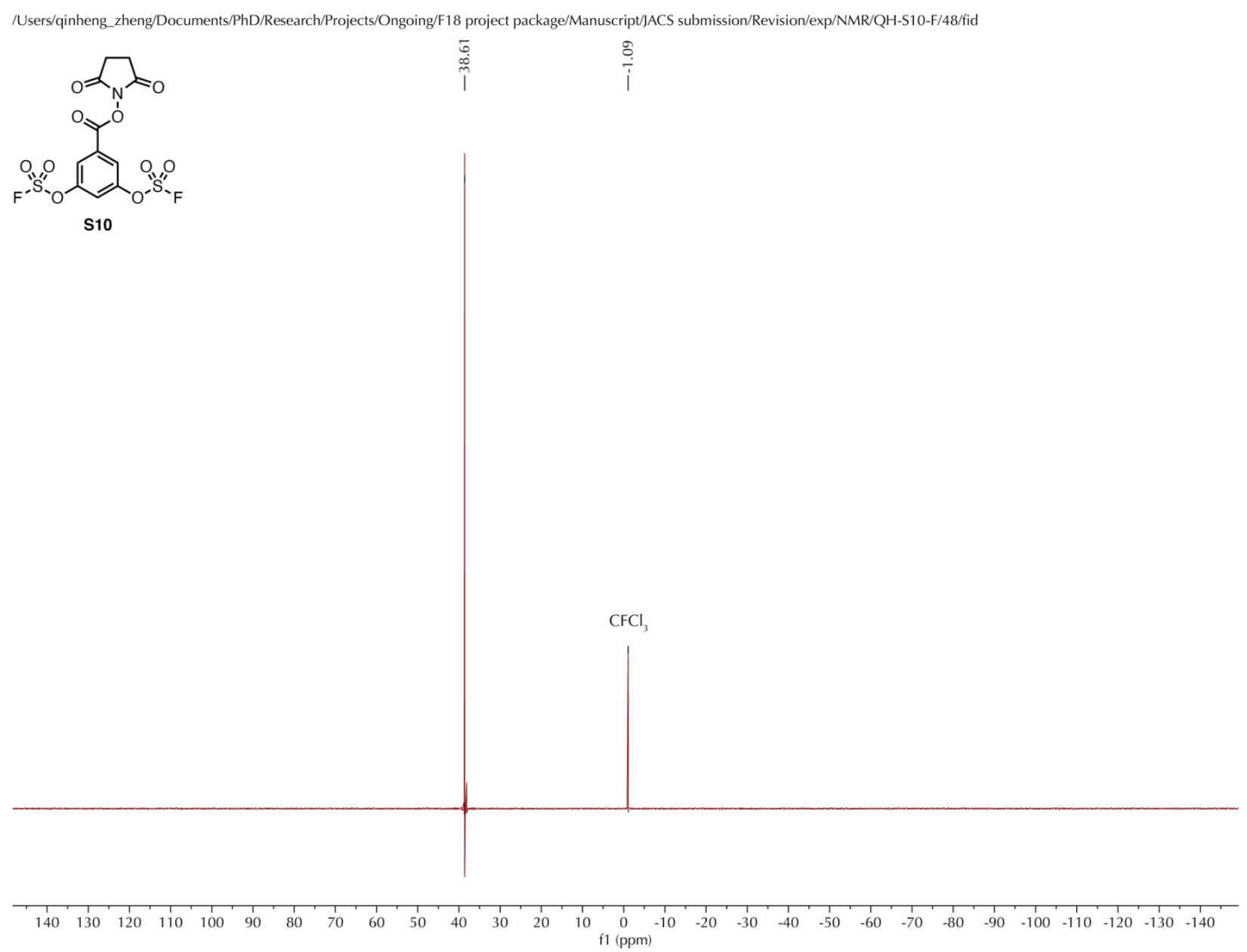

Fig. S115 | ${ }^{19} \mathrm{~F}$ NMR of Compound S10. Solvent: acetone-d6, internal standard $\mathrm{CFCl}_{3}(\delta-1.09$ ppm); Frequency: 376 MHz; Temperature: $298 \mathrm{~K}$. 


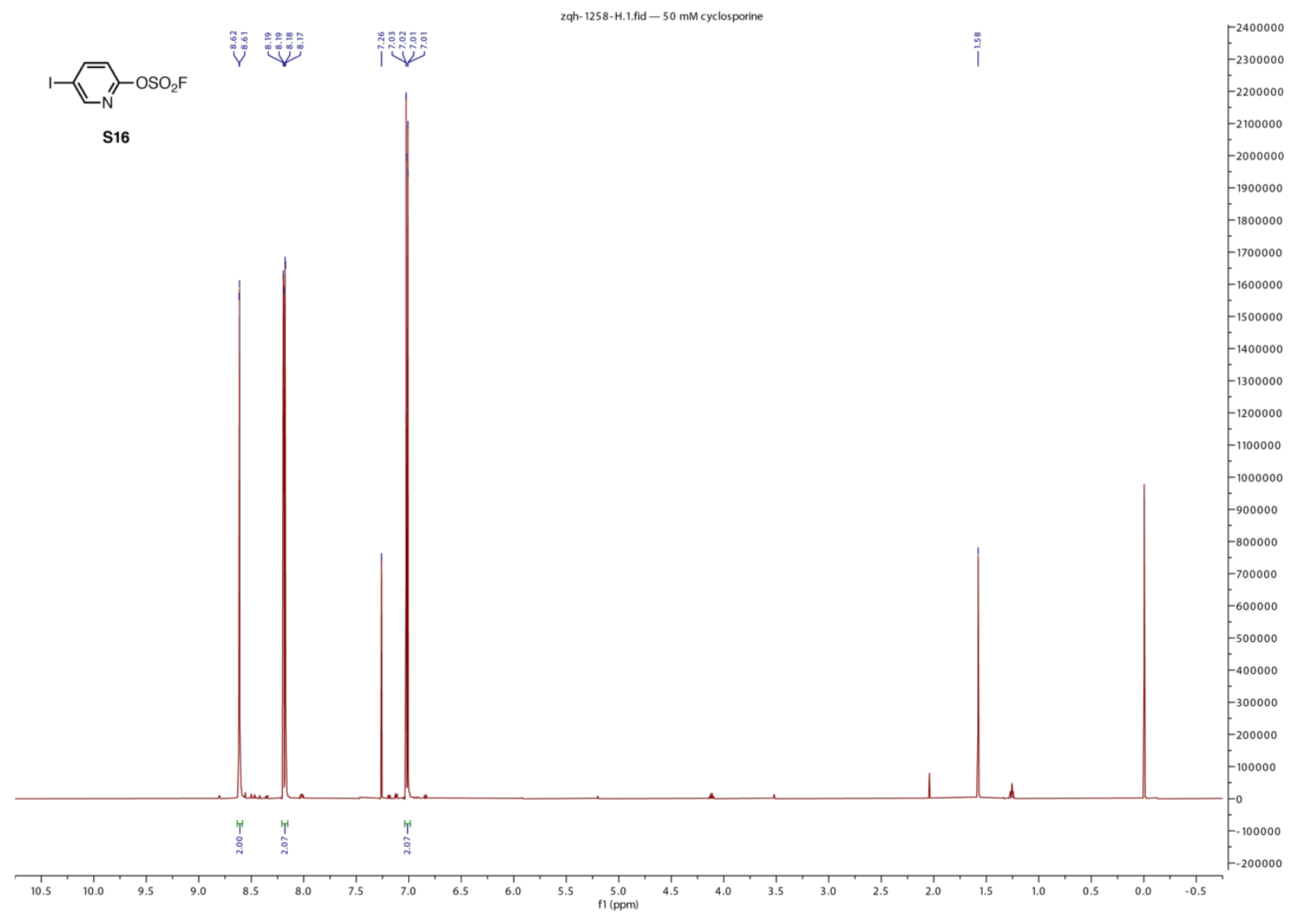

Fig. S116 | ${ }^{1} \mathrm{H}$ NMR of Compound S16. Solvent: $\mathrm{CDCl}_{3}$; Frequency: $500 \mathrm{MHz}$; Temperature: $298 \mathrm{~K}$. 


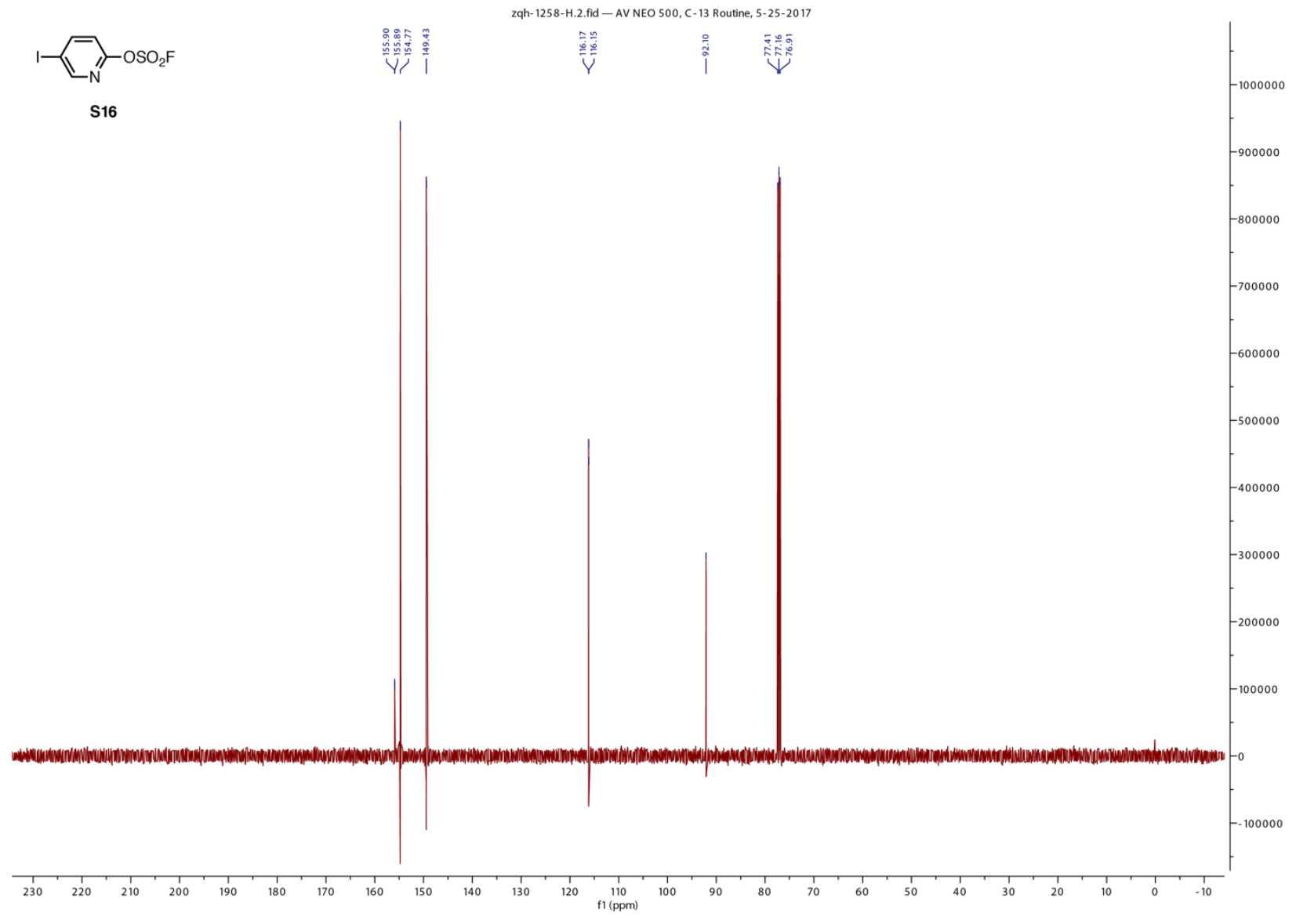

Fig. S117 | ${ }^{13} \mathrm{C}$ NMR of Compound S16. Solvent: $\mathrm{CDCl}_{3}$; Frequency: $126 \mathrm{MHz}$; Temperature: $298 \mathrm{~K}$. 


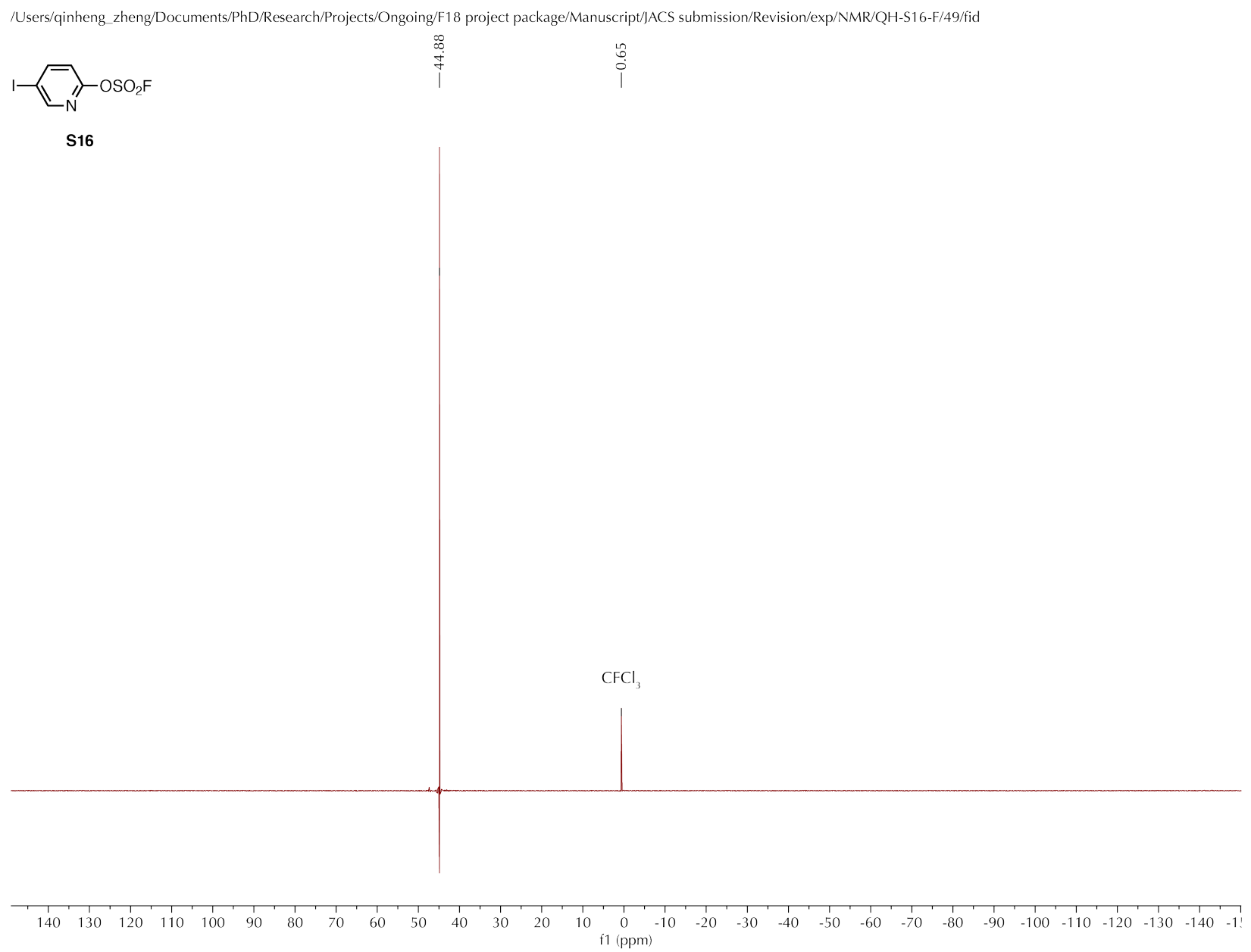

Fig. S118 | ${ }^{19} \mathrm{~F}$ NMR of Compound S16. Solvent: $\mathrm{CDCl}_{3}$, internal standard $\mathrm{CFCl}_{3}(\delta 0.65 \mathrm{ppm})$; Frequency: $376 \mathrm{MHz}$; Temperature: $298 \mathrm{~K}$. 


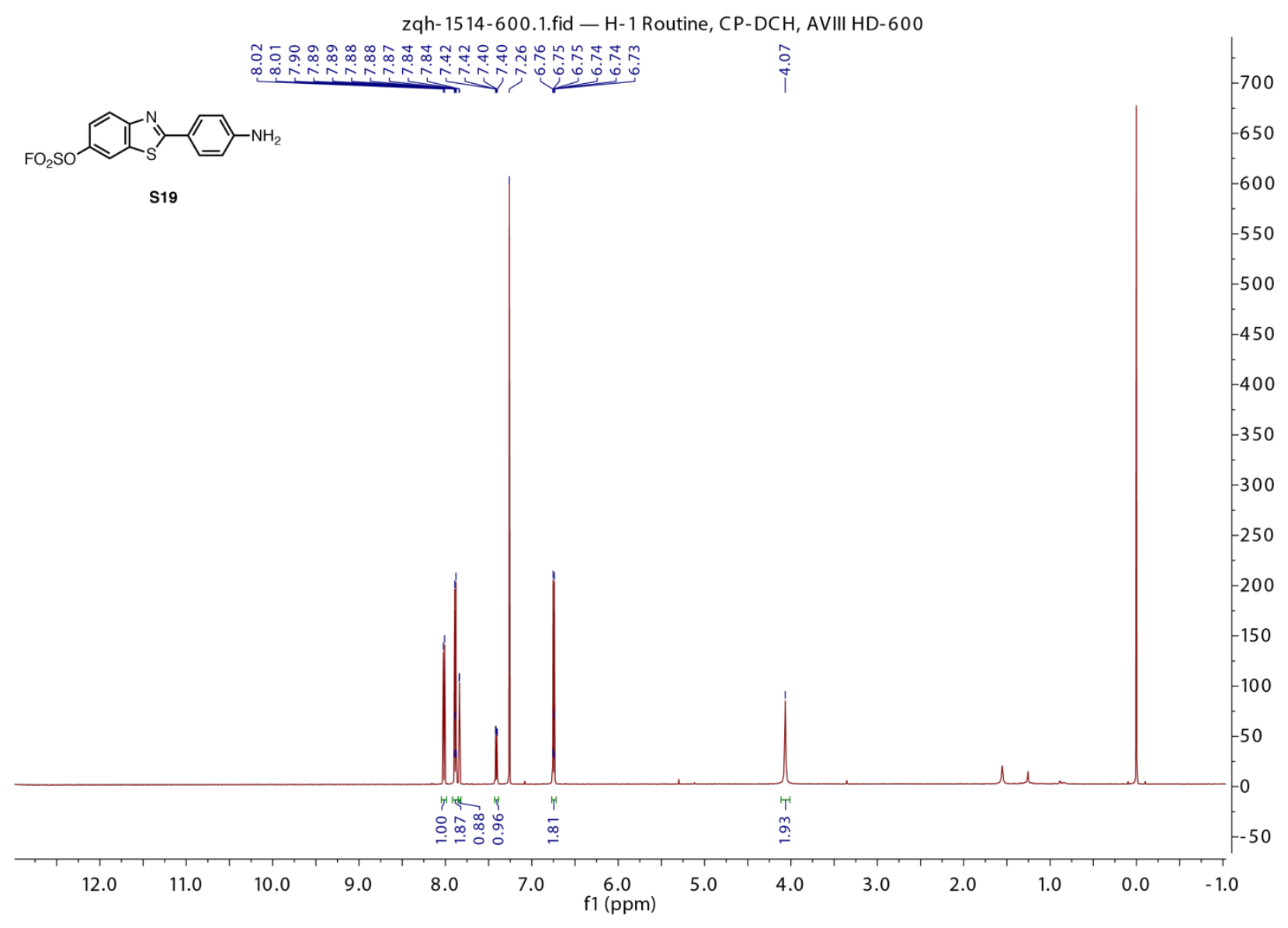

Fig. S119 | ${ }^{1} \mathrm{H}$ NMR of Compound S19. Solvent: $\mathrm{CDCl}_{3}$; Frequency: $600 \mathrm{MHz}$; Temperature: $298 \mathrm{~K}$. 


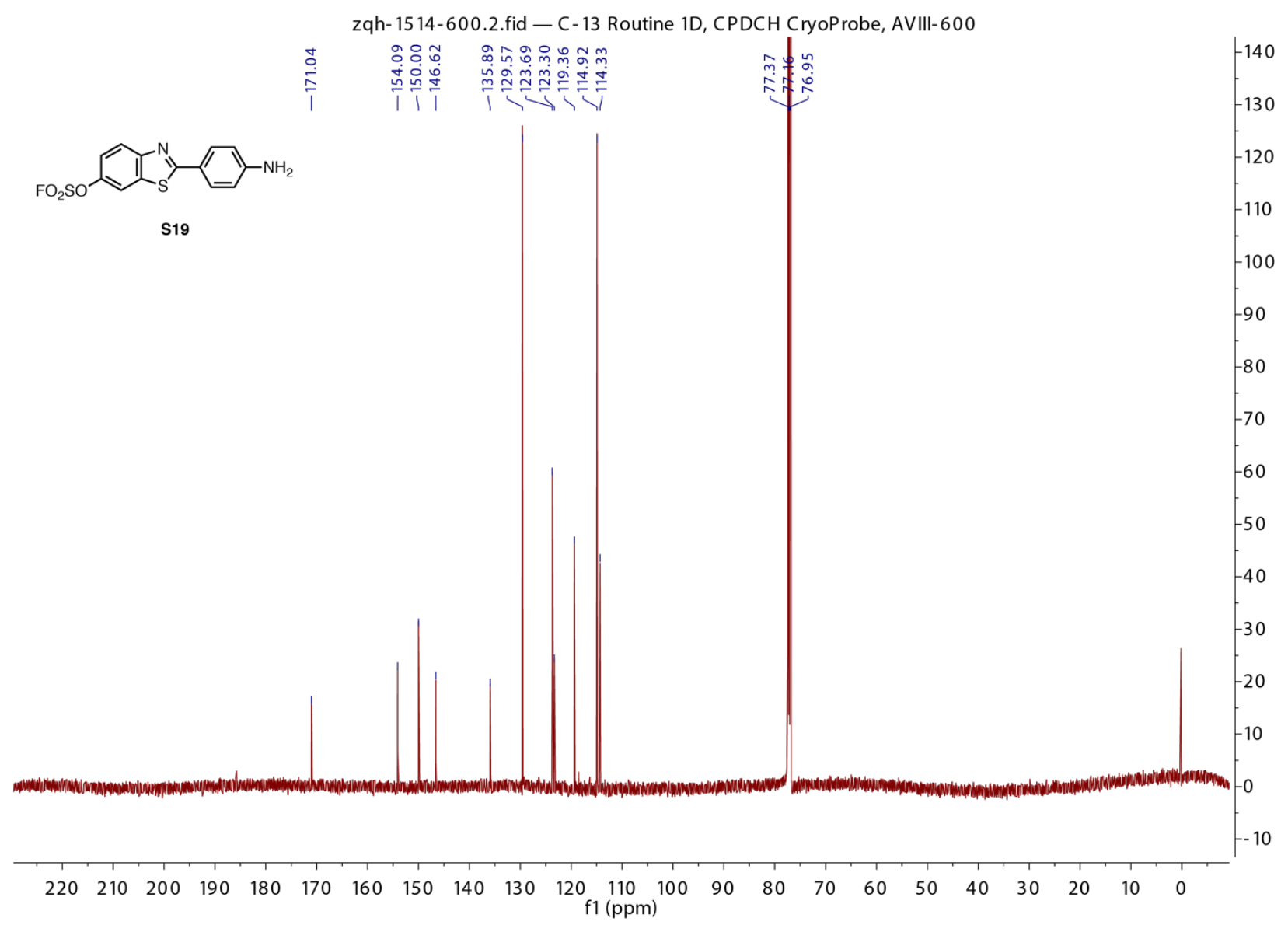

Fig. S120 | ${ }^{13} \mathrm{C}$ NMR of Compound S19. Solvent: $\mathrm{CDCl}_{3}$; Frequency: $151 \mathrm{MHz}$; Temperature: $298 \mathrm{~K}$. 

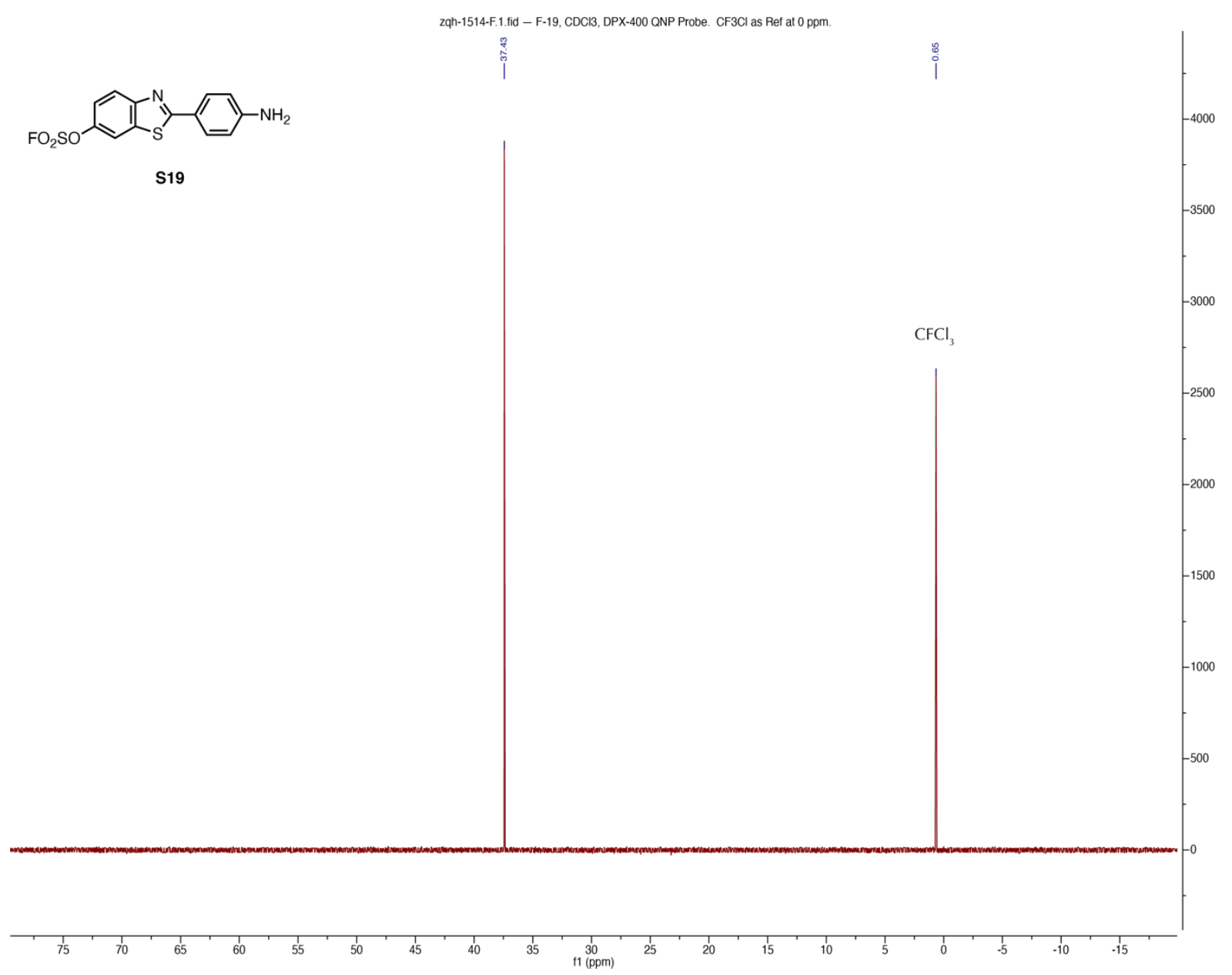

Fig. S121 | ${ }^{19} \mathrm{~F}$ NMR of Compound S19. Solvent: $\mathrm{CDCl}_{3}$, internal standard $\mathrm{CFCl}_{3}(\delta 0.65 \mathrm{ppm})$; Frequency: $376 \mathrm{MHz}$; Temperature: $298 \mathrm{~K}$. 
Zqh-1513-600-20171023.1.fid - H-1 Routine, CP-DCH, AVIII HD-600

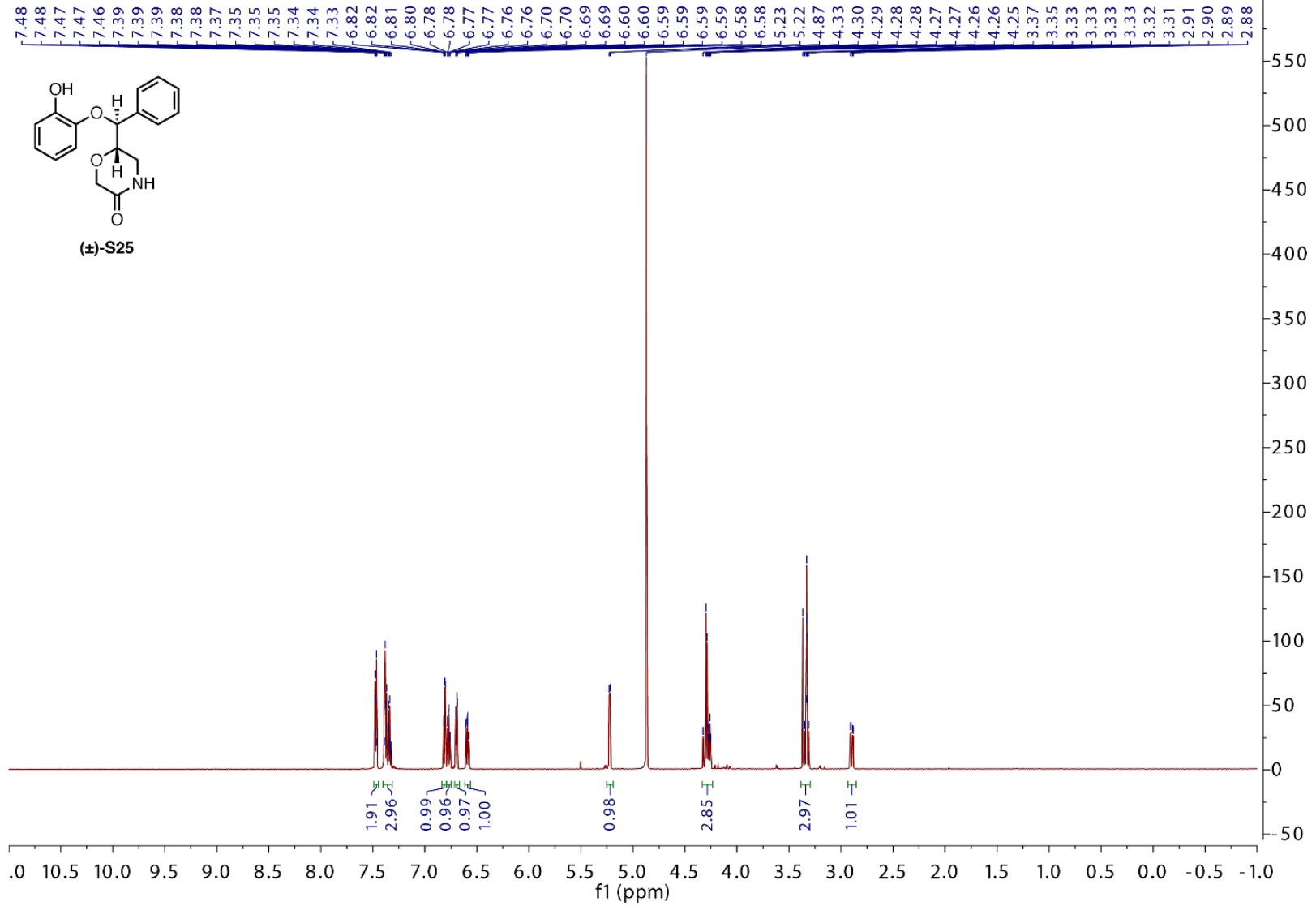

Fig. S122 | ${ }^{1} \mathrm{H}$ NMR of Compound S25. Solvent: MeOD-d4; Frequency: $600 \mathrm{MHz}$; Temperature: $298 \mathrm{~K}$. 


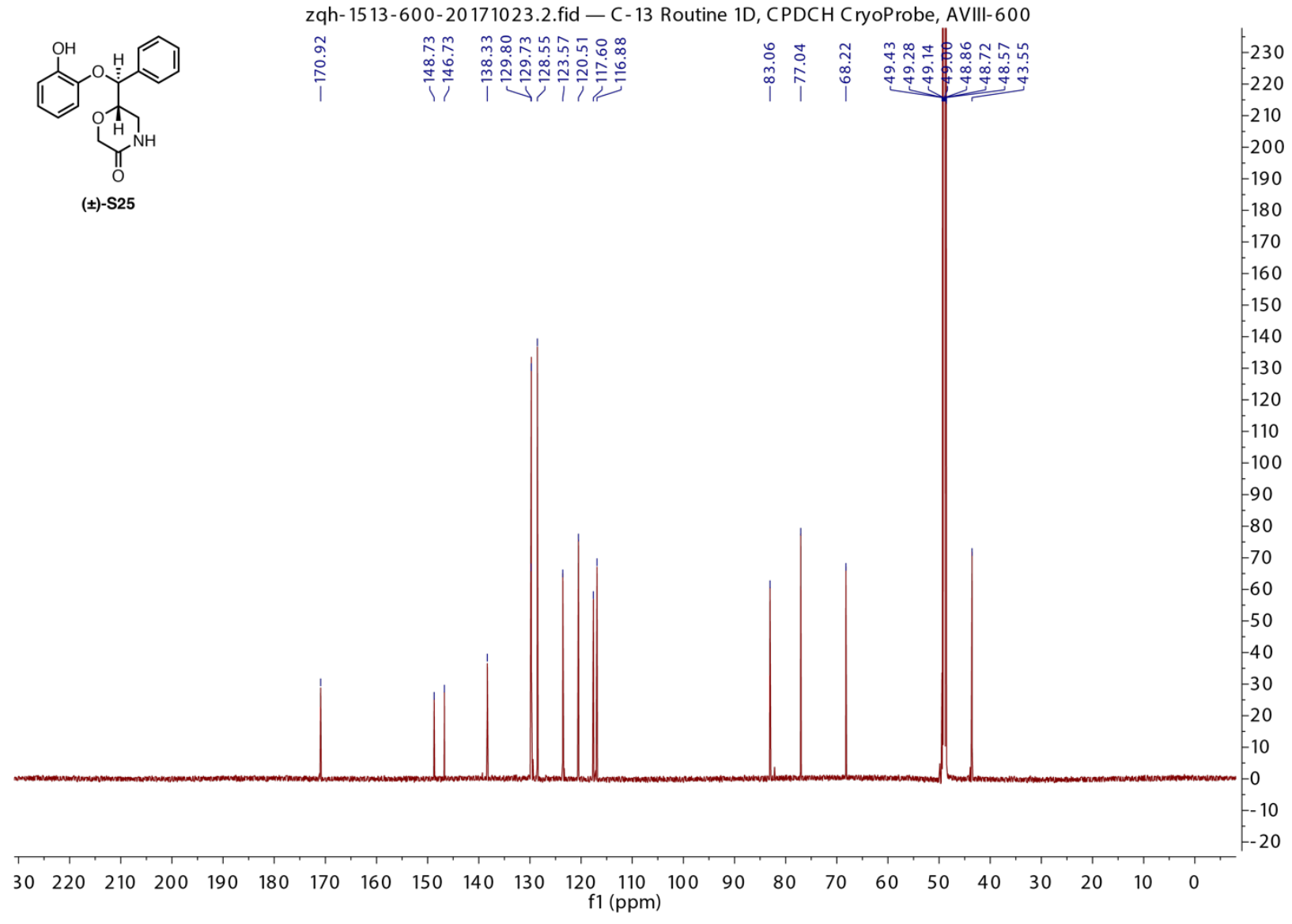

Fig. S123 | ${ }^{13} \mathrm{C}$ NMR of Compound S25. Solvent: MeOD-d4; Frequency: $151 \mathrm{MHz}$; Temperature: $298 \mathrm{~K}$. 
zqh-1516-500.1.fid - $50 \mathrm{mM}$ cyclosporine

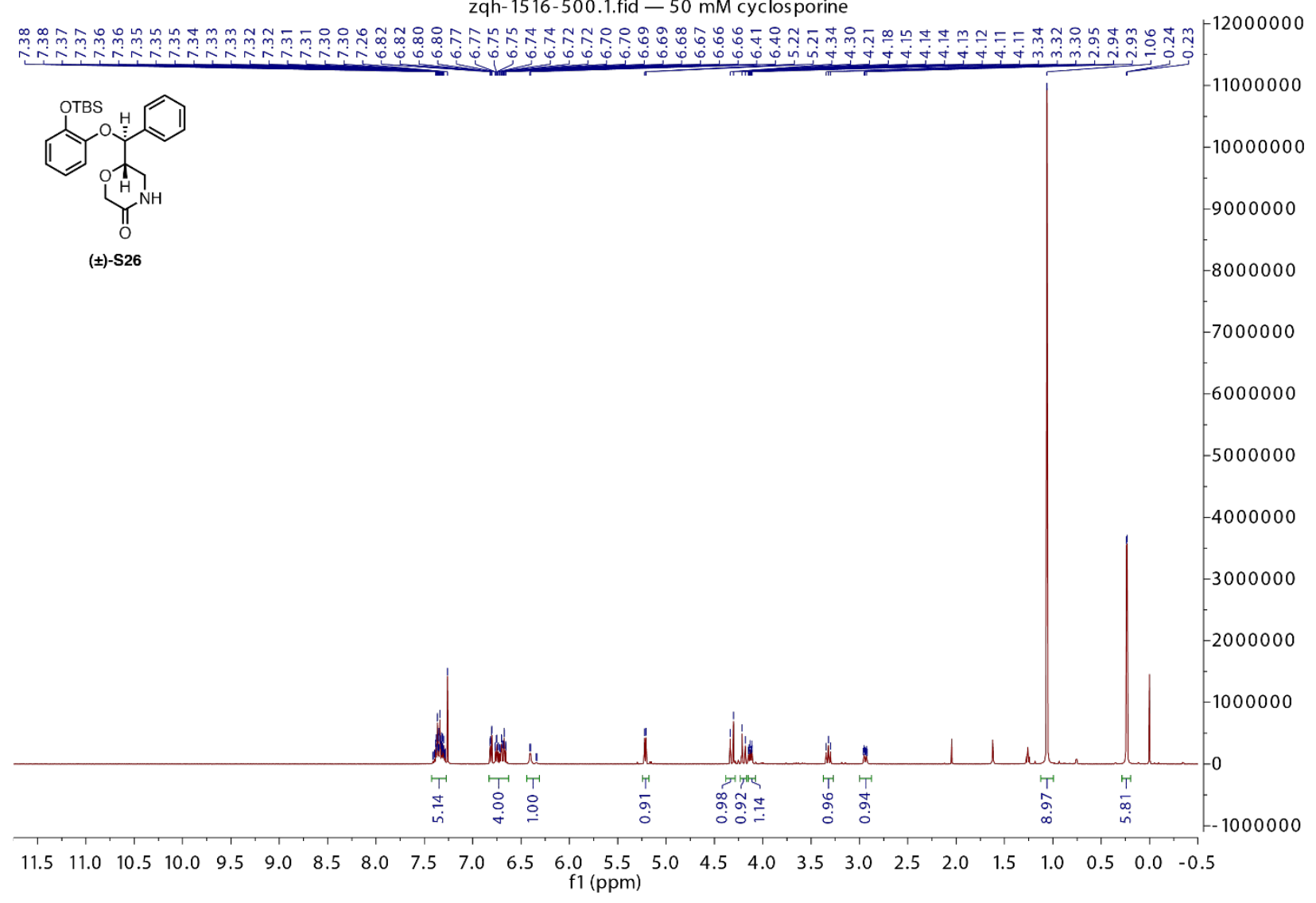

Fig. S124 | ${ }^{1} \mathrm{H}$ NMR of Compound S26. Solvent: $\mathrm{CDCl}_{3}$; Frequency: $500 \mathrm{MHz}$; Temperature: $298 \mathrm{~K}$. 


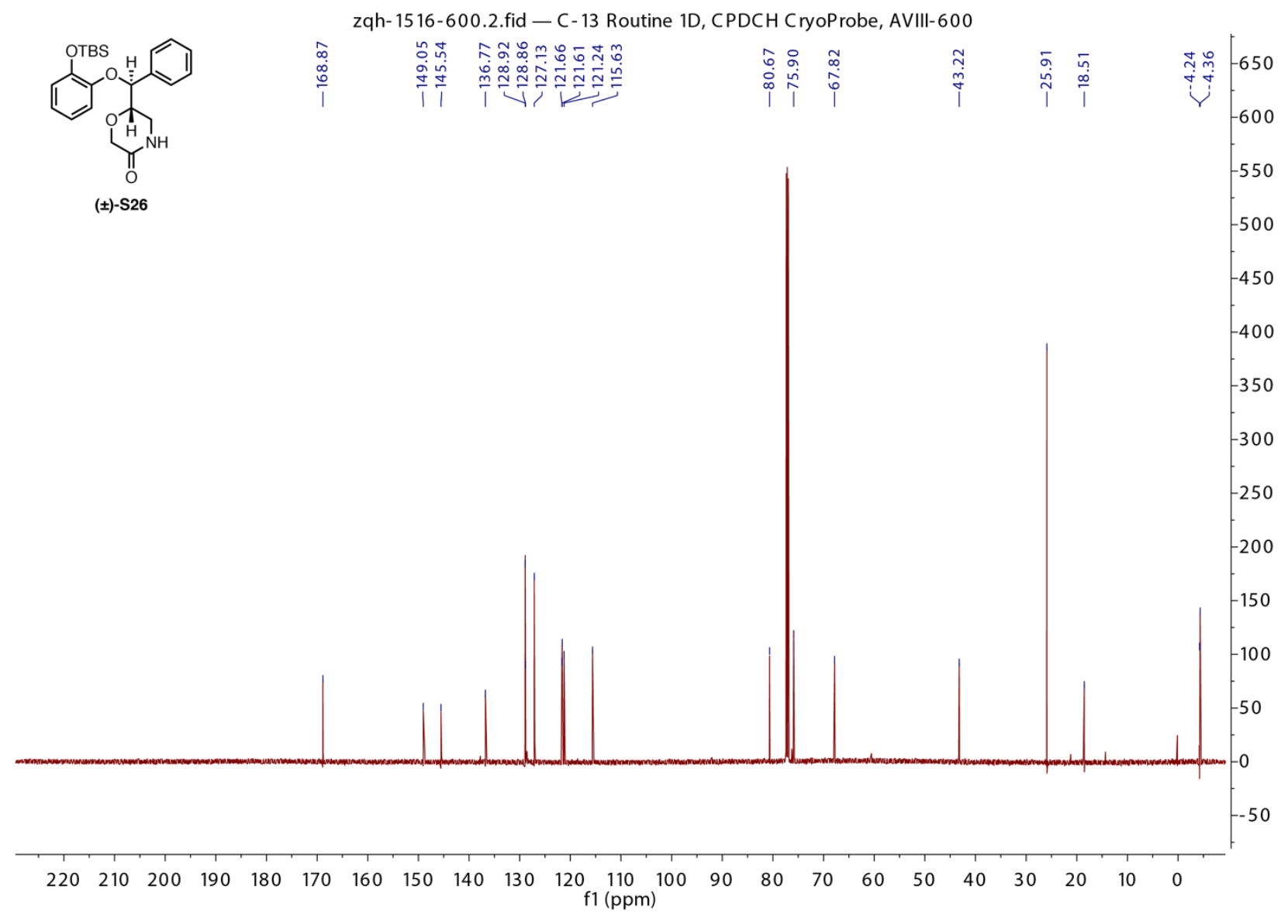

Fig. S125 | ${ }^{13} \mathrm{C}$ NMR of Compound S26. Solvent: $\mathrm{CDCl}_{3}$; Frequency: $151 \mathrm{MHz}$; Temperature: $298 \mathrm{~K}$. 
zqh-1521-600.1.fid - H-1 Routine, CP-DCH, AVIII HD-600 m

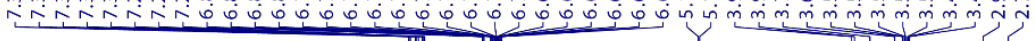<smiles></smiles>

$( \pm)$-S27

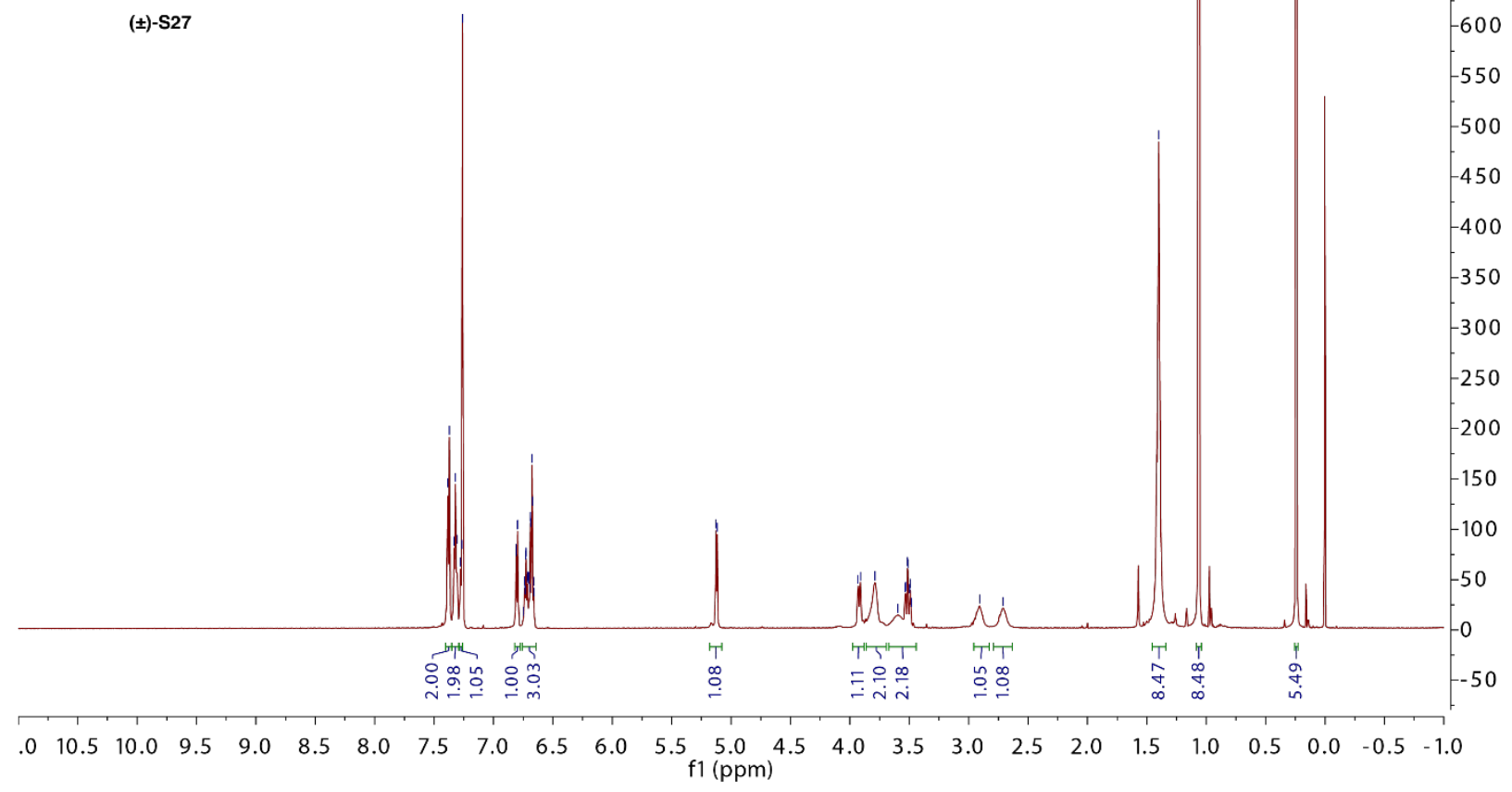

Fig. S126 | ${ }^{1} \mathrm{H}$ NMR of Compound S27. Solvent: $\mathrm{CDCl}_{3}$; Frequency: $600 \mathrm{MHz}$; Temperature: $298 \mathrm{~K}$. 


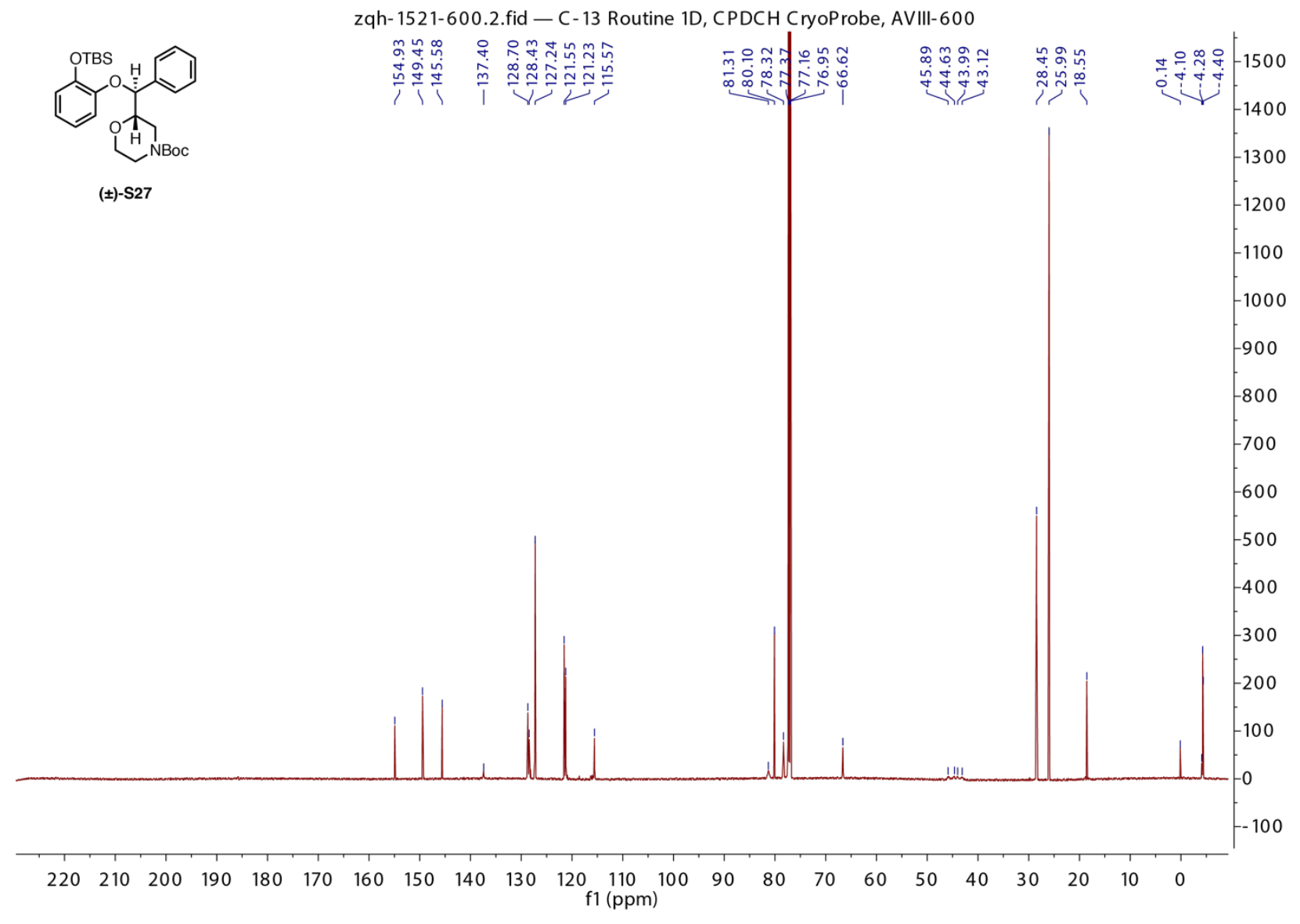

Fig. S127 | ${ }^{13} \mathrm{C}$ NMR of Compound S27. Solvent: $\mathrm{CDCl}_{3}$; Frequency: $151 \mathrm{MHz}$; Temperature: $298 \mathrm{~K}$. 


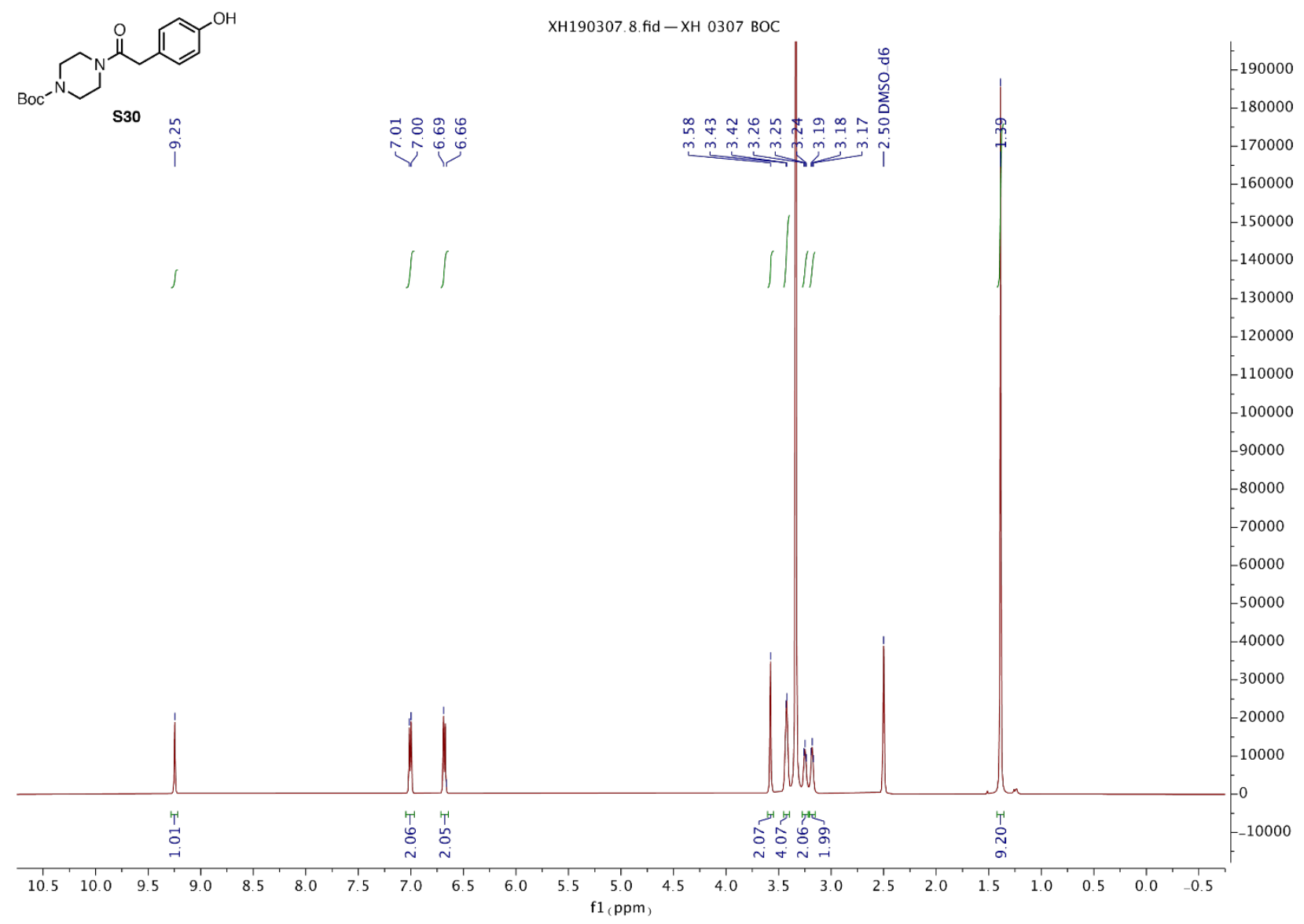

Fig. S128 | ${ }^{1}$ H NMR of Compound S30. Solvent: DMSO-d6; Frequency: 500 MHz; Temperature: $298 \mathrm{~K}$. 


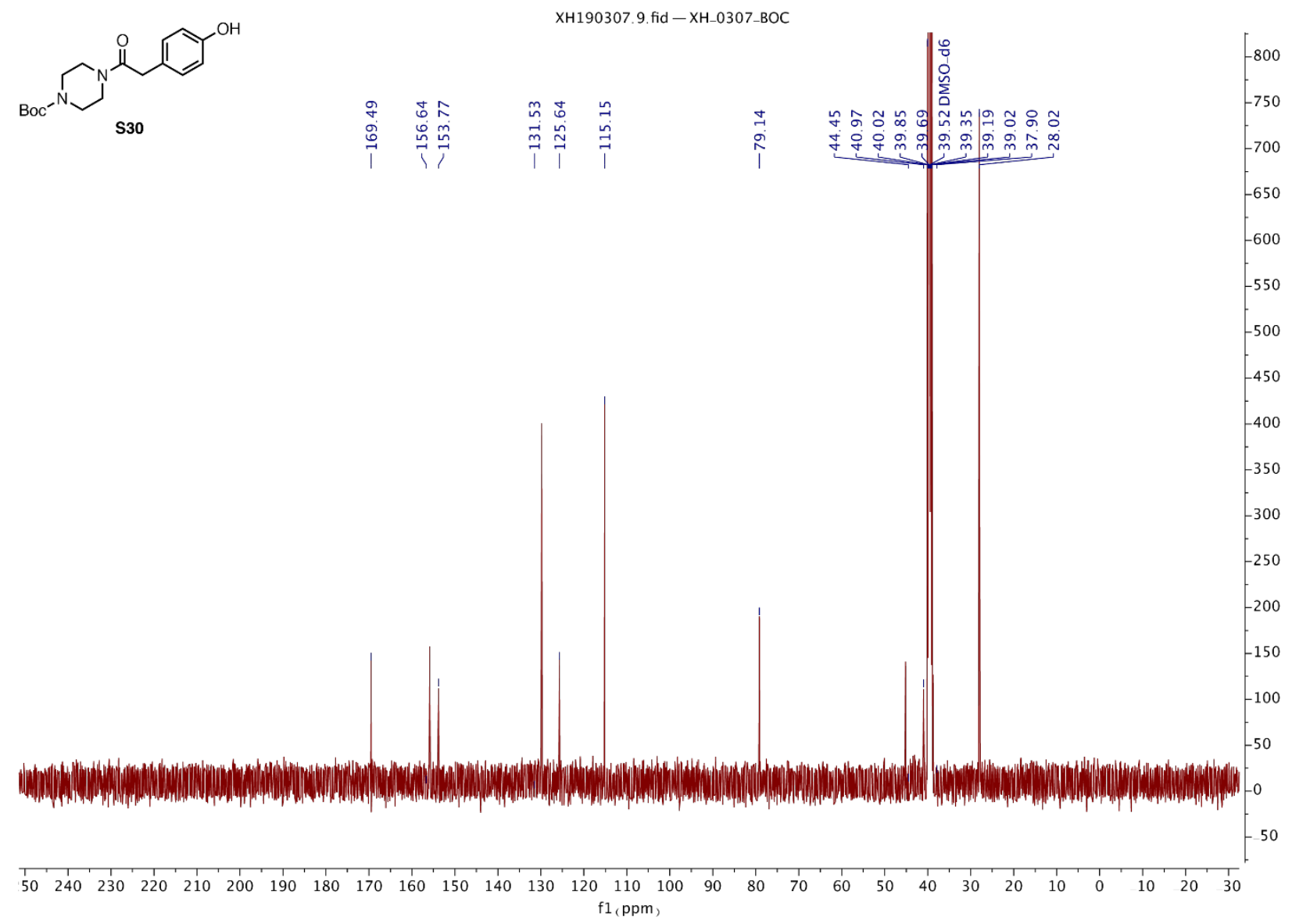

Fig. S129 | ${ }^{13} \mathrm{C}$ NMR of Compound S30. Solvent: DMSO-d6; Frequency: $151 \mathrm{MHz}$; Temperature: $298 \mathrm{~K}$. 


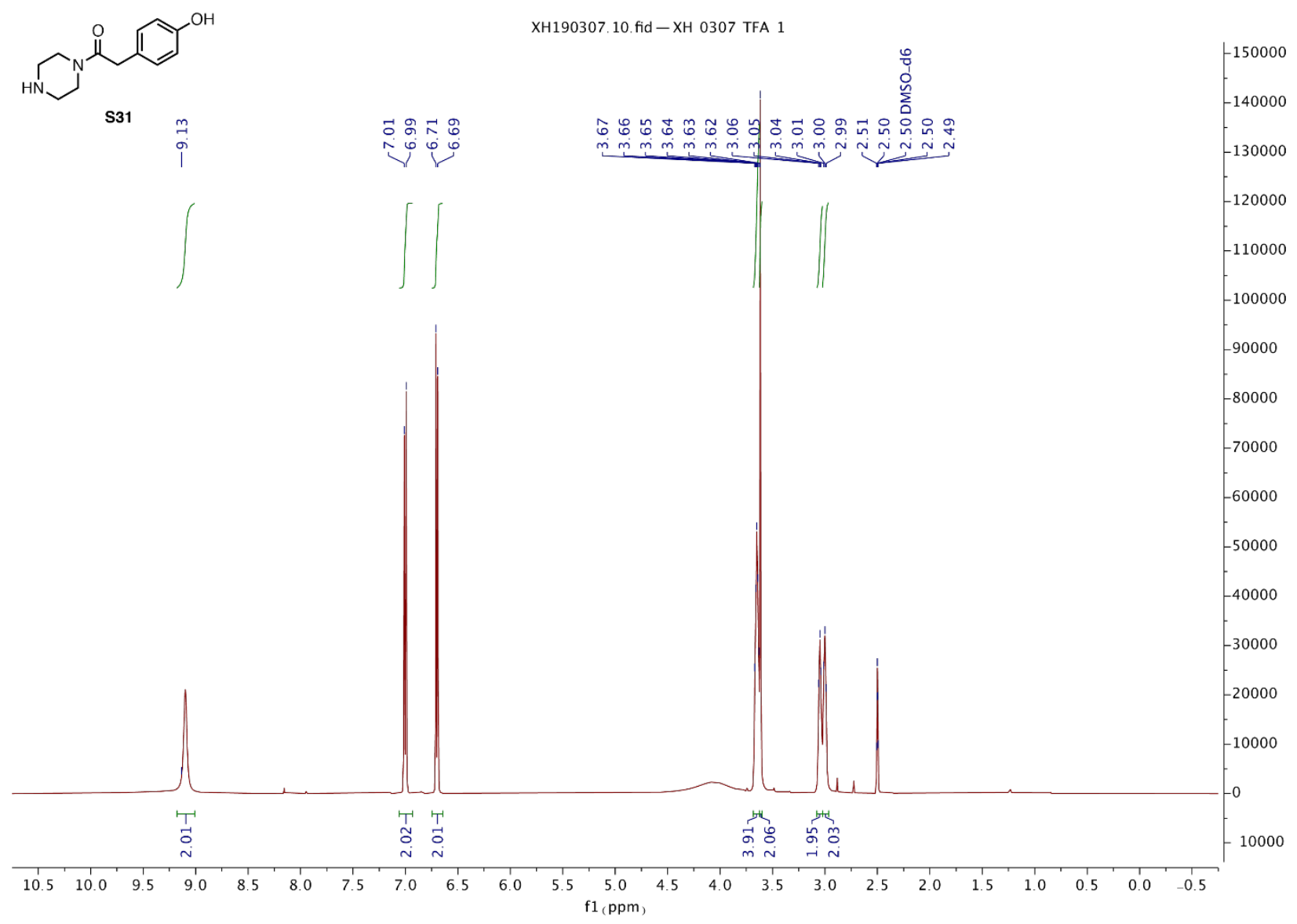

Fig. S130 | ${ }^{1} \mathrm{H}$ NMR of Compound S31. Solvent: DMSO-d6; Frequency: $500 \mathrm{MHz}$; Temperature: $298 \mathrm{~K}$. 


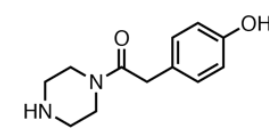

S31

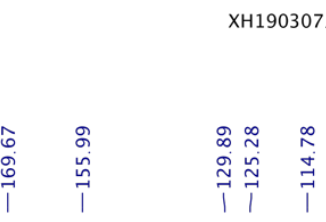

XH190307. 13. fid - XH_0307_TFA_2

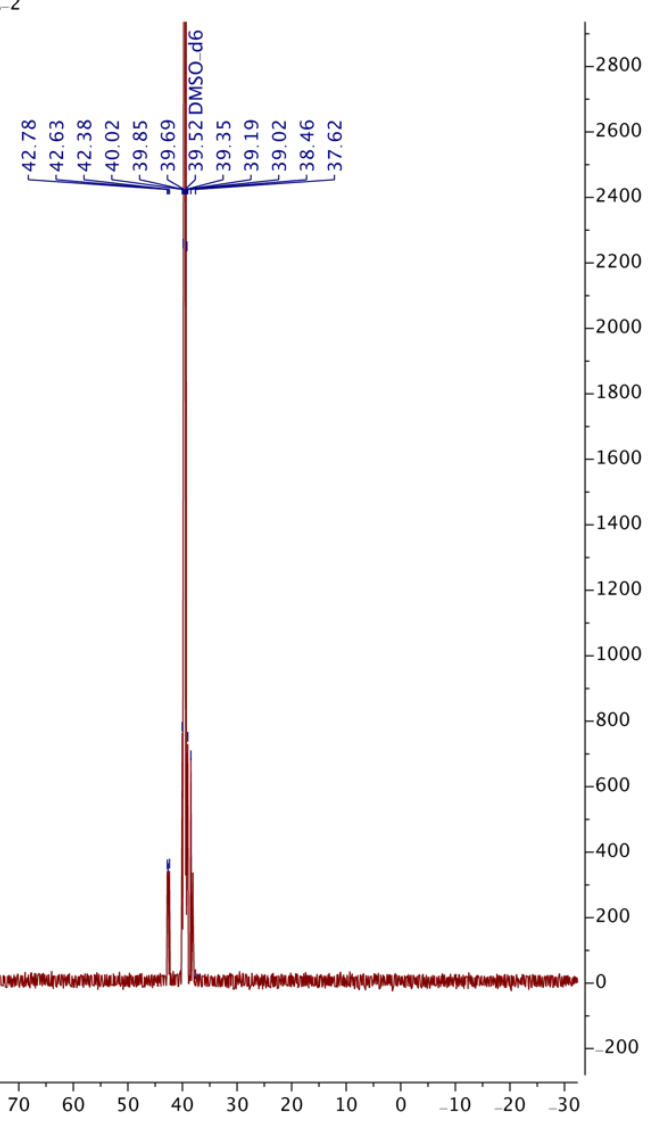

Fig. S131 | ${ }^{13} \mathrm{C}$ NMR of Compound S31. Solvent: DMSO-d6; Frequency: $151 \mathrm{MHz}$; Temperature: $298 \mathrm{~K}$. 


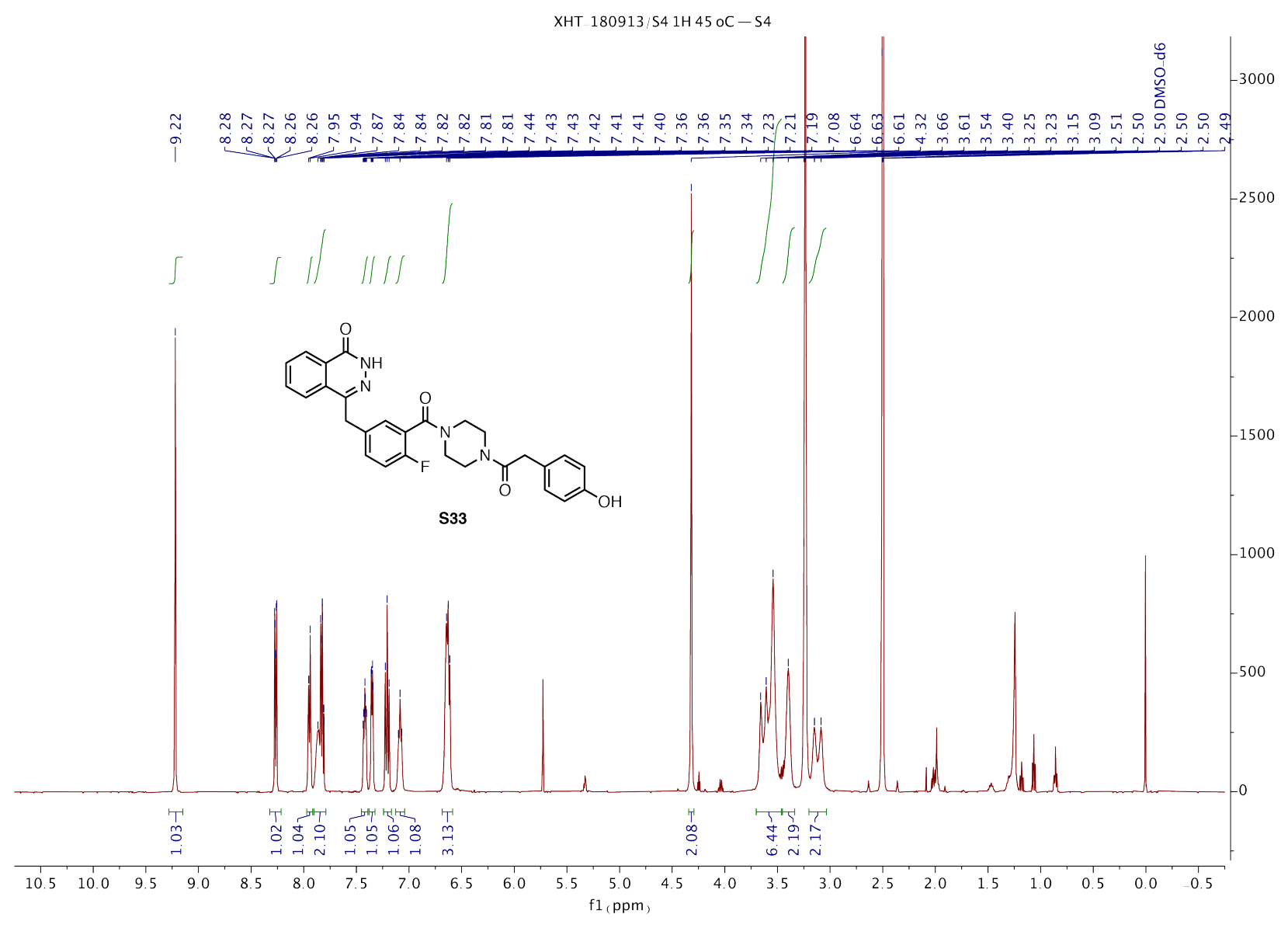

Fig. S132 | ${ }^{1} \mathrm{H}$ NMR of Compound S33. Solvent: DMSO-d6; Frequency: $500 \mathrm{MHz}$; Temperature: $298 \mathrm{~K}$. 


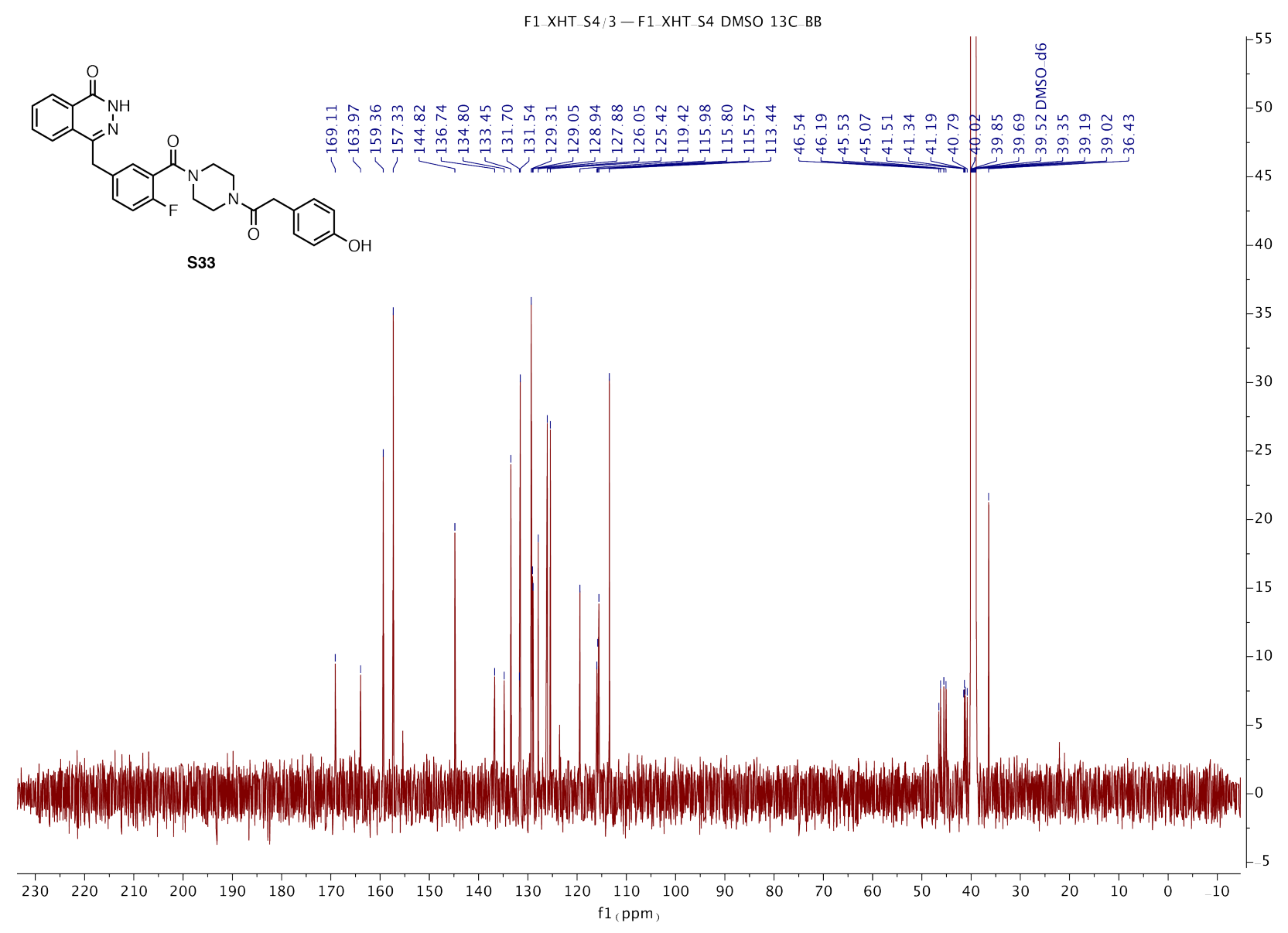

Fig. S133 | ${ }^{13} \mathrm{C}$ NMR of Compound S33. Solvent: DMSO-d6; Frequency: $151 \mathrm{MHz}$; Temperature: $298 \mathrm{~K}$. 
Users/qinheng_zheng/Documents/PhD/Research/Projects/Ongoing/F18 project package/Manuscript/Supporting Information/Characterizations/S33/zqh-2008-F/4/fid
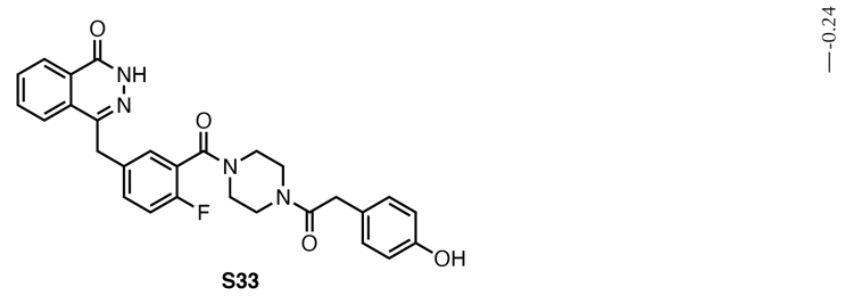

S33
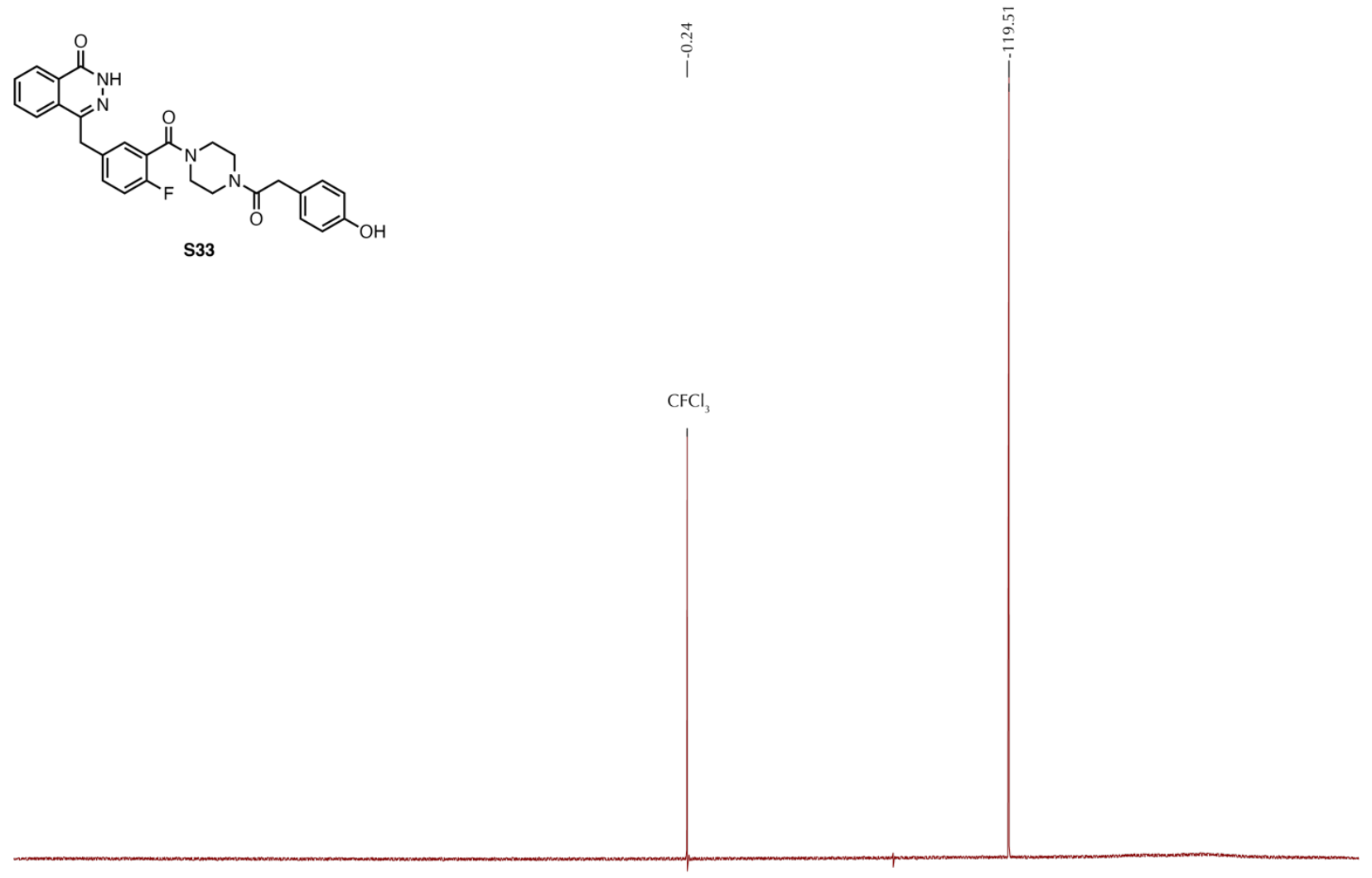

\begin{tabular}{|c|c|c|c|c|c|c|c|c|}
\hline 200 & $\begin{array}{c}1 \\
150\end{array}$ & 100 & $\begin{array}{l}1 \\
50\end{array}$ & $\begin{array}{c}1 \\
0 \\
\mathrm{f} 1(\mathrm{ppm})\end{array}$ & $\frac{1}{-50}$ & -100 & $\begin{array}{l}150 \\
-150\end{array}$ & -200 \\
\hline
\end{tabular}

Fig. S134 | ${ }^{19}$ F NMR of Compound S33. Solvent: DMSO-d6, internal standard $\mathrm{CFCl}_{3}(\delta-0.24$ ppm); Frequency: 376 MHz; Temperature: 298 K. 
zqh-1537-180119.1.fid - $50 \mathrm{mM}$ cyclosporine

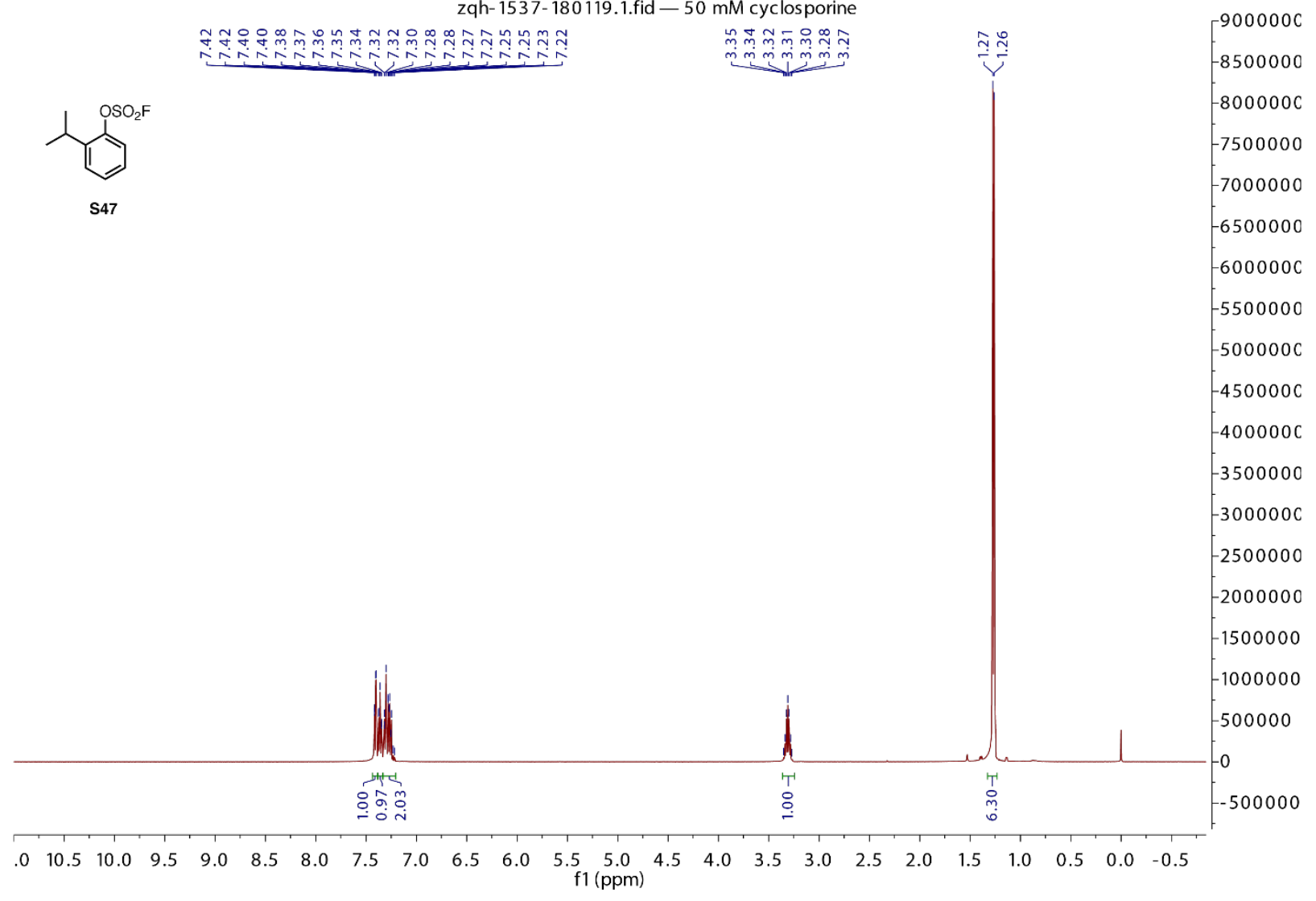

Fig. S135 | ${ }^{1} \mathrm{H}$ NMR of Compound S48. Solvent: $\mathrm{CDCl}_{3}$; Frequency: $500 \mathrm{MHz}$; Temperature: $298 \mathrm{~K}$. 


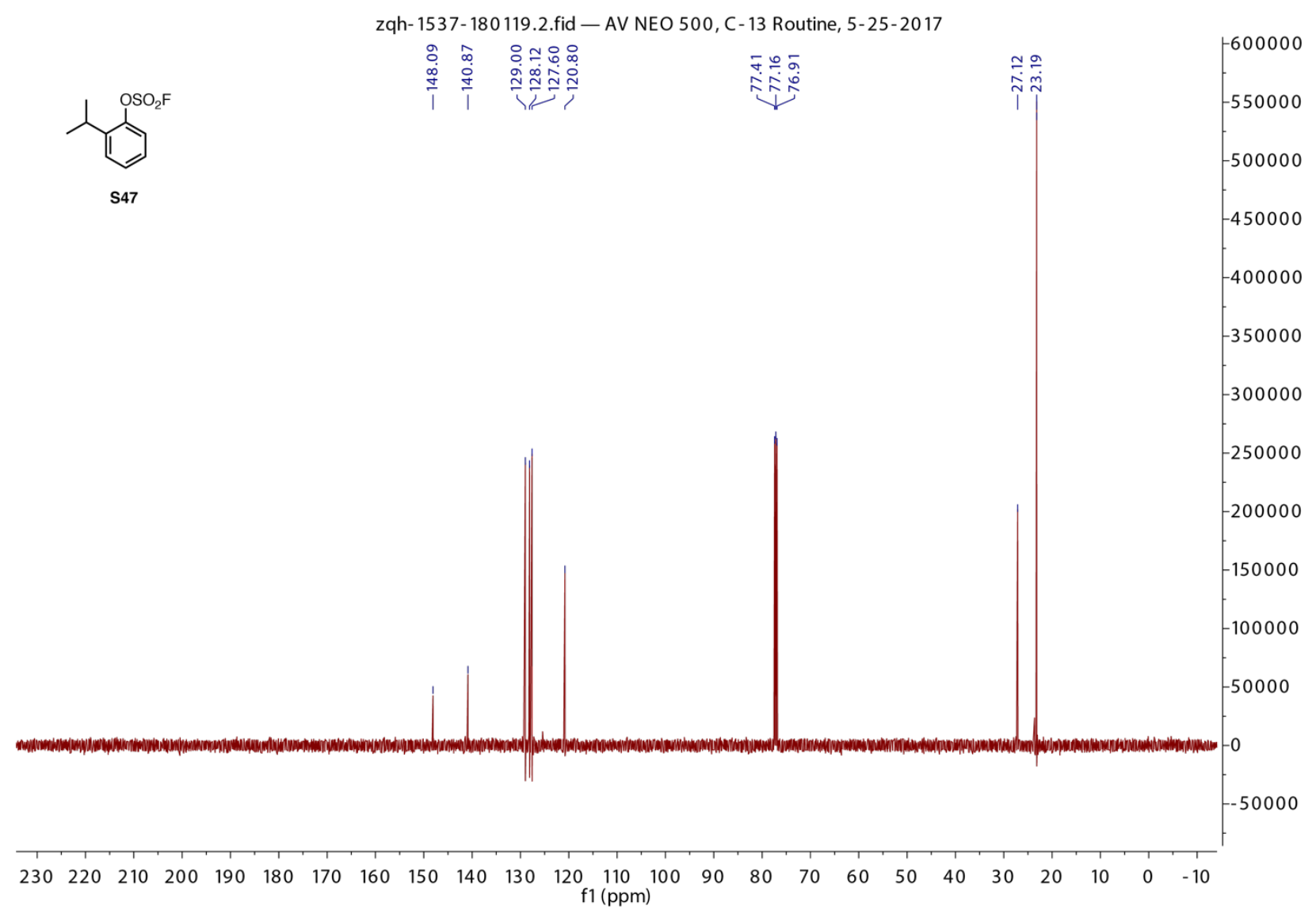

Fig. S136 | ${ }^{13} \mathrm{C}$ NMR of Compound S48. Solvent: $\mathrm{CDCl}_{3}$, internal standard $\mathrm{CFCl}_{3}(\delta 0.65 \mathrm{ppm})$; Frequency: $126 \mathrm{MHz}$; Temperature: $298 \mathrm{~K}$. 


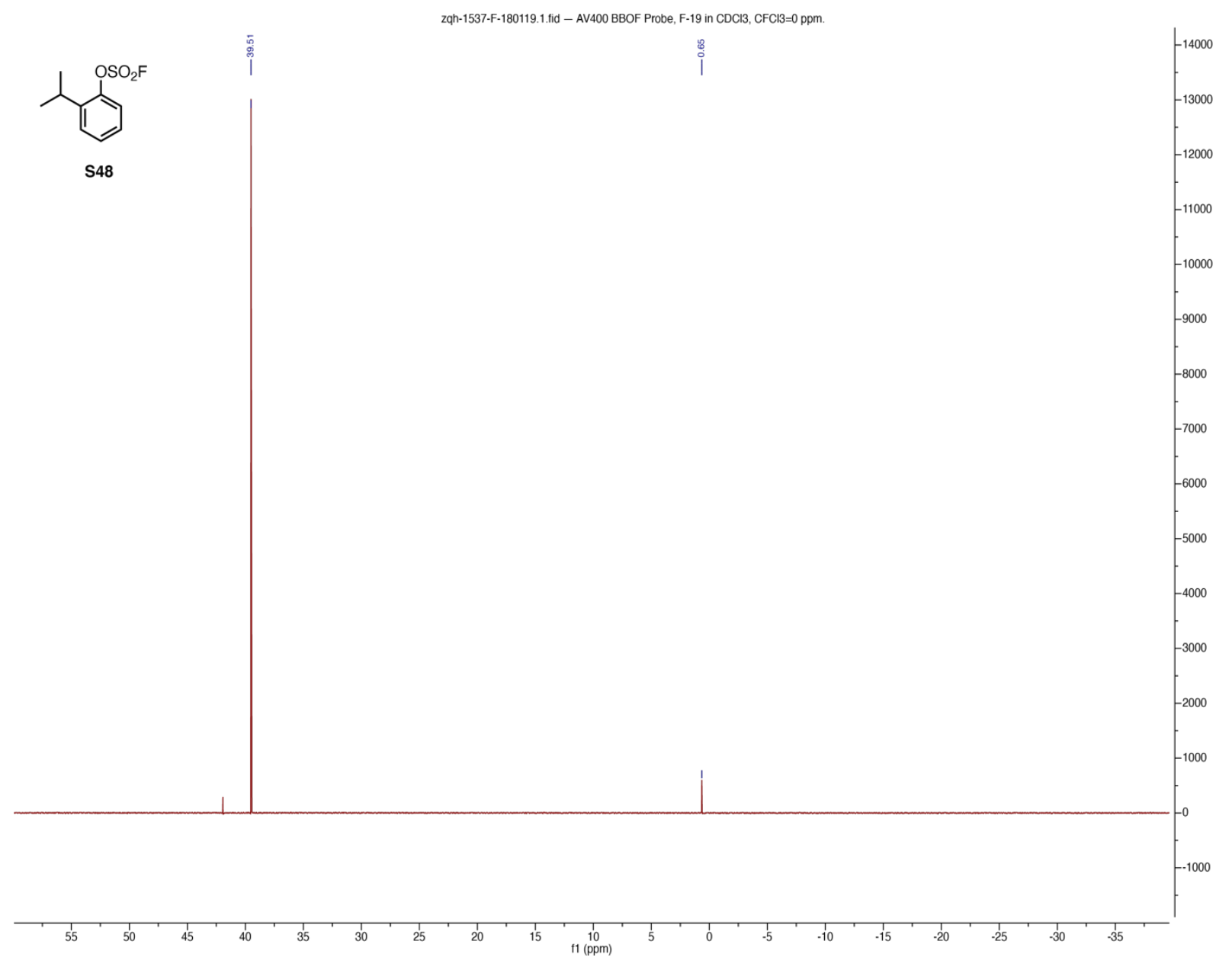

Fig. S137 | ${ }^{19} \mathrm{~F}$ NMR of Compound S48. Solvent: $\mathrm{CDCl}_{3}$, internal standard $\mathrm{CFCl}_{3}(\delta 0.65 \mathrm{ppm})$; Frequency: $376 \mathrm{MHz}$; Temperature: $298 \mathrm{~K}$. 


\section{Additional Reference}

1. Rosenau, C. P.; Jelier, B. J.; Gossert, A. D.; Togni, A., Exposing the Origins of Irreproducibility in Fluorine NMR Spectroscopy. Angew. Chem. Int. Ed. 2018, 57 (30), 95289533.

2. Hanley, P. S.; Ober, M. S.; Krasovskiy, A. L.; Whiteker, G. T.; Kruper, W. J., Nickel- and Palladium-Catalyzed Coupling of Aryl Fluorosulfonates with Aryl Boronic Acids Enabled by Sulfuryl Fluoride. ACS Catal. 2015, 5 (9), 5041-5046.

3. Dong, J.; Krasnova, L.; Finn, M. G.; Sharpless, K. B., Sulfur(VI) Fluoride Exchange (SuFEx): Another good reaction for click chemistry. Angew. Chem. Int. Ed. 2014, 53 (36), 94309448.

4. Domino, K.; Veryser, C.; Wahlqvist, B. A.; Gaardbo, C.; Neumann, K. T.; Daasbjerg, K.; De Borggraeve, W. M.; Skrydstrup, T., Direct Access to Aryl Bis(trifluoromethyl)carbinols from Aryl Bromides or Fluorosulfates: Palladium-Catalyzed Carbonylation. Angew. Chem. Int. Ed. 2018, 57 (23), 6858-6862.

5. Guo, T. J.; Meng, G. Y.; Zhan, X. J.; Yang, Q.; Ma, T. C.; Xu, L.; Sharpless, K. B.; Dong, J. J., A new portal to SuFEx click chemistry: A stable fluorosulfuryl imidazolium salt emerging as an "F-SO2+" donor of unprecedented reactivity, selectivity, and scope. Angew. Chem. Int. Ed. 2018, 57 (10), 2605-2610.

6. Zhang, E. X.; Tang, J. Z.; Li, S. H.; Wu, P.; Moses, J. E.; Sharpless, K. B., Chemoselective Synthesis of Polysubstituted Pyridines from Heteroaryl Fluorosulfates. Chem. Eur. J. 2016, 22 (16), 5692-5697.

7. Baranczak, A.; Liu, Y.; Connelly, S.; Du, W. G. H.; Greiner, E. R.; Genereux, J. C.; Wiseman, R. L.; Eisele, Y. S.; Bradbury, N. C.; Dong, J. J.; Noodleman, L.; Sharpless, K. B.; Wilson, I. A.; Encalada, S. E.; Kelly, J. W., A fluorogenic aryl fluorosulfate for intraorganellar transthyretin imaging in living cells and in caenorhabditis elegans. J. Am. Chem. Soc. 2015, 137 (23), 7404-7414.

8. Liu, Z. L.; Li, J.; Li, S. H.; Li, G. C.; Sharpless, K. B.; Wu, P., SuFEx click chemistry enabled late-stage drug functionalization. J. Am. Chem. Soc. 2018, 140 (8), 2919-2925.

9. Schimler, S. D.; Cismesia, M. A.; Hanley, P. S.; Froese, R. D. J.; Jansma, M. J.; Bland, D. C.; Sanford, M. S., Nucleophilic Deoxyfluorination of Phenols via Aryl Fluorosulfonate Intermediates. J. Am. Chem. Soc. 2017, 139 (4), 1452-1455. 
10. Gao, B.; Zhang, L. D.; Zheng, Q. H.; Zhou, F.; Klivansky, L. M.; Lu, J. M.; Liu, Y.; Dong, J. J.; Wu, P.; Sharpless, K. B., Bifluoride-catalysed sulfur(VI) fluoride exchange reaction for the synthesis of polysulfates and polysulfonates. Nat. Chem. 2017, 9 (11), 1083-1088.

11. Liang, Q.; Xing, P.; Huang, Z.; Dong, J.; Sharpless, K. B.; Li, X.; Jiang, B., Palladiumcatalyzed, ligand-free Suzuki reaction in water using aryl fluorosulfates. Org. Lett. 2015, 17 (8), $1942-1945$.

12. Ren, G.; Zheng, Q.; Wang, H., Aryl Fluorosulfate Trapped Staudinger Reduction. Org. Lett. 2017, 19 (7), 1582-1585.

13. Veryser, C.; Demaerel, J.; Bieliunas, V.; Gilles, P.; De Borggraeve, W. M., Ex Situ Generation of Sulfuryl Fluoride for the Synthesis of Aryl Fluorosulfates. Org. Lett. 2017, 19 (19), 5244-5247.

14. Yang, J.; Seckute, J.; Cole, C. M.; Devaraj, N. K., Live-cell imaging of cyclopropene tags with fluorogenic tetrazine cycloadditions. Angew. Chem. Int. Ed. 2012, 51 (30), 7476-7479.

15. Eising, S.; Engwerda, A. H. J.; Riedijk, X.; Bickelhaupt, F. M.; Bonger, K. M., Highly Stable and Selective Tetrazines for the Coordination-Assisted Bioorthogonal Ligation with Vinylboronic Acids. Bioconjugate Chem. 2018, 29 (9), 3054-3059.

16. Motiei, L.; Pode, Z.; Koganitsky, A.; Margulies, D., Targeted Protein Surface Sensors as a Tool for Analyzing Small Populations of Proteins in Biological Mixtures. Angew. Chem. Int. Ed. 2014, 53 (35), 9289-9293.

17. Zha, Z. H.; Choi, S. R.; Ploessl, K.; Lieberman, B. P.; Qu, W. C.; Hefti, F.; Mintun, M.; Skovronsky, D.; Kung, H. F., Multidentate F-18-Polypegylated Styrylpyridines As Imaging Agents for A beta Plaques in Cerebral Amyloid Angiopathy (CAA). J. Med. Chem. 2011, 54 (23), 8085-8098.

18. Zha, G. F.; Zheng, Q. H.; Leng, J.; Wu, P.; Qin, H. L.; Sharpless, K. B., PalladiumCatalyzed Fluorosulfonylvinylation of Organic lodides. Angew. Chem. Int. Ed. 2017, 56 (17), 4849-4852.

19. Serdons, K.; Terwinghe, C.; Vermaelen, P.; Van Laere, K.; Kung, H.; Mortelmans, L.; Bormans, G.; Verbruggen, A., Synthesis and Evaluation of F-18-Labeled 2Phenylbenzothiazoles as Positron Emission Tomography Imaging Agents for Amyloid Plaques in Alzheimer's Disease. J. Med. Chem. 2009, 52 (5), 1428-1437.

20. Lundt, I.; Steiner, A. J.; Stutz, A. E.; Tarling, C. A.; Ully, S.; Withers, S. G.; Wrodnigg, T. M., Fluorescently tagged iminoalditol glycosidase inhibitors as novel biological probes and diagnostics. Bioorg. Med. Chem. 2006, 14 (6), 1737-1742. 
21. Prabhakaran, J.; Majo, V. J.; Mann, J. J.; Kumar, J. S. D., Chiral synthesis of (2S,3S)-2(2-morpholin-2-yl-2-phenylmethoxy)phenol. Chirality 2004, 16 (3), 168-173.

22. Demko, Z. P.; Sharpless, K. B., An intramolecular [2 + 3] cycloaddition route to fused 5heterosubstituted tetrazoles. Org. Lett. 2001, 3 (25), 4091-4094.

23. Steinkopf, W., Aromatic sulphuric flouride. J. Prakt. Chem. 1927, $117(1 / 3)$, 1-82.

24. Steinkopf, W., On aromatic sulpho-fluoride. J. Prakt. Chem. 1930, 128 (1/3), 63-88.

25. Suter, C., Derivatives of Aromatic Sulfonic Acids. 1 Sulfonyl Halides, Esters, and Anhydrides. In The Organic Chemistry of Sulfur: Tetracovalent Sulfur Compounds, Wiley: New York, 1944; pp 452-458.

26. Zheng, Q.; Woehl, J. L.; Kitamura, S.; Santos-Martins, D.; Smedley, C. J.; Li, G.; Forli, S.; Moses, J. E.; Wolan, D. W.; Sharpless, K. B., SuFEx-enabled, agnostic discovery of covalent inhibitors of human neutrophil elastase. Proc. Natl. Acad. Sci. USA 2019, 116 (38), 1880818814.

27. Gao, B.; Li, S.; Wu, P.; Moses, J. E.; Sharpless, K. B., SuFEx Chemistry of Thionyl Tetrafluoride (SOF4 ) with Organolithium Nucleophiles: Synthesis of Sulfonimidoyl Fluorides, Sulfoximines, Sulfonimidamides, and Sulfonimidates. Angew. Chem. Int. Ed. 2018, 57 (7), 19391943.

28. Brown, D. G.; Boström, J., Analysis of past and present synthetic methodologies on medicinal chemistry: Where have all the new reactions gone? J. Med. Chem. 2016, 59 (10), 4443-4458.

29. Schimler, S. D.; Froese, R. D. J.; Bland, D. C.; Sanford, M. S., Reactions of Arylsulfonate Electrophiles with NMe4F: Mechanistic Insight, Reactivity, and Scope. J. Org. Chem. 2018, 83 (18), 11178-11190.

30. Mahapatra, S.; Woroch, C. P.; Butler, T. W.; Carneiro, S. N.; Kwan, S. C.; Khasnavis, S. R.; Gu, J.; Dutra, J. K.; Vetelino, B. C.; Bellenger, J.; Am Ende, C. W.; Ball, N. D., SuFEx Activation with $\mathrm{Ca}(\mathrm{NTf2}) 2$ : A Unified Strategy to Access Sulfamides, Sulfamates, and Sulfonamides from S(VI) Fluorides. Org. Lett. 2020, 22 (11), 4389-4394.

31. Chen, W.; Dong, J.; Li, S.; Liu, Y.; Wang, Y.; Yoon, L.; Wu, P.; Sharpless, K. B.; Kelly, J. W., Synthesis of sulfotyrosine-containing peptides by incorporating fluorosulfated tyrosine using an Fmoc-based solid-phase strategy. Angew. Chem. Int. Ed. 2016, 55 (5), 1835-1838.

32. Li, Q.; Chen, Q.; Klauser, P. C.; Li, M.; Zheng, F.; Wang, N.; Li, X.; Zhang, Q.; Fu, X.; Wang, Q.; Xu, Y.; Wang, L., Developing covalent protein drugs via proximity-enabled reactive therapeutics. Cell 2020, 182 (1), 85-97. 
33. Chen, W.; Dong, J.; Plate, L.; Mortenson, D. E.; Brighty, G. J.; Li, S.; Liu, Y.; Galmozzi, A.; Lee, P. S.; Hulce, J. J.; Cravatt, B. F.; Saez, E.; Powers, E. T.; Wilson, I. A.; Sharpless, K. B.; Kelly, J. W., Arylfluorosulfates inactivate intracellular lipid binding protein(s) through chemoselective SuFEx reaction with a binding site Tyr residue. J. Am. Chem. Soc. 2016, 138 (23), 7353-7364.

34. Yang, C. J.; Flynn, J. P.; Niu, J., Facile Synthesis of Sequence-Regulated Synthetic Polymers Using Orthogonal SuFEx and CuAAC Click Reactions. Angew. Chem. Int. Ed. 2018, 57 (49), 16194-16199.

35. Navarro, O.; Marion, N.; Mei, J.; Nolan, S. P., Rapid room temperature BuchwaldHartwig and Suzuki-Miyaura couplings of heteroaromatic compounds employing low catalyst loadings. Chem. Eur. J. 2006, 12 (19), 5142-5148.

36. Tolmachova, K. A.; Moroz, Y. S.; Konovets, A.; Platonov, M. O.; Vasylchenko, O. V.; Borysko, P.; Zozulya, S.; Gryniukova, A.; Bogolubsky, A. V.; Pipko, S.; Mykhailiuk, P. K.; Brovarets, V. S.; Grygorenko, O. O., (Chlorosulfonyl)benzenesulfonyl Fluorides-Versatile Building Blocks for Combinatorial Chemistry: Design, Synthesis and Evaluation of a Covalent Inhibitor Library. ACS Combinatorial Science 2018, 20 (11), 672-680.

37. Taitelbaum, H.; Weiss, G. H.; Spencer, R. G. S., Optimization of magnetization-transfer experiments for kinetic rate measurements. NMR Biomed. 1994, 7 (6), 287-292.

38. Hammett, L. P., The effect of structure upon the reactions of organic compounds benzene derivatives. J. Am. Chem. Soc. 1937, 59, 96-103.

39. Hansch, C.; Leo, A.; Taft, R. W., A Survey of Hammett Substituent Constants and Resonance and Field Parameters. Chem. Rev. 1991, 91 (2), 165-195.

40. Zhao, Q.; Ouyang, X. H.; Wan, X. B.; Gajiwala, K. S.; Kath, J. C.; Jones, L. H.; Burlingame, A. L.; Taunton, J., Broad-Spectrum Kinase Profiling in Live Cells with LysineTargeted Sulfonyl Fluoride Probes. J. Am. Chem. Soc. 2017, 139 (2), 680-685.

41. Coenen, H. H.; Gee, A. D.; Adam, M.; Antoni, G.; Cutler, C. S.; Fujibayashi, Y.; Jeong, J. M.; Mach, R. H.; Mindt, T. L.; Pike, V. W.; Windhorst, A. D., Consensus nomenclature rules for radiopharmaceutical chemistry - Setting the record straight. Nucl. Med. Biol. 2017, 55, V-Xi.

42. Cai, L. S.; Lu, S. Y.; Pike, V. W., Chemistry with [18F]fluoride ion. Eur. J. Org. Chem. 2008, (17), 2853-2873.

43. Grant, F. D.; Fahey, F. H.; Packard, A. B.; Davis, R. T.; Alavi, A.; Treves, S. T., Skeletal PET with 18F-fluoride: applying new technology to an old tracer. J. Nucl. Med. 2008, 49 (1), 6878. 
44. ADF Amsterdam Density Functional Software, SCM, Theoretical Chemistry, Vrije Universiteit, Amsterdam, The Netherlands. http://www.scm.com.

45. te Velde, G.; Bickelhaupt, F. M.; Baerends, E. J.; Guerra, C. F.; Van Gisbergen, S. J. A.; Snijders, J. G.; Ziegler, T., Chemistry with ADF. J. Compt. Chem. 2001, 22 (9), 931-967.

46. Guerra, C. F.; Visser, O.; Snijders, J. G.; te Velde, G.; Baerends, E. J., Parallelisation of the Amsterdam Density Functional Program. In Methods and techniques for computational chemistry, Clementi, E.; Corongiu, C., Eds. STEF: Cagliari, 1995; pp 303-395.

47. Grimme, S.; Ehrlich, S.; Goerigk, L., Effect of the Damping Function in Dispersion Corrected Density Functional Theory. J. Compt. Chem. 2011, 32 (7), 1456-1465.

48. Klamt, A.; Schüürmann, G., COSMO - A New Approach to Dielectric Screening in Solvents with Explicit Expressions for the Screening Energy and Its Gradient. J. Chem. Soc. Perkin Trans. 1993, (5), 799-805.

49. Klamt, A., Conductor-Like Screening Model for Real Solvents - A New Approach to the Quantitative Calculation of Solvation Phenomena. J. Phys. Chem. 1995, 99 (7), 2224-2235.

50. Klamt, A.; Jonas, V., Treatment of the Outlying Charge in Continuum Solvation Models. J. Chem. Phys. 1996, 105 (22), 9972-9981.

51. Pye, C. C.; Ziegler, T., An Implementation of the Conductor-Like Screening Model of Solvation within the Amsterdam Density Functional Package. Theor. Chem. Acc. 1999, 101 (6), 396-408. 